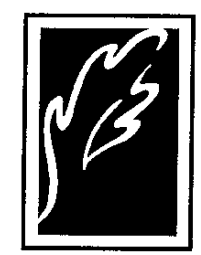

\title{
Abstracts of Presentations
}

Abstracts submitted for presentation at the 1999 Annual Meeting in Montreal, Quebec, August 7-11. The abstracts are arranged alphabetically, by authors' names.

\begin{abstract}
Rhizoctonia and Pythium species associated with black root rot of strawberries in North Carolina. Z. G. ABAD, F. J. Louws, and G. E. Fernandez. North Carolina State University, Raleigh, NC 27695. Phytopathology 89:S1. Publication no. P-1999-0001-AMA.

Black root rot is an important disease affecting strawberries in NC. Rhizoctonia fragariae AG-A and Pythium irregulare were the most predominant organisms associated with the disease in four localities. In Fletcher (Mountains), R. fragariae AG-A, AG-G, AG-?, Pythium Group "HS", and Pythium sp. were present in 11, 10, 9, 2 and 10 samples, respectively. In Vollmer (Piedmont), R. fragariae AG-A, AG-I, P. artotrogus, P. irregulare, P. paroecandrum, and Pythium Group "F" were determined in 7, 3, 4, 1, 1, and 3 samples, respectively. In Clayton (Piedmont), P. irregulare, P. ultimum, Pythium sp. and $R$. fragariae AG-A were detected in 23, 1, 23, and 2 samples, respectively. In Plymouth (Coastal Plain), P. artotrogus, P. irregulare, Pythium Group "F", R. fragariae AG-A, and $R$. solani AG4-HGIII were determined in $1,6,4,3$, and 1 samples, respectively. Fusarium solani, F. oxysporum, Cephalosporium sp., Cylindrocarpon sp., Cylindrosporium sp., Trichoderma sp. and other fungi were isolated occasionally. These diversity of organisms associated with strawberry roots underscores the complex nature of the black root rot disease.
\end{abstract}

Effects of cultural practices on bean root rot and its management. G. S. ABAWI, T. L. Widmer, and J. W. Ludwig. NYSAES, Cornell University. Phytopathology 89:S1. Publication no. P-1999-0002-AMA.

Root rot is a major and damaging disease complex of beans in New York. The major pathogens are Rhizoctonia solani, Thielaviopsis basicola, Pythium ultimum, Fusarium solani f. sp. phaseoli, and Pratylenchus spp. Sub-soiling and raised ridges increased bean yield and/or reduced root rot severity (RRS), but not chisel-plowing or rototilling the planting row. A 2-year rotation out of beans, especially with a grain crop reduced RRS and increased yield. Cover crops incorporated as a green manure (ryegrain, sudangrass, wheat, rapeseed) or composts (brewery and chicken composts, corn silage) reduced RRS and increased yield, but hairy vetch and white mustard did not. The use of high quality, disease-free and fungicide-treated seeds (to control Pythium and Rhizoctonia diseases) is critical for good stand establishment. Snap bean varieties are susceptible to this disease complex, but their yield differed significantly in infested fields. Assessing root rot potential of bean fields in advance will aid in avoiding heavily infested fields, thus averting losses. Planting heavily infested fields late, shallow and at reduced seeding rates will contribute to lower RRS and losses.

Toxins and Fusarium species in rice infected with head blight disease. H. K. ABBAS (1), B. J. Johnson (1), R. D. Cartwright (2), W. Xie (3), W. T. Shier (3), and C. B. Bird (4). (1) USDA-ARS, Stoneville, MS; (2) CES, Univ. of Arkansas, Little Rock, AR; (3) Univ. of Minnesota, St. Paul, MN; (4) Neogen Corp., Lansing, MI. Phytopathology 89:S1. Publication no. P-1999-0003AMA.

Over 100 rice samples infected with scab disease in Arkansas were analyzed for Fusarium spp., DON and zearalenone (F-2). In each 100-kernel sample,

The abstracts are published as submitted. They were formatted but not edited at the APS headquarters office. from 0 to $18 \%$ of the kernels grew Fusarium spp. which were identified as $F$. graminearum. Ten representative isolates were analyzed for toxin production. Six isolates produced DON and 15-ADON (96-290 ppm and 7-29 ppm); 2 isolates produced DON and 3-ADON (233-290 ppm and 332-430 $\mathrm{ppm})$ or nivalenol and fusarenone-x (53-115 ppm and 29-55 ppm). All ten isolates produced F-2 (584-9883 ppm). DON was found in $94 \%$ of 100 samples $(0.1-1.6 \mathrm{ppm})$. F-2 was found in $77 \%$ of 100 samples $(0.01-0.6$ $\mathrm{ppm})$. Aflatoxins were found in 10 samples (20.2-29 ppb) and fumonisins were found in 5 samples $(0.1-0.5 \mathrm{ppm})$. There was a good correlation between the presence of toxins in naturally contaminated rice samples (DON and F-2) and \% kernels that yielded Fusarium of the Roseum-type. These results show that DON, F-2, aflatoxins, and fumonisins can occur on rice infected with scab at levels which may be of concern.

Phytotoxicity of apicidin in duckweed (Lemna pausicostata). H. K. ABBAS (1), R. N. Paul (1), Y.-W. Lee (2), and W. T. Shier (3). (1) USDA-ARS, Stoneville, MS; (2) Seoul Natl. Univ., Suwon, South Korea; (3) Univ. of Minnesota, Minneapolis, MN. Phytopathology 89:S1. Publication no. P-19990004-AMA.

Apicidin (AP), a cyclic tetrapeptide, was isolated from Fusarium semitectum, $F$. sambucinum and $F$. pallidoroseum with broad-spectrum antiprotozoal activity against Apicomplexan parasites due to inhibition of histone deacetylase (HDA). AP at $10 \mu \mathrm{M}$ induced chlorosis and necrosis in duckweed and caused increase in cellular leakage, inhibition of plant growth, and chlorophyll reduction. At $50 \mu \mathrm{M}$, observable ultrastructural effects appeared within $36 \mathrm{~h}$. The treated cytoplasm showed evidence of degeneration and variability from cell to cell, due to the position of the cell in the duckweed frond or to the susceptibility of the individual plant to the toxin. Toxic effects increased with time of incubation. At $72 \mathrm{~h}$, chloroplasts lost their characteristic orientation within cells and became swollen and starchy. In some cells, just starch grains, membrane debris, and cell walls remained and in others, recognizable mitochondria and chloroplasts persisted. The mode of action of AP in plants needs to be determined as it appears that simple inhibition of HDA cannot explain the results.

Studies on thaxtomin A (TA) in scab resistant and susceptible potatoes. I. A. ACUNA, G. C. Strobel, and B. J. Jacobsen. Montana State University, Bozeman, MT. Phytopathology 89:S1. Publication no. P-1999-0005-AMA.

We have reported that glucosylation of TA was correlated with resistance to common scab. This report will provide further confirmation of TA-glucoside, production of radiolabeled TA and bioactivity of TA on resistant and susceptible clones. Acid hydrolysis of TA-glucoside was performed in trifluoroacetic acid-water $1: 3$ for 15 hours at $110^{\circ} \mathrm{C}$. The product of this acid hydrolysis released glucose and free TA as determined by chromatography. ${ }^{14} \mathrm{C}-\mathrm{TA}$ was produced using $50 \mu \mathrm{Ci}$ of ${ }^{14} \mathrm{C}$-phenylalanine and production was studied by extraction with n-butanol after fermentation for $8,9,10,13,15$ and 20 days, purification using TLC and determination by liquid scintillation and radiographic film. ${ }^{14} \mathrm{C}$-TA production was maximized at 11 days with a specific activity of $3,190 \mathrm{dpm} / \mu \mathrm{mol}$. TA bioactivity tests were done on R0.1-6 (resistant) and Ranger (susceptible) clones. R0.1-6 developed less necrosis than Ranger at 3,5 and 7 days after exposure. Parallel test with ${ }^{14} \mathrm{C}$-TA will 
be reported. Atlantic microtubers exposed to $0.3 \mu \mathrm{mol}$ of ${ }^{14} \mathrm{C}$-TA for 7 days had $66 \%$ and $24 \%$ of the radioactivity in the peel and outer cortical tissue, respectively.

Cytospora species on Eucalyptus and the Valsa ceratosperma teleomorph. G. C. ADAMS (1), H. Smith (2), and M. J. Wingfield (3). (1) Michigan State University, East Lansing, MI; (2) ARC - Institute for Tropical and Subtropical Crops, Nelspruit, South Africa; (3) University of Pretoria, Pretoria, South Africa. Phytopathology 89:S2. Publication no. P-1999-0006-AMA.

Cytospora isolates from Eucalyptus grandis and E. camaldulensis were collected from Africa, Asia, Australia and South America. The ITS I, 5.8S, and ITS II regions (ITS) of the ribosomal DNA repeat were sequenced. The 630 bp ITS sequences were compared for homology with approximately 60 unique sequences of other Cytospora species from hardwood, conifer, and herbaceous hosts. Isolates from Eucalyptus grouped into an Australian/Indonesian clade and an African/South American clade. Each clade contained genetically diverse isolates and the two clades were highly divergent from one another. The isolates from Eucalyptus were not closely related to Valsa ceratosperma from other hardwoods despite the similar morphology of the teleomorphs. Valsa ceratosperma from Sumac (Rhus spp.) was not closely related to the two clades on Eucalyptus or to V. ceratosperma from other hardwoods. Apparently, the descriptive morphology of the teleomorph $V$. ceratosperma is shared by at least four genetically distinct species of cankercausing pathogens of which two apparently occur on Eucalyptus.

Enhancing resistance with a lytic peptide gene to plant pathogens by transformation. A. R. ALAN and E. D. Earle. Cornell University, Ithaca, N.Y. Phytopathology 89:S2. Publication no. P-1999-0007-AMA.

Tomato cultivar Mocimor and tobacco cultivar Samsun NN were transformed with a lytic peptide gene (MSI-99) under the control of an enhanced CaMV $35 \mathrm{~S}$ promoter to examine its possible use for improving plant resistance to phytopathogenic organisms. MSI-99 is a synthetic derivative of magainin II, which has two-three fold higher antimicrobial activity than the original peptide. Results from preliminary disease tests in primary transformants of tobacco and kanamycin-resistant $\mathrm{R}_{1} \mathrm{~s}$ of tomato suggested MSI-99 can provide some level of resistance against pseudomonad pathogens of these crops. In general, necrotic lesion development was delayed in leaves of some tobacco transformants inoculated with $P$. syringae pv. tabaci. In tomato, reduction in disease severity was observed when transformants were inoculated with $P$. syringae pv. tomato.

Efficacy of compost water extracts for control of bacterial spot of tomato. J. H. AL-DAHMANI, P. A. Abbasi, S. A. Miller, and H. A. J. Hoitink. Dept. Plant Pathology, The Ohio State University, OARDC, Wooster, OH 44691. Phytopathology 89:S2. Publication no. P-1999-0008-AMA.

Water extracts prepared from composts were sprayed to run-off onto tomato plants to determine their efficacy for control of bacterial spot caused by Xanthomonas campestris pv. vesicatoria. The plant activator benzothiadiazole (Actigard), which induces systemic acquired resistance in tomato, and water were used as controls. Extracts prepared from several types of composts significantly $(P=0.05)$ reduced bacterial spot in greenhouse trials. Filtration and autoclaving of the compost extracts did not affect efficacy. Furthermore, activity of the most effective extracts did not differ significantly $(P=0.05)$ from that of Actigard. In a 1997 field trial, compost extracts sprayed weekly or biweekly onto plants provided marginal control of bacterial spot on fruit $(P=0.1)$, and did not reduce the severity of the disease on the foliage. In a 1998 field trial, when bacterial spot was less severe than in 1997 and Septoria leaf spot was severe, Actigard and compost extracts did not reduce foliar disease severity, whereas a mixture of chlorothalonil and a fixed copper fungicide provided effective control.

Phytotoxicity of selected trichothecenes using Chlamydomonas reinhardtii as a model system. N. J. ALEXANDER, S. P. McCormick, and S. L. Ziegenhorn. MTX, USDA-ARS, National Center for Agric. Util. Research, 1815 N. University St., Peoria, IL 61604. Phytopathology 89:S2. Publication no. P-1999-0009-AMA.

Trichothecenes are potent inhibitors of cytoplasmic protein synthesis. These toxins can effect the severity of plant diseases such as wheat head scab. While many trichothecene-producing fungi share the initial biosynthetic intermediates, Fusarium sp. are unique in the production of trichothecenes containing an oxygen function at $\mathrm{C}-3$. Although the initial trichothecene and the final products have a C-3 hydroxyl group, the intermediate steps are acetylated at C-3. In order to test the proposal that trichothecenes with a C-3 hydroxyl are more toxic to plants, we devised a test using Chlamydomonas reinhardtii for measuring the relative phytotoxicity of various pathway intermediates. Seven pairs of trichothecenes with either a C-3 hydroxyl or C-3 acetyl group were assayed on the growth of Chlamydomonas. Our results confirm that trichothecenes acetylated at C-3 were far less toxic to Chlamydomonas than those with a C-3 hydroxyl group.

Races of Pyrenophora tritici-repentis on durum in the northern Great Plains of the U.S. S. ALI and L. J. Francl. Dept. of Plant Path., No. Dak. State U., Fargo, ND 58105. Phytopathology 89:S2. Publication no. P-19990010-AMA.

The fungus Pyrenophora tritici-repentis, cause of tan spot of wheat, is grouped into five races based on ability to induce necrosis (nec) and chlorosis (chl) symptoms on wheat differentials. Races 1 to 4 were described from spring wheat in the Canadian Great Plains and race 5 was found on durum in North Africa. In the U.S., races 1, 2 and 4 were have been found but the fungal population on durum has not been surveyed previously. Fifty-two single spore isolates of $P$. tritici-repentis were obtained from diseased leaves of durum, collected from the primary durum growing area of North Dakota. The isolates were evaluated individually for their virulence pattern by inoculating wheat differentials in the greenhouse. The isolates were categorized as $94 \%$ race 1 (nec+chl+) and $6 \%$ race 5 (nec-chl+). Results indicate that the pathogen has a diverse population on durum in the northern Great Plains. Also, race 5 was observed for the first time in North America. This race may threaten wheat in the U.S. so cultivars and germplasm should be evaluated for resistance. More isolates are under investigation to obtain a comprehensive virulence pattern of the pathogen population in the U.S.

Characterization of the fungal population associated with crown and root rot of birdsfoot trefoil in Uruguay. N. A. ALTIER (1) and J. V. Groth (2). (1) INIA, Uruguay; (2) University of Minnesota, St. Paul, MN. Phytopathology 89:S2. Publication no. P-1999-0011-AMA.

Birdsfoot trefoil (BFT) fields were selected in a 9-site-matrix of 3 locations and 3 stand ages, and surveyed twice a year during 2 successive years. Twenty-five plants in each of 12 permanent quadrats were sampled at each site and date. Samples of infected crown and root tissues were used for fungal isolation. Fusarium oxysporum was the primary pathogen associated with diseased plants (40\% of isolations). Vegetative compatibility assessed using nitrate non-utilizing mutants was used as a measure of genetic relatedness of F. oxysporum isolates. No complementation was found among 18 isolates (630 pairings of 36 nit complementary mutants), indicating a high degree of genetic diversity in the pathogen population. A culture plate method was used to characterize isolate aggressiveness to BFT seeds and seedlings, based on a 5 -class scale: $1=$ healthy seedling, $5=$ dead seed. Most $F$. oxysporum isolates (36 out of 44) were pathogenic to BFT, and were highly variable in aggressiveness (range: 1.44-3.85). The variability observed in the pathogen population needs to be considered when selecting isolates for resistance screening.

Epidemiological studies on crown and root rot of birdsfoot trefoil in Uruguay. N. A. ALTIER (1) and L. L. Kinkel (2). (1) INIA, Uruguay; (2) University of Minnesota, St. Paul, MN. Phytopathology 89:S2. Publication no. P-1999-0012-AMA.

Birdsfoot trefoil fields in 3 locations of Uruguay were surveyed to determine incidence and severity of crown and root diseases in 1- to 3-yr-old stands. Twenty-five plants in each of 12 permanent quadrats were evaluated at each site $(n=300$ plants per site, 9 sites total). Plants were scored for disease severity following a 5 -class scale: $0=$ no disease, $4=$ dead plant. Crown and root rot occurred in every site, with average incidence (percent infected plants) of 43,96 , and $100 \%$ and average severity of $0.51,1.51$, and 1.86 in 1-, $2-$, and 3-yr-old stands, respectively. Fusarium oxysporum was the primary pathogen associated with diseased plants. Variance to mean ratios for disease severity were consistently less than 1 , suggesting that disease was not aggregated among quadrats in individual sites. Stand counts decreased with age, from 200 plants $/ \mathrm{m}^{2}$ in 1 -yr-old to less than 50 plants $/ \mathrm{m}^{2}$ in 3 -yr-old stands. Stand counts also decreased with increasing disease levels, indicating a relationship between crown and root rot and plant persistence. Resistant cultivars and proper utilization practices should be considered as potential means for disease management. 
Pathogenic variation and DNA polymorphism in Phytophthora spp., causal agent of bud rot of oil palm. E. ALVAREZ (1), J. Sanchez (1), O. Grajales (1), and P. L. Gómez (2). (1) CIAT, Cali, Colombia; (2) CENIPALMA, Bogotá, Colombia. Phytopathology 89:S3. Publication no. P-19990013-AMA.

Phytophthora strains were examined for differences in morphology, pathogenicity and DNA polymorphism. The strains were chosen to be diverse according to geographical origin. Characterization of the strains by morphology was difficult because not all strains produce fungal structures. The strains caused typical symptoms in Oil Palm but varied in Pathogenicity. DNA polymorphism was determined both by restriction fragment length polymorphism (RFLP) of the ribosomal internal transcribed spacer (ITS) and 5.8S DNA amplified by the polymerase chain reaction and by random amplification of polymorphic DNA (RAPD). Restriction digest with HindI, of the product amplified for the ITS region showed three different restriction patterns witch correspond to three species. Twenty random, 10 mer primers were tested, and four gave reproducible bands. Polymorphisms with OPA-02, OPA-04, OPH-04 and OPH-05 single primers differentiated the strains. The results suggest a high genetic diversity among the Phytophthora strains tested.

Evaluation of a Malus germplasm collection for resistance to selected summer diseases in North Carolina. O. ANAS, E. M. Brown, J. Harrison, S. M. Williamson, and T. B. Sutton. NC State University, Raleigh, NC. Phytopathology 89:S3. Publication no. P-1999-0014-AMA.

One hundred ninety-eight Malus accessions representing various species, selections and cultivars was planted at the Mountain Horticultural Crops Research Station in Fletcher, NC in 1995. This planting was established under the guidelines of the Apple Crop Germplasm Committee to evaluate accessions in the Malus CORE subset for susceptibility to diseases. Accessions were maintained using standard orchard management practices, except no fungicides were applied. Sufficient fruit were available to evaluate 92 of the accessions for susceptibility to apple scab (Venturia inaequalis), Brooks spot (Mycosphaerella pomi), black pox (Helminthosporium papulosum), flyspeck (Schizothyrium pomi), and sooty blotch (fungal complex) during the 1996-1998 growing seasons. Ten fruit, arbitrarily selected from each replication (RCBD 4 rep) were scored for the presence or absence of each disease. The percent surface area covered with sooty blotch and flyspeck was estimated. Accessions varied in their susceptibility to scab, Brooks spot and black pox; all were susceptible to sooty blotch and flyspeck, but varied in symptom severity.

Observations on the interaction of Trichoderma harzianum biotype 4 and the cultivated mushroom, Agaricus bisporus. M. G. ANDERSON, D. M. Beyer, and P. J. Wuest. Pennsylvania State University, PA. Phytopathology 89:S3. Publication no. P-1999-0015-AMA.

These studies were conducted to explore the nature of the interaction between Trichoderma harzianum biotype 4 (Th4) and the cultivated mushroom. Th4 potentially functions as a competitor mold, as a mycoparasite, or simply as a compost scavenger aided by primary carbohydrate breakdown by Agaricus. Differential yield loss responses of brown and white spawn strains were observed. White mushroom strains were the most susceptible to Th4, with yield losses of up to $100 \%$. In contrast, brown strains showed $<5 \%$ yield loss. Further examinations focused on the critical role of Agaricus cell wall components in the relationship of these two fungi and the compost substrate. Th4 was grown in liquid media cultures in the absence and presence of Agaricus, as well as in culture filtrate from which Agaricus mycelia had been removed. Scanning electron microscopy was utilized to compare cell wall concentration of calcium oxalate crystals among strains. A commercial enzymatic assay was used to assess enzymes produced by Th4. Results suggest that Th4 functions as both a competitor and a mycoparasite, with induction of either aspect governed by environmental and nutritional regimes.

Ascospore discharge in Gibberella zeae. C. L. ANDRIES and F. Trail. Michigan State University, East Lansing, MI. Phytopathology 89:S3. Publication no. P-1999-0016-AMA.

Gibberella zeae (anamorph Fusarium graminearum), the causal organism of head blight of wheat has caused over $\$ 2.6$ billion in lost revenue to U.S. growers over the last six years. G. zeae, an ascomycete, is thought to survive the winter as mycelia and then undergo sexual reproduction in the spring. Fruiting bodies (perithecia) containing ascospores are formed on the crop debris. It is believed that these ascospores serve as the primary inoculum for the disease. The ability to forcibly discharge ascospores into the air is critical for distribution of the primary inoculum. Studies on the physiology of discharge will be presented. Restriction enzyme mediated insertion (REMI) is being used to generate genetically tagged random mutants of G. zeae. These mutants have are currently being screened for a loss in the ability to forcibly discharge ascospores. A more complete understanding of the formation and dissemination of primary inoculum should lead to novel control methods for this disease.

Potential use of the fungal protein, Nep1, for control of broad-leaf weeds. P. C. APEL-BIRKHOLD (1), N. R. O'Neill (2), J. D. Anderson (3), and B. A. Bailey (1). USDA-ARS, (1) BPDL, (2) SARL, and (3) WSL, Beltsville, MD 20705. Phytopathology 89:S3. Publication no. P-1999-0017-AMA.

An extra-cellular protein, Nep1, with phytotoxic activity to dicot plant species was purified from culture filtrates of Fusarium oxysporum. Nep1 caused necrosis when applied to plant cell suspension cultures and leaf tissues. The ability to cause necrosis when applied as a foliar spray illustrates the potential of using Nep1 in herbicidal preparations. Herbicidal activity of Nep1 was demonstrated on many noxious broad leaf weeds including yellow starthistle, spotted knapweed, velvet-leaf, northern jointvetch, dandelion, sowthistle and others. Application rates of Nep1 as low as $1-5 \mu \mathrm{g} / \mathrm{ml}$ resulted in extensive necrosis to the plants within $24 \mathrm{hr}$. The effectiveness of Nep1 was minimally influenced by dew period, but strongly affected by the rate of application and spray volume. Penetration of Nep1 into the plant was through natural openings such as stomata and hydathodes. Surfactants such as Silwet 77 and Tween 20 greatly enhanced the activity of Nep1. Additional research is being carried out to examine the activity of Nep1 in other types of herbicidal preparations including biological and chemical herbicides.

Modeling the vertical spread of Stagonospora nodorum epidemics on winter wheat. V. M. ARIS, S. Leath, J. E. Bailey, and C. L. Campbell. North Carolina State University, Raleigh, NC 27695. Phytopathology 89:S3. Publication no. P-1999-0018-AMA

Leaf and glume blotch, caused by Stagonospora nodorum, is problematic in all major cereal growing areas of the world. Infection results from splashing of the spores from one leaf level to another, leading to the appearance of lesions on leaves after a temperature-dependent latent period. The infection is most detrimental to yield when it occurs on the flag leaf and the head, reducing grain fill. An epidemiological model was devised to analyze the vertical spread of infection on wheat plants. The model includes host-plant growth stage (presence of susceptible tissue), the amount of secondary inoculum of the pathogen and environmental conditions. Requirements for infection and parameters were obtained and estimated from the literature, and the simulation was run on data collected in Plymouth, NC, during the 199798 growing season. The model accurately predicted the beginning of the epidemic when compared to visual disease assessments. It however had a tendency to overestimate disease when progression was rapid.

Effect of partial resistance on rice blast control with cultivar mixtures. T. ASHIZAWA, K. Zenbayashi, and S. Koizumi. Dept. Lowland Farming, Tohoku National Agricultural Experiment Station, Yotsuya, Omagari, Akita 014-0102, Japan. Phytopathology 89:S3. Publication no. P-1999-0019-AMA.

For the basis of effective control of rice blast disease caused by Pyricularia grisea with multilines, effect of partial resistance on the disease reduction with mixtures of susceptible and resistant rice cultivars was investigated in the paddy field trials from 1997 to 1998 . Four rice cultivars with different levels of partial resistance to blast and a near-isogenic line, developed from cv. Sasanishiki and possessing a complete resistance gene $(P i-z t)$, were used as susceptible and resistant cultivars respectively, and each of the susceptible cultivars was mixed with the resistant line in the proportion of $1: 1$. The mixtures of the susceptible and resistant cultivars reduced leaf and panicle blast and the effectiveness in the blast control was great for mixtures containing cultivars with low levels of partial resistance. Yields in the mixtures were larger than means of component pure stands and the yield increase due to the mixing was high under severe blast disease epidemics.

avrXv4: A new avirulence gene responsible for the hypersensitive reaction in the wild tomato relative Lycopersicon pennellii. G. ASTUA-MONGE (1), G. Minsavage (1), J. B. Jones (1), R. E. Stall (1), and M. J. Davis (2). (1) Dept. Plant Path., Univ. of Florida, Gainesville 32611; (2) Dept. Plant Path., Univ. of Florida, Trop. Res. and Ed. Center, Homestead 33031. Phytopathology 89:S3. Publication no. P-1999-0020-AMA

Tomato race 3 (T3) strains of Xanthomonas campestris pv. vesicatoria (Xcv) elicit a hypersensitive response (HR) in leaves of Lycopersicon pennellii LA716. A total of 600 clones from a genomic DNA library of the T3 strain 91-118 were mobilized by conjugation into the Xcv strain ME-90, virulent on L. pennellii. One cosmid clone, pXcvT3-60 (29 kb insert), induced an HR in resistant plants. Mutagenesis using the Tn3-gus transposon element yielded three mutants unable to elicit an HR in resistant plants. The avirulent phe- 
notype of pXcvT3-60 was confirmed by comparing growth rate in planta and electrolyte leakage among transconjugants carrying the mutated and intact clone, and the wild type T3 strain 91-118. Sequence analysis of the putative avirulence gene is being carried out in order to explore its possible role in eliciting HR and homology with other known avr genes.

Strobilurin-sensitive mutants of Magnaporthe grisea generated by restriction enzyme-mediated integration (REMI). C. AVILA-ADAME, T.-B. Wang, and W. Koeller. Dept. Plant Pathology, NYSAES, Cornell University, Geneva, NY 14456. Phytopathology 89:S4. Publication no. P-1999-0021AMA.

Strobilurin fungicides block the transport of electrons during respiration by binding cytochrome $b$. Difference in sensitivity to strobilurin by several fungi during spore germination and mycelial growth has been related with the expression of the cyanide-resistant respiration. In an attempt to generate mutants more sensitive to strobilurin, the REMI insertional mutagenesis procedure was used to transform the rice blast fungus Magnaporthe grisea. This method allowed the generation of 4,222 transformants that were screened for strobilurin sensitivity in azoxystrobin amended media. Five putative mutants were selected showing $\mathrm{ED}_{50}$ for mycelia growth ranging from 0.006 to 0.02 $\mu \mathrm{g} \mathrm{ml}^{-1}$. The wild type showed an $\mathrm{ED}_{50}$ of $0.03 \mu \mathrm{g} \mathrm{ml}^{-1}$. The $\mathrm{ED}_{90}$ ranged from 0.02 to $0.3 \mu \mathrm{g} \mathrm{ml}^{-1}$ for the putative mutants and more than $10 \mu \mathrm{g} \mathrm{ml}^{-1}$ for the wild type. Two of the five putative mutants were tagged with the hygromycin resistance gene used as a marker for REMI transformation. Cloning of the disrupted gene is in process.

Survival of Tilletia indica teliospores in Montana. M. BABADOOST and D. E. Mathre. Montana State University, Bozeman, MT. Phytopathology 89: S4. Publication no. P-1999-0022-AMA.

Under the auspices of a USDA-APHIS permit, four soil types were used to study survival of teliospores of Tilletia indica, the causal agent of Karnal bunt of wheat, in Montana. The soils were artificially infested with teliospores of T. indica under containment conditions to produce $10^{3}$ teliospores per gram soil. $20 \mathrm{~g}$ of the infested soil was put into a $20-\mu \mathrm{m}$ polyester-mesh bag and sealed. Three bags containing infested soil were placed 2, 10, and 25 $\mathrm{cm}$ deep in PVC tubes, containing the soil. The tubes were buried in the ground at Bozeman, Montana, in October 1997. In June 1998, three tubes of each soil type were removed from the ground and infested soil samples were assayed for presence of $T$. indica teliospores. The extracted teliospores were tested for germination on $2 \%$ WA. T. indica teliospores survived at all three depths in all four soil types through the winter in Montana. However, only $12-35 \%$ of the teliospores were recovered and only $12-19 \%$ of the recovered teliospores germinated. During the 222 days of this study, the temperature was below $0^{\circ} \mathrm{C}$ for 135,134 , and 113 days at 2,10 , and $25 \mathrm{~cm}$ deep in the ground, respectively. The experiment site was covered with snow for more than five months.

Use of a monoclonal antibody to assess the incidence of Botrytis latent infections in strawberry flowers and fruits. R. Bacon (1), A. C. KUSHALAPPA (1), M. Fortin (1), and F. M. Dewey (2). (1) Plant Science Dept., McGill Univ., Ste. Anne de Bellevue, Quebec, Canada H9X 3V9; (2) Plant Science Dept., Univ. of Oxford, Oxford, UK 0X1 3RB. Phytopathology 89: S4. Publication no. P-1999-0023-AMA.

The monoclonal antibody BC12CA4CA9 developed for Botrytis isolated from grapes was evaluated for its efficiency to detect Botrytis in strawberry. The latent flower and fruit infection incidence could be used as a decision tool for timing fungicide applications and marketing strategies. The antibody was tested against $B$. cinerea $(\mathrm{Ag})$ from strawberry or strawberry flowers or fruits, and mixtures of $\mathrm{Ag}$ and strawberries. The absorbance of flowers or fruits was lower than those for $\mathrm{Ag}$ alone or for the mixtures of $\mathrm{Ag}$ and flowers or fruits, at an antibody dilution of 1:800 and Ag dilutions up to 1:1600. The differences were greater for mixtures of $\mathrm{Ag}$ and green or white fruits compared to mixtures of $\mathrm{Ag}$ and flowers or red fruits. Other genera of fungi, associated with commercial strawberry, mixed with Ag or strawberry, had little effect on absorbance. Latent infections were detected in individual strawberry flowers or fruits inoculated with $B$. cinerea.

Transformation of Trichoderma harzianum with GUS and GFP genes enhances monitoring of hyphal growth and biocontrol activity in nonsterile soil. Y.-S. Bae and G. R. KNUDSEN. Department of Plant, Soil, and Entomological Sciences, University of Idaho, Moscow. Phytopathology 89:S4. Publication no. P-1999-0024-AMA.

Trichoderma harzianum was cotransformed with genes encoding green fluorescent protein (GFP), beta-glucuronidase (GUS), and hygromycin B (hygB) resistance. Transformant ThzID1-M3 was mitotically stable over a 6-mo period despite repeated subculturing without selection pressure. ThzID1-M3 was formed into calcium alginate pellets and placed onto buried glass slides in nonsterile soil, and growth, sporulation, and colonization of sclerotia of Sclerotinia sclerotiorum were compared with the wild-type strain. Both strains increased colonization of sclerotia above background levels of colonization by indigenous Trichoderma spp. There were no significant differences in colonization levels between wild-type and cotransformant strains; however, presence of the GFP and GUS marker genes in the cotransformant strain allowed differentiation of introduced Trichoderma from indigenous strains. GFP activity was a useful tool for nondestructive monitoring of hyphal growth in a natural soil. The green color of cotransformant hyphae was clearly visible under UV epifluorescence, while indigenous fungi were barely visible. Green-fluorescing conidiophores and conidia were observed within 3 $\mathrm{d}$ in soil, followed by formation of chlamydospores and disintegration of older hyphal segments. Addition of X-Gluc substrate to recovered glass slides confirmed the activity of GUS in the cotransformant.

Role of prov1 gene encoding extracellular proteinase in Trichoderma virens. Jong-Min BAEK (1), Charles R. Howell (2), and Charles M. Kenerley (1). (1) Texas A\&M University, Department of Plant Pathology and Microbiology, and (2) USDA-ARS, Southern Crop Research Laboratory, College Station, Texas. Phytopathology 89:S4. Publication no. P-1999-0025-AMA.

Strains of Trichoderma virens have been used as biological control agents to protect plants from infection by fungal pathogens. Extracellular hydrolases including chitinases, beta-glucanases and proteinases from $T$. virens have been shown to be induced when strains are grown in the presence of cell wall fragments of phytopathogenic fungi. We have previously shown in vivo that a gene (cht42) encoding an endochitinase plays an important role in the biocontrol activity of $T$. virens. A gene (prov1) encoding an extracellular proteinase was cloned from $T$. virens by screening a genomic cosmid library using the $\mathrm{prbl}$ gene from $T$. harzianum as a probe. The prov1 gene was manipulated in the $T$. virens genome to test the physiological role of this proteinase. Strains of T. virens in which the provl gene was disrupted (PKO) or constitutively overexpressed (POE) were constructed by genetic transformation. Physiological characteristics of the PKO and POE strains including growth rate, proteinase activity, extracellular protein and antibiotic profiles and in vitro growth inhibition of phytopathogenic fungi were determined. The involvement of this gene in the ability of $T$. virens to protect cotton seedlings against Rhizoctonia solani was examined in PKO, POE, and wildtype strains.

Differential contributions of Xanthomonas oryzae pv. oryzae avirulence genes to aggressiveness. J. BAI, S. Choi, and J. Leach. Kansas State University, Manhattan, KS. Phytopathology 89:S4. Publication no. P-1999-0026AMA.

Genomic copies of two Xanthomonas oryzae pv. oryzae avirulence genes, $a v r X a 7$ and $a v r X a 10$, were mutagenized individually and in combination to study their roles in pathogen aggressiveness. These genes are members of a highly related $(>90 \%)$ family. The mutations were confirmed by DNA blot analysis and loss of avirulence function to rice cultivars isogenic for the $\mathrm{Xa} 7$ (IRBB7) or Xa10 (IRBB10) resistance genes. Lesion appearance, lesion length and final bacterial populations of the mutants and the wild type parent PXO86 were determined in cultivars IRBB7 and IRBB10 and the recurrent parent, IR24 (no resistance gene). Compared to PXO86, mutants in avrXa7, including the double mutant (avrXa7-lavrXa10-) showed less severe symptoms and lower final bacterial numbers on all cultivars. The avrXa10 mutants did not show differences compared to PXO86. Complementation with the functional, plasmid-borne copy of avrXa7 restored lesion development and bacterial numbers in the avrXa7- and avrXa7-lavrXa10- mutants. The avrXa10 gene, however, did not restore aggressiveness to the double mutant. Thus, avrXa7 contributes more to pathogen aggressiveness than avrXa10.

Fludioxonil: New opportunity for the control of stem canker and black scurf and Fusarium dry rot diseases of potatoes in Canada. P. S. BAINS (1), H. Bennypaul (1), and C. Schaupmeyer (2). (1) Alberta Agriculture Food and Rural Development, Edmonton, Canada; (2) Alberta Agriculture Food and Rural Development, Brooks, Canada. Phytopathology 89:S4. Publication no. P-1999-0027-AMA.

Fungicides registered in Canada for the control of Rhizoctonia stem canker and black scurf (Rhizoctonia solani) and dry rot (Fusarium spp.) diseases of potatoes are either not very effective or some isolates of the pathogens have developed resistance to the fungicide(s). Field experiments conducted to 
determine the efficacy of fungicides indicated that pre-plant treatment of seed tubers with fludioxonil (Maxim) significantly reduced Rhizoctonia canker on stems and black scurf on progeny tubers. The fungicide caused complete inhibition of in vitro growth of a thiabendazole-resistant isolate of Fusarium sambucinum at $2 \mathrm{ppm}$ (the lowest concentration tested) and as a seed treatment caused reduction in the inoculum potential of soil surrounding the progeny tubers. The results taken together suggest that pre-treatment of potato seed tubers with Maxim could provide an effective control of Rhizoctonia stem canker and black scurf and dry rot diseases of potatoes.

Determination of whole-cell fatty acid profiles of isolates of Rhizoctonia solani AG-4 and AG-7. R. E. BAIRD (1), R. D. Gitaitas (2), and D. E. Carling (3). (1) Entomology and Plant Pathology, Mississippi State University, Mississippi State, MS 39762; (2) Plant Pathology, CPES, University of Georgia, Tifton, GA 31793; (3) Agricultural and Forestry Experiment Station, University of Alaska, Palmer, AK 99645. Phytopathology 89:S5. Publication no. P-1999-0028-AMA.

Fatty acid methyl esters (FAMEs) of isolates of $R$. solani AG-4 and AG-7 were characterized by gas chromatography and analyzed with Microbial Identification System software. Palmitic, steric and oleic acids were common in all isolates from both anastomosis groups and accounted for $95 \%$ of the C14-C18 fatty acids present. Individual fatty acids could not be used for separating AG-4 isolates from AG-7. AG-4 isolates could be distinguished from AG-7 isolates when quantities of FAMEs and key FAME ratios were analyzed with principle components analysis and principle components were plotted. Isolates of AG-7 from Arkansas, Indiana, and Georgia clustered more closely to each other than to AG-7 isolates from Japan and Mexico. A dendrogram analysis cluster constructed from the FAMEs was similar. Euclidean distances of total AG-4 isolates were distinct from total AG-7 isolates. The Arkansas and Indiana AG-7 isolates had a similar Euclidean distance to each another but were different from AG-7 isolates from Japan and Mexico. Georgia AG-7 had a Euclidean distance the same as the AG-4 isolates.

Symbiosis-regulated gene expression and biochemical characterization of a malate synthase, from Laccaria bicolor. S. BALASUBRAMANIAN and G. K. Podila. Dept. of Biological Sciences, Michigan Technological University, Houghton, MI. Phytopathology 89:S5. Publication no. P-1999-0029AMA.

Formation of mycorrhizal associations is mutually beneficial to both the plant host and the fungal partner. In order to utilize the potential benefits of these relationships, a better understanding of the molecular basis of the establishment of the mycorrhizal association is necessary. Recently, we have cloned a cDNA for peroxisomal malate synthase which is induced during early stages of interaction between ectomycorrhizal fungus $L$. bicolor with it host Pinus resinosa. Our goal is to elucidate the mechanism of malate synthase induction during symbiotic interaction and its role in the establishment of symbiosis. Towards this goal, we are pursuing (1) various growth conditions and carbon sources under which malate synthase expression can be induced (2) production and biochemical characterization of the recombinant enzyme and (3) localization of malate synthase expression during symbiotic interaction. Data from the above studies and progress made in elucidating the role of malate synthase in ectomycorrhizal symbiosis will be presented.

Environmental constraints on infection of big bluestem by Puccinia andropogonis. C. W. BARNES and J. V. Groth. University of Minnesota, St. Paul, MN. Phytopathology 89:S5. Publication no. P-1999-0030-AMA.

We characterized some of the variables affecting successful infection by the rust $P$. andropogonis on its two hosts, Comandra umbellata and big bluestem (BBS) Andropogon gerardii, for eventual use in models designed to compare heteroecism with autoecism as evolutionary strategies in northern climates. The strategy of heteroecism in rusts must be advantageous under certain environmental conditions in spite of the added risk of having the rust move between different hosts. Our approach is to study the fungus in a natural system where selection has operated in a relatively stable plant community for a long time. We measured alternate host distances, number of aecia on C. umbellata, and general overhead cover for isolated stands of BBS. In a stepwise regression analysis where rust severity on BBS was used as the dependent variable, number of aecia and cover influenced BBS rust severity ( $p=0.0008, R^{2}=0.23$ ), while distance between hosts did not contribute significantly to BBS rust severity. Results of a 3-way ANOVA showed no significant interactions between the independent variables.
Development and application of TaqMan ${ }^{\mathrm{TM}}$ quantitative PCR assays for the detection of wheat eyespot pathogens. J. BARNETT and J. J. Beck. Novartis Agribusiness Biotechnology Research, Inc., Crop Disease Diagnostics, Research Triangle Park, NC. Phytopathology 89:S5. Publication no. P-1999-0031-AMA.

We have developed TaqMan ${ }^{\mathrm{TM}}$ assays for the detection and quantification of Tapesia yallundae (syn. Pseudocercosporella herpotrichoides W-type) and T. acuformis (syn. P. herpotrichoides R-type) in wheat. These assays differentiate the causative agents of cereal eyespot from other common cereal pathogens. The TaqMan ${ }^{\mathrm{TM}}$ assays provide quantification of disease pressure. Data showing pre-symptomatic detection of W- and R-type eyespot in wheat stem tissues from the U.S. Pacific Northwest is documented and correlated with an established PCR-based screening program*. These assays were developed as a tool for precision fungicide application and to promote sustainable agriculture. TMTaqMan is a registered trademark of Roche Molecular Systems, Inc. *These tests were performed pursuant to licensing arrangements with the Perkin-Elmer Corp. under patent rights owned by HoffmannLaRoche Ltd. and Hoffmann-LaRoche, Inc.

ABOUND ${ }^{\mathrm{TM}}$ : Uptake and redistribution of azoxystrobin in peanuts. D. W. BARTLETT (1), G. A. Kingston (1), and J. N. Lunsford (2). (1) Zeneca Agrochemicals, Jealott's Hill Research Station, Bracknell RG42 6ET, UK; (2) Zeneca Ag Products, Enterprise, AL. Phytopathology 89:S5. Publication no. P-1999-0032-AMA.

ABOUND ${ }^{\mathrm{TM}}$ was registered for use in peanuts in 1997. It is formulated as a $2.08 \mathrm{lb} /$ gallon suspension concentrate of azoxystrobin with recommended use rates of 0.3 to $0.4 \mathrm{lb}$ a.i. per acre in two applications at approximately 60 and 90 days after planting. ABOUND ${ }^{\mathrm{TM}}$ provides excellent foliar disease control against Cercospora leaf spot and peanut rust and against soil-borne diseases such as white mold and pod rot and peg rot. Foliar uptake of azoxystrobin is a gradual process, with $15-20 \%$ of applied material absorbed into leaves within 6 hours of application. Absorbed azoxystrobin diffuses from the point of uptake and is redistributed evenly throughout the leaf in the xylem; $23 \%$ of the azoxystrobin absorbed into peanut leaves had moved systemically above the zone of application after 7 days. Azoxystrobin also has translaminar mobility. The ABOUND ${ }^{\mathrm{TM}}$ that is not absorbed is gradually washed from the leaf surface over time and contributes to the control of soilborne disease.

Analysis of p48, a replicase-associated protein of Panicum mosaic virus. J. S. BATTEN, M. Turina, and K.-B. G. Scholthof. Texas A\&M University, College Station, TX. Phytopathology 89:S5. Publication no. P-1999-0033AMA.

Panicum mosaic virus (PMV), the type member of the Panicovirus genus, is a positive-sense, single-stranded RNA virus that infects grass species. The genomic RNA of PMV is used for translation of two replicase-associated proteins, p48 and p112. Thus far, no known biological function has been assigned to 448 or analogous proteins within the Tombusviridae. However, a series of amino acids immediately upstream from the p48 readthrough amber codon are conserved within the Tombusviridae. Seven amino acids in this conserved region were changed to uncharged alanine residues. Four mutants (Y330A, D363A, C335A, P399A) showed reduced virus replication in millet protoplasts and delayed systemic movement in plants. In addition, these PMV mutants were able to support replication of SPMV, a satellite virus dependent on PMV for replication. Three other mutants (F313A, F357A, and W405A) failed to replicate in either protoplasts or plants. Therefore, these data suggest that this conserved replicase domain plays a role in efficient replication of PMV and trans-acting replication of SPMV.

Diagnostic PCR assay for the detection of Pyrenophora tritici-repentis in wheat. J. J. BECK. Novartis Agribusiness Biotechnology Research, Inc., Crop Disease Diagnostics, 3054 Cornwallis Road, Research Triangle Park, NC 27709-2257. Phytopathology 89:S5. Publication no. P-1999-0034-AMA.

PCR primers have been developed which are specific for the internal transcribed spacer (ITS) region of the nuclear rRNA gene of the causative agent of tan spot in wheat. This primer combination PCR amplifies from purified DNA isolated from multiple isolates of $P$. tritici-repentis. The primers do not cross-react with other common cereal pathogens or from healthy wheat tissue. These primers were used to characterize natural field infections in a trial with controlled fungicide applications. In addition to PCR analysis, the samples were visually assessed for leaf spot disease. The PCR assays successfully demonstrated the presence of the pathogen and the PCR results correlated well with the visual disease assessments. All field plots showed a high level 
of disease prior to fungicide treatment. As the growing season progressed the untreated fungicide plot showed a higher level of disease relative to the fungicide treated plots.

Synergistic interactions between Rhizoctonia solani and Agrobacterium biovar 1 in causing crown gall of cotton. A. A. BELL. USDA-ARS, SCRL, CPRU, College Station, TX 77845. Phytopathology 89:S6. Publication no. P-1999-0035-AMA.

Soreshin lesions caused by Rhizoctonia solani on cotton hypocotyls in the field invariably contained concentrations of Agrobacterium biovar 1 species more than 100 times greater than did adjoining healthy hypocotyl tissues. When cotton seedlings were inoculated sequentially with any of three Agrobacterium strains carrying Ti plasmids (i.e., A. tumefaciens) followed 4-14 days later by $R$. solani, a high frequency of crown gall tumors developed at the soil line. No tumors developed when plants were inoculated with the $A$. tumefaciens strains alone using a variety of wounding techniques. The synergistic interactions were observed with each of eight isolates of $R$. solani from cotton and each of ten different cotton cultivars. Macrophomina phaseoli, Diplodia gossypii or Phoma exigua used with A. tumefaciens failed to induce galls on cotton. The results indicate that $R$. solani or its infections may produce unique metabolites that activate virulence genes in infectious plasmids of A. tumefaciens strains obtained from cotton roots.

Disease incidence of Phytophthora root rot of Fraser fir in North Carolina. D. M. BENSON and L. F. Grand. N.C. State University, Raleigh, NC. Phytopathology 89:S6. Publication no. P-1999-0036-AMA.

A survey of Fraser fir (Christmas tree) growing areas in North Carolina for incidence of Phytophthora root rot was conducted during 1997 and 1998. Representative transplant beds ( 3 to 5 yr-old trees) and field plantings ( 7 to 13 yr-old trees) were surveyed for foliar symptoms of Phytophthora root rot. In transplant beds where a systematic sampling procedure was used, incidence of diseased trees was $0.2 \%$ statewide with a range of $0-11.9 \%$ per location. Recovery of Phytophthora spp. averaged 1.2\% from root samples collected from 50 apparently healthy seedlings at each location. Field plantings were surveyed with a random transect method (>3000 trees/field) or by counting all trees ( $<3000$ trees/field). Statewide, incidence of Phytophthora root rot was $6.3 \%$ with a range of 0 to $75 \%$ per field. Phytophthora spp. were recovered from $1.8 \%$ of apparently healthy trees sampled across the state. $P$. cinnamomi accounted for $97 \%$ of isolates recovered. No difference in disease incidence was found for fields in first, second, or third crop rotation. None of 251 isolates of $P$. cinnamomi tested were insensitive to metalaxyl. Incidence of Phytophthora root rot was similar to that recorded in 1976-77.

Effect of environmental factors on spore germination and pycnidial production of Microsphaeropsis sp., a mycoparasite of Venturia inaequalis. J. BERNIER and O. Carisse. Agriculture and Agri-Food Canada, St-Jean-surRichelieu, Qc., Canada. Phytopathology 89:S6. Publication no. P-1999-0037AMA.

The effect of environmental factors on spore germination and pycnidial production of four strains of Microsphaeropsis sp., a mycoparasite that inhibits pseudothecia production of Venturia inaequalis was examined. The objective was to acquire information on this mycoparasite that could be used to enhance efficacy in the field and to target the best time for application. The effect of temperature (5 to $25 \mathrm{C}$ ) and $\mathrm{pH}(4$ to 8 ) on conidial germination over a $40 \mathrm{hr}$ period was studied on culture media. In addition to temperature and $\mathrm{pH}$, the effect of the photoperiod $(0,8,12,16,24 \mathrm{hr})$ on pycnidia production was evaluated every three days for two to three weeks. Minimum conditions for $100 \%$ spore germination were $15 \mathrm{C}$ for $40 \mathrm{hr}$. Optimum $\mathrm{pH}$ for spore germination was 5 for all strains. Optimum temperature for pycnidia production was 20 or $25 \mathrm{C}$ depending on strain. The temperature range for pycnidia production was between 15 and $25 \mathrm{C}$ except for two strains that produced pycnidia at $10 \mathrm{C}$. Pycnidia production was light dependent and production decreased with increasing $\mathrm{pH}$.

Ontogenic resistance to apple scab, post-infection use of fenarimol, and the distribution of symptom expression. Onofre BERTON, D. M. Gadoury, R. C. Seem, and W. F. Wilcox. Department of Plant Pathology, Cornell University, New York State Agricultural Experiment Station, Geneva 14456. Phytopathology 89:S6. Publication no. P-1999-0038-AMA.

Shoots of McIntosh apple trees inoculated with Venturia inaequalis were shielded from secondary infection. Typical lesions developed after 16 days at leaves 1 (1st unfurled leaf at inoculation) and 2. Chlorotic spots developed at leaves 3-6 on day 16 , but these converted to sporulating lesions over the next 70 days. Leaves $7-13$ were symptomless at day 30 , but some developed inconspicuous symptoms later. Conidia were harvested from symptomless leaves at nodes 7-13 at day 170 and ascospores were released after overwintering. Three post-infection sprays of fenarimol affected initial disease, but not the pattern of symptom expression. Analysis of sensitivity to fenarimol of isolates from sprayed and unsprayed trees indicated that both escape and selection may determine the distribution of sensitivity. The prevalence of late-season scab may be related to fungistasis in older leaves as influenced by ontogenic resistance, sublethal effects of fungicides, and sporulation in symptomless leaves.

Induction of resistance against gray mold rot in carrot roots by chitosan. M. V. BHASKARA REDDY, Ronan Curcuff, Mohammad R. Kasaai, Francois Castaigne, and Joseph Arul. Dept. Food Science and Nutrition and Horticultural Research Center, Laval University, Sainte-Foy, Quebec, Canada, G1K 7P4. Phytopathology 89:S6. Publication no. P-1999-0039-AMA.

The direct and systemic antifungal effect of chitosan (beta-1,4-glucosamine polymer) against Botrytis cinerea in stored carrots was investigated, in comparison to benomyl. Carrots were stored at 4 and $13^{\circ} \mathrm{C}$ for 14 days following the treatment, and were subsequently challenged with $B$. cinerea. The lesion diameter was measured periodically up to 25 days at $4^{\circ} \mathrm{C}$ and 15 days at $13^{\circ} \mathrm{C}$. The level of 6-MM, the principal phytoalexin of carrots was also assayed in the treated periderm tissue before inoculation. Chitosan exhibited antifungal activity, both directly and systemically, and induced 6-MM production. The direct inhibition of the fungus by chitosan was $90 \%$ at $4{ }^{\circ} \mathrm{C}$ and $80 \%$ at $13{ }^{\circ} \mathrm{C}$ at the end of storage period, whereas it was $99 \%$ for benomyl at both the temperatures. The indirect inhibition was $56 \%$ at $4{ }^{\circ} \mathrm{C}$ and $27 \%$ at $13^{\circ} \mathrm{C}$ by chitosan and 87 and $89 \%$ respectively for benomyl treatment. The results indicated that chitosan was as effective as benomyl in direct activity, but chitosan was less effective than benomyl in systemic effect. The systemic effect of benomyl is due to translocation of the fungicide, whereas in the case of chitosan it is likely that a defense signaling system is involved.

Antigenic diversity among peanut stripe Potyvirus (family Potyviridae) isolates. A. I. Bhat (1), S. S. Pappu (2), H. R. PAPPU (1), A. K. Culbreath (1), and J. W. Todd (2). (1) Department of Plant Pathology and (2) Department of Entomology, University of Georgia, Coastal Plain Experiment Station, Tifton, GA 31793. Phytopathology 89:S6. Publication no. P-1999-0040AMA.

Several geographically and biologically distinct isolates of peanut stripe Potyvirus (PStV) were tested against available polyclonal and monoclonal antibodies. In direct antigen coated enzyme linked immunosorbent assay (DACELISA), the polyclonal antisera prepared against the purified virus reacted with all the isolates tested. However, a monoclonal antibody, 3AB5, also prepared against the purified virus showed dramatic difference in its reactivity to the same isolates. Tested against blotch isolates from Georgia, Virginia and Florida, 3AB5 reacted with two out of a total ten. The reaction was either strongly positive or clearly negative. $3 \mathrm{AB} 5 \mathrm{did}$ not react with a necrotic strain of PStV from Taiwan. Results suggest the existence of antigenic diversity among PStV isolates.

Phylogeny of tospoviruses based on intergenic region of $M$ and $S$ RNAs. A. I. Bhat (1), S. S. Pappu (2), H. R. PAPPU (1), C. M. Deom (3), and A. K. Culbreath (1). (1) Dept. of Plant Pathology; (2) Dept. of Entomology, Univ. of Georgia, Coastal Plain Expt. Station, Tifton, GA 31793; (3) Miller Plant Sciences Bldg., Athens, GA 30602. Phytopathology 89:S6. Publication no. P-1999-0041-AMA.

The genome of tospoviruses consists of three RNA segments, S, M and L. While L RNA is in negative polarity with a single open reading frame (ORF), $\mathrm{M}$ and S genomic RNAs have two ORFs each, with ambisense coding strategies. Both S and M RNAs possess an intergenic region (IGR) of varying lengths. The IGRs of both S and M RNAs are reported to modulate transcription. Our analysis of the IGR sequences of all available S and M RNAs indicated the possibility of using this region for the classification of tospoviruses. Comparative analysis indicated that the IGRs exhibit heterogeneity both in length and sequence. IGRs of M RNA were shorter in length compared to the IGRs of their respective S RNA species. Percent identity among the S RNA IGR sequences of distinct tospovirus species varied from 42$57 \%$, whereas it was 79-99\% among strains of the same species. Similarly, when IGRs of M RNAs were compared, there was higher sequence identity among isolates of a distinct tospovirus species (83-100\%) than between tospovirus species (46-59\%). 
Comparison of Verticillium dahliae isolates from cruciferous and noncruciferous hosts. R. G. BHAT and K. V. Subbarao. UC Davis, 1636 E. Alisal St., Salinas, CA 93905. Phytopathology 89:S7. Publication no. P-19990042-AMA.

Representative isolates of Verticillium dahliae from four crucifer and 11 noncrucifer hosts and an isolate of V. albo-atrum from alfalfa were compared for morphology of conidia and microsclerotia, pathogenicity, ability to produce nit mutants, and random amplified polymorphic DNA (RAPD) markers. Crucifer isolates produced a low number of large conidia on PDA compared with $V$. albo-atrum and non-crucifer isolates, which produced abundant, small conidia. Microsclerotia of crucifer and non-crucifer isolates were irregular in shape. Crucifer isolates produced more linear microsclerotia on PDA compared with non-crucifer isolates that produced more globular microsclerotia. Crucifer isolates were severely pathogenic only on crucifer hosts with some exceptions and caused mild infection on few other hosts. Non-crucifer isolates and V. albo-atrum isolate were destructive on their host of origin and showed varying degrees of infection on other hosts tested. Only crucifer isolates did not produce nit s. RAPD marker profiles of crucifer isolates were distinct from others. Many of the markers present in crucifer isolates were not present either in V. albo-atrum or non-crucifer isolates, indicating that crucifer isolates were not the result of parasexual hybridization between $V$. dahliae and $V$. albo-atrum. Thus, crucifer isolates belonged to a separate group in $V$. dahliae.

Pathogenicity of Verticillium dahliae isolates on plants other than their own hosts. R. G. BHAT and K. V. Subbarao. University of California, Davis, 1636 E. Alisal St., Salinas, CA 93905. Phytopathology 89:S7. Publication no. P-1999-0043-AMA.

Pathogenicity of Verticillium dahliae isolates from artichoke, bell pepper, cabbage, cauliflower, chili pepper, cotton, eggplant, horseradish, lettuce, mint, oilseed rape, potato, strawberry, tomato, and watermelon was tested on four crucifers (bok choy, chinese cabbage, radish and oilseed rape) and three non-crucifers (bean, carrot and sugarbeet). Spore suspensions containing approximately $10^{7}$ conidia/ml were used for root-dip inoculation of 30-dayold seedlings in the greenhouse. Plant height, percent disease incidence and disease severity were recorded eight weeks after inoculation. Isolates from crucifer hosts and watermelon caused severe disease on crucifers with the exception of horseradish isolate on chinese cabbage. Isolates from cotton, lettuce, and strawberry were non-pathogenic to crucifers whereas the remaining isolates differentially interacted. Carrot and sugarbeet plants were resistant to all the isolates tested. Bean plants, which have been considered as non-hosts of Verticillium, were susceptible to nine isolates which included the isolates from artichoke, bell pepper, tomato and strawberry among others. Data support the previous conclusion that $V$. dahliae isolates from various hosts have a host range specificity.

In search of the Ralstonia solanacearum siderophore gene. G. BHATT and T. P. Denny. University of Georgia, Athens, GA. Phytopathology 89:S7. Publication no. P-1999-0044-AMA.

$R$. solanacearum, a soil borne phytopathogen that causes wilt disease in a wide variety of plants, produces the siderophore schizokinen. The goal of this project is to isolate and characterize the siderophore biosynthetic genes and determine the role of iron acquisition in pathogenesis. Mutants of the global virulence regulator, PhcA, show increased siderophore production. Downstream of $p h c A$ is the ferric uptake regulator (fur) gene, which suggests that iron may be involved in virulence. Random Tn5 mutants were screened for reduced production of schizokinen using the CAS universal siderophore indicator medium, which was modified for $R$. solanacearum by reducing the PIPES to $0.3 \%$ and using various non-deferrated complex amino-acid mixtures. The first siderophore mutant appeared to have $\operatorname{Tn} 5$ inserted in the sulfite reductase gene, and is thus a cysteine auxotroph. This mutant is too pleiotropic, for our purposes. At least three other mutants (which do not seem to be amino acid auxotroph ht. The siderophore mutants will be tested for changes in virulence and survival.

Antrodia sinuosa is significant in brown heartwood rot of living lemons in Arizona. D. M. BIGELOW (1), M. E. Matheron (2), and R. L. Gilbertson (1). (1) University of Arizona, Tucson, AZ; (2) University of Arizona, Yuma, AZ. Phytopathology 89:S7. Publication no. P-1999-0045-AMA.

Brown heartwood rot has been observed in all mature lemon trees sampled in the Yuma area. Our research has shown brown rot in Yuma lemon orchards is due mainly to two basidiomycetes, Coniophora eremophila Lindsey \& Gilb. and Antrodia sinuosa (Fr.) P. Karst. A. sinuosa was isolated from heartwood rot samples from $63 \%$ of the 40 lemon orchards checked to date. Heterogenic incompatibility tests pairing 26 isolates of A. sinuosa from 11 orchards indicated that they are different genotypes. This implies that infection resulted from airborne basidiospores. Mean length of decay column in inoculated 4-cm diameter lemon branches after six months was $20.7 \mathrm{~cm}$ for $A$. sinuosa compared to $4.7 \mathrm{~cm}$ for $C$. eremophila. Fruiting bodies of $A$. sinuosa have been found in orchards each month since the survey was started in September 1998. C. eremophila has not been found fruiting on lemon trees. A. sinuosa is potentially more destructive than $C$. eremophila because it fruits readily in the field and grows more rapidly.

Effect of soil moisture on tomato seed-to-seedling transmission of Clavibacter michiganensis subsp. migichganensis. C. M. Biggerstaff, M. L. GLEASON, and E. J. Braun. Department of Plant Pathology, Iowa State University, Ames, IA 50011. Phytopathology 89:S7. Publication no. P-19990046-AMA.

To determine the effect of soil moisture on seed-to-seedling transmission of Clavibacter michiganensis subsp. michiganensis $(\mathrm{Cmm})$ in tomatoes, $\mathrm{Cmm}$ infested tomato seeds (cv. Heinz 1916) were germinated in two different media (one composed of $20 \%$ soil, $50 \%$ peat and $30 \%$ perlite, the other a commercial mix of peat and perlite) in sealed plastic cups at six different matric potentials from near saturation to $-0.1 \mathrm{MPa}$. Cups were placed in a growth chamber at $27 \mathrm{C}$ and $75 \% \mathrm{RH}$ under $24 \mathrm{~h}$ light. All seedlings in a treatment were harvested when $40 \%$ of the seedlings had fully expanded cotyledons. After noting presence or absence of attached seed coats, seedlings (including seed coats if attached) were individually macerated in buffer and plated on selective media. There were no significant differences in percent transmission of $\mathrm{Cmm}$ among moisture treatments, although there was a trend toward greater occurrence of $\mathrm{Cmm}$ on seedlings germinated at intermediate matric potentials. $\mathrm{Cmm}$ transmission was highly correlated with seed coat retention; $94 \%$ of $119 \mathrm{Cmm}$-positive seedlings retained their seed coat.

An improved ELISA for detection and quantitation of neomycin phosphotransferase II in plants. W. O. BLISS, J. Q. Xia, and C. L. Sutula. Research Dept., Agdia, Inc., Elkhart, IN 46514. Phytopathology 89:S7. Publication no. P-1999-0047-AMA.

An improved ELISA has been developed to detect and measure neomycin phosphotransferase II (NPT II) in transgenic plants. The test is based on a polyclonal antibody and a monoclonal antibody specific for NPT II protein. The microtiter plate is coated with the polyclonal antibody and incubated with sample. NPT II protein captured on the plate is then detected with the monoclonal antibody and an antimouse antibody-enzyme conjugate. Test conditions were optimized by comparing different buffers, surfactants, blocking reagents, and washing and incubation times. Specificity of the resulting ELISA is much improved compared to currently available NPT II tests. This test can be used with crops such as corn, potato, tobacco, cucurbits and others. NPT II protein can be detected at $0.4 \mathrm{ng} / \mathrm{ml}$, or $40 \mathrm{pg}$ per test well. This improved ELISA provides a reliable way to detect and quantitate NPT II in transgenic plants.

Variation in aggressiveness of Sphaeropsis sapinea RAPD marker groups on several conifers. J. T. BLODGETT and G. R. Stanosz. University of Wisconsin, Madison, WI. Phytopathology 89:S7. Publication no. P-1999-0048AMA.

Diseases caused by $S$. sapinea can result in extensive losses in Christmas tree and ornamental plantings. Hosts with particular value as ornamental or Christmas trees include Scots varieties East Anglia and Austrian Hills, red, and mugho pines, Colorado blue spruce, Douglas-fir, and balsam fir. Seedlings of these species/varieties were wounded and inoculated with isolates of the two RAPD marker groups (A and B) of S. sapinea. Symptom severity (distance from the inoculation site at which necrotic needles were present) resulting from inoculation with group A isolates exceeded that of B isolates on all hosts except blue spruce. The hosts varied considerably in responses to A group isolates. Based on symptom severity, East Anglia Scots pine was most susceptible and balsam fir was least susceptible when inoculated with A isolates. The pathogen was recovered from symptomatic and asymptomatic seedlings inoculated with isolates of both groups. This study emphasizes the importance of characterizing the group(s) of $S$. sapinea encountered and the potential to compare resistance to both groups among coniferous genera, species, and/or varieties. 
Infection, colonization, and disease of Amaranthus hybridus by Alternaria tenuissima. J. T. BLODGETT, W. J. Swart, C. M. Bender, and Weiqun Chen. University of the Orange Free State, Bloemfontein, South Africa. Phytopathology 89:S8. Publication no. P-1999-0049-AMA.

Amaranthus hybridus is a leafy-vegetable crop with potential for cultivation in semi-arid regions of the world. The study objectives were to identify foliar fungi in the crop, test pathogenicity, and determine infection and colonization patterns of leaf tissue. A. hybridus plants were sampled from two sites in South Africa. The most common fungus isolated from asymptomatic, surface-sterilized leaf tissue was A. tenuissima (87\%). Eight isolates were selected for pathogenicity tests using wounded/unwounded leaves. Scanningelectron microscopy observations revealed A. tenuissima spores germinating on the surface and only entering through stomata of unwounded, inoculated leaves. Unwounded, inoculated leaves had no symptoms and light microscopy observations revealed hyphae in mesophyll tissue growing intercellularly with no cell penetration. Seven of the 8 isolates produced brown, circular, necrotic lesions only at the wound site of wounded and inoculated leaves. These tissues were collapsed and colonized. Results suggest that $A$. tenuissima can act as a latent leaf pathogen with an endophytic phase.

Nematode pathogenicity to sugarcane cultivars in Louisiana: Microplot conditions. J. P. BOND (1), E. C. McGawley (1), J. W. Hoy (1), and W. P. Bond (2). (1) Department of Plant Pathology and Crop Physiology, Louisiana State University Agricultural Center, Baton Rouge, LA 70803; (2) Department of Biological Sciences, Southeastern Louisiana University, Hammond, LA 70402. Phytopathology 89:S8. Publication no. P-1999-0050-AMA.

Populations of Tylenchorhynchus spp., Mesocriconema spp., and Trichodorus spp. occur commonly in Louisiana sugarcane soils and increase in density with successive ratoon crops. Three microplot experiments evaluated the damage potential of this community to cultivars that are commonly planted. Two sugarcane cultivars: CP70-321 or LCP82-089 and three nematode infestation levels: $0,1,200$, or 12,000 nematodes per microplot (approximately equal portions of each species) were arranged in a randomized complete block with a $2 \times 3$ factorial treatment structure. Across both cultivars, top weight was reduced at the highest infestation level. Root and plant dry weight were reduced at both infestation levels. Across all treatments, plant dry weight for LCP82-089 was less than that of CP70-321. Final nematode populations at both infestation levels did not differ for all three nematode species. For each species, nematode reproduction was greatest at the low infestation level.

Use of acidic electrolyzed water to obtain axenic cultures of Tilletia indica from wheat or soil samples. M. R. BONDE (1), S. E. Nester (1), J. L. Smilanick (2), R. D. Frederick (1), N. W. Schaad (1), and D. G. Luster (1). (1) USDA-ARS, FDWSRU, Ft. Detrick, MD 21702-5023; (2) USDA-ARS, Fresno, CA 93727. Phytopathology 89:S8. Publication no. P-1999-0051-AMA.

Acidic electrolyzed water (AEW), a product of electrolysis (Super Oxseed Labo JED 020; Advanced $\mathrm{H}_{2} 0$, Alameda, CA) of a dilute solution of $\mathrm{NaCl}$, was very effective for treating wheat or soil wash extracts to obtain axenic cultures of $T$. indica. When debris was extracted from 15 separate 50 -g wheat samples by means of size-selective sieving (Peterson et al., Phytopathology 88:S131), treated 20 min with AEW, and plated on water agar plus antibiotics (AW agar), an average of three non-smut fungal colonies grew per sample. Of $210 \mathrm{AW}$ agar plates seeded with soil extract obtained by sucrosecentrifugation (Babadoost et al., Plant Dis. 82:1357-1361), only 7\% supported microbial growth other than $T$. indica. Contaminants on AW agar seeded with non-treated wheat or soil extracts were too numerous to count. Besides eliminating most non-smut organisms, a 15- to 30-min AEW treatment typically at least doubled $T$. indica teliospore germination at 7 days after plating.

Fruit, blossom and foliar epiphytic populations of strawberry on the California coast. A. C. BORDAS (1), S. T. Koike (2), W. D. Gubler (1), and C. T. Bull (3). (1) UC Davis, Dept. of Plant Pathology; (2) UC Coop. Extension, Salinas, CA; (3) USDA-ARS, Salinas, CA. Phytopathology 89:S8. Publication no. P-1999-0052-AMA.

We have conducted preliminary studies to identify common microbial residents of aerial surfaces of strawberry. Microbial populations of strawberry plants were sampled during the 1997 and 1998 growing seasons. Bacteria and fungi were isolated from plants sampled at two locations, Watsonville and Salinas, CA. The cultivars sampled were Seascape and Selva in 1997 and 1998, respectively. The plant tissues sampled were fully expanded leaves, mature red fruit, and fully opened blossoms. Isolations of bacteria were made on half strength nutrient agar, isolations of fungal populations were made on PDA amended with tetracycline. Bacteria were identified by whole cell fatty acid analysis using the Microbial Identification System (MIS) software package (MIDI, Inc., Newark, DE) with an aerobe library. Fungi were identified using morphological characteristics. Bacteria identified from fruit surfaces include isolates of Pseudomonas, Bacillus, Pantoea, and Yersinia. Fungi identified from fruit surfaces include isolates of Botrytis, Sporobolomyces, Cladosporium, Aspergillus, and Penicillium spp. For both years, greater populations of bacteria and fungi were found on fruit than on blossoms or leaves at both locations.

Evaluation of compost for biological control of dollar spot (Sclerotinia homoeocarpa) on creeping bentgrass (Agrostis palustris). J. I. BOULTER, G. J. Boland, and J. T. Trevors. University of Guelph, Guelph, ON N1G 2W1, Canada. Phytopathology 89:S8. Publication no. P-1999-0053-AMA.

The influence of high quality, reproducible composts on turfgrass health is being investigated. In this study, five compost mixtures (All Treat Farms, Ltd., Arthur, ON) were evaluated for suppression of dollar spot (Sclerotinia homoeocarpa) of creeping bentgrass (Agrostis palustris). Field plots inoculated with $S$. homoeocarpa were topdressed with compost in single or multiple (every 3 weeks) applications from July to October 1998, and disease severity was rated weekly. In most assessments, multiple applications of compost significantly $(P=0.05)$ suppressed dollar spot severity in comparison to untreated controls or the single application treatments, and were not significantly different from disease severity in plots treated with a fungicide standard (chlorothalonil). There were no significant differences among the five compost mixtures in their ability to control dollar spot. The results indicate that applications of quality composts every three weeks can suppress dollar spot in creeping bentgrass at levels comparable to a fungicide and contribute to reduced fungicide use.

Effect of botanical extracts on populations of Phytophthora nicotianae and disease control in the greenhouse. J. H. BOWERS and J. C. Locke. USDA-ARS, U.S. National Arboretum, Floral and Nursery Plant Research Unit, Beltsville, MD 20705. Phytopathology 89:S8. Publication no. P-19990054-AMA.

Botanical extracts are being investigated for control of diseases caused by Phytophthora. Soil infested with chlamydospores of Phytophthora nicotianae (P.n.) was treated with 1, 5, and $10 \%$ aqueous emulsions of formulated extracts of clove ( $70 \%$ clove oil), neem ( $90 \%$ neem oil), pepper (chili pepper and essential oil of mustard), cassia (cassia tree extract), and metalaxyl. Population densities of P.n. were determined at 0 (before treatment), 1, 3, 7, 14 , and 21 days after treatment. Treatment of the soil with 5 and $10 \%$ aqueous emulsions resulted in significant $(P<0.05)$ differences among treatment mean values at each assay date. After 3 days, the clove and cassia extracts added as $10 \%$ aqueous emulsions reduced the population density of P.n. 99.6 and $99.2 \%$, respectively, while the pepper formulation reduced the P.n. population to below the limit of detection $\left(<0.4 \mathrm{cfu} / \mathrm{cm}^{3}\right)$. In the greenhouse after 35 days, $10 \%$ aqueous emulsions of the pepper and cassia extracts suppressed disease development in periwinkle (90-100\% healthy plant stand) compared to the untreated infested soil ( $<5 \%$ stand).

Interaction of glyphosate with microbial biocontrol agents for Canada thistle. S. M. BOYETCHKO, K. L. Bailey, W. Hall, K. Sawchyn, T. Nelson, and J. Derby. Agriculture and Agri-Food Canada, Saskatoon, SK. Phytopathology 89:S8. Publication no. P-1999-0055-AMA.

Application of sub-lethal rates of glyphosate with Pseudomonas syringae pv. tagetis (Pst) and Alternaria sp. (93-109B1) to enhance their efficacy for biocontrol of Canada thistle was investigated. Pst causes apical chlorosis while Alternaria produces extensive foliar necrosis. In greenhouse studies, disease severity and reductions in biomass were significantly greater when Pst was applied with $0.1 \times$ recommended rate of glyphosate, followed by Pst alone or Pst with $0.01 \times$ glyphosate. Sub-lethal rates of glyphosate alone caused no disease or biomass reductions. Application of $1.0 \times$ and $0.1 \times$ glyphosate with Alternaria killed more thistle (49\% and 21\%) than glyphosate alone $(32 \%$ and $4 \%)$. No synergistic effects between glyphosate and Alternaria were observed in field studies.

A technique for evaluating adult plant resistance of sugar beet germ plasm to Aphanomyces cochlioides. J. R. BRANTNER and C. E. Windels. University of Minnesota, Northwest Exp. Stn., Crookston, MN 56716. Phytopathology 89:S8. Publication no. P-1999-0056-AMA.

A technique is needed to reliably evaluate resistance of sugar beet germ plasm of older ( $\geq 6$-wk-old) plants to infection by A. cochlioides. Six-wk-old sugar beet plants were grown in $15-\mathrm{cm}$ diam pots and inoculated with $0,10^{4}$, 
$10^{5}$, and $5 \times 10^{5}$ zoospores of $A$. cochlioides/pot. In another experiment, plants were inoculated $8 \mathrm{wk}$ after seeding with $0,10^{4}, 10^{5}$, and $2 \times 10^{5}$ zoospores/pot. Plants were then placed in a growth chamber at $25-27^{\circ} \mathrm{C}$. After 4 wk, roots were removed, cleaned, and rated for root rot $(0-7$ scale, $0=$ roots clean, $7=$ root completely rotted). Inoculation with $10^{5}$ zoospores/pot separated susceptible from resistant germ plasm. Mean root rot ratings for a susceptible breeding line, moderately susceptible cultivar, moderately resistant cultivar, and resistant breeding line were $4.3,2.2,1.7$, and 2.1, respectively, on 6 -wk-old plants, and $3.8,2.4,2.0$, and 1.8 , respectively, on 8 -wk-old plants. In both trials the susceptible breeding line was different $(P=0.05)$ from all other lines. This technique shows promise in evaluating adult plant resistance of sugar beet germ plasm to A. cochlioides.

Why Ceratocystis and Leptographium species colonized freshly cut log more aggressively than the Ophiostoma complex. C. BREUIL (1), C. Fleet (1), A. Uzunovic (2), and T. Byrne (2). (1) Dept. Wood Science, University of British Columbia, Vancouver, BC, Canada; (2) Forintek Canada Corp., Western Laboratory, Vancouver, Canada. Phytopathology 89:S9. Publication no. P-1999-0057-AMA.

Forests are important to Canada, and a major strength of this sector is a high quality timber resource. However, log and lumber are susceptible to sapstain, a discolouration caused by pigmented fungal cells. Recently, we isolated the main staining fungi affecting the five most commercially important Canadian softwoods. However, the high isolation frequency of a fungal species could not be correlated with the extensive discoloration of log. Although Ophiostoma piceae was the most frequently isolated species in lumber and $\log$, it did not cause deep-stain when it was inoculated in small diameter pine logs. On fresh log the most aggressive and deep sapstainers were $C$. coerulescens, Leptographium spp. and O. minus. In this work, we will discuss the effect of nutritional and environmental factors on wood colonization and discolouration by the different fungal species.

Sycamore dieback in the southeastern United States. K. O. BRITTON (1), T. Leininger (2), and C. J. Chang (3). (1) USDA Forest Service, Athens, GA; (2) USDA Forest Service, Stoneville, MS; (3) Univ. of Georgia, Ag. Expt. Sta., Griffin, GA. Phytopathology 89:S9. Publication no. P-1999-0058-AMA.

Declining sycamore plantations age 5-20 were sampled in 1997 and 1998. Leaf petioles were tested for presence of Xylella fastidiosa. Wood chip samples from discolored xylem, cankers and branches with dieback were used, for isolation of fungal pathogens. Several pathogens were detected in most of the plantations. Positive ELISA tests for X. fastidiosa were obtained from 10 of 15 plantations. Isolations of $X$. fastidiosa on selective media were conclusive in nine plantations. Ceratocystis fimbriata was isolated from all four plantations in coastal North Carolina, and three out of four plantations in coastal Virginia. Botryosphaeria rhodina was infrequently isolated from these sites. B. rhodina was the most common fungal pathogen isolated from all nine other plantations. The most severely affected plantations were those in southern Alabama, which were severely affected when we sampled them, at age 5. Both X. fastidiosa and B. rhodina were isolated from these plantations. The complex of organisms associated with sycamore dieback or decline appears to vary geographically within the southeastern United States.

Population structure of Fusarium circinatum in South Africa. H. Britz (1), T. A. COUTINHO (1), M. J. Wingfield (1), and W. F. O. Marasas (2). (1) Tree Pathology Co-operative Programme (TPCP), Forestry and Agricultural Biotechnology Institute (FABI), University of Pretoria, Pretoria 0002, South Africa; (2) PROMEC, MRC, P.O. Box 19070, Tygerberg 7050, South Africa. Phytopathology 89:S9. Publication no. P-1999-0059-AMA.

Fusarium circinatum (= Fusarium subglutinans $\mathrm{f}$. sp. pini) was first discovered in South Africa in 1994 where it caused devastating losses to Pinus patula seedlings in a nursery. From this first outbreak, 23 vegetative compatibility groups (VCGs) were found among 69 isolates, of which four were dominant. Isolates of the fungus were able to reproduce and thus, the high degree of genotypic diversity found within this population was not surprising. Subsequent to this first report of $F$. circinatum in South Africa, this pathogen has been isolated from P. patula, P. elliottii and P. greggii seedlings, showing root and collar rot, as well as shoot blight symptoms, in five additional nurseries. In this study, we considered whether the F. circinatum population had changed in diversity since its first appearance in South Africa. Nitrate non-utilizing (nit) mutants were generated from 51 new F. circinatum isolates and paired on minimal media with tester strains representing each of the 23 previously identified VCGs. One isolate was found to be heterokaryon self-incompatible (HSI). Eleven isolates identified as $F$. circinatum from $P$. patula, $P$. elliottii and $P$. greggii were vegetatively compatible with tester strains representing four dominant VCGs previously characterized. This suggests that movement of infected plant material contributed to the spread of $F$. circinatum in South Africa. Seven new F. circinatum VCGs were also identified from newly infected nurseries. The report of seven new VCGs in South Africa indicates that sexual reproduction is probably taking place under field conditions.

Essential oils of Monarda didmya and tolerance to powdery mildew. R. W. Brooks, K. D. GWINN, J. F. Green, and S. L. Hamilton. University of Tennessee, Knoxville, TN 37901-1071. Phytopathology 89:S9. Publication no. P-1999-0060-AMA.

Essential oils of many herbs contain antimicrobial compounds (e.g., thymol), but there is little information on the relationship of these compounds to resistance. The purpose of this research was to determine if plants which differ in resistance to powdery mildew, Erysiphe cichoracearum differ in chemical composition. In preliminary garden trials, two commercial cultivars of $\mathrm{Mo}$ narda, Cambridge Scarlet and Adam, were very susceptible to the disease whereas the third, a native Monarda didmya collected locally, had a high degree of disease tolerance. Essential oils were extracted with hexane and analyzed with 2-D thin layer chromatography. Chromatograms were examined under UV light and then developed with phosphomolybdate acid stain. Cambridge Scarlet had few chemical components; whereas, Adam and the native species each had greater than 20 components. The native species appears to have a chemical composition different from either of the two susceptible cultivars. Chemical composition will be further characterized with GC-MS.

Biochemical characterization of corn kernels resistant to infection by Aspergillus flavus and Fusarium moniliforme. R. L. BROWN (1), Z.-Y. Chen (2), and T. E. Cleveland (1). (1) USDA-ARS, SRRC, New Orleans, LA 70179; (2) Dept. Plant Pathology and Crop Physiology, Louisiana State University, Baton Rouge, LA 70803. Phytopathology 89:S9. Publication no. P-1999-0061-AMA.

Several corn genotypes have been shown to be resistant to Aspergillus flavus infection and to aflatoxin production. Two of these lines also inhibited Fusarium moniliforme infection. In the present study, as in previous ones, a genetically altered Fusarium isolate with a GUS reporter gene linked to a beta-tubulin gene promoter is being used to assess both kernel infection and fumonisin production in corn lines previously tested against $A$. flavus. Kernel proteins, both constitutive and infection-induced, previously identified and associated with resistance to A. flavus, will be compared with proteins related to resistance to $F$. moniliforme/fumonisin production using 2-D gel electrophoresis and analysis software. Results may identify common proteins related to resistance to either fungus as well as uniquely expressed proteins. These potential breeding markers may facilitate the development of commercially useful corn lines with resistance to both fungi and/or the production of their toxins.

Physical mapping of Clavibacter michiganensis subsp. sepedonicus. S. E. Brown, A. A. Reilley, D. L. Knudson, and C. A. ISHIMARU. Colorado State University, Fort Collins, CO 80523. Phytopathology 89:S9. Publication no. P-1999-0062-AMA.

Bacterial ring rot of potato is caused by the gram-positive pathogen, Clavibacter michiganensis subsp. sepedonicus $(\mathrm{Cms})$. We are constructing a physical map of the Cms genome for future delineation of sequences required in pathogenicity and virulence. A genomic library with an average insert size of $38 \mathrm{~kb}$ of DNA from the pathogenic strain CIC31 was constructed in a SuperCos-1 vector, and 960 clones representing a 13-fold genome coverage were archived into ten 96 well plates. Purified DNA from cosmids containing Cms DNA was digested with NotI and separated in agarose gels under conditions specifically designed for high resolution of fragments of 1 to $25 \mathrm{~kb}$. FPC software was used to analyze the DNA fingerprints of 255 cosmids. A total of 3,057 bands representing 9,744,020 bp were analyzed, representing a 3.9-fold coverage of the estimated minimal genome size of $2.5 \mathrm{Mb}$. One contig contained 12 overlapping cosmids covering about $75 \mathrm{~kb}$. This physical map provides a foundation for future sequence-anchored maps of $\mathrm{Cms}$.

Development and application of a field screen for resistance to Phytophthora crown rot on strawberry. G. T. BROWNE, M. R. Vazquez, R. J. Wakeman, and H. E. Becherer. USDA-ARS, Univ. of Calif., Davis. Phytopathology 89:S9. Publication no. P-1999-0063-AMA.

Improved genetic resistance of strawberry to soilborne pathogens may become critical as pre-plant soil fumigation is restricted. A new field method was used to determine resistance to Phytophthora cactorum (Pca) and $P$. 
citricola $(P c i)$ in four cultivars grown on fumigated beds near Watsonville, CA. Inoculum was V8-juice-vermiculite-oat medium colonized by $P c a$ or $P c i$ or sterile (control). After infesting soil with $P c a 100 \mathrm{ml}$ at crowns, $50 \mathrm{ml}$ at crowns, and $100 \mathrm{ml}$ beside crowns, cv. Pajaro mortality was 40, 27, and $20 \%$, respectively (controls $0-1 \%)$. Infesting with Pca or Pci $(100 \mathrm{ml}$, at crowns) caused smaller early-season canopies in all cvs. (45-91\% of controls), but final mortality of Aromas and Camarosa was only 0-2\% while that of Diamante and Pajaro was: $42,27 \%$ respectively, for Pca; and 17, 35\% for $P c i$. Fruit yields were inversely proportional to amounts of stunting and mortality. Although $P c a$ caused more damage than Pci, the opposite occurred in greenhouse screens. Apparently, new California strawberry cvs. differ in resistance to Phytophthora spp., and field evaluations may be essential for complete assessment of the resistance.

Canker formation on apple by Botryosphaeria spp. and control with wound treatments. D. BROWN-RYTLEWSKI and P. McManus. University of Wisconsin, Madison, WI. Phytopathology 89:S10. Publication no. P-19990064-AMA.

Botryosphaeria spp. are major apple fruit rot pathogens in warmer temperate climates, but in the upper Midwest where trees are subjected to lowtemperature injury, cankers cause substantial losses. One objective of this study was to determine whether the virulence of Botryosphaeria isolates on apple fruit correlated with virulence on stems, with the goal of developing a fruit-inoculation assay to screen isolates. Detached 'Golden Delicious' apple fruit and intact stems of 2-yr-old 'Golden Delicious' trees were inoculated with mycelia of several isolates of B. obtusa or B. dothidea. We found no correlation between an isolate's ability to rot fruit and its ability to cause stem cankers. A second objective was to test the efficacy of wound treatments in controlling stem cankers caused by B. obtusa and B. dothidea. In field tests at two sites, clove oil, garlic oil, and neem oil were generally less effective than benomyl or kresoxim-methyl. Kresoxim-methyl and other strobilurin fungicides will likely be used to control other apple diseases, and a side benefit may be to control cankers caused by Botryosphaeria spp.

Polymerase chain reaction for detection of Erwinia tracheiphila in cucurbits. B. BRUTON (1), U. Melcher (2), T. Zitter (3), S. Pair (1), J. Fletcher (2), and F. Mitchell (4). (1) USDA-ARS, Lane, OK; (2) Okla. State Univ., Stillwater; (3) Cornell Univ., Ithaca, NY; (4) Texas A\&M Univ., Stephenville. Phytopathology 89:S10. Publication no. P-1999-0065-AMA.

In 1998, a severe wilt was observed in pumpkin in Albany, Monroe, and Orange County, New York. Cut stems revealed darkened xylem rings with numerous tyloses and bacteria in the xylem elements. Biolog data suggested the bacterium was within the genus Erwinia. A partial nucleotide sequence of $16 \mathrm{~S}$ rDNA amplified using general bacterial primers was identical in 523 of 526 positions to that of E. tracheiphila. A primer pair that should amplify a 706 bp fragment only from E. tracheiphila (among sequences available in the database) was designed. Using primers ET1 (5'TGAGTTCCCGACCAAAT3') and ET2 (5'GGGAGGAAGGGACGCTG3'), a DNA fragment of expected size $(0.71 \mathrm{kbp})$ was consistently amplified from E. tracheiphila reference strains (ATCC), symptomatic plant-derived bacterial cultures, greenhouse-inoculated plants, and symptomatic field-collected pumpkin plants, but no band was amplified from greenhouse-grown control plants. The primer pair ET1/ET2 should facilitate diagnosis and epidemiological studies of this disease.

Is adhesive ability required for the colonization of leaves by yeasts? J. W. BUCK and J. H. Andrews. University of Wisconsin, Madison, WI. Phytopathology 89:S10. Publication no. P-1999-0066-AMA.

It has been proposed that phylloplane yeasts attach to leaves by weak interactions (phase I) and then become more strongly bound (phase II) during colonization. To investigate this 2-phase model, we observed adhesion kinetics of the yeast Rhodosporidium toruloides to barley under controlled conditions. Adhesion of wild-type cells decreased over long-term ( $8 \mathrm{~h}$ to 10 d) assays. Ten attachment-minus (Att-) mutants, deficient in phase I attachment, did not adhere after 5-d incubations, also suggesting a lack of stronger, independent phase II adhesion. Long-term adhesion of $R$. toruloides to leaves of a waxless barley mutant was significantly greater than to leaves of the wild-type cv. Bonus. Application of exogenous nutrients to resident, wildtype $R$. toruloides populations resulted in both a rapid recolonization to the apparent carrying capacity of the leaves, and an increase in the total adherent populations. Att- mutants recolonized barley, when supplied with nutrients, after more than $99 \%$ of the cells had been removed by agitation. Thus, adhesion of $R$. toruloides to barley leaves did not follow a 2-phase model, and was not prerequisite for subsequent colonization.
Optimization of in vitro perithecial production of Gibberella zeae on wheat and corn debris. I. BUJOLD (1), T. C. Paulitz (1), M. Tremblay (2), and O. Carisse (2). (1) McGill University, MacDonald Campus, Ste-Anne-deBellevue, Qc., Canada H9X 3V9; (2) Agriculture and Agri-Food Canada, St-Jean-sur-Richelieu, Qc., Canada J3B 3E6. Phytopathology 89:S10. Publication no. P-1999-0067-AMA.

Ascospores, from infected debris over-wintered on the soil surface, are the main source of inoculum of Fusarium Head Blight and Maize Ear Rot. In order to mimic field conditions for testing the effect of biological agents on ascospore production, a method of perithecia production, on different types of debris, was needed. Improvement of existing methods was required to increase reliability and uniformity. Wheat straws, corn stalks, wheat grains and corn kernels, inoculated with macroconidia and placed on humid vermiculite, were evaluated for the quantity and uniformity of perithecia production, in closed and open environments. Perithecial production varied depending on substrate and type of environment. In the open environment, corn kernels were the best substrate while, in the closed environment, more perithecia were produced on wheat straw. The results of the experiment showed that it is now possible to evaluate the potential of biocontrol agents on wheat and corn debris.

Effects of organic and synthetic fertility amendments on nematode trophic dynamics in tomato field soils. L. R. BULLUCK, III, K. R. Barker, and J. B. Ristaino. Department of Plant Pathology, North Carolina State University, Raleigh, NC. Phytopathology 89:S10. Publication no. P-19990068-AMA.

Synthetic fertilizer, cotton-gin trash, swine manure, and a rye-vetch green manure were applied to subplots, while tillage and surface mulch were applied to main plots to evaluate the effects of these amendments on nematode community dynamics at two field locations. Numbers of plant-parasitic and free-living nematodes were identified to genus and trophic group at 2 sampling times over 2 seasons. Soil amendments did not affect plant-parasitic nematodes. However, in both years, populations of bacterivores were higher after planting in soils amended with swine manure, composted cotton-gin trash, or rye-vetch, than in soils with synthetic fertilizer. Numbers of fungivores were also higher in soils with organic versus soils with synthetic fertility amendments. Bongers' maturity index (MI) was higher in soils amended with rye-vetch or fertilizer at planting and lower in soils amended with swine manure or composted cotton-gin trash. As these findings indicate, nematode trophic group dynamics are important tools for understanding soil processes and may be an indicator of soil quality.

Effects of fungicides as seed treatments and foliar sprays on diseases of wheat in Alabama. K. B. Burch and K. L. BOWEN. Department of Plant Pathology, Auburn University, AL 36849-5409. Phytopathology 89:S10. Publication no. P-1999-0069-AMA.

Seed treatment and foliar fungicides were evaluated for their efficacy against leaf rust and Septoria leaf blotch over a five year period. Tests were located in three regions of Alabama and consisted of small plots of a single cultivar of wheat. Seed treatment formulations included triadimenol, captan, and difenoconazole; foliar fungicides included propiconazole, triadimefon, mancozeb, tebuconazole, and azoxystrobin. Disease severities were rated at soft dough stage on flag leaves of 10-30 randomly selected plants in each plot. Though not statistically significant, leaf rust and Septoria leaf blotch were reduced in seed treated plots. Average yield (bu/A) increase was 6\%, and 1000 kernel weights averaged 3\% greater with seed treatment alone. With foliar fungicides, severities of leaf rust and Septoria were reduced an average of $53 \%$ and $36 \%$, respectively. Yields were increased an average of $8 \%$ and 1000 kernel weights increased by $5 \%$ with foliar fungicides alone.

The effect of temperature on sporulation of Oidium sp. on poinsettia foliage. J. M. BYRNE and M. K. Hausbeck. Dept. of Botany and Plant Pathology, Michigan State University, East Lansing, MI. Phytopathology 89: S10. Publication no. P-1999-0070-AMA.

Powdery mildew (Oidium sp.) on poinsettia (Euphorbia pulcherrima) is an economically significant problem in the United States. The effect of temperature on sporulation was quantified using leaf disks cut from mature poinsettia leaves (cv. Freedom Red). Leaf disks (1.7-cm-diameter) were placed on agar disks (2.0-cm-diameter) amended with $30 \mathrm{mg} / \mathrm{L}$ benzimidazole and were appressed to the agar by washers $(2.2-\mathrm{cm}$-diameter). Leaf disks were inoculated with conidia and incubated in petri dishes for 14 days at 15 or 20 C. The number of conidiophores and length of conidial chains on the leaf disks were recorded. The number of conidiophores produced did not vary with temperature. Sporulation was initiated 9 days after inoculation. Sporulation of Oidium sp. on leaf disks was favored by the warmer temperature; 
maximum conidial chain lengths were 4 and 7 conidia at 15 and $20 \mathrm{C}$, respectively. The percentage of conidiophores bearing no conidia were 33.0 and $15.0 \%$, at 15 and $20 \mathrm{C}$, respectively. At $20 \mathrm{C}$, more conidiophores (48.8\%) produced 2 or more conidia than at $15 \mathrm{C}(23.0 \%)$.

Satellite RNAs of Panicum mosaic virus exhibit a high degree of genetic diversity in naturally infected St. Augustinegrass. O. CABRERA (1), M. J. Roossinck (2), and K.-B. G. Scholthof (1). (1) Department of Plant Pathology and Microbiology, Texas A\&M University, College Station, TX 77843; (2) The S. R. Noble Foundation, P.O. Box 2180, Ardmore, OK 73402. Phytopathology 89:S11. Publication no. P-1999-0071-AMA.

St. Augustine decline is a disease caused by Panicum mosaic virus (PMV). PMV is found alone, or associated with a satellite virus (SPMV), and/or satellite RNAs (satRNAs). A recent survey in two locations of Texas indicated that $60 \%$ of the symptomatic PMV-infected St. Augustinegrass (Stenotaphrum secundatum) contains satRNAs, as revealed by RNA blots. A wide array of symptoms was observed under natural field conditions, but symptoms don't appear to be correlated with the presence or absence of a specific satRNA. The symptom expression in St. Augustine decline seems to be influenced by host genotype, nutrition, and environmental conditions. Ribonuclease protection analysis (RPA) of 100 satRNA infected plants revealed a high degree of genetic variability in these satRNAs: $64 \%$ of the satRNAs showed unique RPA patterns. Different, but overlapping populations of satRNAs were found in the two locations.

Possible involvement of L-fucose determinants in soil binding by a basidiomycete. T. C. CAESAR-TONTHAT. USDA-ARS, Sidney, MT. Phytopathology 89:S11. Publication no. P-1999-0072-AMA.

Fungi are known to bind soil particles and micro-aggregates into macroaggregates that are stabilized by amorphous materials. The objectives of this study were to study the role of basidiomycetes in stabilization of soil particles and to determine a possible mechanism of soil binding. A saprophytic lignin decomposer basidiomycete isolated in Eastern Montana was found to stabilize soil into persistent water stable aggregates. This fungus secretes mucilage that acts as a binding agent. Periodate followed by sodium borate treatment indicated that fungal mucilage is composed of polysaccharides. Lectins were used to determine specific carbohydrate containing receptor sites on cell surface. Patches of intensive fluorescence were found on cell surface after FITC-Ulex europaeus Agglutinin I and FITC-Lotus tetragonolobus lectin staining indicating the presence of alpha-L-fucosyl residues. Treatment of fungal mycelia with both fucose specific lectins dramatically reduced the capacity to aggregate soil by $50 \%$. This implicates terminal L-fucose residues in binding to soil particles. A more general adhesive role of fungal cell surface secretions will be discussed.

Genetic diversity of Fusarium oxysporum f. sp. lycopersici based on physiological and molecular markers. G. CAI (1), U. L. Rosewich (2), R. E. Pettway (2), and R. W. Schneider (1). (1) Louisiana State Univ. Agric. Center, Baton Rouge, LA; (2) Univ. of Florida, Gainesville, FL. Phytopathology 89: S11. Publication no. P-1999-0073-AMA.

Thirty-nine isolates of Fusarium oxysporum f. sp. lycopersici (FOL) collected from one tomato field were characterized using vegetative compatibility (VCG) and pathogenicity. Five isolates, all race 2, belonged to a new VCG, VCG0034. All 39 isolates, plus 19 other isolates of FOL and 2 isolates of $F$. oxysporum f. sp. radicis-lycopersici (FORL), were subjected to PCR/RFLP analysis of the intergenic spacer (IGS) region of rDNA. Based on IGS haplotype, vegetative compatibility, pathogenicity, and geographic origin, 20 isolates were selected and parts of their IGS region were sequenced. Bootstrapped parsimony analysis of the sequence data identified a phylogenetic tree with highly significant branches. While VCGs 0030 and 0032 were found to be closely related, the similarity between VCGs 0031 and 0033 , which was suggested by a previous study, was not well supported. VCG 0034 represented a distinct evolutionary lineage that was closely related to FORL. All isolates were further analyzed using homologous RFLP probes from a genomic library of $F$. oxysporum.

Evaluation of Actigard (CGA-245704) for the control of bacterial spot of peach. H. L. CAMPBELL and M. Wilson. Dept. of Plant Pathology, Auburn University, AL 36849. Phytopathology 89:S11. Publication no. P-1999-0074AMA.

Bacterial spot of peach, caused by Xanthomonas campestris pv. pruni, has increased in prevalence in Alabama in recent years due to the planting of spotsusceptible peach cultivars developed in California. Copper bactericides are phytotoxic to peach and the antibiotic oxytetracycline provides inconsistent control. Actigard [CGA-245704 (Novartis Crop Protection)], which induces systemic acquired resistance (SAR) in plants, was evaluated for efficacy to reduce severity of bacterial spot on peach foliage and fruit in 1997 and 1998 using the highly susceptible cultivar O'Henry. Actigard was applied weekly from leaf bud break until harvest at a rate of $140 \mathrm{~g}$ ai/ha. In 1997, Actigard reduced the severity of foliar bacterial spot by $54 \%$ compared to the untreated control. In 1997 and 1998, Actigard increased the number of marketable fruit by $25 \%$ and $16 \%$ respectively. A combination of Actigard and oxytetracycline evaluated in 1998 increased the number of marketable fruit by $30 \%$ compared to the marketable yield from the untreated control. These results warrant further examination of Actigard on different peach cultivars in different geographic locations.

Production of sclerotia of Sclerotium rolfsii on brown wrapping paper for use in studies of southern blight of vegetable crops. C. H. CANADAY. Dept. of Entomology and Plant Pathology, The University of Tennessee, Knoxville, TN 37901. Phytopathology 89:S11. Publication no. P-1999-0075AMA.

A simple, inexpensive method for producing sclerotia of Sclerotium rolfsii has been devised. Strips of brown wrapping paper, $12.7 \mathrm{~cm} \times 88.9 \mathrm{~cm}$ (ca. 11 $\mathrm{g}$ dry wt.), are corrugated with 20 folds and then placed in one-liter beakers with $11 \mathrm{~g}$ sterile oats (dry) and $33 \mathrm{ml}$ distilled water (DW). Beakers are capped with $\mathrm{Al}$ foil and autoclaved for $20 \mathrm{~min}$. After autoclaving, additional sterile DW is added to restore the 1:1.5 ratio of dry wt. materials (oats + paper): water. The contents of beakers are then inoculated with small plugs of $S$. rolfsii cut with a cork borer from the margins of an actively growing culture. Capped beakers are placed in plastic bags to slow moisture loss, then incubated in the dark at $28 \mathrm{C}$. Mycelia of $S$. rolfsii grow over the paper and form sclerotia. Mature sclerotia are easily rubbed-off the paper surface when air-dried. Paper cultures produce up to $2 \mathrm{~g}$ dry sclerotia after 18 da and $4 \mathrm{~g}$ after 40 da. Sclerotia may be mixed with $0.45 \%$ water agar and dispensed with a wide-mouth pipet around the crowns of tomatoes and other vegetables to inoculate plants in field studies.

Periodicity of airborne sporangia of Bremia lactucae. O. CARISSE (1) and V. Philion (2). (1) Agriculture and Agri-Food Canada, St-Jean-sur-Richelieu, Qc., Canada J3B 3E6; (2) IRDA, St-Hyacinthe, Qc., Canada. Phytopathology 89:S11. Publication no. P-1999-0076-AMA.

Several forecasting systems for downy mildew of lettuce are based on the assumption that sporangia infect lettuce leaves in early morning. However, there is no clear indication that sporangia are present at that time. Sporangia of B. lactucae were trapped using a 7-day volumetric spore trap during more than 50 days in 1997 and 1998 . Three periodicity patterns were observed. The most frequent had a peak representing more than $75 \%$ of the daily concentration occurring between 8:00 and 10:00 in the morning. The second pattern was similar except that the peak occurred later. The third pattern was observed on days with low concentrations of sporangia and was characterised by a random distribution occurring mostly during daylight hours. Sporangia release was associated with a drop in relative humidity. On most days, morning sporangia concentration represented about $80 \%$ of the daily concentration indicating that the assumption of nightly production and early morning release of sporangia is valid. However, sporangia release occurring after 10:00 may explain some failures in predicting lettuce downy mildew.

Characterization of anastomosis group (AG) 13 of Rhizoctonia solani. D. E. CARLING (1), R. E. Baird (2), S. Kuninaga (3), and R. D. Gitaitis (4). (1) University of Alaska Fairbanks, Palmer, AK; (2) Mississippi State University, Stoneville, MS; (3) Health Sciences University of Hokkaido, Hokkaido, Japan; (4) University of Georgia, Tifton, GA. Phytopathology 89:S11. Publication no. P-1999-0077-AMA

Isolates of Rhizoctonia solani collected from cotton roots at various times during the growing season were characterized according to anastomosis group (AG). Most of the several hundred isolates recovered were AG-4 but 15 were found to represent a previously undescribed AG. Three isolates chosen as testers gave the category $0(\mathrm{C} 0)$ anastomosis reaction with multiple testers representing each of the 13 known AG. No bridging with testers of other AG was observed but among the 15 isolates, many clones were found. All attempts to induce formation of hymenia and basidiospores failed. Damage to sprouting potatoes by representatives of the new AG was minimal but sprouting seedlings of cauliflower, radish and head lettuce on water agar plates were extensively damaged though not killed. In greenhouse studies, most of the 15 isolates damaged hypocotyls and roots of cotton and could easily be reisolated from the damaged tissue. Fatty acid profiles and ribosomal DNA sequences also will be reported. We propose to call this new group AG-13. 
DNA fingerprinting of the biocontrol agent, Pseudozyma flocculosa: Towards a commercial scale quality control test. S. J. CARON (1), T. J. Avis (1), R. C. Hamelin (2), and R. R. Bélanger (1). (1) Université Laval, Québec, Canada; (2) Ressources Naturelles Canada, Québec, Canada. Phytopathology 89:S12. Publication no. P-1999-0078-AMA.

Sporodex ${ }^{\mathrm{TM}}$ is a commercial formulation of the powdery mildew antagonist Pseudozyma flocculosa. Mass production of the organism can lead to unwanted contamination or mutations which if followed by genetic drift or selection would alter the genetic integrity and potentially the biocontrol property of the organism. We are developing a test to determine the genetic stability of the antagonist. In this context, DNA fingerprinting seems to offer a sensitive and reliable approach to genetically characterize and monitor the biocontrol agent. Randomly Amplified Polymorphic DNA (RAPD), Randomly Amplified Microsatellites (RAMS) and Universely Primed PCR followed by Single Strand Conformation Polymorphism (UP-PCR/SSCP) gave interspecific and intraspecific polymorphisms in the tested fungi. Diagnostic DNA markers derived from these fingerprints are currently under development as Sequence Characterized Amplified Regions (SCARs) to be used in multiplex PCR amplification of DNA to test the genetic stability of the biocontrol agent over time.

Inheritance of resistance to Phaeosphaeria leaf spot of maize. M. L. CARSON. USDA-ARS, North Carolina State University, Raleigh, NC. Phytopathology 89:S12. Publication no. P-1999-0079-AMA.

Phaeosphaeria leaf spot (PLS) is a potentially important maize disease that has recently appeared in the continental United States in winter breeding nurseries in southern Florida. Initial observations and later resistance screening trials indicated that inbred lines related to B73 are particularly susceptible. Parental inbred lines Mo17 (resistant) and B73 (susceptible), their F1, F2, and backcross generations were evaluated for resistance to PLS over two winter nursery seasons in southern Florida following artificial inoculation. Resistance was inherited in a strictly additive manner, was highly heritable $\left(\mathrm{h}^{2}=0.70-.80\right)$, and controlled by 3-4 effective factors. These results are in close agreement with QTL mapping studies using recombinant inbred lines derived from B73 $\times$ Mo17. The transfer of PLS resistance into susceptible inbred lines should be a straightforward breeding process. Should the disease spread from south Florida, the development of PLS resistant female inbred parents to protect hybrid seed production is most important, as most commercial U.S. hybrids are resistant.

Detection of tomato mosaic tobamovirus RNA in ancient glacial ice. J. D. Castello (1), S. O. Rogers (1), W. T. Starmer (2), C. M. Catranis (1), L. Ma (1), G. D. Bachand (1), Y. ZHAO (1), and J. E. Smith (1). (1) State University of New York, College of Environmental Science and Forestry, Faculty of Environmental and Forest Biology, 1 Forestry Drive, Syracuse, NY 13210; (2) Syracuse University, Department of Biology, Syracuse, NY 13244. Phytopathology 89:S12. Publication no. P-1999-0080-AMA.

Tomato mosaic tobamovirus (ToMV) is a very stable plant virus with a wide host range that has been detected in plants, soil, water, and clouds. Because of its stability and prevalence in the environment, we hypothesized that it might be preserved in ancient ice. We detected ToMV by reverse-transcription polymerase chain reaction amplification in glacial ice subcores $<500$ to approximately 140,000 years old obtained from drill sites in Greenland. Subcores that contained multiple ToMV genotypes suggest diverse atmospheric origins of the virus, whereas those containing ToMV sequences nearly identical to contemporary ones suggest that recent ToMV populations have an extended age structure. Detection of ToMV in ice suggests that stable viruses of humans and other hosts might be preserved there, and that entrapped ancient viable viruses may be continually released into the modern environment.

Recovery and survival of Trichoderma through post-crop steam pasteurization in mushroom growing rooms of commercial Pennsylvanian farms. N. J. CATLIN, P. J. Wuest, and D. M. Beyer. Department of Plant Pathology, 210 Buckhout Laboratory, Penn State University, University Park, PA 16802. Phytopathology 89:S12. Publication no. P-1999-0081-AMA.

A current threat to the cultivated mushroom Agaricus bisporus is Trichoderma green mold caused by Trichoderma harzianum. Although mushroom growing rooms are disinfested between crops with post-crop steam pasteurization, Trichoderma as well as numerous other microbes can be recovered from wooden bedboards of Pennsylvania mushroom farms before and after the pasteurization procedure. Air and compost temperatures were monitored during the post-crop steam pasteurization of commercial mushroom farms in Pennsylvania. Temperatures varied between farms and within mushroom growing rooms. Differences were observed between the lengths of time for different areas of a mushroom growing room to reach the recommended pasteurization temperature, and differences were also observed between the lengths of time that the recommended pasteurization temperature was maintained in different areas of a mushroom house.

Resistance to potato $\mathrm{X}$ Potexvirus and potato $\mathrm{Y}$ potyvirus in a Solanum tuberosum and Solanum berthaultii segregating population. F. CELEBI and S. A. Slack. Cornell University, Ithaca, NY. Phytopathology 89:S12. Publication no. P-1999-0082-AMA.

Potato $\mathrm{X}$ potexvirus (PVX) and potato $\mathrm{Y}$ potyvirus (PVY) are important viruses of potato worldwide. We are studying a segregating diploid population derived from reciprocal backcrosses between $S$. tuberosum and $S$. berthaultii in order to identify resistance genes for potential use in sustainable disease control. The segregants were inoculated mechanically with PVX and PVY. Symptoms were visualized in inoculated leaves and new growth and ELISA was used for virus detection after two-four weeks. Graft inoculations were used to further valid resistance responses. Current data suggest that a single major dominant gene for extreme resistance exists for PVX and for hypersensitive resistance exists for PVY. Markers previously established for this population by Bonierbale et al. (Theor. Appl. Genet. 87:973-987, 1994) were used with QGENE and MAPMAKER to localize the PVY resistance gene on chromosome four, a location not previously reported for PVY resistance gene. However, the chromosome location of the PVX resistance gene has not yet been determined.

RFLP analysis of the PCR amplified ribosomal DNA regions ITS and IGS indicates that isolates of Rhizoctonia solani from potato and tobacco represent distinct subgroups within anastomosis group 3. P. C. CERESINI (1), H. D. Shew (2), and M. A. Cubeta (2). (1) Dep. Biology, University of Sao Paulo State, Ilha Solteira, SP, Brazil; (2) Dep. Plant Pathology, North Carolina State University, Raleigh, NC. Phytopathology 89:S12. Publication no. P-1999-0083-AMA.

Anastomosis group 3 (AG-3) of Rhizoctonia solani is frequently associated with diseases of potato and tobacco. The fungus can cause several diseases of potato (stem and stolon canker, and black scurf of tubers), but in tobacco, only causes a leaf spot disease. Previous studies have demonstrated differences in biology, epidemiology, fatty acid profiles, and host range specificity of $R$. solani AG-3 isolates from potato and tobacco. However, questions still remain about their taxonomic relationship to each other. In this study, field populations of $R$. solani AG-3 from potato and tobacco in NC were characterized by RFLP analysis of the PCR amplified ribosomal DNA regions ITS1-ITS4 (digested with Hae III) and IGS (digested with Tru9I and Mbo I). An analysis to estimate the genetic distance among isolates of $R$. solani was performed and indicated that potato and tobacco isolates represent distinct subgroups within AG-3.

Somatic compatibility indicates differences in the population structure of Rhizoctonia solani AG3 associated with diseases of potato and tobacco in NC. P. C. CERESINI (1), H. D. Shew (2), and M. A. Cubeta (2). (1) Dep. Biol., UNESP, Ilha Solteira, SP, Brazil, 15385-000; CNPq, Brazil; (2) Dep. Plant Pathol., NCSU, Raleigh, NC 27695. Phytopathology 89:S12. Publication no. P-1999-0084-AMA.

Anastomosis group 3 is frequently associated with $R$. solani diseases of potato and tobacco. Although isolates from different hosts are taxonomically related, previous studies have shown differences in their biology, fatty acid composition, pathogenicity and ribosomal DNA genes. However, questions remain about differences in the genetic diversity and structure of $R$. solani AG3 populations from potato and tobacco. In this study, field populations of AG3 from potato and tobacco in NC were examined for somatic compatibility. One group of 41 isolates from potato and another of 43 isolates from tobacco were paired in all possible combinations on PDA plus activated charcoal. While only $0.6 \%$ of the pairings among potato isolates were somatic compatible, $9.2 \%$ of the pairings among tobacco isolates showed somatic compatibility. DNA fingerprinting and AFLP procedures will be used, in conjunction with somatic compatibility criteria, to determine whether the structure of these populations is clonal and/or panmictic.

Tomato powdery mildew development under greenhouse, growth chamber and field conditions. R. F. CERKAUSKAS, J. Brown, and J. Zheng. Agriculture and Agri-Food Canada, Greenhouse and Processing Crops Research Centre (GPCRC), Harrow, Ontario NOR 1G0. Phytopathology 89:S12. Publication no. P-1999-0085-AMA

Powdery mildew (Erysiphe sp.) of tomato (Lycopersicon esculentum cv. 'Trust') was studied in the greenhouse, growth chamber, and field in 199798 at GPCRC. In the greenhouse, the area under the disease progress curve 
(AUDPC) and final disease severity (FDS) for each plant and the top (T), middle (M) and bottom-third (B) plant portions were examined. There was no significant difference $(P=0.05)$ in FDS among 7 of 8 rows, and in AUDPC and FDS among the T, M and B portions. Greatest AUDPC and FDS occurred at B. Differences between B and $\mathrm{M}$, and B and T were significant but not between $\mathrm{M}$ and $\mathrm{T}$ segments. FDS differences were significant among $\mathrm{B}, \mathrm{M}$ and $\mathrm{T}$ in a second experiment. In the field, rate and extent of disease development was less on cv. 'Heinz 2478' than in the greenhouse over a similar time period. Earlier inoculation produced significantly greater FDS and AUDPC than later inoculations. Fungicide-treated (Microfine Sulphur) plants had significantly less disease development than plants exposed to inoculum early in the season. Growth chamber results will be discussed.

Characterization of the +1 ribosomal frameshift in the RNA-dependent RNA polymerase gene of citrus tristeza closterovirus. $B$. CEVIK, R. Chandrika, K. L. Manjunath, R. F. Lee, and C. L. Niblett. Univ. of Florida, Plant Path. Dept., Gainesville, FL. Phytopathology 89:S13. Publication no. P-1999-0086-AMA.

Based on sequence analysis, it has been proposed that the putative RNAdependent RNA polymerase (RdRp) gene of citrus tristeza virus (CTV) is expressed by $\mathrm{a}+1$ frameshift. It is suggested that the frameshift occurs at the rare arginine codon in the $5^{\prime}$ of the RdRp open reading frame (ORF) $1 \mathrm{~b}$ which overlaps with the $3^{\prime}$ end of the upstream ORF1a. Sequences of the overlapping region from six different strains of CTV were determined and compared with each other and with four additional sequences available in the Gene Bank. Sequence analysis indicated that the overlapping regions of different strains were $84-100 \%$ identical and highly conserved around the rare arginine codon. Secondary structure analysis of the frameshift region revealed the presence of stem loop structure next to the rare arginine codon in all strains of CTV, indicating that conserved stem loop structure may also be involved in the frameshift. To investigate the involvement and effect of the sequences in the overlapping region in the +1 frameshift, the native and modified sequences of the overlapping region were fused to the GUS and the green fluorescence protein reporter genes. The efficiency of the frameshifting was measured using an Agrobacterium-mediated transient expression method in both tobacco and citrus leaves.

The influence of surface characteristics and nutrients on spore germination in Colletotrichum graminicola. J. CHAKY and L. Vaillancourt. University of Kentucky, Lexington, KY. Phytopathology 89:S13. Publication no. P-1999-0087-AMA.

Spore germination is essential for most fungal pathogens, yet little is known of the mechanisms regulating this process. Conidia of Colletotrichum graminicola germinate efficiently (between 90 and $98 \%$ ) within five hours in drops of plain, sterile water on a hard, hydrophobic surface. Spore germination was measured on a variety of surfaces. A positive correlation was observed between germination rate and surface hydrophobicity $(r=0.938)$. Ungerminated spores were arrested at a point after spore hydration but prior to septation. The hypothesis that stronger adhesion of the spores to more hydrophobic surfaces is related to the increase in germination on those surfaces was tested. A weaker correlation was found between the strength of adhesion of spores to a surface and germination on that surface $(r=0.662)$. Dilute salts in the drops inhibited germination of spores on otherwise inductive surfaces, perhaps by disrupting the adhesive interactions between the spore and the surface. Addition of a carbon source greatly enhanced germination, even in the absence of an inductive surface. These data suggest that spore germination in C. graminicola is regulated in response to at least two separate signals, one nutritional and one tactile.

Nontarget host reactions to inoculation with a mixture of three bioherbicidal fungi: Drechslera gigantea, Exserohilum longirostratum, and E. rostratum. S. CHANDRAMOHAN* and R. Charudattan. Dept. Plant Pathology, University of Florida, Gainesville, FL 32611. Phytopathology 89:S13. Publication no. P-1999-0088-AMA.

The nontarget host reactions of 50 plant species from 11 families to inoculation with three bioherbicidal fungi, Drechslera gigantea $(\mathrm{Dg})$, E. longirostratum (El), and E. rostratum ( $\mathrm{Er})$, as well as a mixture of these fungal plant pathogens were evaluated. The number and age of plants tested varied depending on the growth habit of the species and plant size suitable for inoculation. The plants were sprayed when 1- to 2-week-old with inoculum suspensions containing $2 \times 10^{5}$ to $5 \times 10^{5}$ conidia per $\mathrm{ml}$ in $0.5 \%$ Metamucil. Non-inoculated control plants were sprayed with $0.5 \%$ Metamucil in water. Weed hosts susceptible to the pathogens were included with each batch of test plants. Inoculated plants were held in a dew chamber in the dark for $12 \mathrm{~h}$ $\left(28^{\circ} \mathrm{C}, 100 \% \mathrm{RH}\right)$, then moved to a greenhouse, and observed for disease development over 4 weeks. Similarly, selected crop species $(25$ species from 9 families) were sprayed with the pathogen mixture alone in an oil-based emulsion (Sunspray 6E $80 \mathrm{ml}$, paraffin oil $20 \mathrm{ml}$, and $100 \mathrm{ml}$ spores in water). Noninoculated control plants were sprayed with the emulsion without the pathogens. The reactions of the plants to each pathogen and the pathogen mixture were assessed as: Susceptible - plants that developed necrotic eye-spot lesions; Resistant - plants that developed minute necrotic flecks or noncoalescing/nonexpanding necrotic lesions; Immune - nonsymptomatic plants. In repeated experiments, $\mathrm{Dg}, \mathrm{El}, \mathrm{Er}$, and the pathogen mixture caused disease on all weedy grass species tested, but not on any of the economically important crop plants. The emulsion-based inoculum preparation of the pathogen mixture was also not injurious to the crop species tested. The cereal crops inoculated with the pathogen mixture exhibited extensive accumulation of dark pink to orange or brown-coloration within the host tissue in and around sites of attempted penetration by the fungi. Unlike in guineagrass, a target weed host, the nontarget crop hosts did not have any significant cell collapse or cell death associated with the coloration. Thus, D. gigantea, E. longirostratum, E. rostratum, and a mixture of these pathogens were nonpathogenic to the crop species tested. Therefore, these fungi could be used either alone or as a mixture, to control weedy grasses.

First report of Rhizoctonia solani on Echinacea angustifolia. K. F. CHANG (1), R. J. Howard (1), and S. F. Hwang (2). (1) Crop Diversification Centre South, Brooks, Alberta, Canada; (2) Alberta Research Council, Vegreville, Alberta, Canada. Phytopathology 89:S13. Publication no. P-1999-0089-AMA.

Rhizoctonia solani was consistently isolated from brown lesions on roots and lower stems of Echinacea angustifolia seedlings. Young leaves became shrunken and twisted and, under cool, damp conditions, seedlings collapsed. The pathogen was also isolated from two-year-old crowns and upper roots of field-grown plants. Isolates paired with AG tester strains anastomosed with AG-4. Colonies of cream-colored mycelia grew close to the surface of potato dextrose agar for a week, then produced vertical mycelia, which contacted the lid of the plate under humid conditions. The colonies grew at different rates and in a variety of shapes and types. Some formed dark brown sclerotia, either along the edge or in scattered clusters on the surface of the medium; others formed light brown sclerotia across the surface and interior of the medium. Seedlings were artificially inoculated with each $R$. solani colony type, which was subsequently re-isolated from affected tissues, confirming pathogen identity. The results showed that $E$. angustifolia was very susceptible to damping-off caused by $R$. solani AG-4.

Alternaria leaf spot of Echinacea spp. K. F. CHANG (1), R. J. Howard (1), and S. F. Hwang (2). (1) Crop Diversification Centre - South, Brooks, Alberta, Canada; (2) Alberta Research Council, Vegreville, Alberta, Canada. Phytopathology 89:S13. Publication no. P-1999-0090-AMA.

Alternaria spp. cause leaf spotting on Echinacea angustifolia (Ea), E. purpurea (Ep), and E. pallida (Epa) in Alberta, Canada. Small, light brown to dark purple circular spots, occasionally surrounded by purple or yellow rings ranging from 1.2 to $2.23 \mathrm{~mm}$, coalesced to form large foliar lesions. Young shoots, floral stalks and flowering heads became infected, resulting in dieback. Isolates of Alternaria spp. taken from Ea, Ep and Epa produced light orange to dark gray colonies on potato-dextrose agar. Conidia ranged from 5.7 to $15.7 \times 10.0$ to $28.6 \mu \mathrm{m}$ (avg. $8.8 \times 17.2$ ), had 1 to 4 transverse septa, and were produced in 4 - to 12 -spore chains. In detached leaf assays, Alternaria isolates showed differential pathogenicity on leaves of Ea, Ep and Epa at $30 / 20,25 / 15$ and $20 / 10^{\circ} \mathrm{C}$ (16/8 hours; day/night). Seed of Ea, Ep and Epa showed 90, 48, and $28 \%$ infestation, respectively, with Alternaria spp. Of 100 isolates of Alternaria spp. taken from these seeds, 80, 59 and 49\% caused leaf lesions on Ea, Ep and Epa, respectively. E. angustifolia showed the greatest susceptibility to infection by Alternaria spp.

Relationship of airborne ascospore concentration of Venturia inaequalis to lesion production under natural conditions. J. CHAREST (1), M. Dewdney (1), V. Philion (2), and O. Carisse (1). (1) Agriculture and Agri-Food Canada, St-Jean-sur-Richelieu, Qc., Canada J3B 3E6; (2) IRDA, St-Hyacinthe, Qc., Canada J2S 7B8. Phytopathology 89:S13. Publication no. P-1999-0091AMA.

Apple scab is the most important disease of apple in several parts of the world. The disease is controlled with numerous fungicide applications, but these are costly and becoming less efficient due to the development of resis- 
tance in populations of Venturia inaequalis. Better timing of fungicide applications could be achieved if airborne ascospore concentration (AAC) is considered in decision making. The relationship between AAC and the number of lesions produced was established under field conditions for 5 cultivars: Empire, Jonagold, McIntosh, Royal Gala, and Spartan. During infection periods, potted trees were exposed to natural inoculum and the ascospore concentration was measured using volumetric spore traps. Results showed that there was a significant correlation between AAC and the number of lesions produced. Differences among cultivars were observed and consequently, the ascospore lesion causing efficiency varied with cultivar tested.

Investigation of Salmonella enterica-alfalfa sprout interactions. A. O. CHARKOWSKI (1), S. Lindgren (2), and R. E. Mandrell (1). (1) USDAARS, WRRC, Albany CA; (2) California State University, Sacramento, CA. Phytopathology 89:S14. Publication no. P-1999-0092-AMA.

Several S. enterica outbreaks have been traced to alfalfa sprouts. Sprouts are a good vehicle for $S$. enterica because sprouts are not cooked before being consumed. Seed sterilization is not a foolproof method of preventing outbreaks since small populations of bacteria may survive and multiply to high levels during sprouting. Four strains of $S$. enterica isolated from sprout outbreaks were found to multiply on sprouts during seed germination. Sonication of the sprouts removed half of the bacteria, indicating that the remaining bacteria were firmly attached to or inside the sprouting seedling. Two strains were transformed with pGFP-UV so that they constitutively express green fluorescent protein. These strains were inoculated onto seeds and contaminated sprouts were examined by microscopy. Bacterial colonies were seen on the seed coat and around the base of the root cap. Antibacterial plant extracts are being tested to determine if they reduce $S$. enterica populations on sprouts. A S. enterica ompR mutant, which is reduced in animal pathogenicity, is being tested to determine if it multiplies on sprouts.

Ultrastructural changes of tomato fruit tissues treated by UV-C and inoculated by Botrytis cinerea. M. T. CHARLES (1), J. Arul (1), and N. Benhamou (2). (1) Dept. des Sciences des Aliments et de Nutrition; (2) Dept. de Phytologie, Université Laval, Qc., Canada PQ G1K 7P4. Phytopathology 89:S14. Publication no. P-1999-0093-AMA

Postharvest tomato fruits were treated with the hormic UV dose $\left(3.7 \mathrm{~kJ} / \mathrm{m}^{2}\right)$ and changes in ultrastructure examined by Transmission Electron Microscopy. It was observed that UV induced plasmolysis of the epicarp and of a few mesocarp cell layers leading to the formation of the cell wall stacking zone (CWSZ). In treated fruits inoculated with $B$. cinerea fungal development was restricted to the outer fruit tissues. Ingress of the fungus was hindered by the CWSZ. In the control fruits rapid tissue breakdown was observed. Cytochemical labeling for cellulose and pectin revealed that the CWSZ was less prone to degradation by the cell-wall degrading enzymes secreted by the fungus. In control fruits, wound inoculation resulted in extensive growth of the fungus and breakdown of the host tissue. In UV-treated fruits, hypersensitive death of the host cell at the site of inoculation was evident and the fungus displayed extensive damages. It was concluded that UV induced resistance of tomato to $B$. cinerea was related to the activation of both physical and biochemical defense mechanisms.

Induction of resistance to gray mold and accumulation of the phytoalexin rishitin in tomato fruits by UV-C. M. T. CHARLES, J. Arul, and C. Gosselin. Dept. des Sciences des Aliments et de Nutrition, Université Laval, Qc., Canada, PQ G1K 7P4. Phytopathology 89:S14. Publication no. P-1999-0094-AMA.

UV-induced resistance of tomato to gray mold during storage was studied. Hormic UV dose of $3.7 \mathrm{~kJ} / \mathrm{m}^{2}$ induced resistance gradually. Fruits were susceptible to $B$. cinerea when inoculated immediately after irradiation. The phytoalexin rishitin accumulated in treated tissue reaching a maximum 15 days after treatment. A significant correlation could be established between rishitin accumulation and lesion size in UV-treated tissue specially when rishitin reached inhibitory levels prior to inoculation. Treatment and posttreatment storage conditions affected both rishitin accumulation and disease resistance. Treatment of the fruits at the green mature stage with the hormic dose applied at a fluence rate of $1.23 \mathrm{~kJ} / \mathrm{m}^{2} . \min$ and storage at $13^{\circ} \mathrm{C}$ and 95\% RH favored higher levels of rishitin accumulation and was more effective in controlling gray mold. It was concluded that initial susceptibility was presumably associated with oxidative stress, and that the observed resistance was related to the activation of defense related genes, and specially with accumulation of rishitin to inhibitory levels.
Disruption of Phaeocryptopus gaeumannii pseudothecia development on Douglas-fir needles with fall applications of fungicides. G. A. CHASTAGNER. Washington State University, Puyallup, WA. Phytopathology 89: S14. Publication no. P-1999-0095-AMA.

Swiss needle cast, caused by $P$. gaeumannii is a single cycle disease. Most inoculum that infects young needles is produced by pseudothecia on the previous year's needles. In 1997/98 a test was conducted to determine if fall applications of fungicides could be used to disrupt the development of pseudothecia on needles. Individual branches on eight trees were sprayed to run off with one of five fungicides on November 10, 1997. During the following spring and summer, the effects of these treatments on the development of pseudothecia and production of ascospores were determined. Fall treatments had no effect on the percentage of needle surface covered with pseudothecia, but applications of dodine (1.8 $\mathrm{g}$ ai/l), thiophanate methyl (1.2 $\mathrm{g}$ ai/l), and especially benomyl $(1.2 \mathrm{~g}$ ai/l) significantly delayed the development of pseudothecia during March and April. Azoxystrobin ( $0.12 \mathrm{~g}$ ai/l) partially delayed development in March while applications of myclobutanil $(0.24 \mathrm{~g}$ ai/l) had no effect on pseudothecia development. By mid May, pseudothecia on benomyl treated needles had only produced about $10 \%$ as many spores as those on the nontreated branches.

Effects of temperature on the production of $\mathrm{N}$-acyl homoserine lactone (AHL) and tissue macerating enzymes by Erwinia carotovora ssp. carotovora strain EC153. A. CHATTERJEE, G. Jiang, H. Hasegawa, Y. Cui, and A. K. Chatterjee. University of Missouri, Columbia. Phytopathology 89:S14. Publication no. P-1999-0096-AMA

Erwinia carotovora subspecies atroseptica (Eca), betavasculorum (Ecb) and carotovora (Ecc) produce high levels of exoenzymes such as pectate lyase (Pel), polygalacturonase (Peh), cellulase $(\mathrm{Cel})$, and protease (Prt) at $28^{\circ} \mathrm{C}$. However, the production of exoenzymes by these bacteria is inhibited upon growth at elevated temperatures: at $31^{\circ} \mathrm{C}$ by Eca and at $35^{\circ} \mathrm{C}$ by Ecb and most Ecc strains. By contrast, Ecc strain EC153 produces higher levels of Pel, Peh, Cel and Prt and the transcripts of some of the cognate structural genes: i.e., pel-1, peh-1, and $c e l V$ at $35^{\circ} \mathrm{C}$ than at $28^{\circ} \mathrm{C}$. The elevated levels of exoenzymes at $35^{\circ} \mathrm{C}$ correlate with higher levels of AHL and transcripts of ahll, the structural gene for AHL synthase. EC153 also causes extensive maceration of celery petioles at $35^{\circ} \mathrm{C}$, which contrasts with limited tissue maceration by Ecc strain 71 at this temperature. Our data indicate that EC153 can perform physiological activities better at $35^{\circ} \mathrm{C}$ than at $28^{\circ} \mathrm{C}$, and these activities probably account for greater virulence at the elevated temperature.

A study of the interaction between highly and weakly virulent isolates of Leptosphaeria maculans in Brassica napus using the GUS reporter gene. C. Y. CHEN and G. Seguin-Swartz. AAFC Research Centre, 107 Science Pl., Saskatoon, SK S7N 0X2, Canada. Phytopathology 89:S14. Publication no. P-1999-0097-AMA.

The interaction between highly virulent (HV), GUS+ isolate GL-11 and weakly virulent (WV) isolate Unity of Leptosphaeria maculans was examined microscopically of blackleg susceptible Brassica napus cv. Westar. At 7-10 days post-inoculation, colonization of leaf tissue was extensive with GL-11, resulting in tissue collapse; sporulation was observed. Unity caused little tissue damage; infection hyphae were restricted to $2-3 \mathrm{~mm}$ around the inoculation site and appeared distorted. Lignin was detected in the brown, lesioned tissue. In leaves co-inoculated with GL-11 and Unity, lesions were larger than those caused by Unity, but smaller than those caused by GL-11. Hyphae of GL-11 and Unity were restricted to the brown, lignified zone around the inoculation site. The results indicated that a WV isolate could induce resistance to a HV isolate in B. napus and that the resistance was associated with deposition of lignin.

Expression of GSK-3 and SNF-1 protein kinase homologs of Colletotrichum gloeosporioides $\mathrm{f}$. sp. malvae in culture and during infection of round-leaved mallow, Malva pusilla. G. Chen and P. H. GOODWIN. Dept. of Environmental Biology, University of Guelph, Guelph, ON N1G 2W1, Canada. Phytopathology 89:S14. Publication no. P-1999-0098-AMA.

C. gloeosporioides f. sp. malvae ( $\mathrm{Cgm})$ is a hemibiotrophic pathogen of roundleaved mallow. Two genes belonging to the GSK-3 and SNF-1 protein kinase families were cloned from Cgm and are the first GSK-3 and SNF-1 homologs found in a filamentous fungus. Expression of cggsk and $\operatorname{cgsnf}$ was analyzed and normalized with expression of the Cgm actin gene to determine expression relative to fungal growth in vitro and in planta. Both genes were expressed at relatively low levels in agar culture. However, cggsk and cgsnf were highly expressed at 24 hours after inoculation, which then decreased 
24-fold and 12-fold, respectively, by 72 hours when the level of expression was similar to that in culture, and necrotrophy had begun. During the period of high expression, appressoria and large primary hyphae in plant epidermal cells were developing. cggsk and $\operatorname{cgsnf}$ may play a role in signalling stimuli during the early phases of infection. Based on the timing of expression and sequence similarities to other GSK-3 and SNF-1 homologs, CGGSK could be involved in morphogenesis of infection structures, and CGSNF could transmit nutritional or environmental signals during infection structure formation. Protein kinases form large ( 100) gene families in fungi and are important in many signal transduction pathways that could play critical roles in regulating pathogenicity.

Using 16S rDNA sequences to identify Xylella fastidiosa. J. CHEN (1), D. Banks (1), R. L. Jarret (2), M. Newman (2), C. J. Chang (3), and B. J. Smith (4). (1) Florida A\&M University, Tallahassee, FL; (2) USDA-ARS, Griffin, GA; (3) University of Georgia, Griffin, GA; (4) USDA-ARS, Poplarville, MS. Phytopathology 89:S15. Publication no. P-1999-0099-AMA.

The nucleotide sequences of the small sub-unit ribosomal RNA genes (16S rDNA) were used to identify Xylella fastidiosa, a nutritionally fastidious bacterium. The $16 \mathrm{~S}$ rDNAs from nine strains including seven pathotypes of $X y l$. fastidiosa and one strain of Xanthomonas campestris pv. campestris were amplified through PCR using two conserved primers (forward primer 5'-AGA GTT TGA TCA TGG CTC AG-3' and reverse primer 5'-AAG GAG GTG TGA TCC AGC CG-3') and sequenced. Partial sequences (200 bp from $5^{\prime}$ end) were compared with entries in the GenBank DNA database, including a Xyl. fastidiosa 16S rDNA sequence (M26601). All Xyl. fastidiosa sequences identified M26601 as the most similar sequence (199/200 or 99.5\%). The Xanthomonas rDNA sequence identified a Xanthomonas 16S rDNA as the most similar sequence, contrasting to M26601 as the 50th $(106 / 109$ or $97.2 \%)$. The fact that Xyl. fastidiosa strains are highly homologous in their rDNA sequences indicates that $16 \mathrm{~S}$ rDNA sequences can be used as a signature character to identify this bacterium.

Development of a molecular marker separating subspecies populations of Phialophora gregata. W. CHEN (1), L. E. Gray (2), and C. R. Grau (3). (1) Ill. Nat. Hist. Surv., Champaign, IL 61820; (2) USDA-ARS, Urbana, IL 61801; (3) Dept. of Plant Path., Univ. of Wisconsin, Madison, WI 53706. Phytopathology 89:S15. Publication no. P-1999-0100-AMA.

To study the genetic structure of Phialophora gregata, the causal agent of soybean brown stem rot, a molecular marker was developed that unambiguously separates $P$. gregata into distinct subspecies populations. A pair of PCR primers specific for $P$. gregata was designed to amplify three DNA fragments of about 1020, 830 and $660 \mathrm{bps}$, respectively. These three DNA fragments were used to separate $P$. gregata into type A (1020 bps), type B ( $830 \mathrm{bps})$ and type C ( $660 \mathrm{bps}$ ) isolates. Three adzuki bean isolates from Japan belonged to the type $\mathrm{C}$, whereas more than 200 soybean isolates tested belonged to either the type A or the type B. Both the type A and the type B isolates are found in each of seven midwestern states (IA, IL, IN, MI, MN, OH, and WI). Furthermore, both the type A and the type B isolates were found in the same fields in Illinois and Wisconsin. Preliminary data have shown that the type B isolates preferentially infect certain resistant soybean cultivars (e.g. Bell and S282N) under field conditions.

\footnotetext{
Mapping barley genes for resistance to stripe rust, leaf rust, and scab using resistance gene analog polymorphism and restriction fragment length polymorphism. X. M. CHEN (1), R. F. Line (1), P. M. Hayes (2), T. Toojinda (2), H. Vivar (3), A. Kleinhofs (4), and D. Kudrna (4). (1) USDA-ARS, Pullman, WA 99164; (2) Oregon State University, Corvallis, OR 97331; (3) ICARDA/CIMMYT, Mexico 6, DF, Mexico; (4) Washington State University, Pullman, WA 99164. Phytopathology 89:S15. Publication no. P-1999-0101-AMA.

The doubled haploid lines of Gobernadora $\times$ CMB 643 were evaluated in Mexican fields for resistance to stripe rust (Puccinia striiformis f. sp. hordei), leaf rust ( $P$. hordei), and scab (Gibberella zeae). In addition, scab resistance was evaluated in China; London, UK; and North Dakota. Resistance gene analog polymorphism (RGAP) and restriction fragment length polymorphism (RFLP) markers were used to map the resistance genes. Quantitative trait loci (QTLs) for stripe rust resistance were mapped on chromosomes 2, 3, 4, and 7. A single gene or a cluster of genes for resistance to leaf rust was mapped on chromosome 1 . Resistance genes for scab resistance were mapped on chromosomes 1, 2, 3, 4, and 5. Coincident or tightly linked markers were detected for some of the disease resistance QTLs. These markers should be useful in breeding barley cultivars with resistance to stripe rust, leaf rust, and scab.
}

Characterization of an alkaline protease excreted by Aspergillus flavus and its function in fungal infection of corn kernels. Z.-Y. CHEN (1), R. L. Brown (2), K. E. Damann (1), and T. E. Cleveland (2). (1) Dept. Plant Pathology and Crop Physiology, Louisiana State University Agricultural Center, Baton Rouge, LA 70803; (2) Southern Regional Research Center, USDA-ARS, New Orleans, LA 70179. Phytopathology 89:S15. Publication no. P-1999-0102-AMA.

Infection of corn kernels by Aspergillus flavus and subsequent contamination of aflatoxins in the field and after harvest pose serious health hazards to humans and domestic animals. A major protein found in infected corn kernels was identified as an A. flavus alkaline protease through $\mathrm{N}$-terminal amino acid sequencing and homology comparison. The DNA sequence encoding this protein showed significant homology to the alkaline protease from A. oryzae. This protein purified from concentrated A. flavus medium filtrate was able to degrade gelatin and casein. Infection of corn kernels with an A. flavus mutant expressing high levels of this protein caused kernel rot symptoms more severe than normal. Studies using protease inhibitors indicated that this protein may have two functions: to provide the fungus with sufficient source of energy for growth, and to destroy the host's defense system and help the colonization of corn kernels.

Cactus viruses of the U.S. southwest. Meyer CHESSIN. Division of Biological Sciences, The University of Montana, Missoula, MT 59812. Phytopathology 89:S15. Publication no. P-1999-0103-AMA.

Viruses have been identified in 3 genera of cacti growing wild in the southwestern U.S. Tobamo and potex virus occur in several species of Platyopuntia (prickly pears and beavertail cactus) in Arizona and neighboring states. Another virus of the potex group was described by L. Weathers as responsible for malformation and discoloration in a barrel cactus, Ferocactus acanthodes from Eastern California. The author has observed similar symptoms on barrel cactus in Arizona. M. Nelson and colleagues found the only isometric virus in cacti in the giant cactus or saguaro (Cereus giganteus) at many locations in Arizona. The role of animal vectors and pollen in virus spread will be discussed. Our native cacti represent an excellent plant group in which to study plant viruses in the wild.

Studies on potato virus Y Potyvirus isolates infecting potato and tobacco in South Korea. H. S. Choi (1), A. I. Bhat (2), J. U. Cheon (1), and H. R. PAPPU (2). (1) Plant Pathology Division, Dept. of Crop Protection, National Institute of Agricultural Science and Technology, Suwon, South Korea; (2) Dept. of Plant Pathology; Univ. of Georgia, Coastal Plain Expt. Station, Tifton, GA 31793. Phytopathology 89:S15. Publication no. P-1999-0104-AMA.

Potato virus $\mathrm{Y}$ (PVY) is one of the more commonly occurring viruses in tobacco, potato, tomato and pepper in South Korea. Some PVY isolates produced necrotic spots in Nicotiana tabacum 3 to 5 days after inoculation followed by vein clearing and vein necrosis. The tobacco and potato isolates have been characterized to better ascertain their identity within the PVY subgroup. Using degenerate primers, the $3^{\prime}$ terminal region was cloned and sequenced. Comparison of the $3^{\prime}$-untranslated region ( $3^{\prime}$-UTR) revealed $99 \%$ identity between potato and tobacco isolates. Multiple alignment and cluster dendrograms based on 3'-UTRs placed both potato and tobacco isolates within the PVY-N subgroup. Interestingly, both potato and tobacco isolates were closer to the PVY-N strains reported from other countries than to a tobacco necrotic strain of PVY (PVY-VN) previously reported from Korea.

Sequence analysis and characterization of genes expressed during appressorium formation in Magnaporthe grisea. W. CHOI, E. Fang, and R. A. Dean. Plant Pathology and Physiology, Clemson University, Clemson, SC. Phytopathology 89:S15. Publication no. P-1999-0105-AMA.

Magnaporthe grisea, the rice blast pathogen, requires the formation of a specialized infection structure called an appressorium to infect host plants. We have initiated an EST (Expressed Sequence Tag) analysis utilizing an appressorium-stage specific cDNA library to identify and characterize genes involved in appressorium formation. To date, $2717 \mathrm{cDNA}$ clones have been sequenced from either $5^{\prime}$ or $3^{\prime}$ ends. Approximately $45 \%$ of the sequences significantly matched ( $p$ value $<10^{-3}$ ) sequences in the GenBank database based on BLASTX. Twelve genes were found to be previously identified in $M$. grisea and several clones showed homology to genes associated with pathogenesis in other plant pathogenic fungi. Differential hybridization analysis using high density library filters with cDNA from different developmental stages identified 631 cDNA clones with appressorium stage specific/upregulated expression patterns. Characterization and the possible role of these genes in appressorium formation will be presented. 
Moisture prediction from micrometeorological data by a generalized regression neural network. Y. CHTIOUI (1), L. J. Francl (2), and S. Panigrahi (1). (1) Dept. Agric. Eng. and (2) Dept. Plant Path., No. Dak. State Univ., Fargo, ND 58105. Phytopathology 89:S16. Publication no. P-1999-0106AMA.

Principal component, partial least-square, ridge, and multiple linear regression methods were compared to optimized generalized regression neural networks (GRNN) for estimating moisture occurrence and duration at the flag leaf level of wheat. Moisture on a flat plate sensor was predicted by temperature, relative humidity, wind speed, solar radiation and rainfall. The average absolute error for prediction of moisture occurrence obtained by the GRNN was twice as small as statistical regression methods. Moreover, GRNN correctly predicted $93 \%$ of four wetness duration categories, while the best statistical method correctly predicted $87 \%$. Temporal errors in predicting moisture periods were more highly concentrated around the correct duration for GRNN than linear statistical methods. GRNN automatically fits the appropriate linear or nonlinear relationship from a data pattern. However, GRNN optimization required significantly more computational time than statistical methods. Neural networks have potential for precise and accurate moisture determination in plant disease management.

Relationships of bacterial diseases of brassicas in the Salinas Valley of California. N. A. CINTAS (1), C. T. Bull (1), and S. T. Koike (2). (1) USDA-ARS, PWA, 1636 E. Alisal Ave., Salinas, CA 93905; (2) Univ. Calif. Coop. Extension, Salinas, CA 93901. Phytopathology 89:S16. Publication no. P-1999-0107-AMA.

Brassicas, or cole crops, are a substantial part of the agricultural industry in the Salinas Valley of California. Bacterial diseases such as broccoli head rot, rapini leaf blight, and a new disease of broccolini are increasingly problematic to the industry. Rapini leaf blight is caused by Pseudomonas syringae. The $P$. syringae causing this disease may be a new pathovar. Similar P. syringae strains have also been isolated from leaf blight samples from broccoli and broccolini, and from broccoli head rot samples. The etiology of bacterial broccoli head rot for this area has yet to be elucidated. Attempts to determine the relatedness of the rapini blight pathogen to pathogens of broccoli and other brassicas and to other $P$. syringae pathovars are under way.

Overwintering survival of Claviceps africana, causal agent of ergot disease of grain sorghum. L. E. CLAFLIN and B. A. Ramundo. Kansas State University, Manhattan, KS. Phytopathology 89:S16. Publication no. P-19990108-AMA.

Ergot (Claviceps africana) disease of grain sorghum (Sorghum bicolor) was detected in the grain sorghum producing areas in Texas, Oklahoma and Kansas in 1997. The survival mechanism and dissemination of ergot conidia is basically unknown. Materials consisting of leather, plastic, paper, metal and rubber were cut into $2.5 \mathrm{~mm}$ circular disks and infested with a honeydew suspension consisting of $1.1 \times 10^{7}$ macroconidia. Disks were stored under natural conditions in Guadalajara, Mexico and Manhattan, KS and sampled at monthly intervals from December through May. Disks were placed in sixwell tissue culture plates, PBS was added, and the plates were placed on a rotary/shaker for $1 \mathrm{hr}$. Counts of macroconidia were made using a hemacytometer. Survival of conidia declined rapidly under Kansas conditions. Similar trends were observed in Mexico as populations declined nearly 50\% during March. Conidia viability remained relatively static on rubber and leather disks throughout the experiment. A significant decline in recovery was observed from metal and paper disks.

Cygnus $^{\circledR}$, a strobilurin fungicide for control of diseases on greenhouse and outdoor ornamentals. G. M. CLARK and H. L. Ypema. BASF Corporation, 26 Davis Drive, P.O. Box 13528, Research Triangle Park, NC 27709. Phytopathology 89:S16. Publication no. P-1999-0109-AMA.

Cygnus $^{\circledR}$ (active ingredient: kresoxim-methyl) is a new fungicide developed by BASF. It is registered for use on greenhouse ornamentals since September 1998. Registration on outdoor ornamentals is expected in 1999. Cygnus is a member of the strobilurin-class of fungicides and offers growers a new crop protection compound with excellent activity against important plant pathogens. Strobilurins have a unique target site in fungi: they inhibit respiration. Kresoxim-methyl has a strong affinity for the waxy plant surface and adheres strongly to the leaf surface under various weather conditions. Following application, kresoxim-methyl diffuses laterally over the leaf surface and translaminarly from one leaf surface to the other, thereby exhibiting surface systemic $^{\mathrm{TM}}$ and translaminar activity. Cygnus strongly inhibits spore germination, mycelial growth, and sporulation, in particular of powdery mildews. Cygnus has long residual activity and excellent crop safety. Cygnus has been tested for several years against diseases of indoor and outdoor ornamentals. An overview will be presented of Cygnus' performance against ornamental target diseases.

Evaluation of antioxidants, fungicides, and a plant activator for managing Sclerotinia white mold of cabbage. B. R. CODY, J. Hudyncia, and M. A. Cubeta. Dept. Plant Pathology, North Carolina State University, Raleigh 27695. Phytopathology 89:S16. Publication no. P-1999-0110-AMA.

White mold, caused by Sclerotinia sclerotiorum, is a serious disease of cabbage in North Carolina. In this study, three antioxidants (gluconic acid lactone, propyl gallate and thiourea), 14 fungicides (Benlate, BC012, BC014, Bravo, Fluazinam, fludioxonil, $\mathrm{KHCO}_{3}, \mathrm{NH}_{4} \mathrm{HCO}_{3}$, Quadris, Rovral, Ronilan, Switch, Topsin $\mathrm{M}$ and Vangard), and a plant activator (Actigard) were evaluated in the greenhouse for managing Sclerotinia white mold of cabbage. A bruising wound was made on four expanded leaves of 16, 8- to 12-wk-old cabbage plants (cv. 'Balbro'). After wounding, plants were sprayed with each treatment at the desired rate and placed into a greenhouse chamber $\left(10-21^{\circ} \mathrm{C}\right.$ and $80-100 \% \mathrm{RH})$ in a completely randomized design. Ascospores of $S$. sclerotiorum were released from laboratory produce apothecia twice daily for four consecutive days. Fourteen and 21 days after inoculation, each plant was rated for disease incidence. In each experiment, four compounds and an untreated control were evaluated. Eleven experiments were conducted and each compound was evaluated at least twice in repeated experiments. The compounds BC012, BC014, Benlate, Fluazinam, Quadris, Rovral, Ronilan, Switch, thiourea and Topsin M significantly reduced the incidence of white mold in all experiments.

Discula umbrinella DNA isolation protocol suitable for PCR amplification. S. D. COHEN. Animal and Plant Health Inspection Service, USDA, Riverdale, MD. Phytopathology 89:S16. Publication no. P-1999-0111-AMA.

To increase yield and quality of DNA for detection of differences within Discula umbrinella populations, it was necessary to modify existing protocols for DNA preparation. A protocol was developed for DNA isolation from fresh and freeze-dried mycelia of Discula umbrinella strains collected from Quercus alba and Q. rubra. Fresh $(250 \mathrm{mg})$ or freeze-dried $(10 \mathrm{mg})$ mycelia was harvested and kept at $-20 \mathrm{C}$ overnight. Samples were ground in a liquid Nitrogen-chilled mortar with dry ice and maintained at $-80 \mathrm{C}$ overnight. Isolation of DNA from samples involved a series of extraction, incubation, and precipitation steps. DNA obtained was resuspended in 1/10 Tris-EDTA buffer and incubated at $37 \mathrm{C}$ for 1 hour and $65 \mathrm{C}$ for 1 minute. The concentration of DNA in each sample was estimated by running samples on a $1.2 \%$ bufferless precast gel alongside known concentrations of lambda DNA. Approximately 2.5 to $5.0 \mu \mathrm{g}$ of DNA was isolated from each sample. PCR products were generated by adding $5 \mu 1$ of diluted DNA to a $25 \mu \mathrm{lPC}$ bead mix containing primers, CNL12 and CNS1, specific to the intergenic spacer region of the rDNA.

Sensitivity of Rhizoctonia solani isolates recovered from radish to fludioxonil, azoxystrobin and chlorothalonil fungicides. G. C. COLBURN and S. A. Miller. Dept. Plant Pathology, The Ohio State University, OARDC, Wooster, OH 44691. Phytopathology 89:S16. Publication no. P-1999-0112AMA.

The sensitivity of $R$. solani isolates to various fungicides has been shown to vary among and between anastomosis groups (AG). Radish isolates of $R$. solani belonging to AG 1-1B, AG 1-1C, AG 2-1, AG 2-2, and AG 2-2IIIB were examined for differences in fungicide sensitivity. Sixteen isolates were grown on PDA with five concentrations of fludioxonil, azoxystrobin or chlorothalonil. Linear growth was reduced more by fludioxonil than by the other fungicides. There were significant differences in linear growth reduction among and between the AGs. Radish seeds were treated with the same fungicides and grown in soil infested with individual isolates of $R$. solani. All three fungicide treatments resulted in significantly lower disease severity indices than the control but there were no significant differences between the fungicide treatments. Anastomosis groups did not differ significantly in sensitivity to the fungicides applied to radish seeds, but there were differences between individual isolates.

Dissecting the hypersensitive response of Nicotiana edwardsonii to CaMV: Resistance and necrosis are determined by two separate plant genes. A. B. Cole (1), L. Kiraly (2), and J. E. SCHOELZ (1). (1) University of Missouri, Columbia, MO 65211; (2) Agricultural Biotechnology Center, Gödöllö, Hungary. Phytopathology 89:S16. Publication no. P-1999-0113-AMA.

The gene VI product of cauliflower mosaic virus (CaMV) strain W260 has been identified as an avirulence gene that elicits a hypersensitive response 
(HR) in Nicotiana edwardsonii, an amphidiploid resulting from a cross between $N$. glutinosa and $N$. clevelandii. We present evidence to show that the resistance and necrosis that comprise HR are conditioned by two plant genes. A single gene that elicits necrosis, designated CCD for CaMV cell death, is derived from $N$. clevelandii. Resistance is conditioned by a single, semidominant gene derived from $N$. glutinosa that segregates at a 3:1 ratio (resistance:susceptibility). In addition, we have determined that resistance to CaMV in $N$. glutinosa segregates independently from tobacco mosaic virus resistance which is conditioned by the $\mathrm{N}$ gene and is also present in N. glutinosa.

Germination of conidia of Pleiochaeta setosa in the white lupin rhizosphere. Daniel J. COLLINS (1), R. Rodríguez-Kábana (2), and M. I. Teplitski (3). (1) Dept. of Biology, Oakwood College, Huntsville, AL 35896; (2) Dept. of Plant Pathology, Auburn University, 36849; (3) Dept. of Agronomy, Auburn University, 36849. Phytopathology 89:S17. Publication no. P-19990114-AMA.

Pleiochaeta setosa (Kirchn.) Hughes, is the causal agent of brown spot as well as Pleiochaeta root rot of lupin. Conidia of the fungus are the primary source of inoculum for both diseases. Little is known about the ecology of conidia of $P$. setos $a$ in the rhizosphere of lupin. To study conidia germination in the rhizosphere of lupin, microscope slides were dipped in a water agar suspension of conidia of $P$. setosa, and the slides were placed at a slight angle in soil in small plastic pots. White lupin (Lupinus albus L.) seed were planted in contact with the upper end of each slide, as seeds germinated the roots then grew down and across the agar slide. Germ tubes and hyphae arising from conidia had a positive tropic response to lupin roots, which subsequently became infected. Germination of conidia was highest (89\%) between a mean distance of 0 and $.81 \mathrm{~mm}$ from the root surface. Beyond a mean distance of $1.78 \mathrm{~mm}$ from the root surface, soil fungistasis suppressed conidial germination.

Optimizing a Bacillus sp. biocontrol agent used in the control of sugar beet Cercospora leaf spot. D. P. COLLINS and B. J. Jacobsen. Dept. Plant Pathology, Montana State University, Bozeman, MT 59717. Phytopathology 89:S17. Publication no. P-1999-0115-AMA

This study examines the spatial and temporal variation of the biocontrol agent (BCA) BacB, a Bacillus sp., in the field during a Cercospora beticola epiphytotic. The use of the selective BCA support substrate beta-glucan, at up to $1.0 \%$ spray solution, did not influence differences in population numbers of a spontaneous rifampicin resistant (BacB Rif+) over a 14 day period. BacB Rif + , applied as a spore formulation, declined predictably from 10000 $\mathrm{cfu} / \mathrm{cm}^{2}$ on day 0.5 , to $100 \mathrm{cfu} / \mathrm{cm}^{2}$ on day 14 at the three levels of betaglucan tested. In addition, a high percentage (76-89\%) of isolated cells, on day 4 , were in the form of endospores. A separate study, examining the effects of varying beta-glucan concentration and levels of $\mathrm{BacB}$ at application, demonstrated a complex interaction between beta-glucan, BCA population, and disease severity. Disease severity was significantly decreased, as compared to the control, at an application rate of $1 \times 10^{6} \mathrm{cfu} / \mathrm{ml}$, or higher, with $0 \%$ beta-glucan. Growth chamber experiments indicate that applying the bacteria in the log phase can significantly increase disease control as compared to a spore formulation. Spatial distribution analysis of BacB Rif+ indicates good coverage of the leaf surface four days after application. Spatial distribution studies with polyclonal antibodies against $\mathrm{BacB}$ will also be reported on.

Long term survival of Phytophthora cinnamomi. S. COLLINS (1), B. Shearer (2), J. McComb (1), I. Colquhoun (3), and G. Hardy (1). (1) Murdoch University, Perth, Western Australia; (2) Dept. of Conservation and Land Management, Perth, Western Australia; (3) Alcoa of Australia, Perth, Western Australia. Phytopathology 89:S17. Publication no. P-1999-0116AMA.

The aim of this study was to investigate the long-term survival characteristics of the devastating soilborne plant pathogen Phytophthora cinnamomi in rehabilitated bauxite minesites. A field trial was conducted to determine whether soil depth affects the survival of $P$. cinnamomi over different seasons. Exogenous and endogenous dormancy of chlamydospores was also examined. Soil depth affected $P$. cinnamomi's survival ability. After 10 weeks over summer at 30,10 and $5 \mathrm{~cm}$ depths, $P$. cinnamomi maintained an average survival rate in banksia plugs of $100 \%, 80 \%$ and $25 \%$ respectively. This increased survival with increased depth may be a result of the insulating effect of the soil. It was also found that chlamydospores could become endogenously dormant. Viable chlamydospores which did not germinate after single treatments of submersion in soil extracts, amino acids, or sugars could be triggered by repeated exposure to the same treatments. Further studies are being undertaken to assess these survival characteristics.

Identification of expressed sequence tags (ESTs) involved in fruiting of Agaricus bisporus. P. D. COLLOPY, M. D. Ospina-Giraldo, and D. J. Royse. The Pennsylvania State University, University Park, PA. Phytopathology 89: S17. Publication no. P-1999-0117-AMA.

The 1997-98 button mushroom (Agaricus bisporus) crop in the United States was valued at $\$ 800$ million. To identify genes involved with the formation of fruit-bodies, two unidirectional cDNA libraries were constructed from tissues isolated from different stages of mushroom development on compost. Tissue from the primordium stage, which precedes the formation of a mature mushroom pileus, was used to construct one of the cDNA libraries; tissue from mature basidiomes was used for the construction of the other cDNA library. Randomly picked cDNA clones from both libraries were single-pass sequenced and DNA sequence comparisons were made using the BLAST program. Expressed sequence tags from both libraries were partially identified and categorized. A few of the tags characterized thus far encode enzymes involved in carbohydrate and amino acid metabolism and respiratory pathways. Most tags did not match sequences reported in the databases.

Expression of root-knot nematode/Fusarium wilt resistance in transgenic cotton cultivars. P. D. COLYER (1), T. L. Kirkpatrick (2), W. D. Caldwell (1), and P. R. Vernon (1). (1) Red River Research Station, Louisiana Agric. Exp. Station, Bossier City, LA 71113; (2) Southwest Res. and Ext. Center, University of Arkansas, Hope, AR 71801. Phytopathology 89:S17. Publication no. P-1999-0118-AMA.

Several transgenic cotton genotypes and their nontransgenic parents were evaluated for two years in a naturally infested field for resistance to the rootknot nematode (Meloidogyne incognita)/Fusarium wilt (Fusarium oxysporum f. sp. vasinfectum) disease complex. The moderately resistant cultivar, Stoneville LA887, was included as the resistant control. Wilt ratings were based on stem discoloration, where 0 equals no stem discoloration and 5 equals the entire circumference of the stem was discolored. Root gall ratings were based on a scale of 0 to 5 , where 0 equals no galling and 5 equals severe galling. Ratings were taken from ten plants per replication at the end of the growing season. Overall, root gall ratings were high and wilt ratings were moderate. There were significant differences in wilt or root-knot gall ratings between some parental cultivars and their transgenic progeny, particularly in Paymaster $1560 \mathrm{BG}$. These results indicate that some transgenic cultivars respond differently to the root-knot nematode/Fusarium wilt complex than their parental cultivar. The potential causes and importance of these differences will be discussed.

Barley yellow dwarf virus as a tool for plant breeders. A. COMEAU (1), S. Haber (2), J. Collin (3), and C. A. St-Pierre (3). (1) Agriculture and AgriFood Canada (AAFC), Ste-Foy, Qc.; (2) AAFC, Winnipeg, Man.; (3) Univ. Laval, Ste-Foy, Qc. Phytopathology 89:S17. Publication no. P-1999-0119AMA.

Plant pathologists may be the enemies of plant disease, but we now see one disease as an occasional friend. Barley yellow dwarf virus (BYDV) research led to a new art: cereal breeding based on the pleiotropic effects of BYDV tolerance. Selection under BYDV pressure yields genotypes with fewer $\mathrm{G} \times$ E problems. This bonus will exist, whether BYDV is present or not. Resistance is the ability of the plant to reduce multiplication and spread of virus; tolerance just prevents damage to plants. Tolerance works even if the phloem is highly loaded with virus. The art of using BYDV as a tool took shape gradually. Understanding tolerance genes remains a challenge. Resistance genes seldom map on the same loci as the tolerance genes. Evidence of the value of this novel tool will be shown for wheat, oats, barley and triticale. Modern research tools could shed light on why selection under viral inoculum pressure reduces future $\mathrm{G} \times \mathrm{E}$ problems.

Development and usefulness of ratoon stunting resistant sugarcane cultivars in Florida. J. C. COMSTOCK, J. D. Miller, and P. Y. P. Tai. USDA-ARS, Sugarcane Field Station. Phytopathology 89:S17. Publication no. P-1999-0120-AMA.

Ratoon stunting disease (RSD), caused by Clavibacter xyli subsp. xyli (Cxx), causes sugarcane yield losses. Historically, RSD resistance was not developed because of a lack of a quick assay. Control has been through the use of 
heat-treated (disease-free) seedcane and phytosanitation, which has had variable success. RSD spread from infected plants occurs mostly during harvest by Cxx contaminated base cutters and seedcane cutting operations. Consequently, seedcane is heat-treated annually to ensure a supply of disease-free material. A tissue blot immunoassay of stalks that determines the number of pathogen infected vascular bundles was used to determine RSD reaction of clones. Selections were repeatedly screened and the most susceptible clones were discarded. Disease surveys of growers fields indicate that RSD incidence and rate of spread is related to resistance levels. Resistant cultivars can be grown without RSD control practices. Of the 8 most recently released cultivars, 3 were resistant, 3 were moderately resistant and 2 were susceptible. The genetic variability offers the potential of developing RSD resistant cultivars.

Base cation nutrient dynamics during the first 5 months of decay in black cherry branchwood from the Bousson Experimental Forest in northwestern PA. J. H. CONNOLLY. Husson College, School of Science and Humanities, Bangor, ME 04401. Phytopathology 89:S18. Publication no. P-1999-0121-AMA.

Previous investigations of decomposing wood in the forest environment have shown rapid depletion of potassium from sapwood, and longer term accumulations of calcium. Black cherry (Prunus serotina) branchwood was obtained from trees blown down during a late summer storm in 1997 in order to investigate cation dynamics during the earliest stages of decay. Branchwood was allowed to decay in the field for a period of 5 months during the fall of 1997 and early winter of 1998. After 5 months of decomposition, a mixture of yeast, bacteria, and filamentous fungi was isolated from both the sapwood and heartwood. No basidiomycetes were isolated from any of the samples. Calcium determinations by AAS showed significant increases in bark calcium and calcium retention in sapwood and heartwood. Potassium levels remained the same in the bark and sapwood, but increased $(p<0.001)$ in the heartwood. Magnesium levels did not change after 5 months of decay.

Integration of postharvest control strategies to reduce decay of 'Gala' apples. W. S. CONWAY (1), W. J. Janisiewicz (2), C. E. Sams (3), B. Leverentz (1), and J. D. Klein (4). (1) USDA-ARS, HCQL, Beltsville, MD 20705; (2) USDA-ARS, AFRS, Kearneysville, WV 25430; (3) The Univ. of Tennessee, Knoxville 37901; (4) Department of Field Crops, ARO, The Volcani Center, Israel. Phytopathology 89:S18. Publication no. P-1999-0122-AMA.

The combination of calcium infiltration of 'Gala' apples, followed by inoculation with the bacterial antagonist Pseudomonas syringae and then Penicillium expansum, was the most effective treatment combination in reducing decay on fruit stored for 3 months at $1 \mathrm{C}$. Heat treatment (38 C for 4 days) after inoculation with $P$. expansum, which had been beneficial the previous year, exacerbated decay when used alone or in combination with calcium infiltration or the antagonist on fruit inoculated at harvest and rated for decay after 3 months in storage. This possibly occurred due to over-maturity of the fruit at the time of treatment. Heat treatment of a parallel lot of fruit after wounding, but prior to inoculation with the pathogen, alone or in combination with the antagonist, resulted in excellent control due to the potential wound healing effect of the heat. Combining heat treatment with antagonists is being further investigated to control postharvest apple decay.

Reduction of fire blight incidence in pears, cv. 'Abate Fetel,' by the plant growth regulator prohexadione-Ca. G. COSTA (1), C. Andreotti (1), F. Bucchi (1), E. Sabatini (1), C. Bazzi (1), S. Malaguti (1), and W. Rademacher (2). (1) University of Bologna, 40126 Bologna, Italy; (2) BASF Agricultural Center, 67114 Limburgerhof, Germany. Phytopathology 89:S18. Publication no. P-1999-0123-AMA.

Fire blight, which invaded the country at the beginning of the 90 s is of great concern to Italian pear growers, since 'Abate Fetel,' one of the predominant cultivars, is highly susceptible and no reliable products for control are currently available. Since prohexadione-Ca is known to reduce fire blight severity in apples, analogous experiments have been initiated in pears, both under growth chamber and orchard conditions. Lowered incidences of fire blight were found in all cases. Six year old trees of 'Abate Fetel,' located in an area with high fire blight infestation pressure, were sprayed with prohexadione-Ca (BAS $12511 \mathrm{~W}$ ) four times each at either 50 or $100 \mathrm{ppm}$ of active ingredient at a new shoot length of $6,12,33$ and $45 \mathrm{~cm}$. The resulting final shoot length was 96 and 75\%, respectively, of the control. Whereas an average of 15 fire blight strokes per tree could be found in the controls, this number was reduced to 8 and 4 , respectively, in the treated plants. Fruit yield and quality was not affected.
Comparison of $\mathrm{S}$ strain isolates of Aspergillus flavus from Africa and North America. P. J. COTTY (1) and K. F. Cardwell (2). (1) USDA-ARS, SRRC, New Orleans, LA; (2) IITA, Cotonou, Benin. Phytopathology 89:S18. Publication no. P-1999-0124-AMA.

Aspergillus flavus, the most common aflatoxin-producing species, can be divided into two strains on the basis of sclerotial morphology. The S strain produces numerous small sclerotia and the $\mathrm{L}$ strain produces fewer, larger sclerotia. On average, $\mathrm{S}$ strain isolates produce greater quantities of aflatoxins than L strain isolates. In the current study, West African S strain isolates differed from North American isolates. Isolates from both continents produced aflatoxin $\mathrm{B}_{1}$. However, $40 \%$ and $100 \%$ of West African isolates also produced aflatoxin $\mathrm{G}_{1}$ in $\mathrm{NH}_{4}$ medium and urea medium, respectively. African isolates produced 5 fold to 150 fold more aflatoxin $\mathrm{B}_{1}$ on urea medium than on $\mathrm{NH}_{4}$ medium. Urea had an even greater influence on aflatoxin $\mathrm{G}_{1}$ production. None of the North American S strain isolates produced aflatoxin $\mathrm{G}_{1}$; urea did not significantly increase aflatoxin production by most North American isolates. Adapting aflatoxin management strategies from North America for use in Africa requires consideration of different cultures and agronomic systems. The divergence in fungal communities described here is an additional factor to consider.

In vitro evaluation of fungicides for activity on Phytophthora capsici isolates collected in Georgia. A. S. Csinos and D. B. LANGSTON, Jr. University of Georgia, Tifton, GA. Phytopathology 89:S18. Publication no. P-19990125-AMA.

Phytophthora capsici, the causal agent of crown and fruit rot, has become one of the most destructive cucurbit diseases in Georgia since it was first reported in 1994 subsequent to hurricane Alberto. In vitro sensitivity of three Phytophthora capsici isolates and two isolates of Phytophthora parasitica var. nicotianae to azoxystrobin, $9 \%$ dimethomorph $+60 \%$ ethylenebisdithiocarbamate (EBDC), metalaxyl, cymoxanil, and quaternary ammonium were tested in radial growth experiments. Isolates were grown on V8 agar amended with $0.1,1.0,10.0$ and $100.0 \mu \mathrm{g} / \mathrm{ml}^{-1}$ concentrations of each fungicide. Isolates were incubated at $28^{\circ} \mathrm{C}$ for 5 and 7 days for $P$. capsici and $P$. parasitica var. nicotianae, respectively. Radial growth in millimeters was recorded after incubation and used to calculate $\mathrm{ED}_{50}$ values. Metalaxyl and 9\% dimethomorph $+60 \%$ EBDC demonstrated the greatest activity on P. parasitica var. nicotianae. Only 9\% dimethomorph $+60 \%$ EBDC demonstrated activity on P. capsici with an $\mathrm{ED}_{50}$ value of approximately $1.0 \mu \mathrm{g} / \mathrm{ml}^{-1}$.

Alternatives for methyl bromide fumigation of tobacco and tomato seedbeds. A. S. CSINOS (1), D. R. Sumner (1), A. W. Johnson (2), and C. C. Dowler (2). (1) Dept. Plant Pathology, Coastal Plain Experiment Station, Tifton, GA 31793; (2) USDA-ARS, Coastal Plain Experiment Station, Tifton, GA. Phytopathology 89:S18. Publication no. P-1999-0126-AMA.

Metam sodium (MS) alone at 37.3 GPA and in combination with 1,3-D-C-17 (TC-17) at 10 GPA was applied to plots, tarped with $3 \mathrm{ml}$ plastic and allowed to fumigate for 1,2 and 4 wks and aerated for 1 to 10 days, depending on treatment. An additional test evaluated the method of application of the combination treatment of MS + TC-17 on control of fungi, weeds and various agronomic parameters. As the length of fumigation time increased, stand counts and vigor ratings of both tobacco and tomato seedlings increased and viability of Rhizoctonia solani, Pythium spp. and other soil fungi decreased. The combination of MS + TC-17 was more phytotoxic than MS alone, but tended to control cutleaf evening primrose, bedstraw, wild radish, henbit, red sorrel and cudweed better. TC-17 + MS applied by chisel injection and sprayer rototiller performed better than when both materials were chisel injected. In 20 of the 26 parameters evaluated, MS + TC-17 was not significantly different from methyl bromide (MeBr). MS + TC-17 was significantly better than $\mathrm{MeBr}$ for six of the parameters.

Functional dissection of the tobamovirus replicase: Implications in replicase-mediated resistance. J. N. CULVER, L. G. Eckhardt, and S. P. Goregaoker. Center for Agricultural Biotechnology, University of Maryland Biotechnology Institute and Molecular and Cell Biology Program, University of Maryland, College Park, MD 20742. Phytopathology 89:S18. Publication no. P-1999-0127-AMA.

Segments of the tobacco mosaic tobamovirus (TMV) 183-kDa replicase open reading frame, between 729 to $1069 \mathrm{nt}$ in length, were systemically expressed in Nicotiana benthamiana using a potato $\mathrm{X}$ potexvirus (PVX) vector. Infected plants were then challenged inoculated with $10 \mu \mathrm{g}$ of TMV and monitored for its accumulation. Mock plants and plants pre-infected with the 
unmodified PVX vector rapidly accumulated high levels of challenge virus. In contrast, plants pre-infected with PVX vectors expressing the amino terminus of the RNA-dependent RNA-polymerase domain or the region between the methyltransferase and helicase domains accumulated only low levels of TMV. Frameshift mutations designed to block protein expression from these two replicase segments did not inhibit the accumulation of challenge virus, indicating that the observed resistance is mediated by the protein. Other TMV replicase segments expressed from the PVX vector resulted in only slight or no reductions in the accumulation of TMV.

Management of bacterial spot of tomato and pepper using a plant resistance activator in combination with microbial biocontrol agents. D. CUPPELS (1), F. Sahin (2), and S. Miller (3). (1) Agriculture and Agri-Food Canada, London, ON N5V 4T3; (2) Ataturk Universitesi, 25240 Erzurum, Turkey; (3) Ohio State University, OARDC, Wooster, OH 44691. Phytopathology 89:S19. Publication no. P-1999-0128-AMA.

Bacterial spot is a serious and persistent disease problem for U.S. and Canadian tomato and pepper growers. Bactericide-fungicide combinations will reduce disease severity but not always give effective control. Greenhouse studies were executed to determine the effect of plant resistance activator CGA 245-704, both alone and in combination with the microbial biocontrol agents Bacillus sp. OSU142 and Pseudomonas fluorescens A506, on disease severity and on tomato and pepper seedling growth. CGA 245-704 suppressed disease development but caused a significant reduction in plant dry weight. Plants treated with the OSU142/CGA 245-704 combination did not have spot symptoms and increased in weight by $31-133 \%$. In a tomato field plot, all control treatments reduced disease severity significantly but none increased yield. In a pepper field plot, only the CGA 245-704 combinations reduced disease severity; none significantly affected yield.

Inhibition of phytopathogenic bacteria by chitosan: Ultrastructural and cytochemical aspects. K. M. DAGRY (1), M. V. Bhaskara Reddy (1), Francois Castaigne (1), Joseph Arul (1), and N. Benhamou (2). (1) Dept. Food Science and Nutrition and Horticultural Research Center; (2) Dept. of Plant Science, Université Laval, Sainte-Foy, Quebec, Canada G1K 7P4. Phytopathology 89:S19. Publication no. P-1999-0129-AMA.

Antibacterial activity of chitosan against five phytopathogenic bacteria $(E r-$ winia carotovora, Xanthomonas campestris, Pseudomonas syringae, Pseudomonas solanacearum and Corynebacterium michiganense) isolated from potato tubers and tomato fruit were studied in NB in the concentration range of 1 to $4 \mathrm{mg} / \mathrm{ml}$. The ultrastructural and cytochemical studies were performed (Transmission Electron Microscopy) from cultures grwon on chitosan incorporated NA. The Gram positive bacterium was more sensitive to chitosan than Gram negative bacteria with MIC of $1 \mathrm{mg} / \mathrm{ml}$, whereas, MIC for Gram negative bacteria varied from $1-2 \mathrm{mg} / \mathrm{ml}$. P. solanacearum was resistant to chitosan and only partial inhibition was observed even at $4 \mathrm{mg} / \mathrm{ml}$. Chitosan induced severe morphological alterations in Gram positive bacterium, like cellular expansion and rupture, while Gram negative bacteria did not exhibit such alterations, although retraction of the plasmalemma was evident. Lectin labelling showed discontinuity and rupture of the cell wall in Gram positive bacteria.

Incidence of white pine blister rust in a high-hazard region of Wisconsin. S. E. DAHIR and J. E. Cummings Carlson. Wisconsin Department of Natural Resources, Madison, Wisconsin. Phytopathology 89:S19. Publication no. P-1999-0130-AMA.

The incidence of white pine blister rust, Cronartium ribicola, was determined in 61 pole-small sawtimber stands. Plots were located in northern Wisconsin where the risk of infection has long been considered high. A minimum of 3 , randomly located 10-basal area factor prism plots were established in each stand. Topographic position, aspect, slope, tree density, habitat type, and the presence or absence of bole cankers were recorded. The mean incidence of infection was $7.2 \%$ for all study sites, and $5.9 \%$ excluding the Bayfield Peninsula. The mean incidence of cankered trees on the Bayfield Peninsula $(15.9 \%)$ was significantly higher than elsewhere. The following site factors were significantly correlated with increased incidence of blister rust: more northerly latitude, higher topographic position, northern aspect, low total tree density and absence of a hardwood overstory. Site factors influence the accessibility of pine to wind-blown spores and the microclimate surrounding spore-laden needles. Higher incidence of rust occurred on more humid and nutrient-rich habitat types where Ribes, the alternate host, is more frequently observed.
Influence of cropping patterns on cucurbit virus diseases. J. P. DAMICONE (1), J. V. Edelson (1), T. H. Hammer (1), L. D. Myers (1), and J. L. Sherwood (2). (1) Oklahoma State Univ., Stillwater, OK; (2) University of Georgia, Athens, GA. Phytopathology 89:S19. Publication no. P-1999-0131AMA.

In five trials during 1996 to 1998 , control of potyvirus diseases of pumpkin (WMV and PRSV) was achieved with a ground cover of grain sorghum compared to clean-tillage. Reductions in disease incidence ranged from $36-80 \%$ $(P=0.05)$. Surrounding plots with borders of peanut, soybean, corn, and grain sorghum either was not effective, or was less effective than the ground cover. In 1998, ground covers of soybean and peanut reduced disease incidence by 23 to $51 \%(P=0.05)$, but disease control generally was less than for sorghum. Increases in aphid populations generally preceded disease outbreaks by 7 to 14 days. However, differences in aphid populations among treatments and locations were not associated with levels of virus disease. Marketable yield was not increased by the ground-cover treatments, and yield was reduced by up to $50 \%$ for the ground cover of sorghum in two trials. Attempts to alleviate the yield effects of inter-crop competition with ground covers using grass-selective herbicide applied along pumpkin rows, reduced seeding rates of the ground covers, and mowing were not successful.

Susceptibility of nightshade to Phytophthora infestans. L. M. DANDURAND (1) and C. V. Eberlein (2). (1) Department of Plant, Soil and Entomological Sciences, University of Idaho, Moscow; (2) District III Cooperative Extension, University of Idaho, Twin Falls. Phytopathology 89:S19. Publication no. P-1999-0132-AMA.

Susceptibility of leaves and berries of six nightshade species to infection by Phytophthora infestans was tested. American black and eastern black nightshade were resistant to late blight infection. However, two biotypes of hairy nightshade (smooth and wavy-edged leaf), cutleaf, and bitter nightshade were all susceptible. Survival of the fungus in susceptible species was tested under various environmental conditions. The fungus survived for at least two weeks in plants of both hairy nightshade biotypes when the material was kept in soil at a temperature of $20 \mathrm{C}$. However, the fungus survived $48 \mathrm{hrs}$ at $-15 \mathrm{C}$ only in the smooth leaf hairy nightshade biotype. In the laboratory, oospores of the pathogen were formed in both hairy nightshade biotypes, cutleaf nightshade, and Russet Burbank potato, but not in American black, bitter, or eastern black nightshade.

Influence of silicon on grey leaf spot development in St. Augustinegrass. L. E. DATNOFF and R. T. Nagata. University of Florida, IFAS, Everglades Research and Education Center, Belle Glade 33430. Phytopathology 89:S19. Publication no. P-1999-0133-AMA.

This study investigated the effect of silicon on grey leaf spot, caused by $P y$ ricularia grisea, in St. Augustinegrass. The experiment was a factorial with 10 replications arranged in a RCB in the greenhouse. Main effects were silicon (14 $\mathrm{gm} \mathrm{CaSiO}_{3} / 500 \mathrm{cc}$ soil) and a non-amended control, and subeffects were four St. Augustinegrass cultivars; Bitterblue, Floratam, FX-10 and Seville. Plants were periodically misted to provide optimum leaf wetness that promoted natural infection by $P$. grisea. Disease severity was rated over a 4 week period by estimating \% grey leaf spot on individual leaflets and by performing $\%$ whole plant assessments using a Horsfall-Barratt rating scale. Silicon dramatically reduced \% grey leaf spot infection for Bitterblue (49.3 vs 10.5 ), Floratam (42.7 vs 9.6), FX-10 (4.2 vs 2.2 ) and Seville (24.2 vs 19.6). Similar results were obtained for $\%$ whole plant infection for all the cultivars. Plant silicon content in Si amended treatments increased more than $2 \times$ over the controls for all cultivars. Silicon appears to be a good method for managing grey leaf spot in St. Augustinegrass.

Diversity of the coat protein gene of papaya ringspot virus in Florida. M. J. DAVIS and Z. Ying. University of Florida, TREC, Homestead, FL. Phytopathology 89:S19. Publication no. P-1999-0134-AMA.

Papaya ringspot virus (PRSV) is the most limiting factor in papaya production in Florida. Coat protein gene-mediated resistance in transgenic papaya has been used elsewhere to control the disease; however, the efficacy of this control appears to be greater for strains that are more closely related to that of the source of the gene. Therefore, to enable the development of transgenic PRSV resistant papaya Plants for Florida, we examined the genetic diversity of PRSV strains collected at various locations in south Florida. RT-PCR was used to amplify the coat protein genes of the strains. The nucleic acid sequence of the gene of one strain was determined entirely, and partial sequences were obtained for 27 other strains. Comparison of the sequences with those in nucleic acid databases indicated that Florida strains are more 
related to one another than to strains from other locations throughout the world. Based on these results, the coat protein gene from a strain with one of the most common sequences was chosen for further development of virusresistant transgenic papaya plants for production in Florida.

Variable responses of Botrytis cinerea isolates to captan, thiram and mancozeb in greenhouse crops. N. DELEN (1), N. Tosun (1), Z. Yildiz (1), and M. T. Momol (2). (1) Ege University, Plant Protection Dept., Izmir, Turkey; (2) University of Florida, NFREC, Quincy, FL 32351. Phytopathology 89: S20. Publication no. P-1999-0135-AMA.

Botrytis cinerea can cause significant yield losses on greenhouse grown vegetables and ornamentals in Turkey. Protective fungicides with non-specific mode of action such as thiram (T), captan (C) and mancozeb (M) are applied heavily to control $B$. cinerea and to reduce resistance risk of specific fungicides. Studies conducted since the 1980s showed that some of the B. cinerea isolates become less sensitive (or tolerant) to T, $\mathrm{C}$ and $\mathrm{M}$. Mean $\mathrm{ED}_{50}$ values of collected isolates in 1998 were calculated higher than the isolates collected in 1984 and 1986. Spores of the pathogen are more sensitive to the fungicides studied than its mycelia. When 11 isolates from the 1989 collection with different sensitivities to $\mathrm{T}$ and $\mathrm{M}$ were transferred into non-fungicide medium continuously, sensitivities of most of them were increased. Although 13 isolates collected in 1994-1995 were transferred in non-fungicide medium ten times, sensitivities of nearly half of them were not increased. In greenhouse experiments fungicides are more effective to sensitive isolates than isolates that have high $\mathrm{ED}_{50}$ values.

Complex pathotypes of Phytophthora infestans in western Washington during 1998. M. L. DERIE and D. A. Inglis. Washington State University, Mount Vernon REU, 16650 State Route 536, Mount Vernon, WA 98273. Phytopathology 89:S20. Publication no. P-1999-0136-AMA.

During 1998, 118 isolates of $P$. infestans were collected from various potato and tomato cultivars as well as hairy nightshade in western Washington (WWA). Mating type and allozyme banding pattern was determined for all isolates, with a subset of 30 tested for virulence phenotype on ten potato differentials. From these tests, 72 and $25 \%$ were genotypes of US- 8 and US-11, respectively. US-8 was recovered from tomato for the first time although US-11 has been recovered predominantly from tomato since 1995 . Overall, there was a $54 \%$ increase in recovery of US- 8 and a $49 \%$ decrease in recovery of US-11 from potato compared to a similar study in 1997. In past years, isolates of $P$. infestans have defeated eight or more R-gene potato differentials. US-8 isolates in 1998 infected eight R-gene potato differentials whereas US-11 isolates infected four to six potato differentials. The pathotype $1,2,3,4,5,6,7,10$ was detected for all US-8 isolates. In WWA isolates of $P$. infestans have maintained complex virulence over the last $4 \mathrm{yr}$, regardless of selection pressure by host type or competition from newly introduced genotypes.

Isolation and characterization of potential antagonists for Pythium spp. control. J. T. DE SOUZA and J. M. Raaijmakers. Laboratory for Phytopathology, Wageningen University, The Netherlands. Phytopathology 89:S20. Publication no. P-1999-0137-AMA.

Pythium spp. are important pathogens of a wide variety of crops. On wheat, they cause damping-off, root rot, reduced tillering, delayed maturity and nutrient deficiency. Because of environmental concerns and resistance development, the use of chemicals to control Pythium is being restricted. Hence there is a great interest in application of antagonistic microorganisms to control Pythium spp. Among the antagonists, Pseudomonas spp. that produce specific antibiotics have been implicated in Pythium control. In this study, specific primers and probes were used and developed to isolate Pseudomonas spp. that produce phenazines (Phz), pyrrolnitrin (Prn), 2,4-diacetylphloroglucinol (Phl), or pyoluteorin (Plt) from roots of wheat grown in raw soils. The population of Phl-producers ranged from $2.3 \times 10^{4}$ to $1.4 \times 10^{6}$. Phz and Prn-producers were present at densities ranging from $1.5 \times 10^{4}$ to $3.6 \times 10^{4}$; Plt-producers were not detected. The specificity of newly developed primers and the activity of the isolated strains against various Pythium spp. will be presented.

Isolation of tomato bushy stunt virus ribonucleoprotein complexes from infected plants. B. DESVOYES and H. B. Scholthof. Department of Plant Pathology and Microbiology, Texas A\&M University, College Station, TX 77843. Phytopathology 89:S20. Publication no. P-1999-0138-AMA.

The systemic movement of tomato bushy stunt virus (TBSV), a singlestranded positive-sense RNA virus, in $N$. benthamiana does not require the coat protein $(\mathrm{CP})$. The aim of this study was to begin characterizing complexes that assemble in vivo in the absence of virion formation. For this purpose, $N$. benthamiana plants were infected with a mutant (pHS7) that has 46 nt deleted downstream of the CP-start codon, resulting in a frame-shift to prevent the production of the full-length CP. Ribonucleoprotein complexes were isolated from infected plants and analyzed on Tris-glycine agarose gels followed by western and northern blotting. The results showed that an RNAprotein complex migrated through the gels which reacted with the polyclonal CP-antibodies, suggesting that a truncated form of $\mathrm{CP}$ accumulated which retained the ability to associate with viral RNA. Moreover, initial tests implied that this CP-RNA complex was also associated with replicase and/or movement proteins.

Field evaluation of minimum infection time of Venturia inaequalis for different cultivars. M. DEWDNEY (1), J. Charest (1), V. Philion (2), and O. Carisse (1). (1) Agriculture and Agri-Food Canada, St-Jean-sur-Richelieu, Qc., Canada J3B 3E6; (2) IRDA, St-Hyacinthe, Qc., Canada J2S 7B8. Phytopathology 89:S20. Publication no. P-1999-0139-AMA.

Apple scab is a disease of great importance for apple culture in North America. The primary source of inoculum of $V$. inaequalis is ascospores and to infect apple leaves they require a minimum number of hours of leaf wetness. Information on infection threshold is available mainly for the highly susceptible cultivar McIntosh and may not apply for cultivars with variable levels of susceptibility. The minimum number of hours of leaf wetness required for infection was established under field conditions for 5 cultivars: Empire, Jonagold, McIntosh, Royal Gala, and Spartan. Leaf wetness periods varied from 6 to 42 hours and the experiment was conducted under fluctuating temperatures for infection and incubation. Results showed that there were significant differences between the cultivars. The infection curves showed similar trends but the number of lesions was different for each cultivar. These findings indicate that cultivar susceptibility and adjusted infection curves could be used for improving apple scab management.

Infection periods models for wheat tan spot and Stagonospora blotch. E. D. DeWOLF (1) and L. J. Francl (2). Dept. Plant Path., Ohio State Univ., Wooster, OH 44691; (2) Dept. Plant Path., North Dakota State Univ., Fargo, ND 58105. Phytopathology 89:S20. Publication no. P-1999-0140-AMA.

Infection periods of wheat tan spot and Stagonospora blotch on susceptible wheat plants were correlated with $24 \mathrm{~h}$ summaries of environmental data. Data were modeled by backpropagation neural networks, general regression neural networks, logistic regression and, parametric and nonparametric methods of discriminant analysis. Mean prediction accuracy of ten validation data sets was between $71 \%$ for logistic regression and $76 \%$ for backpropagation models of tan spot incidence. No significant difference was found between methods of modeling tan spot infection. Prediction accuracy of Stagonospora blotch incidence was $86 \%$ and $81 \%$ for backpropagation and logistic regression, respectively. Accuracy of other modeling methods was significantly less than the backpropagation result. The best backpropagation models of tan spot and Stagonospora blotch incidence correctly classified $82 \%$ and $84 \%$ of validation cases, respectively. High classification accuracy and consistently good performance demonstrate applicability of neural network technology to plant disease forecasting.

Genetic analysis of avirulence/virulence in isolates of Magnaporthe grisea from Mali, Africa. M. Diaby (1) and A. H. ELLINGBOE (1). University of Wisconsin, Madison, WI. Phytopathology 89:S20. Publication no. P-19990141-AMA.

Seven isolates were inoculated onto 13 U.S. rice cultivars. The predominant phenotype was avirulence on nine and virulence on four cultivars. Each isolate from Mali was mated with 4 of our highly fertile strains, two of which had mating type Mat 1-1 and two of which had mating type Mat 1-2. Five isolates from Mali had mating type Mat 1-2 and two had mating type Mat 1-1. Progenies from 9 crosses were tested for their avirulence/virulence on the 13 rice cultivars. Segregation for avirulence/virulence occurred on all 13 rice cultivars. Since the fertile isolates are virulent on all 13 rice cultivars, the genes for avirulence are assumed to come from the isolates from Mali. The recovery of progenies that are avirulent on specific rice cultivars from crosses between two virulent strains of $M$. grisea suggests that at least one of the strains had a gene for avirulence which was not expressed, but upon recombination became expressed. The data also show that the isolates from Mali contain many genes that give avirulence on the 13 rice cultivars tested. 
Stem necrosis in cowpea stunt disease caused by a synergism between blackeye cowpea mosaic virus (BICMV) and cucumber mosaic virus (CMV). H. Diallo, R. C. GERGERICH, and K. S. Kim. University of Arkansas, Fayetteville 72701. Phytopathology 89:S21. Publication no. P-19990142-AMA.

Stem necrosis is an early and severe symptom of cowpea stunt disease caused by the synergistic interaction of BICMV and CMV. In 'Monarch' cowpea, stem necrosis occurred 5-8 days after inoculation and was limited to an area $1-2 \mathrm{~cm}$ below the inoculated primary leaves which coincided with the stem area that elongated after inoculation. Light and electron microscopy of symptomatic stems showed characteristic effects of virus infection in all cell types including epidermal, cortical and vascular bundle cells. Virus accumulation in stems of mixedly infected plants was not significantly different from that in single infections. However, many cells in the region of stem necrosis exhibited the characteristic cytopathology of both viruses indicating that individual cells supported replication of both viruses. In addition, affected cells had more cytoplasmic vacuoles and greatly hypertrophied mitochondria. It is suggested that stem necrosis in cowpea stunt is associated with structural and physiological responses of individual cells to the two viruses rather than with increased virus concentration.

Effects of previous crop and tillage on Fusarium head blight of wheat. R. DILL-MACKY (1) and R. K. Jones (1). (1) University of Minnesota, St. Paul, MN. Phytopathology 89:S21. Publication no. P-1999-0143-AMA.

Strips of wheat (W), maize (M) and soybean (S) were established in 1994, 1995, and 1996 under natural rainfall and supplemental mist irrigation sites in a randomized complete block design with 5 replicates. Tillage treatments, moldboard plow (MP), chisel plow (CP), and no-till (NT), were imposed in strips perpendicular to crop strips to establish previous crop-tillage treatments. In the spring following the establishment of previous crop-tillage treatments the hard red spring wheat Norm, susceptible to Fusarium head blight (FHB), was established in all $9 \times 6 \mathrm{~m}$ plots. FHB incidence (DI) and severity (DS) was evaluated visually at soft dough. Plots were harvested at maturity; yield, test weight, visually scabby kernels (VSK), and the deoxynivalenol (DON) content of the grain were determined. DI and DS were greatest in plots following $\mathrm{M}$ and least following S. Although FHB was reduced in MP plots, significant differences were not detected between $\mathrm{CP}$ and NT treatments. Yield, test weight, VSK, and DON were correlated with FHB values. The results of this study suggest that the adoption of chisel plowing may have exacerbated recent epidemics of FHB in the Upper Midwest of the United States.

A simple process for dispersion and in vitro culture of individual basidiospores. A. M. DINER. USDA Forest Service, Southern Institute of Forest Genetics, Saucier, MS 39574. Phytopathology 89:S21. Publication no. P-19990144-AMA.

In vitro display of host genetic disease-resistance requires co-cultured single genotypes of host and pathogen, historically difficult using rust fungi. Single basidiospores of the fusiform rust fungus (FR) have been cultured on preconditioned medium via a protracted process. This report describes a simplified, direct single-spore cast and colony development therefrom. Cleaned FR telia beginning spore cast were applied to one surface of double-sided tape pre-applied to a Petri dish lid inner surface. Lids were placed atop freshly prepared, agar-gelled Harvey and Grasham basal medium supplemented with $0.1 \mathrm{~g} / 1 \mathrm{CaCO}_{3}, 1 \mathrm{~g} / 1$ each of yeast extract and proteose peptone, and $10 \mathrm{~g} / 1$ defatted BSA, then sealed with Parafilm. Double-sided tape was also applied to the dish base, which was then affixed to the platform of an orbital shaker operated 1 hour at 480 orbits $/ \mathrm{min}$ in a $1 \mathrm{~cm}$ orbital radius. Several hundred single spores were cast onto the medium. Inoculated plates incubated inverted at $22 \mathrm{C}$ for 48 hours were examined for rust hyphae and contaminants, then returned to incubation. FR colonies developed at less than $1 \%$, but adequate frequency. Contamination was negligible.

Takeall suppressiveness as a measure of the effects of management on the microbial buffer in soil. N. J. DONOVAN (1), D. Backhouse (2), and L. W. Burgess (1). (1) University of Sydney, Australia; (2) University of New England, Armidale, Australia. Phytopathology 89:S21. Publication no. P-19990145-AMA.

The aim of this study was to establish if residue retention and crop rotation affect the ability of the microbial buffer in soil to suppress an introduced pathogen. Undisturbed soil cores were collected from two long-term tillage trials in north-western NSW, Australia, where takeall has never occurred. Treatments were continuous wheat and wheat-chickpea rotation crossed with stubble retained-zero tillage and stubble burnt followed by cultivation. The soil cores were inoculated with takeall (Gaeumannomyces graminis var. trit- ici) and sown with wheat seed. After five weeks the wheat roots were assessed for disease severity. Stubble retention caused significantly lower disease scores in both continuous wheat and wheat-chickpea rotations. Stubble retention, but not rotation, therefore increased the biological resilience of the soil.

The role of first-crop figs in fungal decay of main-crop figs in California. M. A. DOSTER and T. J. Michailides. Univ. of California, Davis/Kearney Ag. Center, Parlier, CA 93648. Phytopathology 89:S21. Publication no. P-19990146-AMA.

Although first-crop (breba) figs (Ficus carica cv. Conadria) mature in early summer, many of these figs remain in commercial orchards and are collected with the main-crop figs during the repeated harvests in late summer. Although at the time of these harvests in 1996 and 1997 first-crop figs had substantially more decay by fungi in general than main-crop figs, first-crop figs had approximately the same incidence of decay by fungi in Aspergillus section Nigri (causal agents of fig smut) and in Aspergillus section Flavi (producers of the mycotoxin aflatoxin). Furthermore, first-crop figs from each orchard had approximately the same levels of aflatoxin contamination as main-crop figs. First-crop figs, however, may play an important role in fungal decay of main-crop figs (especially by Aspergillus spp.), because firstcrop figs have more fungal colonies sporulating on the fig exterior than main-crop figs (probably resulting in the dispersal of more inoculum). Also, in 1998 we found that fungal colonies were sporulating on first-crop figs during the period of main-crop ripening, a time when these figs become susceptible to fungal decay.

Ecological implications of the response of arbuscular mycorrhizal fungi to light. D. D. DOUDS and G. Nagahashi. USDA-ARS, ERRC, 600 E. Mermaid Lane, Wyndmoor, PA 19038. Phytopathology 89:S21. Publication no. P-1999-0147-AMA.

Germ tube hyphae of arbuscular mycorrhizal [AM] fungi have been shown to branch profusely in response to signals in exudates from host roots, enhancing the probability of contact for appressorium formation. We have noted that hyphae of Gigaspora sp. also branch in response to light. Experiments were conducted with Gigaspora gigantea to detail the effects of light upon the growth of this fungus and determine if light exposure enhances mycorrhizal formation in maize seedlings. Six hour per day exposure to fluorescent light $\left(15.5 \mu \mathrm{E} / \mathrm{m}^{2} / \mathrm{sec}\right)$ caused spores to germinate one day earlier than dark controls. Maize seedlings grown in root compartments which allowed passage of light $\left(40 \mu \mathrm{E} / \mathrm{m}^{2} / \mathrm{sec}\right)$ became significantly more colonized after 20 days of growth (42\% colonized root length) than those grown in root compartments of the same dimensions which did not allow the passage of light (30\% colonized root length). These results indicate that the negatively geotropic growth of germ tubes of Gigaspora sp. may allow increased branching in upper layers of soil with greater light penetration, and increased colonization of roots for ensured supply of $\mathrm{C}$ for the fungus.

Molecular characterization of rhizosphere bacterial communities in Pythium-suppressive soils. M. P. DOUGLAS, M. E. McKellar, and E. B. Nelson. Cornell University, Ithaca, NY. Phytopathology 89:S21. Publication no. P-1999-0148-AMA.

Rhizosphere bacterial communities were studied to determine relationships of specific populations with Pythium suppressiveness in compost-amended soils. Relatively high frequencies of Pythium-suppressive bacteria (primarily Pseudomonas, Bacillus, and Enterobacter) could be isolated from nonsuppressive and suppressive soils. Bacterial communities were further characterized by extracting DNA directly from rhizosphere soil samples. Fulllength 16S rDNA was amplified and cloned. Restriction analyses of clones revealed unique individuals for further sequencing and analysis. Additional primer sets were used to amplify portions of the variable V6 region of the $16 \mathrm{~S}$ rDNA molecule. Unique $16 \mathrm{~S}$ rDNA sequences were separated by denaturing gradient gel electrophoresis (DGGE) procedures. Individual bands were excised and re-amplified for sequencing and analysis. Preliminary results indicate the utility of molecular approaches for analyzing diverse bacterial populations in disease-suppressive soils.

The effect of fungicides on germination of Phytophthora infestans zoospores in soil. T. DUBEY, R. V. James, and W. R. Stevenson. Dept. Plant Pathology, University of Wisconsin, Madison, WI 53706. Phytopathology 89:S21. Publication no. P-1999-0149-AMA.

The effect of foliar fungicides on germination of $P$. infestans zoospores in soil was tested in a growth chamber at $18 \mathrm{C}$. Fungicides $(0,10,50,100$ $\mu \mathrm{g} / \mathrm{ml}$ ai) were sprayed on the surface of sand in plexiglass columns $(10 \mathrm{~cm}$ 
high, $4.5 \mathrm{~cm}$ diam., kept at $18 \mathrm{C})$. P. infestans zoospores $(3.75 \mathrm{ml}$ of a suspension produced by chilling $10^{4}$ sporangia/ml, US- 8 genotype, at $12 \mathrm{C}$ for $2 \mathrm{hr}$ ) were applied to each column $1.5-2 \mathrm{hr}$ after fungicide application. Water $(0.6,1.25,2.5,5.0 \mathrm{~cm})$ was added 0,24 , and $48 \mathrm{hr}$ later to simulate rainfall. Effluent from each column was collected for $24 \mathrm{hr}$ after each "rain". Zoospores were collected on a millipore filter membrane to determine \% germination. Infectivity of propagules remaining in the top and bottom $1-\mathrm{cm}$ layer of soil in each column was tested on potato tuber disks. Zoospore germination and tuber disk infection decreased as chemical concentration increased, but increased as greater amounts of water were applied. Chlorothalonil, cymoxanil, dimethomorph, mancozeb and TPTH reduced zoospore germination by $50 \%$ at concentrations of $20-30 \mu \mathrm{g} / \mathrm{ml}$ (ai) $(0.6 \mathrm{~cm}$ water, three collection intervals averaged).

Trichoderma used alone and combined with Pseudomonas for biocontrol of wheat take-all: Inoculum dosage and placement effects. B. DUFFY and D. Weller. ETHZ, 8092 Zürich, Switzerland; USDA-ARS, Pullman, WA 99164. Phytopathology 89:S22. Publication no. P-1999-0150-AMA.

Variable biocontrol activity of an Australian Trichoderma isolate against wheat take-all disease in Washington State was previously linked to soil factors such as $\mathrm{pH}, \mathrm{N}$ form, $\mathrm{P}$ and \% clay (Phytopathol. 87:1118). This study found that inoculum dose and inoculum placement have a major impact on biocontrol performance. Biocontrol was best (30\% disease reduction) at a ratio of 1:1 with pathogen inoculum ( $1 \mathrm{~g}$ Trichoderma/100 $\mathrm{g}$ soil). However, significant control (7\% reduction) was obtained with much lower doses (0.1:1). Mixture of $1 \%$ Trichoderma with Pseudomonas seed coatings ( $\log 8$ CFU/seed) improved the activity of both agents (Phytopathol. 86:188). In this study, mixture effects depended on the dose of Trichoderma used. Pseudomonas strain Q29-80 improved, and strain Q2-87 reduced, Trichoderma performance regardless of dose. In contrast, strain 30-84 improved the effect of low Trichoderma doses $(<0.5 \%)$ but blocked biocontrol at higher doses. This study demonstrates that manageable doses of Trichoderma can be applied to protect wheat against take-all, and that biocontrol interactions with bacterial agents can vary depending on Trichoderma dose.

The role of calcineurin in dimorphism and pathogenicity in the corn smut pathogen Ustilago maydis. J. W. DUICK and S. E. Gold. Univ. of Georgia, Athens, GA 30602. Phytopathology 89:S22. Publication no. P-1999-0151AMA.

Ustilago maydis is a dimorphic basidiomycete and is the causal agent of corn smut disease. Dimorphism is controlled through signal transduction pathways involving cAMP and the mitogen-activated protein (MAP) kinase cascade. Protein phosphatases have the role of reversing the effects of protein kinase phosphorylation. Post translational modification and specifically protein phosphorylation is a ubiquitous form of regulation in signal transduction pathways. Calcineurin (also referred to as protein phosphatase 2B or PP2B) is a serine/threonine protein phosphatase and, in other systems, has a role in reversing the phosphorylation of the substrates of cAMP dependent protein kinase A. Through a reverse genetic approach, degenerate primers based on the calcineurin catalytic subunit were used to clone a 795 base pair putative calcineurin fragment. Screening of a cosmid library by sib selection led to the recovery of the full-length cosmid clone UMP2B. Characterization of the calcineurin gene and progress toward an understanding of its role in dimorphism and pathogenicity in $U$. maydis will be discussed.

Analysis of global regulator genes controlling pathogenicity factors of Erwinia amylovora and E. herbicola pv. gypsophilae. C. K. Dumenyo, W. L. Ma, A. CHATTERJEE, Y. Cui, Y. Liu, and A. K. Chatterjee. University of Missouri, Columbia, MO. Phytopathology 89:S22. Publication no. P-19990152-AMA.

RsmA, an RNA-binding protein, and $r s m B$, a regulatory RNA, control extracellular protein production and pathogenicity in soft rotting Erwinia species $(\mathrm{Rsm}=$ regulator of secondary metabolites). To determine if similar regulatory factors are operative in non-soft-rotting Erwinia, we cloned the rsmA and $r s m B$ genes of E. amylovora (Ea) and E. herbicola pv. gypsophilae (Ehg). The $r s m A-r s m B$ pair in Ea controls extracellular polysaccharide (EPS) and protease production, motility and pathogenicity. In Ehg, the gene pair controls the levels of transcripts of a cytokinin gene and the production of EPS and yellow pigment. As in E. carotovora, the RsmA homologs in Ea and Ehg behave as negative regulators presumably by affecting RNA stability. $r s m B$ genes, on the other hand, act as positive regulators, mostly by neutralizing the RsmA function. These observations and the physical evidence for the occurrence of RsmA and $r s m B$ homologs suggest that the $r s m A-r s m B$ regulatory system has been conserved in Erwinia species.
Cytological analysis of wheat infection by the leaf blotch pathogen, Septoria tritici. K. E. DUNCAN and R. J. Howard. DuPont Agricultural Products, Wilmington, DE. Phytopathology 89:S22. Publication no. P-1999-0153AMA.

We have investigated the wheat leaf infection process of Septoria tritici (teleomorph Mycosphaerella graminicola) through the combined application of differential interference contrast light, confocal laser scanning, and cryo scanning electron microscopies. Several new aspects of fungal development have been documented, including the presence of extracellular conidial and germling matrices and environment-specific morphogenesis. These data were used to generate a benchmark concept of pathogenesis during the asexual $S$. tritici infection cycle, from conidial adhesion and penetration, to pycnidium formation. Fungal development both on and within wheat plants can now be evaluated to determine the efficacy of crop protectant candidates in unprecedented detail.

Allelic diversity of coniferous rust fungi. M. DUSABENYAGASANI (1), L. Bernier (1), and R. C. Hamelin (2). (1) Centre de recherche en biologie forestière, Pavillon Marchand, Université Laval, Ste-Foy, Québec G1K 7P4; (2) Natural Resources Canada, Canadian Forest Service, Ste-Foy, Québec, G1V 4C7. Phytopathology 89:S22. Publication no. P-1999-0154-AMA.

To analyse and compare allelic diversity in coniferous stem and needle rust fungi, we designed primers flanking introns in the exons of actin, elongation factor and heat shock protein genes. Ten species including Cronartium comandrae, C. comptoniae, C. ribicola, Chrysomyxa ledi, C. ledicola, Milesina fructosa, Peridermium harknessii, Pucciniastrum sp., P. americanum, and Uredinopsis sp. were collected from infected plants throughout the province of Quebec in Canada. Genomic DNA was extracted from single aecidia, pycnidia or urediniospores and amplified by polymerase chain reaction. PCR products were analyzed by single strand conformation polymorphisms (SSCP) and allelic variants were confirmed by DNA sequencing. The three loci sampled were polymorphic among the species tested. At the elongation factor locus, multiple alleles were detected for most rusts studied and heterozygotes were clearly separated from homozygotes by SSCP analyses.

Methyl iodide soil fumigation for the control of peach replant disorder. C. G. EAYRE, J. J. Sims, and H. D. Ohr. (1) USDA-ARS, Fresno, CA; $(2,3)$ University of California, Riverside, CA. Phytopathology 89:S22. Publication no. P-1999-0155-AMA.

Peach replant disorder soils were fumigated with methyl bromide or methyl iodide at rates of 392-448 $\mathrm{kg} \mathrm{ha}^{-1}$. Peach tree growth as indexed by trunk diameter, was evaluated. Trunk diameter of trees grown in fumigated plots was significantly larger than trees in control plots. There was no difference between tree growth in methyl iodide and methyl bromide treated plots. Methyl bromide and methyl iodide were equally effective in controlling Paratylenchus and Trichodorus nematode populations, and in controlling peach replant disorder.

The light effect in powdery mildewed barley is regulated by blue-UVA light in the fungus, Erysiphe graminis hordei. H. H. EDWARDS. Western Illinois University, Macomb, IL. Phytopathology 89:S22. Publication no. P-1999-0156-AMA.

Light between $4-8 \mathrm{~h}$ after inoculation retards by $4 \mathrm{~h}$ subsequent appressorium (AP) formation with PAM (presumed adhesive material), followed by PAM disappearance and primary haustorium formation. Experiments were conducted to determine the quality (action spectrum) of light regulating the process and to determine whether the fungus or the host was responding to light. Filters giving peak transmission in near infrared, red, green, blue and UVA at $8 \mu \mathrm{mol} / \mathrm{m}^{2} / \mathrm{s}$ were used to determine their light-delaying effect. Host tissue sections killed by freezing for $30 \mathrm{~min}$ prior to inoculation were compared with unfrozen sections for disease progress. At $13 \mathrm{~h}$ post inoculation light controls had $63 \%$ AP with PAM and $37 \%$ AP without PAM; light frozen sections had 43 and 57; dark controls had 17 and 81; and dark frozen had 14 and 86, respectively. Thus results were similar whether host was alive or dead indicating the fungus as the light-responding component.

Characterization of two genes required for cercosporin resistance in $\mathrm{Cer}$ cospora nicotianae. M. EHRENSHAFT, K.-R. Chung, A. E. Jenns, and M. E. Daub. Dept. of Plant Pathology, NCSU, Raleigh, NC 27695. Phytopathology 89:S22. Publication no. P-1999-0157-AMA.

Cercospora species synthesize cercosporin, a photosensitizer toxic not only to host and non-host plants, but also to bacteria, fungi and mice. Despite cercosporin's potent toxicity, Cercospora species accumulate high concen- 
trations without harmful effects. We have isolated two C. nicotianae genes required for resistance. One gene, SOR1, is required for resistance to both cercosporin and other singlet oxygen generating photosensitizers. Although photosensitizer resistance is rare in nature, SORI is highly conserved in microbes and plants. We determined that SORI is a novel gene involved in pyridoxine (vitamin B6) synthesis, and that high levels of pyridoxine can protect cercosporin-sensitive mutants. The role of pyridoxine in cellular antioxidant defense was unknown, and is currently being defined. A second gene, $C R G 1$, is specifically required for resistance to cercosporin. Sequences homologous to CRG1 can be detected in other Cercospora species but not in other fungi. Sequence database analysis provides no clues to $C R G 1$ function.

Prevalence of organisms during epidemics of cucumbers leaf spot diseases in North Carolina. S. M. EL-ALLAF and C. L. Campbell. North Carolina State University, Raleigh, NC. Phytopathology 89:S23. Publication no. P-1999-0158-AMA.

Seven fungal pathogens cause epidemics of cucumber leaf spot diseases in North Carolina. To understand how epidemics develop, the prevalence of organisms over time was studied in the summer-fall crop in 19 cucumber fields in Sampson County in 1997 and 1998. Samples of 360 leaves per field were collected weekly and signs of pathogens visible at 20-70x were considered diagnostic. In general, when cucumber followed first-crop cucumber, Colletotrichum orbiculare was the primary colonizing organism early in the epidemic, and disease severity was greater than in those fields in which cucumber followed another crop. Colletotrichum was more prevalent in 1998 than in 1997. Didymella bryoniae was the organism that often initiated the epidemic when cucumber followed another crop. Cercospora citrullina and Corynespora cassiicola occurred more frequently in fields where cucumbers were grown on black plastic than when they were grown on bare soil. Alternaria cucumerina was generally present in all fields at low levels. Our studies confirm that cultural and environmental factors affect pathogen spectrum and prevalence within cucumber fields.

Relative colonization ability of greenhouse-grown maize by four lineages of Cephalosporium maydis from Egypt. E. M. EL-ASSIUTY (1), A. M. Ismael (1), K. A. Zeller (2), and J. F. Leslie (2). (1) Plant Pathology Research Institute, Agricultural Research Center, Giza, Egypt; (2) Dept. of Plant Pathology, Kansas State University, Manhattan, KS 66506. Phytopathology 89: S23. Publication no. P-1999-0159-AMA.

Cephalosporium maydis causes late wilt of maize in Egypt. We recently determined that four genetic lineages of $C$. maydis dominate populations in Egyptian fields. We tested representatives of these four lineages (lineages IIV) for their relative colonization ability of pot-grown maize under greenhouse conditions. Strains from all four lineages were incorporated into the soil before planting. Plants were monitored weekly for disease symptoms. At these intervals, diseased plants were collected and isolates of $C$. maydis were recovered from them. We recovered isolates from lineage II $74 \%$ of the time, isolates from lineage I $13 \%$ of the time, and isolates from lineage III $11 \%$ of the time. We did not recover lineage IV isolates from infected plants in these competition studies. In some cases, we recovered representatives from more than one lineage from the same plant. These results suggest that the four lineages are not equivalent in their pathogenicity to maize.

Characterisation of the melanin pigments from the apple scab pathogen Venturia inaequalis. S. El BASSAM (1), N. Benhamou (2), and O. Carisse (1). (1) Agriculture and Agri-Food Canada, St-Jean-sur-Richelieu, Qc., Canada J3B 3E6; (2) Dépt. de Phytologie, Université Laval, Sainte-Foy, Qc., Canada GIK 7P4. Phytopathology 89:S23. Publication no. P-1999-0160AMA.

To investigate the role of melanin in the interaction between the mycoparasite Microsphaeropsis sp. and the apple pathogen V. inaequalis, melanin was extracted from the cell wall of the pathogen. Its chemical and physical properties were determined using infrared and visible spectra. The characteristics were similar to the synthetic dihydroxyphenylalanine (DOPA) melanin. The precursors of the four melanin biosynthetic pathways were tested for their ability to restore the pigmentation of an albino strain of $V$. inaequalis. Scytalone, an intermediate of the 1,8-dihydroxynaphtalene (DHN) biosynthetic pathway, restored the dark-brown pigmentation. Tricyclazole and pyroquilon, two antipenetrant fungicides, inhibitory to (DHN) melanin synthesis in $P y$ ricularia oryzae, were used to confirm the melanin pathway in wild type $V$. inaequalis. The reddish-brown colour obtained instead of the dark-brown pigment suggests that the pigment extracted from $V$. inaequalis is a DHN melanin.
Osmotic potential effects on a Gaeumannomyces graminis var. tritici (Ggt) isolate and two Phialophora variants. M. L. ELLIOTT (1) and J. M. Henson (2). (1) University of Florida, Fort Lauderdale, FL; (2) Montana State University, Bozeman, MT. Phytopathology 89:S23. Publication no. P-1999-0161AMA.

One Ggt isolate and two Phialophora variants of this isolate (GV01 and GV02), derived via protoplast regeneration, were grown at 20, 25 and $30 \mathrm{C}$ on a basal salts medium adjusted to a range of osmotic potentials using $\mathrm{KCl}$. The basal medium was composed of (per L): $0.75 \mathrm{~g} \mathrm{Na}_{2} \mathrm{HPO}_{4}, 0.75 \mathrm{~g}$ $\mathrm{KH}_{2} \mathrm{PO}_{4}, 0.12 \mathrm{~g} \mathrm{MgSO}_{4}, 0.10 \mathrm{~g} \mathrm{NaCl}, 0.40 \mathrm{~g} \mathrm{NH}_{4} \mathrm{NO}_{3}, 1.8 \mathrm{~g}$ sucrose, $1.0 \mathrm{~g}$ Bacto casamino acids, and $15.0 \mathrm{~g}$ Bacto agar. Ggt and Phialophora GV01 naturally produce minimal melanin pigment, whereas Phialophora GV02 is darkly pigmented. For all three isolates, overall optimal growth was obtained at $25 \mathrm{C}$ on 0.1 molal $\mathrm{KCl}$ medium $(-0.46 \mathrm{MPa})$. Optimal growth at $20 \mathrm{C}$ was obtained on the same medium for Ggt and GV02 and on the unamended basal medium for GV01. Optimal growth at $30 \mathrm{C}$ was observed on 0.3 molal $\mathrm{KCl}$ medium $(-1.35 \mathrm{MPa})$. At $20 \mathrm{C}$ and $25 \mathrm{C}$, a significant decrease $(>50 \%)$ in growth was observed at higher molal $\mathrm{KCl}$ concentrations for Ggt and GV01 than for GV02. Phialophora GV02 appears to be more tolerant of a wider range of osmotic potentials, perhaps due to its increased level of melanin pigmentation.

Systemic and local effects of $\mathrm{NaCl}$ on roots of asparagus affected by $\mathrm{Fu}$ sarium crown and root rot. W. H. ELMER. Connecticut Agr. Exp. Sta., Box 1106, New Haven, CT 06504. Phytopathology 89:S23. Publication no. P-1999-0162-AMA.

Split asparagus root studies were used to determine if $\mathrm{NaCl}$ could suppress Fusarium crown and root rot on roots that were not directly exposed to $\mathrm{NaCl}$. Fusarium-infested asparagus field soil was mixed with potting media and used. On wk 1 and wk 7, one side of each plant was treated with $100 \mathrm{ml}$ of water that contained $0,0.1,0.5$, or $1.0 \% \mathrm{NaCl}$, and the other side received $100 \mathrm{ml}$ of deionized water. After 12 wk., roots from the treated side of the plant had $61 \%$ less root lesions and $41 \%$ less colonization by Fusarium as $\mathrm{NaCl}$ rate increased to $0.5 \%$. No further reduction in disease was observed at the $1.0 \%$ rate. Roots from the nontreated side showed the same trends, but the amount of suppression was significantly less than on the treated side. Fluorescent pseudomonads increased in the treated rhizosphere soil as $\mathrm{NaCl}$ rate increased while the Mn-oxidizing bacteria decreased with $\mathrm{NaCl}$ rate. Fluorescent pseudomonads and Mn-oxidizing bacteria were not affected on nontreated roots. These finding suggest that $\mathrm{NaCl}$ may suppress disease through two mechanisms 1) systemic responses in the host and 2) localized effects on the root and microbes.

Retaining overwintered mummies within the trellis increases grape black rot severity. L. R. EMELE, W. F. Wilcox, D. M. Gadoury, and R. C. Seem. Dept. Plant Pathology, Cornell Univ., NY Agric. Exp. Stn., Geneva 14456. Phytopathology 89:S23. Publication no. P-1999-0163-AMA.

The impact of retaining overwintered mummified fruit within a grapevine trellis on black rot severity, caused by Guignardia bidwellii, was determined in a hedge-pruned vineyard of cv. Delaware. Four spray-timing regimes (myclobutanil at $112 \mathrm{~g} / \mathrm{ha}$ ) and an unsprayed control were used in a split plot design with mummy placement as the split variable. Retaining mummies in the trellis increased fruit infections relative to plots where mummies were dropped to the ground. Omission of fungicides during the critical postbloom period maximized this impact (e.g., 84 vs. $51 \%$ infected when three sprays applied prebloom and 14 vs. $9 \%$ with two pre- and two postbloom sprays in the retained vs. dropped plots, respectively). Recovered conidia were more numerous from mummies in the trellis, but outnumbered ascospores at least 10 -fold from both sources. Retention of mummies within the trellis increases the number of conidia available as primary inoculum which, along with their proximity to developing berries (facilitating splash dispersal), may significantly increase fruit rot relative to that in plots with mummies on the ground.

Vegetative compatibility groups of Monilinia fructicola in Georgia peach orchards. K. M. Emery and H. SCHERM. University of Georgia, Athens, GA. Phytopathology 89:S23. Publication no. P-1999-0164-AMA.

Monilinia fructicola, which causes blossom blight and brown rot of stone fruits, may reproduce sexually or asexually on mummified fruit. Due to climate and certain disease management practices, the frequency of sexual reproduction is low in Georgia peach orchards. To evaluate the genetic diversity of $M$. fructicola in the near absence of sexual reproduction, we are char- 
acterizing populations using vegetative compatibility groups (VCGs). More than 120 isolates were recovered in a hierarchical manner from two sites in Georgia. Initial results with 80 isolates from 19 trees at one site indicate the existence of at least five VCGs. One VCG comprised 53 isolates from five trees. Four other VCGs comprised three to five isolates each. The remaining isolates may each represent a unique VCG. In general, isolates from a common VCG were from trees that were contiguous within or between rows. These data will provide insight into the temporal dynamics of $M$. fructicola in the orchard by allowing comparisons between populations associated with the blossom blight and brown rot phases of the disease. Information on genetic diversity may improve efforts to manage fungicide resistance.

Seedling root and shoot growth of three southern pine species is enhanced with the addition of bacterial amendments to potting media. S. A. ENEBAK (1) and M. S. Reddy (2). (1) School of Forestry and (2) Dept. Plant Pathology, Auburn University, AL 36849. Phytopathology 89:S24. Publication no. P-1999-0165-AMA.

The use of biological agents as soil amendments to enhance seedling growth, decrease seedling disease or increase seedling survival after out-planting may be an effective cultural practice for re-forestation programs using containerized forest-tree nurseries. Loblolly (Pinus radiata), slash (P. elliottii) and longleaf ( $P$. palustrus) pine seed were sown in containers that had been amended with one of 9 biological preparations based on spore preparations of bacilli PGPR. Greenhouse-grown seedlings were collected 8 wk post sowing, and seedling characteristics were measured using a flatbed scanner and WinRhizo software. Seedling response to bacterial soil amendments were species specific. Loblolly pine sown in soil amended with LS256 significantly increased root growth; roots of longleaf pine were enhanced with LS213, and slash pine shoot growth was increased with LS254, LS255 and LS213 over nontreated controls. These results indicate that PGPR-based soil amendments can be used to enhance seedling growth in the production of containerized forest-tree seedlings.

Studies to determine time of susceptibility of grape berry and rachis tissues to infection by Phomopsis viticola. O. ERINCIK (1), L. V. Madden (1), D. C. Ferree (2), and M. A. Ellis (1). (1) Plant Pathology and (2) Horticulture and Crop Science, OARDC, The Ohio State University, Wooster, OH. Phytopathology 89:S24. Publication no. P-1999-0166-AMA.

Inoculations of intact "Seyval" grape clusters in the greenhouse and "Catawba" clusters in the field were conducted at Eichorn-Lorenz growth stages 12 (prebloom) 17, 23, 27, 29, 33 and 35 (veraison, beginning of berry ripening). Potted Seyval vines were trained to two shoots per plant with one cluster per shoot in the greenhouse. Five pots (10 clusters) were used per inoculation, and inoculations were repeated three times. Ten to 20 randomly selected Catawba clusters were inoculated in the field for each of three replications at each growth stage. Results indicate that berry and rachis tissue are susceptible to infection from prebloom through veraison, and that susceptibility increases after bloom through veraison. This differs from information in current literature that indicates berry infection occurs primarily during bloom and shortly after bloom, with decreasing levels of infection as fruit matures. These studies will be repeated in 1999.

Effect of chlorine disinfection prior to planting on black scurf (Rhizoctonia solani) and common scab (Streptomyces scabies) of potatoes. D. ERRAMPALLI and H. W. Johnston. Crops and Livestock Research Centre, Agriculture and Agri-Food Canada, Charlottetown, P.E.I., Canada C1A 7M8. Phytopathology 89:S24. Publication no. P-1999-0167-AMA.

A field experiment was conducted to assess the effects of chlorine, prepared from commercial bleach containing 5.25\% sodium hypochlorite, treatments prior to planting on black scurf and common scab. Potato cv. Russet Burbank, seed pieces were treated with three different treatments: 1) control washed with water, 2) washed with water and then treated with $500 \mathrm{ppm}$ of chlorine solution for $8 \mathrm{~min}$, and 3) washed with water, then treated with 500 ppm of chlorine solution for 8 min followed by the treatment with recommended rate of Easout (Novartis). Significantly higher yields (45 t/ha) were observed in treatment 3 compared to treatment $2(33 \mathrm{t} / \mathrm{ha})$ and control (34 $\mathrm{t} / \mathrm{ha}$ ). A significant reduction in Rhizoctonia disease severity was observed in treatment $3(2.8 \%)$ as opposed to treatment $2(15.9 \%)$ and control (13.2\%). Similarly, treatment $3(4.4 \%)$ showed lowest scab incidence followed by treatment $2(5.2 \%)$ and control $(7.7 \%)$. The results indicate that seed treatment with chlorine followed by Easout is most effective against black scurf and scab.
Biocontrol of kidney bean root rot in Minnesota. C. ESTEVEZ DE JENSEN, R. Meronuck, and J. A. Percich. U. of Minn. St. Paul, MN. Phytopathology 89:S24. Publication no. P-1999-0168-AMA.

Fusarium solani, F. oxysporum and $R$. solani cause a severe root rot on Kidney beans. F. solani is the primary organism involved in the disease complex. When amended into pasteurized soil $0,20,30$ and 40 days after sowing with beans $(\mathrm{Cv}$. Montcalm) infection occurred at all stages of plant development. Disease severity (DS), on a 1-9 scale was $5.3,4,3.8$ and 3.5 , respectively at $0,20,30$ and 40 days after planting. $R$. solani (AG-4) is found in infected roots and causes disease up to 30 days after planting. When plants were inoculated at $0,20,30$, and 40 days after sowing DS was 5, 2.8, 2.2 and 1 respectively. $F$. oxysporum is the most common organism isolated from infected root tissue but produces only mild symptoms (DS 3.6) in the seedling stage. The combination of all three fungi resulted in the highest disease (DS 8) starting at the seedling stage. Seed treatments using either Bacillus subtilis or Trichoderma harzianum, under field conditions reduced DS (4.5 and 4.6 respectively) and increase yields (13\% and $0.3 \%$ ) when compared to seed treated with Captan. Yields from plants grown from seed treated with $B$. subtilis and T. harzianum were (38\% and $22 \%$ ) higher than the untreated control respectively.

Evaluation of barley in the greenhouse and field. C. K. EVANS (1), R. Dill-Macky (1), K. P. Smith (2), and D. C. Rasmusson (2). (1) Department of Plant Pathology and (2) Department of Agronomy and Plant Genetics, University of Minnesota, St. Paul, MN 55108. Phytopathology 89:S24. Publication no. P-1999-0169-AMA.

Seventy-nine barley lines were evaluated for reaction to Fusarium head blight (FHB) in two greenhouse (GH) tests and compared with the checks Chevron, Robust, Stander, and MNBrite and the line MNS 93. Spikes were sprayed at heading with a suspension of $2 \times 10^{5}$ macroconidia/ml. Percentage FHB severity was determined 14 days post-inoculation by counting the kernels per spike (KPS) that were infected and dividing the quotient by the total KPS. Two spikes were evaluated per replicate with five replicates in each GH test. There were significant differences $(P<0.05)$ between GH tests for mean FHB severity which was 38\% in the first test and $62 \%$ in the second. Linear regression of mean FHB severities for entries in the two tests demonstrated a degree of concordance between tests $(R=0.39-0.52, P<$ 0.05 ) that indicate screening of lines in the GH is repeatable to a degree that would be useful in a breeding program. Sixty-five lines were selected for field evaluations at two locations, each with three replicates, in Minnesota in the summer of 1999.

Forecasting light leaf spot of winter oilseed rape in the UK. N. EVANS, B. D. L. Fitt, and S. J. Welham. IACR, Rothamsted, Harpenden AL5 2JQ, UK. Phytopathology 89:S24. Publication no. P-1999-0170-AMA.

Light leaf spot (Pyrenopeziza brassicae) is a serious disease of Winter oilseed rape crops in Britain. Wind blown ascospores from crop debris of the previous season are thought to initiate infection in newly sown crops. The pathogen enters a hemibiotrophic phase during which infections are not readily visible. Localised spread in the spring occurs through splash dispersal conidial infection. Assessment data from regions of the UK were used to produce a model to predict the risk of a crop in a specific region of the UK developing light leaf spot. The forecast is based on crop and weather factors. At the start of the season, a prediction is made for each region using the average weather conditions expected for that region. This forecast is then updated periodically to take account of deviations in actual weather away from the expected values. Three factors form the basis of the model: amount of pod disease the previous summer, Autumn temperatures and the number of Winter rain days above the regional average. The model is currently in a second year of evaluation and has been made available to growers over the internet (http://www.res.bbsrc.ac.uk/molbio/Lls/).

Puccinia recondita f. sp. recondita survival in the southern Great Plains of the USA. M. G. EVERSMEYER (1) and C. L. Kramer (2). (1) USDAARS, Kansas State University, Manhattan, KS; (2) Kansas State University, Dept. of Biology, Manhattan, KS. Phytopathology 89:S24. Publication no. P-1999-0171-AMA.

Severe wheat leaf rust epidemics, which result in economic losses in the southern Great Plains wheat producing region of the USA are usually initiated by $P$. recondita f. sp. tritici inoculum that has survived in local fields between harvest and early spring. Survival of inoculum between Great Plains 
wheat crops depends on the amount of moisture and temperatures occurring between harvest and emergence of the new wheat crop in the fall. Models were developed for an epidemic year beginning at maturity of one wheat crop until maturity of the next crop. Meteorological variables for locations in the central Great Plains were used to model inoculum survival from harvest of one wheat crop to spring development of the next crop. Inoculum survival was recorded on a 0 to 9 scale with 0 indicating no survival and 9 indicating inoculum on all plants in the local field or nursery. Daily deviations of temperature and moisture from the 10-year average were averaged for a 10-day period prior to a date of prediction. A model was constructed for every day of the epidemic year prior to final tiller development in the spring. Inoculum survival was correctly forecast by models three out of the five times prior to fall planting decision time. Models constructed with data collected prior to final tiller development in the spring forecast survival (overwintering) nine out of ten years. Results of models are being used to develop forecasts of final severities and resulting yield reductions.

Integrated pumpkin disease management using a cover crop, host resistance and reduced fungicide application. K. L. EVERTS. University of Maryland, Salisbury 21801, and University of Delaware, Georgetown 19947. Phytopathology 89:S25. Publication no. P-1999-0172-AMA.

Increasing use of hairy vetch cover crop and disease tolerant varieties by pumpkin producers has reduced fruit rot and powdery mildew. A study was conducted to evaluate the benefit of these practices in reducing disease incidence and severity and to develop reduced fungicide application guidelines for pumpkins. A factorial experiment examined the effect of hairy vetch cover crop or bare ground production, variety (moderately resistant, Magic Lantern; susceptible, Wizard) and fungicide schedules: 1) weekly, 2) weekly for five weeks then every 14 days, 3) every 14 days, or 4) no fungicide applied. Magic Lantern had a powdery mildew AUDPC value $62 \%$ lower than that of Wizard. Hairy vetch significantly reduced the incidence of fruit rot. Magic Lantern grown on a hairy vetch cover crop that received a fungicide application every 14 days sustained levels of powdery mildew and black rot that were not significantly different than Wizard sprayed weekly and planted on bare ground (AUDPC was 419 and 767, and black rot infection was 194 and 32 fruit/A, respectively).

Inhibitors of the alpha-amylase from Aspergillus flavus. A. M. FAKHOURY and C. P. Woloshuk. Department of Botany and Plant Pathology, Purdue University, West Lafayette, IN 47907. Phytopathology 89:S25. Publication no. P-1999-0173-AMA.

Aspergillus flavus produces the carcinogen aflatoxin. We have previously shown that, in maize kernels colonized by A. flavus, the $\alpha$-amylase produced by the fungus plays an important role in digesting starch in the endosperm into sugars that promote fungal growth and toxin production. The $\alpha$-amylase from culture filtrates of A. flavus grown on starch medium was partially purified by DEAE-Sephadex column chromatography. To screen for putative inhibitors, the $\alpha$-amylase was incubated with protein extracts from various plant sources. Inhibition of $\alpha$-amylase was determined as a decrease in the amount of reducing sugars released from starch added to the mixture. 200 protein extracts were tested and two inhibited $\alpha$-amylase. The extract from the legume Lablab purpureus reduced $\alpha$-amylase activity by $50 \%$, whereas the extract from Sapindus drummondii inhibited the activity by $82 \%$. Heating at $100^{\circ} \mathrm{C}$ for 10 minutes abolished the inhibitory activity. We are currently isolating and characterizing the specific inhibitory proteins.

Role of algR1 in the regulation of alginate production in Pseudomonas syringae. M. K. FAKHR (1), A. Penaloza-Vazquez (2), and C. L. Bender $(1,2)$. (1) Dept. Microbiology and Molecular Genetics and (2) Dept. Entomology and Plant Pathology, Oklahoma St. Univ., Stillwater, OK 74078. Phytopathology 89:S25. Publication no. P-1999-0174-AMA.

P. syringae is known to produce alginate, an exopolysaccharide which contributes to the virulence and epiphytic fitness of this species. In P. aeruginosa, the response regulator AlgR1 is required for transcription of $\operatorname{alg} D$, an essential gene in the alginate biosynthetic pathway. In the present study, we cloned and characterized the gene encoding algRI from $P$. syringae. An algRI mutant, $P$. syringae FF5.32, was defective in alginate production but could be complemented when algRl was expressed in trans. The $\operatorname{alg} D$ promoter region in $P$. syringae $(P$ salgD $)$ was also characterized and shown to diverge significantly from the $a l g D$ promoter in $P$. aeruginosa. Unlike $P$. aeruginosa, algR1 was not required for the transcription of $\operatorname{alg} D$ in $P$. syringae, and PsalgD lacked the consensus sequence recognized by AlgR1. The differen- tial regulation of algD expression in $P$. syringae and $P$. aeruginos $a$ and the marked divergence in their $\operatorname{alg} D$ promoter regions may reflect the adaptation of these species to plant and human hosts, respectively.

Identification of the PVY MSNR elicitor that induces a systemic hypersensitive response in tobacco. J. P. FELLERS (1), M. A. Conklins (2), and S. A. Lommel (2). (1) USDA-ARS, PSERU, Manhattan, KS; (2) NC State University, Raleigh, NC. Phytopathology 89:S25. Publication no. P-19990175-AMA.

Tobacco has a gene for nematode resistance called RK. Associated with this gene is a systemic hypersensitive reaction when the plant is infected with potato virus Y strain MSNR (PVY MSNR). It is the only PVY strain that will induce this response. The objective of this research was to identify the protein of PVY MSNR that elicits this response. First, we cloned and sequenced the open reading frame of PVY MSNR. The ORF has $90 \%$ identity to PVY O and $92 \%$ identity to PVY N. Each protein of PVY MN was then placed into the cloning site of $\mathrm{p} 2 \mathrm{C} 2 \mathrm{~S}$, a PVX based expression vector. Initial indications show that the coat protein is the elicitor, however, these tests are being repeated to confirm our results.

Organic complexation and chelation of aluminum for suppression of soilborne fungal pathogens. E. FICHTNER (1), H. D. Shew (2), and D. L. Hesterberg (3). N.C. State University, Raleigh. Phytopathology 89:S25. Publication no. P-1999-0176-AMA

Ionic aluminum species in mineral soils suppress a range of soilborne plant pathogens including Thielaviopsis basicola and Phytophthora parasitica. These pathogens also cause disease on many ornamental bedding plants that are produced in organic potting media containing peat. The carboxylic acid and phenolic functional groups in peat chelate phytotoxic $\mathrm{Al}^{3+}$ into a complexed, non-phytotoxic molecule. The toxicity of complexed $\mathrm{Al}^{3+}$ and $\mathrm{Al}(\mathrm{OH})_{2}{ }^{+}$was examined on $T$. basicola and P. parasitica in vitro. Aluminum binding capacity of peat was determined, then 1.5 and $2.5 \mathrm{~g}$ aliquots of peat were amended with either 0.05 or $0.1 \mathrm{~g} \mathrm{Al}_{2}\left(\mathrm{SO}_{4}\right)_{3}$ at $\mathrm{pH} 4.0$ and 6.1 for speciation of $\mathrm{Al}$. Peat suspensions were added to a mineral salt medium in flasks, a single colonized agar plug was introduced into each flask and cultures were grown for $14 \mathrm{~d}$. Significant interactions of $\mathrm{Al}$ level by Al species, and $\mathrm{Al}$ level by peat level were observed for growth suppression of both pathogens. Non-phytotoxic forms of Al were observed to be suppressive to both pathogens in peat and may offer an alternative to fungicides for management of root pathogens in peat-based media.

Pathogen development and host response during infection of grape berries by Uncinula necator. Andrea FICKE (1), D. M. Gadoury (1), R. C. Seem (1), and I. B. Dry (2). (1) Dept. Plant Pathology, N.Y. Agric. Exp. Stn., Geneva 14456; (2) CSIRO Plant Industry, Glen Osmond, 5064 Australia. Phytopathology 89:S25. Publication no. P-1999-0177-AMA.

Grape berries in our study developed ontogenic resistance to powdery mildew within 4 wk after bloom. When berries of cv Concord and Chardonnay were serially inoculated between fruit set and $4 \mathrm{wk}$ later, appressoria were observed $24 \mathrm{hr}$ later on berries in both susceptible (S) and resistant (R) stages. Secondary hyphae were observed after $24 \mathrm{hr}$ on S-Concord and S-Chardonnay fruit, but not R-Concord fruit. Density of colonization and the proportion of viable hyphae were inversely proportional to berry age. Although infection was associated with epidermal necrosis, cessation of pathogen growth preceded cell death by at least $1 \mathrm{wk}$. Expression of two putative PR genes (VvChi3 and VvTL2) was induced $11 \mathrm{hr}$ after inoculation in S- but not R-Chardonnay berries, and dropped to preinoculation levels in S-berries $24 \mathrm{hr}$ after inoculation. Ontogenic resistance appears to operate within 24 hours after inoculation. It may involve transcription of an, as yet, unidentified gene(s), and does not involve a classic hypersensitive response or cell necrosis.

Use of quantitative molecular tools to study mycorrhizospheric interactions. M. FILION (1), C. Leclerc-Potvin (1), M. St-Arnaud (2), C. Hamel (1), and S. H. Jabaji-Hare (1). (1) McGill University, Ste-Anne-de-Bellevue, Qc., Canada; (2) I.R.B.V., Montréal, Qc., Canada. Phytopathology 89:S25. Publication no. P-1999-0178-AMA

Arbuscular mycorrhizal (AM) fungi can reduce the incidence of root diseases. These symbionts have the capacity to interact directly with soil-borne pathogens, or indirectly by stimulating other natural antagonists. However, 
these interactions are still poorly understood. We have developed a new compartmentalized growth system (mycotron), and applied two quantitative molecular methods to study the mycorrhizospheric interactions between the AM fungus Glomus intraradices and different pathogens. First, we used DASELISA assay to investigate the effect of $G$. intraradices on Clavibacter michiganensis subsp. michiganensis in tomato mycorrhizosphere. Second, we used a competitive PCR approach to study the interaction between $G$. intraradices and Fusarium solani f. sp. phaseoli in bean mycorrhizosphere. The results indicated that the AM fungus can reduce pathogen populations in soil, and therefore possess a good biocontrol potential.

Partial characterization of a cucumber mosaic cucumovirus isolate from Ajuga reptans. J. R. FISHER and S. T. Nameth. Dept. of Plant Pathology, The Ohio Agricultural Research Development Center, The Ohio State University, Columbus, OH. Phytopathology 89:S26. Publication no. P-1999-0179-AMA.

Ajuga reptans $\mathrm{L}$. is a perennial ornamental mint commonly grown as a ground cover. Viral symptoms observed on A. reptans include mosaic, ringspots, and oakleaf patterns. Viral-associated dsRNA analysis of A. reptans 'Royalty' revealed a CMV-like banding pattern, and an apparent satellite (sat) RNA. The presence of CMV was confirmed by DAS-ELISA. The identity of the putative satRNA was confirmed by hybridization to a digoxygenin-labeled (S)CARNA-5 cDNA probe. The satRNA was cloned, and is 337 nucleotides long. CMV was transmitted to Nicotiana rustica using the melon aphid (Aphis gossypii), purified, and compared to CMV-Fny and CMV-Q strains by transmission electron microscopy, SDS-PAGE, and western blot analysis. The CMV isolate from A. reptans 'Royalty' is a serological subgroup I isolate, and causes mild mosaic and vein clearing on $N$. tabacum. The isolate infects squash 'Black Beauty', cucumber, and pumpkin systemically, but does not infect french bean (Phaseolus vulgaris) or cowpea. Transmission to Lycopersicon esculentum 'Peto 696' and 'Nema 1401' was unsuccessful.

Fludioxonil, a new reduced risk postharvest fungicide for management of fungal decays of stone fruit. H. Förster and J. E. ADASKAVEG. University of California Riverside, CA. Phytopathology 89:S26. Publication no. P-19990180-AMA.

With the cancellation of postharvest use of iprodione in 1996, development of integrated programs and evaluation of new postharvest fungicides were needed for management of brown rot, gray mold, and Rhizopus rot of stone fruit crops. In comparative studies, fludioxonil $(228 \mathrm{~g} / 378 \mathrm{~L})$ was an excellent wound-protection agent when peach, nectarine, plum, or cherry fruit were wound-inoculated with spores, incubated, and then treated. Control of all three decays was either equal to or better than iprodione and incidence values often were near zero. When fruit were inoculated after fungicide application, the efficacy of fludioxonil generally was reduced or ineffective using nectarine, peach, or plum fruit, but not with cherry fruit. Postharvest treatments with fludioxonil were also very effective in reducing decay of naturally field-infected fruit. Fludioxonil is rated as a "reduced risk" fungicide by EPA, it was placed in the IR-4 program, and it was granted an emergency registration on nectarines, peaches, and plums in 1998. The Novartis product will set a new standard in efficacy and safety as a treatment for postharvest decay control.

Biocontrol of Fusarium wilt of hydroponically-grown basil (Fusarium oxysporum f. sp. basilici) using $\boldsymbol{F}$. oxysporum CS-20. D. R. FRAVEL and R. P. Larkin. Biocontrol of Plant Diseases Laboratory, USDA-ARS, Beltsville, MD 20705. Phytopathology 89:S26. Publication no. P-1999-0181AMA.

Seeds (15/cube) were planted in trays of Oasis [2 $22 \times 3.5 \mathrm{~cm}$ (tall); 276 (= $12 \times 23$ ) contiguous cubes/tray] at a commercial hydroponic facility. At $1 \mathrm{wk}$ after seeding, each of 5 trays was drenched with $900 \mathrm{ml}$ of $10^{6}$ propagules (78\% microconidia $+22 \%$ chlamydospores) of CS-20 or water. After $1 \mathrm{wk}$, cubes were separated and placed in troughs of nutrient solution. After $7 \mathrm{wk}$, CS-20 significantly $(P<0.01)$ reduced the number of dead stems/cube, with 2.0 nontreated and 0.96 treated dead stems/cube. Treated cubes had significantly $(P<0.03)$ fewer stems with wilt symptoms $(0.28 /$ cube $)$ than nontreated ones $(0.76 /$ cube $)$. Disease was in an aggregated distribution that included several troughs, indicating that pathogen from infested seed may have spread while the cubes were still attached. Analysis found $2 \%$ of the seed infested with the pathogen. To monitor pathogen spread, the center cube of each of 3 trays of Oasis seeded with basil was inoculated with $10^{3}$ propagules of the pathogen or water. One wk after inoculation, the pathogen was recovered $13 \mathrm{~cm}$ away from the inoculation site at populations up to $6 \times 10^{4}$ propagules/cube.
Genetic variability of Ophiostoma piceae in Canada. P. GAGNE (1), L. Bernier (1), D. Q. Yang (2), A. Uzunovic (2), and C. Breuil (3). (1) Université Laval, Québec, Qc., Canada; (2) Forintek Canada Corp., Sainte-Foy and Vancouver, Canada; (3) University of British Columbia, Vancouver, BC, Canada. Phytopathology 89:S26. Publication no. P-1999-0182-AMA.

Following a systematic survey conducted at 7 sawmills in 6 provinces, Ophiostoma piceae was found to be the most common staining fungus in softwood in Canada. Genetic variability of a sample of 239 isolates recovered from lumber (fir, spruce and pine) was assessed by RAPD-PCR. Two methods were used to analyze RAPD data for 24 putative loci: 1) analysis of molecular variance (AMOVA) based on haplotype divergence and 2) analysis of allelic frequencies. A total of 237 different haplotypes were observed among the isolates. Results from AMOVA suggested that all of the variability occurred within subpopulations. There was no evidence of any differentiation among strains from different hosts or geographic areas. Analysis of allelic frequencies confirmed that total gene diversity $\left(\mathrm{H}_{\mathrm{T}}=0.414\right)$ was mostly attributable to diversity within populations $\left(\mathrm{H}_{\mathrm{S}}=0.369\right)$, although there was evidence for the occurrence of a moderate level of differentiation among geographically distinct populations $\left(\mathrm{G}_{\mathrm{ST}}=0.112\right)$.

A comparison of four methods to accurately measure dollar spot severity of turfgrass. D. C. GARLING, J. R. Rimelspach, and M. J. Boehm. Department of Plant Pathology, The Ohio State University, Columbus, OH 43210. Phytopathology 89:S26. Publication no. P-1999-0183-AMA.

Dollar spot, caused by Sclerotinia homoeocarpa, is one of the most intensely managed diseases of turfgrass. Measurements of dollar spot severity have traditionally been in the form of visual estimates which do not maximize accuracy and precision, along with preventing minor differences in severity from being recognized. Furthermore, visual assessments may be labor intensive, time consuming, and affected by environmental changes during a rating period. Digital image analysis and multispectral radiometry were evaluated for their ability to accurately assess dollar spot severity in the field. Data were compared with severity assessments obtained via qualitative visual assessments and a grid rating method. Significant differences existed among the four rating methods with digital image analysis providing the most accurate measurements. A study to further investigate the use of digital image analysis and multispectral radiometry is underway.

Effects of planting density and genotype mixture composition on wheat stripe rust: An analysis accounting for limits to the replication of controls. K. A. GARRETT and C. C. Mundt. Oregon State University, Corvallis, OR. Phytopathology 89:S26. Publication no. P-1999-0184-AMA.

The effect of plant density on disease is little known in populations of single host plant genotypes and even less studied in mixtures of host genotypes. We evaluated the effect of four planting densities on infection by Puccinia striiformis in experimental plots with four wheat cultivars planted in purestands and three different mixtures of two cultivars planted in five proportions. Disease severity in mixtures was compared to the weighted mean of severity in the corresponding purestands. Because there was not a unique pair of single-cultivar plots for each of the 240 mixture plots, we devised an analysis based on collapsing the data into independent observations. Stripe rust severity in purestands increased with planting density in 1997 but decreased with planting density in 1998. Disease reduction in mixtures varied with the cultivars included in the mixture. In both years, the greatest mixture effect for reduced disease was at the intermediate planting density of 250 seeds per $\mathrm{m}^{2}$ and the 50:50 genotype frequency.

Effect of $\mathbf{N}$ source on root exudates and yield of eggplants grown in Verticillium infested soil. V. GASKINS (1), D. Fravel (2), D. Roberts (2), J. Buyer (2), C. Brooks (1), and M. Morant (1). (1) University of Maryland Eastern Shore, Princess Anne, Maryland; (2) USDA-ARS, Beltsville, Maryland. Phytopathology 89:S26. Publication no. P-1999-0185-AMA.

Poultry compost and $\mathrm{NH}_{4} \mathrm{NO}_{3}$ were evaluated for their impact on the incidence of Verticillium wilt in susceptible and tolerant eggplant under field and greenhouse conditions. The quantity of root exudates and population density of Trichoderma spp. as affected by amendments were also determined. Roots were treated with antibiotics and exudates were subsequently analyzed by Gas Chromatography. Populations of Trichoderma were determined by plating soil dilutions on modified malt agar. Under greenhouse conditions, the concentration of simple and complex sugars was greater in the presence of the pathogen, regardless of the type of amendment. Trichoderma spp. were not significantly affected by amendment or pathogen infestation, but populations were greater in soil taken at the beginning of the growing season. In 
1998, fruit yield of Dusky (susceptible) was significantly greater than Early Bird (tolerant) when plants were grown in $\mathrm{NH}_{4} \mathrm{NO}_{3}$ amended soil that was infested with $V$. dahliae.

Reduction of smut and bunt diseases by seed treatment with Ustilago hordei pheromone analogs. S. A. Gerhardt, P. J. Kosted, and J. E. SHERWOOD. Montana State University, Bozeman, MT. Phytopathology 89:S27. Publication no. P-1999-0186-AMA.

The culture supernatant of Ustilago hordei has been shown to inhibit mating of Ustilago spp. and teliospore germination of Tilletia spp. due to the presence of pheromone-related mating inhibiting factors (MIF). Disease control by inhibition of the sexual cycle, which is required for pathogenicity by the smut and bunt fungi, was tested using MIF and specific pheromone analogs as seed treatments. Reductions of barley covered smut and common and dwarf bunt in wheat using these compounds have been evaluated in the field and glass house. Crude MIF consistently reduced common bunt infection in the field by $60-80 \%$. Covered smut on Odessa barley was reduced by up to $100 \%$, but control was inconsistent. In glass house experiments, synthetic pheromone analogs were applied as seed treatments. Cysteine, methionine, their methyl esters and YSTC, a peptide sequence found in the MAT-1 $U$. hordei pheromone, reduced barley covered smut by $40 \%$ and the bunt diseases of wheat by $30-100 \%$. Obtaining consistent disease control remains a major goal. Clearly, presentation of these compounds to the fungus at the right time and the right place is critical.

Study of salicylates in plant defense responses. M. GILBERT (1), G. PetitPaly (2), M. Rideau (2), and L. F. Brisson (1). (1) Université Laval, Québec, Canada; (2) Université François Rabelais, Tours, France. Phytopathology 89: S27. Publication no. P-1999-0187-AMA.

Salicylic acid (SA), a small phenolic metabolite, is believed to play a key role in the signaling pathway leading to disease resistance. To pinpoint its importance as a second messenger, tobacco tissue cultures (cultivars SR-1d, BY-2, Xanthi-nc) were established and used as an experimental study system. The expression of selected defense genes (PR-1, PR-2, PR-3, PAL, GST and catalase) and the accumulation of phytoalexin (scopolin and scopoletin) were studied in relation to an external supply of SA. Our results indicate that at $125 \mu \mathrm{M}$, could efficiently induce the defense response in cell cultures. The intensity and kinetic of the response support the view that 1) plant cell culture represents an excellent experimental system and 2) SA may act as a second messenger in the establishment of disease resistance. Taken together, our data strongly suggest that SA leads to the rapid expression of defense response, acting in the stages of the signaling pathway.

Host specialization of Albugo candida. E. Gilijamse, H. Boonstra, M. J. Jeger, and J. M. RAAIJMAKERS. Wageningen Agricultural University, Department of Phytopathology, P.O. Box 8025, 6700 EE Wageningen, The Netherlands. Phytopathology 89:S27. Publication no. P-1999-0188-AMA.

White rust of cabbage, caused by Albugo candida, has become a serious problem in the Netherlands and other European countries. This oomycete fungus is not only found on Brassicaceae, but also on several cruciferous weeds of which shepherd's purse is the most important. To study the level of host specialization of $A$. candida, isolates were collected from Brussels sprouts, broccoli, cauliflower, radish and shepherd's purse and inoculated on each of these five potential hosts. Three distinct groups of isolates were identified: isolates collected from the B. oleracea spp. (Brussels sprouts, broccoli, cauliflower) were compatible with each of these three hosts, but did not cause disease on radish or shepherd's purse; isolates from radish or shepherd's purse only infected their host. At least six other cultivars of Brussels sprouts were not infected by isolates from shepherd's purse. The results suggest that shepherd's purse is not a source of infection for the three B. oleracea spp. Histological data and molecular characterization of the isolates will be presented.

Biocontrol of Erwinia amylovora using bacteriophage. J. J. GILL (1), A. M. Svircev (2), A. L. Myers (2), and A. J. Castle (1). (1) Department of Biological Sciences, Brock University, St. Catharines, ON, Canada; (2) Agriculture and Agri-Food Canada, Southern Crop Protection and Food Research Centre, Vineland Station, ON, Canada. Phytopathology 89:S27. Publication no. P-1999-0189-AMA.

Forty-seven bacteriophage isolates capable of infecting Erwinia amylovora, the fire blight pathogen, were collected in the Niagara Region of southern Ontario, Canada during the summer of 1998. Samples were collected from aerial portions and the soil surrounding apple, pear, crab apple and mountain ash trees which exhibited fire blight symptoms. Phage isolates were collected by enriching samples in a mixture of 6 E. amylovora strains followed by isolation on individual strains. Relatively few isolates ( 8 out of 47) were obtained from aerial portions of trees, and phage were not isolated from trees exhibiting no fire blight symptoms. The phage isolates have been provisionally placed into categories based on plaque morphology and host range; the isolates will be further characterized using a combination of restriction enzyme digests and PCR. The potential biocontrol ability of the phage isolates is currently being assessed using spray applications of bacteria and phage on forced pear blossoms.

Limited movement of cucumber mosaic virus (CMV) on yellow passion flower in São Paulo State, Brazil. R. Gioria (1), L. M. Espinha (2), J. A. M. REZENDE (1), J. O. Gaspar (2), and E. W. Kitajima (1). (1) ESALQ/USP, Piracicaba, SP, Brazil; (2) IBILCE/UNESP, S.J. Rio Preto, SP, Brazil. Phytopathology 89:S27. Publication no. P-1999-0190-AMA.

Symptoms of CMV on yellow passion flower (Passiflora edulis f. flavicarpa) are characterized by bright yellow mosaic on leaves, starting at random points on the vine and diminishing in intensity towards the tip, which becomes symptomless as it grows. To determine whether symptomless portions of the vine are CMV free or represent latent infection, six infected vines were collected in the field and samples were excised from symptomatic and asymptomatic leaves. Biological assay on Nicotiana tabacum Turkish showed that only extracts from symptomatic areas caused systemic mosaic, which was confirmed to be associated to CMV by ELISA. Western blot (immunoblot) confirmed that CMV antiserum labeled a protein of approximately $25 \mathrm{kDa}$ only present on symptomatic areas. Tissue printing assay, with nonradioactive probe specific to CMV RNA, gave positive reaction only for symptomatic tissues. These results showed that asymptomatic portions of the vines are CMV free.

Genetic analysis of maize phytoanticipin detoxification by Fusarium moniliforme. A. E. GLENN and C. W. Bacon. Dept. Plant Pathology, University of Georgia, Athens 30602; USDA-ARS, TMRU, RRC, Athens, GA 30604. Phytopathology 89:S27. Publication no. P-1999-0191-AMA.

While several major diseases of maize are attributed to Fusarium moniliforme, the fungus is also capable of persistent symptomless infections. Such endophytic infections are of concern due to in planta accumulation of mycotoxins. Little is known about fungal factors contributing to either the symptomatic or asymptomatic infections. One possible virulence factor is the detoxification of maize preformed antimicrobial compounds. In vitro assays demonstrate that $F$. moniliforme actively transforms 2-benzoxazolinone (BOA), one of the phytoanticipins, to $\mathrm{N}$-(2-hydroxyphenyl) malonamic acid (HPMA). From 45 diverse strains of $F$. moniliforme screened for tolerance to BOA, only one was sensitive. Sexual crosses and genetic analyses suggest tolerance is determined by functional alleles at two independently assorting loci (Fdb1 and Fdb2). Physiological complementation assays indicate the Fdb1 gene product facilitates the transformation of BOA to an intermediate metabolite, which is in turn transformed to HPMA by the Fdb2 gene product. $\mathrm{Fdb} 1$ and Fdb2 as potential virulence factors will be addressed.

A selective medium for isolating Fusarium moniliforme from maize. A. E. Glenn (1), D. M. Hinton (2), and C. W. BACON (2). (1) Dept. Plant Pathology, University of Georgia, Athens 30602; (2) USDA-ARS, Athens, GA 30604. Phytopathology 89:S27. Publication no. P-1999-0192-AMA.

One class of phytoanticipins produced by maize includes DIMBOA $(2,4-$ dihydroxy-7-methoxy-2H-1,4-benzoxazin-3-one) and its desmethoxy derivative DIBOA. Earlier we showed that 38 strains of Fusarium moniliforme had high tolerance to DIMBOA, DIBOA and their spontaneous products 6-methoxy-2-benzoxazolinone (MBOA) and 2-benzoxazolinone (BOA), respectively. We observed that methods recommended for isolating this fungus resulted in low isolation frequency due to competing fungi. A PDA based medium utilizing commercially available BOA was developed to determine if other fungi in samples of maize would be suppressed, allowing for the selective isolation of $F$. moniliforme and related biological species. An isolate transformed with the gusA reporter gene was used to demonstrate isolation frequency from field grown plants on the BOA medium. The results indicated high isolation frequencies of the transformed $F$. moniliforme from infected plants. This endophytic species was isolated in low frequency from pentachloronitrobenzene amended medium usually recommended for isolation. 
Non-Bt-8 mediated resistance to dwarf bunt in wheat cultivars deriving resistance from PI 178383. B. J. GOATES. USDA-ARS, Aberdeen, ID. Phytopathology 89:S28. Publication no. P-1999-0193-AMA.

Winter wheat cultivars that are highly resistant to dwarf bunt, caused by Tilletia controversa, have been developed for areas of the western U.S. Most of the cultivars derive their resistance from PI 178383, which is known to have the bunt resistance genes Bt-8, Bt-9, and Bt-10. It has been assumed cultivars originating from crosses with PI 178383 likely have all three of these genes because the cultivars were resistant when tested against races that are virulent to Bt-9 and Bt-10, but are avirulent to Bt-8. Resistance to dwarf bunt and common bunt is controlled by the same resistance and virulence genes which follow the classical gene-for-gene system. Field tests repeated 2-3 years with hybrid test races of common bunt demonstrated that the cultivars Hansel, Manning, Promontory, and Weston are susceptible to races that lack virulence to Bt-8, whereas Luke, Lewjain, and Winridge are resistant to these races. All of these cultivars are highly resistant to pathogenic races of dwarf bunt in the U.S. These results demonstrate that resistance to dwarf bunt among U.S. cultivars that derive dwarf bunt resistance from PI 178383 is more broadly based than previously thought.

Characterization and kinetics of kernel epicuticular wax production in corn genotypes resistant and susceptible to aflatoxin contamination. Y. K. GOH, K. E. Damann (1), J. S. Russin (2), C. Grimm, R. L. Brown, and T. E. Cleveland (3). (1) LSU Agr. Ctr., Baton Rouge, LA; (2) SIU, Carbondale, IL; (3) SRRC, USDA, New Orleans, LA. Phytopathology 89:S28. Publication no. P-1999-0194-AMA.

Previous work indicated a role for pericarp wax in conferring resistance of the corn population GT-MAS:gk to aflatoxin contamination. Resistant (GTMAS:gk, T115) and susceptible (RX938, Pioneer 3136) corn were grown and selfed during 1998. Ears were harvested at 7, 14, 21, 28, 35, $42 \mathrm{~d}$ post selfing. Epicuticular waxes were extracted and characterized using GC-MS. The results show that long-chain alkanes, of 21- to 33-carbons, and steroids represent a major fraction of epicuticular waxes in all genotypes at all developmental stages. The fraction of individual components of waxes within these groups either remain the same, decrease with time, or increase with time. Kernel screening assays for aflatoxin production in wax extracted and normal kernels at the last four developmental stages are underway. A correlation between wax components and aflatoxin contamination may provide clues as to which component(s) play a role in conferring resistance.

Multi-year performance of Sovran ${ }^{\circledR}$ against diseases of apples, pears, grapes, pecans and cucurbits. R. E. GOLD and H. L. Ypema. BASF Corporation, 26 Davis Drive, P.O. Box 13528, Research Triangle Park, NC 27709. Phytopathology 89:S28. Publication no. P-1999-0195-AMA.

Sovran $^{\circledR}$ (active ingredient: kresoxim-methyl) is a new fungicide developed by BASF in the NAFTA-region for use in fruits and vegetables. The first registrations of Sovran are expected in 1999. Sovran is a member of the strobilurin-class of fungicides and offers growers a new crop protection compound with excellent activity against important plant pathogens. Strobilurins have a unique target site in fungi: they inhibit respiration. Kresoxim-methyl has a strong affinity for the waxy plant surface and adheres strongly to the leaf surface under various weather conditions. Following application, kresoximmethyl diffuses laterally over the leaf surface and translaminarly from one leaf surface to the other, thereby exhibiting surface systemic ${ }^{\mathrm{TM}}$ and translaminar activity. Sovran combines a strong inhibitory action against spore germination, surface mycelia and sporulation with a long residual activity and excellent crop safety. For several years, Sovran has been evaluated against diseases of apples, pears, grapes, pecans and cucurbits. A comparative overview will be presented of Sovran's performance against target diseases.

The ubc genes encode components of the Ustilago maydis cAMP and MAP kinase signal transduction pathways that are required for filamentous growth and virulence. S. E. GOLD (1), M. E. Mayorga (2), D. L. Andrews (3), and J. W. Duick (4). University of Georgia, Athens, GA. Phytopathology 89:S28. Publication no. P-1999-0196-AMA.

The ubc genes encode components of the Ustilago maydis cAMP and MAP kinase signal transduction pathways that are required for filamentous growth and virulence. Ustilago maydis, the causal agent of corn smut disease, displays dimorphic growth in which it alternates between a budding haploid saprophyte and a filamentous dikaryotic pathogen. We have identified a role for the cAMP signal transduction pathway in the dimorphic switch of this fungus. Haploid strains mutant in the uac1 gene encoding adenylate cyclase are filamentous. Mutagenesis of the uac1 disruption strain allowed the isolation of a large number of budding suppressor mutants named ubc, for Ustilago bypass of cyclase because they no longer require cAMP for budding growth. Analysis of these suppressor mutants led to the identification of 3 new genes which are required for filamentous growth. Two of these genes, ubc3 and ubc4 encode members of a MAP kinase cascade with highest similarity to those of the yeast pheromone response pathway. The ubc2 gene, when mutated, produces a similar phenotype to the ubc 3 and ubc4 mutants and it interacts genetically with ubc4. We describe the roles of the ubc genes in mating and in pathogenicity.

Identification of salicylic acid-induced genes in Arabidopsis thaliana. A. M. GOMEZ and R. Raina. The Pennsylvania State University, University Park, PA. Phytopathology 89:S28. Publication no. P-1999-0197-AMA.

In many plant species, infection by a pathogen leads to a broad-spectrum, long lasting, systemic resistance to subsequent infections by fungi, bacteria and viruses. This response is called Systemic Acquired Resistance (SAR) and salicylic acid (SA) has been shown to act as a signal for its activation. The application of SA to plants induces several defense-related genes that typically accompany SAR. In this work we cloned and partially characterized fragments of several salicylic acid induced genes in Arabidopsis using a PCR-based subtractive hybridization approach. Such genes were found to be induced in response to SA and bacterial pathogens by northern blot analysis. Furthermore, sequence analyses of these genes suggest that they encode proteins with a variety of functions such as signal transduction proteins, transcription factors, and other enzymes involved in different biochemical pathways. We are in the process of constructing antisense plants in order to study the biological function of these genes and their relevance in resistance against pathogens.

Genes expressed during the resistance response of wheat to the fungal pathogen Mycosphaerella graminicola. S. B. GOODWIN (1) and F. I. Urmeev (2). (1) USDA-ARS and (2) Dept. Botany and Plant Pathology, Purdue University, W. Lafayette, IN 47907. Phytopathology 89:S28. Publication no. P-1999-0198-AMA.

Differential display was used to compare gene expression in resistant and susceptible wheat lines following inoculation with the Septoria pathogen, Mycosphaerella graminicola. Treatments were Yecora Rojo (susceptible) and Tadinia (resistant) uninoculated, and the same two cultivars inoculated with M. graminicola. Tadinia possesses the Stb4 gene for resistance. Leaf tissue was collected at $0,3,6,12,24,48$ and 96 hours after inoculation, with a final sampling after 4 weeks. Total RNA was extracted and subjected to differential display using four specific and eight random primers. Following electrophoresis on denaturing sequencing gels and autoradiography, differentially expressed genes were excised, cloned and sequenced. Most sequences had no matches in GenBank. However, three clones had high similarity to a pathogenesis-related protein from Phaseolus vulgaris. Most genes were expressed in both the susceptible and the resistant host. Experiments are underway to confirm the timing of differential expression using both traditional Northern and reverse-Northern analyses.

Survival of Ascochyta lentis in lentil residue on the Canadian prairies. B. D. GOSSEN and D. Derksen. Agriculture and Agri-Food Canada, Research Centre, 107 Science Place, Saskatoon, SK S7N 0X2, and AAFC, P.O. Box 1000A, RR3, Brandon, MB, Canada R7A 5Y3. Phytopathology 89:S28. Publication no. P-1999-0199-AMA.

A trial to assess the survival of A. lentis on naturally-infected lentil residue was set out at Saskatoon SK in fall 1994. The treatments were leaves/pods vs stems, placed in nylon mesh bags and buried at 0,5 and $10 \mathrm{~cm}$ depth in a clay-loam soil. Samples were retrieved at intervals from 1995-98 and pathogen viability was assessed using a plating technique and a bioassay. In fall of 1996, the first differences among treatments were noted; pathogen recovery was higher from material at $0 \mathrm{~cm}$ than 5 or $10 \mathrm{~cm}$ depth. The same pattern of differences continued until the final sampling date in May 1998, but differences were not always significant. Pathogen populations declined after 1995, but the pathogen was still present in all treatments almost $4 \mathrm{yr}$ after collection. In spring of 1996, the leaves/pods on the soil surface were intact, but samples at 5 and $10 \mathrm{~cm}$ had started to break down. Stems were visually intact. By 1998, buried leaf/pod pieces had disintegrated, leaf residue on the soil surface and buried stems were breaking down, but stems on the soil surface were still relatively intact. 
Studies on a new carla virus from potato. R. W. GOTH (1), P. J. Ellis (2), G. deVilliers (2), E. W. Goins (1), N. S. Wright (2), and M. Ballesteros (1). (1) USDA-ARS, Vegetable Lab, Beltsville, MD 20705; (2) PhytoDiagnostics Company Limited, Sidney, BC, Canada V8L 1H3. Phytopathology 89:S29. Publication no. P-1999-0200-AMA.

In 1992, the Scottish Agricultural Science Agency detected a carla virus (code name RLSV) also called Potato Latent Carlavirus (PLCV) with distinct serological and biological characteristics in the cv Red LaSoda. In 1993, the long filamentous rod-shaped virus particle was observed in a clone of the potato cv Red La Soda during routine electron microscope testing of accessions in the Vancouver Collection of Virus-Free Potatoes being grown in the California winter tests. Although the particle size of RLSV/PLCV is similar to Potato Virus S and Potato Virus M, it is serologically distinct. A highly specific monoclonal antibody, Mab 4E12, was developed for RLSV/PLCV. In 1997 and 1998, 137 potato accessions in the U.S. National Varietal Collection maintained at Presque Isle, ME, were assayed for RLSV with TAS ELISA using the 4E12 Mab.

Post-harvest effects of two AM fungi on white rot (Sclerotinia sclerotiorum) in carrot (Daucus carota L.). H. GOTOECHAN and H. Desilets. Horticultural Research Center, Laval Univ., Ste-Foy, Quebec, Canada G1K 7P4. Phytopathology 89:S29. Publication no. P-1999-0201-AMA.

The effects of mycorrhizal inoculation of carrots on the spread of a major post-harvest disease of this crop was assessed. Two cultivars of carrots, sown in the field with and without introduction of a commercial inoculum of Glomus intraradices or Glomus etunicatum were stored in a cold chamber for three months before being infected at the crown with a pure culture of Sclerotinia sclerotiorum. Three weeks following infection, the development of the white rot was assessed. The disease was present on all roots, but the length of the rotted portions of the roots was significantly lower on carrots grown in presence of the AM inocula. The mean length of rotted lesions were 6.01, 5.68 and $5.41 \mathrm{~cm}$, respectively, for the treatment without inoculation, and with Glomus intraradices or Glomus etunicatum. These results indicate that inoculation of carrots at sowing with the AM fungi Glomus etunicatum or Glomus intraradices may reduce spread of the white rot during storage of the produce.

Estimating spread of citrus canker in urban Miami via GPS. T. GOTTWALD (1), X. Sun (2), T. Riley (1), and J. Graham (3). (1) USDA-ARS, Orlando, FL; (2) CREC, University of Florida, Lake Alfred, FL; (3) FDACS, DPI, Gainesville, FL. Phytopathology 89:S29. Publication no. P-1999-0202AMA.

Asiatic citrus canker (Acc) caused by Xanthomonas axonopodis pv. citri (Xac), continues to spread in south Florida despite efforts by the joint state/ federal Citrus Canker Eradication Program (CCEP) to remove and destroy diseased trees. At the request of the CCEP, four areas with low incidence of Xac in urban Miami were identified to study disease spread. The goal was to measure disease gradients in Miami resulting from rainstorms to determine if the current practice of removing exposed trees within 125 feet of diseased trees is adequate to curtail further disease development. To accomplish this, $>13,000$ individual trees in dooryards were located via differential GPS. Trees were assayed for disease severity, age of infection, citrus cultivar, and canopy size. All trees in each area were resurveyed approximately every two months. Spread from rainstorm events was measured up to 1200 feet (90\%), 1900 feet (95\%), and 2700 feet (99\%) from known infected source trees. Percentages represent the proportion of infected trees located within the indicated radius. Results suggest that the current disease control practice is inadequate to suppress further Acc spread.

Use of VA mycorrhizae in annual strawberry production systems. $M$. A. GRABOWSKI, F. J. Louws, G. E. Fernandez, and E. B. Bish. North Carolina State University. Phytopathology 89:S29. Publication no. P-1999-0203-AMA.

Vesicular arbuscular mycorrhizae (VAM) have been suggested as a potential biologically based additive to promote growth and prevent disease. This experiment was designed to evaluate the use of VAM in annually grown strawberry plants. Two sources of inoculum were applied to soilless plug media before tipping of daughter plants. A commercially produced mixture of Glomus intraradices and G. etunicatum, and native soil collected from within wild strawberry colonies were mixed with plug media. Crown volume, leaf area, root dry weight, percent root lesion, and percent mycorrhizal colonization were measured weekly after tipping until field planting ( 5 weeks). Plants inoculated with native soil compared to control and plants inoculated with commercial VAM had greater $(P=0.05)$ leaf area $(135.8,116.55$, and 115.65 $\left.\mathrm{cm}^{2}\right)$ and greater $(P=0.05)$ percent root lesion incidence $(6.5,1.8$, and
$4.5 \%)$. Crown volume and root dry weights were not different between treatments. Percent VAM colonization was higher $(P=0.05)$ in plants inoculated with native soil than those inoculated with commercial VAM, $19.9 \%$ and $3.7 \%$ respectively.

Effect of copper compounds on the survival of Erwinia carotovora subsp. carotovora and their phytotoxicity on two calla lily cultivars. J. A. GRACIA-GARZA (1), T. J. Blom (2), and W. Brown (3). (1) Agriculture and Agri-Food Canada; (2) Univ. of Guelph; (3) OMAFRA, Vineland Station, ON, Canada LOR 2E0. Phytopathology 89:S29. Publication no. P-1999-0204AMA.

Various copper-based compounds were evaluated for the suppression of $E$. carotovora subsp. carotovora (E.c.c.) and their phytotoxicity on two calla lily cultivars in laboratory and greenhouse experiments, respectively. Four different bactericides were tested: Phyton-27, Champ II, Fixed Copper, and analytical copper chloride. Suspensions of E.c.c. were incubated from 0 to 60 $\mathrm{min}$ in a fertilizer solution with serial concentrations of copper (0 to $16 \mathrm{ppm}$ $\mathrm{Cu}^{2+}$ ). Phyton-27 was the most effective product, as bacterial growth was totally suppressed after $30 \mathrm{~min}$ incubation at $1.0 \mathrm{ppm} \mathrm{Cu}{ }^{2+}$. Four times the lethal $\mathrm{Cu}^{2+}$ concentration after the $30 \mathrm{~min}$ incubation was used for the phytotoxicity test of all the compounds. In these tests, disease incidence or growth of plants treated with Phyton-27 or copper chloride were not significantly different from the control. Incidence of disease was lowest in plants treated with Champ II or Fixed Copper; however, these products showed more phytotoxicity than the other two bactericides.

Role of Kunitz trypsin inhibitor in conditioning defense potential in soybean. T. L. GRAHAM, D.-S. Park, and M. Y. Graham. Ohio State University, Columbus, OH. Phytopathology 89:S29. Publication no. P-1999-0205-AMA.

The capacity of soybean cells to respond to the glucan elicitor from Phytophthora sojae is activated by signals associated with hypersensitive cell death. Two endogenous factors, CF-1 and CF-2, differentially lead to phenolic polymer or glyceollin elicitation competency, respectively. The isoflavone genistein, which activates a peroxidase-like Type II NADH oxidase, confers CF-2 activity, whereas a proteinaceous factor is responsible for CF-1 activity. Reduced glutathione, which mimics many aspects of CF-1 function, releases CF-1 into intercellular washing fluids, facilitating its purification. CF-1 activity was associated with a single band on SDS gels of about 21 kilodaltons. Mass-spectroscopy of an endoproteinase lys-C digest and internal microsequencing of the protein revealed a match to Variant $\mathrm{A}$ of the soybean Kunitz trypsin inhibitor, SKTI3. Proteins carrying Kunitz inhibitor domains are well-established components in many mammalian signaling pathways. Several aspects of these reported activities may relate to redox and ionic events associated with the HR and will be discussed in the context of the activation of defense potential in neighboring cells.

Dry rot resistance and steroid glycoalkaloid levels in chitosan treated potato tuber tissue. J. A. GREYERBIEHL and R. Hammerschmidt. Dept. of Botany and Plant Pathology, Michigan State University, East Lansing 48824. Phytopathology 89:S29. Publication no. P-1999-0206-AMA.

Steroid glycoalkaloids (SGA) are secondary metabolites produced by many solanaceous species. SGA are capable of inhibiting spore germination and hyphal growth of many fungi including Fusarium sambucinum, the cause of potato dry rot. Potato tuber wounding induces an increase in SGA at the wound site. It has been suggested that this increase protects the tuber from invasion by wound pathogens such as $F$. sambucinum. However, infections by $F$. sambucinum and other pathogens as well as elicitor treatments suppress SGA. Chitosan, a cell wall component of some fungi, increases tuber resistance to $F$. sambucinum. SGA levels, however, stayed the same or only slightly increased in tuber tissue treated with $0.5 \mathrm{mg} / \mathrm{ml}$ chitosan and decreased in tuber tissue treated with $1.0 \mathrm{mg} / \mathrm{ml}$ chitosan. SGA, are therefore, probably not responsible for the chitosan induced resistance. Additionally, these results suggest that chitosan may be partially responsible for the decrease in SGA accumulation observed during invasion by some pathogenic and nonpathogenic fungi.

Distribution and spread in Louisiana of the luteovirus associated with yellow leaf syndrome of sugarcane. M. P. GRISHAM (1), Y.-B. Pan (1), B. L. Legendre (1), and J. F. Flynn (2). (1) USDA-ARS, SRRC, Sugarcane Research Unit, Houma, LA; (2) ThermoTrilogy Corp., Greenwell Springs, LA. Phytopathology 89:S29. Publication no. P-1999-0207-AMA.

Yellow leaf syndrome (YLS) has been reported to cause yield decline of sugarcane in several countries throughout the world. Symptoms of YLS 
include yellowing of the lower surface of the leaf midrib followed a general yellowing of the leaf blade and dying of the leaf from the tip. In 1996, several foundation plants of three Louisiana cultivars used as sources of tissue for micropropagation were found to be infected by the luteovirus reported to cause YLS. Among germplasm nurseries, two Louisiana cultivars and eight non-Louisiana cultivars were infected by the YLS virus. No characteristic symptoms were observed in either case, but the virus was detected by RTPCR and ELISA. In 1997, virus assays of plants from fields surrounding those planted with virus-infected cane stalks revealed no spread of the virus. However, in 1998, virus spread, most commonly into fields of the leading commercial cultivar in Louisiana (LCP85-384), and development of symptoms among infected plants caused increased concern about the potential effect of the disease.

Effect of the luteovirus associated with yellow leaf syndrome of sugarcane on sugarcane yield and juice quality. M. P. GRISHAM (1), Y.-B. Pan (1), B. L. Legendre (1), and M. A. Godshall (2). (1) USDA-ARS, SRRC, Sugarcane Research Unit, Houma, LA; (2) Sugar Processing Research Institute, Inc., New Orleans, LA. Phytopathology 89:S30. Publication no. P-19990208-AMA.

In 1996, sugarcane plants infected with the luteovirus reported to cause yellow leaf syndrome (YLS) were discovered in Louisiana. A field experiment was established to assess the potential impact of the disease on the Louisiana sugarcane industry. Reverse transcription-polymerase chain reaction (RTPCR) was used to identify virus-infected and non-infected stalks for planting the experiment. Results of the first-year, plant-cane crop and the second-year, first-ratoon crop revealed no effect of virus infection on cane yield or quality of juice from cane stalks; however, higher concentrations of soluble solids, sucrose, and purity were found in juice from virus-infected green leaf tissue compared to healthy leaf tissue. Virus-infected leaves also contained elevated levels of starch. Top green leaves are normally removed from the stalk by the mechanical harvester; however, they may not be removed if the cane is lodged. Leaves delivered to the mill containing elevated levels of starch may cause problems in processing.

Wind dispersal of cleistothecia of Podosphaera clandestina in eastern Washington. G. GROVE, R. Boal, and W. Duplaga. Washington State University. Phytopathology 89:S30. Publication no. P-1999-0209-AMA.

Podosphaera clandestina, causal agent of powdery mildew of sweet cherry, survives winter as cleistothecia in bark fissures and tree crotches in Eastern Washington. Glass slides $40 \mathrm{~mm}^{2}$ in size were coated with silicon grease and attached to 3.0 meter wooden posts vertically positioned at the periphery of an infested cherry orchard. Slides were retrieved at weekly intervals and examined microscopically for cleistothecia. During 1997, over 13,000 cleistothecia of $P$. clandestina were trapped between early August and late December. About $12 \%$ of the cleistothecia trapped during the week immediately prior bud break in 1998 contained viable ascospores. The peak catch in 1998 occurred in November when 667 cleistothecia were trapped. The dispersal of primary inoculum for the initiation of cherry powdery mildew epidemics appears to include dispersal of ascocarps and ascospores. Wind appears to be the primary means of dispersal of cleistothecia onto substrates where perennation occurs and may provide a means of long distance dispersal of $P$. clandestina.

Powdery mildew of grape: Perennation of Uncinula necator in eastern Washington. G. GROVE, G. Davis, B. Duplaga, and R. Boal. Washington State University. Phytopathology 89:S30. Publication no. P-1999-0210-AMA.

Powdery mildew, caused by Uncinula necator, is the most serious disease of wine grapes in Eastern Washington. The pathogen usually produces cleistothecia in profusion on infected leaves, fruit, and canes. At bud burst in 1996, $80 \%$ and $43 \%$, respectively, of overwintered cleistothecia collected from senesced leaves and exfoliating bark of Chardonnay vines contained viable ascospores. Viability declined to $22 \%$ and $28 \%$ on the respective substrates by full bloom. In 1997, the viability of cleistothecia isolated from the bark of Chardonnay vines declined from $63 \%$ in mid-February to $1 \%$ at the end of bloom. In laboratory studies, the largest numbers of ascospores were released between bud burst and bloom. Extensive vineyard surveys during the 19951997 growing seasons failed to provide evidence of perennation of $U$. necator as mycelium in dormant buds. Cleistothecia appear to be the source of primary inoculum for grape powdery mildew epidemics in the arid production regions of Eastern Washington.
Contribution of host-resistance to integrated control of late blight in the Toluca Valley. N. J. GRÜNWALD (1), M. Cadenas (2), O. Rubio (2), A. Rivera (2), and W. E. Fry (1). (1) CEEM Project, Cornell University, NY/Toluca, Mexico; (2) INIFAP, Toluca, Mexico. Phytopathology 89:S30. Publication no. P-1999-0211-AMA

We evaluated the contribution of host resistance as one component of Potato Late Blight management in the Toluca Valley. The National Institute for Forestry, Agriculture and Livestock Research (INIFAP) has produced varieties with high levels of field resistance such as Rosita and Norteña. These varieties have been grown in the Toluca Valley as clones since 1965 and 1979, respectively. In 1998, cultivars Rosita and Norteña showed high levels of field resistance (20\% and $4 \%$ final disease severity) in no-spray controls, whereas the susceptible cultivar Alpha was completely defoliated. Yields of neither Rosita (19t/ha) nor Norteña ( $25 \mathrm{t} / \mathrm{ha}$ ) were affected by disease. Our results correspond well with published field data $(1988,89,92)$ and field notebooks of INIFAP (1965-98). Rosita and Norteña have been grown commercially for 27 and 6 years, respectively, and their resistance to Late Blight has not broken down. Cultivars with such a high level of resistance show promise for use in Late Blight management by permitting a large reduction in the numbers of needed fungicide sprays.

Timing of fungicide applications for Fusarium head blight management of winter wheat. A. P. GRYBAUSKAS. University of Maryland, College Park, MD. Phytopathology 89:S30. Publication no. P-1999-0212-AMA.

Greenhouse and field trials were conducted to examine the effect of timing of fungicide applications on management of Fusarium head blight of wheat. Disease suppression in a greenhouse trial, where inoculation of the wheat head was accomplished with a single drop of a spore suspension of Fusarium graminearum placed on the rachis, was greatest when fungicides were applied one day before or after inoculation in comparison to applications made 7 days before or after inoculation. In greenhouse trials where heads were inoculated by spraying a spore suspension at flowering, disease suppression was greater when fungicide applications were made 3-4 days prior to inoculation rather than 3-4 days after inoculation. Disease suppression in field trials was greatest when fungicide applications were within a few days of inoculation. Multiple floret infections per spike, rapid fungal penetration into the rachis or limited fungicidal activity within the wheat spike reduce the effectiveness of a fungicide. Fungicidal management of Fusarium head blight may require applications very close to actual infection periods.

Comparison of visual disease assessment methods to quantify the impact of alfalfa foliar pathogens on forage yields. J. GUAN and F. W. Nutter, Jr. Iowa State University, Ames, IA. Phytopathology 89:S30. Publication no. P-1999-0213-AMA.

Field experiments were conducted in Ames (1995-1997) and in Nashua (1996-1998), IA to quantify the impact of alfalfa foliar pathogens on alfalfa yields. A range of disease intensity levels was achieved using fungicides. Disease severity, disease incidence, and percentage defoliation assessments were obtained by sampling and visually assessing alfalfa stems each week over 16 alfalfa growth cycles. Single point yield models for each sampling date were developed by regressing either percentage defoliation, disease incidence, or disease severity against yield. Single point models based on defoliation data had a significant relationship with yield in 10 out of 16 growth cycles, whereas this relationship was significant only 4 and 3 times using incidence or severity data, respectively. On average, single point models based on defoliation data obtained just prior to harvest explained $25 \%$ more of the variation in yield than single point models based on incidence or severity data.

Quantifying the impact of alfalfa foliar pathogens on forage yield using remote sensing data. J. GUAN and F. W. Nutter, Jr. Iowa State University, Ames, IA. Phytopathology 89:S30. Publication no. P-1999-0214-AMA.

Field experiments were conducted in Ames (1995-1997) and in Nashua (1996-1998), IA to quantify the impact of alfalfa foliar pathogens on forage yield. Percentage reflectance (PR) values from eight narrow wavelength bands ranging from 460 to $810 \mathrm{~nm}$ were obtained weekly using a hand-held multispectral radiometer for each of 16 alfalfa growth cycles. Vegetation indices and normalized difference vegetation indices were derived from the ratios of specific narrow wavelength bands. Single point yield models were developed by regressing PR values for each specific wavelength and the two derived indices against yield for each growth cycle. Area under the PR curve 
(AUPRC) yield models were constructed by regressing AUPRC values and area under the curve values for the two vegetation indices against yield. PR data in the infrared region explained more of the variation in forage yield than models based on vegetation indices. Both single point and AUPRC models based on $810 \mathrm{~nm}$ data had a better relationship with yield than models based on other wavelengths; however, single point models using $810 \mathrm{~nm}$ PR values explained $17 \%$ more of the variation in yield than AUPRC models.

Potential of fall applications of lime, lime-sulfur and urea in reducing pear scab inoculum in over-wintered leaves and validation of an ascospore maturation model. W. D. Gubler (1), C. J. Feliciano (1), K. J. DELL (1), R. B. Elkins (2), and C. A. Ingels (3). (1) U.C., Davis, CA; (2) U.C. Cooperative Extension, Lakeport, CA; (3) U.C. Cooperative Extension, Sacramento, CA. Phytopathology 89:S31. Publication no. P-1999-0215-AMA.

The effect of lime, lime sulfur, and urea on pear scab (Venturia pirina) ascospore production was investigated. Scab infected leaves were treated in the fall and placed in commercial orchard floors at 3 sites. Leaf samples were examined weekly the following spring for ascospore production and maturation by the squash mount and water discharge techniques. Maturation of ascospores was predicted using a degree day model developed in Oregon. Availability of ascospores in the orchard was monitored with a Burkard spore trap. Lime-sulfur and urea fall treatments were effective in reducing pear scab inoculum. Ascospore production was reduced in lime-sulfur treatments by 97 to $100 \%$, and in urea treatments by 56 to $100 \%$. The model predicted ascospore maturation accurately at 1 site, and earlier at 2 other sites, compared to examination of leaf samples. Spore trap catch continued for 1 to 2 weeks after the predicted date of complete maturation.

A potato tuber aspartic protease with antifungal activity. M. G. Guevara (1), C. R. Oliva (1), and G. R. DALEO (1). Universidad Nacional de Mar del Plata, Mar del Plata, Argentina. Phytopathology 89:S31. Publication no. P-1999-0216-AMA.

Only a few APs have been isolated and characterized from plants and little is known about their biological functions. Recently, we characterized a 40 $\mathrm{kDa}$ AP from tuber discs. Sequence analysis of two tryptic fragments showed homology with other plant APs. The sequence ADISIKEQ from one fragment had 50\% identity with a portion of cyprosin (cardoon) and $37.5 \%$ identity with sequences from oryzasin (rice) and phytepsin (barley). The percentage of similarity was $87.5 \%$ with all three APs. The sequence TNDPGYX from the other one shared $43 \%$ identity and $85.7 \%$ similarity with other portions of the three proteases. Potato AP was able to inhibit the growth of hyphae $(0.5 \mu \mathrm{M})$ and the germination of spores $(1 \mu \mathrm{M})$ of $F$. eumartii, as well as the germination of Phytophthora infestans zoospores at all concentrations assayed. This antifungal activity was not detected in the presence of pepstatin-A. Two other proteases tested (trypsin and pepsin) did not show antifungal activity indicating the specificity of the potato AP. Our results suggest that the potato AP may be involved in the interaction with pathogens.

Evidence for maternal inheritance of kernel wax from maize population GT-MAS:gk resistant to Aspergillus flavus. B. Z. GUO (1), L. P. Lei (1), N. W. Widstrom (1), T. E. Cleveland (2), J. S. Russin (3), and R. E. Lynch (1). (1) USDA-ARS, Tifton, GA; (2) USDA-ARS, New Orleans, LA; (3) Southern Illinois University, Carbondale, IL. Phytopathology 89:S31. Publication no. P-1999-0217-AMA.

Kernels of maize population GT-MAS:gk are resistant to Aspergillus flavus. Earlier studies showed that this resistance is due in part to more pericarp wax, which possesses antifungal activity against A. flavus. Composition of this wax was determined using thin layer chromatography. One major component was unique to wax from GT-MAS:gk kernels. This wax component was present in GT-A2 and GE37, but absent in 9-54C, 8940C, and F54. To determine whether this trait could be useful in a breeding program, we studied the inheritance of this unique wax component in F2:3 families derived from a cross between GT-A2 and 9-54C. Kernel wax from the two parental lines, F1, and F3 families was extracted by dipping kernels in chloroform briefly and separated using TLC. The unique wax component was present in GT-A2, F1, and all 30 F3 families. Because of its non-Mendelian mode of inheritance, these data suggested that this wax component is inherited maternally. Reciprocal crosses of $(\mathrm{GE} 37 \times 8940 \mathrm{C})$ and $(8940 \mathrm{C} \times \mathrm{GE} 37)$ as well as $($ GE37 $\times$ F54) and $($ F54 $\times$ GE37) also demonstrated this maternal inheritance of this wax trait.
Aqueous faba bean root extracts stimulate germination and promote infectivity of Orobanche seeds. H. E. GUTIERREZ and J. O. Kuti. Texas A\&M University, Kingsville, TX 78363. Phytopathology 89:S31. Publication no. P-1999-0218-AMA.

Orobanche crenata is a holoparasitic weed which causes several damage to faba bean (Vicia faba). The most efficient method of control is breeding for resistance. A laboratory method was developed to test the effect of faba bean aqueous root extracts on germinability and infectivity of Orobanche seeds. The seeds were conditioned prior to treatment with extracts from 20 varieties of faba beans using a standard bioassay for evaluation of potential germination stimulants. Of the root extracts from the 20 varieties used, root extracts from 7 varieties stimulated seed germination of Orobanche and infectious Orobanche seeds were obtained from the same varieties in pot experiments. The results suggest that aqueous root extracts may be potentially useful for screening faba bean susceptibility to Orobanche parasitism.

Species of Pythium that affect tobacco transplants in greenhouses. W. A. GUTIERREZ (1) and T. A. Melton (1). (1) North Carolina State University. Raleigh, NC. Phytopathology 89:S31. Publication no. P-1999-0219-AMA.

Pythium root rot, or damping-off is an important disease of tobacco seedlings in greenhouses. This disease appears at any stage of the seedling growth. Pythium species form resting structures (chlamydospores and oospores) that allow them to survive for long periods in soil, but survival mechanisms in the float tray system in greenhouses is unknown. Pieces of tobacco roots were taken from infected seedlings and placed on Par medium and incubated for 2 days in the dark at room temperature. Forty isolates were obtained from commercial greenhouses in North Carolina. Pythium myriotylum, P. dissotocum, $P$. irregulare, $P$. volutum, and $P$. spinosum were identified as potential pathogens of tobacco seedlings. The most prevalent were $P$. volutum and $P$. irregulare. Pathogenicity tests indicated that $P$. myriotylum and $P$. volutum were the most aggressive species at water temperatures above $22 \mathrm{C}$. No aboveground symptoms were observed with the other Pythium species at 22 $\mathrm{C}$, but seedlings showed root rot and a poor root system at transplanting time. Pathogenicity tests at different water temperatures are being conducted to determine the optimal development of these Pythium species.

Biological control of Septoria leaf spot and canker of hybrid poplar under field conditions. L. GYENIS (1), N. A. Anderson (1), and M. E. Ostry (2). (1) Dept. Plant Pathology, University of Minnesota, St. Paul, MN 55108; (2) USDA Forest Service, North Central Research Station, St. Paul, MN 55108. Phytopathology 89:S31. Publication no. P-1999-0220-AMA.

Limiting factors to expansion of hybrid poplar Populus spp. culture are their susceptibility to leafspot and canker diseases caused by Septoria musiva (SM). Three Streptomyces spp. strains (GS-93-3, Strain 93 and Mycostop ${ }^{\circledR}$ ) with biocontrol potential were tested in field trials near Rosemount, MN on one resistant and three susceptible poplar clones. Container-grown trees with six-week old shoots were exposed to natural SM inoculum for four weeks in a hybrid poplar plantation. Five experiments, each with four weeks exposure, were completed during Summer 1998. Individual trees were sprayed once a week with one of the biocontrol strains and evaluated for disease development. Canker control of 100\% was obtained with strain GS-93-3 on susceptible clone NE242. Leaf disease severity on susceptible clone DTAC26 was reduced $44 \%$ and defoliation reduced 32\% with Strain 93 as compared to unsprayed trees. Biocontrol potential of Streptomyces spp. strains against other poplar diseases is being evaluated.

Quantitative indoor assay (QIAssay) identifies quantitative trait loci. S. HABER, B. Gillis, and J. Chong. Agriculture and Agri-Food Canada, Winnipeg, MB. Phytopathology 89:S31. Publication no. P-1999-0221-AMA.

Agronomic and quality trait QTLs have been placed on the molecular linkage map of K/O. Identifying QTLs for BYDV tolerance, however, has proved difficult in the K/O population because the parents do not differ greatly, symptoms are affected by environmental interactions, and scoring is subjective. A QIAssay-based analysis of 68 F10 RILs minimized within-treatment variations caused by environmental interactions, and used objective parameters to score BYDV tolerance. Two disease tolerance QTLs were identified and mapped to the same positions as those found earlier in a study of symptoms of Clintland64 (susceptible)/IL86-5698 (tolerant) RILs; QTLs were also identified for BYD-yield loss components (height loss; loss of flag leaf area; delay of panicle emergence). An additive model of these QTLs with those for disease tolerance could account for the performance of K/O RILs under BYD pressure. Strong QTLs were also identified for BYDV-ELISA titres, but virus titres were not related to performance under disease pressure. 
Time-of-flight mass spectrometry (TOFMS) identifies host-induced mutation associated with attenuated virulence in two isolates of johnsongrass mosaic virus (JGMV). S. HABER (1), D. Seifers (2), Y. She (3), A. Loboda (3), W. Ens (3), and K. Standing (3). (1) Agriculture Canada, Winnipeg, MB; (2) KSU, Hays, KS; (3) Univ. of Manitoba, Winnipeg, MB. Phytopathology 89:S32. Publication no. P-1999-0222-AMA.

Plant virus virulence may be attenuated by passage through different hosts. To determine how attenuated virulence might be linked to host-induced changes to the virus itself, Australian (AU) and Kansas (KS90) isolates of JGMV were maintained in sorghum and passaged through hosts following 5 regimes [a) sorghum only; b) maize with final passage back to sorghum; c) maize only; d) pearl millet with final passage back to sorghum; e) pearl millet only] and the coat protein molecular mass determined by TFMS for each isolate and regime. The original AU and KS90 isolates maintained in sorghum showed single, distinct coat protein peaks of 33597 and 33733 da, respectively. Schemes ' $a$ ', 'b', or 'c' failed to change coat protein molecular mass or virulence assayed by dry-weight loss in test plants) of either isolate; ' $\mathrm{d}$ ' induced no coat protein change and a small reduction in virulence for KS90 only; but 'e' induced a larger and stable reduction in virulence for both isolates accompanied by a clear shift in coat protein molecular mass profiles.

Doppler radar precipitation estimates added to AU-Pnut advisory. A. K. HAGAN (1), K. L. Bowen (1), E. M. Bauske (2), R. R. Getz (2), and S. D. Adams (2). (1) Auburn University, Auburn, AL; (2) AWIS Inc., Auburn, AL. Phytopathology 89:S32. Publication no. P-1999-0223-AMA.

Doppler Radar (WSR-88D) is an alternative to a rain gauge for estimating daily precipitation 'events' of $0.25 \mathrm{~cm}$ for the AU-Pnut disease advisory. A CR-10 automated weather station was placed near three fields of peanut to verify Doppler precipitation estimates. A spray advisory, calculated from both Doppler and on-site weather station data, was issued for fungicide applications to plots in each field. A standard 14-day calendar spray program was included in each trial. Overall, Doppler Radar was as accurate as the automated rain gauge in identifying precipitation 'events' of $0.25 \mathrm{~cm}$. At all sites, the same numbers of fungicide applications were made to both advisory plots, but not always on the same day. Both AU-Pnut advisories saved from one to three fungicide applications as compared with the calendar spray schedule with no loss in leaf spot or stem rot control and no reductions in peanut yield.

Expression of an Agrobacterium vitis oncogene in Petunia hybrida. L. Han, L. Boppuri, and L. G. KOVACS. Missouri State Fruit Experiment Station, Mountain Grove, MO. Phytopathology 89:S32. Publication no. P-1999-0224AMA.

The purpose of this research is to explore the possibility of silencing the iaaM gene, an essential oncogene in crown gall tumors. The iaaM gene from the TA-DNA of A. vitis strain Tm-4 was cloned behind the CaMV 35S promoter, and the resulting construct was introduced into petunia plants. The transformed plants express typical symptoms of elevated auxin levels, including epinasty and enhanced apical dominance. Based on the stability of symptom expression, the transformants fall in two categories. The first category, containing the majority of the transformants, is characterized by a constitutive expression of the symptoms. The second category, containing three transformants, is characterized by symptom expression during fall and winter, and by reversion to wild-type phenotype during spring and summer, in the greenhouse. These latter plants can also be induced to recover from their symptoms by cultivation in the growth chamber and under tissue culture conditions. It is currently being investigated whether the conditional recovery of these plants from the elevated auxin symptoms involves the silencing of the 35S-iaaM transgene.

Identification of a pea pathogenicity gene cluster on a dispensable chromosome of Nectria haematococca MP VI. Y. HAN (1), X. Liu (2), U. Benny (1), H. D. VanEtten (2), and H. C. Kistler (1). (1) University of Florida, Gainesville, FL; (2) University of Arizona, Tucson, AZ. Phytopathology 89: S32. Publication no. P-1999-0225-AMA.

A cluster of genes located on the $1.6 \mathrm{Mb}$ conditionally dispensable (CD) chromosome of Nectria haematococca MP VI has been cloned and identified to be the determinants of pathogenicity to pea. This gene cluster of $25 \mathrm{~kb}$ contains at least six genes that are expressed during infection of pea. In addition to PDA1, which had been identified previously, three of the genes on this cluster can independently confer some level of virulence to an isolate lacking the CD chromosome. Based on DNA sequence analysis, PEP5 (pea pathogenicity gene 5) has been predicted to encode a protein belonging to the major facilitator superfamily of proton-dependent multidrug export systems, while PEP2 has been proposed to encode a product similar to polyadenylate binding proteins (PABPs). PEP2 gene has been expressed in E. coli, and the PEP2 protein has been purified. Western blot analysis using polyclonal antibody against PEP2 protein and functional test of PEP2 on pea indicate that the PEP2 protein has biological activity and is located in pea tissue adjacent to the lesions caused by infection with the fungal pathogen. The inhibitory effect of PEP2 protein on root regeneration of detached pea seedling is in agreement with the proposed function inferred from derived amino acid sequence similarity to PABPs. The deduced amino acid sequence of another transcribed portion (ORF 4) of the PEP cluster and three apparently non-transcribed open reading frames in this $25 \mathrm{~kb}$ region have shown a high degree of similarity to known fungal transposases. The presence of transposable elements combined with other observations such as the different $\mathrm{G}+\mathrm{C}$ content and codon usage of the six genes in the PEP cluster from that of genes on other Nectria haematococca chromosomes suggests an exogenous origin of this region. These features are shared by "pathogenicity islands" of pathogenic bacteria of plants and animals.

Maintaining Fusarium head blight resistance in spring wheat through successive breeding cycles. J. M. HANSEN (1), R. W. Stack (1), and R. C. Frohberg (2). (1) Dept. of Plant Pathology and (2) Dept. of Plant Sciences, North Dakota State Univ., Fargo, ND 58105. Phytopathology 89:S32. Publication no. P-1999-0226-AMA.

Resistance in wheat to Fusarium head blight (FHB) is a character of highly complex inheritance. Introducing such a trait into commercial wheat and maintaining it through successive cycles of crossing to adapted but susceptible parents is a difficult task, requiring a disease testing procedure that is both intensive and reliable. For this purpose we combined extensive FHB screening done in an irrigated field nursery inoculated with Gibberella zeae and intensive greenhouse testing of elite materials. We here report the FHB response in a set of lines representing progeny from first, second, third, and fourth breeding cycles of several different spring wheat crosses. Some first and second cycle progeny showed good FHB resistance but none combined that resistance with the agronomic traits needed for commercial release. A few third cycle and several fourth cycle derived lines combined those traits and some are candidates for release as commercial cultivars.

Elicitation of cotton phytoalexin production by culture filtrates from Trichoderma virens. L. E. HANSON and C. R. Howell. USDA-ARS, SCRL, CPRU, College Station, TX 77845. Phytopathology 89:S32. Publication no. P-1999-0227-AMA.

Several Trichoderma virens (Gliocladium virens) strains have good biocontrol activity against Rhizoctonia damping-off of cotton. In previous studies, biocontrol activity against Rhizoctonia solani on cotton was retained in some UV mutants that were deficient for antibiotic production or mycoparasitism, suggesting that some other factor is important in biocontrol activity. Cotton seedlings treated with effective biocontrol strains of $T$. virens have higher levels of terpenoid phytoalexins in the roots than do seedlings treated with ineffective strains. This suggests that the biocontrol strains can induce resistance responses in the host. Sterile culture filtrates from the effective biocontrol strains also can stimulate increased phytoalexin levels. The activity in the culture filtrates was present in several different media, was heat stable, was insoluble in chloroform, passed through a $5 \mathrm{~K}$ molecular weight cut off filter, and was sensitive to treatment by proteinase $\mathrm{K}$. This suggests that the elicitor activity is due to a protein or proteins. Efforts are being made to isolate the elicitor or elicitors.

Antibiotic production by Trichoderma koningii fusants as compared to the T. koningii parent. L. E. HANSON, R. D. Stipanovic, L. S. Puckhaber, and C. R. Howell. USDA-ARS, College Station, TX 77845. Phytopathology 89:S32. Publication no. P-1999-0228-AMA.

Fusants were made between strains of Trichoderma virens and T. koningii. Two fusants that were morphologically identical to the T. koningii parent differed in a number of characteristics, including the production of antibiotics. The parent strain showed antibiosis against bacteria in the genera Bacillus and Agrobacterium and against the fungi Rhizoctonia solani and Pythium ultimum. The fusant strains also showed antibiotic activity against several bacteria and fungi. Some of the antagonistic activity to the bacteria and to Pythium ultimum was due to acidification of the media by T. koningii. However, chloroform extracts from these strains that were $\mathrm{pH}$ neutral also were active. The HPLC chromatograms from the chloroform extracts from the fusants differed significantly from that of the parent strain, suggesting the 
fusants differ from the parents in secondary metabolite production. The active fraction from the parent strain also differed in mobility on a TLC plate from the active fractions of the fusant progeny. Based on the UV spectra and GC-MS data, all of the antibiotics appear to be related to the koninginin group of antibiotics.

Development of transgenic resistance against Xylella fastidiosa. R. HARAKAVA, D. W. Gabriel, and R. F. Lee. University of Florida, Gainesville, FL. Phytopathology 89:S33. Publication no. P-1999-0229-AMA.

Citrus Variegated Chlorosis (CVC) is a severe disease of orange trees, caused by the xylem-inhabiting bacterium $X$. fastidiosa. Natural resistance to CVC in sweet orange varieties has not been found so far and chemical control is not available. We confirmed an earlier observation (M. J. Davis, personal communication) that tobacco plants can be infected with a Pierce's Disease (PD) strain of $X$. fastidiosa. This host-pathogen system is being used as a model for testing expression of cloned genes that may give resistance to $X$. fastidiosa. Two antibacterial peptides, cecropins A and B, effectively killed a PD strain and a periwinkle wilt strain of $X$. fastidiosa in an in vitro assay. A gene for a modified cecropin was synthesized by PCR using long oligonucleotides. This gene will be attached to a promoter that was recovered from the phenylalanine ammonia-lyase (PAL) gene of sweet orange by inverse-PCR. Xylem-specific expression of a GUS gene under control of the PAL promoter is being verified in transgenic tobacco plants.

Nonhost resistance to Fusarium crown and root rot is associated with induction of hypersensitive responses in Asparagus deniflorus. C. Y. HE and D. Wolyn. University of Guelph, Guelph, Ontario, Canada. Phytopathology 89:S33. Publication no. P-1999-0230-AMA.

Asparagus deniflorus, a wild asparagus species, displayed nonhost resistance in greenhouse trials to Fusarium oxysporum f. sp. asparagi and F. proliferatum, the causal agents of crown and root rot involved in asparagus decline. A. deniflorus was significantly more resistant to the disease than the cultivated A. officinalis. No visible symptoms typical of crown and root rot were observed during the nonhost resistant interaction of A. deniflorus with Fusarium spp. Seedling roots of 8-week-old asparagus plants cultivated in sterile conditions exhibited microscopic cell death 8 hours after inoculation with mycelial hyphae. Cell death in challenged plants was limited to epidermal cells. Culture filtrates and pre-geminated conidia also induced a hypersensitive response (HR) in roots, characterized by rapid necroses, fast browning and reduced infection and penetration. The HR inhibited fungal growth and restricted the spread of the pathogen(s) into healthy tissues. Therefore, the HR appears to be a critical defense mechanism contributing to nonhost resistance of A. deniflorus against Fusarium invasion.

Formulations of Trichoderma stromaticum, a biocontrol agent of the witches'-broom pathogen Crinipellis perniciosa. K. P. HEBBAR (1), S. Lambert (2), J. B. Costa (3), and R. D. Lumsden (1). (1) USDA-ARS, Biocontrol of Plant Diseases Laboratory, Beltsville, MD 20705; (2) Almirante M\&M Mars Farm, Itabuna, Brazil; (3) CEPLAC, Itabuna, Brazil. Phytopathology 89:S33. Publication no. P-1999-0231-AMA.

The witches'-broom disease caused by the fungal pathogen Crinipellis perniciosa results in severe yield losses in cacao plantations in South America. Recently, a new species of Trichoderma, T. stromaticum, was shown to aggressively parasitize the pathogen. A major constraint in large-scale field evaluation of this bioagent is its availability in sufficient quantities. Studies to evaluate the use of T. stromaticum for disease control and to develop inexpensive fermentation and formulation methods was initiated. A simple fermentation technique involved the use of autoclavable 20 liter plastic jar filled with 151 of molasses and brewers yeast medium. The resulting liquid biomass obtained after 5 days growth was used to inoculate various biodegradable carriers. Initial tests have shown that the formulated Trichoderma has a good shelf life (>6 months) and is able to reduce ( 8 fold) formation of basidiocarps on the infected brooms and, in field trials, improve the percentage of healthy pods.

Novel findings from gnotobiotic associations of Peronospora tabacina and Nicotiana species. E. P. HEIST, W. C. Nesmith, and C. L. Schardl. Dept. Plant Pathology, University of Kentucky, Lexington, KY 40546. Phytopathology 89:S33. Publication no. P-1999-0232-AMA.

Until recently, studies of downy mildews has contended the presence and possible interactions of contaminating microorganisms. In order to study downy mildew pathosystems without interference of contaminating mi- crobes, it is necessary to obtain contaminant-free (gnotobiotic) associations of pathogen and host. In our study the pathogen of interest was Peronospora tabacina, which causes blue mold (downy mildew) of tobacco. We obtained contaminant-free inoculum from axenic co-cultures of $P$. tabacina and $N$. tabacum. The resulting sporangia were used to inoculate axenic plants. In all host species studied, we observed growth of the pathogen from the roots. Both hyphae and sporangiophores with asexual sporangia grew from host roots. In some wild species (e.g. Nicotiana repanda) we also observed what appeared to be sexual structures of the pathogen emerging from roots. The gnotobiotic system for studying P. tabacina/Nicotiana associations appears relevant to the natural interactions, and may serve as a model for similar investigations of other downy mildews.

Estimation of yield losses due to BYDV in wheat under artificial inoculation. M. HENRY and J. Segura. CIMMYT Int., Mexico D.F., Mexico. Phytopathology 89:S33. Publication no. P-1999-0233-AMA.

Yield losses due to BYDV (barley yellow dwarf virus) were evaluated in Mexico under artificial inoculation. The experimental design was a complete block design with 4 repetitions, 8 spring wheat entries and 5 treatments (PAV-Mex, RPV-Mex, MAV-Mex, no treatment, and aphicide seed treatment). Inoculations with the three BYDV isolates were done at the three leaves stage with approximately 10 aphids per plant and repeated three weeks later (tillering stage).The parameters measured were yellowing (1-9 scale), chlorophyll content, height, spike number, spike size, biomass, yield and 1000 grains weight. Yield losses ranged from 18 to $77 \%$ with PAV-Mex, 0 to $15 \%$ with RPV-Mex and 9 to $43 \%$ with MAV-Mex. There was a high correlation between losses due to PAV, MAV and RPV in all lines except the most susceptible line URES/Bob White//Opata. Chlorophyll content was correlated to visual assessment of yellowing. All the parameters measured were affected by BYDV but the most severely affected were yield and biomass. The spike number per meter was increased in most of the lines when inoculated with BYDV-PAV, MAV or RPV. Percentage of infection was much lower in the resistant wheat (TC14, developed at CSIRO, Australia) than in the tolerant or susceptible wheat suggesting that some of the resistant plants escaped infection.

Agrobacterium vitis elicits a hypersensitive response on tobacco. T. C. HERLACHE, C. L. Ried, and T. J. Burr. Cornell University, NYSAES, Geneva, NY 14456. Phytopathology 89:S33. Publication no. P-1999-0234AMA.

Agrobacterium vitis is the primary causal agent of crown gall on grape. A. vitis causes a grape-specific necrosis on roots and green tissues. We found that the A. vitis polygalacturonase (PG) is insufficient by itself to cause grape-specific necrosis. Necrosis was found to be inhibited by eukaryotic metabolic inhibitors; a characteristic previously demonstrated for hypersensitive-response and pathogenicity (HR) mechanisms. When A. vitis strains were infiltrated into tobacco leaves, an HR was elicited. The tobacco HR requires an inoculum dose of about $4 \times 10^{8} \mathrm{CFU} / \mathrm{ml}$. Following tobacco leaf infiltration, A. vitis requires about 12 hours to initiate an irreversible HR. This indicates the probable lack of pre-formed HR inducers and the need for bacterial gene expression in planta for HR elicitation. The tobacco HR is blocked by the eukaryotic metabolic inhibitors cobalt chloride and sodium orthovanadate, and is reduced by cycloheximide. A. vitis contains a $h r c V$ homologue. We conclude that $A$. vitis is able to elicit an HR response on tobacco and that the HR mechanism may be related to the mechanism of grape necrosis.

Molecular comparison of citrus tristeza virus isolates from different citrus growing regions. M. E. Hilf, V. A. MAVRODIEVA, S. Korkmaz, and S. M. Garnsey. USDA-ARS, Horticultural Research Laboratory, 2120 Camden Road, Orlando, FL 32803. Phytopathology 89:S33. Publication no. P1999-0235-AMA.

Citrus tristeza virus (CTV) is a widespread pathogen of citrus causing commercially important diseases with greatly variable symptoms. Sequence comparisons of three Florida isolates (T3, T30 and T36), and the Israeli isolate VT indicated a marked diversity in the $5^{\prime}$ region of the virus genome. Understanding the molecular relationships and diversity of CTV by routine cloning and sequencing was hampered by the large 19-kb genome, so a method to make comparisons of numerous isolates was devised. Multiple sequence specific primer pairs derived from analogous positions in the $5^{\prime}$ regions of the T3, T30, T36 and VT genomes were used with immunocapture-RT-PCR to characterize CTV isolates. The pattern of amplified 
markers was termed the genotype of an isolate and was used to estimate the relatedness of isolates. Over $300 \mathrm{CTV}$ isolates from 32 countries were characterized. Genotypes corresponding to T3, T30 and VT were common while the T36 genotype was rare. A few isolates had no specific markers. Commercially important symptoms were most often associated with isolates with either VT or T3 markers.

Differential effects of genes in the gacS regulon on interactions of Pseudomonas syringae pv. syringae $\mathrm{B} 728$ a with snap bean plants in the field. S. S. HIRANO (1), D. K. Willis $(1,2)$, and C. D. Upper (1,2). (1) University of Wisconsin and (2) USDA-ARS, Madison, WI. Phytopathology 89:S34. Publication no. P-1999-0236-AMA.

The population dynamics of mutants of $P$. syringae B728a bearing defects in genes that function at different levels in the gacS regulon were examined in the field. Growth of the non-lesion forming gacS (global activator sensor kinase) and salA (regulated by GacS) mutants were similar to B728a in laboratory leaf infiltration assays. However, in the field, population sizes of the gacS and salA mutants were on average (from plant emergence to 63 DAP) 100- and 5-fold less than wild type, respectively. Population sizes of the salA mutant were more nearly similar to B728a than to the gacS mutant in spite of the mutant's impaired ability to cause disease. The subset of genes in the gacS regulon that are not regulated by SalA appears to have a major role in growth/survival of B728a in the field. SalA regulates expression of $\operatorname{syr} B$ (syringomycin biosynthetic gene). Population sizes of a $\operatorname{syr} B$ mutant were intermediate between those of the salA mutant and B728a. Hence, syringomycin appeared to contribute, in part, to the decreased population sizes of the salA mutant.

Aphid transmission (arena) tests with a cucumber mosaic virus solanaceous natural weed host as virus acquisition source. $\mathrm{H}$. A. HOBBS, D. M. Eastburn, C. J. D'Arcy, J. D. Kindhart, J. B. Masiunas, D. J. Voegtlin, and R. A. Weinzier. University of Illinois, Urbana, IL. Phytopathology 89:S34. Publication no. P-1999-0237-AMA.

Solanum ptycanthum, a species of nightshade found naturally infected with cucumber mosaic virus (CMV) in southern Illinois, was tested for its ability to serve as a CMV source in laboratory aphid transmission "arena" tests. Individual nightshade plants were placed in a water-filled test tube in the center of and touching a ring of bell pepper seedling test plants growing in a $20-\mathrm{cm}$ pot. Approximately one to three hundred individuals of an aphid species were placed on the CMV-infected $S$. ptycanthum plant. The pot was then covered with a cylindrical cage for a period of 2 days to allow the aphids time to acquire CMV and move to the pepper test plants. After 2 days, some aphids were put in alcohol for later verification of identification, and the rest were sprayed and killed with a systemic insecticide. Pepper test plants were observed for symptoms and tested by ELISA about 3 weeks later. Infected plants developed symptoms of stunting and leaf deformation. All aphid species tested transmitted CMV from $S$. ptycanthum, in at least one of 3 or 4 tests. Aphis fabae subsp. solanella transmitted in 2 of 4 tests, Aphis gossypii in 4/4, Myzus persicae in 1/4, Rhopalosiphum padi in 2/3, and Sitobion avenae in 1/3. A. fabae subsp. solanella is commonly found colonizing nightshade in southern Illinois.

Cloning and expression of an extracellular serine proteinase produced by Ophiostoma floccosum. B. HOFFMAN, Z. Hickman, S. H. Kim, and C. Breuil. Forest Products Biotechnology, Wood Science Dept., University of British Columbia, Vancouver, B.C., Canada. Phytopathology 89:S34. Publication no. P-1999-0238-AMA.

The colonization of wood by sap-staining fungi can cause discolorization in the wood, which is objectionable to buyers, and reduces its market value. Chemical treatments of wood, to prevent colonization by sap-staining fungi, have raised environmental concerns and do not possess the duration of effectiveness desired by industry. An understanding of the physiology of sapstaining fungi is needed to develop new treatment methods. Levels of inorganic nitrogen sources in wood are very low, therefore the production of proteinases enabling the utilization of organic nitrogen sources by sap-staining fungi is thought to be key to their survival. An extracellular serine proteinase has been isolated from Ophiostoma floccosum, a commonly isolated sap-staining fungus in Canadian softwood. A genomic $O$. floccosum phage library was screened with a chemiluminescently labeled PCR product produced using proteinase-specific degenerate primers. A clone containing a full-length proteinase coding sequence was obtained and characterized. This gene was then expressed in Saccaromyces cerevisae to study its function.
Establishment and characterization of weedy Rubus tissue cultures for in vitro bioassays of Fusarium avenaceum phytotoxins. P. J. HOLLMANN (1), S. F. Shamoun (2), and S. P. Lee (1). (1) Simon Fraser University, Burnaby, BC; (2) Canadian Forest Service, Victoria, BC. Phytopathology 89:S34. Publication no. P-1999-0239-AMA.

Weedy Rubus species (R. parviflorus, $R$. spectabilis and $R$. strigosus) negatively impact conifer seedling establishment on forest regeneration sites in Canada. Our goal is to manage these weeds using microbial metabolites. As a first step towards microbial-based control, we have established tissue culture bioassays for large scale screening of phytotoxins. Media conditions to induce rapidly growing and friable callus and suspension cultures from leaf discs of the 3 weedy Rubus species were similar (modified MS) except for plant growth regulators used. Fast growing callus tissue from $R$. parviflorus, $R$. spectabilis and $R$. strigosus was induced with $4.5 \mu \mathrm{M} 2,4-\mathrm{D}, 26.9 \mu \mathrm{M}$ NAA/0.45 $\mu \mathrm{M}$ zeatin and $12.4 \mu \mathrm{M}$ picloram respectively. Culture growth was characterized and ability to detect phytotoxins was determined. Callus tissues exposed to metabolites from the potential biocontrol agent Fusarium avenaceum resulted in growth inhibition, discoloration and cell death indicating that our Rubus tissue culture bioassays are effective indicators for phytotoxins.

Effects of water stress and nutrients on the survival of Monilinia fructicola in stone fruit mummies. C. X. HONG and T. J. Michailides. University of California Davis, Parlier, CA. Phytopathology 89:S34. Publication no. P-1999-0240-AMA.

The effect of water potential on survival of Monilinia fructicola (G. Wint.) Honey was determined using stone fruit mummies and potato-dextrose agar (PDA) media amended with sucrose or potassium chloride $(\mathrm{KCl})$. Nectarine, peach, and plum mummies were dried in a fruit dryer at 30 to $35^{\circ} \mathrm{C}$. Water potential of mummy tissues was determined using a Decagon psychrometer after grinding. M. fructicola was considered survived in a mummy if isolated from its inner tissue. The survival of $M$. fructicola in mummy tissues dramatically declined as the water potential decreased. In the in vitro tests, five $4 \mathrm{~mm}$ mycelial plugs were placed equidistantly in each plate of different water potentials and incubated at $25^{\circ} \mathrm{C}$. The fungus was considered survived in a mycelial plug if recovered after exposure to water stress. $M$. fructicola survived much longer on sucrose- than $\mathrm{KCl}$-amended PDA media at -13 to $-22 \mathrm{MPa}$. These data could help understand the variations in survival of $M$. fructicola among different geographic locations, orchards, and between seasons, and assist in the development of disease control strategies.

Population dynamics and diversity of Ralstonia solanacearum in susceptible and resistant tomato plants in the infested field. M. HORITA (1), T. Yoshida (2), and K. Tsuchiya (1). (1) National Institute of Agrobiological Resources, Tsukuba, Ibaraki, Japan; (2) National Research Institute of Vegetables, Ornamental Plants and Tea, Ano, Mie, Japan. Phytopathology 89:S34. Publication no. P-1999-0241-AMA

Bacterial wilt disease of tomato caused by Ralstonia solanacearum (Rs) is very important problem in Japan. To control this disease, we assessed the population dynamics of Rs in tomato plants, and genetic diversity of Rs by using rep-PCR. Susceptible (cv. Odoriko) and resistant (cv. LS-89) tomato plants were cultivated in the infested field during summer. Three weeks after planting, Rs in Odoriko plant was over $10^{6} \mathrm{cfu} / \mathrm{g}$ fresh matter (FM) in the collar. But Rs in LS-89 plant was repressed to under $10^{3} \mathrm{cfu} / \mathrm{g}$ FM. After 5 weeks, all Odoriko plants wilted and died. On the other hand, all LS-89 plants showed no symptom, and Rs was not detected in the collar. rep-PCR analysis of isolates from both tomato plants showed that a specific polymorphic pattern was major at all times.

Antifreeze activity in snow mold fungi. T. HSIANG (1), C. S. Snider (2), G. Zhao (1), and M. Griffith (2). (1) University of Guelph, Guelph, Ontario; (2) University of Waterloo, Waterloo, Ontario, Canada. Phytopathology 89: S34. Publication no. P-1999-0242-AMA.

The production of antifreeze proteins is one way that organisms cope with low temperature environments. The purpose of this research was to survey antifreeze protein production in psychrophilic fungi such as Coprinus psychromorbidus, Sclerotinia borealis, and Typhula spp., as well as the lowtemperature tolerant fungus Microdochium nivale. Antifreeze proteins bind to the prism face of ice and produce hexagonally-shaped crystals, whereas ice crystals in pure water form as perfectly round disks. Using a nanoliter osmometer, we found modified crystals in the hyphal, intracellular and culture filtrate fractions of C. psychromorbidus, T. incarnata, T. ishikariensis, and T. phacorrhiza, indicating antifreeze activity; whereas fractions of $S$. borealis, 
S. homoeocarpa, and $M$. nivale showed no antifreeze activity. We hypothesize that some fungi phytopathogenic at subzero temperatures can promote their growth and survival by producing both intracellular and secreted antifreeze proteins that inhibit the growth of ice in their immediate environment.

Improvement of activity against fungal wheat root diseases by transformation of phenazine biosynthetic genes into Pseudomonas fluorescens. Zhengyu HUANG (1), Dmitri Mavrodi (2), Jos Raaijmakers (3), Robert Bonsall (2), R. James Cook (2), David M. Weller (3), and Linda S. Thomashow (3). (1) Dow AgroSciences, Indianapolis, IN; (2) Washington State University, Pullman, WA; Root Disease and Biological Control Research Unit, USDA-ARS, Pullman, WA. Phytopathology 89:S35. Publication no. P-19990243-AMA.

Three fungal root diseases, take-all (Gaeumannomyces graminis var. tritici), Rhizoctonia root rot (R. solani AG8), and Pythium root rot (Pythium spp.), are major yield-limiting factors of wheat grown in the Pacific Northwest. Many of the bacteria that suppress these pathogens on wheat and other crops utilize antibiotic production as a mechanism of biocontrol. Phenazine-1carboxylic acid (PCA) and 2,4-diacetylphloroglucinol (DAPG) are the two major antibiotics produced by biocontrol bacteria in the wheat rhizosphere. It is reported here that transfer of PCA biosynthetic genes to the DAPGproducing Pseudomonas fluorescens strain Q8r1-96 increased its biocontrol activity against these root pathogens. The transformed strains produced both PCA and DAPG, and colonized roots of wheat as aggressively as did the parental strain.

Blister rust cankering incidence in western white pine families selected for reduced spotting. R. S. HUNT. Canadian Forest Service, Victoria, BC. Phytopathology 89:S35. Publication no. P-1999-0244-AMA.

Inoculated western white pine (Pinus monticola D. Don) families were ranked for relative susceptibility to blister rust (Cronartium ribicola J. C. Fisch.) using their mean percentiles for infection spots (Silvae Genetica 45:75-81). Families ranked low for spots are putatively resistant (Can. J. Bot. 58:574577). Five test plantations ( 23 to 63 families each) had 36 to $88 \%$ of the trees cankered. There was no significant correlation $(p=.05)$ between family cankering from natural sources and family mean percentiles for needle spots from inoculation [Spearman's $R$ values $0.40,0.03,-0.06,-0.07$ and -0.11 ]. To prevent stem infection spotted needles were removed from six inoculated families. Seedlings classified as high and low spotters were planted in 26 paired blocks with four seedlings/block. After 7 years of natural infection the mean cankers/block for two block pairs were equal, 12 had more rust on the high spotters and 12 had more rust on the low spotters. The block mean cankering was 22 and 23 for high and low spotters, respectively. These studies indicate that selection of seedlings with reduced spotting does not increase field resistance to blister rust.

Effect of seeding date and fungicidal seed treatments on root rot, seedling emergence and yield of lentil. S. F. HWANG (1), B. D. Gossen (2), G. D. Turnbull (1), K. F. Chang (3), and R. J. Howard (3). (1) Alberta Research Council, Vegreville, AB; (2) Agriculture and Agri-Food Canada, Research Station, Saskatoon, SK; (3) Crop Diversification Centre - South, Brooks, AB. Phytopathology 89:S35. Publication no. P-1999-0245-AMA.

Early seeding allows lentil crops time to mature in the northern prairie climate, but cold spring temperatures can inhibit germination and predispose seed and seedlings to infection by soilborne pathogens. Inoculated field plots were seeded on three dates between early May and early June in 1996, 1997 and 1998. Emergence and seed yield were lower for the latest seeding date versus earlier dates, and seedling vigor declined as seeding was delayed. Fusarium reduced seedling establishment and seed yield. Experiments were conducted to evaluate the efficacy of Crown and Vitaflo-280 seed treatments in preventing seedling infection by Fusarium. These treatments generally improved seedling emergence and nodulation, reduced root rot, and increased yield compared to an inoculated control. The results demonstrated that the short growing season favours early planting for maximum yield and that seed treatment can minimize losses from seedling blight and root rot.

Effect of weather factors on pycnidium production and occurrence of citrus melanose in the field. A. M. IBANEZ and L. W. Timmer. University of Florida, Citrus Research and Education Center. Lake Alfred, FL. Phytopathology 89:S35. Publication no. P-1999-0246-AMA.

Melanose, caused by Diaporthe citri, affects grapefruit and lemons reducing fruit marketability. Inoculum for fruit infection is produced by pycnidia on dead twigs. To determine the time and conditions required for pycnidium production, symptomatic twigs from grapefruit trees were detached monthly and exposed to field conditions, for 8 months during 1997-98. Pycnidium production was assessed monthly under the microscope and weather monitored. Average temperatures between $15-25^{\circ} \mathrm{C}$ and total rain of $350 \mathrm{~mm}$ or more, during the first 4 months of exposure, triggered production. Pycnidia were fewer and delayed, on twigs collected from May to Sep, when temperatures averaged $25-28^{\circ} \mathrm{C}$ at the beginning of the exposure period. In this situation, cumulative rainfall of $350-850 \mathrm{~mm}$ was needed to initiate the process. Pycnidia producing twigs continue to release conidia from 4 to 8 months, by which time twigs were rotted or highly colonized by saprophytes. Death of infected twigs from Oct to Feb would be, under the right weather conditions, the source of inoculum for infection occurring on young fruit from March to June.

Resistance to melon dieback in Cucumis melo ssp. agrestis Pat 81. A. Iglesias, B. PICO, and F. Nuez. Polytechnic University, Valencia, Spain. Phytopathology 89:S35. Publication no. P-1999-0247-AMA.

Melon dieback is a severe root rot disease of increasing worldwide importance. In horticultural areas of Southeastern Spain it has been related to the presence of two soil fungal pathogens Acremonium cucurbitacearum and Monosporascus cannonballus. During four years, the screening of several $C$. melo accessions has been conducted under natural infestation conditions. The accession Pat 81 consistently exhibited a high level of field resistance, with a high percentage of symptomless plants and a significant delay in symptom appearance. Disease progress and root damage of the F1 hybrids between Pat 81 and highly susceptible melon varieties were intermediate between the parents, indicating a partial dominance of resistance. This high resistance level seems to be related to the regeneration capacity of the root system. Indeed, Pat 81 has a root system more branched than that of the other melon varieties assayed. This root morphology could facilitate the regeneration of new rootlets during the infection process, increasing the water uptake capacity at the end of the growth cycle. The high resistance level found in Pat 81 makes it promising for breeding melons resistant to melon dieback.

Cloning of a specific gene expressed during infection peg formation of Magnaporthe grisea. H. INOUE (1), K. Adachi (2), T. Oku (3), T. Kamakura (4), and T. Hibi (5). (1) Chugoku National Agricultural Experiment Station, Fukuyama, 721-8514, Japan; (2) Purdue University, West Lafayette, IN 47907; (3) Hiroshima Prefectural University, Shoubara, 727-0023, Japan; (4) The Institute of Physical and Chemical Research, Wako, 351-01. Phytopathology 89:S35. Publication no. P-1999-0248-AMA.

Magnaporthe grisea builds up an appressorium and an infection peg when penetrates into rice. A gene specifically expressed during infection peg formation was detected by differential display method in M. grisea. RNAs were extracted from the spores forming infection peg and those forming appressorium. RT-PCR was used to detect specific bands in mRNA of the spores forming infection peg and the specific bands were cloned and sequenced. One clone (A0801) of them consists of 1132 base pairs and has one open reading frame. In putative amino acid alignment of the gene, a DNA binding domain of helix turn helix araC family 1 type was detected. In hybridization with RT-PCR products of the both mRNAs using A0801 as a probe, stronger signal was shown in cDNA from the spores forming infection peg than in those forming appressorium. This clone is supposed to be a part of gene of transcriptional factor expressed during infection peg formation.

Reaction of sorghum hybrids to ergot (Claviceps africana) in south and central Texas. T. ISAKEIT (1), R. Bandyopadhyay (2), and G. N. Odvody (1). (1) Texas A\&M University, College Station and Corpus Christi; (2) ICRISAT, India. Phytopathology 89:S35. Publication no. P-1999-0249-AMA.

Commercial sorghum hybrids were evaluated in 1998 in three locations in Texas for reaction to ergot, either following natural infection or, at College Station, by inoculation with a spore suspension. In a trial in Weslaco, evaluated in January, ergot incidence was $100 \%$ in 37 hybrids, but they differed $(P=0.05)$ in severity $(11-75 \%$ of the head infected). Temperatures below $12 \mathrm{C}$ had occurred 2-3 weeks prior to flowering. In a December trial in Weslaco, ergot incidence was $100 \%$ in 115 hybrids, but severity also differed, ranging from low (1-5 infected florets/head) to $>75 \%$ of the head infected. Frequent rains occurred during flowering in this trial. The same hybrids had 0-5\% incidence and a low severity in June trials in Weslaco and Corpus Christi. Ergot incidence was $0-100 \%$ in a July trial in College Station, but severity was also low. The low disease in these trials was associated with high temperatures and no rain prior to and during the time of flowering. These trials show that ergot can be substantial in some hybrids growing in disease-conducive weather. 
Management of ratoon stunting disease (Clavibacter xyli subsp. xyli) of sugarcane in south Texas with hot water treatment and tolerant varieties. T. ISAKEIT (1) and J. E. Irvine (2). Texas A\&M University, (1) College Station and (2) Weslaco. Phytopathology 89:S36. Publication no. P-1999-0250AMA.

Nine sugarcane varieties, originating from a nursery, were planted in a plot in Weslaco in September, 1994. The nursery was established with seed cane that had either been hot water treated to eliminate the bacterium, or had been inoculated with contaminated sugarcane juice. Yield (sugar and cane/acre) was measured with the plant cane harvest (February, 1996) and first, second and third ratoon harvests (January, 1997-1999, respectively). There was no difference in yield between inoculated and heat-treated varieties with the plant cane harvest. A yield loss trend from ratoon stunting disease (RSD) became apparent with some varieties with the first ratoon harvest. With the second and third ratoon harvests, the reduction in yield from RSD ranged from 4-35\%. The varieties, TCP81-3058, CP87-615, and CP80-1827, were more severely affected by RSD than other varieties, while CP81-1405, CP70321 , and NCO-310 were more tolerant than other varieties. The combination of hot water treatment and tolerant varieties offers a good management strategy for RSD.

Effect of solar radiation on survival of Phytophthora infestans sporangia under glass and plastic greenhouse conditions. R. JAIME-GARCIA (1), R. M. Davis (2), and W. E. Fry (1). (1) Cornell University, Ithaca, NY; (2) Univ. of California, Davis, CA. Phytopathology 89:S36. Publication no. P-1999-0251-AMA.

Sporangia of $P$. infestans were transferred to membrane filters and exposed to solar radiation under glass and plastic greenhouse conditions, and under laboratory and field conditions as controls. Sporangia were exposed for 0 , $0.5,1.0,1.5,2.0,3.0$ and 4.0 hours. After exposure, the sporangia contained on membranes were re-hydrated and transferred onto water agar on petri plates and incubated at $15 \mathrm{C}$ for 24 to $36 \mathrm{hrs}$. Germination of sporangia was assessed by counting at least 300 sporangia per replication. Both glass and plastic filtration reduced, but did not eliminate, the detrimental effect of solar radiation on sporangia. After one hour, sporangia exposed to direct solar radiation germinated at a rate of $4 \%$, whereas those exposed to solar radiation under glass or plastic, germinated at rates of 34 and 29\%, respectively. Sporangia maintained in the lab and not exposed to solar radiation germinated at $66 \%$. After three hours, sporangia exposed to solar radiation filtered through glass, plastic or not filtered had lost ability to germinate, but control sporangia (not exposed to solar radiation) germinated at $>50 \%$.

A cDNA expressed in bean during cell death. J. L. Jakobek and P. B. LINDGREN. Dept. Plant Pathology, North Carolina State University, Raleigh, NC 27695. Phytopathology 89:S36. Publication no. P-1999-0252-AMA.

We have isolated a cDNA clone, designated Hra32, corresponding to a transcript that accumulates in bean leaves during pathogen interactions. Two different patterns of transcript accumulation were observed in response to specific stimuli which resulted in cell death when compared to general stimuli that induced defense responses but not cell death. One pattern of transcript accumulation correlated with the onset of cell death induced by incompatible bacterial and viral pathogens, and a compatible bacterial pathogen. A more transient pattern of Hra32 transcript accumulation occurred in response to general stimuli which induced defense responses, such as phytoalexins, but no cell death. General stimuli included wounding and infiltrations with $\mathrm{Hrp}^{-}$bacterial mutants, non-pathogens, and glutathione. Sequence analysis predicts the Hra32 cDNA to encode a protein of 161 amino acids with four EF-hand calcium binding domains. We have initiated experiments using antisense methodologies to investigate the role of the Hra32 gene in plantpathogen interactions.

Isolation of a cDNA corresponding to a plant gene which is activated by a broad-spectrum of pathogens. J. L. Jakobek, T. A. Sullivan, and P. B. LINDGREN. Dept. Plant Pathology, North Carolina State University, Raleigh, NC 27695. Phytopathology 89:S36. Publication no. P-1999-0253-AMA.

Plant gene promoters which are activated by a broad-spectrum of pathogens precisely when and where needed, would be ideal for genetic engineering strategies for enhancing disease resistance. We used differential screening methodologies to select a cDNA clone, designated pic20 for pathogen induced clone, from Red Kidney bean libraries. Northern analyses demonstrated that the pic20 transcript accumulates rapidly and transiently in bean in response to compatible and incompatible bacterial pathogens, and incompatible Tobacco Necrosis Virus. In contrast, pic20 does not appear to be activated by general stress. Sequence analysis revealed that the pic $20 \mathrm{cDNA}$ encodes a unique cytochrome. A homologous pic $20 \mathrm{cDNA}$ was also isolated from a Bonny Best tomato library. Northern analyses demonstrated that the pic20 gene is activated in tomato in response to Xanthomonas campestris vesicatoria, the causal agent of bacterial spot. These studies suggest that the promoter element from the pic 20 gene may be used to genetically engineer plants with enhancing disease resistance to a broad-spectrum of pathogens.

A simple RT-PCR procedure that allows simultaneous detection and differentiation of peach mosaic virus and cherry mottle leaf virus. D. JAMES (1) and C. Upton (2). (1) Centre for Plant Health, Canadian Food Inspection Agency, 8801 East Saanich Road, Sidney, B.C., Canada V8L 1H3; (2) Department of Biochemistry and Microbiology, University of Victoria, Victoria, B.C., Canada V8W 3P6. Phytopathology 89:S36. Publication no. P-19990254-AMA.

Peach mosaic virus (PMV) and cherry mottle leaf virus (CMLV) are closely related viruses that share some common hosts but cause distinct diseases. An RT-PCR procedure was developed which uses a single oligonucleotide primer pair to simultaneously detect and differentiate the two viruses. A sense primer (100\% complementary to PMV, and $83 \%$ complementary to the corresponding CMLV site with 10 perfectly matched bases at the $3^{\prime}$ end of the CMLV template) was combined with either of two antisense primers with $3^{\prime}$ end complementarity at variable sites. This allowed differential amplification of PMV and CMLV specific fragments, $419 \mathrm{bp}$ and $705 \mathrm{bp}$, respectively. This simple, cost saving approach to detecting multiple viruses may increase the feasibility of using PCR for routine diagnosis of plant viruses.

Reducing the risk of Escherichia coli $\mathrm{O157:H7}$ contamination of apple by an antagonist used to control postharvest decays of pome fruits. W. J. JANISIEWICZ (1), W. S. Conway (2), and B. Leverentz (2). (1) USDAARS, AFRS, Kearneysville, WV; (2) USDA-ARS, HCQL, Beltsville, MD. Phytopathology 89:S36. Publication no. P-1999-0255-AMA.

Application of the antagonist Pseudomonas syringae to wounded 'Golden Delicious' apple as fresh cells prevented E. coli $\mathrm{O} 157: \mathrm{H} 7$ from becoming established in the wounds. This occurred on apples co-inoculated with the two organisms or inoculated with E. coli $\mathrm{O} 157: \mathrm{H} 7$ one or two days after application of the antagonist. In similar tests, the commercial formulation of the antagonist prevented the establishment of E. coli $\mathrm{O} 157: \mathrm{H} 7$ in wounds when inoculated one or two days after application of the antagonist. In wounds not treated with the antagonist, populations of E. coli $\mathrm{O} 157: \mathrm{H} 7 \mathrm{in}-$ creased up to $3 \log$ units during the first $48 \mathrm{hr}$ after inoculation. These results indicate that biocontrol agents developed to control storage decays of fruits may have the additional benefit of preventing the establishment of foodborne pathogens in tissue of wounded and fresh-cut fruits.

Evaluation of AUDPC for late blight on potato to define reaction classes for screening nurseries. J. C. JENKINS (1), J. K. Jones (1), and N. A. Anderson (1). Department of Plant Pathology, University of Minnesota, St. Paul, MN 55108. Phytopathology 89:S36. Publication no. P-1999-0256-AMA.

Eighteen potato entries were evaluated for reaction to the US-8 strain of Phytophthora infestans. Ten potato cultivars and eight breeding lines ranged from susceptible to resistant. Potato plants were inoculated 60 days after planting and late blight severity was scored at 3 to 4 day intervals for 28 days over two field seasons. Elba, Kennebec, and Shepody were included as check cultivars. Comparison among entries was based on the area under the disease progress curve (AUDPC). The mean AUDPC value in 1997 was 600 (range $=$ 45.3-1403.8) and was significantly $(P<0.05)$ greater than the 1998 AUDPC value 341 (range $=48.8-1275.6)$. Spearman rank correlation at $14-18$ days after inoculation $(R>0.97, P<0.05)$ was equal to or greater in successive assessment dates for both years suggesting that optimum evaluation can occur at this date or later. The ability to separate potato entries into resistant, moderately resistant, moderately susceptible, and susceptible reactions facilitates evaluation of partial resistance in large numbers of potato breeding lines.

Isoform patterns of chitinase and beta-1,3-glucanase in maturing corn kernels (Zea mays L.) associated with Aspergillus flavus infection. C. JI (1), R. A. Norton (2), D. T. Wicklow (2), and P. F. Dowd (2). (1) University of Illinois at Champaign-Urbana, Urbana 61801; (2) USDA-ARS, National Center for Agricultural Utilization Research, Bioactive Agents Research, 1815 N. University, Peoria, IL 61604. Phytopathology 89:S36. Publication no. P-1999-0257-AMA.

Isoform patterns of chitinase and beta-1,3-glucanase of maturing kernels of yellow corn infected with Aspergillus flavus were investigated through poly- 
acrylamide gel electrophoreses (PAGE). Proteins on the SDS gel with an apparent molecular weight range of 23-46 kDa were induced in the kernels by $A$. flavus infection. From in-gel (native PAGE) enzyme activity assays, three bands corresponding to chitinase isoforms and two bands corresponding to beta-1,3-glucanase isoforms were detected in the infected kernels. One chitinase isoform of $29 \mathrm{kDa}$ was induced only in the infected kernels, and another one of $28 \mathrm{kDa}$ was present in both infected and non-infected kernels. They were both acidic based on their migration on an acrylamide isoelectric focusing (IEF) gel. For the beta-1,3-glucanase, one isoform of $35 \mathrm{kDa}$ was present in both infected and non-infected kernels, but another one, $33 \mathrm{kDa}$ isoform, was induced only in the infected kernels. Both acidic and basic beta-1,3-glucanase isoforms were detected in the IEF gel. These results indicate that only particular isoforms of the two fungal degradative enzymes might be involved in combating A. flavus in the maturing corn kernels.

Use of SCAR primers for specific identification and monitoring of the antagonistic strain $\mathbf{K}$ of Pichia anomala. M. H. JIJAKLI, S. Cognet, B. Prakoso, and P. Lepoivre. Unité de Phytopathologie, Faculté des Sciences Agronomiques, 2, Passage des Déportés, 5030 Gembloux, Belgium. Phytopathology 89:S37. Publication no. P-1999-0258-AMA.

Pichia anomala strain K was previously selected for its high and reliable protective activity against Botrytis cinerea and Pencillium sp. on post-harvested apples. The large-scale introduction of strain $\mathrm{K}$ requires a specific method able to monitor the population of the antagonistic agent in order to evaluate its ecological fitness and its environmental impact. In this context, RAPD was used to distinguish strain $\mathrm{K}$ from ten other strains of $P$. anomala. The FPA2 $\mathrm{kb}$ fragment, with an approximately size of $2 \mathrm{~kb}$, was specifically amplified by RAPD from the DNA of strain K with the use of OPN-13, one of the 28 tested RAPD primers. Two SCAR (sequence characterized amplified region) primers were designed one containing the OPN-13 primer at the $5^{\prime}$ termini and the other resulted from FPA2kb internal sequence. These SCAR primers allowed the reproducible and specific PCR amplification of one fragment, of expected size, for the sole strain $\mathrm{K}$ as confirmed by Southern analysis. The possibility to transfer this method in practical conditions will be presented.

Reproduction of Heterodera schachtii on Bt-transgenic cabbage. R. Jin, B. S. SIPES, and D. Borthakur. College of Tropical Agriculture and Human Resources, University of Hawaii, 3190 Maile Way, Honolulu, HI. Phytopathology 89:S37. Publication no. P-1999-0259-AMA.

Plant transformation with the Bt toxin has become common to control certain insect pests but unintended side effects may arise from its use. Transgenic cabbage expressing Bt toxin Cry1 Ab3 resistant to the diamondback moth were evaluated for effects on reproduction of Heterodera schachtii. Transformed and nontransformed cabbage plants were inoculated with $H$. schachtii eggs. Cysts and females were dislodged from the roots 6 weeks later. The number of cysts and females per plant did not differ between the transformed and nontransformed cabbage $(P>0.05)$. More eggs developed on the $\mathrm{Bt}$ cabbage than on the nontransformed plants, but their numbers did not differ $(P>0.05)$. The lack of differences between the Bt-transgenic and nontransformed cabbage on the reproduction of $H$. schachtii may be due to lack of ingestion by the nematode because of the toxin size, lack of activity against nematodes, or insufficient expression in the plant roots.

Effect of nitrogen fertilization and fosthiazate on control of Globodera tabacum subsp. solanacearum. C. S. JOHNSON. Virginia Polytechnic Institute and State Univ., Blackstone, VA. Phytopathology 89:S37. Publication no. P-1999-0260-AMA.

Two field experiments were conducted in 1992 and another in 1993 to examine fertilization practices and use of the nematicide fosthiazate to control a tobacco cyst nematode (TCN - Globodera tabacum solanacearum) on fluecured tobacco (Nicotiana tabacum). Suppression of TCN populations by fosthiazate was significant in 1993, but not in 1992. Use of fosthiazate increased tobacco yield and value in all tests. Increasing the amount of sidedress nitrogen by $20 \%$ and $40 \%$ increased midseason TCN populations in 1993 and in untreated soil at one location in 1992. Increasing sidedress nitrogen did not alter tobacco yield or value in any of the three tests. Increasing sidedress nitrogen increased average price where fosthiazate had been used at one 1992 location, but reduced average price in 1993. Increasing sidedress nitrogen fertilization does not appear to be a useful practice to improve TCN control in flue-cured tobacco.
Controlling secondary spread of fire blight with prohexadione calcium. A. L. JONES (1), W. G. D. Fernando (2), and G. R. Ehret (1). (1) Michigan State University, East Lansing, MI; (2) University of Manitoba, Winnipeg, Canada. Phytopathology 89:S37. Publication no. P-1999-0261-AMA.

Apple trees are highly susceptible to fire blight when actively growing, but this period of susceptibility can be reduced to 1 to 2 weeks with a single high-rate application of the growth retardant prohexadione calcium (BAS $125 \mathrm{~W}$, Apogee). Prohexadione calcium inhibits the biosynthesis of gibberellin. Inhibition of gibberellin biosynthesis results in an early cessation of growth and reduced risk of infection by Erwinia amylovora. Trees treated with $250 \mathrm{mg} / \mathrm{L}$ prohexadione calcium late in the bloom period were found to have a significantly lower incidence of secondary shoot blight than unsprayed trees. Also, infections were suppressed on shoots inoculated 7 days after treatment with $250 \mathrm{mg} / \mathrm{L}$ prohexadione calcium. Two applications of $125 \mathrm{mg} / \mathrm{L}$ prohexadione calcium were not as effective as one $250 \mathrm{mg} / \mathrm{L}$ application in suppressing infection or secondary spread. Prohexadione calcium appears to offer a new and novel approach to fire blight control that does not involve the use of antibiotics.

Investigations into coconut diseases of uncertain aetiology. P. JONES (1), C. P. R. Cronjé (2), and J. S. Warokka (3). (1) IACR Rothamsted, Harpenden, Herts., AL5 2JQ, UK; (2) Pathology Division, SASEX, PB X02, Mt. Edgecombe, KwaZulu Natal, South Africa; (3) Research Institute for Coconut and Palmae, Manado, Indonesia. Phytopathology 89:S37. Publication no. P-19990262-AMA.

For most of the 20th Century there have been sporadic outbreaks of lethal diseases in coconuts grown in South East Asia. In Indonesia Natuna wilt and Kalimantan wilt are two such diseases. Phytoplasmas cause some of the most devastating diseases of coconuts in the Americas and Africa and we have compared symptoms and used DNA amplification to determine if either of these diseases is associated with a phytoplasma. Amplification of the $16 \mathrm{~S}-$ 23S rRNA genes by a nested-PCR gave products of $1250 \mathrm{bp}$ in size. The restriction fragment length polymorphism of these amplimers suggested that at least one type of phytoplasma was present in coconut palms in Indonesia. Sequencing of the $16 \mathrm{~S}-23 \mathrm{~S}$ rDNA intergenic spacer region revealed a single copy of the characteristic t-isoleucine gene in all samples, confirming the phytoplasma status of the amplified sequences. Our discovery that phytoplasmas are active in coconut disease epidemics in Indonesia has implications for the sustainability of coconut farming systems in the region.

Rhizosphere bacterial communities associated with hydroponic lettuce: Potential role in biological control of Pythium. D. D. JURKONIE and E. B. Nelson. Cornell University, Ithaca, NY. Phytopathology 89:S37. Publication no. P-1999-0263-AMA.

Roots of hydroponically grown plants provide a simplified habitat for analyzing population dynamics among rhizosphere bacteria suppressive to Pythium. In preliminary experiments, a limited number of bacteria were isolated from roots of hydroponically grown lettuce and identified based on carbon utilization patterns and rDNA sequences. Culture-based community composition was compared with that obtained from community DNA analyses. Total bacterial DNA was extracted from lettuce roots and amplified using three primer sets targeting microbial $16 \mathrm{~S}$ rDNA sequences. Amplified rDNA from two primer sets was separated by denaturant gradient gel electrophoresis (DGGE). Resolved DGGE bands were excised and re-amplified for sequencing and analysis. Full-length 16S rDNA from the third primer set was cloned and digested with restriction enzymes for selection of unique clones for sequencing and analysis. Preliminary results have demonstrated the feasibility of using this multifaceted approach for examining the qualitative nature of rhizosphere bacterial communities which may impact the biology and ecology of Pythium.

Effects of incorporation implement and application rate on dazomet efficacy. J. Juzwik (1), J. T. BLODGETT (1), D. L. Stenlund (2), and R. R. Allmaras (3). (1) USDA Forest Service, (2) MN Department of Transportation, and (3) USDA-ARS, St. Paul, MN. Phytopathology 89:S37. Publication no. P-1999-0264-AMA.

Dazomet (DAZ) is a non-ozone depleting alternative to methyl bromide for preplant soil fumigation in forest nurseries. Two factors that affect efficacy of DAZ fumigation are the uniformity and depth of incorporation of the surfaceapplied, granular product. Trials were conducted in a Minnesota and a Wisconsin (WI) nursery with five tillage implements and two DAZ rates to determine treatment effects on fungal populations by soil depth. Greatest depths of biocidal activity were found with spading machine treatment in both nurseries based on lettuce bioassays. DAZ incorporated by all imple- 
ments was equally effective in reducing Fusarium spp. populations to $12 \mathrm{~cm}$ in both locations with both chemical rates. Reductions of Fusarium spp. below $18 \mathrm{~cm}$ in WI were greatest using the spading machine with either chemical rate. Reductions of Cylindrocladium spp. below $24 \mathrm{~cm}$ in WI were greatest following spading treatment with the high DAZ rate. Results suggest selection of incorporation implement and DAZ rate should be based on vertical distribution of target pathogens.

Nitidulid species associated with fresh wounds on red oaks during spring in Minnesota. J. JUZWIK (1), T. C. Skalbeck (2), and M. F. Neuman (2). (1) USDA Forest Service, St. Paul, MN; (2) University of Minnesota, St. Paul, MN. Phytopathology 89:S38. Publication no. P-1999-0265-AMA.

Nitidulids (Coleoptera: Nitidulidae) are considered the primary vectors of Ceratocystis fagacearum in north central USA. The species within this family most closely associated with the oak wilt disease cycle are being investigated. Beetles were collected from fresh wounds made on healthy red oaks in two east-central Minnesota locations during April, May, and June 1998. Highest numbers of nitidulids were collected within 3 days of wounding during May in both locations. Colopterus truncatus and Carpophilus sayi accounted for $97 \%$ of the total nitidulids collected within 7 days of wounding in May. C. truncatus was predominant on wounds in one location while C. sayi was predominant in the other. A high frequency of the insects $(78 \%)$ carried viable $C$. fagacearum propagules based on serial dilution plating of macerated beetles. These findings, coupled with study results of nitidulid species predominant on oak wilt mats in these same locations, suggest the principal nitidulid species transmitting the pathogen from diseased to healthy oaks in Minnesota are C. truncatus and C. sayi.

Characterization of a new naturally-occurring defective RNA 3 of cucumber mosaic virus. I. B. KAPLAN, S.-M. Wong, and P. Palukaitis. Cornell University, Ithaca, NY. Phytopathology 89:S38. Publication no. P-19990266-AMA.

Passaging the Fny strain of cucumber mosaic virus (CMV) in tobacco sometimes results in the formation and accumulation of an additional viral RNA which is encapsidated along with the three genomic RNAs of CMV. The additional RNA is a deleted form of RNA 3 designated D RNA 3-1. The deletion occurs within the $3 \mathrm{a}$ gene, which promotes viral movement. The deleted region encompasses nucleotides 296(7)-634(5) from the $5^{\prime}$-end of Fny-CMV RNA 3 and it is an in-frame deletion. D RNA 3-1 was cloned and transcripts for RNA 1, 2 and D RNA 3-1 were inoculated onto transgenic plants expressing the CMV movement protein. D RNA 3-1 was able to replicate and to provide coat protein for encapsidation of the CMV RNAs. The presence of D RNA 3-1 had no effect on CMV RNA accumulation in tobacco. In contrast to tobacco, squash plant would not support replication of D RNA 3-1, neither in the systemic leaves nor in the inoculated cotyledons. Various D RNAs 3 were compared for their ability to co-exist during passage, and they displayed a hierarchy of selection and accumulation, which will be described.

Identifying and mapping Fusarium wilt resistance in melon (Cucumis melo L.). T. KARSIES (1), Y. Wang (1), C. E. Thomas (2), and R. A. Dean (1). (1) Clemson University, Clemson, SC; (2) USDA-ARS, U.S. Vegetable Lab, Charleston, SC. Phytopathology 89:S38. Publication no. P-1999-0267AMA.

Fusarium wilt is a very destructive disease in melon production worldwide. The disease can be effectively controlled only by host resistance. There are four races as differentiated by host varieties. Resistance to races 0 and 1 is controlled by a single dominant gene Fom- 2 while resistance to races 0 and 2 is controlled by another single dominant gene Fom-1. Resistance to race 1,2 is polygenically controlled. We have identified DNA markers closely linked to Fom-2 and converted closely linked markers to codominant markers. Screening melon genotypes of diverse origins shown these markers are robust and can be useful in marker-assisted selection. Further progress on identifying markers linked to Fom-1 and mapping Arabidopsis genes onto melon genetic map will be presented.

Antifungal activity of chitosan and chitosan fragments with different molecular weights on postharvest pathogens. Mohammad R. KASAAI (1), M. V. Bhaskara Reddy (1), Gérard Charlet (2), and Joseph Arul (1). (1) Dept. Food Science and Nutrition and Horticultural Research Center; (2) Department of Chemistry and CERSIM, Université Laval, Sainte-Foy, Quebec, Canada G1K 7P4. Phytopathology 89:S38. Publication no. P-1999-0268-AMA.

Antifungal activity of chitosan with different molecular weights $\left(4.21 \times 10^{5}\right.$ to $1.96 \times 10^{6} \mathrm{Da}$ ) was investigated on postharvest pathogens Rhizopus sto- lonifer, Botrytis cinerea, Alternaria alternata and Penicillium digitatum. Chitosan fragments were prepared by oxidative degradation with sodium nitrite, and the molecular weights were determined by viscometry. The antifungal activity was assessed by inhibition of radial growth of the fungus on PDA at chitosan concentrations ranging from $0.75-6.0 \mathrm{mg} / \mathrm{ml}$ and at $\mathrm{pH} 5.0$. Both original and fragments of chitosan inhibited the growth of all fungi tested, with a greater effect at higher concentrations. Among the fungi Rhizopus stolonifer was the least sensitive and, where as Alternaria alternata was the most sensitive to chitosan. The fragments with lower molecular weights exhibited higher antifungal activity at lower chitosan concentrations and this difference between molecular weights diminished as chitosan concentration was increased.

Evaluating collard and kale for resistance to yellows. A. P. KEINATH (1) and M. W. Farnham (2). (1) Clemson University, Charleston, SC; (2) USDAARS, Charleston, SC. Phytopathology 89:S38. Publication no. P-1999-0269AMA.

Collard and kale cropped during the summer may be infected by Fusarium oxysporum f. sp. conglutinans. Seedlings were root-dipped in $10^{7}$ microconidia/ml and grown at $25 / 25$ or $30 / 25 \mathrm{C}$ day/night temperatures. In another test, seedlings were transplanted into naturally-infested sandy soil in Lexington County, SC in June 1997 and 1998. Symptoms were rated visually five times in the growth chamber and three times in the field. Yellows was more severe at 30 than at $25 \mathrm{C}$ but there was no cultivar-by-temperature interaction. Based on final disease incidence (DI) in the field, all five kale and seven of 17 collard lines were more susceptible $(P=0.01)$ than Bravo cabbage, which has well-characterized resistance. DI was 73 to $21 \%$ for susceptible lines, 19 to $5.6 \%$ for resistant lines, and $4 \%$ for Bravo. Cultivar means from growth chamber and field experiments were highly correlated $(P=0.0003)$, although Top Bunch collard was susceptible in the growth chamber but resistant in the field. Uncharacterized resistance to yellows in certain collard cultivars and landraces effectively decreased DI under diseaseconducive conditions.

Genetic and pathogenic diversity of Colletotrichum gloeosporioides isolates infecting Arachis pintoi. S. KELEMU, F. Muñoz, and M. X. Rodriguez. Centro Internacional de Agricultura Tropical, A. A. 6713, Cali, Colombia. Phytopathology 89:S38. Publication no. P-1999-0270-AMA.

Anthracnose, caused by Colletotrichum gloeosporioides, is a disease of increasing importance on Arachis pintoi. The pathogenicity of 91 isolates of $C$. gloeosporioides isolated from A. pintoi in four regions of Colombia was studied on five accessions (CIAT 17434, CIAT 18744, CIAT 18748, CIAT 22160 , and the original host accession corresponding to each isolate). Eightyfour of the isolates were pathogenic on at least one host accession, whereas the remaining seven were non-pathogenic. Differential reactions were observed indicating the existence of pathogenic specialization in C. gloeosporioides on A. pintoi. The genetic variability among these isolates was measured at molecular level by random amplified polymorphic DNA (RAPD), and Southern blot analysis using a repetitive DNA probe (termed CgT1: C. gloeosporioides Transposon 1) generated from an isolate of the pathogen infecting the forage legume Stylosanthes guianensis. A total of 81 band positions were scored and analysis of the RAPD data revealed at least five groups, with the isolates from one region distributed in all the groups.

Modification of aphid choice by a plant virus. S. E. KELLEY. Emory University, Atlanta, GA. Phytopathology 89:S38. Publication no. P-1999-0271AMA.

Previous studies have shown that aphids, an important vector, are attracted to the reddened and yellowed leaves of virally-infected crop plants. Aphid preference for symptomatic plants is paradoxical, because (1) infections in wild plants with these same viruses are most often asymptomatic, and (2) vector preference for infected plants limits the spread of infection. We report here experimental evidence that wild-collected aphids, Schizaphis graminum detected apparently asymptomatic infection by an economically significant, aphid-transmitted luteovirus, barley yellow dwarf (BYDV-variant SGV), in a natural host, Anthoxanthum odoratum. Moreover, feeding on BYDV-infected plants altered aphid preference. In laboratory choice experiments, aviruliferous aphids strongly preferred BYDV-infected plants, but viruliferous aphids strongly preferred uninfected plants. While manipulation of aphid preference can enhance viral spread, it did not improve aphid fitness. Viruliferous and aviruliferous aphid colonies, initiated with single aphids, grew to a similar size on BYDV-SGV infected and uninfected plants. Pathogen manipulation of vector behavior may be an important and widespread phenomenon. 
Influence of variety on incidence of soilborne fungal pathogens in peanut. R. C. KEMERAIT, Jr., and T. A. Kucharek. Plant Pathology Department, University of Florida, Gainesville, FL 32611. Phytopathology 89:S39. Publication no. P-1999-0272-AMA.

Incidence of soilborne, fungal pathogens in three peanut varieties was evaluated during 1998 at Quincy, Florida using a split-plot design. Whole plot treatments were Florunner, Georgia Green, and Fla MDR 98 varieties; subplot treatments were crop age at sampling. Hypocotyls, roots, pegs, and pods were surface sterilized, placed on acidified potato dextrose agar and incubated at $25^{\circ} \mathrm{C}$. Incidence of pathogens was studied with analysis of variance and correspondence analysis. Average incidences of Cylindrocladium parasiticum and Aspergillus niger were significantly higher in Florunner than in Fla MDR 98 or Georgia Green. Average incidences of Rhizoctonia solani and Lasiodiplodia theobromae were significantly higher in Florunner than in Fla MDR 98. There was no significant difference in incidence of A. flavus or Sclerotium rolfsii. Based on correspondence analysis, infections with C. parasiticum, $S$. rolfsii, and $L$. theobromae were associated with greatest disease severity in Florunner. Area under the disease progress curve for Florunner, calculated from field data, was significantly greater than areas for other varieties.

Commercial potential of biological preparations for vegetable transplants. D. S. KENNEY (1), M. S. Reddy (2), R. Rodríguez-Kábana (2), K. Arthur (1), and J. W. Kloepper (2). (1) Gustafson LLC, 1400 Preston Road, Suite 400, Plano, TX 75093; (2) Department of Plant Pathology, Auburn University, Auburn, AL 36849. Phytopathology 89:S39. Publication no. P-19990273-AMA.

Scientists at Gustafson and Auburn University are collaboratively evaluating biological preparations, based on rhizobacteria, for production of vegetable transplants with the aim of developing plants suppressive to various diseases upon transplanting into agricultural fields. Field trials were established in Sanford, FL to test several of these preparations as amendments in potting mix for control of tomato and cucumber against root-knot nematode, anthracnose on cucumber and bacterial spot on tomato. Additional treatments included a mid-season booster using a foliar spray or drench application of rhizobacteria. Several of the biological preparations significantly reduced root-knot nematode damage on cucumber and tomato and also gave protection of anthracnose and bacterial spot. Benefits of suppressive plants, midseason booster application, role of foliar sprays, specifically, the detailed activities of one particular treatment (LS213) will be discussed.

Molecular characterization of aster yellows phytoplasma in parsnip. A.-H. KHADHAIR (1) and I. R. Evans (2). (1) Alberta Research Council, Bag 4000, Vegreville, AB T9C 1T4, Canada; (2) Alberta Agriculture, Food and Rural Development, Edmonton, AB T6H 4P2. Phytopathology 89:S39. Publication no. P-1999-0274-AMA.

Typical phytoplasma yellows symptoms were observed on parsnip (Pastinaca sativa L.) plants grown around Edmonton, Alberta, Canada. Examination of ultrathin sections of leaf midribs by electron microscopy revealed numerous phytoplasma bodies localized in the phloem cells. DNA extracted from the infected leaves was amplified with a 16S rDNA universal primer pair P1/P6 giving the expected PCR product of $1.5 \mathrm{~kb}$. The phytoplasma was confirmed as a member of the aster yellows (AY) group by amplification with the specific primer pair R16R1/F1 that was designed on the basis of AY phytoplasma 16S rDNA sequences. In the direct and nested PCR assays, the expected DNA fragment of $1.1 \mathrm{~kb}$ was amplified with the specific primer set. Similar restriction patterns were found for the $1.1 \mathrm{~kb}$ PCR products of the phytoplasma isolated from parsnip and an AY phytoplasma control after the digestion with restriction endonucleases $A l u \mathrm{I}, H h a \mathrm{I}, R s a \mathrm{I}$ and Sau3A. This is the first reported observation of aster yellows in parsnip in Canada.

Performance of selected antagonists of Fusarium head blight against a range of Gibberella zeae isolates. N. I. KHAN (1), D. A. Schisler (2), M. J. Boehm (1), P. J. Slininger (2), and S. P. McCormick (2). (1) Ohio State University, Columbus, OH 43210; (2) USDA-ARS, NCAUR, Peoria, IL 61604. Phytopathology 89:S39. Publication no. P-1999-0275-AMA.

Fusarium head blight (FHB), caused by Gibberella zeae, is an important disease of wheat and barley. Highly resistant varieties of wheat are not available and labeled fungicides may not be effective or economically feasible. Choline stimulates early germ-tube growth of $G$. zeae and choline utilizing strains may be effective competitors of the pathogen. HPLC and liquid culture techniques were used to screen over 700 microbial strains, obtained from anthers collected in Ohio and Illinois, for their ability to utilize choline. Five antagonists (including three choline-utilizers) reduced disease severity and deoxynivalenol (DON) content in kernels, and increased 100 kernel weights $(P=0.05)$. In two different sets of greenhouse tests employing three $G$. zeae isolates from various locations, bacterial strain AS 43.4 decreased disease severity by $67-95 \%$, and DON content in kernels by $89-97 \%$. AS 43.4 increased 100 kernel weight by more than $200 \%$. Biological control shows great promise as part of an IPM program against FHB.

Nuclear DNA content of North American Armillaria species. M.-S. KIM (1), N. B. Klopfenstein (2), G. I. McDonald (2), K. Arumuganathan (3), and A. K. Vidaver $(1,3)$. (1) Dept. Plant Pathology, University of Nebraska, Lincoln, NE 68583-0722; (2) USDA Forest Service, RMRS, 1221 S. Main, Moscow, ID 83843; (3) Center for Biotechnology, University of Nebraska, Lincoln, NE 68588-0665. Phytopathology 89:S39. Publication no. P-19990276-AMA.

DNA content of nine North American Armillaria species was investigated with flow cytometry. Two or three diploid isolates of A. ostoyae, A. gemina, A. calvescens, A. sinapina, A. mellea, A. gallica, A. nabsnona, North American Biological Species (NABS) X, and NABS XI were analyzed. Fluorescence intensity of the nuclear stain propidium iodide (PI) was measured with the FACScan Flow Cytometer (Becton Dickinson, San Jose, CA). Results indicate that genome sizes of Armillaria species range from $0.11 \mathrm{pg}$ to 0.17 pg per nucleus, depending on species. Among the nine North American Armillaria species tested, A. ostoyae and A. mellea showed relatively small genome sizes $(0.11 \mathrm{pg}-0.12 \mathrm{pg}$ per nucleus) whereas A. gallica showed a relatively large genome size ( $0.17 \mathrm{pg}$ per nucleus). These studies are aimed toward understanding Armillaria gene flow in forest ecosystems.

The presence of common internal transcribed spacers in the sibling sapstain species Ophiostoma piceae and O. quercus. S. H. KIM (1), J. W. Kronstad (2), and C. Breuil (1). (1) Forest Products Biotechnology, Dept. Wood Science, University of British Columbia, Vancouver, BC V6T 1Z4, Canada; (2) Biotech Lab., Dept. Microbiology, Immunology, and Plant Science, University of British Columbia, Vancouver, BC V6T 1Z4, Canada. Phytopathology 89:S39. Publication no. P-1999-0277-AMA.

The Ophiostoma genus is one of the major sapstaining groups in Canadian softwood. About ten Ophiostoma species were identified from over 2000 isolates from a recent Canada-wide survey. In order to study the molecular systematics of the Ophiostoma species, we first accessed the ribosomal internal transcribed spacers (ITS) region to know whether this region would be useful or not. DNA sequences in ITS regions of the two sibling species, $O$. piceae and $O$. quercus, were investigated. These species had at least two ITS types. And these two species shared two types. One type was dominant in $O$. piceae (we called it as OPC type) and the other was dominant in $O$. quercus (we called it as OPH type). The results suggested that the ITS region would not be useful as a phylogenetic tool. It seems that common ITS gene pools are likely to be maintained at different level within these sibling groups in the process of evolution.

Discrete pathovars of Xanthomonas campestris pvs. pelargonii and hederae. S. H. KIM, C. E. Portmann, and T. N. Olson. Plant Disease Diagnostic Lab, PA Dept. of Agriculture, Harrisburg, PA 17110. Phytopathology 89:S39. Publication no. P-1999-0278-AMA.

Koch's postulates were performed for Xanthomonas campestris pvs. pelargonii $(\mathrm{Xcp})$ and hederae $(\mathrm{Xch})$ because $\mathrm{Xcp}$ and $\mathrm{Xch}$ are reported to be indistinguishable with pathogenicity tests and PCR amplification (FLTB Wetenschappen Univ. Gent 60:271-275. 1995). Geranium (G) and English ivy (E) were inoculated with PA isolates of Xcp and Xch. The inoculum cultured for $24 \mathrm{hrs}$ was washed $2 \times$ with $0.01 \mathrm{M}$ phosphate buffer and adjusted to $1 \mathrm{E} 4,6$ and $8 \mathrm{cfu} / \mathrm{ml}$. The inoculum, $10 \mu \mathrm{l}$, was placed on a leaf vein puncture with a $0.5-\mathrm{mm}$ gauge needle. Xcp caused systemic infection and increased its population on $\mathrm{G}$; on E, it occasionally caused a non-progressive local lesion, but did not increase its population. Xch caused a progressive local lesion with occasional chlorotic halo on E; on G, it occasionally caused a non-progressive local lesion, but did not increase its population. Koch's postulates were fulfilled with Xcp on G but not on E, and also with Xch on E but not on G. Xch induced a soft rot with black edge on a potato slice but Xcp did not. Xcp and Xch are distinctly different pathovars. 
Virulence of Korean isolates of soybean mosaic virus and their nucleotide sequences of cylindrical inclusion genes. Y. H. KIM (1), B. C. Lee (2), O. S. Kim (1), J. H. Noh (1), M. K. Kim (1), D. J. Im (1), and K. W. Lee (2). (1) National Crop Experiment Station, Suwon, Korea; (2) Kyungpook National University, Taegu, Korea. Phytopathology 89:S40. Publication no. P-1999-0279-AMA.

Two isolates of soybean mosaic virus (SMV), SC and G5H, were collected in Korea and compared with G2 and G7 strains. SMV-SC isolate was classified into G5 strain group on soybean differential cultivars (Cho and Goodman), but it showed different responses on the G5-resistant Jangbaeg and Hwanggeum (Suwon97) which are widely grown in Korea. SMV-SC caused systemic necrosis on Hwanggeum and severe mosaic symptom on Jangbaeg. SMV-G5H isolate showed similar response with G5 on differential cultivars except for severe systemic necrosis on Ogden. The nucleotide sequences of $\mathrm{SC}, \mathrm{G} 5$, and $\mathrm{G} 5 \mathrm{H}$ in the cylindrical inclusion protein coding regions (CI) of approximately $1.9 \mathrm{~kb}$ were determined. The SC and G5 nucleotide sequences of CI shared $89 \%$ similarity whereas that of G5H shared $67 \%$ and $78 \%$ similarities with SC and G5 sequences, respectively. The sequence homologies were high between SC/G5 and G7, and between G5H and G2.

Genome organization of the geranium virus isolate Gr 57. Gary R. KINARD, Mary Ann Guaragna, and Ramon Jordan. USDA-ARS, U.S. National Arboretum, Floral and Nursery Plants Research Unit, Beltsville, MD 20705. Phytopathology 89:S40. Publication no. P-1999-0280-AMA.

The geranium virus isolate currently identified only by the code Gr 57 was described as causing vein banding and leaf distortion of zonal geranium in Italy (Acta Hort. 432). In immunodiffusion the virus reacted weakly with two antisera to pelargonium ringspot virus (PelRSV), although the coat protein (CP) of Gr 57 was observed at Mr 2000 greater that of PelRSV (38 K). The complete nucleotide sequence is being determined from overlapping cDNA clones and the putative coding regions have been completed. Comparisons to similar viruses - pelargonium line pattern (PLPV), elderberry latent (ELV), and PelRSV - reveal amino acid identities ranging from about $45 \%$ (CP) to $56 \%(\mathrm{RdRp})$. These percentages are at least 10\% higher than comparisons to the carmoviruses carnation mottle, pelargonium flower break, turnip crinkle, and saguaro cactus. Thus, Gr 57 appears to be distinct from, but cluster with PLPV, PelRSV, and ELV in sequence and, like these viruses, express a single subgenomic RNA species.

Yield loss in canola as a function of brown girdling root rot. $\mathrm{H}$. W. KLEINGEBBINCK and D. L. Woods. Agriculture and Agri-Food Canada, Box 29, Beaverlodge, AB. Phytopathology 89:S40. Publication no. P-1999-0281AMA.

Brown girdling root rot of canola, caused by Rhizoctonia solani, is prevalent in the Peace River region of Northwestern Canada. However, few estimates of yield loss are available. Research was conducted to estimate single plant yield loss as a function of disease rating and maggot damage. At maturity, two one-thousand-plant samples were collected from each of six farmers fields seeded to Brassica rapa cv. Reward. Plants were separated into 13 classes based on disease severity ( 5 classes) and cabbage maggot damage ( 3 classes) ratings. Plants in each class were counted and bulked. There was no disease severity by maggot damage interaction. Mean plant weight, mean plant seed yield, harvest index, one-thousand-seed-weight and oil content were significantly reduced on plants with sinking, girdling lesions (DS 4) at the main lateral roots, and on plants with decayed roots (DS 5). No yield loss occurred on plants with lower disease severities. Maggot damage had no effect on these parameters.

Enhancement of vigor of hull-less barley with triticonazole seed treatment. C. J. R. KLITTICH. Rhone-Poulenc Ag Co, Research Triangle Park, NC 27709. Phytopathology 89:S40. Publication no. P-1999-0282-AMA.

Triticonazole is a triazole fungicide with a pending registration in Canada as CHARTER ${ }^{\mathrm{TM}}$ cereal seed treatment. In field and laboratory trials it was found to have excellent selectivity on hull-less barley. Hull-less barley generally has weaker vigor and greater sensitivity to seed treatments than hulled barley varieties. In laboratory tests on two hull-less varieties, CHARTER ${ }^{\mathrm{TM}}$ seed treatments had no negative effects on germination. In vigor testing, CHARTER $^{\text {TM }}$ increased the vigor (measured by accelerated aging) of the hull-less varieties by over $100 \%$ compared with untreated seeds. One of these seed lots was heavily contaminated with Cochliobolus sativus, suggesting that CHARTER ${ }^{\mathrm{TM}}$ seed treatment improves vigor by controlling seed-borne pathogens. In field trials in Manitoba, CHARTER ${ }^{\text {TM }}$ seed treatment improved the stand establishment of seven hull-less barley by an average of $18 \%$. CHARTER $^{\mathrm{TM}}$ cereal seed treatment will be an excellent tool for improving the stand establishment of hull-less barley.
Development of an integrated biological approach to develop transplants suppressive to various plant diseases. J. W. KLOEPPER (1), R. RodríguezKábana (1), D. S. Kenney (2), M. S. Reddy (1), N. Martinez-Ochoa (1), N. Kokalis-Burelle (3), and K. Arthur (2). (1) Dept. Plant Pathology, Auburn University, AL 36849; (2) Gustafson, P.O. Box 660065, Dallas, TX 75266; (3) USDA-ARS, Ft. Pierce, FL 34945. Phytopathology 89:S40. Publication no. P-1999-0283-AMA.

A project was initiated to combine several biological control tactics for protecting tomato against root-knot nematode and fungal pathogens. A transplant system was used to facilitate the use of three components. The components included an organic amendment, designed for nematode control and selection of an antagonistic microflora, a PGPR strain previously shown to control seedling diseases by antifungal activity, and a PGPR strain previously shown to induce systemic protection against foliar pathogens. These components were incorporated into soil-less mix used to produce transplants for field evaluation. An unexpected effect of the integrated system on tomato was a marked promotion of overall seedling growth. In initial field trials, growth promotion was retained for several weeks after transplanting and treated transplants exhibited some reductions in damage from nematodes, $\mathrm{Fu}$ sarium crown rot, and bacterial spot.

Sovran - Fungicidal mode of action and host physiology effects. H. Koehle (1), K. Grossmann (1), G. Retzlaff (1), A. AKERS (1), W. Kaiser (2), and R. Gold (3). (1) BASF AG, Limburgerhof, Germany; (2) University of Würzburg, Germany; (3) BASF Corporation, Research Triangle Park, NC 27709. Phytopathology 89:S40. Publication no. P-1999-0284-AMA.

Kresoxim-methyl (NAFTA-region trade name: Sovran ${ }^{\mathrm{TM}}$ ) is a new fungicide developed worldwide by BASF with main uses in cereals, fruits, vegetables, and ornamentals. Sovran is a member of a new class of fungicides, the strobilurins, which are synthetic derivatives of strobilurin A, a metabolite of the pine cone mushroom Strobilurus tenacellus. Its novel mode of action as an inhibitor of the fungal mitochondrial bc1 complex offers excellent curative and long-lasting protective activity against a broad spectrum of commercially important plant pathogenic fungi. In addition to its safety on target crops, there is growing evidence of kresoxim-methyl's highly positive effects on plant physiology. Although stable to weathering on the leaf surface, kresoxim-methyl is rapidly degraded in the soil and is not harmful to beneficial insects. An overview will be presented of kresoxim-methyl's mode of action, its effects on crop physiology and its fate after application.

Temporal deployment of resistance to Heterodera glycines to maintain soybean yield. S. R. KOENNING. North Carolina State University, Raleigh, NC. Phytopathology 89:S40. Publication no. P-1999-0285-AMA.

The soybean cyst nematode, Heterodera glycines (SCN), is the most damaging pathogen of soybean in the United States. A rotation study was established in 1993 to determine the feasibility of rotating SCN resistant and susceptible soybean cultivars with or without corn to optimize soybean yield, and evaluate the durability of resistance in soybean cv. Hartwig to race 2 of SCN. Twenty-four treatments were arranged in randomized complete blocks such that rotation sequences are repeated each year. Continuous monoculture of either SCN resistant Hartwig or SCN susceptible Hutcheson resulted in the lowest yields of any sequences evaluated. Highest yields were obtained in a sequence of corn-corn-Hutcheson soybean, followed by a sequence of cornHartwig soybean-Hutcheson soybean. Suppression of SCN population densities by resistant Hartwig was equivalent to that achieved with a nonhost corn. Thus, the lower yield of the corn-Hartwig-Hutcheson rotation was a result of the poor yield of the resistant cultivar in the sequence. The cultivar Hartwig has maintained its resistance to the population of SCN after six years of monoculture.

A new leaf spot disease of spinach in California caused by Stemphylium botryosum. S. T. KOIKE (1), D. M. Henderson (1), and E. E. Butler (2). (1) Cooperative Extension, University of California, Salinas 93901; (2) Department of Plant Pathology, University of California, Davis 95616. Phytopathology 89:S40. Publication no. P-1999-0286-AMA.

In 1997 and 1998, a new disease of spinach (Spinacia oleracea) was found in the Salinas Valley (Monterey County) in California. Symptoms are small (2 to $5 \mathrm{~mm}$ diameter), circular, gray green leaf spots that later enlarge and become tan colored. Older spots appear dry and papery in texture, resembling burn due to pesticides. Although sporulation was absent from all spots, Stemphylium botryosum was consistently isolated in pure culture. Representative isolates caused identical symptoms when inoculated onto ten spinach cultivars but did not cause disease when inoculated onto 22 other crop plants. Cell free culture extracts failed to cause symptoms when injected into leaves of spinach and other plants. This is the first report of a spinach disease 
caused by $S$. botryosum. Because the host range of this pathogen appears restricted to spinach, we propose that the fungus be designated S. botryosum f. sp. spinacia.

Biocontrol of parsley powdery mildew and growth inhibition of pathogenic fungi of vegetables by a filamentous fungus which produces a volatile materials. M. KOITABASHI. National Research Institute of Vegetables, Ornamental Plants and Tea, Kurume Branch, Fukuoka, Japan. Phytopathology 89:S41. Publication no. P-1999-0287-AMA.

A filamentous fungus which produces volatile materials isolated from the wheat phylloplane inhibited the occurrence of wheat powdery mildew. This fungus could not be identified because sporulation has not been observed so far, and therefore, it was given the temporary strain name Kyu-W63. The purpose of this study was to clarify whether the inhibitory effect by KyuW63 that was observed in wheat powdery mildew would also be observed in the case of pathogenic fungi vegetables. As a result, this fungus inhibited the growth of Botrytis cinerea and seven kinds of other pathogens on culture medium. These results suggested the possibility of this fungus being used as an effective agent of biocontrol of diseases in the above ground parts of vegetables. Biocontrol of parsley powdery mildew using this fungal strain under the greenhouse conditions was conducted to develop new techniques for the biocontrol of the disease. The final level of the disease severity in the Kyu-W63 treated was 43.5 which was significant difference from the value of 96.4 obtained in the control.

Organic amendments and natural chemicals as components of transplant mixes for control of root-knot nematode. N. KOKALIS-BURELLE (1), R. Rodríguez-Kábana (2), and J. W. Kloepper (2). (1) USDA-ARS, U.S. Horticultural Research Lab, Ft. Pierce, FL; (2) Department of Plant Pathology, Auburn University, Auburn, AL 36849. Phytopathology 89:S41. Publication no. P-1999-0288-AMA.

Germination and growth of 'Rutgers' tomato were evaluated in greenhouse experiments with increasing rates of the organic amendments pine bark, chitin, and hemicellulose, and the phytochemicals citral, and benzaldehyde. Effect of treatments on root-knot nematode egg viability was assessed using alginate films. Plants were evaluated for growth and root condition. Levels of organic amendments had significant effects on seedling germination and growth. Neither citral nor benzaldehyde reduced germination or produced phytotoxicity. Benzaldehyde improved plant growth and root condition at the highest application rate. Significant differences in nematode egg and juvenile viability were observed. Benzaldehyde combined with most amendments significantly reduced egg viability at all concentrations. Both citral and benzaldehyde had a direct effect on nematode development, reducing egg viability and hatch in vitro. The combination of chitin + benzaldehyde significantly improved plant growth and health compared to other combinations tested.

Field evaluation of amended transplant mixes and soil solarization for tomato and pepper production. N. KOKALIS-BURELLE (1), E. N. Rosskopf (1), R. A. Shelby (1), D. O. Chellemi (1), and C. S. Vavrina (2). (1) USDA-ARS, U.S. Horticultural Research Lab, Ft. Pierce, FL; (2) University of Florida, IFAS, Immokalee, FL. Phytopathology 89:S41. Publication no. P-1999-0289-AMA.

Field trials in two Florida locations evaluated tomato and pepper transplants grown in mixes amended with formulations of plant growth-promoting rhizobacteria (PGPR) in a management system including soil solarization. Treatments were assessed for incidence of several naturally occurring tomato and pepper pathogens. Highly significant differences in tomato and pepper transplant growth occurred. There were no effects on foliar diseases, galling, or root condition on tomato. However, yield of extra large tomato fruit and total yield increased with PGPR formulation LS256. PGPR formulation LS261 reduced galling on pepper. Pepper root condition improved with formulations LS213, LS256, LS261, and yield increased with formulations LS255 and LS256. Solarization combined with LS256 on pepper produced yields comparable to methyl bromide. The transplant mix delivery system for root inoculants has demonstrated potential to enhance transplant vigor, provide protection against root-knot nematodes in the field, and enhance yield.

\section{Amplified fragment length polymorphism in populations of Puccinia triti- cina from Canada. J. A. KOLMER. USDA-ARS, North Carolina State Uni- versity, Raleigh, NC. Phytopathology 89:S41. Publication no. P-1999-0290- AMA.}

Isolates (69) of Puccinia triticina from the eastern, prairie, and Pacific regions of Canada were tested for virulence to 22 Thatcher wheat lines, and for molecular polymorphism (AFLP) using 10 primer pairs. There were 37 distinct virulence phenotypes, and 69 molecular phenotypes with 164 AFLP markers. Both virulence and AFLP markers distinguished four major groups of isolates which could be also grouped according to geographic region or in broad virulence groups. The average virulence distance within groups was 0.21 , and between groups was 0.36 . The average AFLP variation within groups was 0.24 , and between groups was 0.38 . Isolates from the prairies with virulence to $\operatorname{Lr} 17$ were in a distinct AFLP group while prairie isolates that were avirulent to $\operatorname{Lr} 17$ were in a different group. Isolates from eastern Canada avirulent to $L r 2 a$ and virulent to $L r 2 c$, and isolates avirulent to $L r 22 b$ were also in distinct groups. AFLP markers will be useful for examination of evolutionary trends in $P$. triticina populations.

Virulence and molecular polymorphism in international collections of Puccinia triticina. J. A. KOLMER (1) and J. Q. Liu (2). (1) USDA-ARS, North Carolina State University, Raleigh, NC; (2) AgrEvo Canada, Saskatoon, SK. Phytopathology 89:S41. Publication no. P-1999-0291-AMA.

Isolates (131) of $P$. triticina from 11 international populations were tested for virulence to 22 Thatcher wheat differential lines, and for molecular (RAPD) polymorphism using 11 primers. The average virulence distance within populations was 0.28 , and between populations was 0.38 . Variation between populations accounted for $26 \%$ of the total virulence variation. Populations from Australia-New Zealand, Spain, Italy, and Britain did not differ significantly for virulence. Populations from Israel, Pakistan, South Africa, eastern Canada, South America, western Canada, and Central Europe were significantly different for virulence. The average RAPD variation within populations was 0.26 , and between populations was 0.39 . Variation between populations accounted for $36 \%$ of the total RAPD variation. Populations from Spain and Italy, and western Canada and South America, did not differ significantly for RAPD variation. The other seven populations differed significantly for RAPD variation. There was 0.50 correlation between virulence and RAPD polymorphism over all populations.

The life cycle of Tilletia spp. is inhibited by fungal pheromone-related compounds and extracts of their mycelia. P. J. KOSTED, S. A. Gerhardt, and J. E. Sherwood. Department of Plant Sciences, Montana State University, Bozeman, MT 59717. Phytopathology 89:S41. Publication no. P-1999-0292AMA.

Interruption of the life cycle of Tilletia spp. to control bunt diseases was analyzed by evaluating extracts from those species. Extracts from $T$. indica, T. contraversa, and T. walkeri were tested on T. indica, T. contraversa, and $T$. caries for their ability to control germination and progression beyond primary sporidia. Extracts found to have activity were further fractionated by HPLC. Fractions from $T$. indica and $T$. walkeri extracts were very inhibitory to $T$. indica and $T$. caries teliospore germination and formation of primary or secondary sporidia. This was similar to results found using Ustilago hordei extracts and pheromone derivatives containing a modified cysteine. U. maydis pheromones were also very inhibitory to germination or sporidial formation of $T$. indica. Several detergents including Triton X-100 and Tween compounds $(20,40,60$, and 80) were investigated for their effects on $T$. indica and T. caries. Triton X-100 and Tween 40 inhibited the formation of primary sporidia in both.

Evaluation of antagonistic bacteria for biological control of Fusarium dry rot of potato. R. KOTAN (1), F. Sahin (1), E. Demirci (1), A. Ozbek (1), C. Eken (1), and S. A. Miller (2). (1) Ataturk University, Erzurum, Turkey; (2) The Ohio State University, OARDC, Wooster, OH. Phytopathology 89: S41. Publication no. P-1999-0293-AMA.

Fusarium sambucinum (teleomorph = Gibberella pulicaris), the causal agent of dry rot disease of potato, is responsible for severe yield losses in the storage. Ten of twenty bacterial strains in three genera (Bacillus, Burkholderia and Pseudomonas) isolated from various environments were antagonistic against Fusarium sambucinum isolate PF-97 in vitro. Bacterial suspension $\left(10^{8} \mathrm{CFU} / \mathrm{ml}\right)$ were prepared for all antagonists and one non-antagonistic bacterium in sterile distilled water, and then individually assayed against PF-97 ( $10^{5}$ conidia/ml) by co-inoculating bacteria and pathogen into wounds $(4 \times 4 \mathrm{~mm})$ in potato tubers (cvs. Agria and Granula). Sterile water was used as control. After 3 weeks incubation at $20^{\circ} \mathrm{C}$ in storage, only one antagonistic strain OSU7 significantly reduced $(95 \%)$ disease severity in potato tubers. However, there were no significant differences in disease severity between potato tubers treated with the remaining strains and with the pathogen alone. 
Genetic variation within a worldwide collection of Didymella bryoniae using AFLP analysis. R. T. KOTHERA (1), A. P. Keinath (1), R. A. Dean (2), and M. W. Farnham (3). (1) Clemson University, Charleston, SC; (2) Clemson University, Clemson, SC; (3) USDA-ARS, Charleston, SC. Phytopathology 89:S42. Publication no. P-1999-0294-AMA.

The fungal pathogen Didymella bryoniae is the causal agent of the foliar disease gummy stem blight on cucurbits. Little is known about the genetic diversity of this fungus. Amplified Fragment Length Polymorphism (AFLP) markers were used to elucidate genetic variation within D. bryoniae. A total of 56 isolates from five states (Florida, Georgia, Oklahoma, South Carolina, Texas) and six countries (China, Greece, Israel, Sweden, The Netherlands, the United States) were examined. Eight different AFLP primer-pair combinations yielded $>51$ polymorphic markers. Markers were scored by presence or absence. A portion of the primer-pair combinations were repeated to verify reproducibility. Cluster analysis will be used to determine genetic diversity within and among geographic regions.

Pathogen aggressiveness and field competitiveness in isolates with mutations in avrBs2. C. S. KOUSIK (1) and D. F. Ritchie. North Carolina State University, Raleigh, NC; (1) Pepper Research Inc., Loxahatchee, FL. Phytopathology 89:S42. Publication no. P-1999-0295-AMA.

Pathogen aggressiveness and field competitiveness were measured on several pepper genotypes during two growing seasons using field isolates of the pepper bacterial spot pathogen, Xanthomonas campestris pv. vesicatoria with different mutations in the avrBs 2 locus. The recovery frequency of a race 4 isolate having one deletion of the 5-bp repeat CGCGC (>70\%) in avrBs2 was greater than a race 4 having one additional 5-bp repeat. However, these two isolates produced similar AUDPC in greenhouse experiments. In field experiments with race 6 isolates having different mutations in $a v r B s 2$, the recovery frequency of the isolate with IS1646 in avrBs2 was highest (66\%), followed by the isolate with a deletion of the 5-bp repeat CGCGC (22\%), one additional 5-bp repeat (8\%), no detectable avrBs2 (2\%), and one additional 12-bp repeat (1\%), respectively. In greenhouse experiments, no significant variations in aggressiveness (AUDPC) of race 6 isolates with different mutations were detected. These results suggest that factors controlling pathogen aggressiveness and field competitiveness may not be linked.

Control of Botrytis cinerea on tuberous begonia with calcium chloride. C. R. KRAUSE (1), L. E. Horst (1), H. A. J. Hoitink (2), and L. V. Madden (2). (1) USDA-ARS, Application Technology Research Unit; (2) Dept. Plant Pathology; $(1,2)$ OARDC, The Ohio State University, Wooster, OH. Phytopathology 89:S42. Publication no. P-1999-0296-AMA.

The efficacy of $\mathrm{CaCl}_{2}$, a reduced-risk protective fungicide, was compared with mancozeb, a conventional fungicide, for control of gray mold caused by Botrytis cinerea, on rooted cuttings of Begonia spp. Treatments consisted of inoculated and uninoculated begonia controls, and plants sprayed weekly with mancozeb or calcium chloride in a polyhouse. Disease severity was evaluated over a 6-wk period using a modified Horsfall-Barrett scale. $\mathrm{CaCl}_{2}$ and mancozeb treatments exhibited significantly $(P=0.05)$ lower AUDPC values than inoculated controls. Furthermore, AUDPC values for $\mathrm{CaCl}_{2}$ did not differ significantly $(P=0.05)$ from those of mancozeb. Mancozeb sprays produced a visible residue on the foliage and flowers whereas $\mathrm{CaCl}_{2}$ did not. Phytotoxic effects were not observed on either foliage or flowers. Flowering was not affected by any treatment. These findings are significant since conventional fungicide use may have to be curtailed due to worker protection standards and other environmental issues.

The presence, distribution, and some etiological characteristics of isolates of Didymella bryoniae in Florida with different levels of sensitivity to benomyl. T. A. Kucharek, C. SEMER, and R. Hoover. Plant Pathology Dept., University of Florida, Gainesville, FL 32611. Phytopathology 89:S42. Publication no. P-1999-0297-AMA.

In 1996 and 1997, 264 isolates of Didymella bryoniae were obtained from watermelon and cantaloupe grown at 111 sites in 23 counties in Florida. Radial growth was determined for each isolate at 5, 50 and $500 \mathrm{ppm}$ of benomyl in APDA twice with four replications per test. The percent of the isolates that were sensitive, resistant, and stimulated at $5 \mathrm{ppm}$ were 22.7, 53.8 , and 23.5, respectively. No sensitive isolates were obtained below Interstate 4. In 1996, three counties on the northern border of Florida had exclusively sensitive isolates, but in 1997, those same counties had sensitive and resistant or stimulated isolates. When 82 isolates were classified into groups (G1-G6), depending upon growth at the three levels of benomyl, it was determined that as sensitivity to benomyl diminished the production of pycnidia and perithecia on V-8 agar also diminished. For the same isolates, as sensitivity to benomyl diminished, virulence tended to increase as determined by lengths of lesions in stems of watermelon in pathogenicity tests in the greenhouse.

Colorimetric detection of specific RT-PCR-amplified sequences of apple stem grooving virus from crude extracts of apple trees tissues. J. Kummert, V. L. A. Marinho, P. Lepoivre, and M. H. JJJAKLI. Unité de Phytopathologie, Faculté universitaire des Sciences agronomiques, B-5030, Gembloux, Belgium. Phytopathology 89:S42. Publication no. P-1999-0298-AMA.

Primers have been selected allowing specific amplification from several Apple Stem Grooving virus (ASGV)-infected plants by reverse transcriptionpolymerase chain reaction (RT-PCR). In view to develop convenient protocols for the routine testing of multiplication material for certification, both the pre- and post-PCR steps have been simplified, together with the optimisation of the RT-PCR reaction. Well designed primers, used with the one-step Titan one-tube RT-PCR system allowed a specific amplification of ASGV sequences directly from clarified crude extracts of leaves and bark tissues of apple trees during both active growth and the dormant season. For the sensitive and specific detection of the amplification products, a colorimetric reaction based on the hybridisation of the amplicon both with a specific biotinlabelled capture probe linked to a streptavidin coated microtiter plate and a digoxigenin-labelled detection probe, and revelation with an alkaline phosphatase labelled anti-DIG has been used.

Pathogenic, morphological and rDNA sequence studies of isolates of Colletotrichum spp. of postharvest fruits. E. E. KURAMAE-IZIOKA, N. A. R. Perez, V. E. Rosa, Jr., and N. L. Souza. Faculdade de Ciencias Agronomicas, UNESP, Botucatu, SP, Brazil. Phytopathology 89:S42. Publication no. P-1999-0299-AMA.

Colletotrichum species cause anthracnose in various postharvest tropical and subtropical fruits. The disease in postharvest fruits of guava, mango and papaya has being reported causing by $C$. gloeosporioides, and in citrus by $C$. acutatum. The aim of this study was to compare isolates of guava, mango, papaya and citrus, through pathogenicity, morphological, cultural and rDNA sequencing. PCR amplifications of the rDNA gene fragment of all isolates were performed using ITS4 and ITS5 primers. Each PCR product was sequenced using ITS4 as a primer. The sequence data was aligned using CLUSTAL W and a phylogenetic tree was constructed. The results showed that through inoculation was observed that $C$. acutatum is pathogenic to guava, papaya and mango and morphologically isolates of mango and papaya were similar to C. gloeosporioides and isolates of guava and citrus were similar to $C$. acutatum. The tree constructed by rDNA sequencing showed that mango and papaya were similar and, guava and citrus were more close related.

Fungicide spray application methods to maximize Sclerotinia control in canola. H. R. KUTCHER (1) and T. M. Wolf (2). (1) Agriculture and AgriFood Canada, Melfort, SK; (2) Agriculture and Agri-Food Canada, Saskatoon, SK. Phytopathology 89:S42. Publication no. P-1999-0300-AMA.

Sclerotinia stem rot [Sclerotinia sclerotiorum] of canola is controlled largely by foliar fungicides in western Canada. Concerns about drift are increasing the use of coarser, low-drift sprays. The objectives of this study were to determine the effect of low-drift nozzles on disease control and their interactions with fungicides. Sprays of benomyl and vinclozolin were applied to flowering canola with conventional flat fan and low-drift nozzles at 275 and $550 \mathrm{kPa}$. Both fungicides reduced disease incidence from $50 \%$ in the untreated plots to between 2 and $10 \%$ in treated plots, with a corresponding $30 \%$ yield increase. Conventional flat fan nozzles (TeeJet XR) and low-drift nozzles (Greenleaf TurboDrop) were equally effective at both pressures. Vinclozolin performance was not affected by nozzles and pressures, whereas benomyl performance was slightly reduced with the low-drift nozzles when operated at low pressure. This interaction was not apparent in canola yield or seed quality. Low-drift nozzle technology may be appropriate for Sclerotinia control in canola provided pressures are adjusted to optimize nozzle performance

Factors affecting growth, sporulation and pathogenicity of chocolate spot fungi (Botrytis species). J. O. KUTI and H. F. Nawar. Texas A\&M University, Kingsville, TX 78363. Phytopathology 89:S42. Publication no. P-19990301-AMA.

Five isolates of chocolate spot fungi (three Botrytis cinerea and two $B$. fabae) varied greatly in growth, sporulation, colony appearance and morphology. While optimum conidial production occurred on both V-8 tomato 
and potato dextrose agar (PDA) media, optimum linear colony growth occurred on V-8 tomato agar medium. In continuous light, sporulation of all of the isolates was 2-3 times greater than in darkness when grown on both media expect in one $B$. cinerea isolate, where sporulation was greater in the darkness when grown on PDA medium. In pathogenicity studies, $B$. cinerea, originally isolated from faba bean, was more pathogenic to faba bean than the two $B$. fabae also originally isolated from faba bean. The other two $B$. cinerea fungi, isolated from grapes and eggplant respectively, were moderately pathogenic to faba bean.

Strategies to improve resistance to potato virus $X$ and potato virus $Y$ in potato plants. I. LABROSSE (1), P. M. Charest (1), and L. F. Brisson (1). (1) Université Laval, Québec, Canada. Phytopathology 89:S43. Publication no. P-1999-0302-AMA.

Potato plants need to defend themselves against attack from a variety of viruses. To circumvent the drawbacks of viral infection, considerable interest has focused on the development of resistant cultivars. In a number of plant species, transgenesis has been exploited successfully to engineer virus resistance. In our study, a number of constructs has been elaborated in order to improve resistance of the potato cultivar Shepody to PVX and PVY viruses. Genes encoding for coat protein of PVY and PVX as well as those included in the Triple Gene Block, coding for the $12 \mathrm{~K}$ and $8 \mathrm{~K}$ proteins, involved in viral movement, were used in different combinations to enhance the specificity of engineered resistance. In addition, another strategy to improve protection was investigated by using a mutated version of the $12 \mathrm{~K}$ gene. A protocol for viral inoculation of cell cultures was developed to select most efficient transformants. These different strategies will be discussed in relation to the post-transcriptional resistance mechanisms.

Host range and resistance to tomato powdery mildew, caused by Oidium lycopersicum. J. A. LAMONDIA, V. L. Smith, and S. M. Douglas. Dept. Plant Pathology and Ecology, Connecticut Agricultural Experiment Station, Windsor, CT 06095. Phytopathology 89:S43. Publication no. P-1999-0303-AMA.

Powdery mildew of tomato was identified as Oidium lycopersicum based on anamorph characteristics. Conidia were produced singly or in pairs on unbranched conidiophores. Appressoria were distinct and lobed, and haustoria were circular. Fibrosin bodies and cleistothecia were not observed. Eastern black nightshade, eggplant, tobacco, and potato were infected in the greenhouse. Reciprocal infection between tomato, nightshade, eggplant and tobacco was demonstrated. Twelve tomato cultivars or lines were evaluated for infection. No fungicides were applied. Powdery mildew was severe in Baxter's Early Bush, Better Boy, Celebrity, Heinz 1439, Roma, Rutgers, Super San Marzano, and Early Girl. Grace, DRW 5007, Hirol 3-21, and Lycopersicon hirsutum PI 247087 exhibited almost complete resistance to O. lycopersicum. Plant introduction L. hirsutum PI 247087 and Hirol 3-21 (tomato crossed to PI 247087 and back-crossed 3 times to tomato) were poorly adapted and did not produce marketable fruit. However, Grace and DRW 5007 (DeRuiter Seeds) were well adapted to Connecticut.

Characterization of Phytophthora capsici populations in Michigan. K. H. LAMOUR and M. K. Hausbeck. Michigan State University, East Lansing, MI. Phytopathology 89:S43. Publication no. P-1999-0304-AMA.

Crown and fruit rot caused by Phytophthora capsici result in substantial loss on cucurbit hosts in Michigan each year. A hierarchal sampling strategy was utilized to assess the incidence and distribution of A1 and A2 mating types and metalaxyl sensitive (MS) and insensitive (MI) strains in Michigan during 1998. Single zoospore isolates (524) from 16 fields (15 cucurbit, 1 pepper) were tested for mating type using known A1 and A2 cultures. Metalaxyl sensitivity was determined based on the growth of isolates on 0,10 , and 100 $\mu \mathrm{g} / \mathrm{ml}$ metalaxyl amended V8 agar. Thirty percent of the isolates were classified as MI, $16 \%$ as intermediate, and $54 \%$ as MS with $70 \%$ of the fields sampled containing insensitive isolates. A total of 267 A1 and 257 A2 isolates were recovered with both mating types being found in every field. Insensitive isolates occurred among both mating types. Oospores were found in diseased cucurbit fruit from four farms. Inoculation studies, and observations of naturally infected fruit, indicate that mixed A1/A2 infections can result in an oospore containing mycelial mat on the surface of the fruit in addition to the asexual sporulation observed with single A1 or A2 infections.

Aphid transmission of a full-length clone of SMYE-potexvirus. S. Lamprecht and R. R. MARTIN. USDA-ARS, Corvallis, OR. Phytopathology 89: S43. Publication no. P-1999-0305-AMA.

An in vivo infectious full-length clone of strawberry mild yellow edge potexvirus (SMYEPV) was constructed using five overlapping cDNA clones. $F$. vesca 'Alpine' could be infected with this clone using particle bombardment or agroinoculation, but not by mechanical inoculation. Plants infected with the full-length clone developed typical strawberry mild yellow edge symptoms. Aphid transmission of the potexvirus from plants infected with the fulllength clone could not be obtained, although in the field the causal agent(s) of mild yellow edge disease is transmitted by aphids. Strawberry plants were infected with both, the SMYEPV full-length clone (isolate MY-18) by agroinoculation and with a wild type isolate (isolate D-74) by aphid transmission. Using an IC-RT-PCR tests that can differentiate between the two isolates doubly infected plants were identified. Aphid transmission from these doubly infected plants to healthy $F$. vesca 'Alpine' seedlings resulted in transmission of the formerly non-aphid transmissible full-length clone (isolate MY-18). These findings give further evidence for a helper virus in the natural occurring disease that facilitates the aphid transmission of the SMYEPV.

Baseline sensitivity distribution of isolates of Pythium aphanidermatum to azoxystrobin. K. Langan, G. OLAYA, and E. Tedford. Zeneca Ag Products, Western Research Center, Richmond, CA 94804. Phytopathology 89:S43. Publication no. P-1999-0306-AMA

Isolates of Pythium aphanidermatum causing Pythium blight of turf were collected from several U.S. golf courses that had no previous exposure to the strobilurin fungicide azoxystrobin. Isolate sensitivity was determined using the following in vivo assay: Perennial ryegrass (Lolium perenne) were sown in $4 \times 4$ inch pots. Two weeks after planting, turf was sprayed with Heritage (azoxystrobin) at rates of $0.4,0.133,0.044,0.015,0.005$ and $0 \mathrm{oz}$ product/ 1000 sq. ft. Twenty-four hours after fungicide application, turf was inoculated by placing four $P$. aphanidermatum colonized ryeberries onto the center of each turf pot. The percentage of turf area infected was measured 5 days after inoculation and $\mathrm{ED}_{80}$ values were calculated. The assay was repeated 4 times for each isolate in order to determine the accuracy of the test. Based on the evaluation of 29 isolates of $P$. aphanidermatum, the $\mathrm{ED}_{80}$ values (oz. Heritage $/ 1000$ sq. $\mathrm{ft}$ ) relative to the percentage turf area infected ranged from 0.029 to 1.002 , with a median value of 0.186 . Baseline information will be used as a reference in future resistance monitoring studies.

Effect of reduced tillage and crop rotation on canola diseases. R. M. LANGE and P. D. Kharbanda. Alberta Research Council, P.O. Bag 4000, Vegreville, AB, Canada T9C 1T4. Phytopathology 89:S43. Publication no. P-1999-0307-AMA.

Brassica napus cvs. Westar and Quantum and B. rapa cv. Reward were grown continuously or rotated with barley over three years (1996-1998) using conventional or reduced tillage. Crop rotation decreased the severity of blackleg, root rot and Alternaria black spot. Tillage method had no effect on blackleg severity in 1996-1998, and did not affect root rot severity in 1997 or 1998. Reduced tillage increased Alternaria black spot severity in Quantum by $0.4 \%$ in 1996 and 2.3\% in 1997, but not 1998. Tillage method did not affect yield in any year of the study. Crop rotation resulted in yield increases of 46 and 47\% over continuous canola in 1997 in the blackleg-susceptible cultivars Westar and Reward. In 1998, yield of the blackleg-tolerant cultivar Quantum was $38 \%$ greater in the rotated vs. continuous plots. One-year seed transmission data indicated that Alternaria brassicae was more prevalent than A. raphani or A. brassicicola in Reward. Results indicate that substantial reductions in canola diseases and increases in yield can result from rotation with barley, and that reduced tillage does not adversely affect either yield or disease severity.

Outbreak of a viral disease affecting soybeans [Glycine max (L.) Merrill] in South Dakota. M. A. C. LANGHAM, D. C. Doxtader, J. D. Smolik, and R. A. Scott. South Dakota State University, Plant Science Department, Brookings, SD 57007. Phytopathology 89:S43. Publication no. P-1999-0308-AMA.

During August 1998, soybean plants [Glycine max (L.) Merrill] displaying prominent mosaic and leaf distortion were observed in southeastern South Dakota. Plants were also stunted, and many pods had only one or two seeds. Ouchterlony double diffusion and ELISA assays with comovirus antisera (R. C. Gergerich, University of Arkansas) demonstrated positive reactions to bean pod mottle comovirus (BPMV). Fifty random samples were collected from farmers' fields in Union, Lincoln, Clay, and Turner counties. The percentage of infected plants per field ranged from 0 to $94 \%$. Percent infection rates from plants collected in mid to late August averaged $44.4 \%$, early September collections averaged 35.5\%, and mid September collections averaged $18.8 \%$. Greenhouse tests with bean leaf beetles (Ceratoma trifurcata Forst.) indicated the virus is beetle transmitted. Host range tests on viral isolates 
from infected soybean demonstrated that these isolates infected Vigna unguiculata (L.) Walp. cv. Monarch and did not infect Phaseolus vulgaris L. cv. Tendergreen.

Plasposon mutagenesis of herbicolin biosynthesis genes in Pantoae agglomerans C9-1. T. A. Lansdell, K. J. Voelsing, P. H. Bauer, and C. A. ISHIMARU. Colorado State University, Fort Collins, CO 80523. Phytopathology 89:S44. Publication no. P-1999-0309-AMA.

Pantoae agglomerans $\mathrm{C} 9-1$ has been shown to be an effective biological control agent of fire blight, caused by Erwinia amylovora. While the mechanism for biocontrol of fire blight by P. agglomerans C9-1 has not been determined, it is known that $\mathrm{C} 9-1$ produces at least two antibiotics, herbicolin $\mathrm{O}$ and $\mathrm{I}$, active against E. amylovora. In this study, the genes for herbicolin production were disrupted by plasposon mutagenesis. Plasmid Tn Mod-RKm ${ }^{\prime}$ was introduced into $P$. agglomerans $\mathrm{C} 9-1$ by electroporation and the resultant Tn Mod mutant library was screened for loss of herbicolin production. From an initial screen of 1100 mutants, two herbicolin I deficient and eighteen herbicolin I and $\mathrm{O}$ deficient mutants were obtained. No herbicolin O deficient mutants were obtained. Plasposon mutagenesis is currently under way in E. coli CIE85, a cosmid clone containing the genes for herbicolin O biosynthesis. The plasposon mutants obtained in this study will allow further assessment of the role of herbicolins in the biocontrol of fire blight.

AFLP-based molecular markers specific to Karnal bunt and other Tilletia species. A. LAROCHE (1), D. A. Gaudet (1), T. Despins (1), L. Lintott (1), and G. Kristjansson (2). (1) Agriculture and Agri-Food Canada, Research Centre, Lethbridge, Alberta, Canada; (2) Canadian Food Inspection Agency, Nepean, Ontario, Canada. Phytopathology 89:S44. Publication no. P-19990310-AMA.

Karnal bunt of wheat, incited by Tilletia indica, is subject to numerous international quarantines designed to prevent its spread. It is difficult to morphologically distinguish $T$. indica from the closely related rice bunt fungus, $T$. barclayana and ryegrass bunt, T. walkeri. DNA fingerprints, generated using the Amplified Fragment Length Polymorphism (AFLP), permitted the identification of T. indica, T. barclayana and T. walkeri, and the isolation of more than 35 species-specific DNA fragments. These fragments were cloned and further characterized by Southern analysis using 28 strains of T. indica, 6 of $T$. walkeri and 4 of T. barclayana. The most specific fragments were sequenced and species-specific PCR primers developed. The fragments ranged between 350 and 1200 bp and none had homology to know sequences. The specificity of these PCR-primer pairs to identify the three Tilletia species was confirmed using an additional strains.

Characterization of a $1.2 \mathrm{~kb}$ satellite RNA associated with pea streak carlavirus. R. C. LARSEN (1), S. D. Wyatt (2), K. Druffel (2), and W. J. Kaiser (3). (1) USDA-ARS, Prosser, WA; (2) Washington State University, Pullman, WA; (3) USDA-ARS, Pullman, WA (retired). Phytopathology 89: S44. Publication no. P-1999-0311-AMA.

A $1.2 \mathrm{~kb}$ satellite RNA was found associated with a strain of pea streak carlavirus (PeSV) isolated from chickpea (Cicer arietinum L.) in eastern Washington State. The satellite did not appear to affect virulence and was not infectious in the absence of helper virus. A cDNA clone of the satellite RNA hybridized strongly with the homologous RNA but not with the $8.1 \mathrm{~kb}$ genomic RNA. Partial sequence analysis of the satellite RNA revealed a putative $501 \mathrm{bp}$ ORF that codes for an $18.6 \mathrm{kDa}$ protein. A 46 amino acid sequence within the putative ORF showed moderate similarity $(51 \%)$ with the coat protein of satellite tobacco mosaic virus. Two short nucleotide sequences of 45 and 37 bases were found homologous to equivalent regions located downstream of the $3^{\prime}$-most ORF and upstream of the poly-A tail of several other carlaviruses. This is the first report of a satellite RNA associated with carlaviruses.

Production of secondary spores by Colletotrichum acutatum on strawberry leaves in the absence of infection. L. F. S. LEANDRO, M. L. Gleason, and F. W. Nutter, Jr. Iowa State University, Ames, Iowa 50011. Phytopathology 89:S44. Publication no. P-1999-0312-AMA.

Detached strawberry leaves (cv. 'Tristar') were spray-inoculated with a suspension of Colletotrichum acutatum conidia and incubated at $26^{\circ} \mathrm{C}$ and $100 \%$ relative humidity. Leaf disks were sampled 3, 6, 9, 12, 15, 18, 21, 24, 36 , and $48 \mathrm{~h}$ after incubation and prepared for microscopic observation.
Droplets of the spore suspension were also deposited on plastic cover slips, incubated as described above, and observed at each sampling period. Germination tubes, hyaline appressoria, and melanized appressoria with hyaline pores were observed on both leaf surfaces and cover slips. Abundant secondary spores were produced by phialides branching from hyphae, and from conidia that germinated with a phialide instead of a germination tube. Secondary spores were viable and were produced in the absence of host penetration. This is the first report of production of secondary spores by $C$. acutatum on asymptomatic strawberry leaves. Production of secondary spores may play an important role in the dissemination of $C$. acutatum on strawberry in the absence of infection.

A PCR ELISA for detection of Rhizoctonia solani, anastomosis group 3 (AG-3). K. LEBLANC (1), P. M. Charest (1), and R. Hogue (2). (1) Laval University, Sainte-Foy, Qc.; (2) IRDA, Sainte-Foy, Qc. Phytopathology 89:S44. Publication no. P-1999-0313-AMA.

Rhizoctonia solani Kühn, anastomosis group 3 (AG-3) causes black scurf of potato in eastern Canada. Other AGs (2-1, 2-2, 5, 8 and 9) are known to be associated with potatoes but they are not pathogenics. A PCR ELISA test for the specific detection of anastomosis group 3 has been developed. For this purpose, DNA from AG 2-1, 2-2, 3, 5, 8 and 9 were extracted. From each AGs, a 179 bp fragment was amplified by PCR with SBU177 and SBI336 primers. Those fragments were cloned and sequenced. There are some polymorphisms in the sequence of the amplified fragments that distinguishes AG-3 from the others AGs. A specific probe for AG-3 was synthesized. The PCR ELISA test using the amplified 179 bp products and the AG-3 probe allows the sensitive and specific detection of AG-3 in the soil.

Allelic differences within and between North American and European populations of Gremmeniella abietina var. abietina. N. Lecours, J. Bérubé, G. Laflamme, and R. C. HAMELIN. Natural Resources Canada, Canadian Forest Service, Ste-Foy, Quebec, Canada. Phytopathology 89:S44. Publication no. P-1999-0314-AMA.

Two loci derived from random amplified microsatellites were sampled in the European race of Gremmeniella abietina var. abietina populations from North America and Europe. At the ACA locus, three alleles were found. Allele A was dominant in continental North America (86\%) but was absent from Newfoundland and Europe. Allele B was present in all populations, but at different frequencies $(13.8 \%, 84.2 \%, 94.7 \%$ in Continental North America, Newfoundland and Europe, respectively). Allele D was present in Newfoundland and Europe but absent from continental North America. At the CGA locus, there were only 3 alleles in continental North America and 2 in Newfoundland but 10 alleles were present in Europe. However, both alleles from Newfoundland were found in Europe, while the dominant continental North American allele (80\%) was absent from Newfoundland and rare in Europe. These results suggest distinct introductions of the EU race in continental North America and Newfoundland and little gene flow between Newfoundland and continental North American populations.

Use of PCR-based assay to detect Rhynchosporium secalis in infected barley seed. H. K. LEE (1), J. P. Tewari (1), and T. K. Turkington (2). (1) Dept. of Agricultural, Food, and Nutritional Science, University of Alberta, Edmonton, AB T6G 2P5; (2) Agriculture and Agri-Food Canada, Lacombe Research Center, 6000C and E Trail, Lacombe, AB T4L 1W1. Phytopathology 89:S44. Publication no. P-1999-0315-AMA.

Leaf scald caused by Rhynchosporium secalis (Oudeman) J. J. Davis is an important disease of barley. The seed-borne phase of this disease can be responsible for early development of epidemics, introduction of the pathogen into new areas, and also for dispersal of new physiologic races. Speciesspecific primers were designed based on sequencing data of a region consisting of the 5.8s RNA gene and internal transcribed spacers 1 and 2 of the barley scald fungus, Rhynchosporium secalis. Five synthesized oligonucleotide primers were tested for their specificity using 29 isolates of $R$. secalis of diverse geographic origins and from different barley cultivars. In addition, 24 isolates of taxonomically related and other microbes isolated from the ecological niche of $R$. secalis were tested to validate the specity of the primers. Primer set of RS4 and RS5 amplified a unique 455-bp single fragment from the DNA of all $R$. secalis isolates but not from the DNA of other microbes. These primers were also tested on the DNA extracted from the seed of $R$. secalis infected barley and were shown to successfully amplify only the predicted DNA fragment. PCR detection of as little as $100 \mathrm{pg}$ of $R$. secalis DNA was possible. 
Nucleotide sequence of beet soil borne mosaic virus. L. LEE (1), E. B. Telford (1), J. S. Batten (2), K.-B. G. Scholthof (2), and C. M. Rush (3). (1) Texas A\&M Agricultural Research Center, Amarillo, TX; (2) Texas A\&M University, College Station, TX; (3) Texas Agricultural Experiment Station, Bushland, TX. Phytopathology 89:S45. Publication no. P-1999-0316-AMA.

Beet soil borne mosaic virus (BSBMV), a proposed member of the Benyvirus genus (formerly Furovirus genus), was identified in Texas (1988) as part of a complex of viruses associated with beet necrotic yellow vein virus (BNYVV), the causal agent of rhizomania of sugar beet (Beta vulgaris L.). Rhizomania is characterized by massive lateral root proliferation, constriction of the main taproot, and stunting. In contrast, the roots of BSBMV infected sugar beets are often asymptomatic. Partial characterization demonstrated that BSBMV was morphologically similar to BNYVV but serologically distinct. The genome of BNYVV consists of four, sometimes five (only in some isolates), RNA species that are polyadenylated at their 3' ends. Similarly, the genome of BSBMV consists of four polyadenylated RNA species. We present here the complete nucleotide sequence and genomic organization for BSBMV. Comparison of BSBMV with BNYVV and other furo-like viruses may further clarify taxonomic relationships among these closely related viruses.

Molecular cloning of rice $m y b$ genes induced by Pyricularia grisea. M. LEE and Y. Yang. Department of Plant Pathology, University of Arkansas, Fayetteville, AR 72701. Phytopathology 89:S45. Publication no. P-1999-0317-AMA.

Plant Myb transcription factors are known to regulate phenylpropanoid biosynthesis, epidermal cell differentiation and hormone-responsive pathways. Recent studies indicate that $m y b$ genes are also involved in virus- and bacterium-induced plant defense responses in tobacco and Arabidopsis. To study the potential role of myb genes in the rice-Pyricularia grisea interaction, DNA fragments (160 bp) of rice myb genes were amplified by PCR and cloned from blast fungus-induced cDNAs using degenerate oligonucleotide primers corresponding to conserved domains of Myb proteins. Based on sequence analysis of the cloned PCR fragments, five distinct groups of rice $m y b$ genes were identified. Two of them were induced by rice blast fungus as shown by northern analysis. By construction and screening of a blast fungusinduced rice cDNA library, the corresponding full-length myb genes have been isolated and are currently being characterized. The preliminary data suggest that $m y b$ genes can be activated by fungal infection and may be associated with host defense responses in monocots.

The effect of within row plant spacing on Botrytis fruit rot and yield in strawberry. D. E. LEGARD, C. L. Xiao, J. C. Mertely, and C. K. Chandler. Univ. of Florida, GCREC, Dover, FL. Phytopathology 89:S45. Publication no. P-1999-0318-AMA.

During the 1997-98 and 1998-99 seasons, replicated experiments were conducted to evaluate the effect of within row plant spacing on the incidence of Botrytis fruit rot (Botrytis cinerea) and marketable yield on annual strawberry. Three cultivars (Camarosa, Rosa Linda and Sweet Charlie) and four plant spacings $(23,30,38,46 \mathrm{~cm})$ were evaluated. Fruit was harvested twice weekly to determine marketable yield and Botrytis fruit rot incidence. Captan was applied weekly to limit the severity of Botrytis fruit rot. There were significant differences in the incidence of Botrytis fruit rot between cultivars with 'Sweet Charlie' having the highest and 'Rosa Linda' the lowest. Early season marketable yield was significantly higher with narrow plant spacings. Plant spacing had no significant effect on Botrytis fruit rot incidence. Thus, wider plant spacing did not reduce Botrytis fruit rot but did reduce early season yield. In Florida, extended ( $>8 \mathrm{hr}$ ) periods of leaf wetness occur most evenings, and increasing plant spacing probably does not cause enough of a reduction in leaf wetness duration to reduce infection by $B$. cinerea.

Hyphal growth of Monilinia vaccinii-corymbosi in blueberry flowers and fruits. J. S. LEHMAN (1), S. Igarashi (1), and P. V. Oudemans (2). (1) Otterbein College, Westerville, $\mathrm{OH} 43081$; (2) Rutgers Blueberry and Cranberry Research Center, Chatsworth, NJ 08019. Phytopathology 89:S45. Publication no. P-1999-0319-AMA.

Hyphal growth of M. vaccinii-corymbosi in flowers and fruits of highbush blueberry cultivars was examined to quantify host resistance to mummy berry disease. Stigmas of cultivars Jersey, Bluecrop, and Weymouth were inoculated with dry conidia and pollen. Flowers harvested after 1 and 4 days were stained and examined for hyphal growth in stylar canals. Fruits harvested after 8 weeks were scored for the presence of hyphae in locules. At days 1 and 4, hyphae grew 2-3 times further in stylar canals of 'Jersey' and 'Bluecrop' than in those of 'Weymouth'. At 8 weeks after inoculation, the mean infection frequencies for 'Jersey', 'Bluecrop', and 'Weymouth' were 0.25 ,
0.11 , and 0.04 , respectively, and differed significantly. In addition, the mean number of infected locules per fruit differed for 'Jersey', 'Bluecrop', and 'Weymouth' (3.9, 2.1, and 1.3, respectively). Results show that highbush blueberry exhibits novel mechanisms of resistance to floral infection and fruit mummification that inhibit growth in stylar canals and colonization of locules by $M$. vaccinii-corymbosi.

Molecular phylogeny, evolution and groupings of Pythium and Phytophthora species based on nuclear ribosomal DNA. C. A. LEVESQUE (1), A. W. A. M. de Cock (2), A. Quail (1), D. O'Gorman (1). (1) Agriculture and Agri-Food Canada, Summerland, BC; (2) Centraalbureau voor Schimmelcultures, Delft, Netherlands. Phytopathology 89:S45. Publication no. P-19990320-AMA.

DNA sequencing of the internal transcribed spacers (ITS 1 and 2) and the 5.8S gene of the nuclear ribosomal DNA has been completed for almost all Pythium and Phytophthora species. The majority of the isolates used in these studies were (neo-)type strains. Classical taxonomy, based primarily on morphological characters, is generally in agreement with the molecular data, especially with respect to groupings above species level (e.g. generic level, group of Pythium spp. with filamentous sporangia). The main exception is a small cluster of Pythium species of which $P$. vexans is a member which appears to be more closely related to Phytophthora than Pythium. If we exclude this group, Pythium and Phytophthora are well separated and appear to be monophyletic. Generally, sequence data between closely related species differ but there are several examples where ITS sequences between different (neo-)type strains were identical. These putative cases of con-specificity will need further study with techniques that give higher resolution.

The use of DNA arrays for multiplex detection of fungi in plant tissue and on rotorod spore samplers. C. A. LEVESQUE and C. H. Harlton. Agriculture and Agri-Food Canada, Summerland, BC. Phytopathology 89:S45. Publication no. P-1999-0321-AMA.

The reverse dot blot hybridization (RDBH) technology developed at Agriculture and Agri-Food Canada for the detection of cranberry fungi has been modified using an improved DNA array application. The cranberry RDBH array consists of 86 different oligonucleotides arranged in duplicate and can detect 25 genera of fungi. Array technology produced membranes with uniform concentration and location of oligonucleotides and made automatic reading of scanned blots possible. In preparation for RDBH analysis, samples of fresh cranberry fruits were processed for both small scale $(<1 \mathrm{~g})$ and larger scale (>1 g-80 g) DNA extractions. DNA was also successfully extracted directly from spores collected by rotorod samplers located in two cranberry fields. The ITS region was amplified and labeled simultaneously with digoxygenin (DIG) by using fungal specific primers. DIG-PCR products were then hybridized with DNA array membranes. For a given sample, fungal species profiles were consistent for different DNA extractions, PCR reactions and hybridizations. Quantification of signals and cross reactivity in spore traps are currently being addressed.

Presence of phytoplasmas in Mexican cacti. N. E. LEYVA-LOPEZ, O. I. Aguilar-Rojas, D. S. Leal-Klevezas, and J. P. Martínez-Soriano. Unidad de Biotecnología e Ingeniería Genética de Plantas CINVESTAV, Apdo. postal 629, Irapuato, Gto., Mexico. Phytopathology 89:S45. Publication no. P-19990322-AMA.

Mexico is the center of origin of a large number of cacti species. Many of them have become popular as ornamental plants and their demand is growing rapidly. In recent years an increasing number of "new" varieties and species with markedly unusual anatomical features are being offered to cacti collectors. Abnormal growth behavior, excessive stem and bud proliferation, mosaics and unusual colors are indications that they may be pathogen-induced disorders. Tissue culture, PCR, RFLPs and DNA sequencing analysis performed in our lab indicate consistently that phytoplasmas are causing most of the observed syndromes.

Agrobacterium-mediated transformation of hybrid poplar with oxalate oxidate gene and the resistance of transgenic plants to oxalic acid and pathogenic fungi. H. LIANG (1), C. A. Maynard (1), R. D. Allen (2), and W. A. Powell (1). (1) College of Environmental Science and Forestry, State University of New York; (2) Texas Tech. University. Phytopathology 89:S45. Publication no. P-1999-0323-AMA

Oxalate oxidase (oxalate:oxygen oxidoreductase, EC 1.2.3.4.) is an enzyme that catalyzes the degradation of oxalic acid to $\mathrm{CO}_{2}$ and $\mathrm{H}_{2} \mathrm{O}_{2}$. It has been shown that this enzyme belongs to the germin protein family which may play 
a role in plant defense. In order to test this hypothesis in Populus species, Agrobacterium tumefaciens strain EHA101, which carries the wheat oxalate oxidase gene (GenBank number M21962) driven by the CaMV 35S promoter, was used to transform Populus $\times$ euramericana "OGY", using the leaf disk method. The incorporation of the oxalate oxidase gene into "OGY" genome was confirmed by polymerase chain reaction (PCR) and Southern blotting analysis. A histochemical assay, using 4-chloro-1-naphthol as the staining reagent, indicated that the transgene was expressed in leaves, stems, and roots. To determine the effects of this transgene, leaf disks of transgenic and control "OGY" plants will be treated with oxalic acid, and the oxalic acid resistance will be scored by the severity of leaf damage. In addition, the potential antimicrobial resistance of transgenic plants will be tested in vivo by infection with the poplar pathogenic fungus Septoria musiva, using the leaf disk method.

Genetic diversity of Xanthomonas campestris pv.juglandis associated with relative virulence to English walnut. S. E. Lindow, M. Hendson, T. A. TURINI, and B. L. Teviotdale. University of California, Berkeley, CA. Phytopathology 89:S46. Publication no. P-1999-0324-AMA.

Isolates of the walnut blight pathogen, Xanthomonas campestris pv. juglandis, were cultured from fruit and leaf lesions, the surfaces of healthy green shoots, and dormant buds of walnut trees grown in six counties in California. Isolates were tested for resistance to copper and genetic variability by RFLP analysis using an internal portion of an IS element found in this species as a probe. Among 680 isolates tested, 24 distinct genotypes were identified which were easily distinguished based on RFLP pattern. Only copper-sensitive strains were isolated from lesions. In 1996 and 1997, 27 strains representing 7 common genotypes were spray inoculated onto young cultivar Chico walnut nutlets on trees and misted for 20 hours to facilitate infection. Copper sensitive strains originating from nuts were more virulent on nuts than those from other sources. Disease severity on each of 4 different walnut varieties inoculated with isolates of a highly virulent genotype was greater than that on trees inoculated in 1998 with isolates of a weakly virulent genotype suggesting that host specificity may not occur in this pathogen.

MoreCrop 2.0: A new expert system for managing diseases of wheat. $R$. F. LINE and R. M. Cu. USDA-ARS, WSU, Pullman, WA 99164. Phytopathology 89:S46. Publication no. P-1999-0325-AMA.

MoreCrop 2.0 is a new information technology system for managing wheat diseases referred to by the acronym MoreCrop (Managerial Options for Reasonable Economical Control of Rusts and Other Pathogens). It is designed to predict diseases and provide managerial options in agronomic zones of the Pacific Northwest. Wheat growers, extension agents, consultants, and other professionals involved in wheat production can use MoreCrop as a decision support system. It is also a powerful tool for research and teaching. The program contains up-to-date information related to wheat cultivars and their characteristics, agronomic zones, diseases and their characteristics, fungicide information, crop managerial options, and other subject matter relevant to wheat production. MoreCrop can be used as an educational tool for understanding the epidemiology and control of wheat diseases. Wheat growers can use the program to predict diseases, build a crop management scenario, analyze a predefined crop management scenario, and test disease control options. MoreCrop can be used as a training and reference tool to solve realtime problems, and it can serve as a prototype in developing crop and disease managerial programs.

Sequence similarity of Cryphonectria hypovirus 1 in Europe and Asia. Y.-C. LIU and M. G. Milgroom. Cornell University, Ithaca, NY. Phytopathology 89:S46. Publication no. P-1999-0326-AMA.

The chestnut blight fungus, Cryphonectria parasitica, is native to east Asia and was introduced into Europe. Based on records of chestnut imports and RFLPs, C. parasitica is thought to have been introduced from Japan, not China. Cryphonectria hypovirus 1 (CHV1) is found throughout Europe wherever C. parasitica is found. It is also found in Asia. We tested the hypothesis that CHV1 was introduced from Japan along with its fungal host. CHV1 isolates were randomly sampled from three regions, Europe, China and Japan. Sequences of viral dsRNAs were compared using $500 \mathrm{bp}$ in the $5^{\prime}$-end noncoding region and $600 \mathrm{bp}$ in ORF B. High levels of nucleotide sequence identity were found among CHV1 isolates sampled from Italy and Japan, while sequences from isolates in China were markedly different. These results suggest that CHV1 was most likely introduced into Italy from Japan, not China.
Sequence analysis of resistance gene analogs from potato. Zhaowei LIU (1), R. Zhang (1), K. G. Haynes (2), and B. J. Christ (1). (1) Dept. Plant Pathology, Penn State University, University Park 16802; (2) USDA-ARS Vegetable Lab, Beltsville, MD 20705. Phytopathology 89:S46. Publication no. P-1999-0327-AMA

We are developing molecular markers to tag late blight resistance genes within a Solanum phureja-S. stenotomum hybrid potato population. A candidate-gene approach was applied to isolate resistance gene analogs (RGAs), which are very useful in identifying the genomic regions containing resistance genes or gene clusters. In this study, different combinations of primers based on conserved motifs within the nucleotide biding site of known plant resistance genes were used to amplify sequences from potato genomic DNA via PCR. Predicted PCR bands consisting of similar sized fragments were cloned and subsequently sequenced. Thirty-six different RGA sequences were identified with high homology to resistance genes RPS2, N and I2C-1 by the BLASTX search. Our preliminary analysis could separate these RGAs into four classes, with RGAs from different classes showing less than $72 \%$ nucleotide sequence homology and RGAs from within each class showing at least $94 \%$ sequence homology. Analysis of deduced amino acid sequences will be presented.

Freezing cycles with temperature minima below $-25^{\circ} \mathrm{C}$ cause winter injury on red spruce. W. H. LIVINGSTON and M. E. Day. Univ. Maine, Orono, ME. Phytopathology 89:S46. Publication no. P-1999-0328-AMA.

Winter injury on red spruce (Picea rubrens) is characterized by appearance of dead, red needles on the current year's growth during late winter and early spring. Freezing cycles can enhance winter injury, and our hypothesis was that minimum temperatures in a cycle must fall below a critical temperature before damage can be detected. Thirty-two red spruce, 2-10 $\mathrm{m}$ height, were sampled over two locations near Orono, Maine, on February 26 and March 4, 1998. Three branch tips growing in full sunlight were collected from the upper half of each tree's crown. Three current-year growth segments, one from each branch, were placed in a plastic bag for freezing treatments of constant $-9^{\circ} \mathrm{C}$, one cycle to $-35^{\circ} \mathrm{C}$, or 4 cycles to $-25,-30,-35$, or $-40^{\circ} \mathrm{C}$. The maximum for a cycle was $3^{\circ} \mathrm{C}$. Treatments were completed simultaneously in separate freezing chambers. Samples were then exposed to $48 \mathrm{hr}$ of light at $20^{\circ} \mathrm{C}$ to allow symptom development. Damage was measured by quantifying color change from green to red using a Regent Instruments image analysis system. Needles remained green for freezing cycles with $-25^{\circ} \mathrm{C}$ minima, but winter injury became evident with colder treatments.

An aphid-transmitted badnavirus associated with yellow leafspot of spiraea. B. E. L. LOCKHART and J. Lachner. Department of Plant Pathology, University of Minnesota, St. Paul, MN 55108. Phytopathology 89:S46. Publication no. P-1999-0329-AMA.

Spiraeas (Spiraea spp.) with symptoms of bright yellow leafspots, leaf distortion, and reduction of leaf size and plant vigor, were found infected with a previously undescribed badnavirus. The disease was observed in Minnesota on 5 cultivars of Spiraea, a widely used landscape ornamental. The disease occurred most frequently in the cv. Anthony Waterer, and could be distinguished from an achlorophyllous sectorial chimera usually seen in this cultivar. A virus present only in symptomatic plants had nonenveloped bacilliform virions similar to those of badnaviruses and was related serologically to Commelina yellow mottle, rice tungro bacilliform and sugarcane bacilliform badnaviruses. The Spiraea virus had a $7.5 \mathrm{~Kb}$ dsDNA genome, segments of which were amplified by PCR using badnavirus-specific oligonucleotide primers. The virus was transmitted from infected to healthy Spiraea by Aphis spiraecola (Patch). An uncharacterized $35 \mathrm{~nm}$ spherical virus was sometimes present in badnavirus-infected plants, and in some Spiraea cultivars showing yellow or reddish leafspot symptoms only the spherical virus was detected.

The impact of compost soil amendment on fungal diseases of turfgrass. C. LOSCHINKOHL, J. W. Rimelspach, and M. J. Boehm. The Ohio State University, Columbus, OH. Phytopathology 89:S46. Publication no. P-19990330-AMA.

A shift from agricultural to residential land use has generated environmental concerns about urban sprawl, including urban waste disposal and soil quality issues. A replicated field study was established to assess the impact of the addition of biosolid and yardwaste compost amendments on the development of turfgrass fungal diseases. Disease severity, establishment rate, and productivity were measured over time on three different species of turf, each 
seeded on both compost-amended and nonamended subsoil. Rust (Puccinia spp.) was significantly more severe on noncompost-amended perennial ryegrass. The impact of compost applications on brown patch (Rhizoctonia solani) and red thread (Laetisaria fuciformis) was also assessed.

Sweetpotato leaf curl virus, the United States isolate: Nucleotide sequence and phylogenetic relationships. P. Lotrakul and R. A. VALVERDE. Louisiana State University, Baton Rouge, LA. Phytopathology 89:S47. Publication no. P-1999-0331-AMA.

The complete nucleotide sequence of the United States isolate of sweet potato leaf curl geminivirus (SPLCV-US) component A was determined from three overlapping PCR clones. The genome organization of component A was similar to those of other whitefly-transmitted geminiviruses. It contained an intergenic region containing six open reading frames. The incomplete direct repeat iterons were also found within the intergenic region with positions and arrangement similar to those of geminiviruses from the old world. The relationships between SPLCV-US and other whitefly-transmitted geminiviruses were investigated by using phylogeny of derived AV1 and AC1 amino acid sequences. The analyses revealed that SPLCV-US has a coat protein which is unique from its counterparts from both the old and new world. Based on the AC1 amino acid sequence, SPLCV-US was found to be more closely related to geminiviruses from the old world, although its position on the phylogenetic branch is still uncertain.

Reduced pathogen-related root damage of phylloxera infested grapevines in organically managed vineyards in California. D. W. LOTTER (1), J. Granett (1), and A. D. Omer (1). (1) Department of Entomology, University of California at Davis, Davis, CA. Phytopathology 89:S47. Publication no. P-1999-0332-AMA.

Secondary infection of roots by fungal pathogens is a primary cause of vine damage in phylloxera (Daktulosphaira vitifoliae) infested grapevines (Vitis vinifera L.). In summer and fall surveys in 1997 and 1998, grapevine root samples were taken from organically (OMVs) and conventionally managed vineyards (CMVs), all of which were phylloxera-infested. In both years, root samples from OMVs showed significantly less root necrosis caused by fungal pathogens than did samples from CMVs, averaging 9\% in OMVs vs. $31 \%$ in CMVs. Phylloxera populations per $100 \mathrm{~g}$ of root did not differ significantly between OMVs and CMVs, although there was a trend toward higher populations in OMVs. Soil parameters, percentage organic matter, total nitrogen, nitrate, and percentage sand/silt/clay also did not differ significantly between the two regimes. Cultures of necrotic root tissue showed significantly higher levels of the beneficial fungus Trichoderma in OMVs in 1997 but not in 1998, and there were significantly higher levels of the pathogens Fusarium oxysporum and Cylindrocarpon sp. in CMVs in 1998 but not in 1997. Greenhouse experiments examining the possible role of two common root pathogen antagonists isolated from OMV rhizospheres, Trichoderma sp. and fluorescent Pseudomonad bacteria, yielded equivocal results. Greenhouse experiments with phylloxera, Fusarium sp., and several inducers/suppressors of systemic acquired resistance (SAR) are currently being carried out to test the hypothesis that SAR plays a role in the reduced root necrosis in OMVs. Implications for further research and for viticulture are discussed.

A spatial model for characterizing and predicting the impact of dwarf mistletoe on song birds. J. E. LUNDQUIST (1) and R. M. Reich (2). (1) USDA Forest Service, Fort Collins, CO; (2) Colorado State University, Fort Collins, CO. Phytopathology 89:S47. Publication no. P-1999-0333-AMA.

Forest disease assessments are mostly based on non-spatial timber-production metrics, and almost always relate to reductions in expected averagestand volume or basal area. Different types of metrics may be needed to more accurately assess their impacts on non-timber resources. Tree diseases are probably essential for many bird species, but little is known about the spatial relationship between tree diseases and bird composition, abundance, or distribution. In this study, a probability model based on minimum threshold theory using a kriged response surface was constructed to predict withinstand spatial distribution of neotropical migratory song birds in relation to the spatial arrangement of canopy openings created by trees killed and deformed by southwestern ponderosa pine dwarf mistletoe (Arceuthobium vaginatum subsp. cryptopodum) in a ponderosa pine (Pinus ponderosa) stand in Manitou Experiment Forest near Colorado Springs in central Colorado. The model was subsequently tested by examining this relationship in diseased stands showing a range of management histories.
Root colonization of Fusarium solani f. sp. glycines in relation to soybean yield, cultivar response and SDS development. Y. LUO and O. Myers. Department of Plant, Soil and General Agriculture, Southern Illinois University, Carbondale, IL 62901. Phytopathology 89:S47. Publication no. P-19990334-AMA.

Field experiments were conducted in southern Illinois in 1997 and 1998 to study the relationships between root colonization of Fusarium solani f. sp. glycines, the causal agent of soybean SDS, and soybean yield loss, cultivar responses and geographic disease distribution. Observations of sequential samplings from four locations demonstrated that some resistant cultivars showed lower initial root colonization level and slower colonization development, but foliar disease index (DX) was not correlated with AUDPC of root colonization. Observations on cultivar Pioneer 9492 in another field with micro-sections showed that yield loss caused by SDS and some yield components were significantly correlated with DX at growth stage R6, but not correlated with root colonization level (CFU/g root) at harvest. Study with sequential samplings in separate fields by GIS analysis demonstrated that geographic distribution of DX at growth stage R6 was significantly correlated with root colonization at growth stage R5, but not with that at early growing season.

Molecular fingerprinting of weed pathogens utilizing amplified fragment length polymorphism (AFLP) and random amplified microsatellite (RAMS) PCR. D. G. LUSTER, E. D. Goley, E. L. Weber, and L. K. Paxson. USDA-ARS, Foreign Disease-Weed Science Research Unit, Ft. Detrick, MD 21702-5023. Phytopathology 89:S47. Publication no. P-1999-0335-AMA.

We are testing the utility of various molecular fingerprinting methods for the discrimination of closely-related weed pathogens. Specifically, we are interested in developing systems to monitor field releases of biocontrol pathogens and identifying genetic markers for virulent strains. The subject of this study was Myrothecium verrucaria, a broad-spectrum weed pathogen that exhibits low virulence unless applied in an invert emulsion, which reduces the dew requirement for infection and renders the pathogen more virulent. We compared two molecular fingerprinting methods - AFLP and RAMS. Both AFLP and RAMS proved their utility in this preliminary study of four Myrothecium species and four isolates of $M$. verrucaria. RAMS fragment analysis provided less information content but was much faster and less labor-intensive, while the additional information yield from AFLP was offset by the need for highly purified DNA and longer, more labor-intensive protocols.

An autumn foliar scab sequential sampling technique to predict the level of "scab-risk" next spring. W. E. MACHARDY (1), L. R. Berkett (2), C. D. Neefus (1), A. R. Gotlieb (2), and D. K. Sutton (1). (1) University of New Hampshire, Durham, NH; (2) University of Vermont, Burlington, VT. Phytopathology 89:S47. Publication no. P-1999-0336-AMA.

Sixty-six autumn assessments of foliar scab, caused by Venturia inaequalis, in 15 predominantly McIntosh commercial apple orchards in New England over several years were analyzed to develop a sequential sampling chart/ graph that predicts with $95 \%$ confidence whether or not an orchard is at risk of unacceptable scab buildup next year if the recommended fungicide dose is reduced. As few as 100 shoots (10 shoots on each of 10 trees) examined in autumn to determine the incidence of foliar scab can predict the level of "scab-risk." Previously, it was necessary to examine 600 shoots (10 shoots on each of 60 trees), a procedure considered too time-consuming to be widely practiced by growers. Sequential sampling statistical methods based on the means and variances of the 66 assessments, in conjunction with previously established action thresholds for reducing the fungicide dose and using sanitation practices based on an autumn assessment of foliar scab incidence, were employed to develop the sequential sampling chart/graph.

Molecular and virulence diversity within Phaeoisariopsis griseola isolates from Central America and implication to resistance breeding in beans. G. S. MAHUKU, C. Jara, J. B. Cuasquer, and G. Castellanos. International Center for Tropical Agriculture (CIAT), A.A. 6713, Cali, Colombia. Phytopathology 89:S47. Publication no. P-1999-0337-AMA.

RAPD and virulence markers were used to determine the extent of variation among 70 isolates of Phaeoisariopsis griseola, the cause of angular leaf spot of bean. Multiple correspondence analysis of RAPD patterns assigned isolates to four groups, with a within-group average similarity coefficient of $85 \%$ and $65 \%$ between groups. No apparent relationships were evident between RAPD profiles, race designation and geographical origin of the isolates. Similarly, thirty-seven races were defined on 12 differential bean lines. Fourteen of the races were widely distributed while 23 were unique to a particular country. Cluster analysis of virulence data separated isolates into 
six virulence groups, with a within-group average similarity coefficient of $88 \%$. Interestingly, three isolates overcome the resistance found in our differential lines. When a representative of this race (63-63), was used to inoculate 70 bean materials previously found to posses resistance genes, only 12 were resistant. The results show that extensive variation occurs within $P$. griseola. However, different races can be separated into groups and within each group, there is relatively little variation. Therefore, the most aggressive isolate from each group can be used for an economic and efficient screening of germplasm for resistance against $P$. griseola.

Stump removal to control Armillaria root disease in jack and red pine. K. I. MALLETT, C. L. Myrholm, and D. W. Ip. Natural Resources Canada, Canadian Forest Service, Northern Forestry Centre, 5320122 St., Edmonton, Alberta, Canada T6H 3S5. Phytopathology 89:S48. Publication no. P-19990338-AMA.

A 3 hectare stand of mature jack pine in southeastern Manitoba was found to have a $28 \%$ incidence of mortality due to Armillaria root disease (ARD) caused by Armillaria ostoyae. In 1992 the stand was harvested and a replicated experiment in which stumps were either removed or left was established. Jack or red pine trees were planted across the treatments. The health of trees within the experimental plots were assessed annually for 6 years. The mean cumulative mortality (after 6 years) due to ARD in the un-stumped treatment planted with jack pine was $12.4 \%$ compared to $4.0 \%$ in the stumped treatment. The mean cumulative mortality in the un-stumped treatment planted with red pine was $13.2 \%$ compared to $8.0 \%$ in the stumped treatment.

Bacterial colonization of cuticular mutants of maize. L. M. MARCELL and G. A. Beattie. Iowa State University, Ames, IA. Phytopathology 89:S48. Publication no. P-1999-0339-AMA.

For many bacterial pathogens, large epiphytic populations contribute to a high probability of disease. To study the influence of the plant cuticle on leaf surface populations, we inoculated several maize mutants that are altered in their cuticle, a.k.a. glossy mutants, with Pseudomonas syringae, a pathogen of corn, and Pantoea agglomerans, a corn saprophyte. Of 11 mutants that we characterized for their surface hydrophobicity, extractable cuticular waxes, and wax crystal morphology, we selected 4 for these studies. Results showed that the tightly associated populations, i.e. those not released by sonication, increased dramatically from $2 \%$ to $75 \%$ over 5 days, indicating that bacteria either became fixed to the leaf surface via EPS production, or that colonization of internal spaces increased over time. The mutants all retained greater initial numbers of bacteria than did the wild type. For the saprophyte, the population dynamics were fairly similar on the mutants and the wild type. For the pathogen, the leaf-associated populations decreased faster on the mutants than on the wild type following inoculation, suggesting that increased leaf surface hydrophilicity did not improve colonization as expected.

Sensitivity of a range of phenotypically variable Burkholderia cepacia isolates to copper and non copper-based bactericides. G. L. MARK, N. A. Gundersheim, and J. W. Lorbeer. Cornell University, Ithaca, NY. Phytopathology 89:S48. Publication no. P-1999-0340-AMA.

Burkholderia cepacia exhibits both phytopathogenic and biological control properties, however, some strains have been shown to be opportunistic human pathogens causing nosocomial and fatal lung infections in immunosuppressed individuals. The bacterium was described in 1950 by Burkholder as the causal agent of sour skin in onions. In 1997 the bacterium was implicated as the cause of a canker disease of onion plants in commercial onion fields in New York. Current thinking suggests that application of copperbased bactericides could be employed as a control strategy. However, preliminary screening suggested that $B$. cepacia isolates exhibited significantly more resistance to Kocide LF (a.i. copper hydroxide) at higher concentrations than the copper-resistant control Xanthomonas campestris pv. vesicatoria strain E3 and this was basal medium-dependent. Sensitivity of phenotypically different phytopathogenic B. cepacia isolates to copper-based and non copper alternative bactericides was evaluated in vitro and results are discussed.

Characterization and quantification of Burkholderia cepacia isolated from onions and organic soil previously cropped to onion. G. L. MARK, J. W. Lorbeer, and N. A. Gundersheim. Cornell University, Ithaca, NY. Phytopathology 89:S48. Publication no. P-1999-0341-AMA.

In recent years bacterial diseases of onion have increased in economic significance in New York. Various phytopathogens have been isolated, including Enterobacter cloacae A, Pseudomonas fluorescens, P. aeruginosa, and Pantoea agglomerans. In particular, Burkholderia cepacia has been detected with frequency in recent years, and has been implicated as the causal agent of canker exhibited by field-grown onion plants. B. cepacia has significant importance as a pathogen both clinically and phytopathogenically and as a biological control agent. Characterization of phenotypically distinct $B$. $c e$ pacia isolates, obtained from a range of non-clinical sources, has been conducted. The B. cepacia isolates characterized exhibited a range of onion hostspecific virulence. Population studies, at a range of organic soil locations, have implied that this phytopathogen can exist at high levels in the soil and that this together with variation in strain type could be dependent on agricultural management practices employed, such as crop rotation.

RAPD marker mapping of Coprinus cinereus. A. MAROOFI and B. C. Lu. University of Guelph, Guelph, Ontario, Canada. Phytopathology 89:S48. Publication no. P-1999-0342-AMA

A genetic linkage map for the basidiomycete fungus Coprinus cinereus, was constructed by using random amplified polymorphic DNAs (RAPD).The inheritance pattern of 56 RAPD markers and two polymorphic traits were analysed among recombinant haploid progeny randomly selected from an interstrain cross of two monokaryons. Markers were segregated into ten linkage groups. Linkage maps were constracted for each chromosome. Size of genome estimated to be 524.8 centimorgan haldane, with an average spacing of $10.93 \mathrm{cM}$ between two markers. A mating compatibility locus and 10 markers were mapped to the 10th chromosome, the longest. The banding pattern of RAPD markers were consistent and the method is useful for making a linkage map.

Challenge inoculation of Nicotiana benthamiana plants transformed with the recombinant monoclonal Fab antibody that binds bean yellow mosaic virus (BYMV) coat protein. Clarissa J. M. MAROON, Leslie M. Palmer, Mary Ann Guaragna, and Ramon Jordan. Floral and Nursery Plants Research Unit, U.S. National Arboretum, USDA-ARS, Beltsville, MD. Phytopathology 89:S48. Publication no. P-1999-0343-AMA.

To generate plants that are resistant to BYMV, $N$. benthamiana plants were transformed with murine genes coding for the Fab region of the monoclonal antibody PTY 35 which reacts with at least six out of nine BYMV isolates. Such genes were derived by PCR using primers specific to the heavy chain $\mathrm{Fd}(\mathrm{Fd})$ and light chain (LC) fragments of the Fab region. Both the Fd and LC genes were subcloned into a single, combinatorial bacteriophage lambda immunoexpression vector. Coexpression of the Fd and LC genes from the combinatorial vector in Escherichia coli resulted in rcFab $(55 \mathrm{kDa})$ which reacted with the BYMV coat protein in ELISA. The rcFab gene was subcloned into the plant transformation vector, pGA643, and was introduced into $N$. benthamiana plants via Agro-transformation. Progeny of the rcFabpositive parental lines are currently being evaluated for resistance to BYMV.

Differentiation of xanthomonads pathogenic to tomato and pepper based upon PCR-RFLP of 16S-23S spacer and groEL genes. L. L. R. MARQUES (1), Y. B. Rosato (2), and G. P. Manfio (1). (1) Fundação André Tosello and (2) Universidade Estadual de Campinas, Campinas, SP, Brazil. Phytopathology 89:S48. Publication no. P-1999-0344-AMA.

Xanthomonas campestris pv. vesicatoria is the causal agent of bacterial leaf spot in tomato and pepper. The occurrence of at least two distinct subgroups, A and B (X. axonopodis pv. vesicatoria and X. vesicatoria, respectively), and atypical strains (nonA/nonB) has been demonstrated. Additional groups, $\mathrm{C}$ and $\mathrm{D}$, including some of the atypical non $\mathrm{A} /$ nonB strains have been considered. In the current study a total of 59 strains from the formerly cited groups were analysed, including 32 isolates from Brazil. Molecular markers evaluated comprised RFLP of $16 \mathrm{~S}$ rDNA, 16S-23S rDNA spacer region and RFLP of a fragment of the groEL gene. The results demonstrated that strains of groups A, B and D can be differentiated on the basis of polymorphisms in the 16S-23S rDNA spacer region and groEL gene. Two distinct groEL RFLP groups were detected for 3 Brazilian strains, suggesting the occurrence of additional groups of xanthomonads pathogenic to tomato and pepper in Brazil.

Intranuclear virus-like particles in leaf cells from a source stock of chrysanthemum, Chrysanthemum morifolium L. E. M. MARTIN, S. C. Goeke, R. C. Gergerich, and K. S. Kim. University of Arkansas, Fayetteville. Phytopathology 89:S48. Publication no. P-1999-0345-AMA.

During the screening of chrysanthemum virus B carlavirus (CVB) in chrysanthemum cuttings from a source stock, striking virus-like particles were noticed in leaf cells known to be infected with CVB. They were non-enveloped, spherical particles of $70-80 \mathrm{~nm}$ in diameter, occurring in the nucleus, usually 
embedded in the chromatin. The particles consisted of an electron-dense outer wall of 15-20 nm in width and electron-lucent center containing fibrillar material. A halo encircled each particle, separating it from the chromatin. Occasional particles in the nucleoplasm often had a dense central core. The nucleolus, in the nuclei that contained virus-like particles, exhibited intriguing structural changes; the entire fibrillar zone of the nucleolus was replaced with fine crystalline masses with homogeneous density. However, chromatin located in the fibrillar centers was not crystallized. Based on morphology, size, consistency in occurrence and associated nucleopathic structures, the particles are believed to be viral. Furthermore, their location and association with chromatin indicate that they may be a DNA virus.

Pathogenicity and virulence of Pythium spp. and binucleate Rhizoctonia isolates recovered from California strawberry production fields. $\mathrm{F}$. $\mathrm{N}$. MARTIN. USDA-ARS, 1636 East Alisal, Salinas, CA 93905. Phytopathology 89:S49. Publication no. P-1999-0346-AMA.

A variety of general, nonspecific root pathogens have been recovered from strawberry roots in the central, coastal production area of California. Pythium spp. were the most commonly recovered pathogen with P. ultimum the most commonly isolated species. In total, approximately 20 different species have been recovered, although several of these have been recovered infrequently. One type of isolate that was commonly recovered has a spherical hyphal swelling and does not sexually reproduce, even when paired with known heterothallic species. Based on comparison of mitochondrial molecular markers it is believed that some of these isolates are P. ultimum that have lost the ability to self and the remainder represent several distinct "species groups". A range in virulence is observed among the recovered species, with some having no apparent effect on strawberry. Binucleate Rhizoctonia isolates also were commonly recovered. The most prevalent anastomosis group (AG) was AGA, followed by AGI and AGG. In controlled tests with the variety Selva a range in virulence was observed between these AGs as well as within an individual AG.

Use of organic amendments, botanical aromatics, and rhizobacteria to induce suppressiveness of tomato to the root-knot nematode Meloidogyne incognita. N. MARTINEZ-OCHOA (1), N. Kokalis-Burelle (2), R. Rodríguez-Kábana (1), and J. W. Kloepper (1). (1) Plant Pathology Dept., Auburn University, AL 36849; (2) USDA-ARS, HRL, Ft. Pierce, FL 34945. Phytopathology 89:S49. Publication no. P-1999-0347-AMA.

Experiments were conducted to determine if addition of organic amendments, botanical aromatic compounds, and rhizobacteria to a soil-less substrate, could reduce root-knot nematode in tomato transplants. Seedlings grown in amended mixes were transplanted after 4 weeks and inoculated with nematode eggs. Plant growth and nematode disease were evaluated 30 days later, and compared to a nontreated control. Some of the organic amendment treatments resulted in significant increase of fresh root and top weights. Combinations of one organic amendment with most rhizobacteria reduced nematode galls and increased plant growth significantly. Some combinations of botanical aromatics with rhizobacteria, but not aromatics alone, increased fresh top and root weights. Results suggest that certain combinations of organic amendments, botanical aromatics, and rhizobacteria may lead to plant growth-promotion and induction of suppressiveness to nematodes in a transplant system.

Effect of an organic amendment and a botanical aromatic on bacterial communities of a tomato transplant plug under greenhouse conditions. N. MARTINEZ-OCHOA, R. Rodríguez-Kábana, and J. W. Kloepper. Department of Plant Pathology, Auburn University, Alabama 36849. Phytopathology 89:S49. Publication no. P-1999-0348-AMA.

Preliminary studies have been conducted to test natural compounds incorporated into a peat-based growing mix as possible control treatments for diseases of tomato. The objective of this research was to test the effect of these compounds as microbial selectors. Certain bacterial communities were monitored, by spiral plating the tomato transplant plugs during a five week period. Populations of chitinolytic, proteolytic, gram positive, and gram negative bacteria were recorded weekly using selective and differential media. Actinomycetes, heat-tolerant, and total bacteria were also quantified. Over time most populations remained constant at 6-8 $\log \mathrm{cfu} / \mathrm{g}$ plug, except the heattolerant bacteria, which increased the first two weeks from 4 to $6 \log$ with the amendment alone, and from 4 to $7 \log$ with the amendment plus botanical aromatic. The soil-less mix contained an initial number of most of the monitored bacterial populations, and several significant differences were observed when comparing populations in treated and nontreated plugs at each point in time.
Plow pan microcosms for VBNC state of biocontrol Pseudomonas fluorescens CHAO. F. Mascher (1), Y. Moënne-Loccoz (2), and G. DÉFAGO (1). (1) Phytopathology, ETH Zürich, Switzerland; (2) Université Claude Bernard (Lyon 1), Villeurbanne, France. Phytopathology 89:S49. Publication no. P-1999-0349-AMA.

Biosafety considerations about persistence and non-target effects hinder the use of biocontrol bacteria in agriculture. Field experiments have shown that the biocontrol agent $P$. fluorescens CHA0-Rif enters a viable but non-culturable (VBNC) state at the water-soaked plow pan. In this study, we reconstructed the microaerobic and reducing environment of a plow pan in soil microcosms. In microcosms with a redox potential of $-54 \mathrm{mV}$ (soil amended with freshly-cut Lolium perenne and flooded with water), $10^{4}$ to $10^{5}$ cells of CHA0-Rif per g soil were in a VBNC state at 60 days. VBNC cells displayed intact plasmic membranes as indicated by the results of a modified LIVE/DEAD BacLight test (Molecular Probes). VBNC cells were not found in soils with low redox potential $(-100 \mathrm{mV}$; flooded soil without organic amendment). These plow pan microcosms were used also to assess the role of regulatory genes in the occurrence of VBNC cells of the strain.

Development of stem lesions on pepper plants inoculated with Phytophthora capsici after treatment with acibenzolar-S-methyl. M. E. MATHERON and M. Porchas. Yuma Agricultural Center, University of Arizona, Yuma, AZ 85364. Phytopathology 89:S49. Publication no. P-1999-0350AMA.

Experiments were initiated to evaluate the effect of foliar applications of acibenzolar-S-methyl (CGA-245704, Actigard) on growth of stem cankers on pepper plants inoculated with Phytophthora capsici. Leaves and stems of two bell pepper (Bell Tower and Emerald Isle) and chile pepper (AZ 9 and AZ 20) cultivars were sprayed four times at 7-day intervals with $300 \mathrm{mg}$ a.i. of acibenzolar-S-methyl/liter of water. These 5-month-old plants were inoculated 7 days after the last treatment by placing a 5 -mm-diameter V8-juice agar disk containing mycelium of $P$. capsici onto a similar sized wound on the plant stem and securing the disk to the wound with plastic tape. Twenty days after inoculation, resultant lesions on each pepper cultivar treated with acibenzolar-S-methyl were 90 to $96 \%$ smaller than lesions on nontreated plants. A subsequent study revealed that the reduction in stem canker length compared to nontreated plants on 4-month-old Bell Tower and AZ 9 peppers receiving from one to four applications of acibenzolar-S-methyl ranged from 80 to $93 \%$ and did not differ significantly.

Insensitivity of Phytophthora capsici to mefenoxam in Georgia. W. L. MATHIS, J. Williams-Woodward, and A. S. Csinos. Dept. of Plant Pathology, University of Georgia, Athens 30602. Phytopathology 89:S49. Publication no. P-1999-0351-AMA.

Phytophthora blight, caused by the pathogen Phytophthora capsici, was first observed in Georgia in 1994. Economic losses have occurred in cucurbit, pepper, and eggplant fields throughout the state. Collection of field isolates began in 1997 following reports of metalaxyl (mefenoxam) failure in infested fields. Laboratory testing of $P$. capsici isolates was conducted by amending V8-juice agar with $0,0.1,1.0,5.0,10.0$, and $100 \mathrm{ppm}$ mefenoxam (Ridomil Gold) on replicate plates. Isolates have been divided into three groups: sensitive, intermediate, and insensitive based on $\mathrm{ED}_{50}$ values and diametrical grown on amended plates in comparison to the control. Laboratory insensitivity was confirmed by greenhouse inoculation of 1- to 2-week-old squash plants following application of mefenoxam at 1 pint and 2 pints per acre rates. Insensitive isolates tested in the presence of mefenoxam were not significantly different from control inoculated plants.

Biological approaches to controlling zoosporic fungi in re-circulating irrigation systems. P. W. MATTHEWS and J. W. Deacon. University of Edinburgh, UK. Phytopathology 89:S49. Publication no. P-1999-0352-AMA.

Manipulation of cation concentrations and the addition of natural lysing chemicals suppress the multi-stage zoosporic infection sequence in vitro. The susceptibility of five stages of the infection sequence of Phytophthora parasitica and Pythium aphanidermatum to various concentrations of $\mathrm{Ca}^{2+}, \mathrm{Mg}^{2+}$ and $\mathrm{K}^{+}$was evaluated for each stage and cumulatively. $\mathrm{K}^{+}$was the most effective at suppressing zoospore release and zoospore motility whereas $\mathrm{Ca}^{2+}$ was the most effective at suppressing mycelial growth and in promoting the germination of cysts. Both gramicidin, a cyclic oligopeptide from Bacillus brevis, and beta-escin, a saponin from Aesculus hippocastanum, lyse wallless motile zoospores but have less effect on walled cysts. Other promising approaches investigated include the suppressive effect of ethanol on zoosporangiogenesis and the natural suppressiveness of semi-commercial, recycled nutrient irrigation solutions. Various combinations of these approaches exhibit both antagonism and synergism. 
Development and evaluation of benzothiadiazole (BTH) treatment for fire blight based on PR protein expression in apple. K. L. MAXSON and A. L. Jones. Michigan State University, East Lansing 48824. Phytopathology 89:S50. Publication no. P-1999-0353-AMA.

The time interval required for BTH to induce systemic acquired resistance (SAR) in apple was determined in order to optimize BTH treatment timing for fire blight. Portions of three genes encoding pathogenesis-related proteins (PR-1, PR-2, PR-8) were sequenced so that specific DNA probes could be designed. The probes were used on Northern blots to individually quantify the expression of each PR protein at designated times after apple seedlings were treated with the SAR inducing chemical, BTH (Actigard). The time period required for the SAR response was determined based on PR protein mRNA expression. This time period should provide an optimum treatment interval for a BTH spray schedule, thereby maintaining a high and continuous SAR response. Data on the time course of SAR induction are being used in the field as a timing aid in establishing the efficacy of BTH treatments for apple fire blight control.

Inheritance of pathogenicity in Phytophthora infestans. H. Mayton, C. D. Smart, B. Moravec, and W. E. FRY. Department of Plant Pathology, Cornell University, Ithaca, NY 14853. Phytopathology 89:S50. Publication no. P-1999-0354-AMA.

In an attempt to understand the epidemiological implications of sexual recombination in $P$. infestans, we evaluated the pathogenicity of a segregating population of progeny. The parental strains were an isolate of US-17 (A1, generally found in tomato fields) and an isolate of US-8 (A2, generally found in potato fields). Fifty-three progeny were obtained, characterized using neutral markers, and analyzed for pathogenicity on both tomato and potato leaflets. Almost all progeny could infect both hosts, however some were more aggressive than others. About 1/3 of the progeny were indistinguishable from the parental isolates on detached leaflets. A subset of 10 of the A2 mating type progeny (ranging from weak to strong pathogens in detached leaflet assay) were also inoculated onto potato and tomato field plots and compared with the pathogenicity of US-8 and US-7 (both A2 strains). All of the 10 progeny were very weakly pathogenic on both potato and tomato, and were displaced by the two field isolates (US-7 and US-8) within 10 days. We hypothesize that sexual progeny are generally less fit in an agroecosystem than the parental strain.

Impact of biological, cultural and narrow-spectrum biocide treatments on growth of apple in orchard replant soils. M. MAZZOLA (1), D. C. Elfving (2), and D. M. Granatstein (2). (1) USDA-ARS, Wenatchee, WA; (2) Washington State University, Wenatchee, WA. Phytopathology 89:S50. Publication no. P-1999-0355-AMA.

Biological, cultural and chemical controls were examined for the ability to promote growth of apple in replant soils. Specific measures were selected for evaluation based on studies that demonstrated the primary role of a fungal complex in development of apple replant disease in Washington. Soil incorporation of fungicides with activity against pythiaceous fungi or Rhizoctonia solani AG 5 enhanced growth of apple in replant soils in greenhouse trials. Application of the same fungicides as a soil drench failed to promote tree growth in field trials. Microbial analysis indicated that soil drench applications failed to reduce apple root infection by the target pathogens. Pseudomonas putida strain $2 \mathrm{C} 8$ enhanced growth of apple in replant soils in greenhouse and field trials. Establishing trees in the previous orchard aisle, rather than the old orchard row, significantly improved tree growth. Excavation of soil in the fall prior to orchard establishment was as effective as methyl bromide fumigation in promoting tree growth and reducing root infection by plant pathogenic fungi.

Manipulation of soil microbial communities through short-term wheat cropping to enhance growth of apple in replant soils. M. MAZZOLA and Y.-H. Gu. USDA-ARS, Wenatchee, WA. Phytopathology 89:S50. Publication no. P-1999-0356-AMA.

The impact of short-term rotations of wheat on microbial community composition and growth of apple in replant soils was assessed in greenhouse and field trials. Soils from the CV and WVC orchards, located $19.2 \mathrm{~km} \mathrm{~N}$ and 6.4 $\mathrm{km} \mathrm{E}$ of E. Wenatchee, WA, respectively, were cultivated to three successive 28-day wheat growth cycles in the greenhouse, and subsequently planted to apple. Cultivation of soil to 'Eltan', 'Penewawa' or 'Rely' wheat enhanced growth of apple in both soils. Wheat cultivation prior to planting apple resulted in a reduction in apple root infection by species of Rhizoctonia, Pythium and Cylindrocarpon, and reduced populations of Pratylenchus spp. Growth of apple in 'Penewawa' cultivated soils typically was superior to that observed for the other wheat cultivars. Wheat cultivation resulted in suppres- sion of Rhizoctonia root rot of apple caused by an introduced isolate of $R$. solani AG 5, and was associated with enhanced populations of Pseudomonas putida. Similar growth results and changes in soil microflora were observed in greenhouse trials using soil that was cultivated to three plantings of 'Eltan' at the $\mathrm{CV}$ orchard over a period of one year.

Diversity in species composition and sensitivity to metalaxyl among populations of Pythium from apple. M. MAZZOLA (1) and C. Andre Levesque (2). (1) USDA-ARS, Wenatchee, WA; (2) Agriculture and Agri-Food Canada, Summerland, BC. Phytopathology 89:S50. Publication no. P-1999-0357AMA.

Studies were conducted to characterize the diversity of Pythium species associated with apple and relative sensitivity of these fungi to metalaxyl, a material commonly utilized in orchard systems to control Phytophthora crown rot. Fourteen different species were identified among isolates of Pythium recovered from apple at six orchards in Washington. Frequently isolated species included $P$. intermedium, P. irregulare, $P$. heterothallicum, and $P$. sylvaticum. P. sylvaticum was the dominant species recovered from apple roots at the two orchard sites exhibiting symptoms of apple replant disease. $\mathrm{EC}_{50}$ values for metalaxyl ranged from 0.08 to $5.77 \mu \mathrm{g} / \mathrm{ml}$. Isolates belonging to what is likely a new species related to $P$. vexans were insensitive to metalaxyl while isolates of $P$. sylvaticum exhibited the greatest range of sensitivities, which appeared to vary in a site-specific manner. Composition of Pythium populations in adjacent conventional and organic blocks in two orchards did not differ, however the relative recovery of Pythium spp. was consistently lower in the organically managed systems.

An Aspergillus flavus NRRL 3357 mutant producing synnemata and stipitate sclerotia. C. E. MCALPIN. USDA, REE, ARS, MWA, National Center for Agricultural Utilization Research, Peoria, IL 61604. Phytopathology 89: S50. Publication no. P-1999-0358-AMA.

The ability to produce stipitate sclerotia and synnemata by a mutant culture derived from Aspergillus flavus NRRL 3357 is reported for the first time. Stipitate sclerotia were observed on Czapek agar (CZA) while synnemata formed on Murashige-Skoog agar (MSA) and on oats agar. Temperature, light and $\mathrm{pH}$ greatly influenced sclerotia and synnemata formation. Sclerotia were abundant when the carbon source in CZA was replaced with dextrose, fructose, melibiose or xylose whereas MSA amended with fructose, mannitol or sorbitol produced numerous synnemata. Sclerotial yield was affected by the nitrogen source and $\mathrm{C}: \mathrm{N}$ ratio of the growth medium. The production of synnemata and stipitate sclerotia by this mutant substantiates the view for an evolutionary link between A. flavus and Stilbothamnium togoense, a tropical fungus that forms these same structures. A single weak band was detected when the genomic DNA of $S$. togoense was fingerprinted using the DNA probe derived from A. flavus, suggesting some degree of relationship between these two fungi.

Band fumigation improves carrot quality with reduced rates of fumigant. M. R. MCDONALD, K. Vander Kooi, and S. Janse. University of Guelph, Department of Plant Agriculture, Muck Crops Research Station, 1125 Woodchoppers Lane, R.R. 1, Kettleby, ON, Canada L0G 1J0. Phytopathology 89: S50. Publication no. P-1999-0359-AMA.

Soil fumigants are applied regularly at rates of $110-220 \mathrm{~L} /$ ha to reduce nematode damage on carrots grown on muck soil. The effectiveness of applying fumigant $20 \mathrm{~cm}$ below the carrot seed in a raised bed was evaluated using Telone II (1,3-dichloroprene, 34 and $57 \mathrm{~L} / \mathrm{ha}$ ) and Telone C-17 (dichloropropene and chloropicrin, $34 \mathrm{~L} / \mathrm{ha}$ ). Plots were established in a commercial field as a paired $T$-test with adjacent treated and untreated areas with four reps (nematode populations) or light reps (carrot quality assessment) per treatment. Soil samples were taken on $3 \mathrm{Jul}$ and at harvest on 14 Oct. Roots were assessed at harvest. Counts of root lesion nematodes (Pratylenchus penetrans) were lower in plots treated with Telone II at $57 \mathrm{~L} / \mathrm{ha}(527 / \mathrm{kg})$ than in untreated plots $(2954 / \mathrm{kg})$ in July but not at harvest. This treatment and Telone C-17 also reduced symptoms associated with high root lesion nematode populations. All treatments reduced the percentage of forked carrots but none affected cavity spot. Band fumigation can improve carrot quality with low rates of fumigant.

Comparison of predictive models for downy mildew infection of grape. W. MCFADDEN-SMITH. University of Guelph, Vineland Station, Ontario, Canada L0R 2E0. Phytopathology 89:S50. Publication no. P-1999-0360AMA.

DMCAST and DMODEL were tested for their ability to predict infection periods of downy mildew (Plasmopara viticola) and reduce the number of 
fungicide sprays on Vitis labrusca (cv. Niagara) and V. vinifera (cv. Chardonnay). Plots were sprayed after infection periods were predicted by models and a 14-day spray interval was followed despite the occurrence of infection periods during that time. Incidence and severity of downy mildew on leaves were compared in plots sprayed protectantly or according to models and in unsprayed checks. The first primary infection period occurred during the first wet period after the vines had reached EL growth stage 12 in both years. Both models accurately predicted primary infection periods for both varieties, but were over-conservative for Niagara for the latter part of the season. Delaying sprays until 2 secondary infection periods had occurred improved the accuracy of predictions in Niagara in 1997. Downy mildew incidence was similar among the 3 sprayed treatments for both varieties and less than the check. Fewer sprays were applied in the Chardonnay ( 2 sprays) and in the Niagara (1 spray) using the models compared to the protectant program.

Characterization of pEA29, the ubiquitous plasmid of Erwinia amylovora, by sequence analysis. G. C. MCGHEE and A. L. Jones. Michigan State University, East Lansing 48824. Phytopathology 89:S51. Publication no. P-1999-0361-AMA.

All natural strains of Erwinia amylovora characterized to date contain a 29 -kb plasmid previously mapped by restriction digest analysis. This plasmid is widely used for identification of E. amylovora, however little is known about the role of pEA29 in E. amylovora. Restriction fragments of pEA29 from E. amylovora strain Ea88 were cloned and sequenced. The sequence was analyzed and a genetic map of pEA29 was generated using homology to existing Genbank entries. The plasmid contained 28,188 bp and open reading frames (ORFs) coding for choline transport, succinic semialdehyde dehydrogenase, the thiG gene, and a portion of transposon TN2501. Further analysis is under way to characterize other ORFs. Plasmid cured strains of Ea88, Ea110, and MR1 lacked the ability to utilize 4-amino-n-butyric acid as a nitrogen source as compared to the parental strains. All cured strains grew on media without thiamine. Sequence and restriction analysis also revealed that E. amylovora possesses a methylation system similar to the dam methylation system in Escherichia coli.

Rhizoctonia leguminicola and its reclassification as an ascomycete. M. E. McGINN (1), C. M. Liddell (2), and S. P. Fernandez-Pavia (1). (1) Dept. Entomology, Plant Pathology and Weed Science, New Mexico State University, Las Cruces, NM 88003; (2) Paradigm Genetics, Research Triangle Park, NC 27709. Phytopathology 89:S51. Publication no. P-1999-0362-AMA.

Rhizoctonia leguminicola, a fungal pathogen of red clover and other legumes, has previously been classified as an anamorph of a theoretical Basidiomycete holomorph. However, our studies have provided strong support that this fungus is actually an Ascomycete that has been misclassified. Four different isolates of $R$. leguminicola were obtained from Wisconsin, North Carolina, Alberta, Canada, and ATCC (\#26280). Portions of the small subunit ribosomal gene (18s) and its flanking internal transcribed spacer (ITS 5-4) from these four isolates were sequenced and analyzed to better characterize and classify this pathogen. Homology searches with these sequences showed a high degree of homology with fungi in the phylum Ascomycota, order Dothideales, while no similarities were found with Basidiomycetes. Multiple sequence alignments indicate that this fungus may belong to a novel family in the Dothideales. However, other conserved regions in the R. leguminicola genome will be sequenced and analyzed to confirm these results.

Impact of powdery mildew on field-grown, fresh-market tomatoes. M. T. MCGRATH. Cornell University, Riverhead, NY. Phytopathology 89:S51. Publication no. P-1999-0363-AMA.

Powdery mildew (PM) developed naturally on staked tomatoes in experiments designed to test Tom-Cast in 1997 and 1998. Symptoms were first observed on 8/14/97 and 8/3/98, which were 65 and 55 days after transplanting, respectively. Leaf death due to PM on untreated plants was $60 \%$ on $9 / 9 / 97$ and 9/1/98. Treatments were initiated 33 and 35 days after transplanting when 37-38 disease severity values (DSV) had accumulated. Chlorothalonil (Bravo Ultrex at 1.7-3.1 kg/ha) controlled PM well on upper but not lower leaf surfaces. This fungicide applied according to Tom-Cast (threshold of 15 DSVs) with 7 and 9 sprays was as effective as a weekly spray program with 12 and 11 sprays in 1997 and 1998, respectively. An alternation of Bravo and azoxystrobin (Quadris at $365 \mathrm{ml} / \mathrm{ha}$ ) applied according to TomCast provided excellent control of PM and the greatest yield. Number of medium to extra large ripe fruit harvested per plant in 1998 was 28 for untreated plants, 37 for plants sprayed weekly with Bravo, 35 for plants sprayed with Bravo according to Tom-Cast, and 43 for plants sprayed with Bravo/ Quadris. Many of the fruit from untreated plots were of poor quality (yellowish red color and sunburnt).

Plant parasitic nematodes associated with cotton production in the delta region of Louisiana. K. S. MCLEAN (1) and G. W. Lawrence (2). (1) Auburn University, Auburn, AL; (2) Mississippi State University, Mississippi State, MS. Phytopathology 89:S51. Publication no. P-1999-0364-AMA.

Six Louisiana delta parishes were surveyed for plant-parasitic nematodes associated with cotton production. In 1997 and 1998, soil samples were collected from 45 cotton fields representing 15,500 acres. Each soil sample was a composite of 20 acres. Nematodes were extracted by gravity screening and sucrose centrifugation and identified to genus. Ten genera of plant-parasitic nematodes were identified. The reniform nematode (Rotylenchulus reniformis) was identified in $61 \%$ or 9,490 acres. The mean reniform population was 12,959 juveniles and adults per $500 \mathrm{cc}$ of soil with $49 \%$ of the samples containing populations above the economic threshold. The root-knot nematode (Meloidogyne incognita) was identified in $20 \%$ or 3,123 acres. The mean root-knot population was 989 juveniles per $500 \mathrm{cc}$ of soil with $21 \%$ of the samples containing populations above the economic threshold. The lesion nematode (Pratylenchus spp.) and lance nematode (Hoplolaimus magnistylus) were identified in $5.0 \%$ or 884 acres and $2.5 \%$ or 398 acres respectively.

Web blight, a foliar disease of New Guinea impatiens. R. T. MCMILLAN, Jr., S. V. Johnson, and W. R. Graves. University of Florida, TREC, Homestead, FL. Phytopathology 89:S51. Publication no. P-1999-0365-AMA.

An outbreak of a foliar disease of New Guinea impatiens, Impatiens hawkeri Bull, was observed in a commercial nursery in south Florida in the late summer and early fall of 1998. Symptoms on two-month-old plants were watersoaked leaf spots increasing rapidly in size and became light to dark brown necrotic areas. Rhizoctonia was isolated from infected leaves and stems on corn meal agar with $100 \mathrm{mg}$ of chloramphenicol per liter, subcultured on half strength potato-dextrose agar and identified as Thanatephorus cucumeris (Frank) Donk (anamorph Rhizoctonia solani Kuehn). Six plants were inoculated with $3 \times 3 \mathrm{~mm}$ agar blocks containing the isolate and 6 control plants received agar blocks without the pathogen. All plants were placed in a modified humidity chamber in a greenhouse at $27^{\circ} \mathrm{C}$ for $72 \mathrm{hr}$. The disease symptoms appeared as water soaked spots $100 \mathrm{~mm}$ in diameter that enlarged to 25 $\mathrm{mm}$ or more, turning dark brown. A whitish mycelium web grew over the leaves and stems, with small brown sclerotia, typical of the disease symptoms found on the infected nursery plants. Thanatephorus cucumeris was consistently re-isolated from all the inoculated plants.

Isolation and characterization of phytoalexins produced by long English cucumber. D. MCNALLY, K. Wurms, C. Labbé, and R. R. Bélanger. Département de Phytologie, Université Laval, Québec, Canada G1K 7P4. Phytopathology 89:S51. Publication no. P-1999-0366-AMA.

Recent findings suggest that phytoalexins are induced within the leaves of long English cucumber following an eliciting treatment. Although two such compounds have been identified to date, it is suspected that several others remain uncharacterized. In order to verify this hypothesis, a bioassay-guided fractionation of methanolic extracts of cucumber leaves treated with an elicitor and infected with powdery mildew was performed. Reverse phase chromatography and HPLC analysis was used to fractionate crude extracts, and germination inhibition assays were used to assess the fungitoxicity of each fraction. This procedure has led to the observation that some compounds with antifungal activity display an important increase in concentration synchronized with a lower disease incidence. These fungitoxic compounds have been purified and collected using column chromatography and preparative HPLC. Analytical methods are being developed to obtain the chemical structure of these compounds. The results of this research will provide novel and much needed information regarding chemical defenses within cucurbits.

Distribution of thrips on flue-cured tobacco and impact on the incidence of spotted wilt in Georgia. Robert M. McPherson (1), H. R. PAPPU (2), and David C. Jones (1). (1) Dept. of Entomology and (2) Plant Pathology, Univ. of Georgia, Tifton, GA 31793. Phytopathology 89:S51. Publication no. P-19990367-AMA.

Flue-cured tobacco fields were surveyed from 1989 to 1991 and 1996 to 1998 to determine the incidence of tomato spotted wilt Tospovirus (TSWV), and the species composition of thrips in Georgia. Five species were commonly encountered all six years and accounted for over $95 \%$ of the 17,000 thrips collected. These included Frankliniella fusca, F. occidentalis, F. bispinosa, F. 
tritici, and Limothrips cerealium. The first three are reported as vectors of TSWV. F. fusca was the most common foliage thrips collected in all years, except 1989, when L. cerealium was the most abundant. In 1989, $22 \%$ of the foliage thrips and $64 \%$ of the flower thrips were found to be vector species. These percentages remained around $60-65 \%$ for both foliage and flower collections in 1990 and 1991. The 1996-1998 foliage collections had a much higher percentages of vector species $(95 \%-97 \%)$ than in the earlier years. A trend in higher incidence of TSWV in Georgia flue-cured tobacco occurred in the past three seasons. Thrips species reported to vector TSWV also comprise a much higher percentage during this same time period.

Evaluating decision tools in disease management. N. MCROBERTS (1) and G. Hughes (2). Plant Biology Department, SAC Auchincruive, Ayr KA6 5HW, Scotland, UK; (2) Institute of Ecology and Resource Management, University of Edinburgh, Edinburgh EH9 3JG, Scotland, UK. Phytopathology 89:S52. Publication no. P-1999-0368-AMA.

Decision making is a key component of disease management. A variety of different types of decision tool are now available to help decision makers in assessing the need to take action in disease management. A valuable decision tool will allow the decision maker to identify successfully those crops in which action must be taken, while guarding against taking action when it is not required. We discuss the use of the Receiver Operating Characteristic (ROC) curve, widely used in clinical scales testing, for evaluating the performance of any type of decision tool, and discuss complications that arise in transferring the method from the medical to the phytopathological context. The phytopathological context contains an important extra source of uncertainty that is not present in the medical context. In the typical medical examples, the true disease status of each individual can be determined independently of the diagnostic scale which is being evaluated and hence the classification of cases and controls can be fixed relative to this independent assessment. In the phytopathological context, cases and controls are typically defined only in relation to some threshold level, and thus the classification of cases and controls varies with the threshold chosen. An example based on fungicide requirements for controlling eyespot disease in wheat is given.

Genomic variation in Clavibacter michiganensis subsp. michiganensis provides a new understanding of bacterial canker of tomato. C. M. MEDINA-MORA (1), N. Werner (1), J. Bell (1), M. Hausbeck (1), F. J. de Bruijn (2), and D. W. Fulbright (1). (1) Dept. Botany and Plant Pathology; (2) PRL-DOE, Michigan State University, East Lansing, MI 48824. Phytopathology 89:S52. Publication no. P-1999-0369-AMA.

Polymerase chain reaction protocols (rep-PCR) using REP, ERIC, and BOX primers resolved five different genotypes of Clavibacter michiganensis subsp. michiganensis. A fourth primer, (GTG)5 revealed further genetic variability and divided each of the genotypes into subgroups. For example, the absence of polymorphic bands in BOX fingerprint type A strain suggested that this group is of low genetic diversity. However, cluster analysis of combined (GTG)5- and BOX-PCR fingerprint patterns of type A revealed 3 subgroups among these isolates. Variability observed with (GTG) 5 has also been useful in determining whether or not specific isolates are found in the same location over time. For example, BOX-PCR fingerprint type D has only been found in two locations in Michigan. Cluster analysis of combined (GTG)5- and BOXPCR fingerprint patterns has indicated that new subgroups of D type genotype are found each year in these locations, potentially indicating that new introductions are made each year.

Formation of infection cushions by Sclerotinia minor on a cellophane membrane in response to peanut stems from resistant and susceptible cultivars. H. A. MELOUK (1) and S. S. Aboshosha (2). (1) USDA-ARS, Entomology and Plant Pathology, Oklahoma State University, Stillwater, OK 74078; (2) Dept. of Plant Pathology, College of Agriculture, Alexandria, Egypt. Phytopathology 89:S52. Publication no. P-1999-0370-AMA.

Four peanut shoots $(12 \mathrm{~cm})$, from 8 -wk-old plants, were placed in a water moistened cellophane bag, which was placed upright in a styrofoam cup (177 $\mathrm{ml}$ ca.) filled with $15 \mathrm{~g}$ perlite. One hundred $\mathrm{ml}$ of fragmented S. minor mycelial suspension ( $1 \mathrm{~g}$ mycelia; fresh wt.) was added to each cup. Cups were placed in a humidity chamber at $100 \%$ RH for 5 days at 27 C. Cellophane bags were then carefully lifted, and outer surface of the cellophane facing the perlite was gently rinsed with cold running tap water for $2 \mathrm{~min}$. Ten, $1 \mathrm{~cm}^{2}$ sections of the cellophane were placed on slides with the inner surface of the cellophane contacting the glass. Squares were stained with lactophenol cotton blue for $3 \mathrm{~min}$, mounted in a glycerin gel, and infection cushions (IC) counted. IC $/ \mathrm{cm}^{2}$ of cellophane was 3.8 in response to Okrun, a Sclerotiniasusceptible peanut cultivar, whereas the IC in response to Southwest Runner, a Sclerotinia-resistant peanut was 2.7 with an $\mathrm{LSD}_{0.05}$ of 0.5 .
Effect of plant sanitation on marketable yield and Botrytis fruit rot of strawberry. J. C. MERTELY, C. K. Chandler, K. C. Burke, and D. E. Legard. Univ. of Florida, GCREC, Dover, FL. Phytopathology 89:S52. Publication no. P-1999-0371-AMA.

Replicated field trials were conducted to evaluate the effects of strawberry plant sanitation on marketable yield and fruit rot caused by Botrytis cinerea in Florida. Sanitation was compared to chemical control (e.g., a conventional weekly captan program plus four iprodione bloom sprays) and combined sanitation/fungicide treatments. In 1995-1996, the incidence of Botrytis fruit rot (BFR) was significantly higher in the sanitation treatment, but yield was not reduced. In 1996-1997, yields in the fungicide treatments $(22,000$ $25,400 \mathrm{~kg} / \mathrm{ha}$ ) were significantly higher than in foliar, fruit, or combined sanitation treatments $(18,800-19,500 \mathrm{~kg} / \mathrm{ha})$, and BFR incidence was significantly lower (2.8-3.8\% compared to $8.2-11.0 \%)$. Results from the ongoing 1998-1999 experiment appear similar to 1996-1997. In these experiments, sanitation alone was inferior to fungicides and ineffective in controlling BFR. Supplementing fungicides with sanitation did not improve disease control or increase yield under Florida conditions.

Nematode-antagonistic activity of compounds produced by fungi associated with soybean cyst nematode. S. L. F. MEYER (1), R. N. Huettel (1), X.-Z. Liu (2), R. A. Humber (3), J. Juba (4), D. J. Chitwood (1), and J. K. Nitao (1). (1) USDA-ARS Nematology Lab, Beltsville, MD 20705; (2) Inst. of Biol. Control, Chinese Acad. of Agri. Sci., Beijing 100081 China; (3) USDA-ARS Plant Protec. Res. Unit, Ithaca, NY 14853; (4) Fusarium Res. Ctr, Penn. State Univ., Univ. Park, PA 16802. Phytopathology 89:S52. Publication no. P-1999-0372-AMA.

Fungi (ca. 250 isolates) were obtained from soybean cyst nematode (SCN; Heterodera glycines) eggs in China. These isolates were assayed for production of compounds antagonistic to SCN and root-knot nematode (RKN; Meloidogyne incognita). To conduct the assays, the fungi were cultured in potato dextrose broth, fungal biomass was removed, and nematode eggs were placed in the culture broths. Mobility of hatched second-stage juveniles (J2) and numbers of hatched eggs were then recorded. Of the 250 culture broths, four suppressed egg hatch of SCN by $80 \%$ or more compared to controls, and 15 suppressed RKN egg hatch by that amount. J2 mobility was inhibited in few of these culture broths. Active compounds are being isolated from culture broths of Fusarium equiseti and a second fungal species.

Presence and incidence of root rot diseases on wheat and maize in a longterm conservation tillage trial in the highlands of Mexico. M. MEZZALAMA, K. D. Sayre, P. R. Grace, and H. J. Dubin. CIMMYT, AP 6-641, 06600 Mexico D.F., Mexico. Phytopathology 89:S52. Publication no. P-19990373-AMA.

In 1998 we measured the presence and incidence of root rot diseases in a long-term conservation tillage trial begun in 1991 on the CIMMYT experiment station at El Batán $(2,240$ masl, mean rainfall $600 \mathrm{~mm})$. Sixteen treatments combining continuous wheat and maize, a wheat-maize rotation, conventional or zero tillage, and residue retention or removal were monitored. The pathogens most frequently isolated from wheat roots were: Fusarium spp., Bipolaris sorokiniana and Helminthosporium spp. The lowest disease incidence on roots was found in continuous wheat under zero tillage with full residue retention. The best yields occurred in the wheat-maize rotation with zero tillage and full residue retention. Fusarium spp., Pythium spp., Rhizoctonia spp., and Macrophomina spp. were isolated from maize roots. The incidence of root rot was lowest in continuous maize under conventional tillage with residue removal. High maize yields occurred for maize in rotation with wheat with conventional tillage and full residue retention. Crop residue management is essential in the adoption of conservation tillage in this area.

Stewart's wilt reactions of food grade white corn and kernel infection by Erwinia stewartii. P. M. MICHENER, J. K. Pataky, and D. G. White. University of Illinois, Urbana, IL. Phytopathology 89:S52. Publication no. P-19990374-AMA.

Seventy-eight food grade white corn hybrids and 18 dent and sweet corn hybrids were evaluated in 1998 for reactions to Stewart's wilt and for kernel infection by E. stewartii. The experimental design was an RCB with four replicates. Plants were inoculated 4 times from 3- to 6-leaf stage and rated 3 and 6 wks after inoculation using a 1 (trace of disease) to 9 (dead plant) scale. Means for Stewart's wilt ratings ranged from 1.3 to 5.7 (grand mean 2.3). Ratings were less than 3 (resistant) for 76 of the 78 white hybrids. Ears were harvested from 10 plants per plot, air-dried, shelled, and kernels bulked. Four 25-kernel samples from each experimental unit (plot) were assayed by ELISA. Kernels from 33 plots representing 16 hybrids tested positive for $E$. 
stewartii. Kernel infection ranged from $0 \%$ to $15.8 \%$ for the 16 hybrids based upon 925 -kernel samples and from $0 \%$ to $33.5 \%$ for the 33 plots. Hybrids with kernel infection greater than 5\% had Stewart's wilt ratings greater than 4.5 (i.e. systemic infection). Hybrids with kernel infection below 5\% had ratings ranging from 1.8 to 4.5 .

Management of Septoria leaf blight of parsley with fungicides and efficacy of a disease predictive model. S. A. MILLER (1), G. C. Colburn (1), and W. B. Evans (2). (1) Dept. Plant Pathology; (2) Dept. of Horticulture and Crop Science, OARDC, The Ohio State University, Wooster, OH. Phytopathology 89:S53. Publication no. P-1999-0375-AMA.

Septoria leaf blight of parsley, caused by Septoria petroselini, first appeared in Ohio in 1996. Resulting reductions in quality led to revenue losses as high as 50\% in 1996 and 1997. Both flat and curly parsley are susceptible to the disease. In a 1997 field trial, the popular flat leaf variety 'Dark Green Italian' was significantly more susceptible than the curly leaf variety 'Forest Green'. In the same trial, application of azoxystrobin (Quadris 2.08F), chlorothalonil (Bravo Weather Stick) and thiophanate-methyl (Topsin M $70 \mathrm{~W}$ ) significantly reduced disease in both varieties. In 1998, Quadris was applied on a 7to 10-day calendar schedule (five applications) or according to the accumulation of disease severity values (DSVs) in the TOMCAST disease forecasting model (two applications). SkyBit weather data were used to calculate DSVs. Septoria leaf blight was significantly reduced in both treatments compared to the untreated control.

Multiplex PCR ELISA detection of Clavibacter michiganensis subsp. sepedonicus in potato core fluid. D. MILLS and B. W. Russell. Dept. Botany and Plant Pathology, Oregon State University, Corvallis, OR 97331-2902. Phytopathology 89:S53. Publication no. P-1999-0376-AMA.

Multiplex PCR ELISA detection of C. m. subsp. sepedonicus (Cms), the causal agent of bacterial ring rot of potato, was evaluated in potato core fluid from cultivar Russet Burbank to precisely control serially diluted inoculum and simulate a diagnostic clinic setting. Detection was accomplished using three primer sets that prime the amplification of three single copy sequences, Cms50, Cms72 and Cms85, found only in Cms mucoid and non-mucoid colony-forming strains. Biotinylated capture probes designated $\mathrm{Cp} 50, \mathrm{Cp} 72$ and Cp85 were used to retrieve digoxigenin (DIG-11-dUTP) labeled amplified DNA and anchor it to a streptavidin-coated microtiter well. Peroxidaseconjugated anti-digoxigenin and a colorimetric substrate, $\mathrm{ABTS}^{\circledR}$, were used to demonstrate the presence of Cms DNA in each sample. The limit of detection of $\mathrm{Cms}$ in the potato core fluid corresponded with 20 or fewer cells per reaction from end-point dilutions. Detection of Cms based on amplification of Cms50, Cms72 and Cms85 sequences by multiplex PCR ELISA is absolutely specific, highly sensitive, and verifiable.

Foliar disease management within staked fresh market tomato populations. D. J. MILLS (1), C. B. Coffman (1), J. R. Teasdale (1), K. L. Everts $(2,3)$, and J. D. Anderson (1). (1) USDA, Beltsville, MD; (2) University of Maryland, College Park, MD; (3) University of Delaware, Newark, DE. Phytopathology 89:S53. Publication no. P-1999-0377-AMA.

The sustainable program at the Beltsville Agricultural Research Center seeks to reduce off-farm inputs, such as fungicides, currently used in fresh market vegetable production. We are investigating foliar disease management of fresh market tomatoes grown in black plastic and hairy vetch mulch, dairy manure compost, and bare ground under no fungicide, weekly fungicide, and the foliar disease forecasting model, TOMCAST. The AUDPC value and canopy necrosis due to early blight declined in tomatoes grown in hairy vetch relative to the other culture methods in 1997 and 1998. In 1998, reduced soil deposition on tomato leaflets and reduced leaflet wetness duration correlated with lower AUDPC values for tomatoes grown in hairy vetch. Scheduling fungicide applications using TOMCAST reduced fungicide input approximately $50 \%$ relative to the weekly schedule without reducing productivity or disease management. We will continue to examine microenvironmental and physiological factors associated with foliar disease reduction in the hairy vetch mulch.

Biology and management of take-all of wheat in Arkansas. E. A. MILUS (1), R. D. Cartwright (2), and C. S. Rothrock (1). (1) University of Arkansas, Fayetteville; (2) Cooperative Extension Service, Little Rock. Phytopathology 89:S53. Publication no. P-1999-0378-AMA.

Take-all is the most important root disease of wheat in Arkansas. This study was conducted in 13 commercial fields with a history of take-all to identify factors associated with take-all and to determine effects of crop rotations. Variables included inoculum density, take-all suppressiveness of soil, soil $\mathrm{pH}$ and nutrients, incidence of root infection in fall and spring, percentage of whiteheads, and susceptibility of grassy weeds. Take-all severity was associated with soil $\mathrm{pH}$ near 7.0, a history of wheat production, and possibly with susceptible grassy weeds. Sulfur or copper deficiency compounded the effects of take-all. A rotation out of wheat for one year greatly reduced take-all in first wheat crop regardless of the rotation crop, but take-all increased in the second wheat crop. Rescuegrass was very susceptible to the pathogen, and several other grasses also appeared to be hosts. Soils were not consistently suppressive. There were significant positive correlations among levels of inoculum, fall and spring infection, and whiteheads, but percent whiteheads greatly underestimated the level of root infection.

Ultrastructure of conidiogenesis in Entomosporium mespili. C. W. MIMS (1), T. Sewall (1), and E. A. Richardson (2). (1) Dept. Plant Pathology, University of Georgia, Athens, GA 30602; (2) Dept. of Botany, University of Georgia, Athens, GA 30602. Phytopathology 89:S53. Publication no. P-19990379-AMA.

Entomosporium mespili is the cause of a serious leaf spot disease of Photinia in the southeastern United States. In this study a combination of SEM and TEM was used to examine conidium development in this pathogen. Conidia developed in acervuli which formed subcuticularly on adaxial and abaxial leaf surfaces. Conidium initials arose from hyphae which developed between the cuticle and epidermis. Development of the first conidium from a conidiogenous cell was holoblastic. Subsequent conidia developed in an enteroblastic fashion. A mature conidium consisted of an apical cell and a basal cell from which two to four small lateral cells arose. The apical and lateral cells each possessed a long, slender, enucleate appendage. Each cell of a conidium contained a single nucleus and a complement of cytoplasmic organelles which were well-preserved by freeze substitution fixation. The conidium wall consisted of a homogenous layer of material whose outer surface was coated with fibrillar material.

Hypersensitive resistance in Capsicum pubescens PI 235047 to Xanthomonas campestris pv. vesicatoria (Xcv) is elicited by avrBs3-2. G. Minsavage (1), J. JONES (1), R. Stall (1), S. Miller (2), and D. Ritchie (3). (1) Univ. of Florida, Gainesville; (2) Ohio State Univ., Wooster; (3) North Carolina State Univ., Raleigh. Phytopathology 89:S53. Publication no. P-19990380-AMA.

Recent discovery of hypersensitive resistance (HR) in C. pubescens PI 235047 to Xcv pepper race 6 (P6) strains initiated interest in characterization of the corresponding avirulence gene(s). Cosmid libraries of P6 strains (avirulent) from Florida (XV1922, weak HR) and Ohio (XV157, strong HR) were constructed in pLAFR3. Clones were mobilized into strain Xcv 259 (P10, virulent) and infiltrated into leaves of PI 235047 to screen for those conferring incompatibility. P10 transconjugants carrying these clones did not elicit HR in C. апnuum differential lines containing $B s 1, B s 2$, or $B s 3$. However, they did elicit HR in Lycopersicon esculentum cv. 7060, as do strains containing the previously cloned avirulence gene $a v r B s 3-2$. P10 transconjugants carrying avrBs3-2 elicited HR in PI 235047. Labeled DNA of avrBs3-2 used as a probe in Southern blot experiments hybridized to DNA of the P6 strains and their corresponding cloned gene(s) indicating homology with the avrBs3 gene family.

Toxin degradation as a strategy for control of Cercospora diseases. T. K. MITCHELL and M. E. Daub. North Carolina State University, Raleigh, NC. Phytopathology 89:S53. Publication no. P-1999-0381-AMA.

The ability of most Cercospora species to cause disease is correlated with cercosporin production. Cercosporin is a photosensitizing polyketide that destroys membranes in infected tissues. Our goal is to identify genes that function to detoxify cercosporin that may have utility in disease control. Several Xanthomonas campestris isolates representing two pathovars show efficient degradation activity. These cercosporin-degrading isolates are resistant to higher levels of the toxin than non-degrading isolates. Screening cercosporin sensitive mutants for ones unable to degrade the toxin was not successful. Over 7000 new UV mutants of a degrading isolate have been evaluated for the loss of toxin degrading ability. We are investigating mutants affected in their degrading activity and anticipate cloning the mutated genes. As cercosporin is degraded, a non-toxic green compound accumulates. This compound was isolated and purified. FAB experiments reveal that the breakdown product has a molecular weight of 16 mass units less than cercosporin. NMR data shows that its structure is highly similar to cercosporin. The complete structure is currently being solved. 
Establishment and reproductive potential of the northern root knot nematode on multiple tissue culture systems. $\mathrm{N}$. A. MITKOWSKI and G. S. Abawi. NYSAES, Cornell University, Geneva, NY. Phytopathology 89:S54. Publication no. P-1999-0382-AMA.

Investigations of the ecology and management of the Northern Root Knot Nematode (Meloidogyne hapla) frequently require large numbers of nematodes for field inoculations. Inoculum sources are commonly produced on tomato in greenhouse pot cultures, requiring considerable space and care. In an effort to maintain large numbers of distinct populations and reduce the space required for storage, a number of tissue culture systems were examined. Root tissue culture systems previously described for tomato and carrot were attempted, along with tissue culture systems developed for onion, celery and lettuce. Agrobacterium rhizogenes was used to transform roots of various hosts. Nematodes were sterilized using sodium hypochlorite and then inoculated into transformed roots on Gamborgs and MS media. The effect of antibiotics and of population source on nematode reproduction was also examined. To date, populations of M. hapla have been successfully established on transformed tomato, onion and carrot roots. The initiation and morphology of galls on transformed roots differed among the various populations of M. hapla.

Assessment of genetic diversity of the northern root knot nematode in New York State. N. A. MITKOWSKI, G. S. Abawi, and N. F. Weeden. NYSAES, Cornell University, Geneva, NY. Phytopathology 89:S54. Publication no. P-1999-0383-AMA.

The Northern Root Knot Nematode (Meloidogyne hapla) is a major pathogen of vegetables, especially in organic soils. In order to understand the biology of the nematode more completely, characterization of the genetic diversity of M. hapla was undertaken, employing a sample of 18 field populations from different vegetable growing regions within the state. A modified North Carolina Differential Host test was performed on the field populations to confirm that only M. hapla was present. From each of the field populations, 10 single female cultures were established on tomato cv. 'Rutgers' in pasteurized soil. Perineal patterns from four nematodes from each single female culture were examined and to-date confirm that the populations are M. hapla. Nematodes from the single female cultures were then placed onto Agrobacterium rhizogenes-transformed tomato roots growing on Gamborgs medium. Sterile juveniles obtained from the latter culture were then used for molecular analysis. RAPD analysis employed 10 basepair primers to identify genetic differences between single female cultures and field populations.

An enrichment technique using cell walls for selection of antagonists to Monilinia fructicola. H. E. MOLINE and J. D. Cohen. USDA-ARS, Horticultural Crops Quality Lab., Beltsville, MD. Phytopathology 89:S54. Publication no. P-1999-0384-AMA.

Most potential fungal antagonists have been identified only after exhaustive non-selective screening. The pathogen we sought to control, Monilinia fructicola, was challenged with potential antagonists that were selected using a crude cell wall preparation from $M$. fructicola as substrate for growth on agar plates. Thirty eight unidentified yeast and bacterial isolates recovered from the surface of "organically grown" peaches grew on M. fructicola cell walls. PDA plates seeded with $1 \times 10^{4} \mathrm{M}$. fructicola spores per $\mathrm{ml}$ were challenged with each of these antagonists at concentrations of $1 \times 10^{9}$ and $1 \times 10^{6} \mathrm{cfu}$ (colony forming units) per ml. Nine of the 38 isolates initially recovered demonstrated antagonism in Petri plate tests and were selected for additional screening on peaches. Although all isolates reduced brown rot incidence on fruit, six were sufficiently antagonistic to warrant further testing. Four pinkpigmented antagonistic isolates were identified as a yeast phase of Rhodosporidium diobovatum, a basidiomycete. Two promising bacterial antagonists were identified as Bacillus pumilus subgroup B.

Evaluation of selected plant essential oils for suppression of Ralstonia solanacearum and Meloidogyne arenaria on tomato. M. T. MOMOL, E. A. Momol, W. A. Dankers, S. M. Olson, J. A. Simmons, and J. R. Rich. University of Florida, North Florida Research and Education Center, Quincy, Florida 32351. Phytopathology 89:S54. Publication no. P-1999-0385-AMA.

Bacterial wilt caused by Ralstonia solanacearum (Rs) is a major disease problem in fresh tomato production fields in north Florida. Meloidogyne arenaria race I (Ma) is one of the plant parasitic nematodes that cause loss on tomato. Essential oils of tea tree (Melaleuca alternifolia), marjoram (Thymus mastichina), oregano (Origanum vulgare), thyme (Thymus vulgaris) and palmarosa (Cymbopogon martini) were tested in vitro and in greenhouse grown tomatoes for their efficacy against Rs and Ma. Also thymol, one of the fractions of thyme oil, was tested in vitro and in greenhouse. Thymol, the vapor effect of palmarosa and thyme essential oils are effective in vitro against Rs. Further evaluation of those essential oils or plant materials from those medicinal plants are being conducted in the greenhouse against Rs and Ma. The possibility of integrating essential oils into the management of bacterial wilt and nematodes on tomato will be discussed.

Impact of soil amendment on soilborne microbes, yield and quality of tomato. M. MORANT (1), E. Philip (1), and K. Evert (2). (1) University of Maryland Eastern Shore, Princess Anne, MD; (2) University of Maryland College Park, Lower Eastern Shore Research and Education Center, Salisbury, MD. Phytopathology 89:S54. Publication no. P-1999-0386-AMA.

A study was conducted to determine whether $\mathrm{N}$ from poultry litter or ammonium nitrate would influence fruit yield and quality of tomato as measured by citric acid and soluble solids contents (SSC). Population densities of Trichoderma and Fusarium spp. in amended soil were also evaluated. Trichoderma was grown on a compost medium for 90 days and $1,930 \mathrm{cfu} / \mathrm{g}$ was used to inoculate eight weeks old seedlings of Liberty (Fusarium resistant) and Bonnie Best (Fusarium susceptible) varieties at the time of transplanting into amended field plots. Natural populations of Fusarium were not pathogenic to tomato. Fruit yield, SSC and citric acid contents were not affected by soil amendments. Fusarium and Trichoderma populations were lowest in July compared to June and August and were greater in the rhizosphere of Liberty. Poultry litter can be used as an alternate $\mathrm{N}$ source for producing tomatoes without negatively impacting yield and quality.

Quantitative ultrastructural analysis of the early events leading to hypersensitive cell death in rust-infected plants. M. J. R. MOULD and M. C. Heath. Department of Botany, University of Toronto, Toronto, Ontario, Canada M5S 1A1. Phytopathology 89:S54. Publication no. P-1999-0387-AMA.

Resistance to the biotrophic cowpea rust fungus in cowpea plants is associated with a resistance gene-dependent cell death process (the hypersensitive response) involving a progression of cytological events. A stereological ultrastructural analysis of infected midvein epidermal cells in both susceptible and resistant plants revealed early changes in nuclear pore and polyribosome density, and nucleolus structure, suggesting that levels of transcription and localized translation significantly increase prior to fungal contact with the plant plasma membrane in resistant cells, whereas they decrease in susceptible cells. In resistant cells, transcriptional activity appears to cease, and the nucleus starts to shrink, at the time when cytoplasmic streaming stops and the cell becomes committed to the death process. By the initiation of protoplast collapse, $31.6 \mathrm{~nm}$ electron-opaque particles containing nucleic acid are visible within the nucleus. The data suggest that induction of hypersensitive cell death begins as the fungus penetrates the outer epidermal wall.

Population structure of Verticillium dahliae isolates from potato fields in Alliston, Ontario. S. I. MPOFU (1), R. Hall (2), K. F. Dobinson (3), and T. Hsiang (2). (1) Agriculture and Agri-Food Canada, Morden Research Centre, MB; (2) University of Guelph, ON; (3) Agriculture and Agri-Food Canada, Southern Crop Protection and Food Research Centre, ON. Phytopathology 89:S54. Publication no. P-1999-0388-AMA.

Verticillium dahliae Kleb. causes Verticillium wilt of potato leading to serious economic crop losses. Isolates of $V$. dahliae collected from potato fields in Alliston, Ontario, were characterised using vegetative compatibility groups (VCGs) and restriction fragment length polymorphisms (RFLPs). Assessment of vegetative compatibility was based on heterokaryon formation between complementary nitrate-nonutilizing mutants. Of 139 isolates, $81 \%$ were assigned to VCG 4B, $18 \%$ to VCG 4A and $1 \%$ to the newly identified VCG 6 . Fungal DNA was digested with EcoRI and probed with pBNKE18 and pTZ19/VtITS using the Southern Hybridization technique. Isolates assigned to VCG 4B were clonally related and designated to RFLP group I. There was no significant difference in the genetic diversity of $V$. dahliae isolates collected from potato stems and soil. Specific RFLP fingerprints were associated with certain VCGs and the results could be used to develop an RFLP-based VCG diagnosis system.

The inhibition of clubroot disease of Chinese cabbage by initial planting leafy daikon. H. MURAKAMI, S. Tsushima, T. Akimoto, and Y. Shishido. Tohoku Natl. Agric. Exp. Stn., Arai, Fukushima, Japan. Phytopathology 89: S54. Publication no. P-1999-0389-AMA.

Clubroot disease incited by Plasmodiophora brassicae causes serious yield loss of cruciferous crops. Disease control has been dependent exclusively on the use of fungicides, and now, the integrate control is required due to the concern about environmental pollution. We report here the effectiveness of 
leafy daikon (leafy Japanese radish, Raphanus sativus) as a decoy plant. The disease index of Chinese cabbage (Brassica rapa) in pots with initial leafy daikon was significantly lower than that in pots without initial planting. Leafy daikon, when grown prior to Chinese cabbage, significantly reduced the number of resting spores in soil. The pathogen infected root hair of leafy daikon and produced zoosporangia but was unable to develop further. These results show that leafy daikon functioned as a decoy plant. The effect was recognized in both conducive and suppressive soils. The identification of soil type and assessing the number of resting spores in soil are necessary for the effective use of leafy daikon in fields because the effects on preventing disease development depends on the dose-response curve obtained from each soil.

Time during pathogenesis of nivalenol and deoxynivalenol production by Fusarium species in wheat. J. G. MURIUKI (1), C. J. Mirocha (1), and R. Dill-Macky (1). (1) University of Minnesota, St. Paul, MN 55108. Phytopathology 89:S55. Publication no. P-1999-0390-AMA.

Fusarium graminearum Schw. and F. culmorum (W. G. Smith) Sacc. occur worldwide on wheat and barley and are the principal pathogens causing Fusarium head blight. Toxins produced by these pathogens can accumulate in infected grains and are implicated in public health. The initial time of toxins detection and their roles in pathogenesis has not been clearly defined. Toxin detection time and the relative aggressiveness of four nivalenol (NIV) producers (F. graminearum, ACR 2705-1, Japan; F. culmorum, France; F. culmorum, 30 and 56, Germany) was compared with aggressiveness of a deoxynivalenol (DON) producer (F. graminearum Butte 86 Ada-11, U.S.A.) on a resistant (2375) and a susceptible (Norm) wheat cultivar. Single spikelets, centrally located in the spikes that were point inoculated during anthesis, displayed symptoms within $72 \mathrm{~h}$ and toxins were detected $48 \mathrm{~h}$ after inoculation. The DON-producing isolate (Butte 86) was more aggressive than the NIV producers, and infection spread 10 days after spikes were inoculated.

Hyphal branching of the arbuscular mycorrhizal fungus, Gigaspora gigantea, is induced by blue and near ultraviolet light. G. NAGAHASHI and D. Douds, Jr. USDA-ARS, ERRC, 600 E. Mermaid Lane, Wyndmoor, PA 19038. Phytopathology 89:S55. Publication no. P-1999-0391-AMA.

The responsive wavelengths for photo-induced hyphal branching of $\mathrm{Gi}$ gaspora gigantea was determined to be in the blue to near ultraviolet light range. To determine the location of the photoreceptors, various lengths of hyphal tips of germinated spores growing in vitro were exposed to high intensity near ultraviolet light for $20 \mathrm{~min}$. Aluminum foil was taped to the Petri dish to expose small rectangular areas of the primary germ tube. No branching occurred if only the first $1 \mathrm{~mm}$ or first $2 \mathrm{~mm}$ of the germ tube was exposed. If the first $3 \mathrm{~mm}$ of the tip was exposed, some branching was noticeable, however, considerable branching occurred when the first $4 \mathrm{~mm}$ of the germ tube $(0-4 \mathrm{~mm})$ was exposed. By exposing shorter segments away from

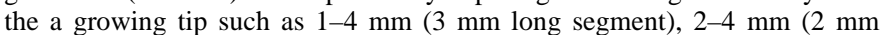
segment) and a 3-4 $\mathrm{mm}(1 \mathrm{~mm}$ segment), the location of the photoreceptor was determined. The first photoreceptor was located between $3-4 \mathrm{~mm}$ from the tip. The first site of branching was approximately $3 \mathrm{~mm}$ distal to the photoreceptor. This result indicated that the photoreceptor and site of branching did not necessarily coincide and suggested a probable involvement of a second messenger during this photo-induction event.

Plant age and inoculum dose dependent resistance in peanut cultivars to groundnut rosette virus disease and aphid vector. R. A. NAIDU, F. M. Kimmins (1), D. J. Robinson (2), P. Subrahmanyam, and P. J. A. van der Merwe. ICRISAT, P.O. Box 1096, Lilongwe, Malawi; (1) NRI, Chatham Maritime, Kent ME4 4TB, UK; (2) SCRI, Dundee DD5 5DA, UK. Phytopathology 89:S55. Publication no. P-1999-0392-AMA.

Peanut cultivars, CG-7, ICGV-SM-90704, JL-24 and ICG-12991, were evaluated for resistance to groundnut rosette virus disease agents (groundnut rosette luteovirus [GRAV], groundnut rosette umbravirus [GRV] and its satellite RNA) and aphid vector (Aphis craccivora) at four different plant ages using 1, 2, 4, and 8 viruliferous aphids/plant. CG-7 and JL-24 were susceptible at all plant ages to infection by the three agents, and the proportion of infected plants containing all three increased with increasing numbers of viruliferous aphids. In ICGV-SM-90704, however, more plants at all ages contained only GRAV, irrespective of the number of aphids used. With ICG12991, no infection was observed in plants older than 14 days, and the percentage of infection with all three agents on younger plants was low, even when 8 aphids/plant were used. The aphid survival, reproduction, and feeding behavior data showed that ICG-12991 has resistance to the aphid vector and this resistance increases with age of the plant.
Multiplication and production of virulence factors, exopolysaccharide, polygalacturonase and endoglucanase, of Ralstonia solanacearum in tomato plants of resistant cultivar LS-89 and susceptible Ponderosa. K. NAKAHO and H. Miyagawa. Chugoku National Agricultural Experiment Station, Fukuyama 721-8514, Japan. Phytopathology 89:S55. Publication no. P-1999-0393-AMA.

Ralstonia solanacearum produces exopolysaccharide (EPS), polygalacturonase (PG) and endoglucanase (EG) which are considered important factors of virulence. We investigated the multiplication and production of such virulence factors of $R$. solanacearum in tomato plants of resistant cultivar LS-89 and susceptible Ponderosa to clarify the mechanism of resistance. Plants were cut-inoculated on their stems just above the cotyledon by adding a drop of bacterial suspension $\left(10^{6} \mathrm{CFU} / \mathrm{ml}\right)$ and then the upper hypocotyls were sampled. In inoculated Ponderosa plants, almost all plants wilted within 8 days after inoculation and the bacterial density in plants increased rapidly and reached $10^{9} \mathrm{CFU} / \mathrm{g}$ in fresh matter. In inoculated LS-89 plants that showed latent infection, the bacterial density increased to $10^{7} \mathrm{CFU} / \mathrm{g}$ in fresh matter and then plateaued. EPS production, and PG and EG activity in plants were significantly higher in Ponderosa than those in LS-89. For two cultivars, production of each virulence factor was plotted against the bacterial density on a logarithmic basis. Analysis of covariance indicated that regressions did not differ significantly between two cultivars. EPS production, and PG and EG activity were highly correlated with the bacterial density. These results indicate that the resistance in LS-89 plants is mainly associated with limitations of bacterial multiplication but not with decreased ability of bacteria to produce such virulence factors.

Analysis of GFLV RNA2 by RFLP analysis of the 1500 bp at the $3^{\prime}$ end amplified by RT-PCR. P. NARAGHI-ARANI and A. Rowhani. Dept. of Plant Pathology, University of California, Davis, CA 95616. Phytopathology 89:S55. Publication no. P-1999-0394-AMA.

A 1500 bp fragment of Grapevine Fanleaf Nepovirus (GFLV) RNA2 was amplified from the 3' end of RNA 2 by immunocapture reverse transcriptase polymerase chain reaction (IC-RT-PCR) and analyzed by RFLP analysis of fragments produced by digestion with AvaII. Nine GFLV isolates from California vineyards, four from the UC Davis clonal virus collection, and one from Italy were analyzed using the above methodology. It was found that GFLV infections were composed of a set of quazispecies. The observation of the quazispecies nature of GFLV infections was further supported by RFLP patterns produced by GFLV extracted from herbaceous hosts. These patterns were different from the ones isolated from grapevine; sometimes dramatically so. Thus, the disease known as fanleaf is caused by a set of quazispecies of the GFLV virus.

Phylogenetic comparisons of Rhizoctonia spp. from Euphorbia spp. and Centaurea spp. from the U.S. and Eurasia. D. Nash (1), A. J. CAESAR (1), and J. M. Henson (2). (1) USDA-ARS, Sidney, MT; (2) Dept. of Microbiology, Montana State Univ., Bozeman, MT. Phytopathology 89:S55. Publication no. P-1999-0395-AMA.

Plant pathogens are being investigated as a component of integrated control of leafy spurge, Euphorbia esula/virgata, and two knapweed species, Centaurea maculosa and $C$. diffusa, respectively. In neighbor-joining analyses, based on distances derived from 400 alignable sites of ITS rDNA four of five strains of Rhizoctonia spp. from knapweeds clustered at the top of the bootstrapping phenogram with a proportion of 63 . Two strains, from Hungary and North Dakota, respectively, branched together with a bootstrap proportion of 65 and differ by a single nucleotide. Two strains, from the southern Slovak Republic and southern Hungary, respectively grouped together with a bootstrap proportion of 100 and a difference of only 9 nucleotides. Two Chinese binucleate strains of widely divergent geographic origin were identical to each other. U.S. and Eurasian strains were often branched, clustered, or grouped together and overall failed to cluster on a geographical basis, indicating that Rhizoctonia spp. are a worldwide continuum, and use of foreign strains would not entail the introduction of highly alien genotypes.

The detached-leaf technique for screening faba bean genotypes for resistance to chocolate spot. H. F. NAWAR and J. O. Kuti. Texas A\&M University, Kingsville, TX 78363. Phytopathology 89:S55. Publication no. P-19990396-AMA.

Detached-leaf testing was found to be a reliable and rapid method for evaluating resistance in faba bean (Vicia faba L.) to chocolate spot disease caused by Botrytis cinerea (ATCC \#23473) and B. fabae (ATCC \#28467 and ATCC \#56970 respectively). Typical chocolate spot lesions were observable on the detached leaves 3-5 days after inoculation with conidial suspensions of the pathogens. It normally takes 14-21 days to observe the lesions on inoculated 
whole plants. Sixty genotypes of faba bean were screened using the detached-leaf method. There were differential genotypic responses to different isolates of the chocolate spot pathogens. Faba bean susceptibility groupings from detached leaf inoculations agreed with those obtained from the whole plant inoculations. B. cinerea was found to be more aggressive pathogen than the two $B$. fabae pathogens in most of the genotypes tested.

Molecular variation in populations of Fusarium proliferatum found in natural soils. M. J. NEUMANN (1), D. A. Carter (1), D. Backhouse (2), B. A. Summerell (3), and L. W. Burgess (1). University of Sydney; (2) University of New England, Armidale, Australia; (3) Royal Botanic Garden, Sydney, Australia. Phytopathology 89:S56. Publication no. P-1999-0397AMA.

There is a paucity of information concerning ascomycete population biology in natural soils. The objective of the work was to study the molecular variation of $F$. proliferatum populations on a local and regional scale in natural soils associated with relict tropical plant species in arid central Australia. Hierarchical soil samples were taken from within the root systems of 15 Livistona mariae palms. Cultures were isolated by soil dilution plating on peptone-PCNB agar and purified from single conidia using carnation leaf agar. At least one isolate was obtained from each tree yielding 271 isolates in total. For the molecular studies ten isolates were chosen from each of the 3 levels of the hierarchical samples. DNA was extracted and PCR using RAPD and ERIC primers was used to get an overview of the variation present. Preliminary work suggests that within a sample, population structure tends to be clonal but variation increases around a single tree and between trees. Further work using RFLPs and larger numbers of isolates is planned.

A selective medium for nitrate-nonutilizing (nit) mutants of Fusarium oxysporum. N. NISHIMURA. National Research Institute of Vegetables, Ornamental Plants and Tea, Kurume, Fukuoka, Japan. Phytopathology 89:S56. Publication no. P-1999-0398-AMA.

A selective medium for nit mutants of $F$. oxysporum was made. When $0.5 \mathrm{ml}$ of the soil sample, which was mixed $10 \mathrm{~g}$ of soil with $90 \mathrm{ml}$ of $0.1 \%$ water agar, was spread over the surface of the medium in each $9 \mathrm{~cm}$ petri dish, nit mutants formed relatively large colonies. Rhizopus sometimes formed colonies, but the growth was inhibited. Almost all the colonies of $F$. solani were strictly suppressed. Penicillium gradually formed distinct colonies. The other fungi were strictly suppressed. The medium contains $1 \mathrm{~g} \mathrm{KH}_{2} \mathrm{PO}_{4}, 0.5 \mathrm{~g}$ $\mathrm{KCl}, 0.5 \mathrm{~g} \mathrm{MgSO}_{4} \cdot 7 \mathrm{H}_{2} \mathrm{O}, 20 \mathrm{~g}$ D-galactose, $2 \mathrm{~g} \mathrm{NaNO}_{3}, 2 \mathrm{~g}$ ammonium tartrate, $0.25 \mathrm{~g}$ chloramphenicol, $10 \mathrm{~g} \mathrm{KClO}_{3}, 0.2 \mathrm{ml}$ trace elements solution, $0.2 \mathrm{ml}$ Befran (Iminoctadine triacetate) soluble liquid 25, $2.5 \mathrm{ml}$ Florid-D solution (containing $25 \mathrm{mg}$ miconazole nitrate. Mochida Pharmaceutical Co.), $20 \mathrm{~g} \mathrm{Agar}$ (1st grade) and $0.25 \mathrm{~g} \mathrm{PCNB} 75 \%$ WP per liter of distilled water. Trace elements solution is the same as Correll et al. used in 1987. PCNB $75 \%$ WP was added after autoclaving for $15 \mathrm{~min}$. After cooling to $55^{\circ} \mathrm{C} \mathrm{pH}$ was adjusted to 3.7-3.9 with $10 \% \mathrm{H}_{3} \mathrm{PO}_{3}$. After pouring, petri dishes were kept for 3-4 days in a dark and windless place and then used.

HR-elicitor of Clavibacter michiganensis subspecies sepedonicus. R. M. NISSINEN (1), S. V. Beer (2), and M. C. Metzler (1). (1) University of Turku, Turku, Finland; (2) Cornell University, Ithaca, NY. Phytopathology 89:S56. Publication no. P-1999-0399-AMA

Gram positive bacterium Clavibacter michiganensis subspecies sepedonicus $(\mathrm{Cms})$ is the causal agent of potato ring rot, an economically important plant disease in northern latitudes. Pathogenic strains of $\mathrm{Cms}$ are recognised by resistant plant species and elicit a hypersensitive response (HR), whereas nonpathogenic strains elicit no visible response. Pathogenicity and HR-elicitation correlate with the survival in hosts: only strains that are able to elicit an $\mathrm{HR}$ are able to multiply and spread within host plant. In vitro, pathogenic $\mathrm{Cms}$-strains secrete HR-eliciting protein into culture supernatant throughout the logarithmic growth phase and this production is $\mathrm{pH}-$ and temperature dependent. Elicitor protein was purified by liquid chromatography and SDSPAGE and microsequenced to obtain $\mathrm{N}$-terminal sequence. Using obtained sequence, degenerate oligonucleotides were prepared and used as hybridisation probes to screen DNA library of $\mathrm{Cms}$ for the corresponding gene.

Transgenic Gala apple expressing attacin $\mathbf{E}$ has increased field resistance to Erwinia amylovora (fire blight). J. L. NORELLI, E. E. BorejszaWysocka, J.-P. Reynoird, and H. S. Aldwinckle. Department of Plant Pathology, Cornell University, Geneva, NY. Phytopathology 89:S56. Publication no. P-1999-0400-AMA.

Genes encoding the lytic proteins attacin E, hen egg white lysozyme, and the cecropin analogs, SB-37 and Shiva-1 have been transferred to Royal Gala apple by Agrobacterium-mediated transformation. In 1998, 2- and 3-yr-old field grown plants of 64 lytic protein-transgenic lines were artificially inoculated with E. amylovora and \% of the current season's shoot length blighted (slb) was determined. 28 transgenic lines developed significantly less fire blight than non-transgenic Royal Gala controls. One transgenic line, TG138, containing the attacin E gene under the control of the proteinase inhibitor II promoter, had only 5\% slb compared with 56\% in non-transgenic Royal Gala controls and 37\% in the moderately resistant Liberty controls. Western analysis of field grown material indicated that TG138 had a high constitutive level of attacin expression. Northern analysis of in vitro material confirmed the constitutive expression of attacin in TG138, but indicated elevated attacin expression $1 \mathrm{hr}$ following leaf wounding.

Comparison of Cylindrocladium spathiphylli and Cylindrocladium pteridis using morphology, host range and PCR RAPDs. D. J. NORMAN, J. M. F. Yuen, P. Strickler, and R. Resendiz. Plant Pathology Dept., University of Florida, IFAS, Apopka, FL 32703. Phytopathology 89:S56. Publication no. P-1999-0401-AMA.

Fifteen C. spathiphylli isolates from spathiphyllum and thirteen C. pteridis isolates from leatherleaf fern were compared using standard morphological characteristics, host range, and by using RAPDs. The morphology of the two species are distinct, with single septate conidia of $C$. pteridis $(55-72 \times 5-7$ $\mu \mathrm{m})$ being significantly larger $(P=0.05)$ than those of $C$. spathiphylli $(48-80$ $\times 5-7 \mu \mathrm{m})$. Vesicle shape of most $C$. pteridis were clavate while those of $C$. spathiphylli were globose. In host range studies, all $C$. spathiphylli isolates produced leaf spots on leatherleaf fern similar to those produced by $C$. pteridis. At a standard conidial concentration, number of lesions produced on fern by C. pteridis were more than $36 \%$ greater than those produced by C. spathiphylli. However, when inoculated onto spathiphyllum plants only two isolates of $C$. pteridis produced root rot similar to that produced by C. spathiphylli. This study shows the importance of examining morphology, host range, and molecular techniques in determining relationship between Cylindrocladium species.

Effect of corn, fallow, and soybean cropping sequences on the population dynamics of soybean cyst nematode. F. W. NUTTER, Jr., G. L. Tylka, W. D. Batchelor, K. A. Elbasher, and S. N. Wegulo. Iowa State University, Ames, IA. Phytopathology 89:S56. Publication no. P-1999-0402-AMA.

Soybean cyst nematode, Heterodera glycines, is an important yield-limiting pest in the U.S. Although crop rotation is recommended as one possible management tactic, little quantitative information is available concerning the benefits of cropping systems. During 1995-97, field experiments were conducted in Ames, IA to quantify the impact of 1,2, and 3 year sequences of corn, fallow, or susceptible soybean on $H$. glycines juvenile and egg population densities. Initial juvenile and egg population densities in 1995 exceeded 30,000 per $100 \mathrm{cc}$ of soil. $\mathrm{H}$. glycines population densities were determined each week by sampling soil cores at $7.5-$ and $15-\mathrm{cm}$ soil depths beginning in mid-April and continuing until mid-November. $H$. glycines population densities were generally higher and more variable at the $7.5-\mathrm{cm}$ soil depth than at the $15-\mathrm{cm}$ soil depth for all cropping sequences. $H$. glycines population dynamics were best described by the negative exponential or linear models with $H$. glycines population densities declining to lower levels following 3 years of fallow compared to 3 years of corn or soybean.

Identification of two genes linked to the wheat stripe rust resistance gene Yr10. C. L. NYKIFORUK, R. Huel, M. M. Frick, R. L. Conner, A. Kuzyk, and A. Laroche. Agriculture and Agri-Food Canada, Lethbridge, Alberta, Canada. Phytopathology 89:S56. Publication no. P-1999-0403-AMA.

Stripe rust (yellow rust), which is incited by Puccinia striiformis Westend. f. sp. tritici Eriks., is one of the most serious leaf diseases of wheat in the world. Stripe rust can cause yield losses in wheat that exceed 75\%. Although numerous disease resistance genes have been isolated in dicots recently, only a few have been reported in monocots. The wheat cultivar Moro is resistant to the prevalent stripe rust races in western Canada. The stripe rust resistance gene Yr10 is located on chromosome 1B in Moro and originates from the Turkish line PI 178383. An alternative source for the stripe rust resistance gene Yr10 has been identified in the Triticum spelta accession 415. In this paper we describe two full-length genomic clones and two overlapping partial cDNA clones that are identical to one of the genomic clones. The identification of that gene was further assessed by its presence in other wheat lines and in T. spelta all reported to carry the stripe rust $\mathrm{Yr} 10$ resistance gene. We will discuss the perfect linkage and structural organization of the three regions of these clones and compare them to other resistance genes. 
Fusarium species microflora on shortleaf and longleaf pine seed. S. W. OAK (1), J. Shelton (2), S. A. Enebak (2), and W. A. Carey (2). (1) USDA Forest Service, Southern Region, Asheville, NC; (2) Auburn University, Auburn, AL. Phytopathology 89:S57. Publication no. P-1999-0404-AMA.

Fusarium species have limited seed efficiency in some bareroot and container nurseries growing longleaf and shortleaf pines for ecosystem restoration. Many Fusaria can cause pre- and post emergence damping off and the pitch canker pathogen ( $F$. subglutinans $\mathrm{f}$. sp. pini), late crop and outplanting mortality. Screening of seedlots of both pines revealed differences in microflora. Fusarium species incidence on longleaf pine seed was very high $(95 \%)$ and most seed were contaminated with 2 or more different species. By contrast, $54 \%$ of shortleaf pine seed were free of Fusarium species and those that were contaminated harbored a single species. The most common species on longleaf pine seed were F. proliferatum (79\% incidence) and F. solani $(56 \%)$, while $F$. subglutinans was recovered from $22 \%$ of all seeds. Fusarium proliferatum was also the most common contaminant on shortleaf pine (24\% incidence) but $F$. solani was recovered from only $4 \%$ of all seeds while $F$. subglutinans was recovered from $15 \%$. Results will be used in studies of methods to limit losses from Fusarium species in bareroot and container nurseries.

Characterization of a new tomato bushy stunt-related tombusvirus associated with lettuce dieback disease in California. C. OBERMEIER (1), J. L. Sears (1), G. C. Wisler (1), H. Y. Liu (1), K. O. Schlueter (1), E. J. Ryder (1), J. E. Duffus (1), and S. T. Koike (2). (1) USDA-ARS, Salinas, CA; (2) Univ. Calif. Coop. Ext., Salinas, CA. Phytopathology 89:S57. Publication no. P-1999-0405-AMA.

A disease causing dieback of Romaine lettuce has been found increasingly in California. Affected lettuce plants exhibit severe stunting, chlorosis and necrosis of older leaves. Plants infected early in their development may die. An isometric virus has been isolated consistently from roots and leaves of symptomatic lettuce plants. Particles are $30 \mathrm{~nm}$ in diameter. Double-stranded RNA profiles are identical to those of TBSV isolates. Cloning of the 3'terminus of the viral genomic RNA revealed $84 \%$ to $88 \%$ nucleotide sequence identity with several TBSV strains. RT-PCR has been successfully applied for detection of the virus in lettuce leaves. Field trials revealed no resistance in Romaine, but did show resistance in several leaf and crisphead lettuce varieties. Although inoculation under greenhouse conditions has not yet reproduced the dieback disease in lettuce, the consistent isolation of this TBSV-related virus from field-grown symptomatic lettuce suggests that it may be the cause of the disease.

Resistance to Xanthomonas campestris pv. vesicatoria and PCR analysis of hot pepper Capsicum chinense varieties. E. N. OKEY and L. W. O'Garro. Dept. of Biological and Chemical Sciences, University of the West Indies, Cave Hill, Barbados. Phytopathology 89:S57. Publication no. P-1999-0406AMA.

Bacterial spot of pepper (Capsicum spp.) caused by Xanthomonas campestris pv. vesicatoria $(\mathrm{Xcv})$ is a destructive disease in the Caribbean. Control measures based on chemical sprays and cultural practices have been ineffective. Introduction of resistant pepper types is proposed as an alternative for disease control. On this basis, forty hot pepper varieties were tested for resistance to $\mathrm{Xcv}$ races using hypersensitive reaction, electrolyte leakage and in planta bacterial growth. PCR analysis of these varieties was also undertaken to determine their relatedness. $X c v$ races P1T1, PIT2 and P2T2 induced hypersensitive reaction on all pepper varieties tested, whereas races P4, P4T1, P4T2, P5T2 and P6T2 did not. Of all race types mentioned above only P1T1, P1T2 and P2T2 induced notable electrolyte leakage and were restricted in growth. Genetic relatedness among the pepper types was generally high but variable. These pepper types contain a high level of race-specific bacterial spot resistance which is probably encoded by gene homologues.

Partial nucleotide sequencing and analysis of the coat protein gene of a new lettuce mosaic virus isolate from Brazil. F. A. Oliveira (1), A. J. Boari (1), and A. R. FIGUEIRA (1). (1) Univ. Federal de Lavras, DFP, C.P. 37, 37200-000 Lavras, MG, Brazil. Phytopathology 89:S57. Publication no. P-1999-0407-AMA.

The lettuce mosaic virus (LMV) has been the most important virus infecting lettuce in Brazil. In the last four years, a new LMV isolate was found in commercial fields, inducing in lettuce and in pea (Pisum sativum L.), symptoms different from those observed in plants infected with others Brazilian LMV isolates. The main difference was observed in lettuce cv. Regina that showed leaves in upright position, closed and compacted at the end of its life cycle. It did not happen when this plant was infected with others Brazilian LMV isolates. Electron microscopy showed pinwheel inclusions and flexuous particles, specific of the potyvirus group, and this virus reacted with polyclonal antibodies raised against LMV. In this work, the 600-bp fragment containing the major part at $5^{\prime}$ end of the coat protein gene, was cloned and sequenced. The conclusions based on data obtained when the nucleotide sequence of this new LMV isolate was compared with others Brazilian and foreign LMV isolates, will be presented and discussed.

Effects of interrupted leaf wetness periods on development of pecan scab. J. K. O'MARA and K. L. Stevenson. Department of Plant Pathology, University of Georgia, Athens, GA. Phytopathology 89:S57. Publication no. P-19990408-AMA.

Experiments were conducted to determine the effects of interruption of a 48-h wetness period by a dry period of $0,1,3$, or $6 \mathrm{~h}$, on germination of conidia of Cladosporium caryigenum on glass slides, infection of detached pecan leaflets, and development of lesions on intact leaves. Interruption of a 48-h wetness period by $3 \mathrm{~h}$ or more significantly reduced germination of conidia on glass slides and on detached leaves, but did not completely prevent germination. Interruption of a 48-h wetness period by a 6-h dry period resulted in significantly fewer appressoria compared to the continuous 48-h wet period. Subcuticular growth of $C$. caryigenum on detached leaflets was significantly reduced when the wetness period was interrupted by $3 \mathrm{~h}$ or more. However, after 21 days, lesion development on intact leaves was not significantly affected by interruption of the wet period. The lack of effect on lesion development suggests that interruption of the wet period by as much as $6 \mathrm{~h}$ delays, but does not prevent, fungal development and lesion appearance. Based on results of this study, wetness periods should be considered additive when interrupted by dry periods of $6 \mathrm{~h}$ or less.

Synergistic interactions of two Verticillium dahliae pathotypes and Pratylenchus penetrans on potato. $M$. A. OMER and R. C. Rowe. Ohio State University, OARDC, Wooster, OH. Phytopathology 89:S57. Publication no. P-1999-0409-AMA.

Microplots were established during 3 years to investigate the effects of two pathotypes of Verticillium dahliae and the root lesion nematode (Pratylenchus penetrans) on severity of potato early dying disease on potato cultivar Superior. With $V$. dahliae alone, isolates from VCG 4A resulted in AUSPC values that were $49 \%, 2 \%$ and $27 \%$ higher than that caused by VCG 4B isolates in 1994, 1995, and 1998, respectively. In contrast, differences in AUSPC between the two pathotypes for plants treated with $V$. dahliae plus nematodes were $53 \%, 15 \%$, and $44 \%$ for the same time period. Moreover, plants grown in soil infested with $4 \mathrm{~A}$ isolates alone, exhibited higher disease severity than those co-infected with 4B isolates plus nematodes. Total tuber weight was highly reduced in plants co-infected with $4 \mathrm{~A}$ isolates plus nematodes compared with those treated with $4 \mathrm{~B}$ isolates plus nematodes. These data indicate that the two pathotypes of $V$. dahliae interact differentially with $P$. penetrans. VCG 4A causes more severe symptoms that result in lower total tuber yield than VCG 4B, suggesting a synergistic rather than additive relationship between VCG $4 \mathrm{~A}$ and $P$. penetrans.

Fatty acid methyl ester (FAME) analysis on the influence of plant type on the rhizosphere community. K. L. ONG, B. A. Fortnum, and D. A. Kluepfel. Department of Plant Pathology and Physiology, Clemson University, Clemson, South Carolina. Phytopathology 89:S57. Publication no. P-1999-0410AMA.

Fatty Acid Methyl Ester (FAME) analysis was used to monitor the rhizosphere microbial community of three plant species (tobacco, corn and soybean) under controlled greenhouse conditions. Fatty acids were extracted directly from rhizosphere soil and from cells $\left(10^{-1}\right.$ soil dilution) grown on R2A enrichment medium. Cluster analysis of the fatty acid retention time profiles separated samples into two clusters based on extraction procedures. Analysis of the fatty acid retention time profiles from direct soil extraction revealed clustering as a function of plant species, supporting previous reports that plant-specific exudates can influence the composition of the rhizosphere community. Distinct clustering as a function of plant species was not observed for samples from R2A cultures. Enrichment with R2A medium did not enhance the clustering observed with direct soil extraction. Also, analysis of individual fatty acid components can assess trends of the rhizosphere community. 
Detection and nucleotide sequence of double-stranded RNA from an isolate of the violet root rot fungus Helicobasidium mompa Tanaka with reduced virulence. H. OSAKI (1), S. Kanematsu (1), I. Okabe (2), N. Matsumoto (2), and Y. Ohtsu (1). (1) National Institute of Fruit Tree Science, Tsukuba, Japan; (2) National Institute of Agro-Environmental Sciences, Tsukuba, Japan. Phytopathology 89:S58. Publication no. P-1999-0411-AMA.

Three double-stranded (ds) RNA species were detected from an isolate of the violet root rot fungus Helicobasidium mompa with reduced virulence. Molecular weights estimated were about 1.30, 1.27 and $1.23 \times 10^{6}$ daltons. The nucleotide sequence of the largest dsRNA (dsRNA1) was analyzed, and one strand was found to contain a single, long open reading frame of $1797 \mathrm{nu}-$ cleotides that encoded a putative polypeptide containing 598 amino acid residues with a molecular mass of $69.9 \mathrm{kDa}$. This polypeptide contained amino acid sequence motifs conserved in putative RNA-dependent RNA polymerases (RDRPs) of RNA viruses. A comparative analysis of the putative product of dsRNA1 showed a sequence similarity to RDRP from Atkinsonella hypoxylon $2 \mathrm{H}$ virus, a partitivirus of the Partitiviridae. Molecular weights of the three dsRNAs and the deduced amino acid sequence encoded by dsRNA1 suggested that the three dsRNA species were derived from a partitivirus that existed in H. mompa.

Genes induced during early infection in pink ear rot of maize. T. OUELLET, A. Saparno, A. Koul, L. Zhu, S. Allard, and L. Harris. Eastern Cereal and Oilseed Research Centre, Agriculture and Agri-Food Canada, Ottawa, Ontario, Canada. Phytopathology 89:S58. Publication no. P-1999-0412-AMA.

Fusarium graminearum attacks a wide range of plant species including maize (ear and stalk rot), barley, and wheat (head blight). Favorable environmental conditions (conducive temperatures and high humidity) can result in $\mathrm{Fu}$ sarium epidemics and millions of dollars lost in crop revenues. F. graminearum infection in the cereals reduces both grain yield and quality and also results in mycotoxin contamination. We have initiated a study of the molecular interactions between $F$. graminearum and maize during infection of the silk channel and ear in susceptible and resistant inbreds. Differential RNA display-RT-PCR has been used to identify genes, from $F$. graminearum and corn, that are elicited in the early stages of infection of maize silk by the fungus. Additionally, infection in resistant inbreds has been compared to that from highly susceptible inbreds using this technique. Unique cDNA fragments originating from either $F$. graminearum or Zea mays have been cloned and characterized. A summary of the findings will be presented.

Microsatellite markers in oat. N. PAL (1) and L. L. Domier (1,2). (1) Dept. Crop Sciences, University of Illinois, 1102 S. Goodwin Ave., Urbana, IL 61801; (2) USDA-ARS, CPRU, 1102 S. Goodwin Ave., Urbana, IL 61801. Phytopathology 89:S58. Publication no. P-1999-0413-AMA.

Microsatellite or simple-sequence-repeat (SSR) markers typically are codominant, multi-allelic, highly polymorphic and occur at random intervals through the eukaryotic genomes. We report here the construction of a small insert SSR-enriched genomic library from oat cv. Clintland64 using streptavidin-coated paramagnetic beads to capture the SSR-containing DNA fragments. The library was enriched for a mixture of di and tri-nucleotide repeats CA, AT, AG, GAA, TCC and TGG. About 130 clones were sequenced to confirm the presence of SSRs and to establish the type and size of repeats. The number of repeats varied from 5 to 35 . So far, 32 primer pairs flanking the SSRs have been designed and used for PCR amplification to confirm the synthesis of products of the expected sizes. The ability of seven primer pairs to detected polymorphisms among four oat lines was evaluated on $4 \%$ agarose and 5\% denaturing polyacrylamide gels. Four of the seven produced polymorphic banding patterns. We are continuing to design and evaluate additional primer sequences.

Agrobacterium virulence gene virJ is required for the assembly or stability of T-DNA transfer channel, a member of the type IV secretion system family. S. Q. PAN. Department of Biological Sciences, National University of Singapore, Singapore 119260; Department of Plant Pathology, China Agricultural University, Beijing, China 100094. Phytopathology 89:S58. Publication no. P-1999-0414-AMA.

A. tumefaciens transfers a specific segment (T-DNA) of its tumor-inducing (Ti) plasmid into plant cells, where the T-DNA becomes integrated into plant chromosomes. The virB and virD4 genes have been implicated in encoding a membrane-associated T-DNA transfer channel, which is a member of the newly recognized type IV secretion system family. Recently we reported that a Ti plasmid harbored virulence gene virJ, which can functionally complement a chromosomal gene $a c v B$, is also required for T-DNA transfer. In this communication, I report that mutation at virJ caused more VirB9 to fractionate in the periplasm and made the membrane-associated VirB7, VirB8, VirB9 and VirB10 more vulnerable to degradation during subcellular fractionation, although the effects on VirB4 and VirE2 were minimal. The mutation also reduced the stability of VirB7 and VirB10 but not VirB8 and VirB9 in the cytosolic fraction. This suggests that virJ is required for the assembly or stability of the VirB protein complex.

An Agrobacterium chromosomal gene is required for tumorigenesis and growth in a vir gene inducing medium. S. Q. PAN $(1,2)$ and $\mathrm{H}$. M. Soo (1). (1) Department of Biological Sciences, National University of Singapore, Singapore 119260; (2) Department of Plant Pathology, China Agricultural University, Beijing, China 100094. Phytopathology 89:S58. Publication no. P-1999-0415-AMA.

A. tumefaciens causes crown gall tumors on plants by transferring a DNA fragment (T-DNA) from the tumor-inducing (Ti) plasmid into plant cells. Another region of the Ti plasmid encodes the virulence (vir) genes that are responsible for processing, transfer and possibly integration of T-DNA. Expression of these vir genes in Agrobacterium requires a minimal medium of $\mathrm{pH} 5.5$ (induction medium or IM). Using a transposon Tn5, we identified a gene that was required for Agrobacterium to grow on this minimal medium and to cause tumors. The gene was found to be located on Agrobacterium chromosome instead of the Ti plasmid. Mutation of this gene did not affect the expression of the vir genes tested, such as virB7, virD2 and virJ, but abolished the expression of at least one protein that is induced on IM by acetosyringone, a signal compound that can induce all known vir genes. This suggests that this chromosomal gene is possibly required for expression of some unknown protein(s) that can be induced by the vir gene inducing signal.

Cloning of an ergopeptine-associated peptide synthetase gene from clavicipitaceous fungi. D. G. PANACCIONE (1), J. Wang (2), C. A. Young (3), D. B. Scott (3), C. L. Schardl (2), and P. Damrongkool (1). (1) Div. Plant and Soil Sci., West Virginia University, Morgantown, WV 26506; (2) Dept. Plant Pathology, University of Kentucky, Lexington, KY 40546; (3) Inst. Molec. BioSciences, Massey University, Palmerston North, NZ. Phytopathology 89: S58. Publication no. P-1999-0416-AMA.

Several fungi in the Clavicipitaceae produce toxic ergopeptines via a complex pathway. The first committed step in the pathway is controlled by $I$ the gene encoding dimethylallyltryptophan synthase; the final steps are catalyzed by peptide synthetases. Analysis of cosmid clones of Claviceps purpurea dmaW revealed that this gene is closely linked to clone Cp605, from one of several peptide synthetase genes previously identified in $C$. purpurea. This clustering is typical of fungal toxin biosynthesis genes and indicates that Cp605 is involved in ergopeptine biosynthesis. Southern analysis of several fungi in the Clavicipitaceae showed that Cp605 is present only in ergopeptine producers. The Cp605 homologue from Neotyphodium lolii has been cloned for further structural and functional analyses because $N$. lolii and a related fungus, unlike several other fungi in the family, contain single copies of the gene.

Effect of Actigard ${ }^{\circledR}$ and Admire ${ }^{\circledR}$ on suppression of tomato spotted wilt Tospovirus in flue-cured tobacco. H. R. PAPPU (1), A. S. Csinos (1), R. A. McPherson (2), and M. G. Stephenson (3). (1) Dept. of Plant Pathology; (2) Dept. of Entomology; (3) Dept. of Crops and Soils, Univ. of Georgia, Coastal Plain Expt. Station, Tifton, GA 31793. Phytopathology 89:S58. Publication no. P-1999-0417-AMA.

Tomato spotted wilt Tospovirus (TSWV) is a major constraint to tobacco production in Georgia. No single control measure is found effective for minimizing the impact of the disease. Foliar applications of Admire ${ }^{\circledR}$ (imidacloprid) and Actigard ${ }^{\circledR}$ (acibenzolar-S-methyl) were tested singly and in combination for their effect in reducing the impact of TSWV. Admire ${ }^{\circledR}$ is currently labeled for use on tobacco for insect control. Actigard ${ }^{\circledR}$, a plant activator, is being submitted for registration. Replicated field trials were conducted in four locations in Georgia. TSWV incidence was recorded based on the number of symptomatic plants and by ELISA. Results showed that both Admire $^{\circledR}$ and Actigard ${ }^{\circledR}$ significantly reduced final disease incidence. The effect was more pronounced when both were applied together. The mode of action seems to be suppression of the symptom expression as the virus could be detected in symptomless plants. This approach potentially offers an effective management tool for spotted wilt on tobacco. 
Simplified extraction of Phytophthora mycelial DNA suitable for PCR amplification. S. S. PAPPU (1), H. R. Pappu (2), and A. S. Csinos (2). (1) Dept. of Entomology and (2) Dept. of Plant Pathology, Coastal Plain Expt. Station, Univ. of Georgia, Tifton, GA 31793. Phytopathology 89:S59. Publication no. P-1999-0418-AMA.

We report a simple and rapid method for amplifying ribosomal sequences from Phytophthora. It offers a simplified alternative to the DNA extraction step. Phytophthora parasitica var. nicotianae, the causal agent of black shank of tobacco, was used to demonstrate the utility of the technique and it may also be applicable to other fungi. One mg of fresh or lyophilized mycelium was added to a microfuge tube containing $50 \mu \mathrm{L}$ of a solution of $20 \mathrm{mM}$ Tris$\mathrm{HCl}(\mathrm{pH} 8.5), 2 \mathrm{mM}$ EDTA, $1 \%$ Triton X-100 and vortexed for $60 \mathrm{sec}$. followed by freezing in liquid nitrogen. The tube was boiled for $15 \mathrm{~min}$ and cooled on ice for two min. The tube was pulse-centrifuged to collect the mycelial matter at the bottom of the tube. The supernatant was used in the amplification reaction. Primer pairs specific to either the elicitin gene of $P$. parasitica or the 5.8S rRNA gene successfully amplified the targeted region. This technique makes it possible to routinely analyze large number of samples relatively quickly and thus can be potentially useful in molecular epidemiological studies.

Ultrastructural study of interactions between Phytophthora fragariae (PF) and a biological control agent, Streptomyces hygroscopicus var. geldanus (SHG), strain EF-76. M. PAQUET (1), C. Beaulieu (2), and P. M. Charest (1). (1) Dept. Phytologie, Université Laval, Québec, Canada; (2) Dept. Biology, Université de Sherbrooke, Sherbrooke, Canada. Phytopathology 89:S59. Publication no. P-1999-0419-AMA.

Among 200 isolates of streptomycetes screened for their ability to control PF, the causal agent of raspberry root rot, 10 among which SHG EF-76 significantly reduced root rot severity on raspberry. EF-76 was shown to secrete both glucanases and geldanamycin. These compounds might be responsible for PF growth inhibition. Antagonistic effects caused by SHG on PF hyphae were periodically observed during an in vitro experiment where PF was incubated in confrontation with SHG. The transmission electron microscopy (TEM) study revealed that the plasma membrane of PF appeared strongly undulated and displaced only $2 \mathrm{~h}$ after the confrontation. Four hours after treatment, cytoplasmic and organelle disorganization was observed; then hyphae of PF appeared moribund $8 \mathrm{~h}$ after co-cultivation. To verify that the main antagonistic mechanism was antibiosis, a second experiment was carried out where hyphae of PF were incubated only with purified geldanamycin.

Cutinase protects bean and cabbage leaves from infection by Sclerotinia sclerotiorum. D. M. PARKER and W. Köller. Department of Plant Pathology, Cornell University, New York State Agricultural Experiment Station, Geneva, NY 14456. Phytopathology 89:S59. Publication no. P-1999-0420-AMA.

Previous research demonstrated that cutinase protects bean leaves from infection by Rhizoctonia solani (AG-1) mycelial fragments. Because this pathogen does not produce spores, a survey of additional plant pathogens was conducted which indicated that the protective activity of cutinase was also effective with $S$. sclerotiorum. Mycelial fragments and ascospores of $S$. sclerotiorum were tested on both cabbage and bean leaves. As with $R$. solani, excised leaf assays demonstrated that protection occurred in the presence of $0.010 \mathrm{mg} \mathrm{ml}^{-1}$ cutinase amended with Tween 20. Treated sites developed small areas of necrotic tissue which did not expand further. The impact of cutinase on infection of bean by other pathogens such as peanut mottle virus, powdery mildew and bean rust was less dramatic. In grape plants, the protective activity was ineffective against black rot and downy mildew and did not result from the induction of SAR.

Fusarium crown and root rot of greenhouse cucumbers in British Columbia - Host range, epidemiology and disease control. M. PARKER and Z. K. Punja. Simon Fraser University, Burnaby, B.C., Canada. Phytopathology 89:S59. Publication no. P-1999-0421-AMA.

Crown and root rot of greenhouse cucumbers, caused by Fusarium oxysporum f. sp. radicis-cucumerinum, in the Fraser Valley of B.C. presently has only been reported from Greece and B.C., but has the potential to spread to other areas. Among 6 species of Cucurbitaceae artificially inoculated with conidia using a root dip method, cantaloupe (Cucumis melo), watermelon (Citrullus lanatus) and squash (Cucurbita sp.) developed symptoms similar to that on cucumber. Reactions of 23 cucumber varieties ranged from highly susceptible to highly tolerant to this disease, and the most susceptible cultivars were Flamingo, Mustang and Serami. Of five cantaloupe varieties tested, all were highly susceptible to the pathogen with 15 spores/seed sufficient to initiate disease and cause damping-off. Disease incidence was greater at 17 and 17-24 C compared to $24 \mathrm{C}$ alone or $32 \mathrm{C}$. Pretreating seeds with Captan, Thiram or a Captan-Thiram mixture prevented seedling damping-off. Disease control measures should include sanitation, use of tolerant cultivars, and pathogen-free seed.

Copper sensitivity of Xanthomonas campestris pv. carotae isolates from central Oregon carrot seed fields. R. L. PARKS and F. J. Crowe. Oregon State University, Corvallis, OR. Phytopathology 89:S59. Publication no. P-1999-0422-AMA.

Xanthomonas campestris pv. carotae commonly incites bacterial leaf blight of carrot in central Oregon. Seed infestation is of primary concern in this production region. Disease management traditionally has included coppercontaining products. A lack of evidence that these products significantly reduce disease led to the collection and testing of $X$. campestris pv. carotae for tolerance to copper. In summer 1998, bacteria were isolated from symptomatic leaves and umbels collected from carrot seed fields near Madras, OR. Ten isolates, identified as $X$. campestris based on yeast-dextrose agar colony characteristics, positive protein digestion, and negative urease production, were obtained. On casitone yeast extract media amended with copper sulfate concentrations ranging from 0 to $0.96 \mathrm{mM}$, growth of all isolates was inhibited by $0.32 \mathrm{mM}$ copper. No isolate was considered resistant to copper. To broaden the scope of inference of this study, the survey will be repeated in 1999 and include a larger number of fields.

Population structure and host specificity of Alternaria sp. causing brown spot of tangerines, grapefruit and tangerine hybrids in Florida. T. L. PEEVER (1), L. Olsen (2), A. Ibanez (2), and L. W. Timmer (2). (1) Department of Plant Pathology, Washington State University, Pullman, WA; (2) University of Florida, CREC, Lake Alfred, FL. Phytopathology 89:S59. Publication no. P-1999-0423-AMA

Isolates of Alternaria sp. causing Alternaria brown spot were sampled from citrus groves throughout Florida planted to different species of citrus including tangerines (Citrus reticulata), grapefruit (C. paradisi) and tangerine hybrids. RAPD markers were used to determine the population structure of the pathogen and to test the hypothesis that host-specialized forms of the fungus exist on these hosts. Isolates were scored for variation at 16 RAPD loci and tested for pathogenicity on the hosts. Significant genetic differentiation was detected among pathogen populations. Populations from two groves where four citrus varieties were growing in close proximity were examined for host-associated differences in allele frequencies. Populations on Nova tangerine were genetically distinct from populations on Murcott tangors, Minneola tangelos and Orlando tangelos at both sites. Leaf inoculations failed to support the host specialization seen with the RAPDs.

Effect of mefenoxam fungicide on aggressiveness of isolates of Pythium aphanidermatum. G. PENG, M. L. Gleason, and F. W. Nutter, Jr. Department of Plant Pathology, Iowa State University, Ames, IA 50011. Phytopathology 89:S59. Publication no. P-1999-0424-AMA.

Radial growth rates of 21 isolates of Pythium aphanidermatum were measured on corn meal agar amended with a range of mefenoxam concentrations $(0,0.005,0.05,0.5,5$, and $50 \mathrm{mg} / \mathrm{l})$. Fifteen isolates showed response curves typical of sensitivity to these fungicides. Mefenoxam appeared to obstruct the formation of cell walls in oogonia of sensitive isolates, and hyphal contents became granular in appearance. The six isolates that were resistant to metalaxyl were also found to be resistant to mefenoxam. EC90 of mefenoxam was calculated as the concentration at which the growth rate of an isolate was reduced by $90 \%$. The values of EC90 ranged from 3.1 to 26.3 $\mathrm{mg} / \mathrm{l}$ among sensitive isolates. Based on EC90 values, the sensitive isolates segregated into several distinct groups. The relationship between isolate aggressiveness and mefenoxam concentration may influence the proliferation of resistant isolates in natural populations of $P$. aphanidermatum.

Impact of soybean agronomic management on location of Sclerotinia white mold lesions. B. W. PENNYPACKER and M. L. Risius. Penn State University, University Park, PA. Phytopathology 89:S59. Publication no. P-1999-0425-AMA.

Narrow row spacing and high plant density increase soybean yield potential, but may increase Sclerotinia white mold. In 1998, experiments were conducted in a field naturally infested with Sclerotinia sclerotiorum to study the 
effect of: 1) row spacing, and 2) the herbicide COBRA on white mold incidence. The spacing experiment had $14^{\prime \prime}, 21^{\prime \prime}$ and $28^{\prime \prime}$ rows with plant density/acre decreasing as row spacing increased. Row width in the COBRA experiment was 14" and the treatments were no COBRA, adjuvant, COBRA applied at growth stage V4 or R1. In the spacing test, lesion location differed $(P=0.05)$ with row width but disease incidence was not affected. A higher percent of lesions was on the main stem of plants in the 14" rows and on petioles and side branches of plants in the $21^{\prime \prime}$ and $28^{\prime \prime}$ rows. Plants treated with COBRA had reduced disease incidence and a higher percent $(P$ $=0.05$ ) of lesions on the petioles and side branches when compared to control plants. Main stem lesions often kill the plant, whereas petiole/side branch lesions are rarely lethal. Results of the first year study suggest row spacing and COBRA show promise as tools to manage Sclerotinia white mold in soybeans.

Survival and inoculum potential of Fusarium graminearum in wheat residues. S. A. PEREYRA (1), R. Dill-Macky (1), and A. L. Sims (1). University of Minnesota, St. Paul, MN. Phytopathology 89:S60. Publication no. P-1999-0426-AMA.

Inoculated wheat straw was placed on the soil surface, at depths of 7.5-10 $\mathrm{cm}$ and $15-20 \mathrm{~cm}$ in field plots after chisel plowing and at $15-20 \mathrm{~cm}$ after moldboard plowing. Straw was sampled from April to November in 1998 and 1999. Residue decomposition was determined by measuring dry weight. Survival of Fusarium graminearum Schw. (F.g.) was determined by isolating fungi from $1.5 \mathrm{~cm}$ stem/node pieces on pentachloronitrobenzene agar. F.g. was identified on carnation leaf agar. Inoculum potential was determined by placing greased slides above nodes, under conditions promoting perithecial formation. Buried residue decomposed faster than residue at soil surface. Significant reductions in the percentage colonization of residues by F.g. were observed at 8 months and appear to correspond to the amount of residue decomposed. Inoculum in surface residue survived at a significantly higher rate than in buried residue. There were no significant differences in inoculum potential among treatments in 1998. Data from this research may assist growers in establishing appropriate crop rotation periods and effective tillage systems in the management of F.g. infected residues.

Detection and characterization of phytoplasma in alfalfa. R. D. PETERS (1), M. E. Lee (1), C. R. Grau (1), L. A. Lukaesko (2), I.-M. Lee (2), S. J. Driscoll (1), R. M. Winberg (1), and N. C. Kurtzweil (1). (1) University of Wisconsin, Madison, WI; (2) USDA-ARS, Beltsville, MD. Phytopathology 89:S60. Publication no. P-1999-0427-AMA.

Alfalfa is the primary forage crop in Wisconsin. Pathogens previously unstudied in alfalfa could be responsible for limiting yield gains. To test this hypothesis, alfalfa leaves and stems showing symptoms of inter-veinal chlorosis and purpling were collected from various sites in Wisconsin in autumn of 1998. Samples were frozen within 24 hours of collection and $0.3 \mathrm{~g}$ used for total DNA extraction. Nested PCR was carried out by amplification of 16S rDNA using phytoplasma-specific primers (R16mF2/R16mR1 followed by R16F2n/R16R2). A sample from Evansville, WI yielded a nested PCR product of the appropriate size $(1.2 \mathrm{~kb})$. Digestion of this product with various restriction enzymes produced RFLP patterns that were identical to published patterns for phytoplasmas in the aster yellows phytoplasma subgroup 16SrI-A. DNA sequencing confirmed this result. This is the first report of the aster yellows phytoplasma in alfalfa. Complementary studies on distribution, modes of transmission, and agronomic impacts of phytoplasma in alfalfa are being conducted.

Modeling infection conditions for Puccinia graminis subsp. graminicola on perennial ryegrass and tall fescue seed crops. W. F. PFENDER and S. S. Vollmer. USDA-ARS, NFSPRC, Corvallis, OR 97331. Phytopathology 89: S60. Publication no. P-1999-0428-AMA.

Once a week for 16 weeks, 40 greenhouse-grown perennial ryegrass (PR) plants (10 wk old) were sprayed with a standardized inoculum of stem rust urediniospores, then placed in the canopy of a 2-ha PR seed field. After $18 \mathrm{hr}$ in the field, plants were returned to the greenhouse and maintained, with no leaf-water contact, until pustules erupted. Correlations were sought between number of infections (pustules) and environmental conditions during field exposure. The experiment was done also with tall fescue (TF). Night temperature below $2 \mathrm{C}$ appeared inhibitory to stem rust infection in both grasses. For PR, pustule number was proportional to nighttime heat units (degreehours above $2 \mathrm{C}$ ) times a hyperbolic saturation function for nighttime wetness (hr of leaf wetness plus hr of RH > 95\%). The nighttime low temperature could be substituted for heat units, with modification of the proportionality constant. For TF, a different proportionality constant was required and the low night temperature gave a better fit than heat units did. For both grasses, the best fit for data included a threshold minimum wetness duration: approx. $1.5 \mathrm{~h}$ for PR and $5 \mathrm{~h}$ for TF.

Transgene suppression of terpenoid defense compound biosynthesis in cotton. M. L. PIERCE, M. Essenberg, Y.-S. Chen, and M. A. Patil. Oklahoma State University, Stillwater, OK. Phytopathology 89:S60. Publication no. P-1999-0429-AMA.

Delta-cadinene synthase ( $c d n 1-\mathrm{C})$ cDNA in anti- and plus-sense orientations with a CaMV35S promoter was transferred by Agrobacterium-mediated transformation. PCR indicated $85-90 \%$ of regenerated plants contain a transgene. Southern analysis of four plants showed 1, 2, 2, and 6 copies. Ability of the transgene to suppress activity of CDN1 was surveyed by determining young leaves' contents of terpenoid aldehydes. Controls averaged $0.24 \mathrm{mg} / \mathrm{g}$ FW (s.d. 0.07); anti-sense plants averaged 0.19 (s.d. 0.14); plus-sense plants, 0.18 (s.d. 0.11 ). The best anti-sense line had $14 \%$ of normal levels, the best four co-suppressed lines had 2 to $8 \%$ of normal. Coker line 312-5a, used for transformation, is susceptible to Xanthomonas campestris pv. malvacearum. We chose pv. vesicatoria to test effects of $c d n 1$-C suppression on disease resistance. In one experiment, bacterial growth yields at 72 and 120 hpi were negatively correlated with CDN1 activities; correlation was strongest for plus-sense transformants (R: 0.70 ). Average CDN1 activity in test plants was $45 \%$ of the control value. Supported by NSF and Okla. Agric. Exp. Sta.

Potyviral infection inhibits the host translation machinery. D. PLANTE (1), J.-F. Laliberte (2), and M. G. Fortin (1). (1) McGill University, Montreal, Canada; (2) Institut Armand-Frappier, Laval, Canada. Phytopathology 89: S60. Publication no. P-1999-0430-AMA.

Potyviruses are ss(+)RNA viruses encoding a single polyprotein that is proteolytically cleaved to yield mature viral proteins. The $5^{\prime}$ end of the viral RNA is covalently linked to the viral protein genome-linked (VPg) which is the N-terminal portion of the larger VPg-Proteinase (VPgPro). VPg has been identified as a virulence determinant for other potyviruses such as TEV, TVMV and PSbMV. Recently, it was shown that VPgPro of turnip mosaic potyvirus (TuMV) interacts with a host factor involved in translation initiation, the cap-binding protein eIF(iso)4E. Binding of eIF(iso)4E to capped mRNAs is the first step of translation initiation. To investigate the biological effects of this interaction, we have used a protoplast transfection system and a full-length infectious cDNA clone. We have shown that TuMV transfection lead to decreased host translation rates; translation decreased for the first 30 hours and recovered over the next 24 hours. We believe that the effect of the virus on translation of host cellular mRNAs is in fact caused by VPgPro: expression of VPgPro alone in protoplasts lead to a similar decrease in translation.

A preliminary study on the causal agent of mango malformation in Egypt. R. C. PLOETZ (1), J. L. Haynes (1), A. Vazquez (1), J. F. Leslie (2), and A. El-Sattar (3). (1) University of Florida, Homestead, FL; (2) Kansas State University, Manhattan, KS; (3) Suez Canal University, Ismailia, Egypt. Phytopathology 89:S60. Publication no. P-1999-0431-AMA.

Mango, Mangifera indica L., is an important domestic and export commodity in Egypt. A major constraint in the production of this fruit is malformation, caused by Fusarium subglutinans. In 1998, a malformation survey was conducted in mango-production areas in the Giza, Ismailia and Sharkaia Governerates in lower Egypt and $75 \mathrm{~km}$ to the south of Giza in the El-Fayoum Governerate. A total of 194 strains were recovered from 80 trees of 20 different cultivars on 18 farms; representative strains from the collection were evaluated for vegetative and sexual compatibility. At least four different VCGs were detected, and strains within each were correlated with farm and Governerate, but not cultivar. Different VCGs were recovered from different panicles on the same tree twice. VC results indicate that strains from lower Egypt are at least partially responsible for the recent appearance of the disease in El-Fayoum.

DF pheromone-producing bacteria from cauliflower seed and plants, may suppress black rot of crucifers caused by Xanthomonas campestris pv. campestris. A. R. POPLAWSKY and W. Chun. University of Idaho, Moscow ID 83844-2339. Phytopathology 89:S60. Publication no. P-1999-0432-AMA.

The Xanthomonas campestris pv. campestris (Xcc) pheromone DF, is needed for epiphytic survival and host infection. pigB mutant strains of the pathogen don't produce DF, but can be extracellularly restored by DF. In one experi- 
ment, a pigB mutant strain showed unusually high levels of epiphytic survival, and two DF-producing strains were isolated from these cauliflower plants and their seed. Isolate 758A was found on leaves at a level of $2.0 \times 10^{4}$ $\mathrm{CFU} / \mathrm{g}$ fresh weight, and isolate $758 \mathrm{~B}$ was obtained from seed at a rate of 1.3 $\mathrm{CFU} / \mathrm{g}$. They were tentatively identified as Stenotrophomonas maltophilia (758A), and X. vesicatoria (758B) with Biolog GN plates. Parent Xcc strain (B-24) and 758A were sprayed on plants separately, and as equal numbered mixtures in two experiments. After three weeks, no lesions were observed with $758 \mathrm{~A}, 1.6$ or 2.1 lesions/plant were observed with B-24, and 0.0 or 0.1 lesions/plant were observed with the mixtures. Thus, although strain 758A may have aided epiphytic survival of the Xcc pigB mutant strain, it has potential as a biocontrol agent for disease-causing strains of $X c c$.

The Xanthomonas campestris pv. campestris DF pheromone and additional regulatory functions of the pig gene cluster. A. R. POPLAWSKY and W. Chun. University of Idaho, Moscow ID 83844-2339. Phytopathology 89:S61. Publication no. P-1999-0433-AMA.

The causal agent of black rot of crucifers, Xanthomonas campestris pv. campestris $(X c c)$, produces the pheromone, DF. This pheromone is needed for xanthomonadin pigment and EPS production, epiphytic survival, and host infection via hydathodes. Two of the seven xanthomonadin transcriptional units, $\operatorname{pig} B$ and $\operatorname{pig} D$, have been previously implicated in the pheromone system. A functional pigB is needed for pheromone production, and pigB mutant strains can be extracellularly restored by DF. The predicted protein product of the proximal end of $\operatorname{pig} B$ has similarity to the $\operatorname{ppr} B$ gene product of Pseudomonas putida, which is thought to have a regulatory function. Additional pig $B$ DNA sequence data will be presented. Further mutation of a pigB mutant strain resulted in an isolate (B24-B2D) which could not be restored for xanthomonadin or EPS production by DF. Subclone pIG202 which contains pigC, pigD, pigE, and pigF, restored strain $\mathrm{B} 24-\mathrm{B} 2 \mathrm{D}$ for response to DF. A subclone containing only pigD was unable to restore strain B24-B2D for response to DF. Thus, other regions of pIG202 are being tested for genes which have a role in DF response.

Transmission of mild and decline-inducing isolates of citrus tristeza virus by the brown citrus aphid. C. A. POWELL, Y. Lin, and R. H. Brlansky. University of Florida, IFAS, IRREC, Fort Pierce, FL 34945, and CREC, Lake Alfred, FL 33850. Phytopathology 89:S61. Publication no. P-1999-0434AMA.

Single aphid transmission (SAT) and multiple aphid transmission (MAT) tests were done using the brown citrus aphid (BCA), Toxoptera citricida (Kirkaldy). Aphids were allowed an acquisition access period of $24 \mathrm{~h}$ on either Duncan grapefruit or Mexican lime plants infected with mild isolates, decline-inducing Florida isolates or a mixture of mild and the declineinducing isolates of citrus tristeza virus (CTV). Single aphids were then transferred to Mexican lime seedlings and allowed an inoculation access period of $24 \mathrm{~h}$. At Fort Pierce, FL SAT were 1.96\%, 0\% and 4.2\% for the mild, decline-inducing and the mixture of the two isolates, respectively. At Lake Alfred, FL the mild isolate was transmitted at $2.5 \%$ and the decline isolate at $1.1 \%$. Using MAT tests (20 aphids) the mild isolate was not transmitted while the decline isolate was transmitted at $10 \%$. In a field test $18 \%$ of trees became infected with CTV within one year. These results suggest that individual BCA are inefficient vectors of CTV and rapid field spread of the virus occurs with high populations of the aphid.

Taxonomic clarification of the dollar spot pathogen: Sclerotinia homoeocarpa Bennett. J. F. POWELL and J. M. Vargas, Jr. University of Minnesota, St. Paul, MN, and Michigan State University, East Lansing, MI. Phytopathology 89:S61. Publication no. P-1999-0435-AMA.

The taxonomic status of the dollar spot pathogen, Sclerotinia homoeocarpa Bennett, has been in question since the 1940's. Previous work has shown that this organism does not belong to the genus Sclerotinia, but should be placed within the genera Rutstroemia, Lanzia, or Moellerodiscus. ITS1 sequences from $S$. homoeocarpa isolates from North America were compared with isolates from Britain, the cultures used to describe the species S. homoeocarpa, and members of the genera Rutstroemia, Lanzia, and Moellerodiscus. Parsimony analysis identified that $S$. homoeocarpa clustered within the genus Rutstroemia. The teleomorphic strain of $S$. homoeocarpa used to describe the species exhibited closer relations to Rutstroemia cuniculi and $R$. henningsianum than to isolates responsible for causing dollar spot. ITS1 and ITS2 sequences of isolates from North America expressed sequence divergences from isolates from Britain of 16 and 15 bases, respectively. Differences in mycelial and stromatal morphology between these groups also exist.
Combining tolerance and resistance to wheat streak mosaic virus (WSMV). M. Pradhan (1) and S. HABER (2). (1) University of Manitoba, Winnipeg, MB; (2) Agriculture Canada, Winnipeg, MB. Phytopathology 89: S61. Publication no. P-1999-0436-AMA.

Both tolerance and resistance to virus infection can contribute to a host's good performance under disease pressure. Tolerance to WSMV infection derived from BW155 (elite, spring bread wheat) was shown to be consistent with 3 dominant genes in analyses of three rounds of crossing to elite, susceptible lines and generation of doubled-haploid (DH) populations from which the most tolerant lines were selected. Resistance to WSMV was derived from KS95H103 (winter wheat with major resistance gene Wsm1) by backcrossing to the susceptible spring wheat cultivar, AC Elsa $(\mathrm{BC} 1 \mathrm{~F} 1=$ '7166'). To combine tolerance and resistance, $120 \mathrm{DH}$ lines were generated from BW155 $\times 7166$ and reciprocal crosses, and screened under disease pressure and controlled conditions which abolished the temperature-sensitive Wsm1-conferred resistance. Lines which performed well in this regime were considered to have derived tolerance from BW155, and those which also contained a closely-linked SCAR marker for Wsm1, to possess both tolerance and resistance to WSMV.

Cloning and sequencing of a peanut Bowman-Birk trypsin inhibitor gene. L. D. PRICE, O. M. Viquez, P. A. Gay, and H. W. Dodo. Alabama A\&M University, Normal, AL. Phytopathology 89:S61. Publication no. P-1999-0437-AMA.

Peanut is an important oilseed crop and a valuable source of protein. It represents an economic and agricultural value worldwide. Peanut crop losses increase on an annual basis. Pathogens and pests account for up to $37 \%$ of the estimated losses worldwide, and $13 \%$ are due to insect attack. Proteinase inhibitors provide natural pesticide resistance against insects and pathogens and are commonly found abundantly in seeds and storage tissues. The objective of this study was to isolate and characterize a Bowman-Birk trypsin inhibitor gene from peanut. A peanut cDNA library in a Lambda gt11 vector was screened utilizing a degenerate oligonucleotide primer which directly corresponds to the reported amino acid sequence of a Bowman-Birk trypsin inhibitor. Eighteen putative positive clones were identified through three rounds and the DNA was isolated and transferred to a nitrocellulose membrane for dot blot analysis. Three of these clones strongly hybridized to the oligonucleotide. Sequence analysis confirmed the identity of the clones. Further investigations for the development of transgenic peanut with enhanced trypsin inhibitor expression is under way.

Development of a PCR-based seed assay for the detection of Alternaria radicina from infested carrot seed. B. M. PRYOR and R. L. Gilbertson. University of California, Davis, CA. Phytopathology 89:S61. Publication no. P-1999-0438-AMA.

A PCR-based seed assay was developed for the detection of $A$. radicina from infested carrot seed. PCR primers for A. radicina were developed based upon the sequence of a random amplified polymorphic DNA (RAPD) fragment generated from total genomic DNA. This assay involved a 5-day incubation step in which seed was maintained under high humidity conditions in order to increase fungal biomass. DNA was recovered by incubation of seed in lysis buffer followed by phenol/chloroform extraction and a silica-based DNA purification step. PCR detection of the target DNA sequence was enhanced by the addition of skim milk to the PCR reaction mixture. The $A$. radicina primer pair was able to direct the amplification of the target DNA sequence from as little as $200 \mathrm{fg}$ DNA, and the PCR-based seed assay detected A. radicina in naturally infested seed lots at levels as low as $0.3 \%$. In samples of $A$. radicina-infested seed that were serially diluted with noninfested seed, the PCR-based assay detected the pathogen at infestation levels as low as $0.1 \%$.

Survival of Trichoderma harzianum, biotype Th4, after post-crop heat treatments during the mushroom crop cycle. C. PUNSHON (1), D. Rinker (2), and R. Hall (1). (1) Dept. of Environmental Biology and (2) Dept. Plant Agriculture, University of Guelph, Guelph, ON, Canada N1G 2W1. Phytopathology 89:S61. Publication no. P-1999-0439-AMA.

Trichoderma harzianum, biotype Th4, causes Trichoderma green mould disease in North America. This disease affects commercial production of mushrooms (Agaricus bisporus), and results in dramatic yield reductions. Previous examination of commercial crops revealed that Th4 could withstand high temperature steam treatment at the end of the mushroom crop cycle. The 
objective of this research was to examine survival of Th4 at temperatures of $55-60^{\circ} \mathrm{C}$. An infested mushroom crop was treated with steam in the growing room $\left(60^{\circ} \mathrm{C}\right)$ at early to late stages of the crop cycle and portions of compost and casing were assessed for survival of the fungus. Before steaming, compost and casing samples were removed and heated in test tubes in a water bath at 55 and $60^{\circ} \mathrm{C}$. Survival was determined by regrowth on agar plates. Survival of $\mathrm{Th} 4$ at $55-60^{\circ} \mathrm{C}$ in test tubes increased later in the crop cycle but remained low and constant in steamed compost and casing. The results suggest that elimination of Th4 by heat becomes more difficult as the mushroom crop ages.

Reductions of Pierce's disease vector activity by management of riparian woodlands. A. H. PURCELL, S. R. Saunders, E. Norberg, and J. R. McBride. University of California, Berkeley, CA. Phytopathology 89:S62. Publication no. P-1999-0440-AMA.

The principal vector of the bacterium (Xylella fastidiosa) that causes Pierce's disease (PD) of grapevines in coastal California is the blue-green sharpshooter (BGSS), Graphocephala atropunctata. Sweep net surveys revealed that two species of blackberry, California mugwort, elderberry, and wild grape were the main breeding hosts of BGSS. Removing these plants from riparian woodlands bordering vineyards reduced the numbers of BGSS captured on yellow sticky traps or by sweep net from $68 \%$ to $99 \%$, compared to adjoining undisturbed control plots in sites on two different streams in Napa Valley during 1995-98. Reductions of BGSS corresponded with the thoroughness of removing targeted species. A third site added during 1998-99 contained several additional species of BGSS's breeding hosts. Restorative plantings that increased plant biodiversity on each site did not increase BGSS trap catches. Effects of vector reductions on the control of PD must await future assessments of newly planted vineyards adjacent to riparian plots. Problems and prospects for implementation will be discussed.

Some properties of a possible potexvirus isolated from Trichosanthes dioptera (Cucurbitaceae) in Florida. D. E. Purcifull (1), G. W. Simone (1), E. Hiebert (1), M. A. PETERSEN (1), S. E. Webb (2), T. A. Kucharek (1), K. A. Beckham (1), and W. E. Crawford (1). (1) Plant Pathology Dept., University of Florida, Gainesville 32611; (2) Central Florida Research and Education Center, University of Florida, Leesburg 34748. Phytopathology 89: S62. Publication no. P-1999-0441-AMA.

In 1986, a virus (1860) was mechanically transmitted to squash from $T$. dioica collected in Dade Co., Florida. The 1860 isolate induced veinal chlorosis and mosaic in squash and pumpkin leaves, and also systemically infected cucumber, watermelon, muskmelon, quinoa, and sesame. Filamentous particles c. $536 \mathrm{~nm}$ long were seen in extracts from pumpkin leaves, and inclusion bodies consisting of bands of particles were seen in thin sections of leaves. In SDS-immunodiffusion, antiserum to SDS-treated, purified 1860 reacted with extracts from the systemically infected test plants. In reciprocal SDSimmunodiffusion tests, the 1860 isolate gave reactions of partial identity with papaya mosaic potexvirus. The 1860 isolate was not transmitted either in a nonpersistent manner by Myzus persicae or in a persistent manner by Aphis gossypii. Based on the results, the 1860 isolate is tentatively identified as a potexvirus.

Aspects of water related to colonization and infection of pomaceous flowers by Erwinia amylovora. P. L. PUSEY. USDA-ARS, Tree Fruit Research Laboratory, Wenatchee, WA. Phytopathology 89:S62. Publication no. P-1999-0442-AMA.

Effect of water on the interaction between Erwinia amylovora and flowers was studied using crab apple as a model. Detached flowers were held at $24^{\circ} \mathrm{C}$ with peduncle submerged in a sucrose solution. In one test, inoculum was applied to the stigmas. After $24 \mathrm{~h}$ in $85 \%$ relative humidity (RH), flowers were subjected to various wetting periods before drying and returning to $85 \%$ RH. Only the flowers subjected to wetting showed detectable bacteria in the floral cup (site of nectaries) and became diseased; incidence was near 100\%, whether drying (30-60 min) was started immediately or $48 \mathrm{~h}$ after applying water. In other tests, inoculum was added directly to the floral cup. As one set of conditions, flowers were held in $10 \%$ sucrose and $\mathrm{RH}$ ranged from 40 to $100 \%$. Alternatively, flowers were held in 85 or $100 \%$ RH and sucrose varied from 0 to $25 \%$. Interrelationships of nectar volume, nectar water potential, nectar sugar, and E. amylovora were consistent with earlier field studies. Results also indicated that flowers with water potentials below -1.5 or $-2.0 \mathrm{Mpa}$ had a relatively low susceptibility. The full relevancy of the study will depend on further research with intact plants.
Selection and field testing of Pantoea agglomerans strain E325 for biocontrol of fire blight of apple and pear. P. L. PUSEY. USDA-ARS, Tree Fruit Research Laboratory, Wenatchee, WA. Phytopathology 89:S62. Publication no. P-1999-0443-AMA.

About 800 epiphytic microorganisms from pomaceous flowers or fruit, including 110 strains of Pantoea agglomerans, were evaluated as potential biocontrol agents for fire blight. Efficacy was assessed as the ability of antagonists to limit the population size of Erwinia amylovora on stigmas of detached crab apple blossoms. The most effective antagonist was $P$. agglomerans strain E325, collected from 'Gala' apple blossoms. Field trials in 1997 and 1998 were done by enclosing apple trees in cages to reduce cross contamination due to bees and to increase daytime temperatures. Bacteria and pollen were applied by brush and subsequent wetting occurred via a mist system. Size of pathogen populations on flowers correlated with disease incidence. Range and statistical separation of mean values for disease incidence among treatments were greater for caged versus non-caged trees. On caged trees, treatments with strain E325 provided from 73 to $79 \%$ control, whereas the standard treatment with Pseudomonas fluorescens strain A506 provided 27 or $37 \%$ control and that with P. agglomerans strain C9-1 provided 44 or 55\% control. A U.S. patent for strain E325 is pending.

Differential expression of rice $P R-1$ and $P R-10$ genes induced by blast fungus, elicitor, and chemical treatments. M. Qi and Y. YANG. Department of Plant Pathology, University of Arkansas, Fayetteville, AR 72701. Phytopathology 89:S62. Publication no. P-1999-0444-AMA.

Pathogenesis-related (PR) proteins are frequently associated with plant disease resistance and are important markers of host defense responses. As an initial step to understand the host defense mechanism in rice, we have identified three distinct $P R-1$ genes and one $P R-10$ gene induced by Pyricularia grisea infection. These rice $P R$ genes were induced sooner and their expression lasted longer after inoculation with the avirulent isolate (resistant interaction) of blast fungus than with its virulent mutant (susceptible interaction). Two of the $P R-1$ genes were constitutively expressed in cell suspension cultures, but the other $P R-1$ gene and the $P R-10$ gene were not detectable in cell suspensions. Neither $P R-1$ nor $P R-10$ genes are significantly induced by salicylic acid. In contrast, they are strongly activated by the cell wall elicitor prepared from blast fungus. One of the $P R-1$ genes and the $P R-10$ gene were also activated by the treatment of benzothiadiazole, a plant defense activator.

Strains of Xylella fastidiosa isolated from diseased orange trees in Brazil have a relatively homogeneous population structure. Xiaoting QIN and John S. Hartung. USDA-ARS Fruit Laboratory, Beltsville, MD 20705. Phytopathology 89:S62. Publication no. P-1999-0445-AMA.

Xylella fastidiosa causes both Citrus Variegated Chlorosis disease of sweet orange and Coffee Leaf Scorch in Brazil. Sixty four strains of X. fastidiosa isolated from diseased citrus and sweet orange in Sao Paulo State were analyzed by REP-, ERIC- and RAPD-PCR in comparison with strains from seven other hosts. No variation was observed among the citrus and coffee strains of $X$. fastidiosa using either REP- or ERIC-PCR. Limited variation was observed with certain primers in RAPD-PCR assays. Variation was observed between these strains and those from other hosts in the same assays. Digestion of a unique PCR amplification product used previously for identification of the citrus strains with endonuclease $C f o$ I revealed a polymorphism between the citrus and coffee strains. Thus the strains of $X$. fastidiosa in Brazil which cause important diseases on citrus and coffee are closely related yet distinguishable. They are quite distinct from all previously described strains of $X$. fastidiosa.

Analysis of viral factors affecting accumulation of tomato bushy stunt virus RNAs. W. P. QIU, J.-W. Park, and H. B. Scholthof. Department of Plant Pathology and Microbiology, Texas A\&M University, College Station, TX 77843. Phytopathology 89:S62. Publication no. P-1999-0446-AMA.

Tomato bushy stunt virus (TBSV), a single-stranded plus-sense RNA virus, is notorious for its prolific replication of genomic RNA and trans-replication of defective interfering (DI) RNAs. This study aimed to analyze the influence of viral RNA sequences versus capsid protein and movement proteins on replication events. Time-course assays indicated that capsid protein or movement proteins did not significantly affect early replication of TBSV, but an RNA segment encompassing these genes enhanced the level of very early replication. Conversely, replication assays using mutants with deletions in the replicase gene delimited a cis-acting RNA element in the $5^{\prime}$ proximal region of the replicase gene that strongly inhibited trans-replication. The relocation of this inhibitory element to a trans-replication competent DI RNA 
prevented trans-replication only when inserted in the opposite orientation. These results imply that TBSV possesses multiple cis-acting regions with stimulatory or inhibitory effects on replication.

Mutations in CCMV RNA 1 that effect phloem-dependent movement in cowpea. S. QUAN and C. M. Deom. The University of Georgia, Athens, GA. Phytopathology 89:S63. Publication no. P-1999-0447-AMA.

The movement of virus progeny throughout a plant host is broadly divided into two phases, cell-to-cell movement and systemic (phloem-dependent) movement. Because systemic movement is the dissemination of virus throughout the plant, understanding how viruses systemically invade plants is central to understanding how these pathogens cause disease. Virus replicase-associated proteins apparently play a role in induction of virus systemic movement. The $\mathrm{T}$ strain of cowpea chlorotic mottle virus (CCMV) does not move systemically in the cowpea plant introduction (PI) 186465, but the mutant strain CCMV-R does move systemically. The viral determinant of systemic movement was previously mapped to RNA1, which encodes a replicase-associated protein that contains amino acid motifs for both a putative methlytransferase domain and a putative helicase domain. We have synthesized and sequenced the RNA1 cDNAs of both strains. By constructing hybrid cDNAs, 5 out of the 9 amino acid differences have been excluded from being determinants of systemic movement. Nucleotide changes responsible for determining systemic movement of the $\mathrm{R}$ strain and the biology of the $\mathrm{T}$ and $\mathrm{R}$ strains on the PI will be discussed.

A computer simulation of fungal expansion based on morphological components. J. A. QUINN. Rohm and Haas Co., Spring House, PA. Phytopathology 89:S63. Publication no. P-1999-0448-AMA.

A new program for WINDOWS based computers calculates growth of colonies and expansion of populations of colonies based on input of a few morphological parameters. These parameters include mean length of the hyphal unit supporting one branch, the time it takes to form that hyphal unit, the number and timing of sporulating structures per hyphal unit, and the number of germ tubes forming over time from the original propagule. Graphic representations of growing colonies are made using this premise (as in Phytopathology 76:883). In addition, with the addition of a few more parameters, the model is expanded to model growth of whole populations, including competition between two strains of fungi with different morphological characteristics. Additional inputs needed are amount and timing of primary inoculum, infection efficiencies of primary and secondary inoculum, amount of host tissue and growth of the host. Finally, a simple model of the effect of adding 1-2 contact fungicides is included. Output includes amount of hyphal tissue, number of colonies and percent infection over time. The program and source code can be downloaded from http://www.rohmhaas.com/businesses/ AgChem/fungcalc/default.htm.

Dithane DF NT Rainshield, a new mancozeb formulation with increased rain-fastness. J. A. QUINN, F. J. Rette, E. C. Kostansek, S. J. Johnson, J. Watts, and R. D. Houghton. Rohm and Haas Co., Research Laboratories, Spring House, PA. Phytopathology 89:S63. Publication no. P-1999-0449AMA.

A new formulation of mancozeb has been developed with improved rainfastness. At normal field use rates (1.2-2.4 kg ai/ha), with full coverage in the greenhouse, $>25 \mathrm{~mm}$ of rain are required before standard mancozeb formulations begin to lose efficacy against Phytophthora infestans or Alternaria solani on potatoes and tomatoes. DITHANE DF NT RAINFAST increases the level of control when rain exceeds $50 \mathrm{~mm}$. In rain-fastness tests, this formulation gave better disease control than that of any other protectant fungicide we tested. Favorable evaluations of the appearance and sprayability of the formulation by growers will also be presented.

RH-7281: Rain-fastness and redistribution. J. A. QUINN, W. J. Wilson, J. Andrews, and F. J. Rette. Rohm and Haas Co., Spring House, PA. Phytopathology 89:S63. Publication no. P-1999-0450-AMA.

RH-7281 is a fungicide under development for control of diseases caused by Oomycetes. As measured by leaf surface soluble residues, it is extremely rain-fast and wind-fast. It also slows loss of mancozeb residues due to weathering when the two materials are co-formulated as a dry flowable. This results in a combination product with very good field performance against potato late blight. Rain-fastness is not greatly affected by simulated rain timing (1, 4 or 24 hrs after application) or intensity of simulated rain (only by amount of rain). RH-7281 has good redistribution from spray deposits to untreated areas of leaves under conditions of low moisture, as measured by control of potato late blight. This is an unusual property, which indicates movement in the leaf surface air boundary layer.

Relationship between root colonization and in situ antibiotic production by Pseudomonas fluorescens. J. M. RAAIJMAKERS (1), R. F. Bonsall (2), and D. M. Weller (1). (1) USDA-ARS, Pullman, WA 99164; (2) Dept. Plant Pathology, Washington State University, Pullman, WA 99164. Phytopathology 89:S63. Publication no. P-1999-0451-AMA.

The role of antibiotics in biological control of soil-borne pathogens and microbial antagonism in natural disease-suppressive soils often has been questioned because of the indirect nature of the supporting evidence. This study demonstrates that the antibiotic 2,4-diacetylphloroglucinol $(\mathrm{Phl})$ is produced on roots of wheat grown in a soil naturally suppressive to take-all of wheat. This result provides, for the first time, biochemical support for a role of Phlproducing fluorescent Pseudomonas spp. in take-all suppressive soils. This study also shows that the total amount of Phl produced on roots of wheat by introduced $P$. fluorescens Q2-87, at densities ranging from approximately $10^{5}$ to $10^{7} \mathrm{CFU} / \mathrm{g}$ root, is proportional to its rhizosphere population density, and that $\mathrm{Phl}$ production per population unit is a constant $\left(0.62 \mathrm{ng} \times 10^{-5} \mathrm{CFU}\right)$. Thus, Phl production in the rhizosphere of wheat is strongly related to the ability of the introduced Pseudomonas strain to colonize the roots.

Diversity and rhizosphere competence of 2,4-diacetylphloroglucinol (Phl)producing Pseudomonas strains. J. M. RAAIJMAKERS, K. Hayes, L. S. Thomashow, and D. M. Weller. USDA-ARS, Pullman, WA 99164. Phytopathology 89:S63. Publication no. P-1999-0452-AMA.

$125 \mathrm{Phl}$-producing Pseudomonas strains were randomly isolated from a takeall suppressive soil. RAPD analysis revealed 16 different groups with a dominant group representing $44 \%$ of the isolates. Q8r1-96, a representative of the dominant group, was compared to two other Phl-producing strains Q2-87 and 1M1-96 for its ability to colonize the wheat rhizosphere and to control take-all. The strains were introduced individually into a raw soil at $10-100 \mathrm{CFU} / \mathrm{g}$ of soil and wheat was grown for eight successive cycles of three weeks each. Q8r1-96 established and maintained rhizosphere population densities that were at least 100-fold greater than those of Q2-87 and 1M1-96. After eight cycles, Q8r1-96 suppressed take-all introduced into the soil whereas Q2-87 and 1M1-96 were not effective anymore. Q8r1-96 establishes a population density of $10^{7} \mathrm{CFU} / \mathrm{g}$ of root with a dose of only $10^{2}$ $\mathrm{CFU} /$ seed, whereas 1M1-96 and Q2-87 need doses of $10^{4}$ and $10^{5}$ respectively. The results suggest that knowledge of the diversity within a group of strains that share a common mechanism may provide a means to improve biocontrol.

Induction of resistance against bacterial and fungal pathogens in apple by prohexadione-Ca. W. RADEMACHER (1), J. B. Speakman (1), J. R. Evans (2), S. Roemmelt (3), and D. Treutter (3). (1) BASF Agricultural Center, 67114 Limburgerhof, Germany; (2) BASF Corporation, Research Triangle Park, NC; (3) Technical University of Munich, 85350 Freising, Germany. Phytopathology 89:S63. Publication no. P-1999-0453-AMA.

Prohexadione-Ca (BAS $125 \mathrm{~W}$ ) is currently being developed as an inhibitor of excessive vegetative growth in apples. In addition to the control of shoot growth, pronounced effects on the incidence of scab (Venturia inaequalis) and fire blight (Erwinia amylovora) have been observed, which are not due to any fungicidal or bactericidal effect of the compound. Prohexadione-Ca induces marked changes in the metabolism of phenylpropanoids, most likely by inhibiting flavanone 3-hydroxylase. The content of flavonoids, such as luteoliflavan and eriodyctiol, is drastically increased and reaches levels in the range of 50 milligrams per gram of dry young shoot tissue. Simple phenols, the identity of which is still unknown, are also detected at far higher concentrations. Since phenylpropanoids have often been found to be involved in defense mechanisms of crop plants, further studies on their role in pathogen resistance in apple are justified from theses results.

Prohexadione-Ca: Effects against scab in apples. W. RADEMACHER (1), G. Stammler (1), and P. Creemers (2). (1) BASF Agricultural Center, 67114 Limburgerhof, Germany; (2) Royal Research Station of Gorsem, 3800 SintTruiden, Belgium. Phytopathology 89:S63. Publication no. P-1999-0454AMA.

Many trials have demonstrated that apple trees treated with the plant growth regulator prohexadione-Ca (BAS $125 \mathrm{~W}$ ) are less susceptible to fire blight. In further investigations, we have studied the effect of this compound against 
apple scab (Venturia inaequalis). Working with apple seedlings and artificial inoculation under glasshouse and field-like conditions, scab infestation could be reduced by pretreatment with prohexadione-Ca. This effect was only marginal if inoculations were made shortly after treatment. However, highly significant effects were found when the time span between application and inoculation was extended to one to four weeks. Preliminary results from orchard trials support these findings. We assume that, similar to the situation with fire blight, changes in phenylpropanoid metabolism are mainly responsible for the reduced scab incidence. It should not be ruled out, however, that anatomical and morphological changes caused by prohexadione-Ca may also contribute to this effect.

Baseline sensitivity distribution of Rhizoctonia solani isolates causing sheath blight of rice to azoxystrobin. V. Rajkovska, G. OLAYA, and E. Tedford. Zeneca Ag Products, Western Research Center, Richmond, CA 94804. Phytopathology 89:S64. Publication no. P-1999-0455-AMA.

Isolates of Rhizoctonia solani were collected from different rice growing regions across the United States and where the strobilurin fungicide azoxystrobin had not previously been used. A sensitivity assay was conducted using turf instead of rice plants. $R$. solani isolates tested in this study were pathogenic and virulent to turf. Sensitivity to azoxystrobin was determined by inoculating perennial ryegrass (Lolium perenne) grown in $4 \times 4$-inch pots. Two weeks after planting, turf was sprayed with azoxystrobin at 10, 5, 2.5, $1.25,0.625$ and $0 \mathrm{mg} / \mathrm{L}$. Twenty-four hours after fungicide application, turf was inoculated by placing four $R$. solani colonized ryeberries onto the center of each turf pot. The percentage of turf area infected was measured 4 days after inoculation and $\mathrm{ED}_{50}$ values were calculated. To validate the reliability of this test, three of the isolates were randomly selected and the assay was repeated 4 times. Based on the evaluation of $31 R$. solani isolates, the $\mathrm{ED}_{50}$ values $(\mathrm{mg} / \mathrm{L})$ relative to the percentage of turf area infected range from 0.352 to 2.778 , with a median value of 1.481 .

Tuber evaluation of late blight resistance (LBR) for nine potato accessions. V. RAMANJULU, Zhaowei Liu, and B. J. Christ. Dept. Plant Pathology, Penn State University, University Park 16802. Phytopathology 89:S64. Publication no. P-1999-0456-AMA.

Nine of the Solanum tuberosum late blight accessions and one cv. Katahdin were examined for tuber reaction to Phytophthora infestans isolate US 8. An incision was made across the center of each tuber and inoculated by placing $0.04 \mathrm{ml}$ of sporangial suspension containing 50000 sporangia/ml (approximately 2000 sporangia/tuber). Tubers were incubated in the dark at $12 \mathrm{C}$ and $90 \%$ RH for 12 days in plastic containers. Four plastic containers represented replications, each containing one tuber/accession. The lesion size and percentage of tuber surface area infected were assessed by a visual rating 12 days after inoculation. There were significant differences in lesion size and severity among the nine LBR accessions and Katahdin. Lesion size ranged from 10 to $99 \mathrm{~mm}$ and severity ranged from 6.3 to $86.3 \%$. In another experiment three different sporangial concentrations $(25000,50000,75000$ sporangia $/ \mathrm{ml}$ ) were used to determine effect of different inoculum concentrations on disease severity. Only three LBR accessions and Katahdin were tested. There were three replications. The lesion size varied from 27 to 67 $\mathrm{mm}$, penetration varied from 3 to $12 \mathrm{~mm}$ and severity varied from 10 to $88.3 \%$. Significant differences in lesion size, depth, and severity were found among the LBR accessions but not among the different concentrations.

Foliar and tuber resistance of late blight in forty-two potato clones. V. RAMANJULU (1), Zhaowei Liu (1), B. J. Christ (1), and K. G. Haynes (2). (1) Dept. Plant Pathology, Penn State University, University Park 16802; (2) USDA-ARS, Vegetable Lab, Beltsville, Maryland 20705. Phytopathology 89:S64. Publication no. P-1999-0457-AMA.

Forty-two clones from a diploid Solanum phureja-S. stenotomum, hybrid population were examined for lesion size and severity of foliage and tuber blight of Phytophthora infestans, isolate US 8. This population is being used for molecular mapping studies in our laboratory. A detached leaf assay was used in assessing foliar resistance. The experimental design was a randomized complete block design with 3 replications. A treatment consisted of a terminal leaflet inoculated with a drop of sporangial suspension (approximately 1500 sporangia/drop) and incubated at $16 \mathrm{C}$ and $70 \% \mathrm{RH}$ for 10 days. For assessing tuber resistance, tubers were inoculated by making an incision across the center of the tuber and placing approximately 2000 sporangia/ tuber within the incision. Tubers were incubated in the dark at $12 \mathrm{C}$ and $90 \%$ $\mathrm{RH}$ for 12 days in plastic containers. A randomized complete block design with 6 replications was used. Each container was a replication containing one tuber/clone. Lesion diameter and severity varied from 0 to $78 \mathrm{~mm}$ and 0 to $100 \%$ on foliage and 0 to $65 \mathrm{~mm}$ and 0 to $52.5 \%$ on tubers. Lesion diameter and severity differed significantly among the clones for both foliage and tuber resistance. The results showed that foliage and tuber blight resistance were not correlated.

Genetic variability of various plant hosts to Claviceps africana. B. A. Ramundo, M. R. Tuinstra, and L. E. CLAFLIN. Kansas State University, Manhattan, KS. Phytopathology 89:S64. Publication no. P-1999-0458-AMA.

Ergot (Claviceps africana) has been a problem in grain sorghum (Sorghum bicolor) in Africa and Asia for nearly 80 years. Ergot was recently introduced to the Americas and Australia and was detected in the United States in 1997. Ergot-resistant germplasm has been identified but these lines are photoperiodsensitive, tall and agronomically undesirable. A research project was initiated to evaluate the host range of C. africana. Various accessions of Sorghum sp. and potential grass hosts were inoculated and evaluated for their reaction to ergot under greenhouse conditions at Manhattan, KS in 1998. Inflorescences were inoculated by spraying a suspension of $2.0 \times 10^{5}$ macroconidia $/ \mathrm{ml}$ at anthesis and repeated after five days. The following accessions were susceptible to $C$. africana: S. drummondii, S. virgatum, S. arundinaceum, S. halepense, and S. bicolor (broomcorn, Tx623, P954063). Ergot symptoms were not observed on S. verticilliflorum (IS142257), S. drummondii (IS14131) finger millet, pearl millet, proso millet, foxtail millet, big bluestem, little bluestem, Osage indiangrass, switchgrass, maize, or Canada wild rye.

Pathogenic variability in Fusarium oxysporum lini on flax. K. Y. RASHID (1) and G. M. I. W. Kroes (2). (1) Agriculture and Agri-Food Canada, Research Centre, Morden, MB, Canada; (2) CPRO-DLO, Wageningen, The Netherlands. Phytopathology 89:S64. Publication no. P-1999-0459-AMA.

Fusarium wilt is a major disease problem affecting flax yield worldwide. Very little is known about the pathogenic variability in this fungus. A total of 64 single-spore isolates of Fusarium oxysporum lini from wilted plants from four locations in Manitoba and Saskatchewan were evaluated for virulence on 40 flax cultivars from diverse genetic background. The interaction of all isolates and cultivars were evaluated in replicated tests under indoor controlled growing conditions. Flax seedlings were inoculated by drenching with a quantitative spore suspension 1 week after seeding, and were assessed for disease severity 3 weeks after inoculation. Virulent isolates were common from all locations on some but not all cultivars, ranging from 4-10 cultivars. Several isolates from all locations were virulent only on 1-2 cultivars. Although some similarities occurred among virulence patterns of certain isolates from the four locations, no identical virulence patterns were identified among the 64 isolates. This demonstrates the complexity of the pathotypes in this pathogen.

New sources of resistance to white mold in Phaseolus vulgaris. Jack B. RASMUSSEN (1), Ken Grafton (2), and Christine Donohue (1). (1) Dept. of Plant Pathology and (2) Dept. of Plant Sciences, North Dakota State University, Fargo, ND. Phytopathology 89:S64. Publication no. P-1999-0460-AMA.

White mold, caused by Sclerotinia sclerotiorum (Lib.) deBary, is a serious disease on dry beans (Phaseolus vulgaris L.) in many parts of the world. It is the major yield-limiting disease in the border states of North Dakota and Minnesota where 950,000 acres are produced. We have initiated research with goals of identifying new sources of resistance to white mold, incorporating that resistance into breeding lines, and developing an understanding of the genetics of resistance. Toward these goals, we have screened the Mexican core collection of $\mathrm{P}$. vulgaris accessions for reaction to $S$. sclerotiorum. This screening, performed in the greenhouse with the "straw test" (Petzoldt and Dickson, 1996), identified several Mexican lines with resistance greater than that found in the resistant cultivar Bunsi. Some of the Mexican lines have been used as parents in crosses with the susceptible cultivar Othello. Progeny of these crosses will be used to develop recombinant inbred populations to identify and map useful QTLs associated with resistance.

Identification and characterization of genes expressed by the rice blast pathogen and host during early stages of infection. P. RAUYAREE, W. Choi, E. Fang, and R. A. Dean. Department of Plant Pathology and Physiology, Clemson University, Clemson, SC 29634. Phytopathology 89:S64. Publication no. P-1999-0461-AMA

Rice blast disease is one of the most serious diseases on rice worldwide. This disease is caused by the filamentous ascomycete fungus Magnaporthe grisea. To further understand molecular mechanisms regulating plant-fungal 
interactions, a cDNA library was constructed from the leaves of the variety Nipponbare infected with Magnaporthe grisea strain 70-15 at 48 hours postinoculation. The international community has selected Nipponbare for whole genome sequencing. The cDNA library was screened by differential hybridization on high-density macroarrays using nylon filters. Hybridization probes were made using plant and fungal genomic DNA as well as cDNA from different stages of fungal development and from rice plants at different times following inoculation with the fungus. Several hundred candidate fungal and plant genes expressed during infection were sequenced from their $5^{\prime}$-ends using ABI 377 sequencers. Results from this study and the putative functions of identified genes will be presented.

Suppression of Aphanomyces root rot of peas by non-pathogenic mutants of Pseudomonas corrugata. B. J. D. REDDY and W. Chun. University of Idaho, Moscow, ID. Phytopathology 89:S65. Publication no. P-1999-0462AMA.

Pseudomonas corrugata, (the tomato pith necrosis pathogen), suppresses growth of many fungi. Four non-pathogenic mutants were identified by screening mini-Tn5 derivatives in tomato plants. Mutants (7-34::Tn5, 9-1::Tn5, 27-27::Tn5, and 53-45::Tn5), and the wild-type parent (0782-6) were applied as $1 \%$ hydroxypropyl methyl cellulose $(4,000 \mathrm{cps})$ suspensions on Columbian green pea seeds (approximately $10^{8} \mathrm{CFU} /$ seed). Treated seeds were dried and planted in cone-tainers containing Aphanomyces euteiches infested field soil (150 oospores/g). At 21 days, emergence, plant height, shoot weight and root weight were recorded. Plants were rated with a disease severity scale $(0=$ healthy, $5=$ dead $)$. Emergence and disease severity ratings for 53-45:: $\operatorname{Tn} 5(53 \%, 3.9), 0782-6(33 \%, 4.0), 27-27:: \operatorname{Tn} 5(40 \%, 4.2)$, and $7-34:: \operatorname{Tn} 5(33 \%, 4.2)$ were statistically significant compared to the control $(17 \%, 4.8)$ and $9-1:: \operatorname{Tn} 5(23 \%, 4.7)$. Similar relationships were observed for mean plant heights and shoot weights but not root weights. Thus, pathogenicity in tomato is not directly related to biological suppression. Nonpathogenic $P$. corrugata can be an effective biological control agent.

Growth promotion and induced systemic resistance (ISR) mediated by a biological preparation. M. S. REDDY (1), R. Rodríguez-Kábana (1), D. S. Kenney (2), C. M. Ryu (1), S. Zhang (1), Z. Yan (1), N. Martinez-Ochoa (1), and J. W. Kloepper (1). (1) Dept. Plant Pathology, Auburn University, Auburn, AL 36849; (2) Gustafson, P.O. Box 660065, Dallas, TX 75266. Phytopathology 89:S65. Publication no. P-1999-0463-AMA.

The biological preparation LS213, which contains formulated spores of $B a$ cillus subtilis strain GBO3, B. amyloliquefaciens strain IN937a and a carrier, was added to soil-less potting mix and used to prepare transplants. Transplants were evaluated for growth promotion and ISR activity against foliar pathogens using the following pathosystems: tomato bacterial spot (Xanthomonas axonopodis pv. vesicatoria) and late blight (Phytophthora infestans), cucumber angular leaf spot (Pseudomonas syringae pv. lachrymans), and tobacco blue mold (Peronospora tabacina). Results showed that LS213 significantly increased seedling growth of all the crops at a level greater than that of the individual components. LS213 also induced disease protection against all the tested pathogens. Hence the synergistic effects of the components of LS213 on seedling growth were related to systemic protection against foliar diseases.

Aqueous formulations of PGPR for control of foliar pathogens. M. S. REDDY, C. M. Ryu, S. Zhang, and J. W. Kloepper. Department of Plant Pathology, Auburn University, Auburn, AL 36849. Phytopathology 89:S65. Publication no. P-1999-0464-AMA.

Powdered formulations of plant growth-promoting rhizobacteria (PGPR) in an organic carrier mixed into soil-less media were recently found to provide seedling growth promotion and to induce systemic disease protection. Enhanced field efficacy should occur with use of mid-season "booster" applications of PGPR, but this requires development and assessment of aqueous formulations of PGPR. The current study was conducted to select specific PGPR mixtures efficacious in reducing foliar diseases when applied as aqueous treatments. Nine different 2-strain aqueous mixtures of PGPR were evaluated as drench or foliar spray in greenhouse trials on tomato against bacterial spot (Xanthomonas axonopodis pv. vesicatoria), on cucumber against angular leaf spot (Pseudomonas syringae pv. lachrymans), and on tobacco against blue mold (Peronospora tabacina) and wild fire (P. syringae pv. tabaci). Results indicated that some aqueous PGPR treatments significantly reduced incidence of all diseases, and that overall, foliar sprays were more effective than drench treatments of the PGPR mixtures.
Maize necrotic streak, a new virus with sequence homology to tombusviruses. M. G. REDINBAUGH $(1,2)$, R. Louie $(1,2)$, D. T. Gordon (2), J. J. Abt (1,2), and R. J. Anderson (1). (1) USDA-ARS and (2) Plant Pathology, OARDC, The Ohio State University, Wooster, OH. Phytopathology 89:S65. Publication no. P-1999-0465-AMA.

A new maize-infecting virus, isolated from Arizona-grown plants, incited chlorotic spots, streaks and spindle-shaped rings with diffuse, necrotic margins on Seneca Chief sweet corn leaves following vascular puncture inoculation of kernels. The virus was not transmitted by rub inoculation, nor by selected aphid or leafhopper species. Purified virions were isometric $(28 \mathrm{~nm}$ diam.) and contained a $31 \mathrm{kDa}$ putative capsid protein and single-stranded RNA. High concentrations of the largest RNA (ca. $4.3 \mathrm{~kb}$ ) were observed in preparations of leaf RNA from symptomatic plants. Randomly primed cDNA clones of viral RNA hybridized with RNAs from virus-infected, but not from healthy, leaves. Sequence comparisons indicated the cDNAs had significant homology with the replicase and capsid genes of several tombusviruses. The data indicated the identification of a new maize-infecting virus, named maize necrotic streak virus, tentatively belonging to the Tombusviridae.

Seed and root rots of ginseng (Panax quinquefolius) caused by Cylindrocarpon destructans and Fusarium spp. R. D. REELEDER, R. Roy, and B. Capell. Southern Crop Protection and Food Research Centre, Agriculture and Agri-Food Canada, London, ON, Canada. Phytopathology 89:S65. Publication no. P-1999-0466-AMA.

Over the past two decades, ginseng has become one of the most valuable herb crops grown in North America. Traditional cropping environments are favourable to disease and significant losses due to root disease are common, despite frequent use of fungicides. Seedlots are often contaminated with pathogens, however, little is known about the causes of seed decay and the role of seed pathogens as incitants of root rots. Data presented show that both Fusarium spp. and Cylindrocarpon destructans are able to rot seeds but that C. destructans is a more virulent root pathogen. A modified rose bengal agar (MRBA) medium containing: $1 \mathrm{~g} \mathrm{KH}_{2} \mathrm{PO}_{4} ; 0.5 \mathrm{~g} \mathrm{MgSO}_{4} \cdot 7 \mathrm{H}_{2} \mathrm{O} ; 50 \mathrm{mg}$ rose bengal; $10 \mathrm{~g}$ dextrose; $5 \mathrm{~g}$ Bacto peptone; $15 \mathrm{~g}$ Bacto agar; $30 \mathrm{mg}$ streptomycin sulfate; $250 \mathrm{mg}$ ampicillin; $10 \mathrm{mg}$ rifampicin; $665 \mathrm{mg}$ Terraclor $75 \mathrm{WP}$; $665 \mathrm{mg}$ Botran $75 \mathrm{WP}$; and $1 \mathrm{~L}$ distilled water was superior to PDA in detecting $C$. destructans in diseased roots. Data to support the role of $C$. destructans as a cause of ginseng replant failure are also presented.

Control of Fusarium root rot of asparagus with different forms of chloride salt. T. C. REID and M. K. Hausbeck. Michigan State University, East Lansing, MI. Phytopathology 89:S65. Publication no. P-1999-0467-AMA.

The objective of this study was to test whether $\mathrm{NaCl}$ and other forms of chloride salt could suppress crown and root rot of asparagus caused by $\mathrm{Fu}$ sarium oxysporum f. sp. asparagi and F. proliferatum. Asparagus seeds were placed in test tubes containing Hoagland's solution and agar (1.2\%) mixed with a low $(17.1 \mathrm{mM})$, or high rate $(34.2 \mathrm{mM})$ of $\mathrm{NaCl}, \mathrm{CaCl}_{2}(17.1 \mathrm{mM})$, $\mathrm{NH}_{4} \mathrm{Cl}(34.2 \mathrm{mM})$, or no chloride. Tubes were infested with $F$. oxysporum or F. proliferatum by adding $0.5 \mathrm{ml}$ of a solution containing $1 \times 10^{6}$ spores $/ \mathrm{cc}$. After 5 weeks, percent of root system diseased was assessed visually using a $0-4$ scale $(0=$ no disease, $1=1-25 \%, 2=25-50 \%, 3=50-75 \%$, and $4=75-$ $100 \%)$. The study was conducted twice for each pathogen with 18 replicates per treatment. The high rate of $\mathrm{NaCl}$ (mean disease 1.5-1.9) consistently reduced disease incited by $F$. oxysporum significantly better than the control (mean disease 2.8-3.5), while $\mathrm{CaCl}_{2}$ was better than the control in only one test. Against $F$. proliferatum $\mathrm{NaCl}$ and $\mathrm{CaCl}_{2}$ decreased disease, but not significantly in all tests. $\mathrm{NH}_{4} \mathrm{Cl}$ gave disease ratings statistically similar to the control with both pathogens.

Evaluation of application methods for in row fumigation with 1,3-dichloropropene (1,3-D) in Florida sand soils. C. RIEGEL, D. W. Dickson, and L. N. Shaw. University of Florida, Gainesville, FL 32611. Phytopathology 89:S65. Publication no. P-1999-0468-AMA.

1,3-D formulated with chloropicrin is the likely replacement for methyl bromide when it is phased out in 2005. 1,3-D has been used in Florida for control of nematodes on many crops, however, its performance has not been consistent on peanut and tobacco. Method of application is a factor that may affect its efficacy. Our objective was to evaluate three types of chisels for application of 1,3-D with and without disking in a field infested with Meloidogyne incognita and $M$. javanica. Treatments included 1,3-D applied at 84 liters/ha with subsurface winged chisels, parachisels and standard chisels (with and without disking), and an untreated control. Tomato seedlings were transplanted in treated rows and second-stage juveniles $(\mathrm{J} 2)$ that penetrated 
the root systems of 10 plants per plot were counted. 1,3-D reduced the $\mathrm{J} 2$ that penetrated the roots of tomato compared to the untreated control $(P<0.05)$. Application with subsurface winged chisels had the highest J2 per root system $(P<0.05)$. Disking after fumigation with the standard chisels resulted in a 4.6 decrease in $\mathrm{J} 2$ per root system. Disking after fumigation with parachisels did not affect the $\mathrm{J} 2$ per root system.

Actigard reduces pepper diseases but may lower yield. A. M. Romero, C. S. Kousik, and D. F. RITCHIE. North Carolina State University, Raleigh, NC 27695-7616. Phytopathology 89:S66. Publication no. P-1999-0469-AMA.

Actigard (benzothiadiazole, BTH) is an inducer of plant defense systems. In field plots, BTH reduced the severity of bacterial spot and post-harvest intensity of soft rot. However, repeated applications were associated with reduced fruit yield. Weekly applications of BTH reduced the yield of all cultivars tested. In contrast, in most cases, biweekly BTH applications or BTH + copper provided disease control without significant yield reduction. Sprayed plots had more fruits than unsprayed controls, although the fruit size was smaller. This reduction in fruit size may be related to a delay in fruit set and/or fruit maturity. While plants untreated or treated with copper + maneb had the highest yields in the first or second harvest depending on cultivar, plants treated with BTH alone or BTH + copper had highest yields in the second or third harvest. BTH-treated plots had a significantly lower proportion of mature-red fruits, compared with untreated plots harvested at the same time. Possibly the continuous activation of resistance induces stress or increases the sensitivity to stresses, and the differential response of cultivars may be related to their inherent robustness.

Variability and mechanism of saskatoon disease response to Entomosporium leaf and berry spot. P. S. RONALD and R. G. St-Pierre. University of Saskatchewan, Saskatoon, SK. Phytopathology 89:S66. Publication no. P-1999-0470-AMA.

Entomosporium leaf and berry spot is the most serious disease of saskatoon (Amelanchier alnifolia) and represents a barrier to consistent and economical fruit production. The reaction of saskatoon cultivars to Entomosporium mespili was determined following artificial inoculation and natural infection. Detached leaves of 14 cultivars were inoculated with a conidiospore suspension under controlled conditions. Disease symptoms resulting from natural infection were assessed for leaves of the same cultivars sampled from a replicated trial. All leaves were cleared with a mixture of Ethanol:Glacial Acetic Acid $(3: 1 \mathrm{v} / \mathrm{v})$ and evaluated for percent necrosis and lesion number. Analysis of data from both experiments revealed significant differences in disease response among saskatoon cultivars. Fluorescence and electron microscopy have been used to examine saskatoon disease response to Entomosporium mespili at the cellular level. Examination of infected leaf tissue from cultivars with varying disease response will provide insight as to the mechanism by which certain host genotypes resist this pathogen.

Biocontrol and root colonization by the gliding bacterium Lysobacter antibioticus. M. R. Rondon (1), B. R. BORLEE (1), S. F. Brady (2), J. A. Gross (1), B. J. Guenthner (1), B. Manske (1), S. J. Raffel (1), J. B. Weisz (1), P. Vincelli (3), J. Clardy (2), R. M. Goodman (1), and J. Handelsman (1). (1) Dept. of Plant Pathology, University of Wisconsin, Madison; (2) Dept. of Chemistry and Chemical Biology, Cornell University; (3) Dept. of Plant Pathology, University of Kentucky, Lexington. Phytopathology 89:S66. Publication no. P-1999-0471-AMA.

We isolated a gliding bacterium designated MAD009 from an agricultural soil and studied its phylogeny and interactions with plants and their pathogens. Nucleotide sequence alignment of the 16S rRNA gene of MAD009 showed $99.7 \%$ identity with the type strain of $L$. antibioticus. MAD009 exhibited antibiosis against a wide spectrum of bacteria and plant pathogenic fungi in an agar plate assay. NMR and MS analysis of material purified by bioassay-guided fractionation identified the phenazine antibiotic, myxin. MAD009 aggressively colonized the surface of soybean roots, and suppressed diseases of tomato caused by Pythium torulosom and Fusarium oxysporum f. sp. lycopersici. The interaction of gliding bacteria with terrestrial plant roots is uncharted territory, warranting further study at the molecular, organismal, and population levels.

Joyrider, a hypervariable element from Fusarium oxysporum. U. L. ROSEWICH, R. E. Pettway, and H. C. Kistler. University of Florida, Gainesville, FL. Phytopathology 89:S66. Publication no. P-1999-0472-AMA.

During the screening of a genomic library of an isolate of Fusarium oxysporum $\mathrm{f}$. sp. radicis-lycopersici VCG 0094, we encountered a ca. 1 kb hypervariable element. Hybridization to Eco RV digested DNA resulted in complex banding patterns (10-15 bands), which differed for most isolates of $F$. oxysporum f. sp. radicis-lycopersici, even when collected from the same field. DNA banding patterns were sometimes even observed to be different for individual single-spored cultures derived from the same naturally infected plant. One of four isolates, repeatedly subcultured on rich agar medium, displayed an altered joyride pattern, after only five generations. Sequence database searches (BLASTX, BLASTN) revealed no sequence similarity to known transposable elements. Highest sequence similarity was to Kaposi's sarcoma-associated herpes-like virus, but over a stretch of only $100 \mathrm{bp}$. The significance of this element in microevolutionary and muational studies is discussed.

Effects of amended transplant mixes and soil treatments on isolation of soilborne fungal pathogens from tomato and pepper roots. E. N. ROSSKOPF, R. A. Shelby, and N. Kokalis-Burelle. USDA-ARS, U.S. Horticultural Research Laboratory, Ft. Pierce, FL. Phytopathology 89:S66. Publication no. P-1999-0473-AMA.

Field trials in Sanford, FL evaluated root colonization of tomato and pepper transplants by several pathogens. Plants grown in soil-less mixes amended with formulations of plant growth-promoting rhizobacteria (PGPR) were transplanted into field plots treated with soil solarization, methyl bromide fumigation, or polyethylene mulch. Incidence of damping-off of pepper transplants was not affected by PGPR strain or soil treatment. Incidence of wilt symptoms in tomato was significantly lower in methyl bromide treated plots and highest in the mulch treatment. Isolation of Phytophthora spp. and Pythium did not differ with crop or treatment in tomato. Greater numbers of colonies of Pythium were isolated from pepper roots in the methyl bromide treatment and fewest in the solarization treatment. Individual PGPR strains affected the numbers of Pythium colonies isolated from pepper, but not from tomato. Numbers of colony forming units of Fusarium were significantly higher in the mulch treatment with no PGPR strain effect.

Diversity among different isolates of rupestris stem pitting associated virus. A. ROWHANI, Y. P. Zhang, D. A. Golino, and J. K. Uyemoto. Department of Plant Pathology, University of California, One Shields Avenue, Davis, CA 95616. Phytopathology 89:S66. Publication no. P-1999-0474AMA.

Grapevine rupestris stem pitting (RSP) is a graft transmissible disease. Grapevine rupestris stem pitting associated virus (GRSPaV) was proven to be associated with the disease. RSP symptoms on indicator host Vitis rupestris $\mathrm{cv}$. St. George includes small pits on the woody cylinder immediately below the inoculum chip bud. Occasionally severe pitting and grooving symptoms extended around the woody cylinder, suggesting the involvement of different strains of RSPaV or other viruses. We compared the coat protein nucleotide sequences of 17 isolates of $\mathrm{RSPaV}$, and the phylogenetic analysis showed that all these isolates fall into three major groups (strains) with about $79 \%$ similarity among them. We have designed PCR-primers that are specific to each strain and used these strain-specific primers to test more than 100 RSPinfected grapevines and found that the majority of these vines carry two or more strains. Very few vines were infected with a single strain. Association of these strains in symptom severity is under investigation. In addition, we have developed universal primers that could detect all three strains in a single PCR-reaction.

Relationship of tree disease and growth rate in a northern hardwood forest. B. D. RUBIN and P. D. Manion. State University of New York, College of Environmental Science and Forestry, Syracuse, NY. Phytopathology 89:S66. Publication no. P-1999-0475-AMA.

It is generally assumed that stress predisposes trees to disease, however it is possible that diseases are a primary stressing agent in the forest system. Forest inventories were conducted in 1970, 1976, 1981 and 1991 at the SUNY College of Environmental Science and Forestry Huntington Forest, in the Central Adirondacks of New York State. Disease and injury problems, including beech bark disease, various cankers, stem rots, injuries, root and butt rots, seams and others, were recorded on 780 of 2229 live trees measured in 1991. Overall, and within 5 common species, healthy trees grew faster in the past 10 years than diseased trees. Trees with cankers, stem rot, injuries, or other disease problems grew significantly slower than their healthy counterparts. Of 758 trees common to all four inventories, there was a significant difference in the growth rates of currently healthy and diseased trees only in the most recent time interval. The relationship between growth rate and disease suggests that diseases reduce the growth rate of trees rather than that diseases infect weakened, slow growing trees. 
Molecular variation of citrus tristeza virus (CTV) in California. L. RUBIO, P. Kong, and B. W. Falk. Plant Pathology Department, University of California, Davis, CA 95616. Phytopathology 89:S67. Publication no. P-19990476-AMA.

Molecular and biological variation has been reported for citrus tristeza virus isolates in different countries. We analyzed molecular variation within and between California isolates in attempts to identify common and/or unique sequences associated with given isolates. Four regions in the CTV RNA, ORF 1(A and F162), part of the capsid protein gene (CP) and the p20 gene, were examined using RT-PCR, single strand conformation polymorphism (SSCP) and nucleotide sequence analysis. Nucleotide sequence comparison between California isolates as well other Genbank available sequences showed that $\mathrm{CP}$ region was the most conserved while the A region was the most variable. Most California isolates were similar to the Spanish isolate T385 in all genome regions. Nucleotide distance between some isolates was not uniform over the different regions studied, suggesting possible recombination events. Our study also revealed that each isolate was composed of a population of different sequence variants with one being predominant. Some isolates were composed of variants with similar nucleotide sequences whereas others had variants that showed large divergence.

Heterogeneous population of defective RNAs in plants infected with lettuce infectious yellows virus (LIYV). L. RUBIO, T. Tian, H.-H. Yeh, and B. W. Falk. Department of Plant Pathology, University of California, Davis, CA 95616. Phytopathology 89:S67. Publication no. P-1999-0477-AMA.

Several defective RNAs (D-RNAs) corresponding to the LIYV genomic RNA2 were detected by northern-blot hybridization and RT-PCR in RNAs extracted from LIYV-infected plants. Several LIYV RNA2 D-RNAs were cloned and sequenced. Our results showed a population of D-RNAs of different size. All contained internal deletions, relative to the wild type LIYV RNA2, and several had unique junction sites. Some D-RNAs contained an extra nucleotide $(\mathrm{G})$ at the junction site, not present in the RNA2 sequence. Others showed deletions between two direct repeats of 2-7 nt. Nucleotide sequence analysis also revealed an identity between LIYV RNA2 and the D-RNAs greater than $99 \%$ within the overlapping regions. In vitro T3 transcripts from two LIYV RNA2 D-RNAs clones were replication competent in protoplasts when co-inoculated with LIYV RNAs 1 and 2, or with only LIYV RNA1.

Production of high quality seed of maturity group IV soybean cultivars in Arkansas. J. C. RUPE, C. M. Becton, and D. Longer. University of Arkansas, Fayetteville, AR. Phytopathology 89:S67. Publication no. P-1999-0478AMA.

There is increasing interest in raising maturity group IV (MG IV) soybean cultivars in Arkansas. While yields can be high, seed quality is often poor, especially from early plantings. To determine optimum production practices for MG IV cultivars in Arkansas, three cultivars representing an early (DeKalb CX411), mid (Asgrow 4715), and late (Riverside 499) MG IV cultivars were planted in April, May, and June at a northern (Fayetteville), central (Marianna) and southern (Hope) location in the state. The cultivars were either treated with a foliar application of benomyl ( $92 \mathrm{~g}$ ai $/ \mathrm{ha}$ ) at beginning R6 or not treated. Yield, germination and seed infection were determined. In general, seed germination was highest and seed infection was lowest with delayed planting at all locations. Seed quality was usually highest at Fayetteville followed by Marianna and was lowest at Hope. Reduced seed germination was not always associated with fungal seed infection. Foliar applications of benomyl were most effective at Hope where seed infection by Phomopsis longicolla was highest, but was inconsistent at the other locations.

The genetics of resistance to turnip mosaic virus in Brassica. R. L. RUSHOLME (1,2), A. G. Sharpe (1), C. E. Jenner (3), S. L. Hughes (3), I. A. Parkin (1), J. A. Walsh (3), and D. J. Lydiate (1). (1) AAFC Saskatoon Research Centre, 107 Science Place, Saskatoon, SK S7N OX2, Canada; (2) John Innes Centre, Norwich Research Park, Norwich NR4 7UH, UK; (3) Horticulture Research International, Wellesbourne CV35 9EF, UK. Phytopathology 89:S67. Publication no. P-1999-0479-AMA.

The Brassica A genome carries a number of genes that confer resistance to different spectra of the twelve distinct pathotypes of turnip mosaic virus (TuMV). Genetic mapping is identifying the genomic positions of individual resistance genes. This information will allow gene pyramiding and the marker-assisted selection of durable resistance to TuMV in Brassica. The genetic dissection of resistance determinants in near-isogenic lines carrying defined resistance genes will facilitate the biological evaluation of different resistance mechanisms. In combination with the ability to construct hybrid virus genomes carrying defined segments of two or more TuMV isolates, this represents an excellent system for resolving the molecular biology of pathogenesis and host resistance for an economically significant crop pathogen. High resolution mapping of Brassica genes for resistance to TuMV is also bringing the cloning of these genes within reach.

Characterization of insertion elements from Xanthomonas oryzae pv. oryzae. M. RYBA-WHITE, N. Sakthivel, C. H. Yun, F. F. White, and J. E. Leach. Department of Plant Pathology, Kansas State University, Manhattan, KS 66506. Phytopathology 89:S67. Publication no. P-1999-0480-AMA.

Three multicopy insertion sequences (IS1112, IS1113 and IS1114) from the genome of Xanthomonas oryzae pv. oryzae, the causal agent of bacterial blight of rice, were sequenced. These elements have been used to characterize the population structure of the pathogen in Asia. IS1112 is $1055 \mathrm{bp}$ and contains 25-bp terminal inverted repeats flanked by a 3-bp direct repeat at the site of insertion. The element contains an open reading frame (ORF) of 395 amino acid residues with similarity to a transposase from Aeromonas salmonicida. IS 1113 is $1323 \mathrm{bp}$ and contains 25-bp imperfect inverted repeats flanked by a 9-bp duplication at the insertion site. The element contains an ORF of 318 amino acid residues with similarity to a transposase from Yersinia pestis. IS1114 is 1510 bp and contains 18-bp imperfect inverted repeats flanked by a 6-bp insertion site. Data on the ORF and transposase similarity will be presented.

Plant growth promotion of tomato by a biological preparation (LS213) and evaluation for protection against cucumber mosaic virus. C. M. RYU, M. S. Reddy, S. Zhang, J. F. Murphy, and J. W. Kloepper. Dept. Plant Pathology, Auburn University, Auburn, AL 36849. Phytopathology 89:S67. Publication no. P-1999-0481-AMA

The biological preparation LS213, which contains industrial formulated spores of Bacillus subtilis strain GBO3, Bacillus amyloliquefaciens strain IN937a and a formulation carrier, was tested for capacity to promote growth of tomato in a transplant system. Evaluations included effects on plant growth of varying concentrations of LS213 in potting media (v/v), specificity to various soil-less media, and susceptibility to CMV. Results showed that LS213, when added to the mix before seeding, significantly increased the growth of tomato seedlings, compared to controls. This growth promotion occurred at all concentrations and in all soil-less mixes tested. At 4 weeks post-inoculation, no significant differences were observed between treatments in percentage of plants infected by CMV. Growth promotion did not relate to reduction in damage to $\mathrm{CMV}$, and disease severity was relatively similar among treatments with the exception that some CMV infected, nonbacterized plants were stunted while none of the infected, LS213-treated plants showed stunting.

Insertion of a luciferase gene cassette into a streptomycetous biocontrol agent. S. SABARATNAM (1), D. Cuppels (2), and J. A. Traquair (2). (1) University of Western Ontario, London, ON; (2) Southern Crop Protection and Food Research Centre, Agriculture and Agri-Food Canada, London, ON. Phytopathology 89:S67. Publication no. P-1999-0482-AMA.

Bioluminescence markers are useful tools in ecological studies of rhizobacteria. The Streptomyces transposon Tn5353, carrying a promoterless luciferase (lux) gene cassette from Vibrio harveyi, was inserted into the genome of a streptomycetous biocontrol agent by electroporation using a Bio-Rad Gene Pulser II unit (25- $\mu \mathrm{F}$ capacitor; 400 parallel resistance). Lysozyme-treated cells, but not intact cells, were efficiently electrotransformed. The transformation efficiency was much higher when the electric field was reduced from $2 \mathrm{kV}$ to $1.5 \mathrm{kV}$ and the plasmid vector concentration was at $200 \mathrm{ng}$. Bioluminescent transformants were identified by exposing 3- to 5-day-old cultures to $\mathrm{n}$-decanal and then to X-ray film for $48 \mathrm{~h}$. The presence of the luciferase gene cassette in the transformants was confirmed by Southern blotting. Bioluminescence will be used to determine the population dynamics and spatial distribution of this biocontrol agent in the rhizosphere and rhizoplane of greenhouse-grown tomato seedlings.

Evaluation of Bacillus isolates as biological control agents of Fusarium dry rot of potato tubers. N. SADFI ZOUAOUI (1), M. Cherif (2), A. Boudabbous (1), and R. Belanger (3). (1) Dept. Microbiology, Faculty Sciences of Tunis 1060, Tunisia; (2) Dept. Phytopathology, Tunisian National Agronomic Institute, 1082 Tn.; (3) Dépt. de Phytologie, Université Laval, Sainte-Foy, Qc., Canada. Phytopathology 89:S67. Publication no. P-1999-0483-AMA.

Fusarium species are often responsible for serious economical losses of potato tubers (p.t.) in the field and during storage in Tunisia. A virulent isolate of Fusarium roseum var. sambucinum was frequently isolated from stored p.t. 
showing severe dry rot. A total of 156 Bacillus isolates were isolated from soil samples collected from different locations in Tn. All isolates were individually assayed against $F$. $r$. var. sambucinum by both the dual culture technique in petri dishes and by coinoculating antagonist and pathogen in wounds in cv. Spunta p.t. Out of the $156 \mathrm{Ba}$. isolates tested, 11 efficiently inhibited the growth of the pathogen in dual culture. These isolates share the same peculiarity of being isolated from salty soils characterised by a high electric conductivity and a low level of organic matter. 7 of these 11 bacteria conferred 98 to $99 \%$ protection of potato tubers from Fu. rot when applied at 24-h culture. The efficacy of these biocontrol agents were also studied in pots in the greenhouse. The mechanisms of $B a$. spp. protection will be studied.

Effect of temperature on tuber infection by Phytophthora infestans A1 and $\mathbf{A} 2$ zoospores. B. SALAS, N. C. Gudmestad, and G. A. Secor. Plant Pathology Department, North Dakota State University, Fargo, ND 58105. Phytopathology 89:S68. Publication no. P-1999-0484-AMA.

Little is known about the effect of environment on tuber infection by Phytophthora infestans $\mathrm{A} 1$ and $\mathrm{A} 2$ zoospores. This study examined the effect of temperature ( 5 to $25 \mathrm{C}$ ) on tuber infection by five A2 and three A1 isolates. Tubers were inoculated on the apical eye and two lateral eyes each with ca. 200 zoospores. Temperature and isolates significantly $(P<0.01)$ affected incidence of tuber infection. Regardless of the mating type, temperatures of 10 and $15 \mathrm{C}$ were the most favorable for tuber infection. Infections declined at 20 and $25 \mathrm{C}$ and there was no infection at $5 \mathrm{C}$. Higher rates of tuber infection occurred with zoospores of A2 mating type than with zoospores of A1 mating type. Treating tubers with $0.5 \%$ sodium hypochlorite to interrupt infection at 3,6,12, and $24 \mathrm{hrs}$ after inoculation at $20 \mathrm{C}$, showed that the minimum time for infection was $6 \mathrm{hr}$. The displacement of the old A1 population by the more aggressive A2 population may have led to higher incidence of tuber infection observed recently.

Molecular epidemiology of tomato yellow leaf curl virus in the Dominican Republic: Identification of inoculum sources during a host-free period. R. SALATI (1), M. K. Nahkla (2), D. P. Maxwell (2), and R. L. Gilbertson (1). (1) Plant Pathology, University of California, Davis, CA 95616; (2) Department of Plant Pathology, University of Wisconsin, Madison, WI 53706. Phytopathology 89:S68. Publication no. P-1999-0485-AMA.

The introduction of tomato yellow leaf curl geminivirus (TYLCV) into the Dominican Republic in the early 1990's devastated a flourishing processing tomato industry. A mandatory 3 month whitefly host-free period has dramatically decreased the incidence of TYLCV in tomato fields early in the growing season but, by the end of the growing season, the incidence of the virus increases drastically. Surveys conducted during the host-free period indicated that volunteer tomatoes or illegal tomato plantings are probably not the initial inoculum source. Monitoring the incidence of TYLCV in whiteflies by PCR and TYLCV primers demonstrated that the incidence of TYLCV rapidly decreased after implementation of the host-free period and gradually increased during the tomato growing season. TYLCV was detected in a number of symptomless weed species in different families. The implications of these findings for TYLCV management in the Dominican Republic will be discussed.

Identification and characterization of a virus associated with severe mosaic of double petunia. M. C. SANCHEZ-CUEVAS and S. T. Nameth. The Ohio State University, Columbus, OH. Phytopathology 89:S68. Publication no. P-1999-0486-AMA.

Double petunia plants (Petunia $\times$ hybrida) with mild to severe mosaic, leaf puckering, and deformation were submitted to OSU for analysis. Rod shaped particles averaging $315 \mathrm{~nm}$ in length were observed by electron microscopy in leaf dips and purified preparations. The virus was transmitted mechanically and induced similar, but less severe symptoms than the common strain of tobacco mosaic tobamovirus (TMV), on indicator hosts. The petunia virus (PV) was antigenically related to TMV and tomato mosaic tobamovirus (ToMV) in test involving antiserum raised against PV. In double-antibody sandwich enzyme-linked immunosorbent assays (DAS-ELISA), PV reacted weakly with antiserum to TMV and negatively with commercial antisera to other tobamoviruses, including ToMV. Electrophoretic analysis showed a single-stranded RNA of approximately $6.5 \mathrm{~kb}$ and capsid protein subunits of $\sim 18 \mathrm{kDa}$. Nucleotide sequence of the coat protein (CP) showed $87 \%$ similarity to the CP region of tobamoviruses, mainly TMV strains. PV was identified as a member of the tobamovirus group based on particle size, and morphology, inclusion bodies, host range, capsid protein sequence and weight, and genome size and properties.
Survey of virus diseases on double petunia in Ohio. M. C. SANCHEZCUEVAS and S. T. Nameth. The Ohio State University, Columbus, OH. Phytopathology 89:S68. Publication no. P-1999-0487-AMA.

Double petunia plants (Petunia $\times$ hybrida) showing virus-like symptoms were collected from greenhouses and garden centers throughout Ohio in the Spring of 1997 and 1998. Double-antibody sandwich enzyme-linked immunosorbent assays (DAS-ELISA) were conducted with antisera to alfalfa mosaic alfamovirus, cucumber mosaic cucumovirus, tobacco aspermy cucumovirus, tobacco streak ilarvirus (TSV), potato virus $\mathrm{X}$ potexvirus, tobacco ringspot nepovirus (TRSV), tomato ringspot nepovirus (TmRSV), tobacco mosaic tobamovirus (TMV), tomato spotted wilt tospovirus (TSWV), impatiens necrotic spot tospovirus, and chrysanthemum B carlavirus, and indirect ELISA with antiserum to the potyvirus group. The ELISAs, viral-associated double stranded (ds) RNA analysis, and light microscopy for detection of inclusion bodies revealed the presence of TMV, TSWV, TmRSV, and TSV. Some plants with virus-like symptoms tested negative for all viruses. The presence of other possible viruses was indicated by dsRNA analysis.

Inoculum potential of postharvest apple DPA drenches. P. G. SANDERSON and D. L. Bennett. Washington Tree Fruit Research Commission, Wenatchee, WA 98801. Phytopathology 89:S68. Publication no. P-1999-0488AMA.

Diphenylamine/thiabendazole (DPA/TBZ) drench mixtures are applied to apple fruit at receipt at storages to prevent superficial scald and postharvest decay. Outbreaks of blue mold and Mucor rot (caused by species of Penicillium and Mucor piriformis, respectively) often occur in fruit that have been treated with contaminated drench mixtures. To determine the rate at which spores of pathogenic species of Penicillium accumulated in commercial drenches, inoculum density was assessed in samples from eight DPA/TBZ drench tanks after each 100-200 bins treated. In addition, wounded apple fruit (cv. 'Red Delicious') were dipped in drench tank mixtures at 250 bin intervals. The proportion of fruit with lesions was determined about 90 days after treatment. Population densities of Penicillium spp. increased linearly up to about 60 bins treated $/ 100$ gal tank capacity $\left(R^{2}=0.72\right.$ and $R^{2}=0.65$ for astatic vol. and static vol. drenchers, respectively). Similarly, the proportion of wounds with lesions increased linearly $\left(R^{2}=0.72\right)$ with inoculum density up to about $45 \%$ of fruit with lesions at $1200 \mathrm{cfu} / \mathrm{ml}$. This information can be used to assess relative risk of decay from drenching practices.

Reduction in severity and incidence of sudden death syndrome and Sclerotinia stem rot in soybean treated with lactofen. S. SANOGO and X. B. Yang. Iowa State University, Ames, IA. Phytopathology 89:S68. Publication no. P-1999-0489-AMA.

Lactofen, a post-emergence herbicide which causes partial foliar necrosis when applied to soybeans, was evaluated for its effects on sudden death syndrome (SDS) caused by Fusarium solani f. sp. glycines (Fsg) and Sclerotinia stem rot (white mold) caused by Sclerotinia sclerotiorum. Soybeans grown in greenhouse soil and in fields infested with Fsg were treated with lactofen and compared with those sprayed with water (control) or three other herbicides (glyphosate, imazethapyr, and acifluorfen). Compared to control, there was a general decreasing trend in foliar and root severity of SDS and in frequency of isolation of Fsg from roots with lactofen application. Conversely, with other herbicides there was a general increasing trend in severity of SDS and isolation frequency of Fsg from roots. Soybeans grown in fields infested with S. sclerotiorum were treated with glyphosate, imazethapyr, and lactofen at early flowering stage (R1). Compared to control, lactofen-treated soybeans consistently had significantly low incidence of white mold and consistent increase in yield.

An improved semiselective agar medium for Acidovorax avenae subsp. citrulli. N. W. SCHAAD and A. Sechler. USDA, Foreign Disease-Weed Science Research Unit, Fort Detrick, MD 21702. Phytopathology 89:S68. Publication no. P-1999-0490-AMA

Acidovorax avenae subsp. citrulli (AAC), the causal agent of fruit blotch of watermelon, is a serious seedborne pathogen of watermelon and cantaloupe. In an attempt to utilize newly developed PCR primers in a Bio-PCR-based technique to detect AAC in watermelon seeds, we found available agar media to be unsatisfactory. Therefore, we developed a new agar medium to cultivate the organism. Our ethanol, brilliant blue, bromcreosol purple (EBB) agar medium contains $1.0 \mathrm{~g} \mathrm{NH}_{4} \mathrm{PO}_{4}, 0.2 \mathrm{~g} \mathrm{KCl}, 0.2 \mathrm{~g} \mathrm{MgSO}_{4} \cdot 7 \mathrm{H}_{2} \mathrm{O}, 0.3 \mathrm{~g}$ yeast extract, $0.5 \mathrm{~g}$ boric acid, $16 \mathrm{~g}$ agar, $0.6 \mathrm{ml}(15 \mathrm{mg} / \mathrm{ml})$ bromcreosol 
purple, $1.0 \mathrm{ml}(10 \mathrm{mg} / \mathrm{ml})$ brilliant blue $\mathrm{R}, 0.2 \mathrm{~g}$ cycloheximide, and $10 \mathrm{ml}$ ethanol. In comparison to King et al's medium B, EBB medium resulted in an increase in recovery of strains of AAC average $118 \%$ and reduced recovery of saprophytic bacteria from watermelon seeds by $88 \%$. Colonies of AAC are visible on EBB medium after 2 days at $37^{\circ} \mathrm{C}$ and are round and $1-2 \mathrm{~mm}$ in diameter after three days. They continue to enlarge and develop olive green centers and a fried egg, ring-like morphology after 3-4 days. Colonies of most seed-associated bacteria are blue and much smaller.

Predicting Fusarium head blight (FHB) and deoxynivalenol (DON) in winter wheat using near real time weather data. A. W. SCHAAFSMA, L. Tamburic-Ilincic, D. Hooker, and C. Duke. Ridgetown College, University of Guelph, Ridgetown, ON, Canada N0P 2C0. Phytopathology 89:S69. Publication no. P-1999-0491-AMA.

In 1998, eleven commercial fields of winter wheat were selected in a 15 by $15 \mathrm{~km}$ block near Ridgetown, ON, on the basis of a significant rain event during anthesis. Samples of fifty primary wheat heads were selected at random from each of 11 areas in each field and a FHB index was applied to the data (the product of percent heads and percent spikelets infected). Eleven corresponding samples of $2 \mathrm{~kg}$ of wheat heads were harvested from each location. After drying and threshing each crop sample, DON content was measured using a quantitative ELISA test. The weather sequence at anthesis produced disease and DON in some of the fields. The FHB index was correlated with deoxynivalenol content. These locations will be superimposed on a geographic information systems map which will contain spatial predictions of weather factors, mainly temperature and rainfall. These parameters will be tested for their contribution to the start of the epidemic observed (epidemic threshold). This paper will report on the testing of these parameters in the 1999 winter wheat crop using remote weather sensing and geographic information systems computation.

All genes necessary for cell-to-cell movement of maize chlorotic mottle virus (MCMV) are expressed from one subgenomic RNA (sgRNA). K. SCHEETS. Oklahoma State University, Stillwater, OK. Phytopathology 89: S69. Publication no. P-1999-0492-AMA.

Analysis using double-stranded RNAs, northern blots, and primer extension reactions showed that MCMV has two sgRNAs of 1,467 and 337 nt with transcription start sites at nt 2971 and 4101, respectively. The small 3' sgRNA has the potential to encode 2.7 and $4.6 \mathrm{kDa}$ peptides, but the function of this sgRNA is unknown. In protoplast inoculation experiments a silent mutation at nt 2965 and a four nt change at nt 2959-2962 stopped the synthesis of the large sgRNA and expression of the coat protein (CP) ORF which begins $\sim 400 \mathrm{nt}$ downstream. Thus, MCMV expresses a $7 \mathrm{kDa}$ ORF, its readthrough protein, $\mathrm{p} 31$, and $\mathrm{CP}$ from the same sgRNA. The function of each ORF was tested individually. Mutant transcripts that were unable to express $\mathrm{p} 7$, or p31, or CP were all capable of replicating in Black Mexican Sweet maize protoplasts. But none of these mutants were able to produce an infection when inoculated to maize plants indicating that $\mathrm{p} 7$, its readthrough protein, and $\mathrm{CP}$ are all necessary for cell-to-cell movement. The function of an ORF for a putative $8 \mathrm{kDa}$ protein, which would require expression via a plus one frameshift near the end of the p7 ORF, has not been tested.

A survey of pest management practices and IPM adoption in the Georgia blueberry industry. H. SCHERM. University of Georgia, Athens, GA. Phytopathology 89:S69. Publication no. P-1999-0493-AMA.

Adoption of IPM may be viewed as a continuum, ranging from no IPM to bio-intensive pest management. Little is known about the level of IPM adoption in the southern blueberry industry and about differences in IPM practices among individual producers. A pest management survey was conducted using an anonymous questionnaire distributed at two blueberry production meetings in Georgia. The questionnaire considered farm and producer characteristics; production problems including arthropods, diseases, weeds, and abiotic constraints; pesticide usage; the adoption of various horticultural and IPM practices; and perceived research and extension needs. Returned questionnaires accounted for $\sim 50 \%$ of the state's blueberry acreage and included a wide range of farm sizes and types. Mummy berry (caused by Monilinia vaccinii-corymbosi) was perceived as the most important disease constraint. IPM adoption was generally low, due in part to a perceived lack of available monitoring and decision tools. Interrelationships between farm characteristics and IPM adoption will be discussed. The results will serve as a baseline for evaluating ongoing research and extension efforts in the blueberry industry.
Epidemiology and control of mummy berry disease of rabbiteye blueberry in Georgia. H. SCHERM, A. T. Savelle, and W. E. Copes. University of Georgia, Athens, GA. Phytopathology 89:S69. Publication no. P-19990494-AMA.

Mummy berry (Monilinia vaccinii-corymbosi) is a persistent problem on rabbiteye cultivars in the south Georgia blueberry belt. Due to a lack of epidemiological data about the disease in this production environment, management recommendations have been conservative. Nevertheless, levels of control in commercial fields often are unsatisfactory. Host phenology, pathogen activity, and disease development were monitored and spores were trapped in multiple sites and cultivars during 3 years. The basic pathogen life cycle was found to be similar to that described previously on highbush cultivars in northern production regions. However, important variations in the timing and extent of key epidemiological events were observed, entailing a considerably lower chilling requirement for mummy germination and apothecium formation; an association between ascospore release and rain fall; an overlapping of ascospore and conidial dispersal periods; the presence of both protracted bloom and spore dispersal periods; and conidial dispersal occurring late during bloom. Spray timing trials involving fewer, targeted applications showed promise in controlling mummy berry.

Prevalence of fruit rotting fungi in blueberry fields in Michigan. A. M. C. SCHILDER and J. M. Gillett. Michigan State University, East Lansing, MI. Phytopathology 89:S69. Publication no. P-1999-0495-AMA.

A survey was conducted in 1998 to determine the prevalence of fruit rotting fungi in blueberries in Michigan. Thirty-three fields on nine farms were sampled 1-3 times between July 17 and August 21 (72 samples total). Cultivars Jersey, Rubel, Elliott, Blueray, Bluetta, Berkeley, Coville, and Spartan were included. One hundred berries per sample were incubated on metal screens in plastic tubs for 7-8 days at $22 \mathrm{C}$. Fruit rot levels varied from 3 to $100 \%$. A general increase in the incidence of fruit rots, especially anthracnose, was noted as the season progressed. Anthracnose (caused by Colletotrichum acutatum, not $C$. gloeosporioides as previously assumed) was the most commonly observed fruit rot, followed by Alternaria (Alternaria spp.) and Botrytis (Botrytis cinerea) fruit rots. Phomopsis vaccinii was isolated from fruit in fields where Phomopsis twig blight and canker was prevalent, and a Pestalotia sp., previously unreported on blueberries in Michigan, was isolated from fruit on several farms. Cultivar differences were most apparent with Elliott, which showed very low Alternaria fruit rot and anthracnose incidence.

Virulence patterns of Puccinia triticina in Nebraska during 1997 and 1998. J. SCHIMELFENIG, J. E. Watkins, and P. S. Baenziger. Dept. of Plant Pathology, University of Nebraska, Lincoln, NE 68583-0722. Phytopathology 89:S69. Publication no. P-1999-0496-AMA.

One hundred twenty one urediniospore isolates of Puccinia triticina collected in Nebraska in 1997 and 178 collected in 1998 were characterized for virulence to 16 near-isogenic, single-gene differentials in a Thatcher genetic background. Sixteen virulence phenotypes were identified from the isolates collected in 1997 and 45 virulence phenotypes were identified in 1998. The most prevalent virulence phenotype in 1997 was MDRR (virulent on $\mathrm{Lrl}, 3$, $3 \mathrm{ka}, 10,11,18,23,24$ and 30). In 1998 virulence phenotypes MDRR and MDRM (virulent on Lrl, 3, 3ka, 10, 11, 18, 23, 24 and 30 and $L r l, 3,3 k a$, $10,11,23,24$ and 30, respectively) were the most prevalent. In 1997 virulence frequency was high to genes $L r l, 3,3 \mathrm{ka}, 10,11,18,23,24$ and 30 , moderate to genes $L r 2 a$ and $2 c$ and low to genes $\operatorname{Lr} 17$ and 26. In 1998 virulence frequency was high to genes $L r 2 c$ and 18 and low to genes $L r 2 a$ and $I$ No virulence was found during both years to genes $\operatorname{Lr} 9,16$ and 21 .

Colonization of potato tuber surfaces by dry rot and sprout inhibiting bacteria. D. A. SCHISLER, P. J. Slininger, and R. J. Bothast. USDA-ARS, NCAUR, Peoria, IL 61604. Phytopathology 89:S69. Publication no. P-19990497-AMA.

To explore microbial persistence and coexistence during tuber storage, colonization of tuber wounds, periderm and eyes was monitored for dry rot biocontrol bacteria Pseudomonas fluorescens bv. V P22:Y:05 (Y05), Enterobacter cloacae S11:T:07 (T07), and P. fluorescens bv. V S11:P:12 (P12). Strains T07 and P12 also inhibit potato tuber sprouting. Tubers were inoculated with 1 strain or 2 strain combinations. Populations were monitored for 84 days. In wounds, inoculated bacteria peaked at $6.45 \mathrm{log} \mathrm{cfu} / \mathrm{cm}^{2}$ after 7 days and gradually declined by 84 days to $4.22 \log \mathrm{cfu} / \mathrm{cm}^{2}$ but initial populations of $6.21 \log \mathrm{cfu} / \mathrm{cm}^{2}$ on eyes dropped to stable values of $\sim 3 \mathrm{log}$ $\mathrm{cfu} / \mathrm{cm}^{2}$ after only 21 days. After 7 days, bacterial inoculants comprised $41 \%$ 
of wound bacteria but only $5 \%$ and $3 \%$ of eye and periderm bacteria, respectively. Inoculated singly, T07 and Y05 reached higher wound populations than P12. T07 had the highest population on eyes $(P=0.05)$. Strain P12 had higher populations in wounds when combined with Y05 than with T07 $(P=$ 0.05 ). This difference in colonization success by P12 was not associated with carbohydrate or amino acid utilization profiles of the strains.

Gram-negative bacteria from Michigan apple orchards carry several tetracycline resistance transposons. E. L. SCHNABEL and A. L. Jones. Michigan State University, East Lansing, MI. Phytopathology 89:S70. Publication no. P-1999-0498-AMA.

Oxytetracycline is used in Michigan apple orchards for the control of fire blight caused by Erwinia amylovora in regions where streptomycin resistance has become a problem. The potential for the development of tetracycline-resistant $\left(\mathrm{Tc}^{\mathrm{R}}\right)$ E. amylovora was evaluated by screening orchards for bacteria carrying potentially transferable $\mathrm{Tc}^{\mathrm{R}}$ genes. By PCR, sequence, and Southern analyses it was determined that $\mathrm{Tc}^{\mathrm{R}}$ in orchard isolates was carried on large plasmids with Tet B in Pantoea agglomerans and Tet A, Tet C, or Tet G in most Pseudomonas isolates. Tet A, Tet B, and Tet C were located, respectively, within a variant of $\operatorname{Tn} 1721, \mathrm{Tn} 10$, and a novel $18 \mathrm{~kb}$ transposon also carrying streptomycin (aadA2) and sulfonamide (sulI) resistance. Two variants of Tet $\mathrm{G}$ were detected; their association with transposons has not been established. None of the $\mathrm{Tc}^{\mathrm{R}}$ plasmids could be introduced into $E$. amylovora, implying that these $\mathrm{Tc}^{\mathrm{R}}$ plasmids probably could not be transferred to E. amylovora in the orchard; however, transfer of $\mathrm{Tc}^{\mathrm{R}}$ might occur following a rare transposition of a $\mathrm{Tc}^{\mathrm{R}}$ transposon to a plasmid capable of mobilization to E. amylovora.

Studies on the molecular basis of SI fungicide resistance in strains of Venturia inaequalis. G. SCHNABEL (1), B. A. Latorre (2), and A. L. Jones (1). (1) Michigan State University, East Lansing, MI; (2) Pontificia Universidad Catolica, Santiago, Chile. Phytopathology 89:S70. Publication no. P-1999-0499-AMA.

Venturia inaequalis strains resistant to sterol biosynthesis inhibitor (SI) fungicides have been reported worldwide, but no reports on the molecular basis of SI resistance in this pathogen have been published yet. The CYP51A1 gene encodes a target enzyme of SI fungicides. Fragments of this gene were PCR amplified from genomic DNA of $V$. inaequalis using degenerate primers. The $3^{\prime}$ and $5^{\prime}$ ends were PCR amplified by an adaptor ligation method. Sequence analysis showed that the gene was $1,575 \mathrm{bp}$ with two introns of 50 bp and $49 \mathrm{bp}$ at positions 238 and 436, respectively. Comparison of the coding nucleotide sequence with the CYP51A1 from Uncinula necator and Penicillium italicum revealed $48.6 \%$ and $51.9 \%$ similarity, respectively. SI resistant strains were screened for a possible mutation site at position 398 by allele specific PCR; none had the mutation. The collection is currently being screened by a 'non-isotopic RNase cleavage assay' for other mutation sites within the CYP51A1 gene. We are also examining $V$. inaequalis for genes encoding efflux pumps known to transport drugs out of fungal cells.

Mating of ascospore- and flag shoot-derived isolates of Uncinula necator. Sabine Schneider (1), B. Stummer (2), H.-H. Kassemeyer (1), R. Blaich (3), E. Scott (2), R. C. Seem (4), and David M. GADOURY (4). (1) Staatliches Weinbauinstitut, 79100 Freiburg, Germany; (2) University of Adelaide, Glen Osmond, SA 5064 Australia; (3) University of Hohenheim, 70599 Stuttgart, Germany; (4) Cornell University, N.Y. State Agric. Exp. Stn., Geneva 14456.

A recent study (Phytopathology 87:670-677) suggested that clones of $U$. necator from flag shoots (FS) were reproductively isolated from clones from ascospores (AS). We crossed 33 FS-isolates from Germany and Australia with AS-isolates from Germany, Australia, and New York on seedling grapevines. Cleistothecia formed in most pairings of + and - mating types, irrespective of other factors. Asci contained 4-6 ascospores, reacted positively with fluorescein diacetate, and swelled in water, but were isotonic in $0.4 \mathrm{M}$ $\mathrm{NaCl}$, indicative of progress towards maturation (Phytopathology 80:393401). A PCR-based analysis of FS- and AS-isolates will be reported. We found no evidence of reproductive isolation among FS and AS populations from 3 continents.

The effect of Fusarium moniliforme infection in maize on infestations of stem and ear borers. F. Schulthess and K. F. CARDWELL. International Institute of Tropical Agriculture (IITA), 08BP0932, Cotonou, Benin. Phytopathology 89:S70. Publication no. P-1999-0500-AMA.

In field trials at the International Institute of Tropical Agriculture, Ibadan, Nigeria, maize cobs artificially inoculated with Fusarium moniliforme had double the number of lepidopteran and four times the number of coleopteran pests than the non-inoculated controls. Surveys in Benin revealed $F$. moniliforme was present in $73 \%$ of plants with stem borer damage compared to $43 \%$ in stems without borers. Field and greenhouse trials were designed to explore the relationship between the fungus and lepidoptera in maize stem. In the field, a significant gradient of $F$. moniliforme infection was induced by a) stem inoculation with $F$. moniliforme ( $81 \%$ infection), b) natural incidence $(22 \%)$, and c) hot water seed treatment and soil fungicide (3.6\% infection). Numbers of Eldana saccharina larvae were significantly higher in the inoculated plots. Oviposition and life table studies showed that plants with high $F$. moniliforme had significantly larger $E$. saccharina egg batches and higher numbers of larvae. It is concluded that reducing $F$. moniliforme incidence in stems and ears would also significantly reduce pest infestations.

The influence of silicon on components of resistance to rice blast. $\mathrm{K}$. W. SEEBOLD (1), T. A. Kucharek (1), L. E. Datnoff (1), and M. A. Marchetti (2). University of Florida, Gainesville, FL; (2) USDA, Beaumont, TX. Phytopathology 89:S70. Publication no. P-1999-0501-AMA.

The addition of silicon $(\mathrm{Si})$ to $\mathrm{Si}$-deficient soils has been shown to reduce the epidemic rate of blast, caused by Magnaporthe grisea, in blast-susceptible and partially resistant cultivars of rice. Four cultivars of rice with differential susceptibilities to race IB-49 of $M$. grisea were fertilized with three rates of calcium silicate fertilizer and inoculated with the pathogen to test the effects of Si on the components of resistance that influence the epidemic rate. The following components of resistance to blast were examined: incubation period, latent period, infection efficiency, lesion size, rate of lesion expansion, sporulation per lesion, and diseased leaf area. For each cultivar, the incubation period was significantly lengthened by increased rates of $\mathrm{Si}$, and the numbers of sporulating lesions, lesion size, rate of lesion expansion, diseased leaf area, and number of spores per lesion were reduced. Lesion size and sporulation per lesion were lowered by $30-45 \%$ at the highest rate of Si. Thus, Si slows the epidemic rate of blast primarily by limiting lesion size and spore production per lesion.

A novel potyvirus isolated from maize in Israel. D. SEIFERS (1), R. Salomon (2), V. Marie-Jeanne (3), S. Haber (4), Y. She, W. Ens, and K. Standing (5). (1) KSU-ARCH, Hays, KS; (2) Volcani Center, Bet-Dagan, Israel; (3) ENSA-INRA, Montpellier, France; (4) Agriculture Canada, Winnipeg, MB; (5) Univ. of Manitoba, Winnipeg, MB. Phytopathology 89:S70. Publication no. P-1999-0502-AMA.

A virus (RS), isolated from maize in Israel was compared to maize dwarf mosaic virus (MDMV), sugarcane mosaic virus strain MDMV-B (SCMVMDB), johnsongrass mosaic virus (JGMV), and sorghum mosaic virus (SrMV) for: serological reaction, host range, mass determination and amino acid sequence of the capsid by Time of Flight Mass Spectrometry (TFMS), and the capsid gene was sequenced. In enzyme-linked immunosorbent assay, antiserum to RS cross-reacted to SCMV-MDB, as did SCMV-MDB antiserum to RS. The RS antiserum was negative against MDMV, JGMV, SrMV, as were antisera of these viruses to RS. RS systemically infected johnsongrass (Sorghum halepense), but not: oat (Avena sativa), pearl millet (Pennisetum glaucum), barley (Hordeum vulgare), or rye (Secale cereale). The RS capsid gene sequence did not cluster with those of MDMV, SCMV-MDB, JGMV, SrMV, and other potyviruses. Amino acid sequence (TFMS) verified the deduced sequence (capsid gene) and established a mass of 34,203 Da.

Mealybugs and pineapple mealybug wilt associated virus are both necessary for mealybug wilt. D. M. SETHER and J. S. Hu. University of Hawaii at Manoa, Honolulu, HI. Phytopathology 89:S70. Publication no. P-19990503-AMA.

Pineapple mealybug wilt associated virus (PMWaV) is a mealybug transmitted closterovirus found in pineapple plants worldwide. PMWaV has been found consistently associated with plants exhibiting mealybug wilt of pineapple (MWP) disease, but can also be found in plants appearing healthy. The etiology of MWP is unclear. A field experiment using a split block design was used to investigate the role of PMWaV and mealybug feeding in MWP. Field treatments consisted of eight plots with PMWaV-free plants and eight plots with PMWaV-infected plants. Nonviruliferous mealybugs (Dysmicoccus spp.) were transferred to four plots of each type at monthly intervals and the remaining plots kept mealybug-free. Plants in all plots not receiving mealybug inoculations appeared healthy and normal. PMWaV-free plants in plots receiving mealybugs exhibited green spotting on the leaves indicative of $D$. neobrevipes feeding but did not develop MWP symptoms. MWP symptoms began appearing $11 / 2$ months after mealybug exposure only in plots with PMWaV-infected plants receiving mealybug inoculations. Symptoms included leaf tip dieback, reddening and wilting. 
Effects of irrigation frequency, clipping management, and fungicides on development of Rhizoctonia brown patch in tall fescue. D. M. SETTLE (1), J. D. Fry (1), and N. A. Tisserat (2). (1) Dept. Horticulture, Forestry and Recreation Resources; (2) Dept. Plant Pathology, Kansas State University, Manhattan, KS 66506. Phytopathology 89:S71. Publication no. P-1999-0504AMA.

Irrigation, clipping management, and fungicides were evaluated in tall fescue for their influence on brown patch development, caused by Rhizoctonia solani. Turf in all plots received the same total amount of water; half were irrigated daily, the others three days weekly. Water was applied between 0430-0600 h to all plots. Clippings were either bagged or returned using a mulching mower. Preventive applications of azoxystrobin and curative applications of chlorothalonil were evaluated for control efficacy. Irrigation frequency and clipping management did not influence disease severity. Turf in mulched plots had better quality and higher leaf nitrogen levels by late August. Three applications of azoxystrobin (Heritage at $0.3 \mathrm{~kg}$ a.i. $/ \mathrm{ha}$ ) at 5 week intervals beginning 1 June 1998 resulted in less than 5\% disease and excellent turf quality. However, untreated plots with up to $80 \%$ blighting in mid-July were nearly symptom free 25 days later.

Expression of the cauliflower mosaic virus polycistronic 35S RNA in yeast. M. SHABABI, J. Bourque, and J. E. Schoelz. University of Missouri, Columbia, MO 65211. Phytopathology 89:S71. Publication no. P-1999-0505AMA.

We are utilizing Saccharomyces cerevisiae as a model system to examine the translation strategy of the polycistronic 35S RNA of cauliflower mosaic virus (CaMV). The 35S RNA of CaMV consists of a 600 nucleotide leader sequence, followed by six genes. To measure expression in yeast, the chloramphenicol acetyltransferase (CAT) gene was fused into different locations within the CaMV leader sequence and in-frame into each of CaMV genes VII, I, II, and III. Expression of reporter-fusions in yeast was quantitated by CAT ELISA. The level of CAT protein in yeast transformed with gene VIICAT was significantly higher than that of the monocistronic CAT control, which indicates that ribosomes are shunted through the leader to gene VII, a mechanism proven to exist in plants. The level of CAT expression of gene I and III-fusions was $0.5 \%$ the level of the CAT control. In contrast, the gene II-CAT fusion was $10 \%$ that of the CAT control, an indication that ribosomes may gain access to gene II through a shunting mechanism or an internal ribosomal entry site.

Growth and spore production by Alternaria eichhorniae. Y. M. SHABANA (1), R. Charudattan (2), and M. A. Elwakil (1). (1) Dept. Plant Pathology, Faculty of Agriculture, Mansoura University, Egypt; (2) Dept. Plant Pathology, University of Florida, Gainesville, FL 32611. Phytopathology 89: S71. Publication no. P-1999-0506-AMA.

Alternaria eichhorniae is being developed as a bioherbicide to control waterhyacinth (Eichhornia crassipes) in Egypt. A virulent isolate, A. eichhorniae 5 (Ae5), was studied to select media, light, aeration, and $\mathrm{pH}$ conditions suitable for its cultural growth and spore production. Waterhyacinth leaf-extract plus fresh potato-dextrose agar (WHFPDA) and waterhyacinth leaf-extract plus dextrose agar (WHDA) promoted the best mycelial growth, while limabean agar (LBA) and modified Richard's agar (MRA) were least favorable. Abundant sporulation occurred on LBA and WHDA. Cultures grown in petri plates with normal aeration, compared to plates sealed with Parafilm, and incubated under continuous light at $30 \mathrm{C}$ yielded maximum levels of mycelial growth and sporulation. At $\mathrm{pH} 7$, most mycelial growth but least sporulation were seen. At $\mathrm{pH} 5.6$ and 9.7, abundant sporulation but only moderate to sparse mycelial growth were obtained. Of five spore-production methods evaluated, a biphasic system was the most effective with respect to spore yield, time, and materials.

Seed transmission of Stagonospora nodorum in wheat. D. A. SHAH and G. C. Bergstrom. Cornell University, Ithaca, NY. Phytopathology 89:S71. Publication no. P-1999-0507-AMA.

Stagonospora nodorum can be transmitted from infected wheat seeds to seedlings, thus initiating epidemics of Stagonospora nodorum blotch. Yet the quantitative relationship between seed and seedling infection incidence is poorly understood. We measured seed transmission in four naturally-infected lots (53-96\% seeds infected) grown at five temperatures $(9,13,17,21,25 \mathrm{C})$ in controlled-environment chambers. Lesion incidence on coleoptiles and first leaves was recorded at the second leaf emerged stage. First leaves were incubated on Bannon's medium for $14 \mathrm{~d}$ under near ultraviolet light; pycnidial formation confirmed infection. On average, $50 \%$ of infected leaves were asymptomatic. Seed-to-coleoptile transmission at all temperatures was nearly $100 \%$. Transmission to the first leaf ranged from 38 to $3 \%$, decreasing nonlinearly with increasing temperature. Assuming a transmission rate of $10 \%$ (average rate at $17 \mathrm{C}$ ), seed (5\% infected) sown to achieve a stand of 200 seedlings $\mathrm{m}^{-2}(67 \mathrm{~kg}$ seed/ha or $1 \mathrm{bu} / \mathrm{a})$ would average one infection focus in every $1 \mathrm{~m}^{2}$, placing every plant within the documented range of conidial splash dispersal.

Sensitive detection of viroids from herbaceous and woody hosts by RTPCR-probe capture hybridization (RT-PCR-ELISA). A. M. SHAMLOUL and A. Hadidi. Agricultural Research Service, U.S. Department of Agriculture, Beltsville, MD. Phytopathology 89:S71. Publication no. P-1999-0508AMA.

A rapid and sensitive assay for the specific detection of plant viroids using RT-PCR-probe capture hybridization (RT-PCR-ELISA) was developed. Using viroid specific DNA primers and capture probes, the assay was applied successfully for the detection of the following viroids from their respective infected tissues: potato spindle tuber, chrysanthemum stunt, avocado sunblotch, peach latent mosaic, and apple scar skin. Clarified sap extract from infected leaf tissue was treated first with GeneReleaser ${ }^{\mathrm{TM}}$ polymeric matrix to remove inhibitors of RT-PCR reactions. Viroid cDNA was then synthesized and amplified using viroid specific primers in RT-PCR assays. The amplified viroid cDNA (amplicon) was DIG-labeled during the amplification process using a modified one tube RT-PCR-DIG labeled method. The amplicon was then detected in a colorimetric hybridization system in a microtiter plate using a biotinylated cDNA or cRNA capture probe. This system combines the specificity of molecular hybridization, the ease of the colorimetric protocol, and is at least 100 fold more sensitive than gel electrophoretic analysis in detecting the amplified product. Viroid cRNA may replace viroid cDNA as the capture probe. Six to seven hours are needed to complete the RT-PCR-ELISA assay for viroid detection from infected leaf tissue.

The occurrence and assessment of fungal parasites as potential biological control agents of western hemlock dwarf mistletoe. S. F. SHAMOUN. Canadian Forest Service, Victoria, BC. Phytopathology 89:S71. Publication no. P-1999-0509-AMA.

Western hemlock dwarf mistletoe (WHDM) (Arceuthobium tsugense subsp. tsugense) is a parasitic plant of several conifers and causes substantial reduction in tree growth, lowering wood quality and causing mortality. A field survey was conducted in the coastal southern region of British Columbia to collect and identify fungal parasites associated with WHDM. A total of 223 isolates of more than 20 ascomycetes and fungi imperfecti were isolated and identified. Two new fungal records were discovered, Colletotrichum gloeosporioides on WHDM on western hemlock, and a new species of Nectria on swollen branches infected by the shore pine pathotype of WHDM. Assessment of the biological control potential of fungi collected is under way. Hemlock seedlings, aged 2 yr. and 5 yr., were infected with WHDM seeds under greenhouse conditions. After 6 months, swellings were detected on branches and aerial mistletoe shoots were observed on seedlings at 18 and 6 months, respectively. Two fungi, C. gloeosporioides and $N$. neomacrospora were applied singly and in combination to WHDM clusters. The results and their applications under partial cutting systems will be discussed.

A synergistic interaction between geminivirus DNA components results in increased symptom severity and viral DNA levels in infected plants. L. P. SHARP, Y. M. Hou, E. R. Garrido-Ramirez, P. Guzman, and R. L. Gilbertson. Department of Plant Pathology, UC Davis, Davis, CA 95616. Phytopathology 89:S71. Publication no. P-1999-0510-AMA.

A previously uncharacterized Texas pepper geminivirus DNA-A component (chino DNA-A) cloned from tomatoes with symptoms of the chino del tomate disease has a unique synergistic interaction with pepper huasteco geminivirus (PHV). When co-inoculated with PHV the chino DNA-A component is able to move systemically in Nicotiana benthamiana, tomato and pepper plants. This synergy results in an increase in symptom severity compared with plants infected with PHV alone. In the presence of chino DNA-A, increased levels of PHV DNA's were detected in N. benthamiana. A coat protein mutation of the chino DNA-A did not influence the synergistic interaction with PHV. The chino DNA-A component also moved systemically in $N$. benthamiana with tomato leaf crumple geminivirus (TLCrV). However, no corresponding increase in symptom severity or levels of TLCrV DNA's was detected in plants co-inoculated with chino DNA-A and TLCrV. Together, these results suggest a virus-specific synergy between chino DNA-A and PHV that is not dependent on the chino DNA-A coat protein. 
Melanolytic activity of microorganisms and antagonism to Verticillium dahliae. K. G. SHETTY and K. V. Subbarao. University of California, Davis, 1636 E. Alisal St., Salinas, CA 93905. Phytopathology 89:S72. Publication no. P-1999-0511-AMA.

Melanin is a dark colored pigment present in many plant pathogenic fungi and is synthesized using various phenolic precursors. It imparts protection to the fungal propagules against extreme environmental conditions and soil microbial hydrolytic enzymes. Soil microorganisms showing melanolytic activity (MA) on fungal melanin may increase the susceptibility of the fungus to both abiotic and biotic stresses. Six actinomycetes, 4 antagonistic fungi, 4 Verticillium spp., 7 myxobacterial spp., 3 unidentified myxobacterial isolates and 3 unidentified bacteria were screened for MA on a synthetic melanin (SM) medium with combinations of $\mathrm{C}$ and $\mathrm{N}$ supplements. Among the organisms tested, only one actinomycete showed MA, but it had no antagonistic effect on $V$. dahliae. Limited melanolytic activity was observed when bacteria associated with unidentified myxobacteria were co-inoculated onto peptone supplemented SM plates. Myxobacterial isolates were antagonistic to $V$. dahliae. The relationship between MA and the antagonistic activity against $V$. dahliae was found to be weak.

Management of Verticillium wilt in strawberry using vegetable crop rotation. K. G. SHETTY (1), K. V. Subbarao (1), and F. N. Martin (2). (1) Dept. Plant Pathology, UC Davis; (2) USDA-ARS, 1636 E Alisal St., Salinas, CA 93905. Phytopathology 89:S72. Publication no. P-1999-0512-AMA.

The effect of vegetable crop rotations and residue amendment on strawberry plant diameter (PD), Verticillium wilt severity (VWS), and marketable yield were compared with MB + chloropicrin fumigation (MBCP) during 1997-98 at two sites. The Watsonville site (WS) had moderate level of background Verticillium inoculum (10 microsclerotia (MS)/g soil) and the Spence field site (SS) had no detectable MS. After the first rotation, the MS in broccoli treatment at WS was reduced to 1, while the lettuce treatment had 11 MS. At both sites broccoli plots had higher PD than other treatments. The VWS in broccoli plots was the lowest at SS, and at WS, broccoli treatments had the least VWS next only to fumigated plots. At WS during the final harvest, yield was $23 \%$ and $39 \%$ lower in broccoli and lettuce plots, respectively, compared with fumigated control. No significant difference in yield among treatments was observed in the absence of Verticillium wilt. Under moderate disease pressure, broccoli rotation is a feasible alternative for reducing Verticillium wilt severity in strawberry.

Effects of selective fungicides on etiology and control of peanut pod rot in North Carolina. B. B. SHEW and J. E. Hollowell. N.C. State University, Raleigh, NC 27695-7616. Phytopathology 89:S72. Publication no. P-19990513-AMA.

Rhizoctonia solani and Pythium spp. were the fungi most frequently associated with pod rot symptoms in a recent survey of peanut (Arachis hypogaea) grown in NC, but the etiology and economic importance of pod rot remain unclear. Selective fungicides were used to understand pod rot biology and control disease. Peanut was planted in five fields having different disease histories over two years and was treated with tebuconazole alone, mefenoxam alone, both fungicides, or neither. Symptomatic pods were assayed for pathogens, incidences of major diseases were recorded, and yield data were taken. The relative frequency of recovery of Pythium spp. and $R$. solani from pods varied with field history. Use of mefenoxam suppressed recovery of Pythium spp. and sometimes increased yield. Treatments with tebuconazole generally suppressed recovery of $R$. solani and increased yield. Effects of fungicides were additive. Yield increases associated with tebuconazole application were related to control of stem, peg, and pod rot caused by Sclerotium rolfsii in addition to pod rot caused by $R$. solani.

Morphological and molecular characterization of Phytophthora glovera sp. nov. from tobacco. H. D. SHEW, Z. G. Abad, G. Olivera, and J. A. Abad. N.C. State University, Raleigh, N.C. Phytopathology 89:S72. Publication no. P-1999-0514-AMA.

The cause of the yellow stunt disease of tobacco was investigated in several states in southern Brazil. Based on morphological and molecular characterization, the primary pathogen was identified as a new species of Phytophthora, and has been named Phytophthora glovera sp. nov. P. glovera produces globose, obpyriform and irregular semipapillate sporangia which originate in unbranched or simple sympodial sporangiophores; antheridia are amphigynous and/or paragynous, some with irregular digitate projections. The ITS 1, ITS 2 regions of rDNA of six $P$. glovera isolates were amplified using PCR, and the sequences compared with 25 Phytophthora spp. using phylogenetic analysis. $P$. glovera is closely related to P. citricola, $P$. syringae and P. capsici. The Phytophthora spp. examined formed 2 main phylogenetic groups, papillate and nonpapillate species. RFLP analysis also was conducted using with Msp I, Alu I, Taq I, Hinf I, and Rsa I. Msp I separated $P$. glovera from P. citricola and other Phytophthora species. P. glovera represents a major threat to tobacco production in the region.

Characterization of the locus FIC1 of Fusarium moniliforme affecting fumonisin biosynthesis. W. B. SHIM and C. P. Woloshuk. Dept. Botany and Plant Pathology, Purdue University, West Lafayette, IN 47907. Phytopathology 89:S72. Publication no. P-1999-0515-AMA.

We have generated transformants affected in fumonisin B1 (FB1) biosynthesis by random plasmid integration of a vector containing the hygromycin $\mathrm{B}$ (hygB) marker into the genome of wild-type $F$. moniliforme M3125. One transformant, FT536, did not produce FB1 in cracked corn or in corn extract medium, but produced as much FB1 as the wild type in defined medium containing sucrose and ammonium phosphate. Random ascospore analysis of a sexual cross indicated that hygB phenotype segregated with the mutant phenotype. Southern analysis suggested that a deletion of $2 \mathrm{~kb}$ of the fungal genome occurred at the insertion site of the transformation vector. We have rescued the flanking DNA at the disrupted locus in FT536 and used PCR to obtain the deleted region from the wild type strain. Sequence analysis showed that the disrupted locus contains a gene that encodes a product with similarity to a class of proteins that bind to protein kinases. The data suggest that the locus FIC1 (Fumonisin Inhibited on Corn) is involved in regulation of FB1 biosynthesis.

Decomposition of canola stubble fiber by solid state fermentation with Cyathus olla. T. C. SHINNERS and J. P. Tewari. University of Alberta, Edmonton, Alberta, Canada. Phytopathology 89:S72. Publication no. P-19990516-AMA.

The white wood-rotting fungus, Cyathus olla, is being studied for its potential of being developed into an inoculant intended to accelerate canola stubble decomposition, and hence reduce the incidence of the stubble-borne diseases of this crop. In the field, $C$. olla infested stubble appears soft and macerated, but the extent of decomposition incited by this fungus is not known. The purpose of this study was to quantify changes in fiber content of canola stubble as a result of solid state fermentation with $C$. olla. Sterile canola root powder, moistened with water, was inoculated with $C$. olla and incubated for 45 days at $25^{\circ} \mathrm{C}$. Following incubation, the Goering-Van Soest method was used to determine the fiber content. Results indicated that all isolates significantly reduced the lignin content of canola stubble when compared with the uninoculated control. These results confirm that $C$. olla is capable of lignin degradation in vitro, but field testing must follow in order to assess its decomposing activity under natural conditions.

Use of cyprodinil for control of Botrytis cinerea on apples. P. L. SHOLBERG and K. E. Bedford. Agriculture and Agri-Food Canada, Pacific AgriFood Research Centre, Summerland, BC, Canada. Phytopathology 89:S72. Publication no. P-1999-0517-AMA.

Botrytis cinerea causes two diseases of apple in British Columbia (BC), calyx-end rot on developing fruit and gray mold rot on apples in storage. Cyprodinil (Vangard) is known to be very effective against $B$. cinerea. Trials to evaluate cyprodinil on 'Gala' and 'Spartan' apples were conducted in 1998 at the Pacific Agri-Food Research Centre, Summerland, BC. Apple tree replicates were sprayed to run-off at different timings beginning at bloom with cyprodinil alone and in combination. At harvest apples from each treatment replicate (10 apples) were subjected to one of five postharvest treatments and stored for 3 months at $1^{\circ} \mathrm{C}$. Upon removal from storage, apples were wounded and inoculated with $B$. cinerea or saline solution and incubated at $20^{\circ} \mathrm{C}$ for 7 days when rot diam. were measured. Cyprodinil used alone or in combination as bloom sprays did not control postharvest rot although $B$. cinerea populations on fruit were reduced. Cyprodinil applied as a postharvest treatment shortly after harvest significantly reduced rot diameters of 'Spartan' and 'Gala' apples 6.5 and $55.1 \%$, respectively.

Properties of a geminivirus from Dicliptera sexangularis. J. Sim and R. A. VALVERDE. Louisiana State University, Baton Rouge, LA. Phytopathology 89:S72. Publication no. P-1999-0518-AMA.

Dicliptera sexangularis (Acanthaceae) showing severe yellow mottle and leaf distortion symptoms was collected from the vicinity of Fort Myers, Florida. The virus was transmitted at a high rate by the sweetpotato whitefly (Bemisia tabaci) biotype B. Mechanical transmissions were successful from Dicliptera to Dicliptera. Other hosts included Nicotiana benthamiana and N. clevelandii. Total DNA from infected plants hybridized with a probe specific for 
tomato yellow leaf curl geminivirus. The whole component A of this geminivirus, designated dicliptera yellow mottle virus (DYMV) was amplified by PCR, cloned, and sequenced. The A component contained four open reading frames and an intergenic region containing a conserved stem-loop structure. The genome organization was similar to other Begomoviruses. Phylogenetic relationships between DYMV and other geminiviruses were investigated using derived $\mathrm{AC} 1$ and $\mathrm{AV} 1$ aminoacid sequences. DYMV is closely related to geminiviruses from the new world.

Whitefly transmission and detection of sweetpotato chlorotic stunt virus. J. Sim and R. A. VALVERDE. Louisiana State University, Baton Rouge, LA. Phytopathology 89:S73. Publication no. P-1999-0519-AMA.

Sweetpotato chlorotic stunt virus (SPCSV) is a whitefly transmitted closterovirus and a component of a serious viral disease complex in Africa. A whitefly transmitted isolate from the cultivar White Bunch, designated SPCSV-US, was used for transmission experiments. SPCSV-US induced consistent foliar chlorosis and leaf distortion on Ipomoea nil 'Scarlet O'Hara'. However, it did not induce symptoms on sweetpotato (I. batatas) 'Beauregard'. These two hosts were used in whitefly transmission studies. The sweetpotato whitefly (Bemisia tabaci) biotype B and the banded-winged whitefly (Trialeurodes abutilonea) were tested as vectors. Transmission rates were higher with $B$. tabaci than with T. abutilonea. SPCSV-US was detected by RT-PCR using primers specific for closterovirus heat shock protein 70 . The virus was more consistently detected from roots than from foliar tissues of Scarlet O'Hara. RT-PCR detection from sweetpotato was not consistent.

Systemic infection of onion seedlings by Aspergillus niger and Fusarium sp. K. L. SIROIS, D. P. LoParco, and J. W. Lorbeer. Cornell University, Ithaca, NY. Phytopathology 89:S73. Publication no. P-1999-0520-AMA.

Onion seed inoculated with spores of Alternaria sp., Aspergillus sp., Aspergillus niger, Fusarium sp., and Penicillium sp. or non-inoculated onion seed placed in a treatment of a spore containing soil growth medium seeded with the same fungi were grown under greenhouse conditions. Individual seedling parts (roots, basal plates, lower leaves, leaf tips, and the seed coat remnants) were examined at various ages for the presence of the fungi used in the inoculations. Systemic infections of the onion seedlings by A. niger and $F u$ sarium sp. were detected at similar levels from treatments of both seed inoculations and spore incorporation in the soil growth media. The infections began in the roots of the seedlings and moved systemically into the basal plates and lower leaves over time. Neither fungus was detected in the leaf tips of the seedlings. The fungi may have moved systemically into the leaf tips if the experiment was prolonged. The seed coat remnants were only available on one A. niger treatment. It was examined and A. niger was recovered from it.

Onion seed infection levels subsequent to sequential exposure of onion seed stalks and flower parts to Aspergillus niger. K. L. SIROIS, J. W. Lorbeer, and M. A. Holcomb. Cornell University, Ithaca, NY. Phytopathology 89:S73. Publication no. P-1999-0521-AMA.

Susceptibility of onion seed stalks and flower parts to infection by the fungus Aspergillus niger Teigh. was evaluated in greenhouse experiments. Seed stalks and flowers received a one time inoculation of A. niger at 7 different stages of plant development. The plants were allowed to mature with no further manipulations and the seed was collected when mature capsules formed. Evaluation of the seed revealed a broad susceptibility period to infection by A. niger. Treatments inoculated prior to flowers opening through mature capsule formation, 5 stages of plant development, were detected with high levels (82-100\%) of A. niger on the seed. A seed infection level of $16 \%$ was detected on seed from plants receiving a syringe injection of a spore suspension to the immature seed stalk. Observations of A. niger mycelial growth and sporulation within the lacunar area of the immature seed stalk inoculation were observed at the time of mature seed head collection. The infection levels indicated a high risk potential and long susceptibility period for infection of onion seed in years of heavy sporulation of the A. niger fungus.

Quantitative analysis of wild-type and mutant RNAs of pea enation mosaic virus using fluorescent, real-time RT-PCR. J. S. SKAF and G. A. de Zoeten. Department of Botany and Plant Pathology, Michigan State University, East Lansing, MI 48824. Phytopathology 89:S73. Publication no. P-19990522-AMA.

The genus Enamovirus (Family: Luteoviridae) contains a single member, pea enation mosaic virus-1 (PEMV-1). PEMV-1 participates in a disease complex with the Umbravirus PEMV-2 to cause the pea enation mosaic disease. We used quantitative, real time, SYBR Green RT-PCR to evaluate the replication and accumulation of clones containing mutations in the VPg gene relative to wild type clones. In this poster, we will present data indicating that VPg clones containing mutations in key amino acids (i.e. tyr2 or ser 3) and that are incapable of establishing infections in plants also failed to replicate and accumulate in isolated protoplasts. These results suggest that the VPg encoded by PEMV-1 is involved in the replication of RNA1. VPg mutants that caused milder and delayed infections in plants accumulated to lower levels (100 to 1000 fold) in protoplasts. We will also present information on the use of fluorescent probes specific to RNAs 1 and 2 in TaqMan RT-PCR to determine the spatial and temporal accumulation of viral RNA in infected plants.

Biological control of potato sprouting by dry rot antagonistic bacteria. P. J. SLININGER, D. A. Schisler, K. D. Burkhead, and R. J. Bothast. NCAUR, USDA-ARS, Peoria, IL. Phytopathology 89:S73. Publication no. P-19990523-AMA.

Chemical sprout inhibitors are applied to over $50 \%$ of the potato harvest to extend storage time. In the U.S., CIPC (1-methylethyl-3-chlorophenylcarbamate) is the only synthetic chemical registered for postharvest sprout control of stored potatoes, and it is the most widely used sprout inhibitor worldwide. Due to environmental and health safety concerns, the use of CIPC is becoming more restricted, and alternative sprout control methods are sought. Six bacteria strains, exhibiting superior dry rot suppressiveness in previous research, were grown on two different liquid culture media and sprayed to Russet Burbank potatoes. In growth chamber and pilot experiments repeated at two storage sites in two successive years, all six isolates demonstrated significant sprout control capabilities when applied after growth on at least one of the culture media supplied. Of the six strains tested, Pseudomonas fluorescens bv. V S11:P:12 and two strains of Enterobacter cloacae, S11:T:07 and S11:P:08, exhibited highest relative performance levels with sprout control being statistically similar to that of $16.6 \mathrm{ppm}$ CIPC thermal fog after five months storage.

A taxonomic and phylogenetic review of the genus Amylostereum. B. Slippers, M. J. Wingfield, B. D. Wingfield, and T. A. COUTINHO. Forestry and Agricultural Biotechnology Institute (FABI), University of Pretoria, Pretoria 0002, South Africa. Phytopathology 89:S73. Publication no. P-1999-0524AMA.

Amylostereum areolatum and A. chailletii are well known for their association with various woodwasp (Siricidae) species. These fungi have, however, often been misidentified due to the rarity or absence, as well as similarity, of their sporocarps. Furthermore, no complete phylogenetic study of the genus Amylostereum has been done. The aim of this study was, therefore, to investigate the taxonomic and phylogenetic relationships between the different Amylostereum spp. using sequence and RFLP data from the nuc-IGS-rDNA and mt-SSU-rDNA regions. The relationship between Amylostereum spp. and 86 other Basidiomycetes species was also considered using sequence data from the mt-SSU-rDNA region. Both DNA regions confirmed earlier hypotheses that $A$. areolatum is the most distantly related species in the genus, while A. laevigatum and A. ferreum are the most closely related. These analyses also showed that the fungal symbiont of Sirex areolatus is not $A$. chailletii, as was previously thought, but an Amylostereum spp. more closely related to A. laevigatum and A. ferreum. RFLP fingerprinting of the IGS region successfully delineated the different Amylostereum spp. and this now presents a quick and accurate identification tool for this group of fungi. RFLP and sequence analysis of the IGS region, however, also identified heterogenic sequences for the DNA region in isolates of A. areolatum. These sequences make it possible to compare isolates of $A$. areolatum from populations of the fungus that are separated due to their association with different woodwasp species. Sequence data of the mt-SSU also showed that the four Amylostereum spp. are more closely related to Echinodontium tinctorium, than to Stereum spp. and Peniophora spp. as was previously hypothesized. This study represents the first molecular study of the genus Amylostereum and sheds new light on its taxonomic and phylogenetic relationships.

Identification of Leucostoma species isolated from apple and stone fruit cultivars in South Africa. W. A. SMIT (1) and G. C. Adams (2). (1) ARC Fruit, Vine and Wine Research Institute, Stellenbosch, South Africa; (2) Michigan State University, East Lansing, MI. Phytopathology 89:S73. Publication no. P-1999-0525-AMA.

Leucostoma canker of pome and stone fruit cultivars, caused by either Leucostoma cincta (anamorph Leucocytospora cincta) or Leucostoma persoonii (anamorph Leucocytospora leucostoma) is common in many parts of the world. Leucostoma canker causes extensive perennial cankers that result in die-back of branches and girdling of trunks. Symptoms of this disease were 
observed in South Africa, but the isolation and identification of the pathogen has never been reported. The objective of this study was to identify the Leucostoma species associated with cankers on apple and stone fruit cultivars in South Africa. All Leucostoma isolates were grouped phenotypically based on morphological criteria, and size polymorphisms in the nuclear small subunit of the ribosomal DNA repeat. The ITS region of the repeat was amplified by PCR and sequenced for representative isolates. Isolates were identified as $L$. persoonii based on homology. All isolates were screened for a Hin fI restriction site in the ITS and for a corresponding $268 \mathrm{bp}$ fragment indicative of the species $L$. persoonii.

Occurrence and pathogenicity of Leucostoma (Leucocytospora) species associated with peach canker in South Africa. W. A. SMIT and L. Smit. ARC - Fruit, Vine and Wine Research Institute, Stellenbosch, South Africa. Phytopathology 89:S74. Publication no. P-1999-0526-AMA.

A severe die-back of peach branches associated with cankers was noted in commercial orchards in South Africa. Though producers had generally attributed the symptoms to Pseudomonas syringae, examination of dead and dying branches in severely affected peach orchards showed that the bacterium was not associated with active cankers. This suggested a fungal pathogen, such as Leucostoma, as the cause of infection. Leucostoma canker is frequently misdiagnosed as bacterial canker, since many of the early symptoms are indistinguishable. The aim of this study was primarily to determine the cause of the disease. In addition, the virulence of a wide range of isolates on peach was compared. This study has shown that the causal agent of the canker disease of peach in South Africa is a species of Leucostoma. Canker and die-back symptoms were found in most orchards throughout the major peach production areas. Leucostoma canker is considered as the principal canker disease occurring in those orchards. Bacterial canker, caused by pathovars of $P$. syringae, was not found in our survey of orchards where canker and die-back were endemic.

RAPD marker differentiation of Botryosphaeria dothidea from other fungi with Fusicoccum anamorphs. D. R. SMITH and G. R. Stanosz. Dept. Plant Pathology, Univ. Wisconsin, Madison, WI 53706. Phytopathology 89:S74. Publication no. P-1999-0527-AMA.

Identification of B. dothidea, B. ribis, and B. parva often depends on morphological characters of their Fusicoccum anamorphs because they are more commonly encountered and because the teleomorphs are difficult to distinguish. However, morphological characters of these anamorphs and the anamorphic fungus $F$. luteum are also very similar and often influenced by substrate, making identification difficult and causing taxonomic confusion. We have analyzed RAPD markers to examine relationships among 49 putative $B$. dothidea, 35 putative $B$. ribis, $2 B$. parva, and $2 F$. luteum isolates from diverse hosts and locations. A phenogram was produced using UPGMA analysis of DNA fragment presence-absence data. Twenty-five putative $B$. dothidea isolates formed a group of high similarity that we conclude represents $B$. dothidea. A second much less similar group consisted of putative $B$. dothidea, B. ribis, and B. parva isolates and may represent $B$. ribis. A third low similarity group contained putative $B$. dothidea, B. ribis, and $F$. luteum isolates. Examination of relationships among isolates in the two more heterogeneous groups continues.

Postharvest high pressure washing of citrus fruit with sodium bicarbonate to control green mold. D. Sorensen (1), J. L. Smilanick (2), and D. A. MARGOSAN (2). (1) Sunkist Growers, 222 W. Lindmore, Lindsay CA 93247; (2) USDA-ARS, 2021 S. Peach Ave., Fresno, CA 93727. Phytopathology 89:S74. Publication no. P-1999-0528-AMA.

Postharvest high pressure washing (HPW) cleans and removes scale insects from citrus fruit. Alone it does not control citrus green mold. We evaluated HPW to apply $\mathrm{Na}_{2} \mathrm{CO}_{3}$ (SBC) to replace SBC-containing soak tanks for green mold control. Fruit were wound-inoculated with Penicillium digitatum spores $24 \mathrm{hr}$ prior to treatment. SBC at $18 \mathrm{C}$ applied for $35 \mathrm{~s}$ in a tank or by $\mathrm{HPW}$ at $2150 \mathrm{kPa}(320 \mathrm{psi})$ was compared. SBC pH was 8.3 and contained $200 \mu \mathrm{g} / \mathrm{ml}$ free $\mathrm{NaOCl}$. Concentration of SBC was $1 \%, 3 \%$, and $3 \%$ (wt/vol) in tests 1,2 , and 3 , respectively. Tests had 6 replicates of 60 oranges and 75 lemons each. Fruit were stored for 2 wk at 10 C. Among oranges, HPW or tank treatment were equally effective in all tests. Among lemons, the HPW was slightly inferior, equal, and superior to tank treatment in tests 1,2 , and 3, respectively. HPW with SBC reduced decay from $97 \%$ in the controls to a mean of 17 and $20 \%$, for lemons and oranges, respectively. SBC tank treatment reduced it to a mean of 22 and $19 \%$, respectively, among lemons and oranges. SBC can be applied by HPW or soak tanks with equal effectiveness.
Detection of dsRNA in the butternut canker fungus. P. Spaine (1), S. Schlarbaum (2), and S. MCELREATH (3). (1) USDA Forest Service, 320 Green Street, Athens, GA 30602; (2) Dept. of Forestry, Wildlife and Fisheries, University of Tennessee, Knoxville, TN. 37901; (3) Dept. of Forest Resources, Clemson University, Clemson, SC 29634. Phytopathology 89:S74. Publication no. P-1999-0529-AMA

Butternut Juglans cinerea is being killed throughout it range by a putative exotic fungus, Sirococcus clavigignenti-juglandacearum. In areas where the fungus is believed to have been introduced, tree cankers have shown signs of healing. This study is to determine if there may be an association between healing butternut cankers and dsRNA positive strains of Sirococcus. Initially, single isolates from five sites in North Carolina, two in Wisconsin, and one in Alabama were examined. After phenol-chloroform extraction, samples were purified with Whatman CF-11 cellulose and analyzed by agarose gel electrophoresis. DsRNA was found in isolates from three of the NC sites and the AL site, but not in the isolates from WI. Collection and analysis of additional isolates is in progress.

Fusarium head blight reaction of durum wheat lines conditioned by Triticum dicoccoides chromosome substitutions. R. W. STACK (1), E. Elias (2), and L. R. Joppa (3). (1) Dept. of Plant Pathology and (2) Dept. of Plant Sciences, North Dakota State Univ.; (3) USDA-ARS, Northern Crop Sci. Lab., Fargo, ND 58105. Phytopathology 89:S74. Publication no. P-1999-0530AMA.

Fusarium head blight (FHB) is a serious disease problem on durum wheat. To date, the resistance to FHB available in hexaploid wheat sources has not successfully been transferred to durum - a tetraploid wheat. Triticum dicoccoides is a wild tetraploid wheat that possesses many interesting traits. In the 1980's, USDA geneticist L. R. Joppa produced a set of lines derived from 'Langdon' durum, each with a different pair of chromosomes from T. dicoccoides substituted for the corresponding durum chromosomes. We tested these lines for FHB response by inoculation with Fusarium graminearum under controlled conditions. Two of the substitution lines were significantly less susceptible and two were significantly more susceptible than the durum parent, which itself showed a moderately susceptible FHB reaction. Since each line differs by an entire chromosome pair, the results suggest that FHB resistance genes compatible with the durum genome are present on at least four different chromosomes.

Tolerance to $\boldsymbol{V}$. dahliae in Craigella tomatoes. A. STANKIEWICZ and J. Robb. Dept. of Molecular Biology and Genetics, University of Guelph, Guelph, Ontario, N1G 2W1. Phytopathology 89:S74. Publication no. P-19990531-AMA.

Quantitative PCR diagnostics allow more accurate assessment of pathogen levels in infected plants than previously possible. In a recent study to investigate development of $V$. dahliae in its tomato host two isolates of cv. Craigella, with and without the Ve-gene, were inoculated with one of four isolates, including a standard race 1 or 2, and non-host isolates, DvdE6 (eggplant) and -P13 (potato), identified as non-pathogenic based on symptom expression. Plants were infected by root drench. Symptoms were scored and the upper half of the stem was sampled after 6,10 and 21 days. Nucleic acids were extracted and the amount of fungal DNA/gm plant tissue was determined. Races 1 and 2 produced predictable diseases scores and, generally, the highest colonization levels. In the P13 interactions fungal biomass and symptoms were reduced as expected in a non-host reaction. The E6 interactions were less consistent; in one experiment colonization levels were in the resistant or susceptible host range but disease scores were lower suggesting Craigella is a host with tolerance for E6. Tolerance developed later in the second experiment.

Differences in responses of juvenile Populus clones to inoculation with Septoria musiva allow canker disease resistance screening. G. R. STANOSZ and J. C. Stanosz. Dept. Plant Pathology, Univ. Wisconsin, Madison, WI 53706. Phytopathology 89:S74. Publication no. P-1999-0532-AMA.

Widespread use of hybrid poplars as a short rotation, intensive culture (SRIC) woody crop in eastern North America continues to be hindered by a scarcity of highly productive clones with resistance to canker disease caused by Septoria musiva. Breeding efforts currently are not complemented by a reliable, standardized method to screen clones for disease resistance. Using a fresh leaf scar-agar plug technique, shoots of 27 poplar clones (replicated in each of two independent field trials) were inoculated with an aggressive isolate in late July of their first growing season. Clones had been selected to represent a range in longer-term performance, based on literature reports of 
damage from cankers (in come cases attributed to $S$. musiva) and personal observations. In November, canker incidence ranged from 5-100\%. Mean canker length ranged from $7 \mathrm{~mm}$ to $57 \mathrm{~mm}$ and mean percentage of stem circumference girdled ranged from $10 \%$ to $94 \%$. Responses of clones were indicative of reported/observed longer-term field performance, indicating the potential to screen clones prior to other field tests and release to growers.

Incidence of the reniform nematode in West Tennessee cotton fields. T. S. STEBBINS (1), M. A. Newman (2), and D. L. Cook (1). (1) University of Tennessee, Nashville, TN; (2) Jackson, TN. Phytopathology 89:S75. Publication no. P-1999-0533-AMA.

Sampling for the second year of a long term survey was conducted in fall 1998 to determine the presence of phytopathogenic nematodes, in particular the reniform nematode, Rotylenchulus reniformis, in West Tennessee cotton growing areas. There were 1547 soil samples collected in selected fields, representing about $7 \%$ of the $450,000 \mathrm{~A}$ of cotton grown in Tennessee. A composite sample was taken from soil cores collected randomly across each field. Nematodes were extracted using a semi-automatic elutriator, followed by centrifugation, sugar-flotation, and sieving. $R$. reniformis was detected in 28 samples and confined to 5 growers in two counties. Nematode counts ranged from 1 to 268 per $200 \mathrm{cc}$ of soil tested. This information will be combined with the survey in 1997 to gain a better knowledge of the nematode status in Tennessee cotton fields and to facilitate rotation decisions and other control efforts.

Continuous application of the biocontrol bacterium, Pseudomonas putida 06909, improves biocontrol of Phytophthora parasitica on citrus. K. C. STEDDOM and J. A. Menge. University of California, Riverside, CA. Phytopathology 89:S75. Publication no. P-1999-0534-AMA.

In an effort to control the citrus root rot pathogen, Phytophthora parasitica, the biocontrol bacterium, Pseudomonas putida 06909, was applied yearly or continuously with every irrigation. Populations of $P$. parasitica were significantly reduced $95 \%$ by a yearly application of the fungicide metalaxyl and the nematicide fenamiphos the first year as compared to the untreated control. Continuous applications of $P$. putida did not affect $P$. parasitica populations the first year. In the second year, $P$. parasitica populations were significantly reduced $72 \%$ by the chemical treatment and $93 \%$ by the continuous application treatment. The yearly applications treatment did not reduce $P$. parasitica populations in either year. Yield on the 5-yr-old trees was significantly decreased by $32 \%$ in the continuous applications treatment as compared to the control; however, it was not significantly different from the $19 \%$ reduction seen in the chemical treatment. This is likely due to the high Phytophthora populations seen in the control treatment, which stressed the tree and increased yield.

PCR-based differentiation of MAT-1 and MAT-2 from Gibberella fujikuroi mating population H. E. T. Steenkamp (1), B. D. Wingfield (1), T. A. COUTINHO (1), M. J. Wingfield (1), W. F. O. Marasas (2), and J. F. Leslie (3). (1) Forestry and Agricultural Biotechnology Institute (FABI), University of Pretoria, Pretoria 0002, South Africa; (2) PROMEC, MRC, P.O. Box 19070, Tygerberg 7050, South Africa; (3) Dept. of Plant Pathology, KSU, Manhattan, Kansas. Phytopathology 89:S75. Publication no. P-1999-0535AMA.

Fusarium subglutinans $\mathrm{f}$. sp. pini is a pathogen of pine and belongs to the $\mathrm{H}$ mating population of the Gibberella fujikuroi species complex. Isolates of this biological species are heterothallic, with individuals of either MAT-1 or MAT-2 mating type. Identifying mating type by sexual crosses is a timeconsuming procedure and results are often inconclusive. A fast and reliable method for differentiating the two mating types is, therefore, needed. We designed PCR primers from conserved regions of the MAT-1 and MAT-2 idiomorphs. One primer pair was designed from the alpha domain in the MAT-1 idiomorph. The other was designed from the MAT-2 HMG domain. A PCR reaction containing both these primer pairs amplified either an $800 \mathrm{bp}$ fragment, for MAT-2 isolates, or a $200 \mathrm{bp}$ fragment, for MAT-1 isolates. It was, thus, possible to determine the mating types of strains from Gibberella fujikuroi mating population $\mathrm{H}$ in single $\mathrm{PCR}$ reactions.

Wisconsin's field experience with azoxystrobin fungicide for control of early blight on potato. W. R. STEVENSON, R. V. James, R. E. Rand, and L. A. Flak. Dept. of Plant Pathology, University of Wisconsin, Madison, WI 53706. Phytopathology 89:S75. Publication no. P-1999-0536-AMA.

Early blight, Alternaria solani, is an annual threat to commercial potato production in Wisconsin. Protectant fungicides are typically applied every 5-10 days for control. During 1998, an Experimental Use Permit (EUP) was ap- proved by the US-EPA for limited use of azoxystrobin fungicide on approximately 2,000 acres ( 800 ha) of commercial potatoes. Fifteen growers split 26 fields into areas treated every 5-10 days from midseason to vinekill with either a standard protectant fungicide program or alternating treatments with azoxystrobin and chlorothalonil fungicides. The fields represented three soil types and potatoes grown for fresh market, processing and seed. Fields were rated weekly for early blight severity and yields were determined at harvest. Treatment with the azoxystrobin/chlorothalonil program vs. the "standard" program improved early blight control, contributed to a retention of green foliage up to three weeks longer, increased yield, increased tuber size, increased crop values and reduced the total amount of fungicide active ingredients applied for early blight control by $30.3 \%$.

Ecological and mechanistic compatibility as criteria for antagonist mixtures for control of fire blight. V. O. STOCKWELL (1), K. B. Johnson (1), and J. E. Loper (2). (1) Oregon State University, Corvallis, OR; (2) USDAARS, Corvallis, OR. Phytopathology 89:S75. Publication no. P-1999-0537AMA.

Mixtures of antagonists can enhance disease control compared to single inoculants providing strains are ecologically compatible. Combining Pseudomonas fluorescens A506 with strains of Pantoea agglomerans often results in greater population sizes of the antagonists on blossoms, but control is not enhanced compared to single strains. We propose that mechanistic incompatibility, whereby a member of a mixture interferes with the mode-of-action of its co-inoculant, compromises the efficacy of our mixture. Herbicolins or microcins produced by P. agglomerans 252 were important in control of fire blight on pear blossoms in a 1998 field trial. Pa252 reduced disease incidence by $72 \%$, whereas a non-antibiotic producing mutant did not provide significant control compared to water-treated trees. In cultural assays, Pf A506 detoxified antibiotics produced by $P a 252$, presumably by the production of extracellular protease (Ecp). We have obtained an Ecp- mutant of PfA506 and will evaluate its ecological and mechanistic compatibility with $P a 252$ in field trials on biological control of fire blight of pear.

Impact of raw and composted paper mill sludge decomposition level on root rot incidence. A. G. STONE and L. R. Cooperband. University of Wisconsin, Madison, WI. Phytopathology 89:S75. Publication no. P-1999-0538AMA.

Organic matter type and decomposition level have been shown to influence Pythium root rot incidence in container mixes, but do they in sandy field soils? Paper mill sludge (PS) and PS composted with bark (PSB) were tested for suppressiveness as they decomposed using a cucumber/Pythium ultimum bioassay. PS (aged for $6 \mathrm{mo}$ in the lab) and PSB both reduced $(P=0.06)$ root rot incidence in potting mixes ( 1 amendment: 4 Metromix, v/v) relative to Metromix alone. In freshly amended sandy field soils, fresh PS increased $(P$ $=0.09)$ and PSB strongly reduced $(P=0.001)$ root rot incidence. However, in field soil samples collected 6 mo after amendment, both amendments suppressed root rot relative to the control in at least one test, but neither was consistently highly suppressive in repeated tests. These data preliminary suggest that fresh PS (raw cellulose) is conducive to Pythium, while more decomposed PS may be weakly suppressive. In contrast, PSB is highly suppressive initially, but the level of suppression is reduced as the material decomposes as has been shown for other bark composts. More complete growth chamber data will be related to 1999 field snap bean root rot incidence.

Impact of raw and composted paper mill sludge on potato disease incidence. A. G. STONE, W. R. Stevenson, R. V. James, and L. R. Cooperband. University of Wisconsin, Madison, WI. Phytopathology 89:S75. Publication no. P-1999-0539-AMA.

Raw paper mill sludge (PS), composted PS (PSC), PS composted with bark (PSB), and peat (PT) were incorporated into a sandy field soil at low (L) and high $(\mathrm{H})$ rates $\left(\mathrm{PS}, 22 / 44 \mathrm{Mg} \mathrm{ha}^{-1}\right.$; others, 38/76 $\mathrm{Mg} \mathrm{ha}^{-1}$ ) to determine the effect of amendment type and rate on potato disease incidence. No late blight and little early dying were observed. Early blight incidence was higher $(P=$ 0.05 ) in PS L and PSC L and H than the control due to nitrogen stress. Aerial black leg (ABL) (Erwinia carotovora subsp. carotovora) incidence was higher $(P=0.05)$ than the control in PS H and PT L and lower in PSB H and PT H. PSB L and H and PSC H increased $(P=0.05)$ the common scab lesion area index. However, only PSB L increased $(P=0.05)$ the proportion of potatoes with scab tuber surface area $>10 \%$. Silver scurf incidence was higher $(P=0.05)$ than the control in PS L and H, PSB H, and PSC H treatments. Leak incidence was high overall $(4-17 \%)$, but lower $(P=0.10)$ than the control in PSB L, PSC H and PS H treatments. There was no treatment effect 
$(P=0.05)$ on black scurf incidence, which was very low overall. We will investigate the effects of repeated amendment applications in a three yr vegetable rotation.

Differentiation of Xanthomonas campestris pvs. pelargonii and hederae by PCR. M. A. SULZINSKI (1) and S. H. Kim (2). (1) Department of Biology, University of Scranton, Scranton, PA 18510; (2) Plant Disease Diagnostic Lab, PA Dept. of Agriculture, Harrisburg, PA 17110. Phytopathology 89: S76. Publication no. P-1999-0540-AMA.

Pennsylvania isolates of Xanthomonas campestris pvs. pelargonii (Xcp) and hederae (Xch), identified by fulfilling Koch's postulates, were tested using PCR primers XcpM1/XcpM2, previously described as specific for Xcp. With this primer pair, the $200 \mathrm{bp}$ specific product was produced only with Xcp; no visible products of any size were produced with Xch. Xcp and Xch were also tested separately with ERIC and REP PCR primers, which target conserved enterobacterial DNA sequences and generate fingerprints after PCR and gel electrophoresis. The two pathovars were distinguishable after PCR using REP primers. The Xch REP fingerprint included a unique major product absent from the Xcp fingerprint. The two pathovars generated similar fingerprints after PCR using ERIC primers. Xcp and Xch have been reclassified into a species of $X$. hortorum Vaut. Other workers reported Xcp and Xch were indistinguishable by pathogenicity and by PCR. These two pathovars are sufficiently divergent to allow their molecular differentiation by PCR, which can be used to screen geraniums for Xcp infection.

Cloning and characterization of a symbiosis regulated signal transduction gene from Laccaria bicolor. S. SUNDARAM, H. Suzuki, S. J. Kim, and G. K. Podila. Michigan Technological University, Houghton, MI. Phytopathology 89:S76. Publication no. P-1999-0541-AMA.

Formation as well as functioning of ectomycorrhizae involve a complex set of interactions between the plant and fungal partners. Early events of these interactions are crucial for the establishment of the symbiotic organ. We have cloned a cDNA coding for a Ras protein which is regulated in the ectomycorrhizal fungus Laccaria bicolor during the early stages of its symbiotic interactions with red pine (Pinus resinosa). This clone shows extensive sequence homology with other known ras genes including the human p21 ras. A recombinant gene coding for this Ras was able to complement a ras mutation in Saccharomyces cerevisiae indicating functional homology. The recombinant gene was expressed in E. coli and the protein synthesized was purified. Data from temporal and spatial expression of Ras protein and its importance in development of symbiosis will be presented.

Survival of detached sporangia of Phytophthora infestans under ambient conditions. M. A. SUNSERI and D. A. Johnson. Washington State University, Pullman, WA. Phytopathology 89:S76. Publication no. P-1999-0542AMA.

Sporangia of Phytophthora infestans, strain US-8, were placed on filter paper squares or coverslips and were either exposed to direct sunlight or shaded to determine survival ability. Temperature (T), relative humidity (RH), and solar irradiance were recorded over time. Following a range of exposures, sporangia were rehydrated in a mist chamber and tested for viability by infection on potato tuber slices and germination on rye or water agar. Most sporangia exposed to T above $32 \mathrm{C}$ and $\mathrm{RH}$ values below $20 \%$ became non-viable within $1 \mathrm{hr}$; shading from direct sunlight maintained viability for at least $2 \mathrm{hr}$. Sporangia exposed to direct sunlight, $\mathrm{T}$ between 25 and $32 \mathrm{C}$, and $\mathrm{RH}$ above $20 \%$ were viable for up to $4 \mathrm{hr}$. The tuber assay was a more reliable measure of sporangial viability than germination on agar medium; $95 \%$ of the unexposed controls caused infection. Additional studies with exposure under various weather conditions, particularly cool wet periods, are needed to build a model for long-distance transport of viable sporangia in the Pacific Northwest.

The cytoplasmic inclusion protein of TuMV interacts with histone $\mathbf{H 3}$ of Arabidopsis thaliana. H. TAMPO (1), D. Plante (1), J. F. Laliberte (2), and M. G. Fortin (1). (1) McGill University, Ste-Anne-de-Bellevue, Qc., Canada; (2) Institut Armand-Frappier, Laval, Qc. Phytopathology 89:S76. Publication no. P-1999-0543-AMA.

Turnip Mosaic Potyvirus (TuMV) belongs to the picorna-like supergroup of positive-strand RNA viruses. The TuMV genome encodes a large polyprotein that is processed by its own proteases to yield the mature products. One of those products, the Cytoplasmic Inclusion (CI) protein was shown to have RNA helicase and ATPase activities and has been speculated to be involved in viral replication, but the biological functions are still unclear. In order to identify host factors that may be involved in virus replication, we used the yeast two-hybrid system to identify proteins from A. thaliana, a TuMV host, that interact with the CI protein. We identified several candidate clones and sequencing revealed that two of candidates were a full length clone of histone $\mathrm{H} 3$ and a truncated histone $\mathrm{H} 3$ clone. The interaction of $\mathrm{CI}$ with the truncated histone $\mathrm{H} 3$ was confirmed by in vitro assays. It is tempting to speculate that the interaction between $\mathrm{CI}$ and histone $\mathrm{H} 3$ may be involved in the transcriptional shutdown observed for some potyviruses.

Analysis of phytoplasmal proteins isolated by two dimensional gel electrophoresis. M. TANAKA (1), B. Zhong (2), and I. Matsuda (1). (1) National Agriculture Research Center, Tsukuba, Japan; (2) Zhejiang University, Zhejiang, China. Phytopathology 89:S76. Publication no. P-1999-0544-AMA.

Several phytoplasmal proteins were isolated from garland chrysanthemum plants infected with onion yellows (OY) phytoplasma by two dimensional gel electrophoresis (2D-E). Phytoplasma-enriched fractions were prepared from uninfected and OY-infected plants, and subjected to 2D-E. Comparative analysis of 2D-E patterns found a number of protein spots which were detected specifically in OY-infected preparations. N-terminal amino acid sequences of four specific proteins with greater amounts than others were determined by automated Edman degradations. Computerized homology search in protein sequence database revealed that these proteins showed high sequence similarities with proteins derived from prokaryote closely related with phytoplasma such as Mycoplasma pneumoniae and M. genitalium. These results indicates these four specific proteins separated by $2 \mathrm{D}-\mathrm{E}$ were originated from OY phytoplasma.

Gene transfer system for the tree pathogenic fungus Nectria galligena. P. TANGUAY and L. Bernier. Centre de recherche en biologie forestière, Université Laval, Québec, Qc., Canada. Phytopathology 89:S76. Publication no. P-1999-0545-AMA.

Perennial Nectria canker, otherwise known as European canker, is caused by the ascomycete fungus Nectria galligena and occurs throughout the temperate zone where it causes important losses on pomaceous fruit trees and on a broad spectrum of deciduous forest trees. To facilitate the molecular understanding of the interactions between the pathogen and its hosts, a DNA-mediated transformation system was developed. Protoplasts were produced by enzymatic digestion of the cell wall of germinating conidia with Novozym 234, in the presence of sucrose, and transformed to hygromycin B resistance using plasmids pCB1004, pAN7-1, and gGFP. Transformation efficiency ranged from 1-10 transformants/ $\mu \mathrm{g}$ linearized vector DNA. Ninety-five percent of the transformants analysed were mitotically stable following 8 weeks of subculture into non-selective medium. Southern analysis showed integration of multiple copies at ectopic sites into the genome and tandem array insertion at some loci. This transformation system will undoubtedly be important for cloning and manipulating pathogenicity genes in Nectria galligena.

Testing a "lineage-exclusion" strategy for breeding rice resistant to blast disease. A. L. TAPIERO and M. Levy. Purdue University, West Lafayette, IN. Phytopathology 89:S76. Publication no. P-1999-0546-AMA.

Populations of the rice blast fungus Pyricularia grisea Sacc. (teleomorph Magnaporthe grisea (Hebert) Barr.) in a given region typically expresses a phylogenetic organization of distinct lineages. Each lineage exhibits a definable virulence spectrum shared historically among all of its members. The "lineage-exclusion" hypothesis suggests that combining resistance genes to exclude all the observed virulence spectra of the prevalent lineages can provide durable resistance to rice blast. We have used the progeny from a two near-isogenic lines (NIL) cross to test this hypothesis. True-breeding complementary resistant lines to Colombian lineages were planted at different sites for several years in Colombia. The inheritance of the resistant genotype was confirmed using tightly resistance loci linked RFLP markers. Isolates from infected plants showed no major changes in virulence and lineage composition. The pyramid infecting isolates clustered as members of the previously reported SRL-6 family, the only lineage not excluded by the two resistance genes used. Pathogenically these isolates showed their ability to re-infect the pyramid host of origin and both NILs as well.

Sequence comparison between common and resistance breaking strains of raspberry bushy dwarf virus. S. M. Taylor (1) and R. R. MARTIN (2). (1) Oregon State University, Corvallis, OR; (2) USDA-ARS, Corvallis, OR. Phytopathology 89:S76. Publication no. P-1999-0547-AMA.

Three strains of the bipartite virus raspberry bushy dwarf (RBDV) have been reported. The common strain found in North America, South America, Australia, New Zealand and Europe and the resistance breaking strain found only 
in Europe are serologically indistinguishable while the black raspberry strain from North America is distinct. Resistance to RBDV is conferred by a single dominant gene, $\mathrm{Bu}$. The resistance breaking strain is able to infect all raspberry cultivars containing the $\mathrm{Bu}$ loci. The sequence of a full-length clone of the common strain was determined and compared to the previously published sequence of the resistance breaking strain. Nucleotide homology between the two isolates was $97.6 \%$ for RNA 1 and $97.6 \%$ for RNA 2. Comparison of the predicted RNA 1 protein product of the two strains showed $97.9 \%$ homology. The predicted movement protein and the subgenomic coat protein from RNA 2 demonstrated $98.6 \%$ and $98.5 \%$ amino acid homology respectively. The differential rate of virus spread under field conditions in the Pacific Northwest was also investigated.

Comparison of the genomes of three strains (YS, YP and DP) of soybean dwarf luteovirus. H. TERAUCHI, S. Kanematsu, K. Ishiguro, and S. Hidaka. Tohoku National Agricultural Experiment Station, Morioka, Japan. Phytopathology 89:S77. Publication no. P-1999-0548-AMA.

Soybean dwarf virus (SbDV) is divided into four strains, namely YS, YP, DS and DP. YS and YP cause yellowing of soybeans, while DS and DP cause severe dwarfing. YS and DS are transmitted by Aulacorthum solani, while YP and DP are transmitted by $I$ To evaluate the relationships between genomes and symptom expression or aphid transmission, we analyzed the nucleotide sequences of the genomes of YS, YP and DP. The complete genomes of YS, YP and DP consist of 5853, 5841 and 5707 nucleotides, respectively. The positive-sense strand of each of these strains specifies five ORFs, which corresponds to the arrangement of a Tasmanian isolate (SbDV-TAS) characterized previously. The deduced amino acid sequences indicated that in all five ORFs, YS and YP showed the greatest similarity. However, in the $5^{\prime}$ half of ORF5, the similarity between YP and DP was highest. In the barley yellow dwarf luteovirus (BYDV) genome, this domain is thought to be related to aphid transmission. Similarly, it appears that the readthrough domain of SbDV may control aphid transmission.

Expression of resistance to the southern root-knot nematode, Meloidogyne incognita, in Capsicum chinense and $C$. annuum at high temperatures. J. A. THIES and R. L. Fery. U.S. Vegetable Laboratory, USDA-ARS, Charleston, SC 29414. Phytopathology 89:S77. Publication no. P-1999-0549AMA.

Expression of resistance to the southern root-knot nematode, Meloidogyne incognita (Mi), in Capsicum chinense and C. annuum was determined in growth chambers at 24,28 , and $32^{\circ} \mathrm{C}$. Two $C$. chinense germplasm lines, PA426 (resistant) and PA-350 (susceptible), and two C. annuum cultivars, Charleston Belle (resistant) and Keystone Resistant Giant (susceptible), were used in these experiments. Root galling, numbers of eggs per g root, and $\mathrm{Mi}$ reproductive index increased as temperature increased for both the Mi resistant PA-426 and Charleston Belle, and the susceptible PA-350 and Keystone Resistant Giant. Overall, root gall severity and nematode reproduction were less $(P<0.05)$ for the resistant PA-426 and Charleston Belle than for the susceptible PA-350 and Keystone Resistant Giant. However, both resistant genotypes exhibited a partial loss of resistance at the higher temperatures. Although resistance was compromised at high temperatures, cultivars possessing this resistance may be a useful component of integrated systems designed to manage soilborne pests in hot climates.

Enhanced suppression of soybean cyst nematode with combinations of biocontrol agents. H. TIAN, R. D. Riggs, and D. L. Crippen. Dept. of Plant Pathology, Univ. of Arkansas, Fayetteville, AR 72701. Phytopathology 89: S77. Publication no. P-1999-0550-AMA.

A potential fungal biocontrol agent, ARF18, for soybean cyst nematode $(\mathrm{SCN})$ was combined with chitinolytic bacteria to evaluate their efficiency in control of SCN. Five bacterial isolates $(\mathrm{C} 6, \mathrm{C} 10, \mathrm{C} 11, \mathrm{C} 31, \mathrm{C} 54)$ previously proven to be effective in suppression of SCN, and two isolates of ARF18 (TN, BG) were used in this research. The fungal and bacterial isolates were mixed in all combinations with a pasteurized sandy soil or soil amended with $0.4 \%(\mathrm{w} / \mathrm{w})$ chitin at $0.001 \mathrm{~g}$ mycelium and $10^{5-6}$ colony forming units per $\mathrm{g}$ dry soil, respectively. In treatments without chitin, the combination of BG with C6 or C11 suppressed SCN egg numbers when compared with the nontreated check or with checks of fungus or bacterium alone $(p=0.05)$. In treatments and checks with chitin, all combinations of TN and BG with C10 or $\mathrm{C} 11$ greatly reduced the population level of $\mathrm{SCN}$ when compared with the chitin, chitin + fungus or chitin + bacterium checks $(p=0.05)$. The results showed that application of ARF18 with some of the chitinolytic bacteria can provide significantly enhanced control of SCN.
Dynamics of bacterial populations on lettuce leaves after addition of nutrients. V. TOUSSAINT (1), C. E. Morris (2), and O. Carisse (1). (1) Agriculture and Agri-Food Canada, St-Jean-sur-Richelieu, Qc., Canada; (2) INRA Avignon, Montfavet, France. Phytopathology 89:S77. Publication no. P-19990551-AMA.

Bacterial leaf spot of lettuce, caused by Xanthomonas campestris pv. vitians has recently become important in North America. To investigate potential biological control, we studied the influence of nutrients on population dynamics and competition between the saprophytic bacteria (SB) and $X . c$. pv. vitians. Nutrient solutions $(0.2 \mathrm{M})$ were applied once on lettuce leaves at four different growth stages. Bacterial population sizes were measured initially and daily for four days after application. Significant effects on number of SB were observed for the first lettuce growth stage. Nutrient broth (NB) increased significantly SB population size relative to populations on plants treated with water. Mannitol caused an increase in SB population size, but it was not significant relative to water-treated plants. Phenylalanine and rhamnose did not have an effect on SB populations. The differences observed were not due to an increase leaf wetness duration as no differences were observed between plants treated with water only and untreated plants.

Genetic relationships among fine fescue endophytes and their hosts. L. P. TREDWAY (1), M. D. Richardson (2), J. F. White, Jr. (1), and B. B. Clarke (1). (1) Rutgers University, New Brunswick, NJ; (2) University of Arkansas, Fayetteville, AR. Phytopathology 89:S77. Publication no. P-1999-0552AMA.

Amplified fragment length polymorphisms (AFLPs) were utilized to study the genetic relationships among 15 Epichloë festucae isolates obtained from four fine fescue species. AFLP fingerprinting revealed the presence of four distinct clades, each containing E. festucae isolates from a single host species. The hard and Chewings fescue clades were more closely related to one another than to any other clade. Growth rates in vitro also supported the similarity of hard and Chewings fescue isolates. AFLP results were compared to phylogenetic relationships among the fine fescues, which were estimated from rDNA sequences. The host and endophyte phylogenies differed significantly, indicating that these organisms have not undergone strict coevolution in their development. The concentration of ergovaline within infected tissue was measured using HPLC. Ergovaline concentration was not closely related to the genetic relationships among endophytes or hosts. The concentration of this alkaloid may be determined by an interaction between endophyte and host genotypes.

A genetic interaction between common bean and its rhizobial partners; strain specific compatibility with a nod-resistant host. A. T. TRESE and S. Bashore. Ohio University, Athens, OH 45701. Phytopathology 89:S77. Publication no. P-1999-0553-AMA.

Race specific resistance to plant disease is often conditioned by alleles at a single genetic locus. In such cases, the pathogen population frequently includes several races that are differentially able to cause disease on host plants with particular resistance gene alleles. A similar genetic pattern is possible in other plant-microbe interactions. We have identified a recessive allele in common beans (Phaseolus vulgaris L.) that conditions strain specific restriction of nodulation when homozygous, the first genetic locus of this type identified in beans. Furthermore, we have identified a limited number of bacterial isolates that are capable of fully nodulating the nodulation-restrictive mutant host. Using green fluorescent protein tagged bacteria we will describe the step in nodulation that is blocked in the mutant plant's interaction with incompatible rhizobia, and the mode of infection used by the overcoming isolates. In addition, we will provide data on the ability of our mutant to restrict rhizobia, already resident in field soils, from occupying nodules.

PCR amplification of Phytophthora infestans from 19th century herbarium specimens. C. TROUT GROVES, G. R. Parra, and J. B. Ristaino. North Carolina State University, Raleigh, NC. Phytopathology 89:S77. Publication no. P-1999-0554-AMA.

Dried potato and tomato lesions containing the late blight pathogen Phytophthora infestans were sampled from the Farlow Herbarium, Royal Botanic Gardens Mycological Herbarium and the USDA National Fungus Collections. Protocols for DNA extraction and PCR amplification were optimized using modern herbarium specimens. Various modifications of a CTAB extraction protocol including column purification and ethanol precipitation were effective for obtaining PCR quality DNA from herbarium specimens. A new PCR primer called HERB1 used in combination with PINF, a $P$. infestans specific primer successfully amplified an 100 base pair fragment of the ribosomal DNA from 20 of 66 herbarium samples tested to date. We have suc- 
cessfully amplified DNA from an Irish specimen collected by David Moore in 1846 and British samples collected by John Lindley, M. J. Berkeley, and C. E. Broome in 1845 , 1846, and 1847, respectively. Molecular studies of herbarium specimens have the potential to open a new window to epidemics of the past.

Pathogenicity of vegetative compatibility groups of Verticillium dahliae in Solanaceae. L. TSROR, M. Hazanovsky, S. Leviush, and S. Sivan. Agricultural Research Organization, Gilat Experiment Station, Israel. Phytopathology 89:S78. Publication no. P-1999-0555-AMA.

Potato plants inoculated with VCG4B had significantly more severe symptoms, a higher colonization level, and the lowest weight, as compared with those inoculated with VCG2B and VCG2A. In tomato, VCG2A caused significantly more severe symptoms and a higher colonization level than did VCG4B and VCG2B. No correlation was observed between virulence and origin of isolates, however, isolates from potato colonized potato plant tissue significantly more than isolates from cotton, eggplant and tomato. In pepper, only one VCG2B isolate originated from paprika was virulent and caused severe symptoms and plant death. Isolates, originated either from paprika grown in plots cultivated previously with potato, or from the soil in these plots, although colonized pepper tissues did not cause disease. However they caused moderate to severe symptoms on potato. These findings indicate a correlation between VCGs and virulence to potato and tomato; VCG4B is virulent primarily to potato and VCG2A to tomato, and that the virulence of an isolate not necessarily correlate to its origin host, and may reflect the history of the plot.

Nitrogen fertilizer influence on aflatoxin contamination of corn in Louisiana. K. M. TUBAJIKA (1), H. J. Mascagni (1), K. E. Damann (1), and S. J. Russin (2). (1) Louisiana State Univ. Agricultural Center, Baton Rouge, LA; (2) Dept. Plant, Soil, and General Agriculture, Southern Illinois Univ., Carbondale. Phytopathology 89:S78. Publication no. P-1999-0556-AMA.

Studies were conducted to determine the influence of nitrogen rates, $\mathrm{N}$ application time and starter nitrogen fertilizer on aflatoxin contamination by Aspergillus flavus. Fertilizer $\mathrm{N}$ rates $(0,50,100,150,200$, and $250 \mathrm{lb} / \mathrm{A})$, either at planting or the six-leaf growth stage, with and without starter $\mathrm{N}$ fertilizer (10 lb N/A) were evaluated. Application of starter, $\mathrm{N}$ rates, and the interaction of starter, $\mathrm{N}$ application timing, and $\mathrm{N}$ rates significantly affected aflatoxin levels. The application of $10 \mathrm{lb}$ N/A starter to plants reduced the aflatoxin levels by $20 \%$ compared to the no starter control. The application of $200 \mathrm{lb} \mathrm{N} / \mathrm{A}$ at planting resulted in $43 \%$ reduction of aflatoxin levels in plants compared to those in check plots.

Analysis of the association between Phomopsis leaf blight and leaf spot incidence in perennial plantings of strawberry. W. W. TURECHEK and L. V. Madden. The Ohio State University, Wooster 44691. Phytopathology 89:S78. Publication no. P-1999-0557-AMA.

Association of leaf blight and leaf spot of strawberry was assessed at several commercial farms in Ohio over 3 yr. For each field, 1 or 2 transects were randomly chosen and the presence or absence of each disease was recorded from $n=15$ leaflets in $N=70$ evenly-spaced sampling units. The Jaccard similarity index was used to measure disease association. Standard errors were obtained using the jackknife procedure, and data randomizations were used to determine the expected value for an independent arrangement of the two diseases. A standard-normal test was then performed to evaluate the null hypothesis of no association. Results showed that only 4 of 52 data sets had significant associations. Rank correlation statistics and a new SADIE procedure (sensu J. Perry) were used to determine the degree of covariation between the two diseases. Covariation was detected in $21 \%$ and $15 \%$ of the data sets using rank-correlation and the SADIE approach, respectively. Total disease incidence (spot and blight) was accurately predicted on the assumption of independence.

Turmoil in the tropics: An interdisciplinary course for the next century. J. UCHIDA, B. Sipes, and C. Evensen. University of Hawaii, Honolulu, HI. Phytopathology 89:S78. Publication no. P-1999-0558-AMA.

Students have great difficulty in understanding the complex interactions between agricultural production systems, population growth, urbanization, and environmental quality. We are developing a scientifically-based course which provides undergraduate students with the foundation for making critical judgements concerning agriculture and the environment. The course is integrated with the world-wide-web and employs electronic discussion groups to increase effectiveness and efficiency of instruction. The objectives of the course are: to create a science-based environmental issues course highlighting the interactions among agricultural production systems, human demands, and environmental quality; to introduce and expose students to the many aspects of research, product development, environmental management, and scientific activity which occur in land grant colleges; and to provide students with a holistic perspective and appreciation for agriculture and environmental quality required by a growing population, for use as enlightened citizens. Case studies, discussion questions, and laboratory/field exercises assist students in learning and evaluating environmental and agricultural issues.

Three species of Phytophthora causing Catharanthus blight in Hawaii. J. Y. UCHIDA and C. Y. Kadooka. University of Hawaii, Honolulu, HI. Phytopathology 89:S78. Publication no. P-1999-0559-AMA.

Catharanthus roseus or periwinkle is a very popular bedding plant in Hawaii as it is in the continental United States. A wide range of bright colored and cool pastel flowers on hardy, drought resistant plants, make periwinkle an ideal choice for many landscapers. In Hawaii, Phytophthora palmivora, $P$. meadii and P. nicotianae have been isolated from diseased plants. Phytophthora nicotianae has been the most frequently encountered and has been reported from other parts of the country. The symptoms of Phytophthora diseases are similar for all three species. Within 48 hours after foliar inoculation, tiny black flecks form on leaves. These expand to form spots $3-5 \mathrm{~mm}$ in diameter, with blights developing in a week. In comparative studies of foliar inoculation, $P$. meadii caused the most severe disease, killing plants in 3 weeks. Stem rots and loss of parts of the plant occurred for the other species in 3 weeks.

Tomato spotted wilt virus on Anthurium andraeanum and similarity of symptoms to bacterial blight. R. S. UCHIDA, D. Ogata, J. Y. Uchida, and N. Nagata. University of Hawaii, Honolulu, HI. Phytopathology 89:S78. Publication no. P-1999-0560-AMA.

Tomato spotted wilt virus (TSWV) was recently found on diseased potted anthurium plants. Small yellow-green patches, $5-10 \mathrm{~mm}$ in diameter, were the first symptoms on anthurium leaves. As the disease progressed, these patches enlarged, became circular, and yellowish with shallow brown pitting on the surface. Large spots and blights over $30 \mathrm{~mm}$ long also developed. Infected young leaves or flowers had water-soaked flecks, spots and blights closely resembling typical bacterial blight symptoms. However, TSWV infections did not produce bacterial ooze, and high numbers of bacterial cells associated with water-soaked flecks were absent. TSWV infections killed young shoots. TSWV was detected by ELISA from spots on mature leaves, infected petioles, symptomless areas of diseased leaves and roots. The same samples were negative for impatiens necrotic spot virus. The western flower thrips Frankliniella schultze $i$ and the onion thrips Thrips tabai are important vectors in Hawaii.

Management of dollar spot of creeping bentgrass on golf course fairways employing zinc and manganese supplements. W. UDDIN, C. F. Mancino, M. D. Soika, and E. Soika. The Pennsylvania State University, University Park, PA. Phytopathology 89:S78. Publication no. P-1999-0561-AMA.

Effects of trace elements on development on dollar spot on 'Penneagle' creeping bentgrass (Agrostis palustris) (1/2 inch mowing-height), was evaluated. Chlorothalonil, mancozeb, manganese sulfate, zinc sulfate, manganese sulfate and zinc sulfate, and mancozeb supplemented with manganese sulfate and zinc sulfate, were applied at full (standard) and half-rates at 7 and 14 day intervals prior to and following the inoculation of turf with Sclerotinia homoeocarpa. Five, six, and seven weeks after inoculation, disease incidence (number of necrotic spots), and severity (Index $0-10$, where $0=$ no necrosis, and $10=>90 \%$ of necrotic turf area) were assessed. There were significant effects of trace elements $(P=0.0001)$ on disease incidence and severity when they were applied at full-rate (14-day intervals) prior to and following inoculation. There were also significant effects $(P=0.0001)$ of rate and timing of application on disease incidence and severity. This study suggests that dollar spot management with mancozeb fungicide may be enhanced with manganese and zinc supplements.

Influence of turfgrass age on development of gray leaf spot (blast) of tall fescue. W. UDDIN, F. E. Moorman, M. D. Soika, and G. Viji. The Pennsylvania State University, University Park, PA. Phytopathology 89:S78. Publication no. P-1999-0562-AMA.

Influence of turfgrass age on development of gray leaf spot of 'Rebel III' tall fescue was evaluated in controlled environment chambers. Four- to elevenweek-old tall fescue plants were inoculated with conidia of Pyricularia 
grisea, and disease incidence (DI) (\% leaves infected), disease severity on leaf blades (DSL), and disease severity on potted-turf (DSP) were evaluated 5 days after inoculation. The effects of turfgrass age on DI, DSL, and DSP were significant $(P=0.001)$. DI, DSL, and DSP were negatively correlated ( $r^{2}=0.64, P=0.03 ; r^{2}=0.30, P=0.02 ;$ and $r^{2}=0.81, P=0.02$, respectively) with turfgrass age. DI, DSL, and DSP may be estimated by the quadratic models $y=115.9-12.1 x+0.49 x^{2}, y=5.63+0.35 x-0.4 x^{2}$, and $y=6.35+$ $0.93 x-0.12 x^{2}$, respectively, where $x=$ age in weeks. Additionally, DSL and DSP were positively correlated with DI, and they may be estimated by linear models $y_{\text {DSL }}=2.87+0.05 x\left(r^{2}=0.43, P=0.0001\right)$ and $y_{\text {DSP }}=-0.35+$ $0.12 x\left(r^{2}=0.61, P=0.0001\right)$, respectively, where $x=\mathrm{DI}$. The predictive models may be applied in the development of a disease management program following turf overseeding or re-establishment.

Testing the role of the amino terminus of the coat protein in host range determination of potyviruses. Z. ULLAH (1), A. Gal-On (2), B. Raccah (2), and R. Grumet (1). (1) Michigan State University, East Lansing, MI; (2) The Volcani Center, Bet Dagan, Israel. Phytopathology 89:S79. Publication no. P-1999-0563-AMA.

Coat protein $(\mathrm{CP})$ plays several roles in the life cycle of potyviruses; the amino terminus (NT) of the CP has been shown to be involved in aphid transmission and systemic movement of the virus. Since the ability to spread systemically is a critical factor in successful infection, we sought to examine if the NT of the CP plays a role in host range determination. The NT of the $\mathrm{CP}$ in the full length infectious clone of ZYMV was switched with the respective regions of TEV and WMV, and the recombinant constructs tested on hosts and non-hosts of ZYMV. All the constructs showed symptoms of comparable severity on susceptible squash plants. This indicates that the NT of the $\mathrm{CP}$ is functional in facilitating systemic movement even in typically nonhost species. Interestingly, however, 6-8 weeks after inoculation there was a gradual loss of symptoms from the plants inoculated with the chimeric virus carrying TEV NT. None of the constructs showed symptoms on beans, $N$. benthamiana or tobacco indicating that, in these examples, the NT of the $\mathrm{CP}$ is not sufficient to expand the host range of the potyvirus.

Transgenic expression of $\mathrm{CFP}$ enhances cercosporin resistance in a sensitive fungus. R. G. UPCHURCH $(1,2)$, M. S. Rose $(1,2)$, and T. M. Callahan (2). (1) USDA-ARS, Raleigh, NC; (2) NC State University, Raleigh, NC. Phytopathology 89:S79. Publication no. P-1999-0564-AMA.

Cercosporin, a photosensitizing polyketide produced by phytopathogenic fungi in the genus Cercospora, is toxic to a variety of organisms and has been demonstrated to be an essential factor for disease progression in several plant hosts. Previously we demonstrated that $C F P$, a light-regulated gene from the soybean pathogen $C$. kikuchii, encodes a protein essential for wild type virulence and cercosporin production and resistance. Sequence analysis indicates that $C F P$ is a member of the Major Facilitator Superfamily of transporters, many of which confer resistance to antibiotics and toxins. To further characterize the role of $C F P$ in cercosporin resistance and to determine its utility as a source of transferable toxin resistance, a $C F P$-P1 promoter construct was introduced into Cochliobolus heterostrophus. Expression of CFP in this cercosporin-sensitive fungus enhanced resistance to exogenous toxin.

Scale and growth as factors in spread of $P$. syringae pv. syringae in the bean phyllosphere. C. D. UPPER $(1,2)$, K. K. Reid (2), M. K. Clayton (2), and S. S. Hirano (2). (1) USDA-ARS and (2) University of Wisconsin, Madison, WI. Phytopathology 89:S79. Publication no. P-1999-0565-AMA.

Spread of $P$. syringae from seed inoculated source plants to other bean plants across $6 \mathrm{~m}$ of bare ground was detected ca. one day after source plant emergence. Spread across $20 \mathrm{~m}$ of bare ground was detected about three days later. By 14 days after emergence spread was not different across these distances. Thus, on this scale, spread was not greatly affected by distance. Spread to cultivars that harbor large numbers of $P$. syringae was greater than spread to plots planted to cultivars that normally carry smaller numbers of this bacterium. Spread to plants inoculated with $P$. syringae or planted three weeks before the source plants was diminished relative to spread to plants planted at the same time as the source plants. Thus, the nature of the habitat to which the bacteria were spreading, was very important in determining the final amount of spread. During conditions conducive for bacterial growth, the amount of spread was much greater than during periods unfavorable for bacterial growth. Spread occurred in the absence of rain, but the amount of spread was relatively small during periods which were unsuited for bacterial growth.
Assessment of oversummer survival of Colletotrichum gloeosporioides in strawberry plant debris in Florida. A. UREÑA-PADILLA (1), D. E. Legard (1), and D. J. Mitchell (2). (1) University of Florida, GCREC, Dover, FL; (2) University of Florida, Gainesville, FL. Phytopathology 89:S79. Publication no. P-1999-0566-AMA.

A field experiment was conducted during 1998 to evaluate the ability of Colletotrichum gloeosporioides, which causes crown rot of strawberry, to oversummer in plant debris under field conditions in Florida. Eighty strawberry crowns naturally infected with $C$. gloeosporioides were divided in pairs. Each pair was placed inside of a Miracloth bag with $50 \mathrm{cc}$ of nonfumigated field soil. Bags were buried at a depth of $15 \mathrm{~cm}$. At $0,7,14,21$, $42,56,71,85$, and 162 days after burial, one bag was recovered from each of four replicated plots (eight crowns total). The crowns were surface sterilized, sectioned and plated onto semi-selective medium containing ampicillin, streptomycin, iprodione and Tergitol in potato dextrose agar. Detection of $C$. gloeosporioides at 0 days was $87 \%$ (seven crowns) followed by $100 \%$ in the next three weeks. At 42 days, $C$. gloeosporioides was detected in six crowns (75\%) and declined to $0 \%$ after 56 days. These data support the hypothesis that $C$. gloeosporioides does not oversummer under field conditions found in Florida. The study will be repeated during 1999.

Production of hydrolytic enzymes and antibiotics by Tilletiopsis spp., antagonists of powdery mildew fungi. E. J. URQUHART and Z. K. Punja. Simon Fraser University, Burnaby, BC, Canada. Phytopathology 89:S79. Publication no. P-1999-0567-AMA

Activities of beta-1,3 glucanases (GL) and chitinases (CH) in 5 species of Tilletiopsis was assessed after 7 days of growth in a defined liquid medium. Total GL and exo-GL activity were assayed using the Somogyi and glucose oxidase methods, respectively. Levels of GL production ranged widely between isolates, with endo-GL responsible for the majority of the activity. $\mathrm{CH}$ activity (exo- and endo-) as assessed with specific fluorescent chitin substrates was negligible in all isolates. GL and $\mathrm{CH}$ production over time in culture was low at 4 days but increased gradually until 21 days. Antibiotic activity in T. pallescens (ATCC 96155) culture filtrate was assessed over time against Cladosporium cucumerinum spore germination. Activity was present at 4 days and increased up to 10 days and then decreased. Sephadex G-25 separation of lyophilized 10 day filtrate produced 3 active fractions. The limited production of hydrolytic enzymes but significant production of antibiotics early during growth suggests that antibiosis could play a role in biological control activity in these yeasts.

Hypovirulence in Didymella bryoniae associated with dsRNA. R. R. URS (1), D. E. Mayhew (2), and P. D. Roberts (1). Dept. of Plant Pathology, SWFREC, University of Florida, Immokalee, FL; (2) Plant Pest Diagnostics Center, 3294 Meadowview Road, Sacramento, CA. Phytopathology 89:S79. Publication no. P-1999-0568-AMA.

Strain (98-18) of Didymella bryoniae isolated from watermelon seedlings with symptoms of gummy stem blight showed abnormal lysis and irregular production of fruiting bodies. A species of dsRNA (approx. $4.3 \mathrm{kd}$ ) was associated with isolate $98-18$ as well as other isolates showing abnormal mycelial growth, but not with isolates showing normal growth in culture. No virus particles were found in electron microscopic studies. Attempts to transmit the dsRNA to normal isolates by hyphal anastomosis and infiltration through growth media were unsuccessful. Pathogenicity studies with isolate 98-18 and a dsRNA free isolate (RJ2) were performed on several cucurbit hosts. The disease severity index of 98-18 was approximately half of RJ2 on watermelon, and one-third of RJ2 on cantaloupe. Zucchini and yellow squash were resistant to both cultures when tested.

Tests of the ability of a colorless Ophiostoma piliferum strain to prevent spread of pigmented fungi in lodgepole pine logs. A. UZUNOVIC and D. Domanski. Forintek Canada Corp., Vancouver, Canada. Phytopathology 89:S79. Publication no. P-1999-0569-AMA.

Cartapip 97 (a colorless strain of $O$. piliferum, Clariant, USA) has been already successfully used in biological pulping processes on wood chips. We investigated its primary and secondary resource capture on green lodgepole pine logs. Cartapip and four bluestain challenge fungi were inoculated separately as pre-colonized grain into short logs. Suspensions of fungal propagules were also sprayed onto replicate logs with two types of artificially produced wounds. One type included removing a $4 \times 10 \mathrm{~cm}$ strip of bark with phloem; the other wound included penetrations through the bark into the wood xylem. The challenge fungi included Ceratocystis coerulescens, 
Leptographium sp., Ophiostoma piceae and O. minus. Different treatments included inoculating fungi on their own; mixing together challenge fungi and Cartapip; Cartapip first followed by later inoculation with challenge fungi ( 2 or 10 days later); and challenge fungi first followed by later inoculation with Cartapip ( 5 days later). The resulting staining patterns of growth and competition between Cartapip and the challenge fungi were studied, measured and are discussed.

Characterization of isolates of Macrophomina phaseolina using a simplified AFLP technique. G. J. VANDEMARK (1), O. Martinez V. (2), and V. Pecina Q. (2). (1) USDA-ARS, Prosser, WA; (2) CINVESTAV del IPN, Irapuato, Gto. Mexico. Phytopathology 89:S80. Publication no. P-1999-0570AMA.

A simplified protocol for detecting amplified restriction length polymorphisms (AFLPs) was used to evaluate genetic diversity among isolates of Macrophomina phaseolina collected from different hosts and locations. Fifteen different selective primer pairs were evaluated. No significant differences were observed between primer pairs, grouped based on the \% AT of the selective nucleotides, for several parameters that define primer utility. Relationship matrices generated with each group of AFLP primers were highly correlated $\left(r^{2}>0.92\right)$. Isolates were very diverse and could not clearly be grouped based on the geographic locations from which they were obtained. Genetic relationships among isolates were very robust. Relationships were determined using both the 'genetic similarity' method of Nei and Li and the 'genetic distance' method of Skroch. We conclude that both methods are equally effective for determining intraspecific genetic relationships when the majority of markers are polymorphic.

Apparent partial powdery mildew resistance in transgenic oat genetically engineered to express rice or barley chitinase genes. M. VAN DE MORTEL (1), G. Baldridge (2), W. Bushnell (2), D. Somers (1), K. Torbert (1), and R. Zeyen (2). (1) Agronomy and Plant Genetics and (2) Plant Pathology, University of Minnesota, St. Paul, MN 55108. Phytopathology 89:S80. Publication no. P-1999-0571-AMA.

$\mathrm{GAF} /$ Park oat was transformed singly with barley or rice chitinase genes, using a plasmid construct containing the CaMV $35 \mathrm{~S}$ promoter and the maize alcohol dehydrogenase 1 intron to drive expression. Transgenic lines were advanced by selfing after selection by positive Southern and Northern blot analysis for the chitinase transgenes, and by ELISA testing for NPTII selectable marker protein. In one experiment, transgenic lines and parental controls were screened for powdery mildew resistance with a Minnesota glasshouse isolate of Blumeria graminis $\mathrm{f}$. sp. avenae. The parent oat line, GAF/Park was rated totally susceptible ( 4 on a $0-4$ scale) while selected transgenic rice or barley chitinase containing lines, in T3 to T5 generations, were rated at 2 to 3 for apparent partial powdery mildew resistance. Northern blotting and RT PCR testing revealed the existence of barley and rice transgene transcripts in plants with apparent partial powdery mildew resistance.

Morphological, cultural and pathogenic characteristics of Coniothyrium zuluense isolates from different plantation regions in South Africa. L. M. van Zyl, T. A. COUTINHO, and M. J. Wingfield. Tree Pathology Co-operative Programme, Forestry and Agricultural Biotechnology Institute (FABI), University of Pretoria, Pretoria 0002, South Africa. Phytopathology 89:S80. Publication no. P-1999-0572-AMA.

Coniothyrium canker, caused by Coniothyrium zuluense, is the most serious stem disease of Eucalyptus spp. in sub-tropical regions of South Africa. This disease is typified by necrotic bark lesions that coalesce to form large kinoimpregnated cankers along the stems. The strategy currently used to manage Coniothyrium canker in plantations is to deploy Eucalyptus species or clones that are tolerant to the disease. Considerable success has already been achieved in this regard, but the long-term durability of tolerance is of concern. Thus, forest managers are interested in the genetic diversity of the pathogen and its potential to overcome disease tolerance in planting stock. In this study, 343 isolates of $C$. zuluense from different plantation regions in South Africa were compared on the basis of colony colour, conidial morphology, growth characteristics on agar and virulence to a susceptible E. grandis clone. Conidia of all C. zuluense isolates were similar in size and shape. The fungus is slow growing in culture, which is indicative of its apparent biotrophic habit with optimum growth observed at $30^{\circ} \mathrm{C}$. Isolates of C. zuluense displayed considerable variation in colony colour and pathogenicity to inoculated trees. Variation in morphology and pathogenicity amongst isolates suggests that $C$. zuluense has been present for an extended period of time, or that it is changing rapidly due to strong directional selection pressures.
The effect of density and intercropping with maize on early leaf spot of peanuts. L. M. Veilleux (1), M. A. BOUDREAU (1), and B. Shew (2). (1) Warren Wilson College, Asheville, NC; (2) North Carolina State University, Raleigh, NC. Phytopathology 89:S80. Publication no. P-1999-0573AMA.

Twelve $10 \times 10$ meter plots were established in 3 completely randomized treatments with 4 replicates each: a high density peanut monocrop (HDM), a low density peanut monocrop (LDM), and an intercrop (INT) of peanuts and maize in which the peanuts were planted at the same density as in the LDM treatment. A focal epidemic was initiated by inoculation with Cercospora arachidicola and severity evaluated in 16 quadrats at 4 times to characterize spatial and temporal progress. Area under the disease progress curve (AUDPC) was reduced 50\% in the INT treatment and 32\% in the LDM treatment $(P<.05)$ relative to the HDM treatment. AUDPC in the INT and LDM treatments were not different $(P>.20)$ by the Tukey-Kramer test. Rates of disease progress based on a logistic model did not differ among treatments $(P>.50)$. The results of this study indicate that intercropping does have an effect on severity of peanut early leaf spot. They further suggest that the reduction in severity is due to a decrease in host plant density and not to the presence of a non-host intercrop.

Effect of cycloheximide on systemic acquired resistance in cucumber. L. VELASQUEZ and R. Hammerschmidt. Department of Botany and Plant Pathology, Michigan State University, East Lansing, MI 48824. Phytopathology 89:S80. Publication no. P-1999-0574-AMA.

During the development of SAR in cucumber, there is systemic expression of chitinase, glucanase and peroxidase as well as the enhanced ability to block subsequent challenge infection by fungi through rapidly induced-cell wall changes. However, it is not know if new translation/transcription beyond that expressed during the resistance induction phase are needed to block fungal penetration into SAR-expressing tissues. Leaf disks of cucumber plants expressing SAR were treated with the protein synthesis inhibitor cycloheximide and challenged with the fungus Colletotrichum lagenarium. The effect of cycloheximide on induced plants was an increase in penetration of the fungus into the tissue, and symptom development was comparable to noninduced plants. Challenge of cycloheximide treated control and induced tissues did not result in further increase in peroxidase and chitinase activity.

Beauvericin not an acute toxin to duckling bioassay. R. F. VESONDER (1), W. Wu (2), and C. E. McAlpin (1). (1) Mycotoxin Research and Bioactive Agents Research, NCAUR, USDA-ARS, Peoria, IL; (2) Department of Biochemistry, University of Wisconsin, Madison, WI. Phytopathology 89: S80. Publication no. P-1999-0575-AMA.

Acute toxic effect of beauvericin (BEA) was investigated in newly hatched white Pekin ducklings by oral doses. The purified BEA administered by gastric intubation produced no 7-day median lethal dose response at doses up to $100 \mathrm{mg} / \mathrm{kg}$ body weight compared to T-2 toxin and moniliformin (MON) 7-day median lethal dose of 4.5 and $4.1 \mathrm{mg} / \mathrm{kg}$ body weight respectively. Two isolates of Fusarium subglutinans were fermented on rice at $25 \mathrm{C}$ for 21 days. Mycotoxin analysis of the fermented rice for BEA and MON by analytical HPLC revealed only the presence of BEA. Each Fusarium-fermented rice containing BEA, when dried and mixed into a poultry diet ( $10 \%$ by weight), caused no acute mortality in baby Pekin ducklings. Ducklings fed Fusarium-infected rice containing MON caused acute mortality (less than 48 hr) and correlated significantly with the amount of MON in the fermented rice. BEA role in poultry mycotoxicoses has not been investigated and these results demonstrate BEA is not an acute toxin to ducking bioassay and further studies are needed to determine its role in longer feeding studies.

Characterization of Pyricularia grisea isolates from perennial ryegrass from various geographic regions in the United States. G. VIJI, B. Wu, W. Uddin, and S. Kang. The Pennsylvania State University, University Park, PA. Phytopathology 89:S80. Publication no. P-1999-0576-AMA.

Pyricularia grisea isolates from perennial ryegrass were compared with strains from several gramineous hosts using a number of molecular markers including MGR586, mating type genes, a host specificity gene (PWL2), ITS sequence of genes encoding ribosomal RNA and Pot2. The ryegrass isolates contained only a few copies of MGR586, indicating that they are distinct from rice pathogens. These isolates belonged to the same mating group (Mat1-2). Not all ryegrass isolates contained the PWL2 gene. ITS of the ryegrass isolates was amplified and sequenced. The sequence was identical among the 
ryegrass isolates and showed highest similarity to those from Eleusine and Triticum species. DNA fingerprinting using Pot2 showed that the ryegrass isolates exhibited no significant variation (87-97\% identity) among themselves and showed limited similarity to isolates of $P$. grisea from Triticum species. In a pathogenicity study, seven of the eight ryegrass isolates caused disease symptoms on hard red winter wheat, soft white winter wheat or triticales. Both molecular and pathogenicity data suggest that isolates of $P$. grisea from wheat and ryegrass are related.

Milsana $^{\circledR}$ bioprotectant: An effective IPM tool for ornamental plants. H. VON AMSBERG and K. H. Ferrand. KHH BioSci, Inc. Phytopathology 89:S81. Publication no. P-1999-0577-AMA.

Milsana bioprotectant is an extract from Reynoutria sachalinensis. The diluted extract renders treated plants more resistant to certain plant diseases, especially powdery mildew. This unique product, containing the main active substances physcion and its glucoside, induces natural resistance in the treated host plant. Resistance is due to an increase of several phenolics in the treated leaf tissue. The present formulation lends stability to the extracts from R.s. for at least 15 months. Data are presented showing effective control of powdery mildew in roses. Data also are presented showing that both the technical macerated plant material R.s. as well as the formulated extract have low mammalian toxicity. Results demonstrate the effective, preventative application of Milsana bioprotectant in various greenhouse-grown ornamental plants. The use of this organic, natural extract lends itself well to IPM concepts such as fungicide resistance management, organic crop production, and reduction of conventional pesticide residues on plants.

\section{A simple technique to evaluate Nectria coccinea infection pattern in beech} forests. V. VUJANOVIC, J. Brisson, and M. St-Arnaud. University of Montreal and Jardin botanique de Montreal, Qc., Canada. Phytopathology 89:S81. Publication no. P-1999-0578-AMA.

The beech bark disease (BBD) is caused by the beech scale insect Cryptococcus fagisuga Lind. and the ascomycetous fungal species Nectria coccinea var. faginata Lohm on Fagus grandifolia Ehrh. The disease was recently reported (1995) in the Montreal region, Québec, Canada. In order to determine the BBD distribution patterns in Muir's Wood old-growth forest (ass. Acereto-Fagetum americanae), we developed a simple and precise technique using a transparent frame $(30 \times 20 \mathrm{~cm})$ containing a screen of 24 squares $(5 \times$ $5 \mathrm{~cm})$. The use of a frame is based on the fact that both the insect and the fungus fructifications usually occur in clusters on the bark. Using this technique, we measured BBD spread and development based on a combined estimation of the fungus (perithecia and sporodochia) and insect frequencies $(0-4)$ and cover densities (0-4) expressed by different bark damage classes $(0-3)$. The observed fungal colonies were tentatively identified in laboratory as either $N$. coccinea and $N$. galligena based on culture characteristics. The results of spread and development were compared with attributes of forest physiognomy and structure that appear to influence BBD (forest composition, trees spatial distributions and cover density, stem heights and diameters, crown index and stem-bark expositions).

New records of antagonism and hyperparasitism interactions against two pine parasitic fungi. V. VUJANOVIC, M. St-Arnaud, and P. Neumann. University of Montreal and Jardin botanique de Montreal, Qc., Canada. Phytopathology 89:S81. Publication no. P-1999-0579-AMA.

Ascomata of Cyclaneusma minus (Butin) DiCosmo, Peredo \& Minter and $C$. niveus (Pers.:Fr.) DiCosmo, Peredo \& Minter (Rhytismatales) were collected from 27 Pinus hosts (species, varieties, forms and cultivars) in the Montreal Botanical Garden (MBG) arboretum. C. minus is known as a more destructive parasite than $C$. niveus, especially to Pinus sylvestris L. trees, attacking needles of any age over a wide range of environmental conditions. During this study, we frequently observed an undeveloped $C$. minus ascomata, on chlorotic and necrotic rings of needles in 9 different pine hosts, associated always with mycelia and fructifications of Anthostomella sabiniana S. Francis (Xylariales). Preliminary co-culture tests on PDA have shown a typical antagonistic interaction in which $A$. sabiniana produced antibiotic-like reactions controlling growth of $C$. minus mycelia. Also, we observed a Tapesia species (Helotiales) inhabiting living ascomata of Scoleconectria cucurbitula (Tode:Fr.) C. Booth (Hypocreales) which is the causal agent of scoleconectria canker and dieback of 18 different pine hosts in MBG. Tapesia sp. has shown a biotrophic hyperparasitic action on Scoleconectria ascomata occurring usually on Pinus sylvestris 'Waltererii' and P. flexilis 'James' hosts. Isolation of the fungus on various media was unsuccessful.
Purification and partial characterization of a beta-1,4- $\mathrm{N}$-acetylglucosaminidase from the mycoparasite Stachybotrys elegans. M. K. WAJAHATULLAH, C. Archambault, and S. H. Jabaji-Hare. McGill University, Ste-Anne-de-Bellevue, Qc., Canada. Phytopathology 89:S81. Publication no. P-1999-0580-AMA.

Stachybotrys elegans, a mycoparasite of Rhizoctonia solani, produces two beta-1,4- $N$-acetylglucosaminidases, one chitobiosidase and one endochitinase when grown on minimal synthetic medium supplemented with purified chitin as the sole carbon source. A $68 \mathrm{kDa}$, beta-1,4- $N$-acetylglucosaminidase (E.C. 3.2.1.30; NAG-68) was purified to homogeneity using ammonium sulfate precipitation, ion exchange and size exclusion chromatographies. It had $\mathrm{pH}$ and temperature optima of 5.0 and $40 \mathrm{C}$, respectively. Among the six metal ions tested, only $\mathrm{Fe}^{2+}$ showed a stimulating effect on the activity of NAG-68. The $\mathrm{K}_{\mathrm{m}}$ and $\mathrm{V}_{\max }$ calculated on $p$-nitrophenyl- $N$-acetyl-beta-Dglucosaminide were $62.5 \mathrm{mmol}$ and $0.89 \mathrm{mmol} / \mathrm{hr}$, respectively. Immunoblotting experiments, using polyclonal antibodies against NAG-68, are in progress to study the spatial and temporal distribution of this exochitinase during interaction between $S$. elegans and $R$. solani.

Intraspecific variation within Acidovorax avenae subsp. citrulli, the watermelon fruit blotch pathogen. R. R. WALCOTT (1), R. D. Gitaitis (1), F. H. Sanders (1), and B. B. Langston, Jr. (1). (1) University of Georgia, Tifton, GA. Phytopathology 89:S81. Publication no. P-1999-0581-AMA.

To assess the diversity of Acidovorax avenae subsp. citrulli (Aac), 119 strains from watermelon, cantaloupe and pumpkin were compared using pulse field gel electrophoresis of Spe I digested whole cell DNA and gas chromatographic analysis of fatty acid methyl esters. A total of 29 unique DNA fragments resulted from DNA digestion and 14 distinct restriction enzyme digestion patterns (haplotypes) were observed. Based on cluster analysis, two major haplotype groups (A and B) were recognized. Group A accounted for $84 \%$ (8 haplotypes) of the strains, while group B accounted for $16 \%(6$ haplotypes) of the strains Fatty acid composition varied quantitatively and qualitatively for the Aac strains. Although strain clustering based on fatty acid profiles was somewhat different, most of the group B strains still formed a distinct fatty acid group. The two groups of strains appear to have biological significance. Group A represent the watermelon fruit blotch strains that appeared in Florida, Georgia and elsewhere in 1989-94 and cause significant fruit rot. Group B strains included isolates from cantaloupe, watermelon, pumpkin and the ATCC type strain, which was present in the U.S. from 1965 and has limited ability to infect watermelon fruit. Aac strains appear to be of at least two distinct lineages which may be of significance in screening for resistance.

Evidence for vir genes in the non-pathogenic Agrobacterium vitis strain F2/5. S. G. WALKER and D. A. Cuppels. Southern Crop Protection and Food Research Center, Agriculture and Agri-Food Canada, London, Ontario. Phytopathology 89:S81. Publication no. P-1999-0582-AMA.

Agrobacterium vitis strain F2/5 protects grape vines from crown gall formation by pathogenic A. vitis strains. The mechanism of protection, which is specific for grape, is unknown and the genes controlling this protection have not been identified. It has been hypothesized that environmental signals from grape vines activate the $\mathrm{F} 2 / 5$ protective genes. We assayed the F2/5 genome for vir gene sequences by Southern blotting using vir gene sequences present on pGV204 (cloned from the A. tumefaciens Ti plasmid pTiAch5) as a probe. A 6.1 Kbp EcoR1 fragment of F2/5 chromosomal DNA hybridized strongly with the probe. This fragment was cloned and was used to screen a cosmid library of F2/5. Three over-lapping cosmid clones with homology to the 6.1 $\mathrm{Kbp}$ fragment were isolated. Limited sequencing of these cosmid clones has identified regions with high homology to the vir gene regulon of the A. tumefaciens Ti plasmids pTiA6NC and pTiC58.

Screening for resistance to scab in soft red winter wheat. S. L. WALKER, S. Leath, and J. P. Murphy. North Carolina State University, Raleigh 276957616. Phytopathology 89:S81. Publication no. P-1999-0583-AMA.

A total of 86 current soft red winter wheat cultivars were tested for resistance to Fusarium head blight (FHB). Testing was conducted in replicated field plots for two years among six locations. Each entry was rated on a per plot basis for disease incidence (percent infected heads per plot), and disease severity (mean level of disease on infected heads). Plant maturity was also recorded. Mean disease incidence ranged from 2.2-75.4\%. Mean disease severity ranged from 10.9-70.9\%. Disease severity and incidence were used to calculate a general disease index score. Disease index scores ranged from $0.24-52.7 \%$. Levels of resistance to FHB varied among the entries, but high 
levels of resistance were not detected. Taking maturity into account, FL302, L930605 and VA93-54-429 had the lowest disease index scores. These cultivars may be sources of minor gene resistance to FHB.

Three layered mechanisms of defense against fusiform rust slash pine families. C. H. WALKINSHAW. USDA Forest Service, Southern Research Station, Pineville, LA. Phytopathology 89:S82. Publication no. P-1999-0584AMA.

Previous reports identify slash pine progeny that resist formation and growth of fusiform rust galls. This report describes three more resistant traits for these progeny. They are a reduced rate of spread of the fungus in the cambium, fewer haustoria per cortical cell, an increase in the amount of hyphal and host-cell necrosis in the cambium and needle traces. Family differences for these traits in tissue 21, 60 and 90 days after inoculation were significant for highly resistant susceptible progeny. However, differences in traits among nine field isolates were not significant. These light microscopical studies add a third resistant mechanism to the parent trees that resist formation and growth of galls. When galls form they remain smaller than average and the pathogen invades less tissue. This layered resistance reduces the probability of mortality in slash pines.

Evaluation of banana cultivars for resistance to black leaf streak on Guam. G. C. WALL. University of Guam, Mangilao, GU. Phytopathology 89:S82. Publication no. P-1999-0585-AMA.

For a second season, banana cultivars originally received in tissue culture from SPC were grown in a field plot at Radio Barrigada Experiment Station and rated under natural disease pressure for resistance to black leaf streak, caused by the foliar pathogen Mycosphaerella fijiensis. Amount of disease was estimated as the proportion of leaves with lesions to the number of total leaves per plant. Cultivar Yangambi had the fewest number of diseased leaves. A banana cultivar being promoted locally for use as a windbreak, Santa Catarina (SC), was the most susceptible. Cultivars Bluggoe, Blue Java, Ducasse, Mysore, and two locally collected ones, Horn and Praying Hands, were all superior to SC.

Incidence of Fusarium species in diseased roots and crowns of hosta plants. B. Wang and S. N. JEFFERS. Clemson University, Clemson, SC. Phytopathology 89:S82. Publication no. P-1999-0586-AMA.

Hosta is one of the most popular herbaceous perennials planted in landscapes and, therefore, grown in nurseries. A disease not reported previously was observed on hosta plants at two wholesale nurseries in South Carolina in 1997 and 1998. Typical symptoms were stunting of plants, vascular necrosis in roots, and decay in crowns. Pieces of symptomatic roots and crowns were placed on modified Nash-Snyder medium and potato dextrose agar. Fusarium spp. were recovered from all of the 15 symptomatic plants collected in Oct 1998; 51 isolates were saved and identified based on morphological characteristics. Five species were found, but $F$. solani, an unidentified species, and $F$. oxysporum were predominant. $F$. solani and $F$. oxysporum were found in both roots and crowns, but Fusarium sp. was found only in crowns. Overall, F. solani, Fusarium sp., and F. oxysporum were detected in 73, 60, and $27 \%$ of the plants, respectively. Discoloration of the vascular system in roots and crowns was caused by representative isolates of $F$. solani and $\mathrm{Fu}$ sarium $\mathrm{sp}$. in a preliminary pathogenicity test. This suggests the involvement of Fusarium spp. in root and crown rot of hosta plants grown in nurseries.

Cloning and characterization of a redox-responsive cutinase from Monilinia fructicola. G. Y. WANG (1), T. J. Michailides (1), B. M. Hammock (2), and R. M. Bostock (1). (1) Dept. Plant Pathology and (2) Dept. Entomology, Univ. California, Davis, CA 95616. Phytopathology 89:S82. Publication no. P-1999-0587-AMA.

A peach isolate of the brown rot fungus $M$. fructicola produced several extracelluar cutinases in cutin-amended media. The predominant $18 \mathrm{kD}$ cutinase was purified by 2-D gel electrophoresis, partially digested with Lys C, and the sequences of the resulting peptides determined. Degenerate primers deduced from these sequences were used for MOPAC PCR with M. fructicola cDNA as a template, and the resulting PCR products subcloned and sequenced. A 162 bp partial cDNA with homology to other known fungal cutinases was isolated and then used to screen a Zap Express cDNA library prepared from cutin-induced mycelium of $M$. fructicola. From a series of full-length cDNA clones, we deduced a cutinase protein of 201 amino acids, which includes a 20-amino acid secretory signal peptide, cutinase/lipase consensus sequences containing active site serines, and a novel histidine substitution in the D-H active site motif. Naturally occurring antioxidants such as caffeic acid and glutathione suppressed cutinase mRNA accumulation and enzyme activity in M. fructicola cultures.

Relative virulence of Ascochyta isolates from Alberta and evaluation of field peas for susceptibility to the ascochyta disease complex. H. WANG (1), S. F. Hwang (1), K. F. Chang (2), G. D. Turnbull (1), and R. J. Howard (2). (1) Alberta Research Council, Vegreville, AB, Canada T9C 1T4; (2) Crop Diversification Centre South, Brooks, AB, Canada T1R 1E6. Phytopathology 89:S82. Publication no. P-1999-0588-AMA.

The ascochyta disease complex exhibits various forms on field peas. Foot rot and black stem can cause stem collapse and make a crop unharvestable. Leaf and pod spot can damage seed, reduce yield and cause seedling blight if infested seed is planted. Relative virulence of over 100 Ascochyta isolates, collected from pea fields in Alberta from 1996-1998, were evaluated on 10day-old seedlings by the excised leaf assay technique. Twenty-eight isolates were avirulent while the others produced lesions of various size on pea leaves. Five isolates, four virulent and one avirulent, were used to assess susceptibility of 20 field pea cultivars available in Alberta, including 13 yellow types and 7 green types. Based on symptom development, the yellow-type cultivars Swing and Eiffel, and the green-type cultivar Orb, were most susceptible. Carneval, Montana and Voyageur (yellow types) and Adagio (green type) were highly resistant to ascochyta infection.

High sensitivity of DNA heteroduplex mobility assay (HMA) for characterization of closely related phytoplasma strains. K. WANG and C. Hiruki. Dept. of Agr., Food and Nutr. Sci., University of Alberta, Edmonton, AB. Phytopathology 89:S82. Publication no. P-1999-0589-AMA.

Heteroduplex mobility assay (HMA) offers a simple, rapid and highly sensitive means to detect and estimate the genetic divergence between the closely related phytoplasma strains. The partial $16 \mathrm{~S}$ rDNA fragment of aster yellows phytoplasma was cloned into a plasmid vector. A series of mutants that contain 1 to 5 base differences and 1 to 3 base deletions was obtained through in vitro mutation. The results of HMA indicated that 1 to $2 \%$ mismatches or a single-base gap between closely related sequences can be detected. The $16 \mathrm{~S}$ rDNA fragments amplified from eight clover proliferation (CP) and twelve alfalfa witches'-broom (AWB) phytoplasma isolates collected from different places and years in Alberta were subjected to restriction fragment length polymorphism (RFLP) and HMA analyses. The differences of two CP and one AWB phytoplasma isolates from others were detected by HMA but not by RFLP. Therefore, HMA provides a useful, analytical method in delineating genetic diversity of phytoplasmas when other methods such as RFLP are not readily applicable to differentiate between very closely related phytoplasmas.

Seven geographic populations of Heterodera trifolii have two genetic identities and host specificities. S. WANG, R. D. Riggs, and Y. Yang. Department of Plant Pathology, University of Arkansas, Fayetteville, AR 72701. Phytopathology 89:S82. Publication no. P-1999-0590-AMA.

Seven geographic populations of Heterodera trifolii collected from Arkansas, Kentucky, Pennsylvania and Australia were compared for morphological, host specificity, and genetic differences. No significant morphological differences were found among the populations. Reproduction on carnation (Dianthus caryophyllus) and curly dock (Rumex crispus) differed among populations. Tests with 15 cultivars of carnation resulted in significant differences between two groups of populations. One group of 2 populations did not produce mature females on 13 cultivars. And the other 5 populations produced significant numbers of mature females on most cultivars. Tests with curly dock also revealed two groups: 4 populations reproduced efficiently and 3 reproduced poorly. DNA analysis with the Amplified Fragment Length Polymorphisms procedure revealed two significant genotypes which appeared to match that of their ability to reproduce on curly dock but not on carnation.

A novel method to isolate expressed esophageal gland secretory genes from Heterodera glycines. X. WANG (1), X. Ding (2), T. Maier (3), M. Goellner (1), T. J. Baum (3), R. S. Hussey (2), and E. L. Davis (1). (1) North Carolina State University, Raleigh, NC; (2) University of Georgia, Athens, GA; (3) Iowa State University, Ames, IA. Phytopathology 89:S82. Publication no. P-1999-0591-AMA.

The systematic identification of esophageal gland secretory peptides has been hampered by the nematode's obligate parasitic relationship with its host and the minute material that can be obtained for analysis. A novel method to 
isolate genes encoding nematode secretory proteins was developed using a RT-PCR technique and a yeast signal peptide-selection system. The mRNA derived from microaspiration of esophageal gland cell contents from parasitic stages of the soybean cyst nematode (SCN), Heterodera glycines, was purified by binding to oligo(dT)-linked magnetic beads and subsequently amplified using random-primed reverse transcription and PCR. The PCR products were further cloned into a secretion-specific vector and transformed into yeast enabling the specific selection of putative nematode secretory genes. The presence of known SCN gland secretion genes in the cDNA pool and yeast-selected clones confirmed the integrity of this method.

Identification of host proteins interacting with zucchini yellow mosaic potyvirus replicase. X. WANG, Z. Ullah, and R. Grumet. Michigan State University, East Lansing, MI. Phytopathology 89:S83. Publication no. P-19990592-AMA.

Effective interaction between a virus and its host is critical for establishment of successful infection. We sought to examine this interaction by identifying host plant proteins associating with certain viral-encoded proteins of zucchini yellow mosaic potyvirus (ZYMV). A cucumber (Cucumis sativus L.) leaf cDNA library was constructed for use in the yeast two-hybrid system, and screened using the ZYMV replicase (NIb) as bait. Clones showing binding activity to $\mathrm{NIb}$ were identified, verified via isolation and retransformation into yeast, and partially sequenced. To date, we have obtained partial DNA sequence for 16 independent clones. Among the proteins identified based on sequence homology, one is elongation factor EF1-alpha, which has been found frequently in association with bacterial, animal, and plant viral replication complexes. These results suggest that EF1-alpha is also a component of the potyviruses replication complexes. Other types of clones appear to encode Dna J, protein phophatase, poly-A binding protein, and as well as several unknown proteins. We are further investigating these proteins and their interactions with $\mathrm{NIb}$

Generation of species-specific marker for the identification of Stachybotrys elegans. X. B. WANG (1), C. Leclerc-Potvin (1), P.-M. Charest (2), and S. H. Jabaji-Hare (1). (1) McGill University, Ste-Anne-de-Bellevue, Qc., Canada; (2) Université Laval, Ste-Foy, Qc., Canada. Phytopathology 89:S83. Publication no. P-1999-0593-AMA.

Rhizoctonia disease of potato caused by Rhizoctonia solani AG-3 is a problem of worldwide occurrence. Stachybotrys elegans, a soil-borne fungus, is a destructive mycoparasite of $R$. solani and an effective biocontrol agent. The purpose of this study was to develop a reliable PCR assay for the detection of S. elegans in planta, in soil samples, and also during interaction with its host. Genomic DNA of $S$. elegans isolates was subjected to RAPD amplifications. One RAPD amplicon specific to $S$. elegans was cloned, fully sequenced and species-specific primers were designed. The specificity of these primers were tested against DNA extracted from greenhouse soil inoculated with $S$. elegans, $R$. solani only, or with both fungi, as well as from in vitro hyphalhyphal interaction zone of these two fungi. This molecular approach offers a rapid and routine assessment of the mycoparasite in different types of biological samples. It also provides a tool for predicting the presence of S. elegans during interaction with its host.

Current status of groundnut rosette disease in Kenya. A. W. Wangai (1), H. R. PAPPU (2), C. M. Deom (3), and R. A. Naidu (3). (1) National Plant Breeding Research Center, Njoro, Kenya; (2) Dept. of Plant Pathology; Univ. of Georgia, Coastal Plain Expt. Station, Tifton, GA 31793; (3) Miller Plant Sciences Bldg., Athens, GA 30602. Phytopathology 89:S83. Publication no. P-1999-0594-AMA.

Groundnut rosette disease is the most destructive virus disease of groundnut in sub-Saharan Africa, the only region where it has so far been reported. The disease is endemic in the groundnut growing regions of Western Kenya. In some years, it occurs in epidemic proportions and can be responsible for $100 \%$ yield losses. Two main forms of the disease have been described, chlorotic and the green rosette. Chlorotic rosette has been the predominant form in all of sub-Saharan Africa while green rosette has been reported in the western and southern regions of Africa. Preliminary disease surveys conducted in western Kenya in 1997-1998 showed the incidence of the disease in the farmers field to be $24-40 \%$ in Homabay, Kendubay and Kisumu regions and 30\% in Cheplamus, the Rift Valley region. Green rosette was observed for the first time on cultivars Nyaela red and Homa bay local at an incidence of 5.3\% in the Kendu Bay region. All the seven varieties grown locally were susceptible to field infection.
Characterization of resistance in Vaccinium to Monilinia vaccinii-corymbosi. L. A. WASILWA, P. V. Oudemans, J. S. Lehman, and N. Vorsa. Rutgers Blueberry Cranberry Research Center, Chatsworth, NJ 08019. Phytopathology 89:S83. Publication no. P-1999-0595-AMA.

A series of studies were conducted to determine if the fungus Monilinia vaccinii-corymbosi (Mvc) has developed races specific to different Vaccinium spp. and to investigate heritability of resistance in interspecific crosses. Infection frequencies of diploid Vaccinium spp. by isolates of Mvc from three hosts were determined. $V$. corymbosum $(\mathrm{Vc})$ isolates were used to evaluate resistance in crosses with $\mathrm{Vc}-\mathrm{P} 1$ and $V$. darrowi $(\mathrm{Vd})-\mathrm{P} 2$ parents, F1, F2, and backcross generations. Mummified fruit were observed on $3(\mathrm{Vc}, \mathrm{Vd}$, and $V$. elliottii (Ve)) of the 7 Vaccinium spp. Although, all 3 sources of Mvc were able to infect $\mathrm{Ve}$, only the $\mathrm{Vc}$ population was able to infect $\mathrm{Vc}$ and $\mathrm{Vd}$. Genomes with high levels of Vc (P1, backcross to P1, F1) were most susceptible to Mvc whereas those with a high level of Vd (P2 and backcross to P2) showed greater resistance. Resistance among the F2 progeny ranged between highly resistant to highly susceptible. The results demonstrate that heritable resistance exists in interspecific crosses however, the possible presence of distinct races of Mvc should be considered in future resistance screening.

Grapevine canopy density affects the development of fungal diseases. L. P. WEARING, W. McFadden-Smith, K. H. Fisher, and R. Hall. University of Guelph, Guelph, ON, Canada N1G 2W1. Phytopathology 89:S83. Publication no. P-1999-0596-AMA.

Reducing the density of a grapevine canopy increases air movement and decreases duration of leaf wetness, and may therefore decrease development of fungal diseases. Canopy density can be altered by trellising or pruning procedures. Experiments were conducted in 1998 at two research vineyards in Ontario to examine the effect of different pruning systems in Vitis labrusca and different trellising systems in $V$. vinifera grapes on canopy density and incidence of three diseases: phomopsis cane and leaf spot (PCL) [Phomopsis viticola], downy mildew (DM) [Plasmopara viticola] and powdery mildew (PM) [Uncinula necator]. Sprayed and unsprayed plots in both vineyards with the lowest canopy densities had the lowest incidence of PCL. Within unsprayed plots in the $V$. vinifera vineyard, those with the lowest canopy density had the lowest incidence of DM. The incidence of PM was high and was not affected by trellising system or canopy density. This study shows that a reduction in canopy density through trellising or pruning operations can be accompanied by a decrease in the incidence of fungal diseases.

Partial characterization of an ilarvirus found in squash (Cucurbita pepo L.) in central Florida. S. E. WEBB (1), D. E. Purcifull (2), S. M. Garnsey (3), and E. Hiebert (2). (1) CFREC, University of Florida, Leesburg, FL; (2) University of Florida, Gainesville, FL; (3) USDA-ARS, Orlando, FL. Phytopathology 89:S83. Publication no. P-1999-0597-AMA.

A virus was first found in zucchini squash in 1991 that did not react with antisera to any of the common viruses affecting cucurbits in Florida. Symptoms in squash included mosaic, chlorotic spotting, and puckering of the leaves. Leaf dip preparations showed possible isometric particles. The virus, found again in 1998 in yellow squash, reacted strongly in ELISA with antiserum to tobacco streak virus (TSV) (Agdia, Elkhart, IN). The squash isolate also infected calabaza, cucumber, cantaloupe, loofah, quinoa, jimsonweed, and Mexican sunflower, but its host range differed from those reported in Florida for the bean red node strain and the escarole necrosis isolate of TSV. Rate zonal centrifugation on linear (12\% to $46 \%)$ sucrose gradients of extracts clarified by calcium phosphate gel and concentrated by differential centrifugation resulted in three light scattering zones with typical ilarvirus properties. This is the first report of an ilarvirus found naturally infecting C. pepo.

Economic damage thresholds for common rust on corn inbreds. S. N. WEGULO, C. A. Martinson, J. M. Rivera-C., and F. W. Nutter, Jr. Iowa State University, Ames, IA. Phytopathology 89:S83. Publication no. P-1999-0598AMA.

Economic damage thresholds (EDTs) are important in disease management decision-making. EDTs for common rust, Puccinia sorghi, on corn inbreds were calculated using the equation $E D T=C /(k d)$ where $E D T$ is the disease severity (\%), above which it is profitable to spray fungicides (chlorothalonil, mancozeb, and propiconazole), $C$ is the cost of control, $k$ is a measure of the effectiveness of control ( $k=0$, no control; $k=1$, complete control), and $d$ is the slope of the damage function relating disease severity $(x)$ to net returns (y). EDTs for the most profitable fungicide treatments (at least 3 consecutive sprays at 10-14 day intervals initiated on the first spray date) calculated using actual $k$ values ranged from 0.3 to $2.4 \%$ in 1992 and 5 to $17 \%$ in 1993 . When complete disease control was assumed $(k=1)$, EDTs for the most 
profitable treatments ranged from 0.3 to $2.3 \%$ in 1992 and 2 to $13 \%$ in 1993 . This study indicates that when conditions are favorable for rust development on corn inbreds, fungicide sprays may be most profitable when started at EDTs between 0 and 5\% and continued for up to three or more spray applications, depending on days to maturity and label restrictions.

Dissemination of Xanthomonas campestris pv. vitians during lettuce transplant production. É. WELLMAN-DESBIENS (1), C. E. Morris (2), and O. Carisse (1). (1) Agriculture and Agri-Food Canada, St-Jean-sur-Richelieu, Québec, Canada; (2) INRA, Station de pathologie végétale, Avignon, France. Phytopathology 89:S84. Publication no. P-1999-0599-AMA.

Bacterial leaf spot of lettuce is a re-emerging disease in North America. The symptoms begin as water-soaked spots located along the leaf margin. As the disease progresses, spots become necrotic and coalesce. The spread of the bacteria was studied under greenhouse conditions. Following the introduction of an infection focus representing $0.1 \%$ of the plants, the proportion of contaminated transplants was determined using a rifampicin-resistant strain. Results indicated that irrigation disseminates X.c.v. efficiently. At the end of the transplant production period (4 weeks) 77 and $99 \%$ of the plants were contaminated for the first and second trial, respectively. This study showed that X.c.v. can survive as an epiphyte on the leaf surface without causing typical symptoms for the entire duration of transplant production. These findings suggest that the population of X.c.v. builds up before symptoms become detectable and consequently, precise detection tools may be required to determine if control measures are needed.

Survey for soil suppressiveness to Heterodera schachtii. A. WESTPHAL and J. O. Becker. University of California, Riverside, CA. Phytopathology 89:S84. Publication no. P-1999-0600-AMA.

In greenhouse trials, 59 soils from Imperial, Santa Barbara, and Riverside County, CA were examined for biological suppressiveness to $H$. schachtii. The soil samples were from areas that are periodically cropped with beet cyst nematode hosts. For each soil, five 300-g samples of a fumigated (methyl iodide, $500 \mathrm{~kg} / \mathrm{ha}$ ) and untreated portion were mixed with greenhouse-reared H. schachtii inoculum (80-100 eggs/g soil). Each replicate sample was placed into a transparent cup and adjusted to 16-25\% moisture and closed with a lid. After 5 weeks incubation in the dark, soil in each cup was seeded with mustard-greens, Brassica juncea, and arranged in the greenhouse in a randomized complete block design. After 11 weeks, females of the cyst nematode visible through the translucent cups were counted. Two weeks later, cysts were extracted and counted. In 6 soils, the numbers of females were significantly higher in the fumigated than in the untreated portion of the soils. In 2 of these 6 soils and 2 additional soils significantly fewer eggs/cyst of $H$. schachtii were detected in untreated portions than in fumigated ones, suggesting biological suppression of the beet cyst nematode.

The transcriptional activation domains of AvrXa7 and AvrXa10 are required for virulence and avirulence. Frank F. WHITE, Bing Yang, Weiguang Zhu, Nick Wills, and Lowell B. Johnson. Department of Plant Pathology, Kansas State University, Manhattan, KS 66506. Phytopathology 89:S84. Publication no. P-1999-0601-AMA.

The avrXa7 and avrXa10 genes of Xanthomonas oryzae pv. oryzae direct the elicitation of resistance in a gene-for-gene manner in rice lines carrying the resistance gene $X a 7$ and $X a 10$, respectively. We have localized a transcriptional activator domain in the $\mathrm{C}$ terminus of both proteins. One mutant, with replacements at three hydrophobic amino acid residues in the C-terminal domain, was defective for transcriptional activation in a yeast assay and avirulence activity in rice. Replacement of a defective domain with the transcriptional activation domain from the herpes virus protein VP16 restored the ability of the bacteria expressing the hybrid proteins to elicit a resistance reaction. The mutation also affects the virulence attributes of avrXa7. The activation domain from VP16 partially complements the loss of activity due to deletion of the native domain in AvrXa7. The data demonstrated that a transcriptional activation domain in this gene family has a critical function in pathogenicity and avirulence.

Concentration of cyanide evolution in various sudangrass cultivars correlated to suppression of Meloidogyne hapla. T. L. WIDMER and G. S. Abawi. NYSAES, Cornell University. Phytopathology 89:S84. Publication no. P-1999-0602-AMA.

Sudangrass cv. Trudan 8 has been demonstrated to suppress infection of vegetables by Meloidogyne hapla (Mh). Trudan 8 and other sudangrass cultivars contain the cyanogenic glucoside, dhurrin, which decomposes to HCN in the presence of glucosidase. This is the primary mechanism involved in suppression of Mh. The cyanide ion level in leaf tissue of 14 tested cultivars of sudangrass varied between 0.04 (cv. SX-8) to $1.84 \mathrm{ppm}$ (cv. 840F). The suppressive activity of the sudangrass cultivars against $\mathrm{Mh}$ was assessed in greenhouse tests by incorporating various amounts of leaf tissue into organic soil. After 1 week, eggs of Mh were added to the soil ( $8 \mathrm{eggs} / \mathrm{cc}$ soil) and then were planted to lettuce as the indicator plant. After 8 weeks, the lettuce roots were washed and rated for root-galling severity (RGS) incited by Mh. Incorporation of tissues of sudangrass resulted in a reduction of RGS up to $54 \%$ compared to those growing in a nonamended control. The data also suggested a correlation between the content of cyanogenic compounds in leaf tissues and the suppression level against Mh in soil.

Control of tropical soda apple (Solanum viarum Dunal) by application of Erwinia carotovora in combination with reduced levels of herbicides. H. I. Wiersma (1), P. D. ROBERTS (2), J. Arnold (1), J. J. Mullahey (2), and R. R. Urs (2). (1) Okeechobee High School, Okeechobee, FL; (2) SWFREC, University of Florida, Immokalee, FL. Phytopathology 89:S84. Publication no. P-1999-0603-AMA.

The bacterium, Erwinia carotovora, was combined with reduced doses of two commercial herbicides, dicamba (3,6-dichloro-o-anisic acid) and triclopyr (3,5,6-trichloro-2-pyridinyloxy acetic acid), to control tropical soda apple. Six-week-old, greenhouse-grown, potted plants were spray-inoculated with a suspension of E. carotovora combined with either triclopyr at $1361 \mathrm{ppm}$ or dicamba at $1229 \mathrm{ppm}$ (both at $25 \%$ of recommended rate). Plant mortality was $100 \%$ and $88.5 \%$, respectively, and no regrowth occurred after 72 days. Plant mortality from either herbicide alone was $82 \%$ but plants regenerated after 65 days. Plants inoculated with bacteria alone were unaffected. In field trials, mortality of plants treated with E. carotovora combined with either herbicide was over $98 \%$ whereas either herbicide alone was $91 \%$. As in the greenhouse experiment, herbicide-treated plants showed regeneration whereas no regeneration of plants occurred when bacterium was combined with herbicide.

Efficacy of new apple scab fungicides in New York. W. F. WILCOX and J. A. Burr. Dept. Plant Pathology, Cornell Univ., NY State Agr. Expt. Sta., Geneva, NY 14456. Phytopathology 89:S84. Publication no. P-1999-0604AMA.

Rotational fungicide programs that included kresoxim-methyl (k-m) at 37 $\mathrm{mg} / \mathrm{L}$ provided control of apple scab (Venturia inaequalis) that was superior (1996 and '98) or equivalent (1997) to DMI plus mancozeb standards. Superior performance was associated with applying k-m in the first two sprays following unprotected infection periods, thus suppressing sporulation from early foliar infections. Control was improved when the k-m rate was increased to $60 \mathrm{mg} / \mathrm{L}$ in the first two sprays but not after bloom. In 1998, trifloxystrobin at 19 and $37 \mathrm{mg} / \mathrm{L}$ provided control comparable to k-m at 37 and $60 \mathrm{mg} / \mathrm{L}$, respectively. Cyprodinill (56-94 mg/L) provided only fair control from 1996-98 unless tank-mixed with mancozeb. Fenbuconazole solo $(37 \mathrm{mg} / \mathrm{L})$ was superior to myclobutanil $(50 \mathrm{mg} / \mathrm{L})$ plus mancozeb, and provided $81 \%$ control of fruit scab vs. $35 \%$ for tebuconazole solo $(67 \mathrm{mg} / \mathrm{L})$. In 1998, the frequency of myclobutanil-resistant $V$. inaequalis isolates in this orchard was $20 \%$.

Comparison of enzyme activities in germinating seed of endophyteinfected and endophyte-free tall fescue. A. J. Williams and K. D. GWINN. University of Tennessee, Knoxville, TN 37901-1071. Phytopathology 89: S84. Publication no. P-1999-0605-AMA.

Infection of tall fescue Festuca arundinacea, with the endophytic fungus, Neotyphodium coenophialum, is correlated with increased resistance to preemergence damping-off caused by Rhizoctonia zeae, R. solani and Pythium aphanidermatum. The objective of this research was to determine if selected enzymes were affected by endophyte infection and/or germination. Genetically similar seed lots with either a 95\% endophyte infestation level (E+) or a $0 \%$ infection level (E-) were scarified and soaked in sterile water. Seed were ground in liquid nitrogen and extracted with buffer. Enzyme activities were determined with standard protocols. Peroxidase activity, monitored at various intervals between 9 and $24 \mathrm{~h}$, was significantly different between E+ and Eat all times; the rate of increase was also greater for $\mathrm{E}+$ than $\mathrm{E}-$ treatments. Catalase and superoxide dismutase activities were determined only at 0 and $24 \mathrm{~h}$. Catalase activity was greater at $24 \mathrm{~h}$ than at $0 \mathrm{~h}$, but there were no differences between E+ and E- treatments. Preliminary results for superoxide dismutase suggest trends similar to catalase. 
Evaluation of potential biocontrol agents for crown rot of banana. S. M. WILLIAMSON (1), M. Guzmán (2), O. Anas (1), D. H. Marín (3), X. Jin (4), and T. B. Sutton (1). (1) North Carolina State University, Raleigh, NC; (2) CORBANA, San José, Costa Rica; (3) BANDECO, San José, Costa Rica; (4) EcoScience Corporation, East Brunswick, NJ. Phytopathology 89:S85. Publication no. P-1999-0606-AMA.

Potential biocontrol agents were evaluated for their ability to reduce crown rot of banana caused by Fusarium moniliforme. Pedicels of banana fingers were immersed in the fungal spore suspension $\left(1 \times 10^{5}\right.$ conidia $\left./ \mathrm{ml}\right)$ first and then were immersed in a suspension of the potential biocontrol agent. After 14 days of incubation at $14^{\circ} \mathrm{C}$, pedicels were cut in half longitudinally and the percentage of diseased tissue estimated. ESC11 and BW7 provided the best control. The commercial standard, thiabendazole + imazalil, ESC11, and BW7 reduced disease severity by an average of $69 \%, 62 \%$, and $41 \%$, respectively. Concentrations of $5 \times 10^{7} \mathrm{cfu} / \mathrm{ml}$ of ESC11 and $1 \times 10^{8} \mathrm{cfu} / \mathrm{ml}$ of BW7 were needed to reduce disease severity. The growth or viability of ESC11 and BW7 was inhibited in vitro by thiabendazole, imazalil, and aluminum potassium sulfate, chemicals routinely used in banana packing houses. The ability of ESC11 and BW7 to provide control decreased when aluminum was present on artificially inoculated pedicels.

Fishing downstream in the Gac regulon of Pseudomonas syringae B728a. D. K. WILLIS (1,2), J. J. Holmstadt (1), A. K. Savage (1), C. A. Hinckley (1), J. L. McEvoy (1), and T. G. Kinscherf (1). (1) University of Wisconsin and (2) USDA-ARS, Madison, WI. Phytopathology 89:S85. Publication no. P-19990607-AMA.

The two-component regulatory gene pair gacS (formerly lemA) and gacA has been shown to regulate a diverse set of phenotypes in Pseudomonas syringae pv. syringae B728a, including the production of extracellular protease, syringomycin, and homoserine lactone, as well as field fitness and disease manifestation on bean. Recent results have demonstrated that the salA gene is a positive regulator of a subset of the Gac regulon, being involved in syringomycin production and the formation of disease lesions. We have undertaken further delineation of this regulon, using a $T n 5 l a c Z$ reporter system, to systematically detect genes whose expression are differentially affected by gacA. Both positively and negatively gacA-affected insertions have been isolated. DNA sequence analysis identified insertion sites in alginate, rhamnolipid, and rotamase loci, among others, as well as in several genes of unknown function. The results are suggestive of previously unanticipated avenues for future experimentation.

Striga hermonthica infection of wild Pennisetum. J. P. WILSON (1), D. E. Hess (2), and W. W. Hanna (1). (1) USDA-ARS, Forage and Turf Research Unit, Tifton, GA 31793; (2) ICRISAT, B.P. 320, Bamako, Mali. Phytopathology 89:S85. Publication no. P-1999-0608-AMA.

Resistance to $S$. hermonthica in 275 wild P. glaucum accessions was assessed in an infested field in Samanko, Mali in 1997. Transformed values for emerged number of Striga plants [ $\log ($ striga +0.05$)]$ were correlated with days to flowering $(R=0.82, P=0.0001)$, and negatively correlated with downy mildew incidence $(R=-0.65, P=0.0001)$. The equation predicting $\log ($ striga +0.05$)(Y)$ to days to flowering (DTF) and downy mildew incidence $(\mathrm{DMI})$ was $\mathrm{Y}=0.103+(0.014 \mathrm{DTF})-(0.008 \mathrm{DMI})$. An agar-gel assay was used to evaluate 13 diverse, wild $P$. glaucum accessions for their ability to induce germination of Striga seed. The wild Pennisetums induced less germination of Striga seed $(<1 \%)$ than the landrace Toronio $(4 \%)$ and sorghum E 36-1 (14\%). Within the wild Pennisetums, percent Striga germination was negatively correlated with Striga emergence in $1997(R=-0.69, P=0.01)$. Selecting Striga resistance can be confounded by date of host flowering and downy mildew incidence. Differences in stimulant production by the Pennisetums are not responsible for differences in Striga infestation in the field.

RH-7281, a new fungicide for the control of foliar oomycete diseases. W. J. WILSON, A. R. Egan, E. L. Michelotti, and D. H. Young. Rohm and Haas Company, Research Laboratories, Spring House, PA 19477. Phytopathology 89:S85. Publication no. P-1999-0609-AMA.

RH-7281 is a novel fungicide currently under development by Rohm and Haas Company. This fungicide has an exceptionally favorable toxicological and environmental profile which provides an excellent safety margin for consumers, applicators and the environment. RH-7281 demonstrated outstanding efficacy against Plasmopara viticola, Phytophthora infestans and Pseudoperonospora cubensis in field trials conducted worldwide. It has strong protectant activity with limited curative properties. Rainfastness and residual activity are strengths of this fungicide. RH-7281 has a different mode of action from other Oomycete fungicides. It arrests nuclear division by binding to tubulin. RH-7281 acts after spore germination to inhibit germ tube elongation, thus inhibiting fungal penetration and mycelial growth. The fungicide controls phenylamide-resistant strains of late blight and downy mildew. This product will provide growers with an important new tool for resistance management and an option for IPM programs.

Examination of viral interactions in relation to disease severity and resistance in the virus yellows complex of sugarbeet. W. M. WINTERMANTEL and J. L. Sears. USDA-ARS, Salinas, CA 93905. Phytopathology 89:S85. Publication no. P-1999-0610-AMA.

Virus yellows is a disease complex composed of different genera of plant viruses. Beet yellows closterovirus (BYV), beet western yellows luteovirus (BWYV), and occasionally, beet mosaic potyvirus (BtMV), are the main components. BtMV alone may not contribute to economically significantly disease loss. All of these viruses are transmitted by aphids, and all are usually present at some level in infected fields. Although beet-free periods are useful in managing virus yellows, the increased range and population of the black bean aphid has made this disease more difficult to control in recent years. In this study, sugarbeet varieties exhibiting differential levels of resistance to the yellows complex viruses were inoculated with every possible combination of one, two or all three viruses. Interviral effects were identified and correlated using quantitative molecular techniques. Correlation of stunting and symptom severity with different virus combinations indicate that disease is more severe when all three viruses are present than when plants are infected by one or any combination of two viruses.

A new disease of greenhouse-grown tomatoes caused by tomato bushy stunt virus (TBSV). G. C. WISLER, J. L. Sears, H.-Y. Liu, C. Obermeier, and J. E. Duffus. USDA-ARS, Salinas, California. Phytopathology 89:S85. Publication no. P-1999-0611-AMA.

A previously undescribed disease of hydroponic, greenhouse-grown tomatoes was detected in the Central United States. Symptoms include stunting of affected plants, leaf necrosis, fruit and flower drop, and truss necrosis. Although fruit appears to be normal, the stem end shows a ring of necrosis after the calyx is removed, and the internal part of the fruit shows necrosis that is primarily restricted to the vascular tissues. TBSV has been consistently isolated from symptomatic foliage, trusses and fruit. No fungal or bacterial organism has been isolated from symptomatic tissues. Virus particles measure $30 \mathrm{~nm}$ in diameter. The dsRNA profile is identical to those of known TBSV isolates. Koch's postulates were completed by pouring inoculum, increased in Nicotiana benthamiana from single local lesions, into $10 \mathrm{~cm}$ pots with tomato 'Trust' seedlings. Foliage and truss necrosis was produced by this method, and TBSV was re-isolated from affected tissues. Based on the unique fruit symptoms observed, this may be a different isolate or strain of TBSV than previously identified in tomato.

Physical modes of action of azoxystrobin against grapevine downy mildew (Plasmopara viticola). F. P. WONG and W. F. Wilcox. NYSAES, Cornell University, Geneva, NY 14456. Phytopathology 89:S85. Publication no. P-1999-0612-AMA.

The physical modes of action of the strobilurin fungicide, azoxystrobin, were evaluated on Vitis vinifera 'Riesling' seedlings using $P$. viticola as a model pathogen. Protectant, post-infection, post-symptom, and translaminar activity of azoxystrobin were tested at a dose of $250 \mathrm{mg} / \mathrm{L}$. Azoxystrobin provided $100 \%$ disease control when applied at 1 to 5 days before inoculation. Applications at 1,3 , and 5 days after inoculation had little effect on the incidence of disease, but sporulation from these lesions was reduced by 93,62 , and $96 \%$, respectively, relative to the check. Post-symptom applications of azoxystrobin resulted in a $77 \%$ reduction of resporulation from diseased tissue, relative to the check. Apparent translaminar activity was most pronounced when the lower surface of the leaf was inoculated 5 days after treatment of the upper leaf surface ( $100 \%$ disease control). In contrast, control was $<50 \%$ when leaves were similarly inoculated 1 and 3 days after treatment. The azoxystrobin- $P$. viticola model provides a basis for the general understanding of the physical modes of action for the strobilurin fungicides.

Regional assessment of prevalence of Sclerotinia stem rot of soybean. F. Workneh, X. B. YANG, and A. L. Hiel. Department of Plant Pathology, Iowa State University, Ames 50011. Phytopathology 89:S85. Publication no. P-1999-0613-AMA.

In the last decade, there have been reports of considerable increase in soybean damage by Sclerotinia stem rot, caused by Sclerotinia sclerotiorum, in the northcentral United States. To determine the prevalence and distribution 
of the disease in the region, investigations were conducted in the fall of 1995-1998 in Iowa, Minnesota, and Missouri, and of 1995 and 1996 in Illinois and Ohio. In each state, soybean fields were randomly selected and 20 soybean stems were collected from each field. Over the four-year period, stem samples, along with tillage information, were collected from 1983 fields and assessed for the presence or absence of the disease. Minnesota had the greatest prevalence followed by Iowa, Illinois, and Ohio. The disease was not detected in Missouri. In the states in which it was detected, the prevalence was greatest in 1996, ranging from 0.8 in Ohio to $19.5 \%$ in Minnesota. Overall, there were significant differences among tillage practices in prevalence of the disease. Minimum-till had greater disease incidence than either no-till or conventional-till fields.

Spatial analysis on lettuce downy mildew (Bremia lactucae) in the Salinas Valley using geostatistics and GIS. B. M. WU (1), A. H. C. van Bruggen (1), K. V. Subbarao (1), and G. G. H. Pennings (2). (1) University of California, Davis, CA; (2) Origin Nederland B.V., Barneveld, The Netherlands. Phytopathology 89:S86. Publication no. P-1999-0614-AMA.

Lettuce downy mildew occurs every growing season in coastal California. However, the spatial patterns of the disease and the distance over which the pathogen's spores may be carried have not been determined. During 19951998, we conducted several disease surveys at the field- and valley scales in the Salinas Valley. Geostatistical analyses were then carried out on the survey data. Semivariograms from surveys at field- and valley scales showed that the range of influence of lettuce downy mildew varied from 100 to 5000 meters. Diseased plants showed an aggregated distribution at the field scale. Cluster analysis on interpolated disease incidence on different dates in GIS demonstrated that the Salinas Valley could be divided into two areas, north and south of Salinas City, with high and low disease pressure, respectively. Seasonal and spatial trends along the valley suggested a temperature-effect on this disease, but further investigation is required to confirm this.

Infection process of Phomopsis amaranthicola on Amaranthus spp. and implications for biological control. G. S. WYSS and R. Charudattan. University of Florida, Gainesville, FL. Phytopathology 89:S86. Publication no. P-1999-0615-AMA.

Phomopsis amaranthicola, indigenous to Florida, is being evaluated extensively as a bioherbicide for Amaranthus spp. in greenhouse and field trials. The infection process of this pycnidial fungus that causes a stem- and leafblight was studied on a highly susceptible host, $A$. viridus, and a resistant host, A. spinosus, for eight days. The fungal structures were stained selectively using aniline blue. Spore adhesion and fungal invasion could not be observed on A. spinosus. On A. viridus, the conidia germinated within $24 \mathrm{~h}$ over anticlinal cell junctions. The cuticle directly below the conidium was penetrated by a very short penetration peg. Appressorium formation was not observed on leaf, plastic film or dialysis membrane. Two days after inoculation there was some intercellular, but no intracellular, fungal growth and necrosis in a small group of cells. From day six the necrotic area expanded and became macroscopically visible. The leaf abscised on day eight. Even with a prolonged six-day latent period and reduced intracellular growth, $P$. amaranthicola causes leaf drop and therefore reduces the competitive advantage of $A$. viridus.

Determination of serological relationship among Bacillus thuringiensis (Bt) cry proteins using polyclonal antibodies in ELISA. J. Q. XIA, S. Hindman, and C. L. Sutula. Research Dept., Agdia, Inc., Elkhart, IN 46514. Phytopathology 89:S86. Publication no. P-1999-0616-AMA.

Polyclonal antibodies specific for Bt Cry1Ab, Cry1Ac, Cry1C, Cry9C, and Cry2A proteins were produced by injecting rabbits with the purified Bt Cry proteins. Serological cross-reaction of the antibodies was determined by testing each Bt Cry protein against each antibody in a modified procedure of DAS-ELISA. Antibody to Cry1 Ab showed $17 \%$ cross-reaction with the Cry1 Ac protein, and Cry1 Ac antibody had $28 \%$ cross-reaction with Cry1 Ab protein. Cry1 Ac and Cry1 Ab antibodies showed no cross reaction with $\mathrm{Bt}$ Cry1C, 9C and 2A proteins. The antibodies to Bt Cry1C, Cry9C and Cry2A were very specific showing no reactivity with any of the other Cry proteins tested. These serological relationships among the Bt Cry proteins correlate with the amino acid sequence identities shared in the Bt Cry proteins. These specific and sensitive ELISAs could also be used to detect Bt cry proteins in commercial Bt formulations. Applications of the ELISAs for detection and quantification of the Bt Cry proteins in transgenic plant tissues were also explored.
Comparative study on epidemics of strawberry fruit diseases under plastic tunnel and field production systems in Florida. C. L. XIAO, C. K. Chandler, J. F. Price, and D. E. Legard. Univ. of Florida, GCREC, Dover, FL 33527. Phytopathology 89:S86. Publication no. P-1999-0617-AMA.

During 1998-99 season, epidemics of Botrytis fruit rot (Botrytis cinerea), powdery mildew (Sphaerotheca macularis $\mathrm{f}$. sp. fragariae) and anthracnose fruit rot (Colletotrichum acutatum) on strawberry were compared between large plastic tunnel and field production systems. Treatments were arranged in a split-plot design with two main plots (field and tunnel) and four subplots, including combinations of two cultivars (Sweet Charlie and Camarosa) and two Captan spray programs (at 7 or $14 \mathrm{~d}$ intervals). Weather variables were monitored in both field and tunnel. Marketable yield and incidence of fruit diseases were determined twice weekly. Early season yields were significantly higher in tunnel than in field. Botrytis fruit rot was significantly lower on 'Sweet Charlie' $(<1 \%)$ in tunnel than in field $(13 \%)$ by the end of February. Anthracnose fruit rot was also lower in tunnel. Powdery mildew on 'Camarosa' was higher in tunnel $(14 \%)$ than in field $(<1 \%)$. Increased temperature and reduced leaf wetness mainly contributed to the decrease in Botrytis fruit rot and increase in powdery mildew incidences in tunnel.

Isolation of plant compounds inhibitory to mycotoxin production. $\mathrm{H}$. $\mathrm{Xu}$, S. Annis, L. Velaquis, R. Hammerschmidt, and F. TRAIL. Dept. Botany and Plant Pathology, Michigan State University, East Lansing, MI. Phytopathology 89:S86. Publication no. P-1999-0618-AMA.

We have developed a novel assay, based on genetically engineered strains of A. parasiticus, to screen for compounds that inhibit transcription of aflatoxin biosynthetic genes. This assay can be used for initial screening and purification of compounds inhibitory to fungal growth, expression of aflatoxin biosynthetic genes and sporulation. Using this assay, we have identified compounds from black pepper with fungicidal activity and with inhibitory activity to transcription of aflatoxin biosynthetic genes. In addition, the assay can be used to screen for compounds active against other mycotoxigenic fungi.

Purification of a putative repressor involved in the thermoregulation of the phaseolotoxin-resistant ornithine carbamoyltransferase (ROCT) of Pseudomonas syringae pv. phaseolicola. R. Xu, K. B. Rowley, G. Mocz, and S. S. PATIL. University of Hawaii, Honolulu, HI. Phytopathology 89:S86. Publication no. P-1999-0619-AMA.

The production of phaseolotoxin-resistant ornithine carbamoyl transferase (ROCT) and phaseolotoxin by Pseudomonas syringae pv. phaseolicola is thermoregulated; ROCT and phaseolotoxin are produced at $18^{\circ} \mathrm{C}$ but not at the optimum growth temperature, $28^{\circ} \mathrm{C}$. At $28^{\circ} \mathrm{C}$ (but not at $18^{\circ} \mathrm{C}$ ) the pathogen produces a protein which binds to an upstream fragment from the gene $(\operatorname{argK})$ encoding ROCT. Footprinting experiments using an upstream sequence from $\arg K$ and a semipurified protein isolated from P.s. pv. phaseolicola grown at $28^{\circ} \mathrm{C}$ identified distinct nucleotide motifs to which the protein specifically binds. The DNA-binding protein is further purified by heparinagarose chromatography. Southwestern blots of the protein using the specific nucleotide sequence as a probe identified a band of $\sim 30 \mathrm{kDa}$. The N-terminal sequence of this protein is determined. These results indicate that thermoregulation of $\arg K$ (and perhaps of phaseolotoxin genes) at high temperature is caused by the repressor protein produced at this temperature.

Bioassay of Trichoderma harzianum strains for control of rice sheath blight. T. XU (1), G. E. Harman (2), Y. L. Wang (3), and Y. Shen (3). (1) Zhejiang Univ., 310029 Hangzhou, China; (2) Cornell Univ., Geneva, NY; (3) National Rice Res. Inst., Hangzhou, China. Phytopathology 89:S86. Publication no. P-1999-0620-AMA.

Rice sheath blight caused by Rhizoctonia solani is the most serious disease in China. Since no resistant cultivars available, the practical control is achieved only through application of fungicides. The purpose of this work is to evaluate the potential of Trichoderma harzianum (TH) strains NF9, TC3 and P1 for control of the disease. The TH strains produced sharp inhibition zone alone the interface on the dual culture; the mycelial growth of the pathogen was inhibited by P1, NF9, TC3 with $100 \%, 55 \%$ and $56 \%$, respectively, on the filter culture. The hyphal coiling and penetration of the TH strains on the pathogen was observed; the sclerotia of the pathogen were penetrated and parasized after treatment with $\mathrm{TH}$ stain conidial suspension. In growth chamber assay the disease was reduced significantly and the rice seed germination was increased by the soil treatments or seed coating with the TH strains. In greenhouse and nethouse the disease control at heading stage was achieved by NF9 and TC3 with $83 \%$ and $77 \%$, respectively. 
A volatile chemical produced by older pepper plants is an important factor in resistance against infection by Phytophthora capsici. X. L. XU (1), D. Hemmes (2), and W. H. Ko (1). (1) University of Hawaii at Manoa, Honolulu, HI; (2) University of Hawaii at Hilo, Hilo, HI. Phytopathology 89:S87. Publication no. P-1999-0621-AMA.

Compared with pepper seedlings, old pepper plants at the flowering stage are more resistant to infection by Phytophthora capsici zoospores. The differences in cuticle thickness, number of stomata per comparable surface area, and other physical characters were analyzed, but chemical factors appear to be of major importance. When extracting leaf juices of pepper seedlings and flowering pepper plants, a volatile substance was noted from the older plants which inhibits germ tube growth of $P$. capsici zoospores. This volatile substance appears to be the primary factor in the resistance of older pepper plants against infection by $P$. capsici zoospores.

Diversified pathogenicity in isolates of Fusarium oxysporum f. sp. lactucae to lettuce cultivars. N. YAMAUCHI, S. Horiuchi, and M. Satou. Morioka Branch, National Research Institute of Vegetables, Ornamental Plants and Tea, Morioka, Japan 0200123. Phytopathology 89:S87. Publication no. P-1999-0622-AMA.

Lettuce root rot (Fusarium oxysporum f. sp. lactucae) has been reported from some areas in Japan. Pathogenicity to lettuce cultivars was examined in isolates of the pathogen obtained from crisphead type and butterhead type from different areas (Nagano, Fukuoka and Shizuoka). Isolates from crisphead type caused severe symptoms towards cultivars of crisphead type (Exceed, Texasgreen and Steady) and leaf type (Redfire), whereas slight symptoms towards butterhead type (Natsuyou kurosarada, Okayama saradana and Waya head). On the contrary isolates from butterhead type revealed high pathogenicity towards butterhead type cultivars, and clearly lower to crisphead type and leaf type cultivars. The results suggest that the pathogen isolates vary in pathogenicity to lettuce cultivars, i.e., highly pathogenic to a cultivar type from which the isolates is obtained.

A putative chemosensory receptor gene in the soybean cyst nematode. Y. YAN and E. L. Davis. North Carolina State University, Raleigh, NC. Phytopathology 89:S87. Publication no. P-1999-0623-AMA.

The soybean cyst nematode ( $\mathrm{SCN}$ ), Heterodera glycines, is the most damaging pathogen of soybean. Disorientation of parasitic nematodes by affecting their ability to detect chemical signals may present a powerful means to control the nematodes. Guanylyl cyclases represent a new class of sensory receptors that have been identified in mammals, and they also exist in Caenorhabditis elegans. We have identified a guanylyl cyclase receptor cDNA in SCN (HG- $g c y-1)$. HG- $g c y-1$ encodes a 1151 aa protein which consists of a 22 aa signal peptide, 519 aa extracellular domain, 277 aa kinase-like domain and a 273 aa catalytic domain. This gene has 24 introns and spans more than $7 \mathrm{~kb}$ in the genome. Strong homology exists in the kinase-like and catalytic domain between HG-gcy-1 and the cyclases from C. elegans, but not in the extracellular domain. HG-gcy-1 extracellular domain has six cysteine residues conserved within the ligand-binding domain of known cyclase receptors. Experiments are in progress to determine if gyanylyl cyclases are localized to chemosensory organs in SCN and to confirm their potential function in nematode chemotaxis.

Role of rhizobacteria in tomato early blight control. Z. YAN (1), M. S. Reddy (1), Q. Wang (2), R. Mei (2), and J. W. Kloepper (1). (1) Department of Plant Pathology, Auburn University, Auburn, AL 36849; (2) PEEI, China Agricultural University, Beijing, 100094, P. R. China. Phytopathology 89: S87. Publication no. P-1999-0624-AMA.

Seven strains of PGPR from Auburn and 7 strains of YIB (yield increasing bacteria) from Beijing were evaluated for biocontrol potential against tomato early blight caused by Alternaria solani under field and greenhouse conditions in Alabama and in field trials in Beijing. Bacteria were applied as amendments in soil-less mix before seeding of tomato cv. Solarset. At the time of transplanting, seedlings treated with Auburn strains were rated for growth promotion. Results indicated that 6 out of 7 Auburn strains significantly improved seedling growth. Among these 6, 3 strains significantly reduced early blight symptoms under greenhouse conditions and one strain under Alabama field conditions. Six of the 7 YIB strains significantly reduced early blight symptoms at the Alabama site, but only one strain provided significant protection at the Beijing site. These results indicate that efficacious biocontrol rhizobacteria do not necessarily need to be isolated from the region of intended use.
Microbial community structure of Phytophthora infected and noninfected avocado roots. C. H. YANG, D. E. Crowley, and J. A. Menge. University of California, Riverside, CA. Phytopathology 89:S87. Publication no. P-1999-0625-AMA.

Rhizosphere microbial communities may influence the ability of root disease causing fungi to colonize plant roots. In this study, culturable and nonculturable microorganisms from avocado roots were examined using 16S rDNA fingerprints generated by denaturing gradient gel electrophoresis (DGGE). Root tips from mature trees in a Phytophthora root rot infested orchard were collected, and communities associated with healthy and infected roots were compared. Statistical analysis of the banding patterns were conducted using correspondence analysis of the DNA banding patterns. The results showed that microbial communities associated with the healthy roots were highly structured and similar in replicate trees. In comparison, bacterial communities from infected roots on the same trees were significantly different from those of healthy roots, and were more variable between replicate samples. The data suggests that root infection caused severe disruption in the community structure, which was manifested by increased variability in species composition and changes in the relative predominance of different bacteria in the rhizosphere community.

Relationship between stem pigment production and field resistance of soybean to Sclerotinia sclerotiorum. X. B. YANG, P. Lundeen, and M. D. Uphoff. Department of Plant Pathology, Iowa State University, Ames 50011. Phytopathology 89:S87. Publication no. P-1999-0626-AMA.

Previous studies in our laboratory show that soybean stems when placed in oxalic acid solution $(40 \mathrm{mM})$ produce a red pigment in the solution, and the pigment intensity of the oxalic acid solution after 24 hours was significantly and negatively correlated with the level of field resistance to Sclerotinia stem rot caused by Sclerotinia sclerotiorum. Studies were conducted to determine repeatability of this method with a larger number of cultivars under multiple environments and to investigate the source of variation in pigment production. Three sets of cultivars with 63,64 , and 35 cultivars respectively, were tested. These cultivars had various levels of field resistance (10 to $80 \%$ disease incidence) under four different environments and the levels of resistance were consistently correlated with pigment production, despite the larger number of cultivars. The value of correlation coefficients changes from $r=0.4$ to $0.54(P<0.001)$. For thirteen standard check cultivars that had consistent field resistance response in all environments, the level of their field resistance was correlated with pigment production at values of $r>0.95$. Large variations in pigment production between individual plants within cultivars were observed, which indicated that an increased number of replications are needed.

Structure and regulation of the pathogen-inducible mybl promoter from tobacco. Y. YANG and M. Qi. Department of Plant Pathology, University of Arkansas, Fayetteville, AR 72701. Phytopathology 89:S87. Publication no. P-1999-0627-AMA

Tobacco mybl gene is specifically induced by tobacco mosaic virus (TMV) infection during the hypersensitive response and development of systemic acquired resistance, following the rise of endogenous salicylic acid (SA). The mybl gene is also rapidly activated (within $15 \mathrm{~min}$ ) by exogenous SA treatment and behaves as an immediate early gene whose transcriptional activation is independent of de novo protein synthesis. In this study, we have isolated and sequenced a $2 \mathrm{~kb}$ genomic fragment containing the $m y b 1$ promoter. The transcription start site of mybl was determined using primer extension and found to be located at $163 \mathrm{bp}$ upstream of the translational start codon. Furthermore, the $5^{\prime}$ unilateral deletion derivatives were generated from the 2 $\mathrm{kb} m y b 1$ promoter and fused to the GUS reporter gene. Both transient expression assay and stable transformation have been carried out for the promoter analysis. Preliminary results indicate that the TMV- and SA-responsive element(s) reside in a 350 bp region near the transcription start site.

Ultrastructural and cytochemical aspects of the interaction between Glomus etunicatum and Rhizoctonia solani in potato. M. K. YAO, N. Benhamou, S. Yelle, and H. Desilets. Université Laval, Sainte-Foy, Quebec, Canada G1K 7P4. Phytopathology 89:S87. Publication no. P-1999-0628-AMA.

Potato plantlets pre-inoculated by the vesicular-arbuscular fungus Glomus etunicatum, were challenged with Rhizoctonia solani. In nonmycorrhizal potato plants, ultrastructural investigations of $R$. solani-infected root tissues showed an abundant colonization of all tissues including the vascular stele 
and marked host tissue damage. Chitin in the pathogen cell walls was regularly labelled whereas cellulose was irregularly distributed indicating host cell wall degradation. In mycorrhizal potato plants, pathogen spread was restricted to a few epidermis and outer cortex cells. Host cells invaded by the pathogen were often filled with an amorphous material. Host intercellular spaces were filled with a fibrillar material and/or with an electron-opaque material that lined the inner surface of the areas neighboring the pathogen. Plant cell wall integrity was preserved as judged by the regular labelling of cellulose. By contrast, the intensity of chitin labelling over the pathogen cell wall decreased. These observations lead us to suggest that the deposition of this material in the intercellular space strengthens the cell wall which in turn become less vulnerable to fungal cell wall degrading enzymes. The material filling plant cells may act not only as a barrier to fungal spread, but also as a fungistatic and/or fungitoxic material. The restriction of $R$. solani in a few plant cells and the marked damage of invading hyphae of the pathogen suggest that the defense system is activated in mycorrhizal plants.

Fusarium moniliforme production of fumonisin $\mathrm{B}_{1}$ suppressed by Trichoderma viride. I. E. YATES (1), F. Meredith (1), C. W. Bacon (1), and A. J. Jaworski (2). (1) USDA-ARS, Russell Agricultural Research Center, Athens, GA; (2) University of Georgia, Athens, GA. Phytopathology 89:S88. Publication no. P-1999-0629-AMA.

A Trichoderma viride strain isolated from corn root segments was demonstrated to limit $F$. moniliforme growth and fumonisin $\mathrm{B}_{1}$ production. $T$. viride decreased radial extension of $F$. moniliforme by $46 \%$ and $90 \%$ after 6 and 14 days, respectively, during co-cultivation on potato dextrose agar. After 14 days co-cultivation, F. moniliforme colony diameter was less than at 5 days suggesting lysis of $F$. moniliforme mycelia. $F$. moniliforme $\mathrm{FB}_{1}$ production decreased by more than $80 \%$ when both organisms were inoculated the same day onto corn kernels, and more than $70 \%$ when inoculation of T. viride was delayed by 7 days after $F$. moniliforme inoculation. These results are the first to demonstrate that $T$. viride can suppress $\mathrm{FB}_{1}$ production by $F$. moniliforme, thereby functioning to control mycotoxin production. These results suggest that this isolate may be useful in biological control as a pre-harvest agent to inhibit $F$. moniliforme growth during kernel development and/or as a post-harvest agent to suppress $\mathrm{FB}_{1}$ accumulation when kernels are dried inadequately.

Suppression of apple shoot susceptibility to fireblight by prohexadione-Ca (Apogee). K. S. YODER. VPI \& SU, Winchester, VA 22602. Phytopathology 89:S88. Publication no. P-1999-0630-AMA

The plant growth regulator prohexadione-calcium (P-Ca, Apogee) was evaluated for suppression of fireblight in apple shoots. Shoot tips growing actively at the time of treatment were inoculated one, two, or three wk after P-Ca treatment. Streptomycin (strep) was also applied to trees previously treated with P-Ca $250 \mathrm{mg} / \mathrm{L}$ and to untreated trees the day of the first inoculation. At the time of the 3-wk inoculations shoots were rated for growth actively progressing, stopping or stopped. P-Ca $250 \mathrm{mg} / \mathrm{L}$ followed with strep and inoculated 7 days later, gave a synergistic effect: $82 \%$ reduction of shoot blight incidence, compared to $50 \%$ reduction by P-Ca without the follow-up strep application, and only $20 \%$ reduction by strep applied alone. Infection incidence was highest on both test cultivars from 3-wk inoculations. All treatments involving P-Ca gave significant control but strep, applied two weeks earlier, did not. P-Ca $250 \mathrm{mg} / \mathrm{L}$ treatment resulted in reduced susceptibility: more shoots with growth stopping at the time of the 3-wk inoculations and fewer shoots infected. Use of the growth suppressant effect of P-Ca to reduce tree susceptibility represents a novel way to manage shoot blight.

Mechanism of action of the oomycete fungicide RH-7281. D. H. YOUNG and R. A. Slawecki. Rohm and Haas Company, Spring House, PA. Phytopathology 89:S88. Publication no. P-1999-0631-AMA.

The mechanism of action of RH-7281 was found to be unique among Oomycete fungicides. RH-7281 rapidly arrested nuclear division in Phytophthora capsici germlings and destroyed the microtubule cytoskeleton. In studies using isolated bovine tubulin RH-7281 inhibited the in vitro assembly of tubulin into microtubules. Treatment of $P$. capsici mycelium with radiolabeled RH-7281 and subsequent analysis of radiolabeled protein revealed a highly specific covalent binding to the beta-subunit of tubulin. Binding of RH-7281 to tubulin in P. capsici was inhibited by structural analogs, and the ability to inhibit binding was correlated with fungitoxicity. Binding to tubulin was also inhibited by the experimental antimicrotubule fungicide zarilamide, suggesting a common binding site on tubulin. We conclude that the fungitoxic mechanism of RH-7281 involves inhibition of nuclear division as the result of covalent binding to beta-tubulin and disruption of the microtubule cytoskeleton.

Laboratory studies to assess the risk of resistance development to RH7281. D. H. YOUNG, S. L. Spiewak, and R. A. Slawecki. Rohm and Haas Company, Spring House, PA. Phytopathology 89:S88. Publication no. P-19990632-AMA.

Studies were conducted to evaluate the risk of resistance development to RH-7281, a new Oomycete fungicide which acts on microtubules. RH-7281, metalaxyl and dimethomorph were compared with respect to the ease with which fungicide-resistant mutants could be isolated and their level of resistance. Attempts to isolate mutants of Phytophthora capsici and P. infestans resistant to RH-7281 by mycelial adaptation on fungicide-amended medium were unsuccessful. Similarly, no RH-7281-resistant mutants of $P$. capsici could be isolated following chemical mutagenesis of zoospore cysts. In parallel experiments with metalaxyl, highly-resistant mutants were readily obtained. For dimethomorph, chemical mutagenesis yielded moderatelyresistant mutants and adaptation did not induce resistance. Failure to isolate mutants resistant to RH-7281 may be due to the diploid nature of Oomycetes and the likelihood that target-site mutations would be recessive. It is concluded that RH-7281 is not a high risk fungicide with respect to resistance development. However, as with any site-specific fungicide, appropriate precautions against resistance development should be taken.

RAPD analyses of isolates of Botrytis cinerea sensitive and resistant to benzimidazole and dicarboximide fungicides. L. F. Yourman, S. N. JEFFERS, and R. A. Dean. Clemson University, Clemson, SC. Phytopathology 89:S88. Publication no. P-1999-0633-AMA.

Phylogenetic analyses were conducted on random amplified polymorphic DNA (RAPD) fingerprints of 56 isolates of $B$. cinerea collected from greenhouse-grown ornamental crops. There were 17 isolates sensitive to both thiophanate-methyl and vinclozolin $\left(\mathrm{S}^{\mathrm{T}} \mathrm{S}^{\mathrm{V}}\right), 18$ isolates resistant to both fungicides $\left(\mathrm{R}^{\mathrm{T}} \mathrm{R}^{\mathrm{V}}\right.$ ), $16 \mathrm{R}^{\mathrm{T}} \mathrm{S}^{\mathrm{V}}$ isolates, and $5 \mathrm{~S}^{\mathrm{T}} \mathrm{R}^{\mathrm{V}}$ isolates. Isolate fingerprints were distinguished based on fungicide sensitivity. $\mathrm{S}^{\mathrm{T}} \mathrm{S}^{\mathrm{V}}$ isolates usually were grouped closely together. Isolates resistant to thiophanate-methyl and/or vinclozolin were relatively independent or were grouped with other isolates of the same phenotype. To elucidate relationships among sensitive and resistant isolates, analyses were conducted on RAPD fingerprints of $\mathrm{S}^{\mathrm{T}} \mathrm{S}^{\mathrm{V}}$ parents and 57 mutant progeny selected from fungicide-amended medium. Genotypes of $S^{T} R^{V}$ progeny were similar to those of their parents; however, $R^{T} R^{V}$ or $\mathrm{R}^{\mathrm{T}} \mathrm{S}^{\mathrm{V}}$ progeny were distant from each other, $\mathrm{S}^{\mathrm{T}} \mathrm{S}^{\mathrm{V}}$ parents, and $\mathrm{S}^{\mathrm{T}} \mathrm{R}^{\mathrm{V}}$ siblings. Consequently, resistance to thiophanate-methyl caused a more dramatic change in the genotype than did resistance to vinclozolin.

Cloning of the full length cDNA of $\mathrm{Cro} \boldsymbol{r}$ I from the white pine blister rust fungus, Cronartium ribicola. X. YU and A. K. M. Ekramoddoullah. Natural Resources Canada, Canadian Forest Service, Pacific Forestry Centre, 506 West Burnside Road, Victoria, BC V8Z 1M5, Canada. Phytopathology 89: S88. Publication no. P-1999-0634-AMA.

The white pine blister rust fungal protein Cro $r$ I has recently been identified (Ekramoddoulla et al., 1999, Can. J. Bot., in press) in infected white pine tissues. To further characterize Cro $r \mathrm{I}$, an expression cDNA library from poly(A)+ mRNA of Cronartium ribicola mycelia was immunoscreened and the full length cDNA was cloned. Sequence analysis indicated an open reading frame of 492 bases encoding a protein of 163 amino acid residues with a molecular mass of $17.8 \mathrm{kD}$ and a predicted isoelectric point of 8.93. Based on the N-terminal sequences, the secreted portion of the Cro $r$ I protein should be 136 and the predicted N-terminal signal peptide should be 27 amino acid residues. One possible $\mathrm{N}$-glycosylation site and four possible phosphorylation sites were found during ScanProsite database search. Hydrophobicity analysis by the Kyte-Doolittle method indicates the secreted protein is hydrophilic but the signal peptide portion is very hydrophobic. Several sequence discrepancies were found between our reported RT-PCR Cro $r$ I sequence (AF046860) and the full length cDNA of Cro $r$ I.

Application of phloroglucinol (PHL) production as a phenotypic marker for selecting better biocontrol bacteria. M. Zala, C. Gyawali, B. DUFFY, C. Keel, and G. Défago. ETHZ, 8092 Zürich, Switzerland. Phytopathology 89:S88. Publication no. P-1999-0635-AMA.

Isolating and screening new biocontrol agents is a labor intensive hit-or-miss endeavor. We analyzed 6 yrs screening data (1992-97) for clues to improve our chances of obtaining superior strains in the future. Over 3000 strains 
were isolated from roots grown in $>30$ soils from every arable continent, and prescreened in the greenhouse against Pythium on cucumber and Fusarium on tomato. The top 300 were further tested in repeated trials. In the cucumber system, when the performance of all fluorescent Pseudomonas strains $(n=$ 230) was considered, $9.6 \%$ gave superior biocontrol $(>60 \%$ plant wt increase compared to nontreated control). By considering only PHL producers $(n=$ 76 ), the frequency of superior strains jumped to $26.3 \%$; whereas only $1.3 \%$ of nonPHL strains $(n=154)$ were so effective. In contrast, $58.4 \%$ of the nonPHL strains gave less than $30 \%$ wt increase, but only $1.3 \%$ of the PHL strains were so ineffective. Results from all 6 yrs, and both screening systems were similar. Also, all PHL strains produced cyanide $(\mathrm{HCN})$ suggesting a genetic or ecological linkage. Still $\mathrm{HCN}$ was less effective than PHL as a phenotypic marker for obtaining superior strains.

Accelerated identification of eastern white pine families resistant to white pine blister rust. P. J. ZAMBINO and C. H. Michler. USDA Forest Service, North Central Forest Research Station, Rhinelander, WI. Phytopathology 89: S89. Publication no. P-1999-0636-AMA.

Blister rust resistance in eastern white pine (Pinus strobus) is expressed as a quantitative trait and is difficult to measure. Historically, resistance has been identified by inoculating seedlings having mature fascicle (secondary) needles with the blister rust fungus Cronartium ribicola and determining percent mortality several years after inoculation. To test if younger seedlings could be screened for resistance, we inoculated 5-month-old seedlings cut to either a $2.0 \mathrm{~cm}$ crown of primary needles and cotyledons or to a crown of 20 primary needles, and 16-month-old seedlings bearing two flushes of secondary needles. Use of the 5-month-old seedlings allowed differences to be determined within a year of inoculation, i.e., about half the time after inoculation required for tests using 16-month-old seedlings. Furthermore, most characterizations of family resistance/susceptibility were consistent across experiments when criteria were based of rates of mortality (weeks until $\mathrm{LD}_{50}$, slope and area under mortality curve) rather than on mortality a set period of time after inoculation.

Breaking nonhost powdery mildew penetration resistance in small grain cereals. R. ZEYEN (1), W. Kruger (1), T. Carver (2), and M. Lyngkjaer (2). (1) Plant Pathology, University of Minnesota, St. Paul, MN; (2) Institute for Grassland and Environmental Research, Aberystwyth, Wales, U.K. Phytopathology 89:S89. Publication no. P-1999-0637-AMA.

Special forms, formae speciales (f. spp.), of Blumeria graminis infect either wheat, oat, or barley. Fungal germlings fail to penetrate nonhost cells. Mannose and 2-deoxy-D-glucose (DDG) treatments broke nonhost resistance. The lower epidermis of leaf segments was stripped. Upper surfaces were inoculated and floated on $1.0 \mathrm{mM}$ DDG, 5.0 or $10 \mathrm{mM}$ mannose, or distilled water for $42 \mathrm{~h}$ in darkness. Mannose and DDG allowed fungal penetration and haustorium development. Mannose and DDG may be competitive inhibitors of glucose metabolism and reduce the potential of plant cells to resist penetration. DDG may have an indirect effect on callose synthesis and other processes. In contrast to host penetration resistance, nonhost penetration resistance is unaffected by inhibition of phenolic compound synthesis (Carver et al. 1994. Physiol. Mol. Plant Path. 41:397-409). Mechanistically, nonhost penetration resistance shares great similarity to that conditioned by the recessive mlo alleles in barley to B. graminis f. sp. hordei.

Tagging stem rust resistance gene $\mathrm{Sr} 26$ in wheat using RAPD technique. J. Zhang and Y. JIN. South Dakota State University, Brookings, SD. Phytopathology 89:S89. Publication no. P-1999-0638-AMA.

Gene Sr26 confers resistance to a wide range of pathotypes of Puccinia graminis f. sp. tritici. This gene is used extensively in breeding for stem rust resistance in wheat. To determine its presence in a complex genetic background of other stem rust resistance genes, a genetic marker for $\mathrm{Sr} 26$ is needed. In this study, we attempted to tag $S r 26$ using the random amplified polymorphic DNA technique. A segregation population for $\operatorname{Sr} 26$ was developed from a cross between LMPG-6 and Sr26/9*LMPG, a near isogenic line of LMPG-6 with Sr26. Genomic DNAs were isolated from the parents and $95 \mathrm{~F}_{3}$ resistant and susceptible families. Polymorphism between parents was evaluated with 300 random primers. Seven primers produced polymorphic bands between the two parents. These primers were tested against the DNA bulks of $F_{3}$ resistant and susceptible families and DNA of each family. The polymorphic fragment OPH11(850) generated by OPH11 showed in Sr26/9*LMPG, $\mathrm{F}_{3}$ resistant DNA bulks and most of families with $\mathrm{Sr} 26$. OPH11 was found to be closely linked $(5.6 \mathrm{cM})$ to $\operatorname{Sr} 26$. This marker is being used to develop allele-specific marker for $\mathrm{Sr} 26$.
Relationship of cell wall-degrading enzymes to virulence of Didymella bryoniae. J. X. ZHANG (1), B. D. Bruton (1), and C. L. Biles (2). (1) USDAARS, South Central Agri. Res. Lab, Lane, OK 74555; (2) Dept. of Biology, East Central Univ., Ada, OK 74820. Phytopathology 89:S89. Publication no. P-1999-0639-AMA

To evaluate virulence factors of Didymella bryoniae on cantaloupe fruit, three virulent and two hypo-virulent isolates were compared for the production of cell wall-degrading enzymes polygalacturonase (PG), B-galactosidase (B-Gal), and cellulase (Cx) in vitro and in vivo. Lesion size on 10-dayold fruit averaged $7.9 \mathrm{~cm}^{2}$ for virulent isolates, and $4.4 \mathrm{~cm}^{2}$ for hypo-virulent isolates. PG activity in pectin shake culture ranged from 287.4 to 361.2 and 137.8 to 185.2 units/g fungal dry wt for virulent and hypo-virulent isolates, respectively. Average PG activity (units/mg protein) of virulent isolates in decayed cantaloupe fruit was 4.4 times greater than that of the two hypovirulent isolates. Mean B-Gal activity in pectin shake culture was 50.9 and 15.5 units/g fungal dry wt for virulent and hypo-virulent isolates, respectively. Mean Cx activity of virulent isolates in vivo was 2.3 times higher than that of hypo-virulent isolates. Cell wall-degrading enzymes PG, B-Gal, and $\mathrm{Cx}$, seem to be important virulence factors of $D$. bryoniae in the development of black rot of cantaloupe fruit.

Relationship between in vitro and in vivo testing of PGPR for induced systemic resistance against tobacco blue mold. S. ZHANG, M. S. Reddy, C. M. Ryu, and J. W. Kloepper. Department of Plant Pathology, Auburn University, Auburn, AL 36849. Phytopathology 89:S89. Publication no. P-19990640-AMA.

Two experimental systems were developed for demonstrating induced systemic resistance (ISR) activity by plant growth-promoting rhizobacteria (PGPR) against tobacco blue mold, caused by Peronospora tabacina. Five PGPR strains (SE-34, 90-166, 89B-61, T4 and C9) with known ISR activity in other crops were evaluated on tobacco cultivars Xanthi-nc and KY14 in a gnotobiotic microtiter dish assay (in vitro test) and in a whole-plant assay (in vivo) under greenhouse conditions. PGPR strains were applied as a drench after seed germination, and P. tabacina was applied as a foliar spray or drop 7 days after induction with PGPR. All PGPR strains significantly reduced severity of blue mold compared to non-induced controls in both the in vitro and in vivo tests, except for strain $\mathrm{C} 9$ which had no effect in vitro. Protection with 2 strains was equivalent to that from treatment with salicylic acid. PGPR strains which induced resistance against blue mold did not move from the inoculated roots to leaves, suggesting that the mode of protection against blue mold is due to systemic effects induced by the PGPR.

Use of the green fluorescent protein to monitor gene expression and colonization by Xanthomonas campestris pv. vesicatoria. Y. ZHANG (1), J. Jones (1), and M. Wilson (2). (1) Department of Plant Pathology, University of Florida, Gainesville, FL 32611; (2) Biology Department, The Colorado College, 14 East Cache La Poudre, Colorado Springs, CO 80903. Phytopathology 89:S89. Publication no. P-1999-0641-AMA.

Two variants of the green fluorescent protein (GFP) from Aequorea victoria were used as a reporter gene in $X$. campestris pv. vesicatoria, causative agent of bacterial spot disease of pepper and tomato. The heterologous GFP can be constitutively expressed at high levels when driven by trp- or npt-promoters in a mid-copy number plasmid, allowing bacterial cells to be visualized using epifluorescent microscopy of colonized plant leaf tissue. Induced expression of $h r p G$ in plant tissue could be clearly detected when the $h r p G$ promoter was fused with $g f p$ gene. In contrast, no induction could be detected for expression of $h r p X v$ gene using the same method. The population of X. campestris pv. vesicatoria in tomato leaf tissue and disease development were slightly reduced by the expression of GFP.

A strategy for rapid cDNA cloning from double-stranded RNA templates of plants infected with RNA viruses by using Taq DNA polymerase. Y.-P. ZHANG and A. Rowhani. Department of Plant Pathology, University of California, Davis, CA. Phytopathology 89:S89. Publication no. P-1999-0642AMA.

A fast and efficient cDNA cloning procedure was developed using doublestranded RNA (dsRNA) as template source, standard cDNA synthesis reagents and random hexamers for making cDNAs, and Taq DNA polymerase to add additional (A) at the ends of cDNAs. TA cloning kit was used to ligate the cDNAs to vectors, and electroporator to transform the DNAs to E. coli cells. dsRNAs of four viruses from grapevine were used for cloning in this experiment. These viruses included grapevine rupestris stem pitting virus, grapevine leafroll associated virus 5, two uncharacterized viruses one each 
from marafivirus and vitivirus groups. Primers were developed from the sequences of these cDNA clones and used in RT-PCR for the detection of these viruses in host plants.

Inter simple sequence repeat (ISSR), a useful tool for examining fungal species complexes. S. ZHOU, D. R. Smith, and G. R. Stanosz. Dept. Plant Pathology, Univ. Wisconsin, Madison, WI 53706. Phytopathology 89:S90. Publication no. P-1999-0643-AMA.

Simple sequence repeats (SSR) or microsatellites are ubiquitous in eukaryotic genomes. Using an SSR as a single primer to amplify the sequences between two SSRs by PCR can yield a multilocus marker system. We have used ISSR to produce fingerprints for isolates of closely related taxa and species complexes within the genus Botryosphaeria and related anamorphic fungi. These fungi are most often encountered in their anamorphic states, which can be difficult to identify based on morphological characters. Further, some of these fungi cannot be differentiated by comparison of ITS sequences. One group examined included isolates of $B$. dothidea, B. ribis, B. parva, $B$. corticis, and B. mamane; another included isolates of B. obtusa, Sphaeropsis sapinea (A type and B type), and the fungus referred to as $S$. sapinea $\mathrm{f}$. sp. cupressi. Cluster analyses showed that within each putative species, more than $75 \%$ similarity in banding patterns were observed, while less than $50 \%$ similarity was observed between different species. These results indicate that ISSR can be another useful technique for the differentiation of closely related fungal species.

Molecular phylogeny of Botryosphaeria species and associated anamorphic fungi based on analysis of internal transcribed spacer (ITS) and 5.8s rDNA sequences. S. ZHOU and G. R. Stanosz. Dept. Plant Pathology, Univ. Wisconsin, Madison, WI 53706. Phytopathology 89:S90. Publication no. P-1999-0644-AMA.

Diseases of many woody plants, especially those low in vigor or under stress, are caused by Botryosphaeria species and associated anamorphic fungi in Fusicoccum, Dothiorella, Diplodia, Lasiodiplodia, Sphaeropsis, Macrophoma, and Phyllosticta. Classification/identification of these fungi can be confusing/difficult and relationships within the group are poorly understood. Morphological characters are variable and overlapping, and anamorphs are the most frequently encountered states. We have analyzed ITS and 5.8s rDNA sequences from 47 isolates of at least 17 taxa. Results indicate that this group is not monophyletic. Within the main group comprised by most of the isolates, however, species with light and narrow conidia formed one monophyletic group and species with darker and wider conidia form a second monophyletic group. Many closely related species could be clearly differentiated. At least one potential species complex was discerned, however, and identical or highly similar sequences among other groups comprised of putatively different taxa also were noted.

Effects of developmental stage of watermelon on fungicidal control of anthracnose. X. G. ZHOU and J. A. Duthie. Wes Watkins Agr. Res. and Ext. Center, Oklahoma State Univ., Lane, OK 74555. Phytopathology 89:S90. Publication no. P-1999-0645-AMA.

The effectiveness of fungicidal control of anthracnose caused by (Colletotrichum orbiculare) varies with the developmental stage of the crop but this variation has not been assessed critically. In field experiments that conducted over two years, treatments were arranged in a split plot design. Three dates of planting were randomized to whole plots. Weekly applications of chlorothalonil were initiated at the stage of vining, flowering, fruiting, or control consisted of no fungicide application as subplots. An epidemic was initiated in each plot when plants in plots assigned to the first, second, and third planting date had reached the stage of the fruiting, flowering, and vining, respectively. The effectiveness of chlorothalonil varied considerably with the developmental stages at which applications and epidemics were initiated. Chlorothalonil was most effective when applications were applied prior to the crop stage at which epidemics were initiated; otherwise it was least effective. Application initiated at the flowering stage was sufficient to control anthracnose regardless of when epidemics started.

Comparison of linkage maps of loci controlling resistance to Leptosphaeria maculans in Brassica napus and B. napus-B. juncea recombinant lines. B. ZHU, M. H. Borhan, D. J. Somers, and S. R. Rimmer. Agriculture and Agri-Food Canada, Saskatoon, Canada. Phytopathology 89:S90. Publication no. P-1999-0646-AMA.

Doubled haploid (DH) lines, developed from a single F1 plant for crosses between a susceptible cultivar Westar and a resistant line of B. napus (RB87-62) and a recombinant line of B. napus-B. juncea (DH88-752), were employed for molecular analysis for both cotyledon and adult plant resistance to Leptosphaeria maculans, the cause of black leg. The arrangement and distances of closely linked RAPD, AFLP and RFLP markers on resistance linkage maps demonstrated short-range similarity between $B$. napus and B. napus $-B$. juncea recombinant lines. It seems likely that, independent of origin, $B$. juncea resistance genes were introgressed to the same region of $B$. napus genome by homoeologous recombination after B- genome chromosomes pairing with $\mathrm{A}$ - or $\mathrm{C}$ - genome chromosomes.

Inheritance of resistance to Leptosphaeria maculans in Brassica napus and B. napus-B. juncea recombinant lines. B. ZHU and S. R. Rimmer. Agriculture and Agri-Food Canada, Saskatoon, SK, Canada. Phytopathology 89:S90. Publication no. P-1999-0647-AMA.

Inheritance of resistance to Leptosphaeria maculans was studied in Brassica napus (RB8762) and a B. napus-B. juncea recombinant line (DH88-752). These resistant lines and a susceptible cultivar Westar, were crossed in a complete diallel. Parents, F1 and F2 progenies were evaluated with cotyledon and stem inoculations with isolate PL86-12. For crosses between Westar and either resistant parents, the segregation of F2 populations fit 3:1 for both cotyledon and adult plant reaction, indicating a single dominant gene. Resistance in cotyledon and adult plant was controlled by different, but linked genes. The results were confirmed by segregation data from F3 families and doubled haploid populations derived from a single F1 plant for two crosses. Lack of segregation in the cross between the two resistant lines indicated that the $B$. juncea resistance gene was introgressed to the same region of the $B$. napus genome. Incubation at high temperature (28C) affected expression of resistance in both cotyledons and adult plants resulting in significant distortion of segregation ratios.

A nondestructive PCR assay for detection of Clavibacter michiganensis subsp. michiganensis on tomato seeds. N. Zriba, M. L. GLEASON, T. C. Harrington, and J. P. Steimel. Dept. of Plant Pathology. Iowa State University. Ames, IA 50011. Phytopathology 89:S90. Publication no. P-1999-0648AMA.

A nondestructive PCR assay was developed for detection of Clavibacter michiganensis subsp. michiganensis $(\mathrm{Cmm})$ on tomato seeds. Sonication of seeds in sterile deionized water was followed by a two-step filtration. PCR was performed directly on the filtrate using the $\mathrm{Cmm}$-specific primers CMM-5 and CMM-6 (Dreier et al., Phytopathology 85:462-468). The sensitivity of the assay was compared to that of a destructive agar plate bioassay, the Georgia Department of Agriculture (GDA) assay. Both PCR and GDA methods detected one $\mathrm{Cmm}$-infested seed per 10,000 in ten of ten assays. The PCR assay detected one Cmm-infested seed in 30,000 four times in ten, whereas the GDA assay detected one Cmm-infested seed per 30,000 ten times out of ten. Using the CMM-5 and CMM-6 primers, 25 of $28 \mathrm{Cmm}$ isolates were detected. When CM3 and CM4 primers (Santos et al., Seed Sci. and Technol. 25:581-584) were used, all $27 \mathrm{Cmm}$ isolates tested were detected. The nondestructive PCR assay was 9-11 days faster than the agar plate bioassays. Sonication of seeds for the PCR assay did not reduce seed germination. 


\section{Vol. 89, No. 6 (Suppl.), 1999}

The following abstracts were submitted for presentation at the 1999 American Phytopathological Society Annual Meeting.

Distribution of Soybean Cyst Nematode, Heterodera glycines, in Ohio Between August 15, 1998, and March 15, 1999. Y. ALPTEKIN, N. J. Taylor, J. B. Eisley, and R. M. Riedel. The Ohio State University, Columbus. Phytopathology 89:840. Publication no. P-1999-0650-AMA.

Between August 15, 1998, and March 15, 1999, 3,764 samples from agronomic soils were sent to the C. W. Ellett Plant Pathology Diagnostic Clinic. No soybean cyst nematodes (SCN) were found in approximately $60 \%$ of the samples. Of the positive samples $31 \%$ were below levels which generally caused damage to SCN-susceptible soybeans ( $<200 \mathrm{eggs} / 200 \mathrm{~cm}^{3}$ soil). $16 \%$ Samples were above levels recommended for planting SCN-resistant soybeans $\left(5,000\right.$ eggs $/ 200 \mathrm{~cm}^{3}$ soil). Highest population level detected was 56,000 eggs/ $200 \mathrm{~cm}^{3}$ of soil. As a result of this survey, SCN infestations were found in the 7 counties previously not known to have SCN, Franklin, Holmes, Lorain, Marion, Van Wert, Wayne, and Williams. Fifty-one (of 88) Ohio counties are now known to have SCN infestations including almost all major soybean producing counties.

Characterization of a Potato Proteinase Inhibitor Specific Against Microbial Proteases. M. Feldman, C. Oliva, C. Casalongué, and G. I. I. B. Daleo. Fac. Cs. Exac. \& Nat. Univ. Nac. de MdP. Argentina. Phytopathology 89:840. Publication no. P-1999-0651-AMA.

Proteinase inhibitor proteins (IPs) are widely distributed in the plant kingdom and it has been suggested that they may take part in plant protection against pests. Many of them have been described in Solanaceae but only in a few cases the production of proteinase inhibitors has been shown to be induced by a pathogen. We describe the partial characterization of an IP with inhibitory activity against microbial serine proteinases (proteinase $\mathrm{K}$ and subtilisin) which is strongly induced in potato leaves upon infection with Phytophthora infestans $(P i)$. Potato leaves from Solanum tuberosum cv. Pampeana were inoculated for 0,24 , and $48 \mathrm{~h}$ with spores of $P i$. The kinetics of induction during infection showed an increase of inhibitory activity after $24 \mathrm{~h}$. The purified inhibitor was satable at $80^{\circ} \mathrm{C}$ for $10 \mathrm{~min}$ and a molecular mass of $60 \mathrm{kDa}$ has been determined by gel filtration. The amount of purified IP $(0.79 \mu \mathrm{g})$ producing a $50 \%$ of inhibition of proteinase $\mathrm{K}$, inhibited only $31 \%$ the activity of subtilisin and about $4 \%$ that of two proteinases of animal origin (trypsin and chymotrypsin). Since fungal proteinases are involved in the infection process, the strong induction of an inhibitor with high specificity for proteinase $\mathrm{K}$ could represent a plant defense reaction.

The Leaf Spot Complex of Wheat in Western Canada. J. GOLD, A. Tekauz, and J. Gilbert. Cereal Research Centre, Agriculture and Agri-Food Canada, Winnipeg, MB. Phytopathology 89:840. Publication no. P-1999-0652-AMA.

Leaf spot diseases of wheat (Triticum aestivum) cause annual yield losses of about $10 \%$ in western Canada. These include tan spot, spot blotch, Septoria tritici blotch, Stagnospora nodorum blotch and Septoria avenae blotch caused by, respectively, Dreschlera tritici-repentis, Bipolaris sorokiniana, Septoria tritici, Stagnospora (=Septoria) nodorum, and Septoria avenae f. sp. triticea. No wheat cultivar registered in Canada has effective resistance to all five diseases. The 1997 growing season was conducive to development of both leaf spots and Fusarium head blight (FHB); leaf spotting in Manitoba caused losses of about $\$ 40$ million dollars, more than FHB. A prairie-wide collaboration has been established to study the leaf spot complex. Thirty widely grown spring wheat cultivars, comprising six types, are being evaluated in Manitoba, Saskatchewan, and Alberta, at three sites each. In 1998 differences in severity ratings to $D$. tritici-repentis, $S$. tritici, and S. nodorum were noted among the cultivars inoculated in Manitoba plots. Initial data for disease ratings and identification of pathogens isolated from sample leaves from noninoculated plots are reported. 


\section{Vol. 89, No. 6 (Suppl.), 1999}

The following abstracts are to replace the abstracts "Relationship of airborne ascospore concentration of Venturia inaequalis to lesion production under natural conditions," Charest et al. (89[suppl]:S13-S14), and "Field evaluation of minimum infection time of Venturia inaequalis for different cultivars," Dewdney et al. (89[suppl.]:S20), respectively.

Relationship of airborne ascospore dose of Venturia inaequalis to lesion production under natural conditions. J. CHAREST $(1,2)$, M. Dewdney $(1,2)$, V. Philion (3), P. Dutilleul (1), T. Paulitz (1) and Carisse, O (2). (1) McGill University, Ste. Anne de Bellevue, Qc H9X 3V9, (2) Agriculture and Agri-Food Canada, St. Jean sur Richelieu, Qc., Canada, J3B 3E6. (3) IRDA, St. Hyacinthe, Qc., Canada, J2S 7B8. Publication no. P-1999-0091-AMA.

Apple scab is the most important disease of apple in several parts of the world. The disease is controlled with numerous fungicide applications, but these are costly and becoming less efficient due to the development of resistance in populations of Venturia inaequalis. Better timing of fungicide applications could be achieved if airborne ascospore concentration (AAC) is considered in decision making. The relationship between AAC and the number of lesions produced was established under field conditions for 5 cultivars; Empire, Jonagold, McIntosh, Royal Gala, and Spartan. During infection periods, potted trees were exposed to natural inoculum and the ascospore concentration was measured using volumetric spore traps. For each cultivar there was a positive correlation between AAC and the number of lesions produced. Jonagold and McIntosh were the most susceptible cultivars followed by Royal Gala, Empire and Spartan.

Relative cultivar susceptibility to ascospores of Venturia inaequalis under greenhouse conditions. Dewdney M. (1,2), d'Estienne B. (2), Charest J. $(1,2)$, Paulitz, T. (1), and Carisse O. (2). (1) McGill University, Ste. Anne de Bellevue, QC H9X 3V9; (2) Agriculture and Agri-Food Canada, St. Jean sur Richelieu, QC, Canada, J3B 3E6. Publication no. P-1999-0139-AMA.

In eastern North American apple culture, apple scab is the disease of greatest importance. The majority of North American apple scab experiments have used the highly susceptible cultivar McIntosh. Very little is known about the susceptibility of other commercial cultivars. The relative susceptibility of 20 common cultivars of central and eastern Canada to $V$. inaequalis was tested under greenhouse conditions. The cultivars used in the experiment were Cortland, Early Geneva, Empire, Golden Delicious, Golden Russet, Idared, Jersey Mac, Jonagold, Jonamac, Lobo, Lodi, McIntosh, Mutsu, Northern Spy, Paulared, Red Cortland, Red Delicious, Royal Gala, Spartan, and Vista Bella. The trees were inoculated with highly infected McIntosh leaves that were overwintered naturally. The factors of infection studied were disease severity, incubation time, lesion size, and conidial production. The difference among the cultivars was tested for each variable and multivariable grouping. A hierarchical pairwise comparison test was also carried out to rank the cultivars. From preliminary results, Red Cortland was the most susceptible cultivar and Paulared was the least. 


\section{Erratum}

Vol. 89, No. 6 (Suppl.), 1999

The following abstract was submitted for presentation at the 1999 American Phytopathological Society Annual Meeting.

Current situation of head blight (scab) of wheat caused by Fuarium graminearum in Iran. H. Saremi, Faculty of Agriculture, Zanjan University, Zanjan, Iran. Publication no. P-1999-0653-AMA.

Head bight or white head (scab) of wheat caused significant losses in the most wheat grown areas of Iran, specially in the northern parts of the country. Recently which susceptible cultivars such as Flat and Gloestan are used the disease is severely distributed in northern provinces and causes up to $90 \%$ yield losses. Our surveys show that $F$. graminearum was the main pathogen associated with head blight and other Fusarium species, $F$. culmorum, $F$. crookwellense and $F$. avenaceum were isolated at low frequency. Currently a national project has been organised to survey on situation of the disease (distribution, yield losses, pathogenecity, epidemiology and control) in Iran. For example, the study is undertaken to indicate which one of two populations (Group 1 or Group 2) of $F$. graminearum is responsible for the disease. Data we have found, our future work and the obstacles will be reported. 